\title{
Environmental Assessment of Urgent-Relief Acceptance of Foreign Research Reactor Spent Nuclear Fuel
}

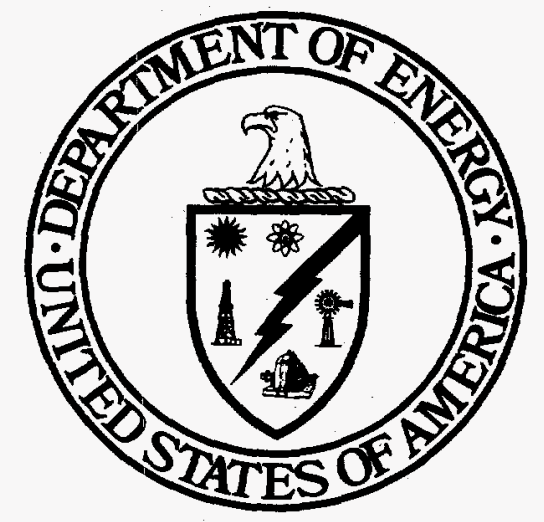

\section{April 1994}

U.S. Department of Energy Washington, DC 20585 


\section{FOREWORD}

The proposed action as described in this Environmental Assessment consists of:

o The acceptance of 409 spent fuel elements (in fifteen full casks) from eight foreign research reactors in Europe;

o The shipment of the spent fuel by commercial or chartered vessel from Europe to any one of five ports of entry in the United States (Wilmington, North Carolina; the Army Military Ocean Terminal at Sunny Point, North Carolina; Charleston, South Carolina; Savannah, Georgia; and Jacksonville, Florida);

o The transport by truck of the spent fuel from the port of entry to Savannah River Site, near Aiken, South Carolina, for storage in an existing underwater pool.

The Environmental Assessment analyzes the acceptance of alternative numbers of spent fuel elements (ranging from 0 to 953) as alternatives to the proposed acceptance of 409 spent fuel elements, and overland transport by rail as an alternative mode of ground transportation.

Upon further consideration, and in an effort to balance the domestic and international interests at stake, the Department of Energy (DOE) has decided that, rather than implementing the proposed action described in the Environmental Assessment, the preferred approach for implementing the urgent-relief acceptance of foreign research reactor spent fuel is:

o To ship the spent fuel by commercial or chartered vessel from Europe to the Army's Military Ocean Terminal at Sunny Point, North Carolina, to the maximum extent practicable, (rather than allowing the shipper to select from among any one of the five proposed ports as described in the Environmental Assessment); and

o To transport the spent fuel overland to the Savannah River Site by rail (rather than by truck).

The preparation of this Environmental Assessment included a broad effort to engage elected officials, federal agencies, nonproliferation and environmental public interest organizations, and members of the public in consideration of the proposed acceptance of foreign research reactor spent fuel. Those efforts included distribution of two separate drafts of the Environmental Assessment for comment in October 1993 and February 1994, briefing of federal, state, and local officials, and meetings with interested parties. For example, DOE and the Department of State hosted an all-day public meeting in Washington, D.C. on February 10, 1994 to provide representatives of key stakeholders an opportunity for constructive dialogue. In addition, DOE held several meetings concerning the proposed acceptance of foreign research reactor spent fuel in the Hampton Roads area, Virginia; Brunswick County and Wilmington, North Carolina; Charleston and Mount Pleasant, 
acceptance of foreign research reactor spent fuel in the Hampton Roads area, Virginia; Brunswick County and Wilmington, North Carolina; Charleston and Mount Pleasant, South Carolina; Savannah, Georgia; and Jacksonville, Florida. These locations were chosen because of their proximity to ports of entry analyzed in the Environmental Assessment.

DOE's decision to change the preferred approach for implementing the urgent-relief acceptance of foreign research reactor spent fuel is a result of DOE's consideration of stakeholder's comments. DOE believes that the change in the preferred approach fairly balances stakeholders' concerns in the United States with the crucial international interests at stake in the near-term support of the Reduced Enrichment for Research and Test Reactors program, a key nonproliferation initiative to minimize and eventually eliminate the use of highly enriched uranium in civilian reactor programs worldwide. 


\section{TABLE OF CONTENTS}

LIST OF FIGURES $\ldots \ldots \ldots \ldots \ldots \ldots \ldots \ldots \ldots \ldots \ldots \ldots \ldots \ldots \ldots \ldots$

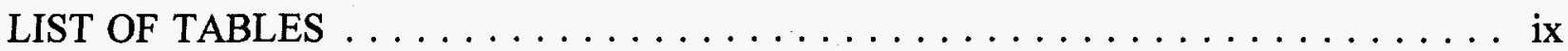

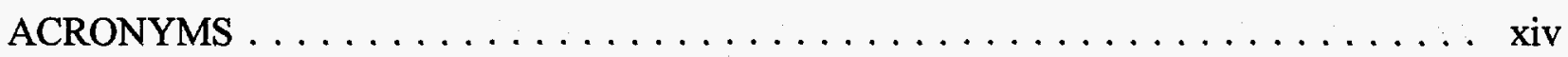

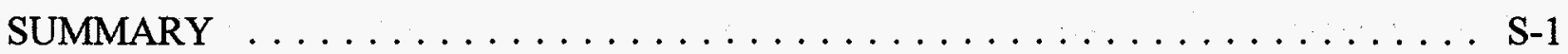

1.0 PURPOSE AND NEED FOR ACTION $\ldots \ldots \ldots \ldots \ldots \ldots \ldots \ldots \ldots \ldots$

2.0 IDENTIFICATION OF REACTORS IN NEED OF URGENT RELIEF . . . . . . . 2-1

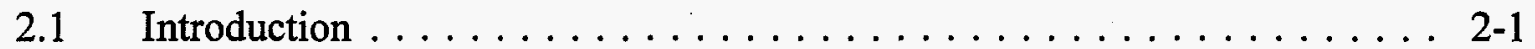

2.2 Criteria For Determining Reactors In Need Of Urgent Relief . . . . . . 2-4

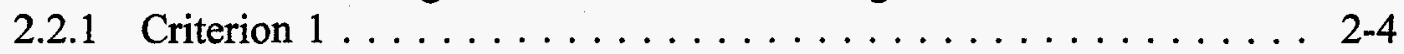

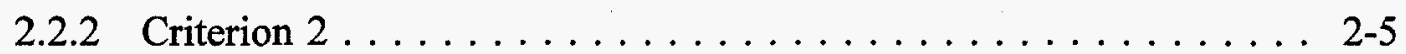

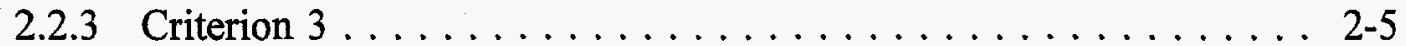

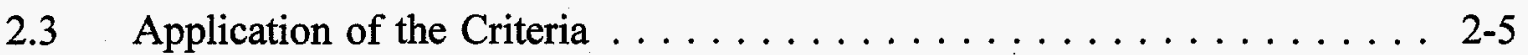

2.3.1 Reactor Profiles ...................... 2-7

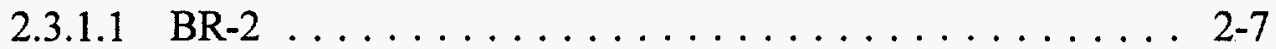

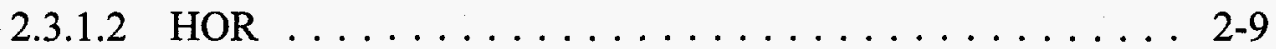

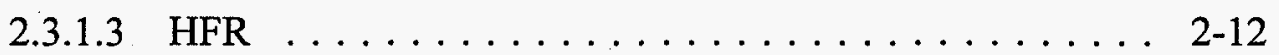

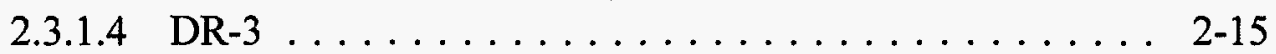

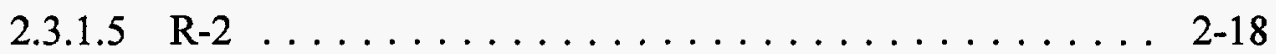

2.3 .1 .6 BER-II . . . . . . . . . . . . . . . . . 2-22

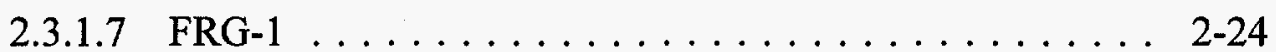

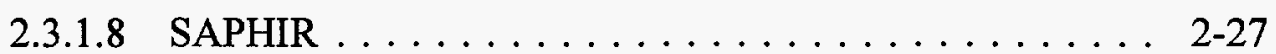

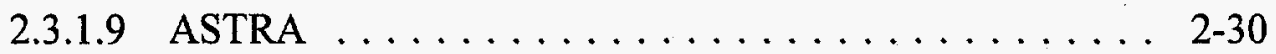

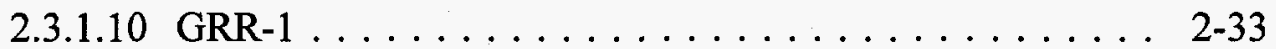

2.3.1.11 HIFAR ................. 2-35

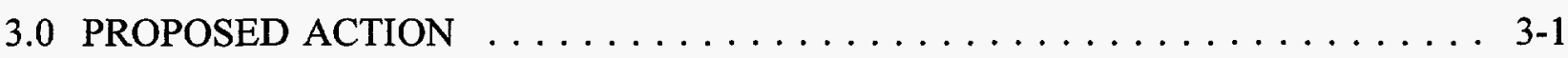

$3.1 \quad$ Proposed Action . . . . . . . . . . . . . . . . . . . 3-1

3.1.1 Acceptance of 409 Spent Fuel Elements Based on No

Reprocessing and Shipment of Full Casks . . . . . . . . . . . 3-3

3.1.2 Proposed Mode of Ocean Transport . . . . . . . . . . . . . 3-4

3.1.3 Proposed Ports of Entry $\ldots \ldots \ldots \ldots \ldots \ldots$. . . . . . . . . . .

3.1.4 Proposed Mode of Overland Transport . . . . . . . . . . . . 3-10

3.1.5 Proposed Storage at the Savannah River Site ... . . . . . . . . 3-11 
4.0 ALTERNATIVES TO THE PROPOSED ACTION . . . . . . . . . . . 4-1

4.1 Acceptance of Alternative Numbers of Spent Fuel Elements . . . . . . . . 4-1

4.1.1 No Action Alternative . . . . . . . . . . . . . . . . 4-1

4.1.2 Acceptance of 953 Spent Fuel Elements as Requested by the Eleven Research Reactors . . . . . . . . . . . . . . . . 4-1

4.1.3 Acceptance of 359 Spent Fuel Elements Based on No Reprocessing and Acceptance of Partial Casks . . . . . . . . 4-2

4.1.4 Acceptance of 291 Spent Fuel Elements Based on Reprocessing and Acceptance of Full Casks . . . . . . . . . . . . . . 4-3

4.1.5 Acceptance of 248 Spent Fuel Elements Based on Reprocessing and Acceptance of Partial Casks . . . . . . . . . . . . . 4-3

4.1.6 United States Purchase of European-Reprocessed HEU . . . . . 4. 4-4

4.2 Receipt of Spent Fuel Elements at Alternate Ports . . . . . . . . . . . 4-5

4.2.1 Alternate Commercial Ports . . . . . . . . . . . . 4-5

4.2 .2 Alternate Military Ports . . . . . . . . . . . . . . . 4 4-6

4.3 Transport of Spent Fuel Elements By Rail from Commercial or Military Ports of Entry to the Savannah River Site . . . . . . . . . . . 4-6

4.4 Alternatives Considered But Not Analyzed in Detail . . . . . . . . . . . 4-8

4.4.1 Transport of Spent Fuel Elements by Air to the United States . . . 4-8

4.4.2 Receipt of Foreign Research Reactor Spent Fuel Elements at Alternate DOE Facilities . . . . . . . . . . . . . . . . . 4-9

4.4.3 Spent Fuel Storage Assistance for Foreign Research Reactors . . . 4-10

4.4.4 Transport of Spent Fuel by Barge from Port of Entry to the Savannah River Site ..................... 4-10

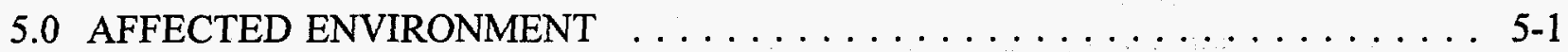

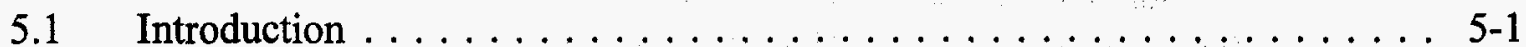

5.2 Marine Environment . . . . . . . . . . . . . . . . 5-1

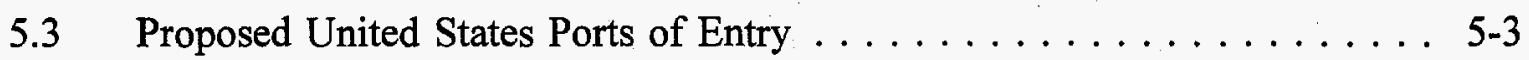

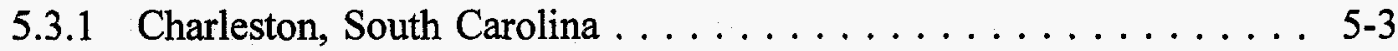

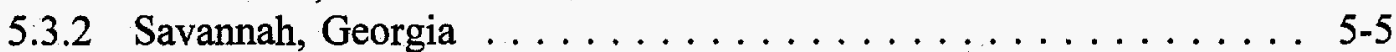

5.3 .3 Jacksonville, Florida . . . . . . . . . . . . . . . 5-6

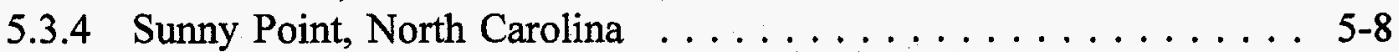

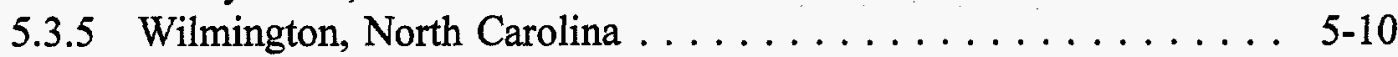

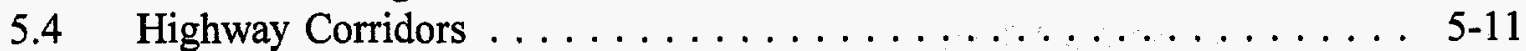

5.5 Savannah River Site . . . . . . . . . . . . . . . . . 5-12

5.5.1 General Site Description . . . . . . . . . . . . . 5-12

5.5.2 Description of the Receiving Basin for Offsite Fuels . . . . . . 5 5-12

5.5.3 Radiation Levels in the Affected Environment at the Savannah

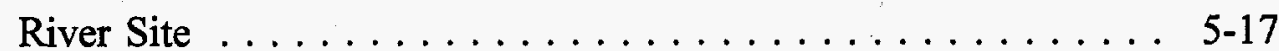


6.0 ENVIRONMENTAL IMPACT ANALYSIS $\ldots \ldots \ldots \ldots \ldots \ldots \ldots \ldots \ldots .6 \ldots \ldots$

6.1 Impacts of Proposed Action . . . . . . . . . . . . . . . . 6-4

6.1 .1 Marine Environment . . . . . . . . . . . . . . 6-5

6.1.1.1 Impacts of Routine Operations . . . . . . 6-5

6.1.1.2 Impacts of Accidents . . . . . . . . . . 6-6

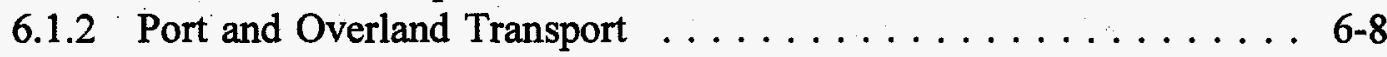

6.1.2.1 Impacts of Routine Operations . . . . . . . 6-9

6.1.2.2 Impacts of Accidents . . . . . . . . . . 6 6-13

6.1.2.3 Summary of Transportation Radiological Risks ... 6-19

6.1.2.4 Non-Radiological Transportation Impacts . . . . . 6 6-20

6.1.3 Savannah River Site . . . . . . . . . . . . . . . 6-22

6.1.3.1 Impacts of Routine Operations . . . . . . . 6-22

6.1.3.2 Impacts of Accidents . . . . . . . . . . . . . . 6- 6-24

6.2 Impacts of Alternatives to the Proposed Action . . . . . . . . . 6-29

6.2 .1 No Action . . . . . . . . . . . . . . . . . . 6 6-29

6.2.1.1 Direct Impact Upon the Reactor Operators and

National and Regional Communities ........ 6 6-29

6.2.1.2 Impact Upon U.S. Nonproliferation Policy . . . . . 6-30

6.2.2 Alternative Numbers of Fuel Elements . . . . . . . . . . 6-30

6.2.3 Receipt of 409 Spent Fuel Elements at Alternate Commercial or Military Ports .................... 6-34

6.2.4 Transport of 409 Spent Fuel Elements by Rail from Proposed Ports of Entry to the Savannah River Site . . . . . . . 6-36

6.2.5 Transport of Low or Highly Enriched Uranium to the United States After Reprocessing Spent Fuel Abroad . . . . . . . . 6 6-40

6.3 Cumulative Impacts . . . . . . . . . . . . . . . . . 6-40

6.3.1 Cumulative Transportation Impacts $\ldots \ldots \ldots \ldots \ldots \ldots \ldots 6$ 6-41

6.3.1.1 NUREG-0170 and Other Studies on Population

Exposures .................. 6-41

6.3.1.2 Estimated Doses for the Proposed Action ... . . 6 6-42

6.3.1.3 Summary of Cumulative Transportation Effect . . 6 6-43 Evaluation

6.3.2 Cumulative Storage Impacts $\ldots \ldots \ldots \ldots \ldots \ldots \ldots \ldots$ 6-43

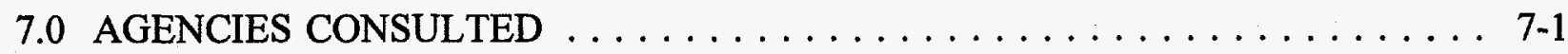

APPENDIX A . . . . . . . . . . . . . . . . . . A-1

SUPPLEMENTAL MATERIAL REGARDING THE NEED FOR THE

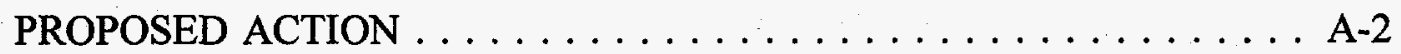

APPENDIX B ............................ B-1

CRITERIA FOR EVALUATION OF SITES FOR STORAGE OF FOREIGN

RESEARCH REACTOR SPENT NUCLEAR FUEL . . . . . . . B-2 
CRITERIA FOR INITIAL SELECTION AND ANALYSIS OF MARINE PORTS OF ENTRY FOR FOREIGN RESEARCH REACTOR SPENT

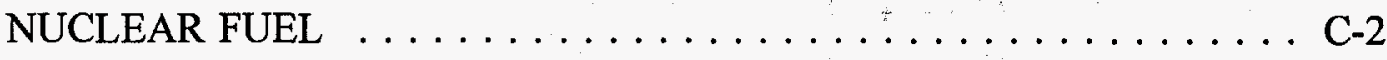

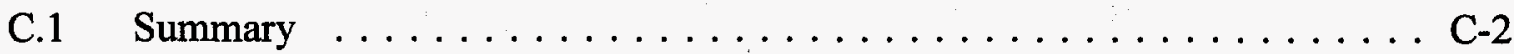

C.2 Port and maritime industry data collection activities $\ldots \ldots \ldots \ldots \ldots$ C-2

C.2.1 Inventory of United States seaports . . . . . . . . . C-2

C.2.2 U.S. Merchant Marine Academy Workshop on Port

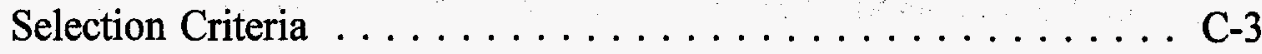

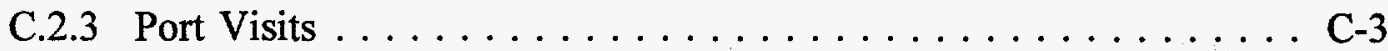

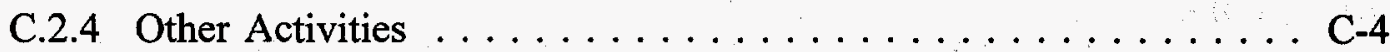

C.3 Port Selection Criteria and Screening Process . . . . . . . . . C-4

C.4 Application and Results of the Port Selection Screening Process ... . . . C-5

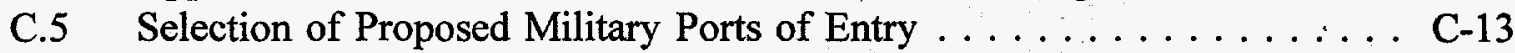

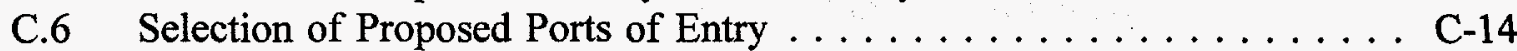

C.7 Public Law 103-160, National Defense Authorization Act for FY1994 . . C-14

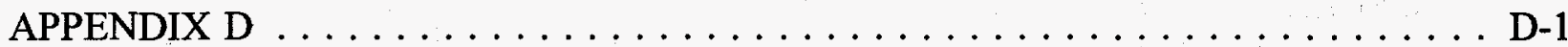

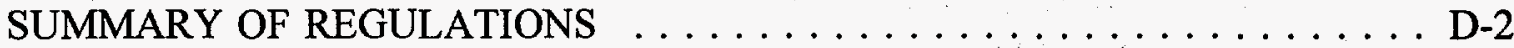

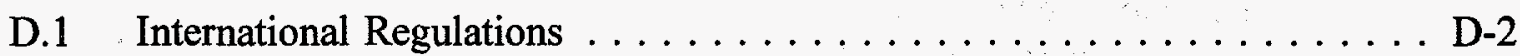

D.2 Domestic Regulations . . . . . . . . . . . . . . . D-3

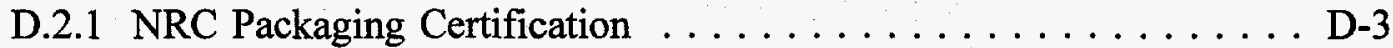

D.2.2 Transportation Regulations ............... D-4

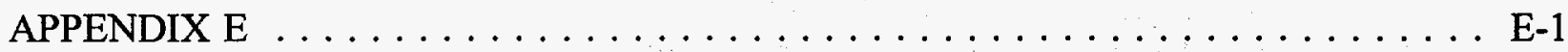

INPUT PARAMETERS FOR TRANSPORTATION RISK ANALYSIS $\ldots \ldots \ldots$ E-2

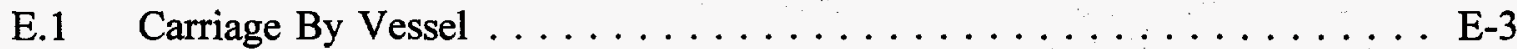

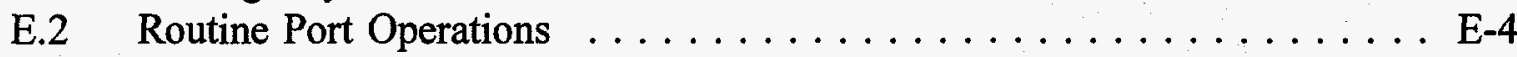

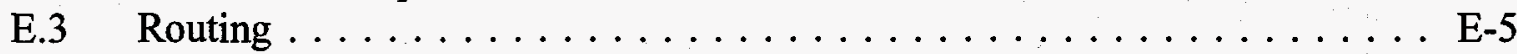

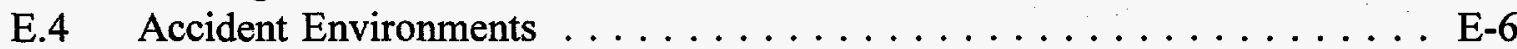

APPENDIX F . . . . . . . . . . . . . . . . . . .

RADIONUCLIDE INVENTORIES OF FOREIGN RESEARCH REACTOR

SPENT NUCLEAR FUEL $\ldots \ldots \ldots \ldots \ldots \ldots \ldots \ldots \ldots$ F-2

APPENDIX G . . . . . . . . . . . . . . . .

RISK ANALYSIS OF FOREIGN RESEARCH REACTOR STORAGE AT

SAVANNAH RIVER SITE $\ldots \ldots \ldots \ldots \ldots \ldots \ldots \ldots \ldots \ldots \ldots \ldots \ldots \ldots$

G.1 Risk . . ........................

G.1.1 Release Scenarios $\ldots \ldots \ldots \ldots \ldots \ldots \ldots \ldots \ldots \ldots$ G-2

G.1.2 Methodology .................... G-3

G.1.3 Accident Frequencies $\ldots \ldots \ldots \ldots \ldots \ldots \ldots \ldots \ldots$ G-4

G.1.4 Accident Consequences . . . . . . . . . . . . . . G-4

G.1.4.1 Nuclear Criticality . . . . . . . . . . . . G-8 


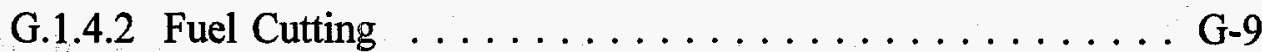

G.1.4.3 Fuel Rupture in Storage .............. G-10

G.1.4.4 Release of RRF Waste Tank Activity ......... G-10

G.1.5 Risk Analysis . . . . . . . . . . . . . . . G-10

G.2 Conclusions $\ldots \ldots \ldots \ldots \ldots \ldots \ldots \ldots \ldots \ldots \ldots \ldots \ldots \ldots \ldots$

APPENDIX H ........................... H-1

OPERATIONAL ASPECTS OF TRANSPORTATION $\ldots \ldots \ldots \ldots \ldots \ldots \mathrm{H}-2$

APPENDIX I . . . . . . . . . . . . . . . . . . . . . . I-1

DISCUSSION OF MARITIME TRANSPORT OPTIONS $\ldots \ldots \ldots \ldots \ldots \ldots \mathrm{I}-2$

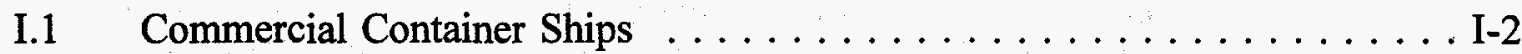

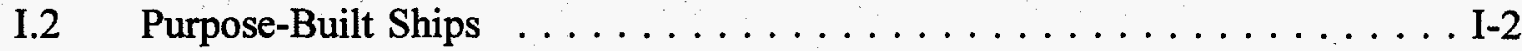

I.3 Military-Controlled Vessels $\ldots \ldots \ldots \ldots \ldots \ldots \ldots \ldots \ldots \ldots \ldots$ I-3

APPENDIX J . . . . . . . . . . . . . . .

DESCRIPTION OF ALTERNATE PORTS OF ENTRY $\ldots \ldots \ldots \ldots \ldots . . . . .2$

J.1 Port of New York and New Jersey - Elizabeth, New Jersey, Terminals . . J J-2

J.2 Hampton Roads . . . . . . . . . . . . . . . . . J-2

J.2.1 General Information . . . . . . . . . . . . . J-4

J.2.2 Equipment and Operations/Newport News Marine Terminal (NNMT) ...................... J-5

J.2.3 Equipment and Operations/Norfolk International Terminal (NIT) . . J-5

J.2.4 Equipment and Operations/Portsmouth Marine Terminal (PMT) . . J-6

J.3 Kings Bay Naval Submarine Base, Georgia $\ldots \ldots \ldots \ldots \ldots \ldots$ J-6

J.4 Port of Morehead City Terminal $\ldots \ldots \ldots \ldots \ldots \ldots \ldots \ldots \ldots$ J-8

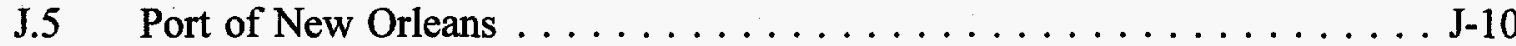

J.6 Port of Oakland . . . . . . . . . . . . . . . . .

J.7 U.S. Naval Weapons Station, Yorktown, Virginia $\ldots \ldots \ldots \ldots \ldots$ J-11

APPENDIX K . . . . . . . . . . . . . . . . . . . . . . . K-1

U.S. DELEGATION RESEARCH REACTOR SITE VISIT QUESTIONS $\ldots \ldots \mathrm{K}-2$

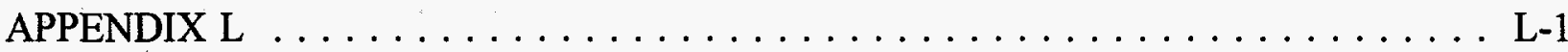

ENVIRONMENTAL CONSEQUENCES ASSOCIATED WITH ALTERNATE PORTS AND NUMBERS OF CASKS $\ldots \ldots \ldots \ldots \ldots \ldots \ldots \ldots$ L-2

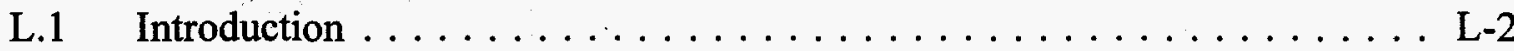

L.2 Comparison Between Alternate Ports and Proposed Ports .......... L-2

L.3 Comparison of Alternate Representative Routes for Truck Shipment From Sunny Point and Wilmington to Savannah River Site ....... L-2

L.4 Comparison Between Intermodal Transfer Methods for Transfer

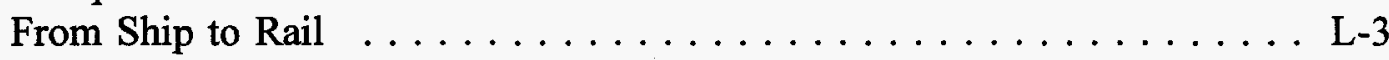

L.5 Conclusion $\ldots \ldots \ldots \ldots \ldots \ldots \ldots \ldots \ldots \ldots \ldots \ldots \ldots \ldots \ldots \ldots \ldots \ldots \ldots$

LITERATURE CITED $\ldots \ldots \ldots \ldots \ldots \ldots \ldots \ldots \ldots \ldots \ldots$ LIT-1 


\section{LIST OF FIGURES}

Figure 5-1. Location of the Savannah River Site . . . . . . . . . . . . . 5-13

Figure 6-1. Maximum Incident-Free Doses for Potentially Exposed Individuals for

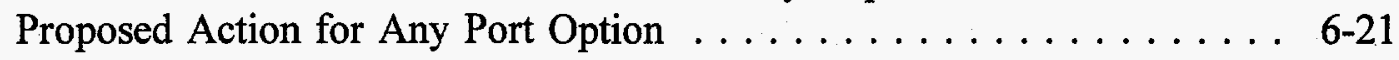

Figure 6-2. Schematic View of the Reactor Basin for Offsite Fuel . . . . . . . . . 6-23

Figure G-1. Individual Site Boundary Risks from Potential Accidents .......... G-5

Figure G-2. Collocated Worker Risks from Potential Accidents . . . . . . . . . . . G-6

Figure H-1. Representative Rail Routes . . . . . . . . . . . . . . . H-6

Figure H-2. Representative Highway Routes $\ldots \ldots \ldots \ldots \ldots \ldots \ldots \ldots$ H-7 
Table 1-1. $\quad$ Status of RERTR Program Participants - Foreign Research and Test Reactors with Power $\geq 1 \mathrm{MW}$ that Use or Formerly Used HEU of U.S.

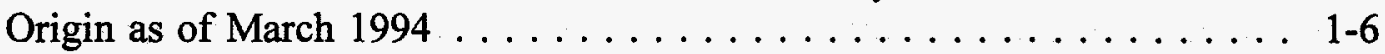

Table 2-1. Number of Foreign Research Reactors That Use or Formerly Used HEU and LEU of United States Origin . . . . . . . . . . . . . 2-1

Table 2-2. Application of the Criteria by Determining Reactors in Need of Urgent-Relief . . . . . . . . . .

Table 2-3. Risoe Spent Fuel Storage Capacity ................ 2-16

Table 2-4. Location of All Ninety-one Lifting Plugs as of January 27, 1994 . . . . . . 2-17

Table 3-1. Research Reactors In Need of Urgent Relief . . . . . . . . . . . . . . . 3-1

Table 3-2. Representative Total Transportation Cost to Reactor Operator . . . . . . . 3-6

Table 3-3. Ports Closest in Proximity to the Savannah River Site . . . . . . . . . . 3-9

Table 3-4. Highway and Population Characteristics Associated with the

Representative Routes for the Proposed Ports . . . . . . . . . . 3-10

Table 4-1. Acceptance of Alternative Numbers of Spent Fuel Elements . . . . . . . . 4-2

Table 4-2. Transportation Costs Per Type of Shipment . . . . . . . . . . . 4-8

Table 5-1. Sea Distances From Foreign Ports to the Proposed Ports of Entry . . . . . 5-1

Table 5-2. Representative Highway Distances from U.S. Ports of Entry to the Savannah River Site . . . . . . . . . . . . . . . 5-12

Table 6.1-1. Ship's Crew (Cargo Inspectors) Dose for Incident-free Shipment of 409 Elements Through the Proposed Ports of Entry Assuming Three Intermediate Port Stops . . . . . . . . . . . . . . . . 6 6-6

Table 6.1-2. Description of Risk Groups for Port Handling and Overland Transport . . 6-9

Table 6.1-3. Maximum Individual Incident-Free Radiological Impacts for the Proposed Action: 409 Spent Fuel Elements Shipped to the Savannah River Site via Highway Transportation . . . . . . . . . . . 6-10

Table 6.1-4. Incident-Free Radiological Risk for the Proposed Action: Shipment of 409 Spent Nuclear Fuel Elements to the Savannah River Site via Highway Transportation $\ldots \ldots \ldots \ldots \ldots \ldots \ldots \ldots . \ldots \ldots$ 6-11

Table 6.1-5. Hypothetical Accident Conditions for Type B Packages . . . . . . . . 6 6-16

Table 6.1-6. Radiological Accident Risks in Port: 409 Spent Fuel Elements Shipped Assuming Three Intermediate Port Stops and One Cask Per Ship, Versus No Intermediate Port Stops and Eight Casks Per Ship . . . . . . . 6-16

Table 6.1-7. Radiological Accident Risks for Highway Transportation: 409 Spent Fuel Elements Shipped to the Savannah River Site via Truck . . . . . .

Table 6.1-8. Transportation Radiological Impacts for Shipment of 409 Elements via the Proposed Ports and Truck Overland Transport Assuming Three Intermediate Port Stops and One Cask Per Vessel . . . . . . . . . . 6-20

Table 6.1-9. Transportation Radiological Impacts for Shipment of 409 Elements via the Proposed Ports and Truck Overland Transport Assuming No Intermediate Port Stops and Eight Casks Per Vessel . . . . . . . . . . . 


\section{LIST OF TABLES (Continued)}

Table 6.1-10. Maximum Annual Nonradiological Fatalities Associated with Highway Shipments for the Proposed Action . . . . . . . . . . . . . . .

Table 6.1-11. Radionuclide Releases and Frequencies Associated with a Potential Accident at the Savannah River Site . . . . . . . . . . . . . . .

Table 6.1-12. Consequences and Risks from Potential Accidents Maximally Exposed Individual at the Site Boundary

Table 6.1-13. Consequences and Risks from Potential Accidents, Co-located Worker Maximally Exposed Individual . . . . . . . . . . . . . . .

Table 6.1-14. Consequences and Risks From Potential Savannah River Site Accidents, Offsite Population . . .....................

Table 6.2-1. Transportation Radiological Impacts for Shipment of 953 Elements via the Proposed Ports and Truck Overland Transport Assuming Three Intermediate Port Stops and One Cask per Vessel . . . . . . . . . . .

Table 6.2-2. Transportation Radiological Impacts for Shipment of 953 Elements via the Proposed Ports Assuming No Intermediate Port Stops and Eight Casks Per Vessel

Table 6.2-3. Transportation Radiological Impacts for Shipment of 359 Elements via the Proposed Ports and Truck Overland Transport Assuming Three Intermediate Port Stops and One Cask Per Vessel . . . . . . . . . . .

Table 6.2-4. Transportation Radiological Impacts for Shipment of 359 Elements via the Proposed Ports and Truck Overland Transport Assuming No Intermediate Port Stops and Eight Casks Per Vessel . . . . . . . . . .

Table 6.2-5. Transportation Radiological Impacts for Shipment of 291 Elements via the Proposed Ports and Truck Overland Transport Assuming Three Intermediate Port Stops and One Cask Per Vessel . . . . . . . . . . .

Table 6.2-6. Transportation Radiological Impacts for Shipment of 291 Elements via the Proposed Ports and Truck Overland Transport Assuming No Intermediate Ports and Eight Casks Per Vessel . . . . . . . . . . .

Table 6.2-7. Transportation Radiological Impacts for Shipment of 248 Elements via the Proposed Ports and Truck Overland Transport Assuming Three Intermediate Port Stops and One Cask Per Vessel . . . . . . . . . .

Table 6.2-8. Transportation Radiological Impacts for Shipment of 248 Elements via the Proposed Ports and Truck Overland Transport Assuming No Intermediate Port Stops and Eight Casks Per Vessel . . . . . . . . . 6-34

Table 6.2-9. Transportation Radiological Impacts for Shipment of 409 Elements via the Alternate Ports and Truck Overland Transport Assuming Three Intermediate Port Stops and One Cask Per Vessel . . . . . . . . . .

Table 6.2-10. Transportation Radiological Impacts for Shipment of 409 Elements via the Alternate Ports and Truck Overland Transport Assuming No Intermediate Port Stop and Eight Casks Per Vessel 


\section{LIST OF TABLES (Continued)}

Table 6.2-11. Transportation Radiological Impacts for Shipment of 409 Elements via the Proposed Ports and Rail Overland Transport Assuming Three Intermediate Port Stops and One Cask per Vessel . . . . . . . . . . . . . 6-38

Table 6.2-12. Transportation Radiological Impacts for Shipment of 409 Elements via the Proposed Ports and Rail Overland Transport Assuming No Intermediate Port Stops and Eight Casks per Vessel . . . . . . . . . . . .

Table 6.2-13. Incident-Free Radiological Risk for the Alternative Action: Shipment of 409 Spent Nuclear Fuel Elements to the Savannah River Site via Rail Transportation with Direct Ship-to-Rail Intermodal Transfer at the Port of Entry . . . . . . . . . . . . . . . . . . .

Table 6.3-1. Cumulative Individual Annual Radiation Dose for Maximally Exposed Individuals in Proposed Ports of Entry . . . . . . . . . . . . . . . . 6-44

Table C-1. Capability to Unload Containerized Cargo . . . . . . . . . . . . C-8

Table C-2. Seaports Meeting First Criterion and Evaluated for Lowest Population . . C-10

Table C-3. Closest in Proximity to the Savannah River Site . . . . . . . . . . . . . C-12

Table C-4. Distance from Sea for Ports with Most Appropriate Facilities, Lowest in Population, and Closest in Distance . . . . . . . . . . . . C-13

Table E-1. Highway Route for Proposed Port of Charleston to the Savannah River Site . . . . . . . . . . . . . . . . . . . . . . . . E E-7

Table E-2. Highway Route for Proposed Port of Jacksonville to the Savannah River Site . . . . . . . . . . . . . . . . . . . . . . E-8

Table E-3. Highway Route for Proposed Port of Savannah to the Savannah River Site . . . . . . . . . . . . . . . . . . . . . . . . . . . . . . E E-9

Table E-4. Highway Route for Proposed Port of Sunny Point to the Savannah River Site . . . . . . . . . . . . . . . . . . . . . E-10

Table E-5. Highway Route for Proposed Port of Wilmington to the Savannah River Site . . . . . . . . . . . . . . . . . . . . . . . E E-11

Table E-6. Summary of Highway Route Data for all Ports of Entry . . . . . . . . . E-12

Table E-7. Accident Severity Categories Used in Analysis . . . . . . . . . . . . . E-12

Table E-8. RADTRAN Accident Probability Data by Mode . . . . . . . . . . . . . E-13

Table E-9. Release Fractions for Foreign Research Reactor Spent Fuel By Accident Severity Category . . . . . . . . . . . . . . . . . . . E-14

Table F-1. Radionuclide Inventories of Foreign Research Reactor Spent Nuclear Fuel $\ldots \ldots \ldots \ldots \ldots \ldots \ldots \ldots \ldots \ldots$ F-3

Table F-2. Input Parameters for Radionuclide Inventory Estimates . . . . . . . . . F-8

Table G-1. Potential Accident Radionuclide Releases and Frequencies . . . . . . . . . G G-4

Table G-2. Site Boundary Maximally Exposed Individual Consequences and Risks from Potential Accidents . . . . . . . . . . . . . . . . . G-7

Table G-3. Collocated Worker Consequences and Risks from Potential Accidents ... G-7 Table G-4. Offsite Population Consequences and Risks from Potential Accidents . . . G-8 
Table J-1. Distances in Kilometers (km) Between Foreign Ports and Alternative Atlantic Ports ......................... J-3

Table J-2. Distances from Proposed Alternate Ports of Entry to the SRS . . . . . . J-4

Table L-1. Transportation Radiological Impacts for Shipment of 953 Elements via the Proposed Ports and Truck Overland Transport Assuming No

Intermediate Port Stops and One Cask Per Vessel . . . . . . . . . . . . . L-4

Table L-2. Transportation Radiological Impacts for Shipment of 409 Elements Via the Proposed Ports and Truck Overland Transport Assuming No Intermediate Port Stops and One Cask Per Vessel . . . . . . . . . . . . . . L-4

Table L-3. Transportation Radiological Impacts for Shipment of 359 Elements Via the Proposed Ports and Truck Overland Transport Assuming No Intermediate Port Stop and One Cask Per Vessel . . . . . . . . . . . . . L-5

Table L-4. Transportation Radiological Impacts for Shipment of 291 Elements Via the Proposed Ports and Truck Overland Transport Assuming No Intermediate Port Stops and One Cask Per Vessel . . . . . . . . . . . . . L-5

Table L-5. Transportation Radiological Impacts for Shipment of 248 Elements Via the Proposed Ports and Truck Overland Transport Assuming No Intermediate Port Stops and One Cask Per Vessel . . . . . . . . . . . . . . L-6

Table L-6. Transportation Radiological Impacts for Shipment of 953 Elements Via the Alternate Ports and Truck Overland Transport Assuming Three Intermediate Port Stops and One Cask Per Vessel . . . . . . . . . . . . L-6

Table L-7. Transportation Radiological Impacts for Shipment of 359 Elements via the Alternate Ports and Truck Overland Transport Assuming Three Intermediate Port Stops and One Cask Per Vessel . . . . . . . . . . . . L-7

Table L-8. Transportation Radiological Impacts for Shipment of 291 Elements via the Alternate Ports and Truck Overland Transport Assuming Three Intermediate Port Stops and One Cask Per Vessel . . . . . . . . . . . . . L-7

Table L-9. Transportation Radiological Impacts for Shipment of 248 Elements via the Alternate Ports and Truck Overland Transport Assuming Three Intermediate Port Stops and One Cask Per Vessel . . . . . . . . . . . . . L-8

Table L-10. Transportation Radiological Impacts for Shipment of 953 Elements via the Alternate Ports and Truck Overland Transport Assuming No Intermediate Port Stops and One Cask Per Vessel . . . . . . . . . . . . . L-8

Table L-11. Transportation Radiological Impacts for Shipment of 409 Elements Via the Alternate Ports and Truck Overland Transport Assuming No Intermediate Port Stops and One Cask Per Vessel . . . . . . . . . . . . . . . L-9

Table L-12. Transportation Radiological Impacts for Shipment of 359 Elements via the Alternate Ports and Truck Overland Transport Assuming No Intermediate Port Stops and One Cask Per Vessel 


\section{LIST OF TABLES (Continued)}

Table L-13. Transportation Radiological Impacts for Shipment of 291 Elements via the Alternate Ports and Truck Overland Transport Assuming No Intermediate Port Stops and One Cask Per Vessel . . . . . . . . . . . L L-10

Table L-14. Transportation Radiological Impacts for Shipment of 248 Elements Via the Alternate Ports and Truck Overland Transport Assuming No Intermediate Port Stops and One Cask Per Vessel . . . . . . . . . . . . L L-10

Table L-15. Transportation Radiological Impacts for Shipment of 953 Elements via the Alternate Ports and Truck Overland Transport Assuming No Intermediate Port Stops and Eight Casks Per Vessel . . . . . . . . . . L-11

Table L-16. Transportation Radiological Impacts for Shipment of 359 Elements via the Alternate Ports and Truck Overland Transport Assuming No Intermediate Port Stops and Eight Casks Per Vessel .......... L-11

Table L-17. Transportation Radiological Impacts for Shipment of 291 Elements via the Alternate Ports and Truck Overland Transport Assuming No Intermediate Port Stops and Eight Casks Per Vessel . . . . . . . . . . . L L-12

Table L-18. Transportation Radiological Impacts for Shipment of 248 Elements via the Alternate Ports and Truck Overland Transport Assuming No Intermediate Port Stops and Eight Casks Per Vessel . . . . . . . . . L-12

Table L-19. Transportation Radiological Impacts for Shipment of 409 Elements via the Proposed Ports and Truck Overland Transport Assuming Three Intermediate Port Stops and One Cask Per Vessel . . . . . . . . . . . . L L-13

Table L-20. Transportation Radiological Impacts for Shipment of 409 Elements via the Proposed Ports and Truck Overland Transport Assuming No Intermediate Port Stops and Eight Casks Per Vessel . . . . . . . . . L L-13

Table L-21. Incident-Free Radiological Risk for the Alternative Action: Shipment of 409 Spent Nuclear Fuel Elements to the Savannah River Site via Rail Transportation with Ship-to-Truck/Truck-to-Rail Intermodal Transfer at the Port Of Entry . . . . . . . . . . . . . . . . L L-14 


\section{ACRONYMS}

ACDA Arms Control and Disarmament Agency

AEC U.S. Atomic Energy Commission

ANL Argonne National Laboratory

ANSTO Australian Nuclear Science and Technology Organization

BEIR Biological Effects of Ionizing Radiation

BNFL British Nuclear Fuels, Limited

CEDE committed effective dose equivalent

CEQ Council on Environmental Quality

CERL Construction Engineering Research Laboratory

CFR U.S. Code of Federal Regulations

COCA Certificate of Competent Authority

$\mathrm{COPH}$ Cargoes of Particular Hazard

CRUD Chalk River unidentified deposits

DDRF dose and dose-rate reduction factor

DMA Defense Mapping Agency

DOE U.S. Department of Energy

DOT U.S. Department of Transportation

DTS Defense Transportation System

EA Environmental Assessment

EBRII Experimental Breeder Reactor II

EC European Community

EIS Environmental Impact Statement

EPA U.S. Environmental Protection Agency

EM Environmental Management

ERDA U.S. Energy Research and Development Administration

ESQD explosive safety quantity distance

ETF Effluent Treatment Facility

Euratom European Atomic Energy Community

FMC Federal Maritime Commission

FONSI finding of no significant impact

FRH Fredric R. Harris

FRR foreign research reactor 


\section{ACRONYMS (Continued)}

HEU highly enriched uranium

HFR High Flux Reactor

HMI Hahn-Meitner Institute (Germany)

HOR Hoger Onderwijs Reactor

HRCQ highway-route-controlled quantities

IAEA International Atomic Energy Agency

ICRP International Commission of Radiological Protection

IMCO Intergovernmental Maritime Consultative Organization

IMDG international maritime dangerous goods

IMO International Maritime Organization

INEL Idaho National Engineering Laboratory

INFCE International Nuclear Fuel Cycle Evaluation

IR

installation restoration

IRI Interfaculity Reactor Institute (Netherlands)

ISO International Standards Organization

LCF latent cancer fatality

LEU low enriched uranium

LLEA local law enforcement agency

LT long ton

MARAD U.S. Maritime Administration

MHW mean high water

MLW mean low water

MOT Military Ocean Terminal

MOTSU Sunny Point Military Ocean Terminal

MSC Military Sealift Command

MTHM Metric Tons of Heavy Metal

MURR Missouri University Research Reactor

NAC Nuclear Assurance Corporation

NCDCR North Carolina Department of Cultural Resources

NCRP National Council on Radiation Protection and Measurements

NCSPA North Carolina State Ports Authority

NEA Nuclear Energy Agency

NEPA National Environmental Policy Act of 1969

NID negligible individual dose

NIT Norfolk International Terminal 


\section{ACRONYMS (Continued)}

$\begin{array}{ll}\text { NNMT } & \text { Newport News Marine Terminal } \\ \text { NPT } & \text { Treaty on Non-Proliferation of Nuclear Weapons } \\ \text { NRC } & \text { U.S. Nuclear Regulatory Commission } \\ \text { NSF } & \text { Navy Security Force } \\ & \\ \text { OECD } & \text { Organization for Economic Cooperation and Development } \\ \text { ORNL } & \text { Oak Ridge National Laboratory } \\ \text { OSHA } & \text { Occupational Safety and Health Administration } \\ & \\ \text { PAT } & \text { Plutonium Air Transport } \\ \text { pCi } & \text { picocurie } \\ \text { PEIS } & \text { programmatic environmental impact statement } \\ \text { PMT } & \text { Portsmouth Marine Terminal } \\ \text { PSI } & \text { Paul Scherrer Institute } \\ & \\ \text { RBOF } & \text { Receiving Basin for Offsite Fuels } \\ \text { rem } & \text { roentgen equivalent man } \\ \text { RERTR } & \text { Reduced Enrichment for Research and Test Reactors } \\ \text { RI/FS } & \text { Remedial Investigation/Feasibility Study } \\ \text { RO/RO } & \text { Roll On/Roll Off } \\ \text { RRF } & \text { Resin Regeneration Facility } \\ & \\ \text { SAR } & \text { safety analysis report } \\ \text { SI } & \text { Système International (International System) } \\ \text { SKI } & \text { Swedish Nuclear Power Inspectorate } \\ \text { spent fuel } & \text { spent nuclear fuel } \\ \text { SNIF } & \text { Standard Neutron Irradiation Facility } \\ \text { SNL } & \text { Sandia National Laboratories } \\ \text { SOP } & \text { standard operating procedure } \\ \text { SPA } & \text { State Ports Authority, South Carolina } \\ \text { SPCC } & \text { Oil Spill Prevention Control and Countermeasures Plan } \\ \text { SRS } & \text { Savannah River Site } \\ \text { SRTC } & \text { Savannah River Technology Center } \\ \text { ST } & \text { short tons } \\ \text { TEU } & \text { twenty foot equivalents } \\ \text { TNT } & \text { Trinitrotoluene } \\ \text { TRIGA } & \text { General Atomics Design Research Reactor } \\ \text { TRR } & \text { Taiwan Research Reactor } \\ & \\ & \end{array}$




\section{ACRONYMS (Continued)}

U.K. United Kingdom

USCG U.S. Coast Guard

USEC United States Enrichment Corporation

USMMA U.S. Merchant Marine Academy

VIT Virginia International Terminals

VPA Virginia Port Authority

WSRC Westinghouse Savannah River Company 


$\begin{array}{ll}\text { cu. } & \text { cubic } \\ \mathrm{ft} & \text { feet/foot } \\ \mathrm{g} & \text { gram(s) } \\ \mathrm{hr} & \text { hour(s) } \\ \mathrm{in} . & \text { inch(es) } \\ \mathrm{kg} & \text { kilogram(s) } \\ \mathrm{km} & \text { kilometer(s) } \\ \mathrm{L} & \text { liter(s) } \\ \mathrm{m} & \text { meter(s) } \\ \mathrm{mi} & \text { mile(s) } \\ \mathrm{mil} & \text { million } \\ \mathrm{min} & \text { minute(s) } \\ \mathrm{MLW} & \text { mean low water } \\ \mathrm{MW} & \text { Megawatt(s) } \\ \text { sq. } & \text { squared }\end{array}$




\section{Department of Energy}

Washington, DC 20585

April 22, 1994

\section{Dear Citizen:}

The Department of Energy has completed the Environmental Assessment (EA) of Urgent-Relief Acceptance of Foreign Research Reactor Spent Nuclear Fuel and issued a Finding of No Significant Impact (FONSI) for the proposed action. The EA and FONSI are enclosed for your information.

The Department has decided to accept a limited number of spent nuclear fuel elements $(409$ elements) containing uranium that was enriched in the United States from eight research reactors in Austria, Denmark, Germany, Greece, the Netherlands, Sweden, and Switzerland. This action is necessary to maintain the viability of a major U.S. nuclear weapons nonproliferation program to limit or eliminate the use of highly enriched uranium in civil programs. The purpose of the EA is to maintain the cooperation of the foreign research reactor operators with the nonproliferation program while a more extensive Environmental Impact Statement (EIS) is prepared on a proposed broader policy involving the acceptance of up to 15,000 foreign research reactor spent fuel elements over a 10 to 15 year period.

Based on an evaluation of transport by commercial container liner or chartered vessel, five eastern seaboard ports, and truck and train modes of transporting the spent fuel overland to the Savannah River Site, the Department has concluded that no significant impact would result from any combination of port and mode of transport. In addition, no significant impacts were found from interim storage of spent fuel at the Savannah River Site.

Five ports of entry were proposed in the EA for the receipt of this spent fuel (Wilmington, North Carolina; the U.S. Army Military Ocean Terminal at Sunny Point, North Carolina; Charleston, South Carolina; Jacksonville, Florida; and Savannah, Georgia). We have decided to use Sunny Point, North Carolina, as the port of entry, to the maximum extent practicable, and to transport the spent nuclear fuel overland by rail to the Department's Receiving Basin for Offsite Fuels (RBOF) at the Savannah River Site near Aiken, South Carolina, for interim storage. RBOF is currently capable of receiving and storing this spent fuel within its present capacity.

The Department plans to accept up to 15 spent fuel casks lexpected in two to three ocean shipments) over the next several months. The first shipments could occur as soon as this summer. In preparing the EA, the Department has worked closely with the Sunny Point port authorities to assure the utmost safety in the handling of spent nuclear fuel.

The Department considers that the decision to accept this small number of urgent-relief shipments will not prejudice decisions to be made under the broader EIS discussed above. The EIS is scheduled to be issued as a draft for public comment at the end of 1994. The final EIS and Record of Decision are scheduled to be complete by the end of 1995 .

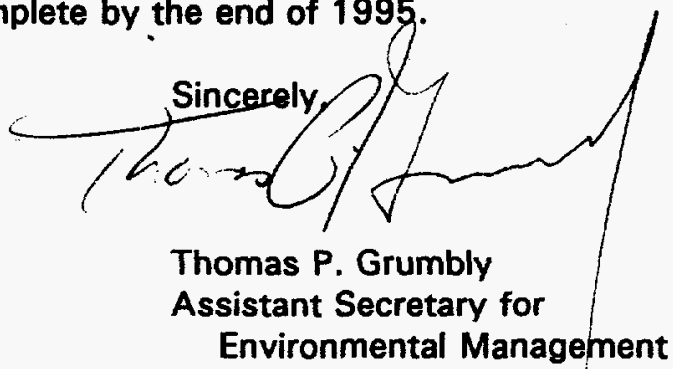

2 Enclosures 
[6450-01-P]

\section{U.S. Department of Energy}

Finding of No Significant Impact

for the

Urgent-Relief Acceptance of

Foreign Research Reactor Spent Nuclear Fuel

AGENCY: United States Department of Energy (DOE)

ACTION: Finding of No Significant Impact

SUMMARY: In compliance with the National Environmental Policy Act, 42 U.S.C. 4321 et seq., the Council on Environmental Quality's implementing regulations, 40 C.F.R. Parts 1500-1508, D0E's implementing procedures, 10 C.F.R. Part 1021, and Executive Order 12114, Environmental Effects Abroad of Major Federal Actions, the DOE has prepared an Environmental Assessment (DOE/EA-0912, April 1994) to evaluate the potential environmental impacts of the proposed urgent-relief acceptance of foreign research reactor spent nuclear fuel.

The Environmental Assessment analyzed the potential environmental impacts under the proposed action of accepting up to 409 spent nuclear fuel elements from eight reactors in Europe for storage in an existing DOE wet storage facility to meet the urgent needs of certain foreign research reactor operators and to avoid failure of a key United States nuclear weapons nonproliferation objective of minimizing and eventually eliminating the use of highly enriched uranium in civil programs worldwide. Specifically, the Environmental Assessment analyzed the potential impacts of transporting the spent nuclear fuel elements by commercial or chartered vessel from eight reactors in Europe to any one of five ports of entry in the United States (Wilmington, North Carolina; the Army 
Military Ocean Terminal at Sunny Point, North Carolina; Charleston, South Carolina; Savannah, Georgia; and Jacksonville, Florida), off-loading the spent fuel at the port of entry and transporting it by truck or rail to the Savannah River Site, near Aiken, South Carolina; and storing the spent fuel there until decisions are made regarding interim storage and ultimate disposition. The Nuclear Waste Policy Act authorizes ultimate disposal of the spent fuel in a geologic repository.

In October 1993, DOE provided a draft Environmental Assessment for comment to the States of Georgia and South Carolina, and the Commonwealth of Virginia, and interested individuals and organizations. In February 1994, DOE provided a revised draft Environmental Assessment to the States of Florida, Georgia, North Carolina, and South Carolina, the Commonwealth of Virginia, and to individuals and groups known to have an interest in the proposed action, and requested that comments on the draft Environmental Assessment be submitted by March 7, 1994. On February 10, 1994, Federal, State and local government representatives, citizen groups, individuals and members of the international community attended a meeting in Washington, $D C$, to present their views concerning the proposed action. DOE also held public meetings in communities potentially affected by the proposed acceptance of foreign research reactor spent fuel. On March 18, 1994, the comment period on the draft Environmental Assessment was extended until April 8, 1994, to provide an additional opportunity for stakeholders to provide comments. The Environmental Assessment has been revised, where appropriate, to reflect comments received during the comment period. 
Based on an evaluation of the use of either commercial or chartered vessels, the proposed ports of entry and alternative modes of transporting the spent nuclear fuel (truck or train) from the port of entry to the Savannah River Site, DOE has concluded that no significant impact would result from receipt of the spent fuel at any of the five proposed ports and overland transport by rail or truck from the port of entry to the Savannah River Site. Therefore, based on the analysis in the Environmental Assessment and after careful consideration of all comments from Federal, State and local officials, members of the public and from the international community, DOE has determined that the acceptance of up to 409 spent nuclear fuel elements from eight foreign research reactors in Europe for storage at the Savannah River Site does not constitute a major Federal action significantly affecting the quality of the human environment, within the meaning of the National Environmental Policy Act. Accordingly, an Environmental Impact Statement is not required and the DOE is issuing this Finding of No Significant Impact.

However, upon further consideration, and in an effort to balance the domestic and international interests at stake, DOE has decided to implement the proposed action as follows. The spent fuel will be shipped either by commercial or chartered vessel from Europe to the Army's Military Ocean Terminal at Sunny Point, North Carolina to the maximum extent practicable (rather than allowing the shipper to select from among any one of the five proposed ports as described in the Environmental Assessment), and transported overland by rail (rather than truck). Should DOE determine that another port or mode of transport (from among those considered as the proposed action) is necessary, DOE will provide direct notice of the change to State and local government officials of the affected 
States and will notify the public through local media and other means, as appropriate.

ADDRESSES AND FURTHER INFORMATION: Persons requesting additional information regarding this action or desiring a copy of the Environmental Assessment should contact:

Mr. David Huizenga

Office of Environmental Management

U.S. Department of Energy (Mail Stop EM-30)

1000 Independence Avenue, SW

Washington, DC 20585

(202) $586-9441$

Copies of the Environmental Assessment are available for public review at the following DOE reading rooms and public libraries:

Aiken, South Carolina

DOE Public Reading Room

Gregg-Graniteville Library

171 University Parkway

Aiken, SC 29801

(803) $641-3465$

Charleston, South Carolina

Charleston County Public Library 404 King Street

Charleston, SC 29403

(803) 723-1645

Savannah, Georgia

Chatham County Public Library 2002 Bull Street

Savannah, GA 31499-4301

(912) 234-5127
Jacksonville, florida

Haydon Burns Public Library

Attn: Technical Services Dept.

$122 \mathrm{~N}$. Ocean Street

Jacksonville, FL 32202

(904) $630-2665$

Wilmington, North Carolina

New Hanover County Public Library

Attn: Daniel Horn

201 Chestnut Street

Wilmington, NC 28401

(910) 341-4390

Brunswick County, North Carolina

Brunswick County Manager's Office

Attn: Joyce Johnson

P.0. Box 249

45 Courthouse Drive

Bolivia, NC 28422

(910) 253-4331 
Mashington, $D C$

DOE Freedom of Information

Reading Room

Forrestal Building, Room 1E-190

1000 Independence Avenue, SW

Washington, DC 20585

(202) $586-6020$

For general information regarding DOE's National Environmental Policy Act process, please contact:

Ms. Carol M. Borgstrom

Office of National Environmental Policy Act Oversight

U.S. Department of Energy (Mail Stop EH-25)

1000 Independence Avenue, SW

Washington, DC 20585

(202) $586-4600$ or $(800) \quad 472-2756$

SUPPLEMENTARY INFORMATION: In the 1950's, as part of the "Atoms for Peace" program, the United States began providing assistance in the peaceful application of nuclear technologies to countries that agreed to forego the development of nuclear weapons. This assistance included the provision of highly enriched uranium for use in research reactors around the world. After irradiation in the reactor, the used (spent) fuel was transported to the United States, where it was reprocessed to extract the uranium still remaining in the spent fuel. In this way, the United States maintained control of the highly enriched uranium, which otherwise could be used to make nuclear weapons.

To reduce the danger of nuclear weapons proliferation, the United States began a program in 1978 aimed at minimizing and eventually eliminating the use of highly enriched uranium in civilian reactor programs worldwide. This effort (the Reduced Enrichment for Research and Test Reactors Program) was directed at replacing the highly enriched uranium used in research reactors with low 
enriched uranium, a material that is not directly usable in nuclear weapons. Research reactors are of particular interest because the major civilian use of highly enriched uranium is as fuel in research reactors. If research reactors worldwide were to convert to low enriched uranium fuels, highly enriched uranium essentially would be eliminated from use in civil commerce.

For research reactors converting to low enriched uranium fuel, acceptance of spent fuel by the United States was viewed as essential to offset the substantial expenses and reduction in reactor efficiency and capability resulting from conversion. The United States accepted highly enriched uranium spent fuel for several decades, until the program was allowed to expire in 1988.

DOE decided in mid-1993 to prepare an Environmental Impact Statement on a new proposed policy to accept, over a 10-15 year period, up to 15,000 spent fuel elements containing uranium enriched in the United States. The goal of the proposed long-term policy would be to recover highly enriched uranium exported from the United States, while giving foreign research reactor operators sufficient time to develop their own long-term solutions for storage and disposal of spent fuel. Although the Environmental Impact Statement is under preparation, DOE does not expect to complete the analysis and make a decision on whether to implement the policy until mid to late 1995.

Because DOE has not accepted any spent fuel containing uranium enriched in the United States for more than five years, several foreign research reactor operators are running out of storage capacity and facing safety and regulatory 
issues associated with the presence of spent fuel at their sites. If the United States is unable to commit now to the near-term acceptance of a small amount of foreign research reactor spent fuel, several reactor operators soon will either shut down their reactors or ship their spent fuel offsite for reprocessing. Neither option would serve the nonproliferation interests of the United States. Thus, at the urging of the Department of State, DOE is proposing to accept a small number of highly enriched uranium spent fuel elements in the near term for storage in an existing federal facility in South Carolina.

DOE believes that preparation of the Environmental Assessment, which analyzes the potential environmental impacts of the proposed urgent-relief acceptance of a small number of spent fuel elements before the Environmental Impact Statement is completed, fully complies with the National Environmental Policy Act and its implementing regulations. The proposed near-term acceptance is justified independently of the decision on whether to establish a new policy on the proposed long-term acceptance of foreign research reactor spent fuel. Until the Environmental Impact Statement is completed and a decision made whether to implement the proposed long-term acceptance policy, the proposed acceptance of a small number of spent fuel elements is necessary to maintain the United States program of encouraging the conversion by research reactors to low enriched uranium fuel. Further, while there is an obvious relationship between the two proposals, a decision to accept such a small number of fuel elements does not foreclose or prejudice future decisions regarding establishment of a new spent fuel acceptance policy, or the decisions regarding interim storage or ultimate disposition of spent nuclear fuel. (In the Programmatic Spent Nuclear Fuel Management Environmental Impact Statement, due to be completed by June 1995, DOE 
is considering where to manage all spent fuel within the DOE complex nationwide for the interim period prior to ultimate disposition.)

In October 1993, to ensure that countries currently possessing spent fuel continue to support the nonproliferation initiatives of the United States embodied in the Reduced Enrichment for Research and Test Reactor Program until the ongoing Environmental Impact Statement can be completed, DOE issued for comment a draft Environmental Assessment which evaluated the proposed urgentrelief acceptance of up to 700 elements of foreign research reactor spent nuclear fuel containing uranium enriched in the United States. It was apparent from the comments that DOE received in response to the October 1993 draft that many people did not agree that there is a need for the United States to accept this spent fuel. Others expressed concerns regarding DOE's plans for implementing the proposed action. Subsequent to the release of the October 1993 draft Environmental Assessment and after consideration of comments received, teams of experts from the United States visited foreign research reactors in Europe and Australia to assess the near-term need for acceptance of foreign research reactor spent fuel elements before the Environmental Impact Statement on the proposed long-term acceptance policy is completed.

In February 1994, a revised draft Environmental Assessment, which included revisions made in response to comments received on the October $1993 \mathrm{draft}$ Environmental Assessment, was prepared and issued for public review and comment. The proposed action evaluated in the February draft Environmental Assessment was to accept 448 highly enriched uranium spent fuel elements shipped by sea to any one of seven ports (Newport News, Norfolk, or Portsmouth, Virginia; Charleston, 
South Carolina; Wilmington, North Carolina; Savannah, Georgia; and Jacksonville, Florida) and then by truck to DOE's Savannah River Site near Aiken, South Carolina, for storage. The comment period on the revised draft Environmental Assessment was scheduled to close on March 7, 1994. On February 10, 1994, DOE and the Department of State co-hosted a meeting of stakeholders from State and local governments, Congress, environmental and non-proliferation public interest groups, other private sector interest groups, foreign research reactor operators and key affected communities. The purpose of that meeting was to involve stakeholders in a meaningful and constructive dialogue on the proposed urgent-relief acceptance of a small number of spent fuel elements from foreign research reactors. Subsequent to that meeting and based on concerns raised by local communities potentially affected by the proposed action, DOE extended the comment period on the February draft Environmental Assessment until April 8, 1994.

PROPOSED ACTION: The DOE proposes to accept up to 409 spent nuclear fuel elements containing highly enriched uranium of United States origin from eight research reactors in seven European countries (Austria, Denmark, Germany, Greece, Netherlands, Sweden and Switzerland). The spent fuel would be shipped across the ocean in up to 15 spent fuel transportation casks from the country of origin to one or more United States eastern seaboard ports. The casks are expected to be transported in the next several months either by commercial container ships or chartered ships. Several casks could be transported together on a single ship to any one of the five proposed ports of entry: Wilmington and the United States Army's Military Ocean Terminal at Sunny Point, North Carolina; Charleston, South Carolina; Savannah, Georgia; and Jacksonville, Florida. 
After arriving in the United States, the casks would be transported to DOE's Savannah River Site near Aiken, South Carolina, where the fuel elements would be stored underwater in an existing storage facility (the Receiving Basin for Offsite Fuels).

\section{ENVIRONMENTAL IMPACTS OF THE PROPOSED ACTION:}

Routine Operation: During routine (non-accident condition) ocean transport, there would be no impact to the marine environment. Radiation exposure from the very small radiation fields being emitted from the casks -. about 1 millirem per hour at 1 meter from the cask surface -- would be limited primarily to crew members who inspect the cargo on a daily basis to ensure secure stowage and structural safety of the vessel. Incident-free dose estimates to these crew members would be essentially the same regardless of the port of entry, largely because the exposure is proportional to the numbers of inspections over time. Distances and time of transit are similar from the European ports to the proposed United States ports of entry. Assuming that the ship makes three intermediate port stops and then unloads at the fourth stop, the incident-free dose to a ship cargo inspector is estimated to be $4.3 \mathrm{millirem}$ for shipments into Sunny Point and Wilmington, North Carolina; 4.5 millirem for shipments into Charleston, South Carolina; and 4.6 millirem for shipments into Jacksonville, Florida and Savannah, Georgia. The likelihood of a single fatal cancer among the entire crew of all the ships used in the proposed action is approximately one in 450,000 . If no intermediate port stops are assumed, the collective dose would be reduced by approximately 30 percent. 
Because container cargo handling is relatively uniform throughout the world, exposure to port workers (handlers/inspectors) also would be essentially the same regardless of the port of entry. Using a conservative assumption, i.e., the same handler/inspector inspects all shipments, the maximally exposed port worker would receive a dose of approximately 5.2 millirem. The collective exposure (assuming the same crew of handlers/inspectors for all shipments) to the handlers/inspectors is estimated as 0.078 person-rem $10.0052 \mathrm{rem} \times 15$ workers). The likelihood of a single individual port worker dying from cancer as a result of the proposed action is about 1 in 380,000 . Dose to members of the general public during port operations would be extremely low because residences are separated from dock facilities by buffer spaces such as parking lots, warehouses and other port facilities.

During truck transport of the spent fuel from the port of entry to the Savannah River Site, the maximally exposed individual truck crew member (assuming the same person is involved in all truck shipments) would receive 2.4 millirem for shipments from Charleston, South Carolina; 2.7 millirem for shipments from Savannah, Georgia; 4.1 millirem for shipments from Wilmington, North Carolina; 4.5 millirem for shipments from Sunny Point, North Carolina; and 3.9 millirem for shipments from Jacksonville, Florida. The likelihood of a single crew member dying from cancer as a result of transporting spent fuel from Sunny Point to the Savannah River Site is about 1 in 440,000 .

The maximum exposure to an individual not actively involved in shipping the spent fuel during routine transport was estimated for two cases: (1) a member of the public who lives beside the highway route (this individual was assumed to 
be exposed to each of the 15 truck shipments at a distance of 30 meters); and (2) an individual located near a stopped truck, e.g., in a traffic jam. The maximum in-transit dose under the first instance was calculated to be 0.002 millirem for routine operations. A dose of 0.002 millirem would increase the risk of a latent cancer fatality by 1 in one billion. For the second case, an individual could receive doses higher than 0.002 millirem depending on the duration of the stop and the distance of the individual from the truck. For example, in the unlikely event that a person was standing outside a stopped truck for a period of $1 / 2$ hour at a distance of two meters, the person could receive a dose of one millirem.

Since port workers, inspectors, and truck drivers are not considered radiation workers, as defined by the Nuclear Regulatory Commission (NRC), the maximum annual allowable exposure for these personnel would be $100 \mathrm{millirem}$, the same radiation dose limit established by the NRC to protect the individual members of the general public. As discussed above, during normal transport of the spent nuclear fuel, the maximum annual exposure to the public, port workers, inspectors, and truck drivers would be well below the 100 millirem dose limit, and no doses 1 arge enough to result in acute health effects are predicted among either the workers or general public for the proposed action. The cumulative annual incident-free dose from the proposed activity to all persons potentially exposed would range between 0.12 person-rem (Charleston and Savannah) and 0.16 person-rem (Sunny Point).

Currently, the average annual individual worker dose at the Receiving Basin for off-Site Fuels (RBOF) for all operations (unloading, handling and storage of the 
spent nuclear fuel elements) is approximately 150 millirem. Based on very conservative assumptions, i.e., all 409 spent fuel elements are received in a one-year period and the same individuals unload all 15 casks, the maximum annual increase in the average individual dose to a worker at RBOF is estimated to be 60 millirem. This dose would be well below both the DOE limit of 5,000 millirem per year for radiation workers and the DOE Administrative control level of 2,000 millirem per year per person, for all DOE activities. Once the spent fuel elements were stored under water in the RBOF, the increase in radiation exposure to facility personnel from the storage of the foreign spent fuel elements would not be detectable.

Only minor environmental impacts would be expected from the proposed action because the receipt and storage of up to 409 spent fuel elements represents only a small increase to existing site activity and involves no new construction. Approximately 15 cubic feet of laundry type waste and 5.5 cubic feet of solid waste would be generated per cask. The proposed action would add less than 4 percent to the average annual solid waste normally generated at RBOF. Receipt and storage of foreign research reactor spent nuclear fuel would have no effect on the types, quantities or utilization of hazardous compounds stored at RBOF, and no incremental risk to workers would be expected.

Accident Conditions: The Environmental Assessment evaluates the potential for accidents during ocean transport (port departure, ocean crossing, and port arrival), overland transport, and storage at RBOF. 
In the extremely unlikely event of an accidental fire at sea in which a cask was sufficiently damaged by the fire to release its contents, members of the ship crew near the fire would be exposed to the released radioactive material. However, any crew member close enough to the fire to suffer a significant radiation dose likely would be more severely injured from the fire than the radiation dose. If crew members were to survive the fire, radiological impacts would be similar to those resulting from a severe accident in port, which would result in a maximum exposure to workers and the public of approximately 0.21 person-rem. This exposure would result in an approximately one in 9,500 chance of one additional cancer in the entire exposed population. If such an accident were to occur at sea, however, there would be essentially no exposure to members of the public, and all released activity would be deposited in the ocean. Assuming that the spent fuel cask lay on the ocean floor where it slowly released its radioactive inventory, the peak doses to biota residing on the ocean floor in or near the uppermost sediment layer are estimated to be 0.11 rad (radiation adsorbed dose) per year for fish, 0.17 rad per year for crustaceans and 7.3 rad per year for mollusks. The radioactive material would be expected to disperse and to be diluted due to the influence of ocean currents. Since deleterious effects of chronic irradiation have not been observed in natural populations at dose rates of less than 365 rad, no significant impacts would be expected. Further, uranium, the major constituent of the spent fuel, has not been found to bioaccumulate in fish and bioaccumulates only slightly in crustaceans and mollusks. No significant chemical hazard would be expected from the release of the contents of the spent fuel elements into the open ocean. 
Spent fuel casks are designed to withstand at least a 15-meter immersion, and it has been demonstrated that the cask seals will remain intact at much greater depths. Further, damaged and undamaged casks can be recovered readily from water up to 200 meters deep. Recovery from depths of up to 2,000 meters may be possible, but would be costly.

In an extreme situation, where the accident occurs in ccastal wasters, the spent fuel is not recovered, and both the spent fuel and cask are damaged, the peak dose to an individual is estimated to be 11 millirem per year. This individual is assumed to reside near the shore and to eat seafood (fish, mollusk, seaweed) harvested from the area in the immediate vicinity of the spent fuel cask.

In the event of the most severe port accident (major mechanical damage, fire, oxidation of 100 percent of the fuel, and release of radioactive material from a cask containing 33 spent fuel elements), the dose to a maximally exposed individual, i.e., an individual assumed to be standing outside approximately 100 feet away from the event and remaining there for 24 hours, would be $25 \mathrm{rem}$. At such close distance, it is highly probable that the individuals, if not evacuated, would be harmed more by the explosion and fire engulfing the cask than by the radiation dose. If the individual were inside a building approximately 100 feet away and remained there for 24 hours after the accident, the dose would be reduced to 0.22 rem. At a more likely distance, where an individual may be located outside for a period of 24 hours after the accident, the dose at 0.6 miles would be $0.21 \mathrm{rem}$. If the person were inside at the same distance, the dose would be $0.002 \mathrm{rem}$. When considered in conjunction with the unlikely probability of occurrence (approximately 1 chance in 7.7 million), the 
accident has an extremely small risk. For example, the risk of developing a single fatal cancer for the most severe case, i.e., individual outside, 100 feet away for 24 hours receiving 25 rem, is about 1 chance in 600 million.

In the event of an overland accident, assuming the surrounding population remains there for a 24 -hour period, the estimated population dose risk is 0.0000015 person-rem for transport from Savannah, 0.0000018 person-rem from Charleston, 0.0000028 person-rem from Wilmington, 0.0000024 person-rem from Jacksonville, and 0.0000035 person-rem from Sunny Point. While there would be slightly different risks among the different ports, no significant impacts would result.

Four hypothetical accidents at RBOF were evaluated that could potentially release radionuclides to the atmosphere. These accidents include: 1) a nuclear criticality incident; 2) a fire and explosion at RBOF; 3) accidental cutting of fuel element cores; and 4) rupture or failure of fuel elements during underwater storage. The maximum dose was attributed to the unlikely accident of 1000 foreign fuel elements rupturing during storage at RBOF. This event would result in an 8.3 millirem maximum dose to the individual at the site boundary and a 70 person-rem dose for the offsite population. The probability of such an accident occurring, however, would be less than one in 2000 years. When the probability is taken into account, there would be an additional 1 in 500 million chance that the individual at the site boundary would develop a fatal cancer, and a 1 in 55,000 chance that a single fatal cancer would occur in the exposed populations. 


\section{ENVIROMMENTAL IMPACTS OF ALTERMATIVES: Alternatives considered in the}

Environmental Assessment include no action, receipt of a greater or lesser number of spent fuel elements, alternate ports of entry, al ternative modes of transport from the receiving port to the Savannah River Site, and reprocessing abroad and transport of low or highly enriched uranium to the United States.

No Action: Under the No Action Alternative, there would be no environmental impact in the United States. However, United States nonproliferation policy would be adversely affected. Foreign reactor operators will try to avoid shutting down their reactors. The operators of two reactors can elect to reprocess thejr spent fuel at an existing facility in Scotland, although one of the two would need United States authorization to do so. Reprocessing would allow the uranium to be extracted for reuse, and thus would increase the threat of nuclear proliferation. Reactor operators in Belgium and Germany resorted to reprocessing on four occasions in 1993 and 1994.

Six of the eight research reactors from which DOE proposes to accept spent fuel either do not have the option to reprocess their spent fuel or could not obtain regulatory authority to reprocess in time to avoid shutdown. Shutdown of these reactors would severely undermine the United States' credibility as a reliable partner in matters of nuclear cooperation. This, in turn, could influence other reactor operators to cease their conversion to low enriched fuel or to revert to the use of highly enriched fuel if they have already converted. In fact, several reactor operators have stated that, if the United States is unable to accept spent fuel, they will cancel or delay their reactor conversions to low enriched uranium fuel. Such actions would encourage development of a world 
market for highly enriched uranium, thereby undermining a key aspect of the United States nonproliferation program.

Selection of the No Action Alternative would also adversely affect the upcoming 1995 international conference on the Treaty on the Non-Proliferation of Nuclear Weapons. The conference will consider the indefinite extension of the Treaty, which the United States strongly supports. Other Treaty parties will want assurance that the United States has fulfilled its obligations under the Treaty to share the benefits of peaceful nuclear cooperation. If several countries that are parties to the Treaty are compelled to shut down their research reactors, thereby foregoing the benefits from these reactors, the United States may be accused, fairly or unfairly, of not sharing the benefits of peaceful nuclear cooperation. Such an accusation, however ill-founded, could create or increase opposition to the indefinite extension of the Treaty, which is the foundation for the international nuclear weapons nonproliferation regime.

Greater or Lesser Number of Spent Fuel Elements Accepted: In addition to the proposed action (shipment of up to 409 spent nuclear fuel elements), the environmental impacts of shipping alternative numbers of spent fuel elements (i.e., 953, 359, 291, and 248 spent fuel elements) were also considered in the Environmental Assessment. The risks for the 953-element alternative are slightly more than double the risks for shipping 409 elements through the proposed ports. Conversely, the risks of shipping 359, 291 and 248 elements are less than the risks for shipping 409 elements. While there are differences in the risks depending upon the number of elements shipped, the impacts associated with the shipment of any alternative number of elements are extremely small. 
Acceptance of up to 409 spent fuel elements would allow the foreign research reactors to ship full casks, and would not force the two reactors that can ship spent fuel to Scotland for reprocessing to do so. (Acceptance of 359 spent fuel elements, i.e., shipment in partially full casks, also would not force these two reactors to reprocess.) In proposing to accept full casks, DOE took note of the fact that there is no significant difference in the environmental impacts between shipping full and partially full casks. Further, shipping full casks is the customary shipping procedure, and more cost-effective. Accordingly, proposing to accept full casks appeared to be a prudent course to encourage the continued participation of foreign research reactors in the Reduced Enrichment for Research and Test Reactors Program.

Other Ports of Entry: The Environmental Assessment al so evaluated the impacts of shipping 409 spent fuel elements through alternate commercial and military ports using two assumptions: (1) no intermediate port stops and eight casks per vessel; and (2) three intermediate port stops and one cask per vessel. Dose to handlers and port workers would be essentially the same from port to port. During ocean transport, dose to the ship's crew would be generally the same regardless of the port of entry. However, dose to the truck's crew showed some slight variation consistent with the distance of travel, i.e., slightly higher doses are associated with greater distances traveled. The dose to the ship's crew and the dose to the truck crew would be well below the 100 millirem limit for nonradiation workers.

None of the alternate ports appeared as advantageous for the proposed receipt of spent fuel as the five proposed ports based on the application of screening 
criteria drawn from the National Defense Authorization Act for Fiscal Year 1994, and additional criteria recommended by a panel of maritime experts at a DOEsponsored workshop on port selection criteria for shipments of spent fuel. While there are comparative advantages and disadvantages among the five proposed ports, all five of the proposed ports appear comparatively more advantageous than other United States seaports for the proposed action.

Other Modes of Overland Transport: The spent nuclear fuel could be transported by rail from the port of entry to the Savannah River site. The incident-free dose to spent fuel cask handlers would depend on how the casks were handled in port. If two casks are shipped per rail car, the handler would continue to receive a small dose from the first loaded cask as the second cask is loaded. Dose would also be influenced by the number of cargo transfers required. For example, if the spent fuel cask cannot be off-loaded directly from the ship to a rail car, spent fuel cask handlers would receive an additional small dose during the transport by truck to the rail car and from the transfer of the cask from the truck to the rail car. In addition, rail cargo is inspected after loading and prior to off-loading. As a result, transport by rail would result in a slightly higher dose to port handlers/inspectors and rail crew than transport by truck. Dose to the public, however, would be generally lower, partly because rail stops would normally occur in rail yards (removed from the general population). For example, rail transport from Sunny Point to the Savannah River Site would result in an annual dose of 0.16 person-rem total to port handlers/inspectors, other port workers and rail crew, and in a dose of 0.0017 person-rem to members of the public. Truck transport of the spent fuel from Sunny Point to the Savannah River Site would result in an annual dose of 0.08 
person-rem to port handlers/inspectors, other port workers and truck crew and a dose of 0.067 person-rem to members of the public. Neither mode of transport would result in a significant health effect.

Reprocessing Abroad and Transport of Low or Highly Enriched Uranium to the United States: The potential environmental impact of transporting low enriched uranium by ship to the United States after reprocessing the spent fuel abroad was analyzed in detail in two recently issued Environmental Assessments prepared by the United States Enrichment Corporation. Low enriched uranium was found to be a common commercial product that has been shipped safety around the world in large quantities by air, water, and land transport modes for over 30 years without significant impact. Consequently, if the spent nuclear fuel elements were reprocessed in Europe (i.e., at Dounreay, Scotland), blended down to low enriched uranium, and the low enriched uranium was returned to the United States, no significant impacts would be expected.

If the spent fuel were reprocessed in Scotland, but not blended down, then highly enriched uranium could be transported from Scotland to the United States for blending. The shipment of highly enriched uranium would require extensive security activities and would involve the use of military assets for protection and safety. The military has had considerable experience in shipment of highly enriched uranium and has safely transported such materials throughout the world without significant impact.

These options, however, would not serve the nonproliferation interests of the United States. As discussed above and in greater detail in the Environmental 
Assessment, reprocessing would likely result in reactor operators postponing conversion from highly enriched uranium fuel, or reverting back to its use if conversion has already been completed. This is because the only current reprocessor of highly enriched uranium does not reprocess low enriched uranium fuel, and reactor operators have only limited capacity to store spent fuel generated as a result of operating. Thus, to continue operating, research reactors would have to continue to use highly enriched uranium fuels. In addition, for those reactors for which United States consent is not required for reprocessing to occur, there is no mechanism to implement or to enforce a blending requirement by the reactor operators or reprocessors. Consequently, reactor operators could elect to have their fuel reprocessed, but not blended. This would result in the continued use of highly enriched uranium fuel by research reactors, contrary to United States nonproliferation policy.

Enhanced Storage in Europe: DOE considered but rejected as unreasonable the alternative of assisting foreign research reactors to expand spent fuel storage capacity at the reactor sites or at other sites in Europe. By the time new facilities could be constructed and licensed, or existing facilities modified, the reactors from which DOE proposes to accept spent fuel would have been forced to send their spent fuel to Scotland for reprocessing, where that is an option, or to shut down. For the reasons discussed above and in greater detail in the Environmental Assessment, forcing research reactors to shut down or reprocess would undermine the gains already realized in converting to low enriched uranium fuels under the Reduced Enrichment for Research and Test Reactors Program. The governments in the countries where these reactors are located have stated that acceptance of spent fuel has become a measure of the United States' reliability 
in worldwide nuclear cooperation. A perceived lack of reliability could complicate upcoming negotiations for renewal of important nonproliferation agreements.

CUMULATIVE IMPACT: In addition to the environmental impacts from the proposed action, the Environmental Assessment also considered the cumulative dose of transporting other shipments of spent fuel to the Savannah River Site and shipments of low-level radioactive materials to the Barnwell facility, east of the Savannah River Site. No significant cumulative effects were identified.

DETERMINATION: Based on the analyses in the Environmental Assessment, and after Careful consideration of comments received, DOE has determined that the acceptance of up to 409 spent nuclear fuel elements from eight foreign research reactors in Europe for storage at the Savannah River Site does not constitute a major federal action significantly affecting the quality of the human environment, within the meaning of the National Environmental Policy Act. Therefore, an Environmental Impact Statement is not required and DOE issues this Finding of No Significant Impact.

Based on an evaluation of the five proposed ports of entry (Jacksonville, Florida; Savannah, Georgia; the Army Military Ocean Terminal at Sunny Point, and Wilmington, North Carolina; and Charleston, South Carolina) and alternative modes of transporting the spent nuclear fuel from the port of entry to the Savannah River Site (truck or train), DOE has concluded that no significant impact would result from any combination of proposed port and mode of transport from the port of entry to the Savannah River Site. 
However, upon further consideration, and in an effort to balance the domestic and international interests at stake, DOE has decided to implement the proposed action as follows. The spent nuclear fuel will be shipped by commercial or chartered vessel from Europe to the Army's Military Ocean Terminal at Sunny Point, North Carolina to the maximum extent practicable (rather than allowing the shipper to select from among any one of the five proposed ports as described in the Environmental Assessment) and transported overland by rail (rather than truck). Should DOE determine that another port or mode of transport (from among those considered as the proposed action) is necessary, DOE will provide direct notice of the change to State and local government officials of the affected states and will notify the public through local media and other means, as appropriate.

Issued at Washington, D.C., this 22 day of Apri1, 1994.

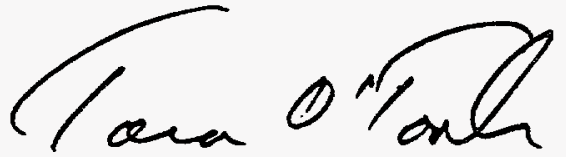

Tara O'Toole, M.D., M.P.H. Assistant Secretary

Environment, Safety and Health 


\section{SUMMARY}

\section{S. 7 Background}

In the 1950's, as part of the "Atoms for Peace" program, the United States began providing assistance in the peaceful application of nuclear technologies to countries that agreed to forego the development of nuclear weapons. This assistance included the provision of highly enriched uranium for use in research reactors around the world. After irradiation in the reactor, the used (spent) fuel was transported to the United States, where it was reprocessed to extract the uranium still remaining in the spent fuel. In this way, the United States maintained control of the highly enriched uranium, which otherwise could be used to make nuclear weapons.

Nuclear research reactors play an important role In medical researeh and treatment, and have advanced the development of materals for industrial and agricultural use 1 I Europe, for example, there are approximately 8,000 to 10,000 medieal treatments per day using medical isotopes produced 10 foreign researeh reactors, Research reactors are also used to train internationat inspectors of military and cril nuclear factilties

To reduce the danger of nuclear weapons proliferation, the United States began a program in 1978 aimed at minimizing and eventually eliminating the use of highly enriched uranium in civilian reactor programs worldwide. This effort (the Reduced Enrichment for Research and Test Reactors Program) was directed at replacing the highly enriched uranium used in research reactors with low enriched uranium, a material that is not directly usable in nuclear weapons. Research reactors are of particular interest because the major civilian use of highly enriched uranium is as fuel in research reactors. If research reactors worldwide were to convert to low enriched uranium fuels, highly enriched uranium essentially would be eliminated from use in civil commerce.

\section{Summay at a Glance}

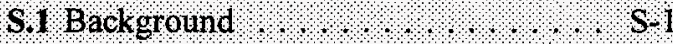

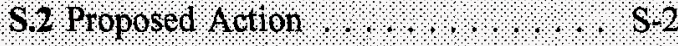

S.3 Need for Proposed Action $.4 . \% .4$ S.3

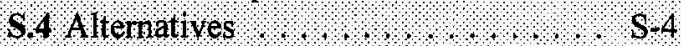

S.5 Impacts from Proposed Action $: .8 \%$ S. 4

S.6 Impacts from Alternatives .0 .4 .4 S.8

S7 DOE Responses to Comments: $:$. S-9

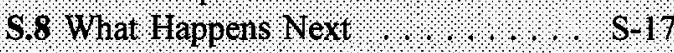

For research reactors converting to low enriched uranium fuel, the United States acceptance of spent fuel was viewed as essential to offset the substantial expenses and reduction in reactor efficiency and capability resulting from conversion. The United States accepted highly enriched uranium spent fuel for several decades, until the program was allowed to expire in 1988. At that time, the United States Department of Energy (DOE) committed to prepare an environmental review of the potential impacts of a 10 year extension of the program for accepting foreign research reactor spent fuel. In 1991, DOE issued an environmental assessment of the potential environmental impacts of the proposed extension. DOE received numerous critical comments from the public that any long-term policy should not be implemented until an environmental impact statement under the National Environmental Policy Act was prepared.

DOE decided in mid-1993 to prepare an Environmental Impact Statement on a new proposed policy to accept, over a 10-15 year period, up to 15,000 spent fuel elements 
containing uranium enriched in the United States. The goal of the proposed long-term policy would be to recover highly enriched uranium exported from the United States, while giving foreign research reactor operators sufficient time to develop their own long-term solutions for storage and disposal of spent fuel. Although the Environmental Impact Statement is under preparation, DOE does not expect to complete the analysis and make a decision on whether to implement the policy until mid- to late-1995.

Because DOE has not accepted any spent fuel containing uranium enriched in the United States for more than five years, several foreign research reactor operators are running out of storage capacity and facing safety and regulatory issues associated with the presence of spent fuel at their sites. If the United States is unable to commit now to the nearterm acceptance of a small amount of foreign research reactor spent fuel, several reactor operators soon will either shut down their reactors or ship their spent fuel offsite for reprocessing. Neither option would serve the nonproliferation interests of the United States. Thus, at the urging of the Department of State, DOE is proposing to accept a small number of highly enriched uranium spent fuel elements in the near term for storage in an existing federal facility in South Carolina.

\section{S.2 The Rropossd Action: Purposse and Seope}

DOE is proposing the urgent-relief acceptance of 409 spent fuel elements from eight foreign research reactors in seven European countries. These countries are Austria, Denmark, Germany, Greece, Netherlands, Sweden, and Switzerland.

The spent fuel would be shipped across the ocean in spent fuel transportation casks (multiton steel containers) from the country of origin to one or more United States eastern seaboard ports. Up to 15 casks containing spent fuel would be transported by ship over several months. Several casks could be transported together on a single ship.

\section{How Reactors Needing Urgent Relief Were Identified}

Reactor selection was based on on-site storage facility inspections by teams composed of staff from DOE and the Department of State and the application of specific criteria. A reactor was identified as meeting the urgent-relief criteria if, because of the lack of near term spent fuel storage space or presence of other spent fiel storage problems, the reactor operator was likely to 1) retreat from the conversion to low enriched fuel, 2) reprocess spent fuel to avoid shut down, or 3) shut down.

Five ports of entry are proposed: Wilmington, North Carolina; the United States Army's Military Ocean Terminal at Sunny Point, North Carolina; Charleston, South Carolina; Savannah, Georgia; and Jacksonville, Florida (Figure 1). Eight alternate ports of entry

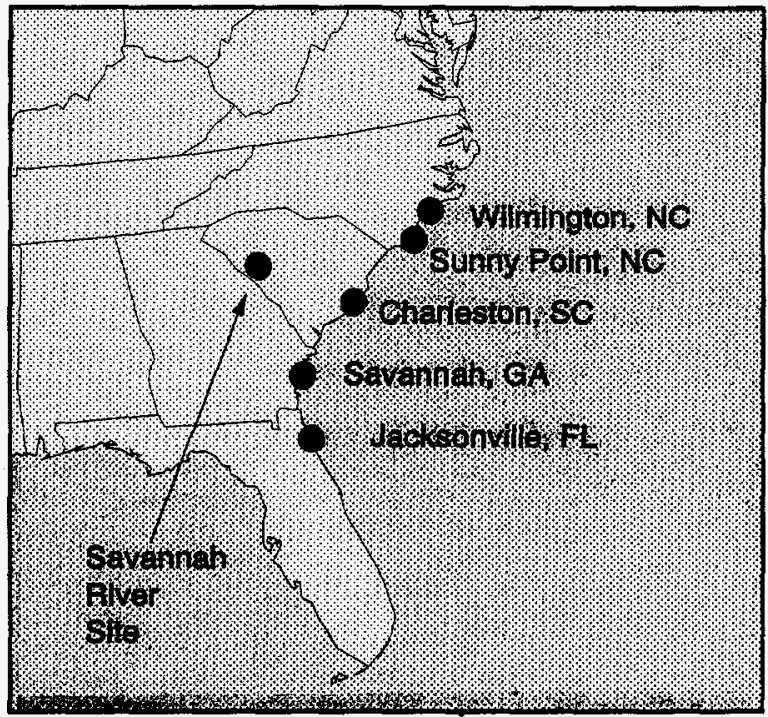

Figure 1 Savannah River Site and Proposed Ports of Entry

were considered and are analyzed in this Environmental Assessment. To provide the reactor operators and shippers maximum flexibility, casks could be transported either by commercial container ships or chartered ships. 
After arriving at United States ports, the casks would be transported by truck to DOE's Savannah River Site in South Carolina (Figure 1). There, the fuel elements would be removed from the casks and stored underwater in an existing storage facility. The spent fuel will be stored at the Savannah River Site until such time as the environmental reviews for long-term storage or other disposition of spent fuel are completed. The Nuclear Waste Policy Act of 1982 (as amended) authorizes the disposal of this spent fuel in a geologic repository.

This Environmental Assessment evaluates the potential environmental impacts of implementing the proposed action. Alternatives to this action are also evaluated. The proposed action and alternatives were developed as a result of input received from reactor operators, citizens in United States port cities and along potential transportation routes, shippers, public interest groups, and other interested stakeholders.

This chapter provides a brief overview of the Environmental Assessment and summary responses to comments received on previously released drafts. Please refer to the full Environmental Assessment for detailed technical information.

S3 Neod for the Proposed
Action

The failure of the United States to accept the foreign research reactor spent fuel proposed in this Environmental Assessment could have a number of adverse consequences.

Reactor operators will try to avoid shutting down their reactors. The operators of two reactors can elect to reprocess their spent fuel at an existing facility in Dounreay, Scotland. Reprocessing at Dounreay would allow the uranium to be extracted (for reuse) and would provide an interim solution for storing the resulting waste. Indeed, four reactor operators in Belgium and Germany resorted to reprocessing in 1993 and 1994. Reprocessing increases the threat of nuclear proliferation because it encourages the continued use of highly enriched uranium.

The remaining six reactor operators either do not have the option to reprocess' their spent fuel or could not obtain regulatory authority to reprocess in time to avoid shutdown. Shutdown of these reactors would severely undermine the United States' credibility as a reliable partner in matters of nuclear cooperation. This, in turn, could influence other reactor operators to cease their conversion to low enriched fuel or to revert to the use of highly enriched fuel if they have already converted. In fact, several reactor operators have stated that, if the United States is unable to accept spent fuel, they will cancel or delay their reactor conversions to low enriched uranium fuel. Such actions would encourage development of a world market for highly enriched uranium, thereby undermining a key aspect of the United States nonproliferation program.

Another crucial consideration in proposing to accept a small number of spent fuel shipments is the upcoming 1995 international conference on the Treaty on the Non-Proliferation of Nuclear Weapons. The conference will consider the indefinite extension of the Treaty, which the United States strongly supports. Other Treaty parties will want assurance that the United States has fulfilled its obligations under the Treaty to share the benefits of peaceful nuclear cooperation. If several countries that are parties to the Treaty are compelled to shut down their research reactors, thereby foregoing the benefits from these reactors, the United States may be accused, fairly or unfairly, of not sharing the benefits of peaceful nuclear cooperation. Such an accusation, however ill-founded, could create or increase opposition to the indefinite extension of the Treaty, which is the foundation for the international nuclear nonproliferation regime. 
The following alternatives to the proposed action were considered:

- Take no action.

- Accept more or less spent fuel than in the proposed action. (See box called, "How Alternative Numbers of Spent Fuel Elements Were Selected.")

- Use alternate ports of entry. These could include Elizabeth, New Jersey; Kings Bay Naval Base, Georgia; Morehead City, North Carolina; Newport News, Norfolk, Portsmouth, and Yorktown Naval Weapons Station, Virginia; New Orleans, Louisiana; and Oakland, California. The Kings Bay and Yorktown terminals are military ports; the others are commercial ports.

- Transport spent fuel by rail to the Savannah River Site.

- Transport low or highly enriched uranium to the United States after spent fuel is reprocessed abroad. This would be an alternative to accepting spent fuel elements. The highly enriched uranium would either be converted to low enriched uranium by blending, or would be transported directly.

Four more alternatives were considered but not analyzed in detail because various technical, regulatory, and legal constraints render them either impossible or impractical to implement in the timeframe associated with the proposed action:

- Transport the spent fuel by air to the United States.

- Use DOE storage facilities other than the Savannah River Site.
How Alternative Numbers of Spent Fuel Elements Were Selected

The proposed action specifies acceptance of 409 spent fuel elements. Alternatively, more or fewer elements could be accepted:

1 953-the number of spent fuel elements originally requested by the reactor operators for shipment (includes spent fuel from reactors that were later eliminated from the proposed action)

- 359 - I partial, rather than full, casks were shipped (Some reactors could ship partially filled casks and avoid shutdown),

14291 or 248 -if full $(291)$ or partial $(248)$ casks were shipped from only those reactors that cannot reprocess.

Assist foreign research reactors in expanding fuel storage in their own countries.

- Transport spent fuel by barge to the Savannah River Site.

\section{S.5. EmWTonnewt Thparts from the Proposed Action}

Impacts were estimated for the following three phases of the proposed action:

- Bringing 409 spent fuel elements in casks across the ocean to one or more United States ports.

- Receiving spent fuel in the ports and transporting it by truck to the Savannah River storage site.

- Storing the spent fuel at the Savannah River Site. 


\section{Measuring Radiation Exposure}

Potential radiological impacts are estinated for the lighest radiation ex posure ony single person might reeelve, as well as the collective exposture a particular population night get such as all those living in the vicinity of a port Two primary units of radiation measurement are used in this Assessment to estimate these impacts; the rem and person.rem.

The rem is a unit of radiation dose. Becaluse? ren is a relatively large dose, the unit actually: used most frequently is the milliten (nten), which is equal to 111000 of a rem. 11 is estimated that hie average individual in the United States receives a background dose of about 360 mrem per year from all sources. (See Figure 2) For: example, a chest x ray results in a dose of 8 : nren By regulation, the naximum annual exposure from routine nucleat activities to a nember of the general public camnot exceed 100 nren above the background dose. The naximun Individual exposure fron the proposed action under non accident conditions would becto a port. worker (about 5 nrem from unloading all fifteen casks).

Radiation exposure to a population or a group of persons is measured in penson-rem, The rotal. population exposure (all the person-tems) is: determined by adding up all the individual doses. in the exposed group. This neasurement is: particularly important when trying to take into account the potential impacts of very snall doses on very large populations (for example, all those: fiving along the truck route).

Using a conversion factor, the estinated exposures can be converted into possible numbers of liealth effects. Because the exposures predicted in this study are fat less than those known to cause immediate illness or fatality, only delayed health effects can be estimated: A delayed effect is: measured in latent (future) cancer fatalities, for a general pepulation, a collective dose of 2,000 person-ren is estinated to result in one additional: latent cancer fatality. The total poputation exposure for the proposed action is estimated to be: between 0.12 and 0.16 person-rem under nonaccident conditions, nore than 12,000 tines less than the population dose that would prodice one predicted latent cancer fatality:
Potential impacts of each phase are described in the following sections. See Chapter 6 in the Environmental Assessment for more details.

\section{S.5.1 Impacts from Ocean Transport}

Under routine (non-accident) conditions, radiation exposure to the ship crew during ocean transport would be less than 0.005 rem. This exposure would be from the very small radiation fields being emitted from the casks -less than $1 \mathrm{mrem}$ per hour at 1 meter from the cask surface. This radiation dose estimate would be essentially the same for all proposed ports of entry, largely because it depends on the number of inspections conducted over a given period of time. Because all of the distances from the European ports to the United States ports are very similar, the number of inspections would essentially be the same.

DOE considered what would happen if accidents were to occur during ship transport of spent nuclear fuel. The two most likely kinds of ocean accidents from maritime shipping experience were investigated: 1) a ship collision, which in this Environmental Assessment was assumed to result in an onboard fire, and 2) loss of a cask at sea, resulting in the spent fuel being released into the water. If a collision and fire caused the contents to be released, the major impact to the crew would probably be from the fire, not the resultant radiation exposure. Radioactive particles could be dispersed over the ocean, but would not be in large enough amounts to have a measurable impact on the environment. The spent fuel cask is robust and the spent fuel is in a solid metallic form. Therefore, release of spent fuel contents during a ship collision and fire is unlikely.

Immersing a cask in water does not cause the radioactive contents to be released immediately. Casks can be recovered in water up to 200 meters deep. Thus, if a cask were 
to fall overboard near shore or in port, the most likely places for this to occur, it would be recovered.

If a cask sank in the deep ocean and could not be recovered, it would gradually degrade and its contents would be released over many years. The added impact to the marine environment over time would be minimal, because of the very large volume of water that would mix with the spent fuel.

What about radiation exposure to people living on land if contents of a spent fuel cask were released into the ocean? The highest-impact location where such a release could occur would be in coastal waters, because of the proximity to on-land populations. The highest radiation dose to a person on land in the event of such a release would be 11 mrem over a year's time. This is about 3 percent of the annual average radiation dose received by an individual living in the United States (See Figure 2).

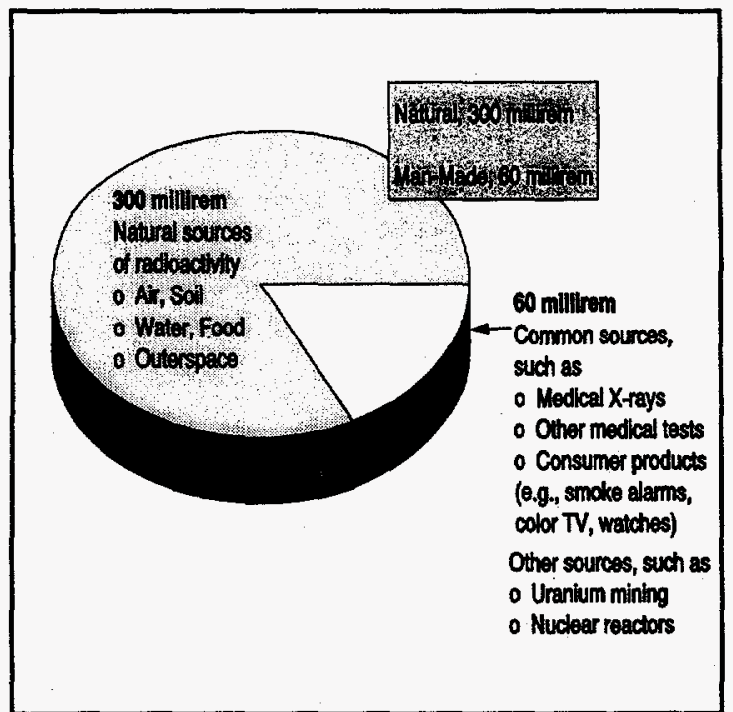

Figure 2 Typical Sources of Yearly Radiation Exposure for a United States Resident. Radiation doses estimated in this Environmental Assessment would be in addition to the exposure shown here.

\section{S.5.2 Impacts from Port Receipt and Truck Transport}

Radiation doses were estimated for port workers who would handle spent fuel casks, truck crews who would transport the casks to the Savannah River Site, and people on and along the truck route. These doses were calculated for all the ports and truck routes in the proposed action. Radiation doses were estimated for normal operations and accident conditions.

The highest dose any member of the general public might receive while the spent fuel is in transit would be about $1 \mathrm{mrem}$. In this scenario, a person would be located about 6 feet from a cask for 30 minutes, in a traffic jam, for example. The more typical dose would be 0.002 mrem for a person located along the roadway while trucks pass by. This exposure is a small fraction of the 360 mrem received each year from background radiation from all sources. (See Figure 2.) This is for any port or truck route in the proposed action.

Port workers and truck drivers would receive a slightly higher dose than residents of port cities and persons along truck routes, because they would be in closer contact with the spent fuel casks over a longer period of time. The highest potential dose of about 5 mrem would result in the unlikely event that the same port worker unloaded all 15 casks.

The total annual exposure from routine operations to all the workers and general public from the proposed action would range from 0.12 to 0.16 person-rem, depending on the port used. Doses this small would result in an increased potential for a single future cancer death of less than 1 in 12,000 for the entire exposed population.

In more than three decades of shipping spent fuel into and within the United States, no accident has ever occurred in which a cask was punctured or spent fuel contents released. 
However, for completeness, DOE investigated what would happen under the most extreme accident conditions -- in which a cask was breached, engulfed in flame, and its contents released. A person standing about 100 feet from the cask for 24 hours while this happens would receive a radiation dose of $25 \mathrm{rem}$. If that same person were shielded by being in a house 100 feet away from the burning cask for 24 hours, the dose would be reduced to 220 mrem (about 60 percent of annual background radiation from all sources). For comparison, it takes a dose of about 600 rem to cause imminent death. The chances of an accident of this severity occurring are approximately 1 in 8 million.

This Environmental Assessment also considered traffic accidents from the transport of spent fuel by truck. Potential deaths from this kind of accident (nonradiological) were calculated for all port routes in the proposed action. These calculations are based on frequency and distance. Because there would be only fifteen casks transported a maximum distance of about 440 miles, no accident fatalities would be expected.

\section{S.5.3 Impacts from Spent Fuel Storage at the Savannah River Site}

The proposed receipt and storage of 409 spent fuel elements at the Savannah River Site would result in extremely small increases in radiological emissions and waste generation at the site. No other environmental impacts are anticipated. This is because storing the elements in the existing Receiving Basin for Offsite Fuels would represent only a very small increase in ongoing site activities and involve no new construction. In the unlikely event that the same worker were to unload all 409 spent fuel elements, the maximum additional exposure would be 60 mrem, about 1 percent of the limit established by DOE for radiation workers.

\section{Spent Fuel and Shipping Casks}

A typical spent fuel elenent from a research reactor is about 40 inches $\times 3$ inches $x 3$ inches. and weighs from 9 to 13 pounds. The elements. are solid metal. They contain various forms of uraniun, as well as radioactive byproducts, including trace amounts of plutonium.

Spent fuel elements are transported in stainless. steel packagings called transportation casks, or: ust casks (Ftgure 3), A full cask can carry. from 13 to 64 spent fuel elements from research. reactors, depending on fuel element design and cask capacity. The casks are certified as "Type B' by international regulations. 10 receive this certification, a cask must demonstrate that its contents do not release radiation above a specified low limit 0 tem per hour at 1 neter from the cask surface) after withstanding severe accident conditions. These conditions include being dropped onto a steel post, subjected to extrenely high temperature $(1475 \%$ ), and: submersed in water

Type B casks have been used for years to transport spent fuel elements in the United States and around the world. No cask has ever: been punctured or had any of its contents released, ever in actual highway accidents.

The casks are designed to provide shielding from radiation. Hewerer, an extremely low tadiation field is present outside the cask 4 usually less than one niren per hour at one meter away from the cask. (This dose is well under the linit allowed by the Naclear Regulatory (Commission), spent fuel cask design and transportation must also comply with requirenents established by the 1.5 . Department of Tratsportation.

Four hypothetical accidents at the storage facility were evaluated that could potentially release radionuclides to the atmosphere. These accidents include: 1) a nuclear criticality incident (a release of energy as a result of a self sustaining nuclear chain reaction); 2) fire and explosion at the storage facility resulting 
from a flammable or explosive concentration of vapors; 3 ) accidental cutting of fuel element cores (the portions of the element containing uranium) during preparation for storage; and 4) rupture of fuel elements during underwater storage.

The maximum dose would result from the unlikely accident of 1000 foreign fuel elements rupturing during storage. This event would result in a maximum dose to the individual at the site boundary of $8 \mathrm{mrem}$, and a 70 personrem dose for the offsite population. The probability of such an accident occurring, however, would be less than once in 2000 years. Taking this probability into account, there would be an additional 1 in $500,000,000$ chance that the individual at the site boundary

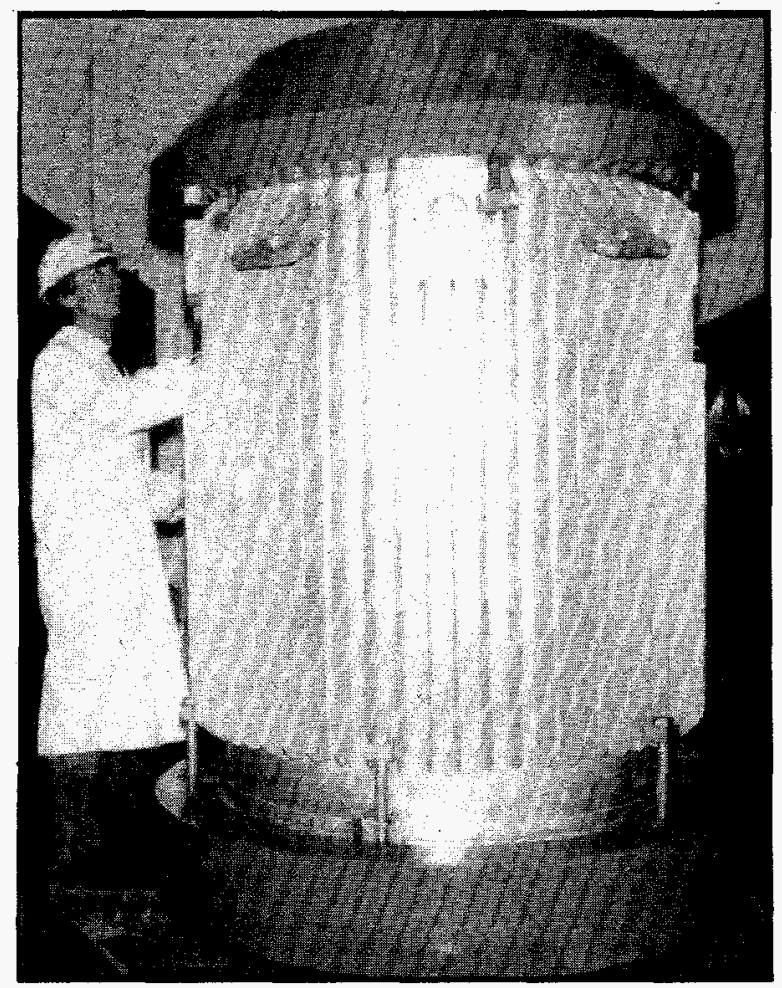

Figure 3 Typical Shipping Cask for Research Reactor Spent Fuel

would develop a fatal cancer and a 1 in 55,000 chance that a single fatal cancer would occur in the exposed population.
S. 6 Impacts from Alternatives to the Proposed Action

Impacts from the alternatives to the proposed action were calculated and are discussed below.

\section{S.6.1 Take No Action}

If no action were taken to receive the urgentrelief spent fuel into the United States, no additional environmental impacts would occur here. However, failure to accept spent fuel from the eight reactors would likely have other impacts, as explained in Section S.3. Chief among these is the increased potential for worldwide proliferation of nuclear weapons.

\section{S.6.2 Accept Alternative Numbers of Spent Fuel Elements}

Estimates were made of the potential dose and resulting fatal cancers if various numbers of spent fuel elements were received by the ports and transported. The numbers considered were 953, 359, 291, and 248. (See box called, "How Alternative Numbers of Fuel Elements Were Selected.")

As might be expected, the risks go up when the numbers of fuel elements increase, and down when they decrease. The risks for the 953-element alternative are almost double the risks for the 409 fuel elements in the proposed action. However, as with the proposed action, the impacts associated with the shipment of any of the alternative numbers of elements are extremely small. 


\section{S.6.3 Use Alternative Receiving Ports}

The potential radiation doses for some of the alternate ports are slightly higher than those of the proposed ports. For other alternate ports, the potential radiation doses are the same or lower. These variations depend primarily on the distance from the Savannah River Site. The chance of developing one additional fatal cancer ranges from 1 in 7,500 to 1 in 10,000, depending on the port. This is for normal and accident conditions. In general, the alternative port cities are further away from the Savannah River Site and the potentially exposed populations are larger.

\section{S.6.4 Transport Spent Fuel by Rail to the Savannah River Site}

The estimated radiation doses for using rail transport are slightly higher than those for using trucks. This is primarily because of the slightly increased inspection time involved in rail transport. As for the risks from truck transportation, the risks of transport by rail are extremely small. The chances of developing one additional fatal cancer are 1 in 9,000 for transport from the proposed ports.

\section{S.6.5 Transport Low or Highly Enriched Uranium to the United States after Spent Fuel is Reprocessed Abroad}

Two Environmental Assessments were done in 1993 and 1994 to estimate impacts of transporting low enriched uranium by ship into the United States. The author of these assessments, the United States Enrichment Corporation, determined that transport of large quantities of low enriched uranium to and through the United States resulted in no significant impacts. Because the alternative being discussed here would involve much smaller quantities of low enriched uranium than in the above-mentioned assessments, the potential impacts would also be much less.

The impacts of bringing back reprocessed highly enriched uranium to the United States were not quantitatively analyzed for this environmental assessment. However, the military has considerable experience in shipment of highly enriched uranium and has safely transported such materials throughout the world. DOE has safely stored highly enriched uranium, without incident, at various United States facilities for many years.

\section{S.7 DOE Responses to Comments}

DOE began preparation of this document, the "Environmental Assessment of Urgent-Relief Acceptance of Foreign Research Reactor Spent Nuclear Fuel", in 1993. The first draft was distributed for public comment in October 1993. After review of the comments received and on-site inspections of ten research reactors in Europe and one in Australia (three of which are no longer included in the proposed action), DOE developed a second draft and distributed it for public comment in February 1994. DOE also held several public meetings, including a meeting attended by representatives of key stakeholders on February 10, 1994, to discuss the proposed action and its domestic and international policy implications.

DOE has considered all of the comments received during the development of this final Environmental Assessment. The following sections summarize the major areas in which comments were received and provide DOE's responses. These and additional comments are addressed in the Environmental Assessment. 


\section{S.7.1 Need to Accept the Spent Fuel}

Several commentors urged DOE to accept the urgent-relief spent fuel elements. These commentors cited the need to reduce the potential for nuclear proliferation. They also emphasized the importance of keeping what is perceived by the foreign research reactor community to be a longstanding commitment to take back spent fuel.

Other commentors questioned the need for spent fuel acceptance. The following section summarizes the key issues raised by these commentors, followed by DOE's responses.

\section{There is no urgent need to accept spent nuclear fuel.}

As described in detail in Chapter 1 of the Environmental Assessment, if the spent nuclear fuel is not accepted by the United States, it is likely that there will be increased commerce in and use of highly enriched uranium worldwide. President Clinton's nonproliferation policy seeks to minimize the availability of weapons-usable material. The conversion of research reactors to low enriched uranium fuel and the United States acceptance of spent fuel containing highly enriched uranium are two key objectives of this policy.

DOE and the United States Department of State sent inspection teams to every reactor considered for urgent relief. Through on-site inspections and application of uniform criteria (see Chapter 2), these teams determined that the eight reactor operators identified in the Environmental Assessment's proposed action have valid and urgent needs for spent fuel storage relief. DOE limited the relief specified in the proposed action to those fuel elements that need to be shipped to the United States in the near term.
The foreign research reactor operators should find their own storage solutions, such as adding more fuel storage facilities in their own countries.

Under the long-term proposed policy being considered in the Foreign Research Reactor Spent Fuel Environmental Impact Statement, DOE would accept foreign research reactor spent fuel for a fixed period of no more than 15 years. This would allow the United States to recover highly enriched uranium exported by this government, and would give the reactor operators sufficient time to establish their own long-term storage sites or plan for reactor shutdown in an orderly way.

Adding more spent fuel storage at the reactor sites or at other sites in Europe as an alternative to the proposed action, however, is not a practical solution in the time needed to respond to the urgent needs of the eight reactors considered. By the time new facilities were constructed and licensed, or existing facilities modified, some reactors would have been forced to send their spent fuel to Dounreay for reprocessing, where that is an option, or to shut down.

The United States should let the foreign research reactors reprocess or shut down rather than accept their spent fuel.

Reactor operators who decide to reprocess now are more likely to postpone their conversions from highly enriched uranium fuel, or revert back to its use. This is because the only current reprocessor of such fuels (the United Kingdom Atomic Energy Authority's facility in Dounreay, Scotland) does not reprocess low enriched uranium fuel and the reactor operators have only limited capacity to store spent fuel generated as a result of operating. Thus, the research reactors would have to continue to use highly enriched uranium fuels to continue operating. Reactor operators prefer to use highly enriched uranium fuel because research reactors run more efficiently using this fuel 
than low enriched uranium fuel. Foreign governments and reactor operators have indicated since the beginning of the Reduced Enrichment for Research and Test Reactors Program that their willingness to participate in this key nonproliferation program was contingent upon the willingness of the United States to continue to accept foreign research reactor spent fuel.

Shutdown of these research reactors would be a serious blow to the reactor operators and their communities. Chapter 2 of the Environmental Assessment contains a complete description of the situation at each reactor. These descriptions identify the importance of each of these reactors to the country and region in which the reactor is located. In addition to providing important medical isotopes, the research reactors serve as major research tools for electronics, biology, medicine, and engineering, as well as major training facilities in nuclear technology. For example, the research reactor operating in Austria is used by the International Atomic Energy Agency to train personnel who conduct international inspections of weapons and civilian nuclear facilities.

Reprocessing or shutting down foreign research reactors would undermine the gains of the Reduced Enrichment for Research and Test Reactors Program. The governments in the countries where these reactors are located have stated that renewal of the acceptance of spent fuel has become a measure of United States reliability in worldwide nuclear cooperation. A perceived lack of reliability could complicate upcoming negotiations for renewal of important nonproliferation agreements.

To eliminate the proliferation potential created by reprocessing, the uranium extracted during reprocessing could be blended and converted to low enriched uranium. Alternatively, the United States could purchase the highly enriched uranium and blend it here.

These options are considered in Chapter 4 of the Environmental Assessment. Neither option, however, would serve the nonproliferation interests of the United States, since reprocessing would likely result in perpetuating the use of highly enriched uranium fuel. In addition, for those reactors for which United States consent is not required for reprocessing to occur, there is no mechanism to implement or enforce a blending requirement by the reactor operators or reprocessors. Consequently, reactor operators could have their fuel reprocessed, but not blended. This would result in the continued use of highly enriched uranium fuel by research reactors, which is contrary to the United States nonproliferation policy.

\section{S.7.2 Other Policy Issues}

Several commentors raised questions about United States policy issues related to the decision of whether to accept spent fuel. These comments, and DOE's responses, are summarized here.

The United States should not consider accepting spent fuel from other countries until we have a permanent solution for our own nuclear waste storage problem.

The United States has invested several billion dollars in developing the capability to dispose of spent fuel. Currently, the feasibility of locating a geologic repository in Nevada is being assessed. If the technical and scientific viability of geologic disposal is confirmed and regulatory requirements are met, a repository could be ready by the year 2010 . (Although a disposal facility is not yet open, the technology to store spent fuel safely for many decades does exist.) Any uncertainties related to the availability of geologic disposal are clearly offset by the benefits of minimizing the availability of highly enriched uranium. 
Our allies are too committed to nuclear nonproliferation to continue using highly enriched uranium fuel. They will convert to low enriched uranium fuel regardless of whether the United States accepts foreign research reactor spent fuel.

Several foreign research reactor operators have expressed the view that if the United States decides not to accept any near-term spent fuel shipments, they plan to terminate their participation in the Reduced Enrichment for Research and Test Reactors Program and rely instead on highly enriched uranium fuels. The decision to use highly enriched uranium would not result from a lack of commitment to nonproliferation. Reactor operators would be driven to use highly enriched uranium because they have no other viable options to deal with their spent fuel storage problem and the reprocessing option is only available for highly enriched uranium fuel.

DOE should not expect other countries to use low enriched uranium fuel when United States research reactors are still using highly enriched uranium fuel.

$\mathrm{DOE}$, at the request of the United States National Security Council, is reviewing the policy of using highly enriched uranium, fuel in United States domestic research reactors, including those owned and operated by United States government agencies. Regarding the domestic university reactors, of the eighteen reactors with power greater than 1 megawatt, eight have converted to low enriched fuels, six more are in some stage of the conversion process, and two do not have a qualified fuel that would permit them to convert. (Reactors with less than 1 megawatt of power usually have lifetime cores and do not generate spent fuel.) Regarding the government-owned reactors, of the seven with power greater than 1 megawatt, two have no qualified fuel, two need further analysis but initial indications are that there is no qualified fuel, and two face an uncertain future. There is one reactor that could convert but has not initiated a conversion plan. The use of low enriched uranium is being considered for a new reactor proposed for the Oak Ridge National Laboratory.

The conversion of many of the remaining research reactors to low enriched fuel depends on the development of advanced high-density fuels. The United States should develop these fuels.

DOE agrees that the advanced fuel development program should be initiated. At the present time, funds are being sought and a five year funding plan has been developed. DOE anticipates commitment of these funds in the near future. It is expected that Argonne National Laboratory will begin this program in fiscal year 1994.

DOE should accept only the minimum number of fuel elements needed to satisfy the criteria of Chapter 2. The number of fuel elements should not be increased simply to permit each reactor to fill its casks.

Fifteen full casks containing 409 spent fuel elements are proposed to be accepted in the Environmental Assessment. Four of the eight reactors included in the proposed action could theoretically ship partially filled casks and not have to shut down or be forced to reprocess their spent fuel. This would reduce the number of elements to be accepted by 50 , for a total of 359 . Fifteen casks would still need to be shipped, however.

In proposing to accept full casks, DOE took note of the fact that there is no significant difference in environmental impacts between shipping full and partial casks. Moreover, requiring reactor operators to transport partial casks is viewed by all operators as being unnecessarily expensive because the transportation costs (which run into hundreds of thousands of dollars) are essentially the same for full as for partially full casks. Based 
on these considerations, shipment of full casks is a prudent course to encourage the continued participation of foreign research reactors in the Reduced Enrichment for Research and Test Reactors Program.

\section{S.7.3 National Environmental Policy Act Considerations}

The major comments and responses related to compliance with the National Environmental Policy Act are as follows.

The proposed action should not be implemented before completion of the Foreign Research Reactor Spent Fuel Environmental Impact Statement.

DOE believes that preparation of the Environmental Assessment fully complies with the National Environmental Policy Act and its implementing regulations. The proposal to accept a small number (409) of spent nuclear fuel elements is justified independently of the decision on whether to establish a new policy on long-term acceptance of foreign research reactor spent fuel. Until the Environmental Impact Statement is completed and a decision made on whether to implement the proposed long-term spent fuel acceptance policy, the proposed acceptance of spent fuel is necessary to maintain the United States program of encouraging the conversion by research reactors to low enriched uranium fuel. Further, while there is an obvious relationship between the two proposals, a decision to accept such a small number of fuel elements does not foreclose or prejudice future decisions regarding establishment of a new spent fuel acceptance policy or the decisions regarding ultimate disposition of spent nuclear fuel.

The notification of the proposed action was not well publicized. The draft Environmental Assessment was not widely available, and there was insufficient time to review and comment.
Under DOE's regulations implementing the National Environmental Policy Act, environmental assessments are provided to affected state(s) and Indian tribes for a preapproval review period of 14 to 30 days. However, for this Environmental Assessment, DOE felt it was important to expand the review process to provide opportunities for broader public involvement. Therefore, DOE took the following actions.

In October 1993, more than 100 copies of the draft Environmental Assessment were sent to public interest groups nationwide and officials in states that could be affected by the proposed action. (In the October draft, the proposed ports of entry were in the Hampton Roads area, Virginia, and Charleston, South Carolina.) Notices of the Assessment's availability were placed in local newspapers of these affected communities, as well as communities surrounding the Savannah River Site.

In response to comments, a second draft was prepared and distributed for public comment in February 1994. About 130 copies of the revised draft were sent to the governors of the affected states, mayors in the proposed port communities, port authorities, environmental and nonproliferation interest groups, reactor operators and their countries' embassies, Congressional delegations, and all those who had commented on the October draft.

In February 1994, DOE and the Department of State co-hosted a meeting to encourage an exchange of views among the foreign and domestic interests represented. Subsequent to that meeting, an additional 200 copies of the February draft Environmental Assessment were distributed in response to requests for copies. In addition, DOE has held meetings concerning the proposed receipt of foreign research reactor spent fuel in the Hampton Roads area, Virginia; Brunswick County, and Wilmington, North Carolina; Charleston and Mount Pleasant, South Carolina; Savannah, 
Georgia; and Jacksonville, Florida. These locations were chosen because of their proximity to the proposed ports of entry for the foreign research reactor spent fuel.

In response to requests, the comment period on the February draft Environmental Assessment was extended until April 8, 1994.

\section{S.7.4 Port Selection}

DOE should not consider the Sunny Point Military Ocean Terminal as a proposed port of entry because ammunition and high explosives are off-loaded at the port.

The Army's Military Ocean Terminal at Sunny Point is a defense transportation facility used to move military cargo into and out of the United States. The majority of the cargo is dry cargo, primarily ammunition. Because Sunny Point was designed for handling ammunition, each wharf has been designed and built so that an explosion at one wharf or at one of the holding areas would not cause a detonation of explosives at another wharf. Therefore, workers at the Sunny Point Terminal could safely unload spent fuel on one wharf without concern for an accident on another vessel impacting the spent fuel. In fact, there has never been an explosion accident at Sunny Point.

DOE should consider Sunny Point as a proposed port of entry because of the low population in the area surrounding the port.

The population in the area surrounding the port of entry is one of the factors that DOE considered in selecting ports of entry for the proposed acceptance of spent fuel. Indeed, Sunny Point has the lowest population density in the vicinity of the port (179 people per square kilometer) of all the proposed ports. (For a comparison of all five proposed ports, please refer to Table 3-4 in Chapter 3 of the Environmental Assessment.) In addition, Southport, the town closest to the Sunny Point
Terminal, has the lowest population density (27 people per square kilometer) of all the cities (or towns) closest to the proposed ports. Both of these factors are important. However, the size of the population along the route to the Savannah River Site is also important. No one port has the lowest population in all three categories. Among the five proposed ports, Sunny Point has the fourth highest number for total population potentially exposed along the entire route from the port to the Savannah River Site.

DOE failed to comply with the requirements of the National Defense Authorization Act because, after applying the port selection criteria set forth in the Act, it proposed multiple ports of entry rather than one port.

The Act provides that the Secretary of Energy "shall, if economically feasible and to the maximum extent practicable, provide for the receipt of spent nuclear fuel...at a port of entry in the United States which...(1) has the lowest human population in the area surrounding the port of entry; (2) is closest in proximity to the facility which will store the spent nuclear fuel; and (3) has the most appropriate facilities for, and experience in, receiving spent nuclear fuel." No one port clearly stands out as the best in comparison to all other seaports in meeting all of the criteria set forth in the Act, or other criteria recommended by a panel of maritime experts at a DOE-sponsored workshop. Each of the proposed ports has comparative advantages and disadvantages over the other four proposed ports, but all five appear comparatively more advantageous than other United States seaports. Thus, because no one port met all of the Act's criteria, as well as other criteria recommended by experts in the maritime industry, DOE proposed that any one of five ports of entry could be used.

DOE should not consider ports that have never handled spent fuel before because the port workers would not know how to safely handle spent fuel. 
As part of DOE's efforts in preparing the Environmental Assessment, DOE sponsored a workshop at the United States Merchant Marine Academy on port selection criteria for shipments of spent fuel. Participants in the workshop included experts from key sectors within the maritime industry. The experts agreed that any port capable of handling an ocean-going cargo vessel is capable of receiving and handling spent fuel shipments. The port workers at such ports would have experience in handling containerized cargo, and thus would be fully capable of safely handling the containers in which spent fuel would be shipped.

\section{S.7.5 Transportation and Emergency Preparedness}

Several commentors raised issues concerning aspects of the land transportation of the spent fuel. The major issues and responses follow.

Roads and transportation infrastructure surrounding certain areas of the ports are not satisfactory for heavy truck use.

The truck shipments would not exceed the "legal-weight" limits, as specified by the Department of Transportation. Therefore, impacts on the roads would be similar to those normally associated with loading and unloading cargo at the proposed ports. The Department of Transportation regulates the routing of trucks transporting radioactive materials, and requires the use of interstate highways to the maximum extent practicable for shipments of spent fuel. A State Routing Agency can select an alternative route if consistent with Department of Transportation guidelines. The use of local streets for pickup, delivery, and access to the preferred routes (interstate highways and approved state alternate routes) is covered by Department of Transportation regulations. Additional information on transportation activities has been added to the Environmental Assessment in Appendix $\mathrm{H}$.
Communities and rural areas are not capable of handling an emergency involving radioactive waste.

Existing emergency response plans are in effect for each port city. State plans also are in effect to cover emergencies along state highways. DOE, in cooperation with state and local governments, plans to provide training, if needed, to emergency responders in each of the states in which spent fuel is transported to. prepare them to react in the unlikely event of an accident. Should a transportation accident occur, DOE would deploy radiological assistance teams to provide technical assistance to state and local officials, if requested.

Accident consequences actually would be higher than those calculated in the Environmental Assessment.

The Environmental Assessment includes an analysis of extremely rare but potentially severe accidents, up to and including accidents in which 100 percent of the spent fuel might be oxidized, resulting in dispersion of radioactive particles. (Oxidization of spent fuel would be similar to the rapid rusting of iron.) The amount of radioactivity assumed to be released in such accidents was based on empirical data, and there is no evidence to support the release of larger amounts of radioactivity. Furthermore, the Environmental Assessment assumes that people located downwind from the site of such a severe accident are exposed to the original level of deposited particles for 24 hours and only then evacuated. This assumption tends to overstate the risk. Exposures for residents of the area around the accident site also were calculated, including the possibility of exposure to low levels of radioactivity that might be present after clean-up was complete. 
Accident-related doses to people beyond onehalf of a mile from an accident site were not calculated.

In the Environmental Assessment, radiation exposure from hypothetical accidents was calculated for the population located in areas out to $80 \mathrm{~km}$ downwind. Potential radiation exposure was also calculated for incident-free transportation, including people within onehalf of a mile of the transportation corridor (for example, those living next to or driving on the road).

Only the "best" or "safest" transportation casks should be used to transport spent fuel.

Each cask used to transport spent fuel is designed and certified for use only with specific types of fuel. Differences in the size and shape of the fuel elements used in the various reactors are responsible for much of the variation in the different casks considered in the Environmental Assessment. These superficial differences should not be interpreted as affecting the performance of the casks because all casks are certified to the same minimum international standards. Thus, there is no single "best" or "safest" cask.

\section{S.7.6 Spent Fuel Storage}

Several comments were submitted concerning the storage of spent fuel in the United States. The major issues and responses follow.

The Spent Fuel Working Group Report, issued by DOE in November 1993, identified several issues at the Receiving Basin for Offsite Fuels, including seismic evaluations, accidents involving "tornado missiles" (objects picked up by high winds), the lack of an updated safety analysis report, the lack of basin leakage detection systems, and enhanced training for personnel. In light of the issues identified in the report, the Receiving Basin for Offsite Fuels appears incapable of safely storing spent fuel.
Although the Spent Fuel Working Group Report identifies these issues, it also notes that "the overall quality of design and facility management have ensured safe storage of aluminum-clad reactor irradiated nuclear materials in the basin for over 10 years." (Reactor irradiated nuclear materials include spent nuclear fuels.) Most of the issues in the report had been previously identified; measures to address them were already in place at the time the report was released.

A Safety Analysis Report identifies the hazards associated with facility operation, evaluates the engineered systems relied upon to eliminate, control or mitigate hazards, and analyzes potential accident scenarios and the resulting consequences. Issues concerning seismic evaluations, accidents involving tornado missiles, and safety are being addressed in a new Safety Analysis Report and related technical evaluations that are being prepared for the Receiving Basin for Offsite Fuels. That facility has an existing, approved Safety Analysis report that considers the accident consequences of seismic and tornado events. Any operational changes or new activities proposed for the Receiving Basin for Offsite Fuels would undergo a technical review to ensure that their potential impacts are within those considered in the existing safety documentation. Measures to address the lack of a basin leakage detection system are being evaluated. The Savannah River Site continues to monitor the groundwater in the Receiving Basin for Offsite Fuels area, as well as sitewide, and to monitor the water losses of that facility for evaporation trending. Modifications to ongoing qualification and training programs have been made to address issues identified in the Spent Fuel Working Group Report. 
Interim storage and subsequent disposal of spent fuel have not been addressed adequately in the Environmental Assessment.

Chapter 6 of the Environmental Assessment addresses the impacts of receipt of spent fuel at the Savannah River Site. DOE proposes to store the spent fuel in the near term in an existing underwater pool at the Receiving Basin for Offsite Fuels, along with a much larger inventory of essentially identical spent fuel that is already stored there. Future plans for interim storage of spent fuel (storage of the spent fuel prior to ultimate disposal) are being analyzed in the Foreign Research Reactor Spent Fuel Environmental Impact Statement and the Environmental Impact Statement for Programmatic Spent Nuclear Fuel Management. Those reviews will include consideration of new storage technologies and facilities for spent nuclear fuel, including dry storage facilities, at all DOE sites. Decisions regarding the long-term management of the small amount of spent fuel covered by this Environmental Assessment cannot be made in advance of DOE's nationwide decisions. Ultimate disposition of the spent fuel in a geologic repository is authorized by the Nuclear Waste Policy Act of 1982 (as amended).

\section{S.8 What Happens Next}

DOE will decide whether to implement the proposed action or any of its alternatives, including port selection and cask capacity, based on the analyses in the Environmental Assessment. DOE's final decision will be published in the Federal Register shortly after completion of the Environmental Assessment. The Federal Register notice will be made widely available to interested stakeholders, including organizations and individuals who commented on the Environmental Assessment. In addition, DOE will announce its decision to the media.
If you would like further information on this Environmental Assessment, please contact the following people.

* For information on the Environmental Assessment, contact:

Mr. David Huizenga

Office of Waste Management

Office of Environmental

Management, EM-30

U.S. Department of Energy

1000 Independence Avenue, SW

Washington, D.C. 20585

(202) $586-0370$

* For information concerning the National Environmental Policy Act review process, contact:

Ms. Carol Borgstrom, Director

Office of NEPA Oversight

Office of Environment, Safety

and Health, EH-25

U.S. Department of Energy

1000 Independence Avenue, SW

Washington, D.C. 20585

(202) $586-4600$ or (800) $472-2756$ 


\subsection{PURPOSE AND NEED FOR ACTION}

The United States Department of Energy (DOE) is in the process of preparing the Foreign Research Reactor Spent Fuel Environmental Impact Statement on the proposed adoption and implementation of a policy for the acceptance from foreign research reactors of up to 15,000 spent nuclear fuel elements containing enriched uranium of United States origin. The proposed policy would be in effect for a period of up to fifteen years. This Environmental Impact Statement is scheduled to be released in draft form for public comment by the end of December 1994, and the final Environmental Impact Statement is scheduled to be completed by the end of June 1995. (Refer to Appendix A for background information.)

In the interim, to meet the urgent needs of certain foreign research reactor operators and to avoid failure of a key United States nuclear weapons nonproliferation objective of minimizing and eventually eliminating the use of highly enriched uranium (HEU) in civil programs, DOE proposes to accept a small number (409) of foreign research reactor spent fuel elements for storage in an existing DOE wet storage facility. The Council on Environmental Quality (CEQ) has been consulted about the proposed policy and DOE's proposal to accept a small number of spent fuel elements prior to completion of the Environmental Impact Statement. The acceptance of a small number of spent fuel elements is the subject of this Environmental Assessment. The following chapters contain a detailed description of the proposed near-term action and alternatives, as well as an analysis of their potential environmental impacts.

This Environmental Assessment is being undertaken as part of broader United States efforts to prevent the spread of nuclear weapons to additional countries, which is a fundamental foreign policy and national security objective of the United States. A key element of United States nonproliferation policy has been to minimize and eventually eliminate the use of HEU - a nuclear weapons usable material - in civil nuclear programs worldwide. Research reactors are of particular interest in this endeavor because the major civil use of HEU is as fuel in nuclear research reactors. If research reactors were to convert to low-enriched uranium (LEU) fuels, HEU would essentially be eliminated from use in civil commerce.

Research reactors play a vital role in fundamental scientific research, as well as provide important medical, agricultural and industrial applications. For example, research reactors have proven vital to cancer therapy and radioimmunoassay blood testing. There are approximately 8,000 - 10,000 medical treatments per day in Europe using medical isotopes produced in research reactors. Neutron radiography provided by research reactors has enabled researchers to diagnose defects in metals and engines of many varieties, and to conduct research on new materials, computer chips, and chemicals. Radioisotopes produced in research reactors have been used in leak detection in industrial components and equipment, aluminum production, and semiconductors and solar panel research. Neutron scattering experiments done in research reactors have provided insights into the biostructure of organic substances, and have advanced the development of magnetic and superconducting materials. Research reactors also have been used in the environmental sciences to study waste migration, mine drainage, diffusion and transport of pollutants, water chemistry, sediment transport, atmospheric dispersion and toxic waste management. Research reactors also serve as major training facilities in nuclear technology. For example, the research reactor operating in 
Austria is used by the International Atomic Energy Agency to train personnel who conduct international inspections of weapons and civil nuclear facilities worldwide.

In order to reduce the danger of nuclear weapons proliferation posed by commerce in HEU used to fuel research reactors, the United States, in the past, adopted two mutually dependent policies, the Reduced Enrichment for Research and Test Reactors (RERTR) Program and the Offsite Fuels Policy. The relationship between these two programs and a brief status of each are discussed below.

The RERTR Program, initiated in 1978 and still ongoing, is aimed at reducing the demand for HEU by developing high density, LEU fuels - not directly usable in nuclear weapons - to replace the HEU fuels used in both domestic and foreign research reactors. Forty-two foreign research reactors that use or formerly used HEU of United States origin and that operate at power levels equal to or greater than 1 megawatt have been key participants in the RERTR Program since the late 1970s. The program has been successful in bringing about the conversion to LEU fuel of a significant number of these reactors. Many of the remaining reactors are involved in extensive technical cooperation with the Argonne National Laboratory in various studies and evaluations that are part of the LEU conversion process. Although substantial effort has been invested by foreign research reactor operators, the LEU conversion process is not irreversible. As shown in Table 1-1 at the end of the Chapter, fifteen of the 42 reactors have been fully or partially converted and three reactors have ordered LEU fuel elements for conversion. Three reactors are technically unable to utilize the LEU fuels that are currently available, two reactors do not need to be refueled because their cores will last for the lifetime of the facility, and three reactors have been or plan to be shut down. The remaining sixteen reactors are in various stages of the conversion process.

The Offsite Fuels Policy has been regarded as an essential complement to the RERTR Program. Under the Offsite Fuels Policy, the United States accepted the return of foreign research reactor spent fuel containing HEU of United States origin. ${ }^{1}$ This policy was designed to deter the stockpiling of spent fuel containing HEU in foreign countries, and to recover the fuel value of the remaining HEU. The United States accepted HEU spent fuel under the Offsite Fuels Policy until the policy lapsed in 1988. (In 1992, the Offsite Fuels Policy for LEU spent fuel also lapsed. The latter policy had been established in 1986 as an incentive for research reactors to convert to LEU fuels under the RERTR Program.)

The Offsite Fuels Policy offered reactor operators a solution for managing research reactor spent fuel that was not otherwise available. Thus, it was seen by the operators, at least after the initiation of the RERTR Program, as an essential quid pro quo for incurring the

\footnotetext{
${ }^{1}$ Acceptance of foreign research reactor spent fuel by the United States is consistent with nuclear weapons nonproliferation policies pursued since the 1950 's. The United States historically has engaged in cooperative activities and promotion of peaceful uses of nuclear technologies in other countries. As part of this nuclear cooperation, beginning with the "Atoms for Peace" program in the 1950's, the United States provided HEU for use as fuel in research and materials testing reactors and in special purpose nuclear reactors around the world. Although HEU could be used in nuclear weapons, HEU was provided to these countries as part of an arrangement under which countries agreed to forego development of nuclear weapons if the United States would assist them in peaceful applications of nuclear technologies. The first shipment of irradiated fuel from a foreign research reactor came to a United States government facility in Idaho from Canada in 1958. Irradiated fuel elements from foreign research reactors have been received at the Savannah River Receiving Basin for Offsite Fuels since 1963.
} 
substantial technical difficulties and financial expenses of converting to LEU fuel. Foreign governments and reactor operators have indicated since the beginning of the RERTR Program that their willingness to participate in this key nonproliferation program was contingent upon the willingness of the United States to continue to accept spent fuel from their research reactors.

Because the United States has not been in a position to take back HEU fuel for over five years, several foreign research reactor operators have run out of storage capacity or face safety and regulatory issues associated with the presence of spent fuel at their sites. If the United States is unable to accept any near-term foreign research reactor spent fuel shipments, several reactor operators soon will either shut down their reactors or ship their spent fuel to the United Kingdom Atomic Energy Authority's facility in Dounreay, Scotland (referred to in this Environmental Assessment as Dounreay) for reprocessing. ${ }^{2}$

Not all reactor operators have the option to ship spent fuel to Dounreay for reprocessing. The Dounreay facility is the only facility currently able and willing to reprocess foreign research reactor spent fuel, and then only on the condition that the reprocessing customer take back the reprocessed wastes. Some of the countries in which the foreign research reactors are located do not have a domestic waste repository or other facility for storing reprocessed wastes, and for those countries reprocessing is not an option. Those reactor operators without a reprocessing option thus may be forced either for safety reasons or other regulatory reasons to shut down, with the attendant loss of credibility for the RERTR Program, if near-term spent fuel shipments to the United States do not occur.

The consequences of reactor shutdowns resulting from a failure by the United States to accept near-term shipments of foreign research reactor spent fuel would reach well beyond the impacts on affected reactors. It is likely that other reactor operators, believing that the United States had not proven to be a reliable partner in matters of nuclear cooperation, would seek alternatives to reliance on the United States until indigenous solutions for their spent fuel storage issues could be found. Reduced reliance on the United States likely would result in the abandonment of the RERTR Program by many of the foreign participants, thus foreclosing the longer-term policy choices to be made after completion of the Foreign Research Reactor Spent Fuel Environmental Impact Statement. Indeed, some foreign research reactor operators have stated categorically that, if the United States is unable to accept any near-term spent fuel shipments, they would terminate their participation in the RERTR Program, and rely on HEU fuels in the future.

To avoid shutdown, three reactor operators have already shipped some of their spent fuel to the United Kingdom for reprocessing. Forcing reactor operators to pursue the reprocessing option, however, would engender a number of consequences adverse to United States nonproliferation interests. First, if a research reactor were forced to reprocess in order to avoid shutting down, the reactor operator and the foreign government involved would likely

\footnotetext{
2 The term "reprocessing" refers to the chemical separation of HEU and other nuclear materials from the fission products of the spent fuel element. Historically, the United States reprocessed foreign research reactor spent fuel received under the Offsite Fuels Policy.
} 
perceive that the United States had not kept its part of a bargain which, in their view, was and remains a key condition for their participation in the RERTR Program.

Second, while the United States government has full confidence in the physical protection and safeguards systems in place at the Dounreay reprocessing facility, reprocessing of spent fuel containing HEU would likely mean that the research reactors pursuing this option would continue operations on the HEU fuel cycle. The research reactor licensing authorities require research reactors to have in place specific means of disposing of their spent fuel, and neither Dounreay nor any other available facility is currently accepting aluminum clad research reactor spent fuel containing LEU for reprocessing. Hence, the research reactors would have to continue to use HEU fuels. This may result in reactor operators delaying or canceling plans to convert to LEU, or, in some cases, reconverting from LEU to HEU fuels.

If some reactor operators were to withdraw from the RERTR Program and rely instead on HEU fuels, with attendant lower costs and enhanced performance, other operators would demand to be put on the same footing. Since the United States under the Energy Policy Act of 1992 is barred from exporting HEU to virtually all foreign research reactors, reactor operators seeking continued use of HEU would be forced to seek alternate suppliers. The former Soviet Union and China have the largest surpluses of HEU, and should they choose to provide a ready supply of HEU, additional research reactor operators may be enticed to abandon the RERTR Program and reconvert to HEU.

Additionally, a number of the countries involved are exporters of research reactors. In recent years, they have required those reactors exported to other countries to be fueled with LEU. However, if reactor operators begin delaying or canceling plans to convert to LEU, and thereby continue to use HEU, foreign reactor purchases would demand HEU-fueled reactors. This could lead to renewed international commerce in weapons-useable HEU and would be directly antithetical to the policy goal of seeking to minimize and eventually eliminate the civil use of HEU.

Some commentors have questioned whether the proposed acceptance of spent fuel to avoid forcing reactor operators to reprocess $\mathrm{HEU}$ is consistent with the United States policy of continuing to grant prior consent to Japan and western European nations for reprocessing of power reactor spent fuel. The United States policy of continuing to grant prior consent to Japan and western European nations for reprocessing of power reactor spent fuel is not at odds with the nonproliferation interests that underlie the proposed action. The United States believes that the growing quantities of plutonium in international commerce present a threat to the nonproliferation regime. In countries where material control and accountancy or physical protection systems are not sufficiently rigorous, there is a risk of diversion or theft of such materials. In addition, even in countries with effective nonproliferation commitments, the presence of unneeded stocks of plutonium could raise security concerns on the part of neighboring countries. Accordingly, United States policy is not to encourage the civil use of plutonium.

Nevertheless, the United States also is committed to being a reliable nuclear trading partner and to avoiding interference in legitimate nuclear programs. Therefore, for countries that have large, well established civil reprocessing and plutonium facilities and comprehensive 
nonproliferation commitments, the United States will continue in appropriate instances to grant prior consent for reprocessing on a predictable and long-term basis. Undertaking to use United States consent rights to block reprocessing would lead to confrontation with key allies and jeopardize their support for the broader United States nonproliferation agenda.

Finally, another crucial consideration in proposing to accept in the near term a small number of spent fuel shipments from foreign research reactors is the 1995 international conference on the Treaty on the Non-Proliferation of Nuclear Weapons (NPT). The Treaty itself mandates that 25 years after entry into force (i.e., 1995) a conference shall be held to determine whether the Treaty should continue indefinitely or be extended for an additional fixed period or periods. The United States strongly supports indefinite extension of the NPT, which is the foundation for the international nuclear nonproliferation regime. One key to the success of the 1995 NPT conference is likely to be the ability of the United States to convince other NPT parties that the United States has fulfilled its obligations under Article IV of the Treaty to share with countries the benefits of peaceful nuclear cooperation. If several countries that are parties to the NPT are compelled to shut down their research reactors and are thereby forced to forego the medical and scientific benefits of these reactors, or are forced to seek reprocessing, the United States, fairly or unfairly, may be accused of not sharing the benefits of peaceful nuclear cooperation. Such an accusation, however ill-founded, is likely to be made not only by the affected countries but also by other countries, particularly those which already are opposed to indefinite extension of the Treaty.

In summary, the failure of the United States to accept any near-term research reactor spent fuel shipments likely would have adverse consequences that extend well beyond the impacts on affected reactors. Those impacts, whether in the form of shutdowns or reprocessing, would compromise the RERTR Program, the broader policy goal of minimizing the civil use of HEU, and the ability of the United States to pursue indefinite extension of the NPT - the foundation of international nuclear weapons nonproliferation efforts. Thus, DOE has prepared this Environmental Assessment to consider the potential environmental impacts of accepting a small number of research reactor spent fuel elements in the near term in order to preserve the viability of the RERTR Program while the broad policy issues of accepting approximately 15,000 spent fuels elements are analyzed in the Foreign Research Reactor Spent Fuel Environmental Impact Statement. 
Table 1-1 Status of RERTR Program Participants - Foreign Research and Test Reactors with Power $\geq 1 \mathrm{MW}$ that Use or Formerly Used HEU of U.S. Origin as of March 1994

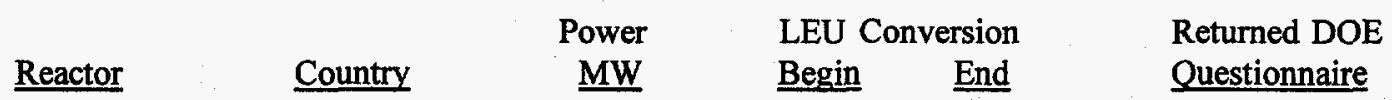

A. REACTORS FULLY CONVERTED ${ }^{\mathrm{ab}}$

$\begin{array}{llllll}\text { 1. } & \text { RA-3 } & \text { Argentina } & 2.8 & 1990 & 1990\end{array}$

2. ASTRA

Austria

1990

1990

$1992 \quad 1993$

3. NRU

Canada

1988

1990

$1979 \quad 1979$

$1991 \quad 1991$

$1991 \quad 1991$

$1993 \quad 1994$

$1991 \quad 1991$

$1987 \quad 1987$

$1990 \quad 1993$

$1978 \quad 1987$

Questionnaire

5. OSIRIS

8. JMTR

9. PARR

10. PRR-1

11. R2

Philippines

Sweden

Taiwan

50

No

Yes

Summary

Yes

No

Yes

No

Yes

No

No

Yes

Yes

B. REACTORS PARTIALLY CONVERTED

13. IEA-R1 Brazil

14. TRIGA Romania 14

15. SAPHIR Switzerland 10

$1981 \geq 1995$

$1992 \geq 1995$

$1986 \quad 1996$

No

Yes

Yes

C. REACTORS THAT HAVE ORDERED LEU FUEL ELEMENTS FOR CONVERSION

16. GRR-1 $\quad$ Greece $\quad 5 \quad 1994 \geq 1997 \quad$ Yes

17. HOR Netherlands $\quad 2 \quad 1995 \geq 1997 \quad$ Yes

$\begin{array}{llllll}\text { 18. } & \text { TR-2 } & \text { Turkey } & 5 & 1994 & \geq 1997\end{array}$

D. REACTORS NOW TESTING OR HAVE TESTED LEU PROTOTYPES

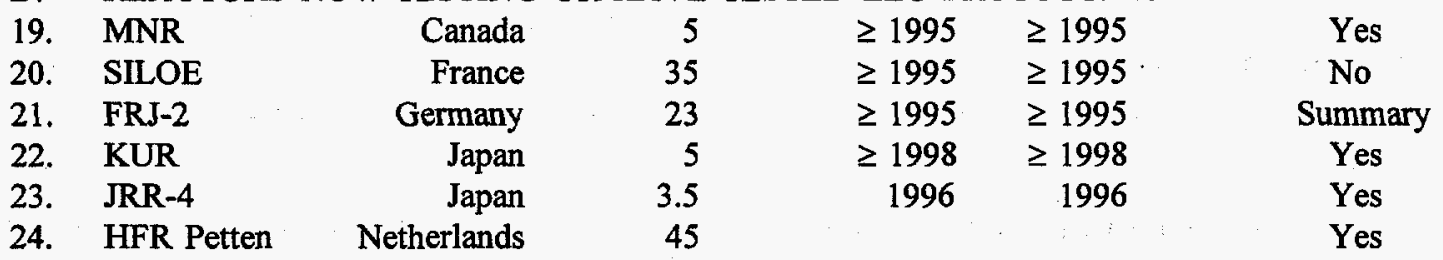




\section{Table 1-1 Status of Foreign Research and Test Reactors with Power $\geq 1$ MW that Use or Formerly Used HEU of U.S. Origin as of March 1994 (continued)}

\begin{tabular}{|c|c|c|c|}
\hline \multicolumn{4}{|c|}{ LEU Conversion } \\
\hline eactor & Country & MW & Begin \\
\hline
\end{tabular}

\begin{tabular}{|c|c|c|c|c|c|c|}
\hline E. & REACTO & NNING CO & ION & & & \\
\hline 25. & La Reina & Chile & 5 & $\geq 1995$ & $\geq 1995$ & Yes \\
\hline 26. & BER-II & Germany & 10 & 1995 & 1997 & Yes \\
\hline F. & REACTO & Г CAN BE & ERTI & & & \\
\hline 27. & HIFAR & Australia & 10 & & & Yes \\
\hline 28. & FMRB & Germany & 1 & & & Yes \\
\hline 29. & FRM & Germany & 4 & & & Yes \\
\hline 30. & IRR-1 & Israel & 5 & & & Yes \\
\hline 31. & TRIGA & Korea & 2 & & & No \\
\hline 32. & TRIGA & Mexico & 1 & & & No \\
\hline 33. & RPI & Portugal & 1 & & & Yes \\
\hline 34. & SAFARI $^{\mathrm{c}}$ & S. Africa & 20 & & & Yes \\
\hline
\end{tabular}

G. REACTORS THAT CANNOT BE CONVERTED WITH CURRENT TECHNOLOGY

35. BR-2 Belgium 80 Y

36. RHF $\quad$ France 57

37. ORPHEE $\quad$ France $14 \quad$ No

H. LIFETIME CORES

38. Scarabee $\quad$ France 20 No

39. R2-0 Sweden 1 Yes

I. REACTORS TO BE SHUT DOWN

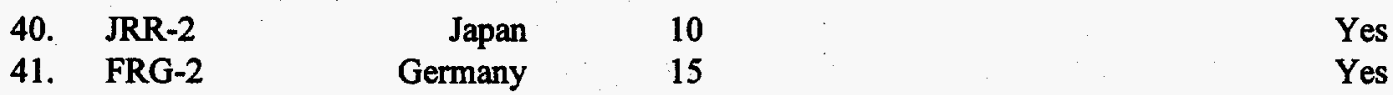

J. REACTORS SHUT DOWN

42. NRX Canada $24 \quad$ Summary

a The TRR-1/M1, a $1 \mathrm{MW}$ research reactor in Thailand, was converted from plate-type HEU fuel to Triga LEU fuel in 1977, before the RERTR Program was initiated. The reactor operator returned DOE's spent fuel questionnaire in June 1993.

' The JRR-3M, a $20 \mathrm{MW}$ research reactor in Japan, was converted upward in enrichment from very low enriched $\mathrm{UO}_{2}$ fuel to LEU ( 19.8\%) plate-type fuel between 1983 and 1990 . The Japan Atomic Energy Research Institute returned DOE's spent fuel questionnaire in April 1993.

' SAFARI currently uses HEU of South African origin. 



\subsection{IDENTIFICATION OF REACTORS IN NEED OF URGENT RELIEF}

\subsection{Introduction}

The RERTR Program is one of the primary mechanisms used to implement the United States policy objective of minimizing and eventually eliminating the use of HEU in civil programs. The criteria described in this section were developed to determine whether conditions exist that, in the absence of near-term acceptance of spent fuel by the United States, would threaten the RERTR program, thereby potentially foreclosing broad policy initiatives that are being analyzed in the Foreign Research Reactor Spent Fuel Environmental Impact Statement.

Method by Which Foreign Research Reactors Were Identified as Needing Urgent Relief. Since the inception of the RERTR program in 1978, DOE, in coordination with the Department of State, has maintained close contact with the operators of foreign research reactors fueled with uranium enriched in the United States. There are currently 134 foreign research reactors that have used HEU and LEU of United States origin. As shown in Table 2-1, 42 reactors have power levels that are equal to or greater than 1 megawatt and use

Table 2-1. Number of Foreign Research Reactors That Use or Formerly Used HEU and LEU of United States Origin

\begin{tabular}{||c|c|l||}
\hline $\begin{array}{c}\text { Number of } \\
\text { Reactors }\end{array}$ & \multicolumn{1}{|c|}{$\begin{array}{c}\text { Enrichment } \\
\text { of Fuel }\end{array}$} & \multicolumn{1}{|c|}{ Description } \\
\hline 42 & HEU & Power equal to or greater than 1 MW \\
\hline 13 & LEU & Power equal to or greater than 1 MW \\
\hline 79 & HEU, LEU & Power less than 1 MW; Lifetime Cores \\
\hline \hline Total 134 & & \\
\hline
\end{tabular}

or have formerly used HEU of United States origin. Reactors with power levels that are equal to or greater than 1 megawatt require regular refueling and, accordingly, accumulate spent fuel in their storage pools. These reactors are the focus of this Environmental Assessment because they may require urgent shipment of spent fuel.

In the spring of 1993, DOE sent questionnaires to all 42 foreign research reactors with power levels that are equal to or greater than 1 megawatt and have used fuel containing HEU of United States origin. The purpose of the questionnaire was to elicit information concerning the amount and condition of the spent fuel at the various reactors. Twenty-six of the 42 reactor operators returned the full questionnaire, and three reactor operators returned summaries of their spent fuel inventories. Fifteen foreign research reactor operators with heightened concern over their ability to meet spent fuel storage needs organized under the auspices of the Edlow International Company, a major nuclear material shipping company, in an effort to convince DOE to renew acceptance of foreign research reactor spent fuel. The 
members of the Edlow group performed a peer review of their respective spent fuel storage needs and provided DOE with a list prioritizing the reactors with the most urgent needs, identifying how many spent fuel elements needed to be accepted, and when the shipments needed to be made.

In addition to the data in the returned questionnaires and the information provided by the Edlow group, DOE also collected information directly from the reactor operators, the staff of the RERTR program at Argonne National Laboratory, the International Atomic Energy Agency, and foreign government embassy staffs. Based upon this information and upon comments received on the October 1993 Draft Environmental Assessment, DOE concluded in late 1993 that it needed to observe first-hand the conditions at eleven foreign research reactors that appeared to possibly have a need for acceptance of some of their spent fuel. The eleven reactors visited by United States inspection teams are: HIFAR (Australia); ASTRA (Austria); BR-2 (Belgium); DR-3 (Denmark); BER-II (Germany); FRG-1 (Germany); GRR-1 (Greece); HFR Petten (Netherlands), HOR (Netherlands); R-2 (Sweden) and SAPHIR (Switzerland). Before the site visits, these eleven reactors had requested DOE to accept approximately 950 spent fuel elements prior to completion of the Foreign Research Reactor Spent Fuel Environmental Impact Statement.

For planning purposes, DOE assessed the needs of these eleven reactors through December 1995. This date was based on the June 1995 planned completion date for the Foreign Research Reactor Spent Fuel Environmental Impact Statement, allowing an additional six months for the Department to make a decision on the proposed policy.

Reactor Site Visits. In January 1994, site visits were conducted at the eleven research reactors in Europe and Australia by two teams of representatives from DOE and the Department of State. The purpose of the visits was to evaluate, based on first-hand observation, the current spent fuel storage situation at each of the eleven reactors, and to explore all feasible alternatives to sending spent fuel to the United States before December 1995.

To ensure that the necessary information was obtained from each reactor, a "protocol" was developed, provided to each reactor operator prior to the visit, and reviewed in detail during the site visit discussions. This protocol consisted of sixteen questions designed to elicit, among other things, a detailed description of current spent fuel storage conditions at the reactors, the estimated number of additional spent fuel elements that would be generated in the near term (through December 1995), the reason why near-term acceptance was being requested, and all feasible alternatives to sending spent fuel to the United States in the near term. (The protocol can be found at Appendix K.) This information was deemed necessary to determine whether any near-term need really existed and, if so, the minimum number of spent fuel elements that would need to be accepted to allow the reactors to continue operating through December 1995. Because the decision to make the site visits was not made until December 1993, some of the reactor operators were unable to provide all of the information called for by the protocol at the time of the site visits. In those cases, the reactor operators later supplemented the information gathered during the site visits. This supplemental information was taken into consideration, along with all other available information, in preparation of this Environmental Assessment. 
Although the order of events varied somewhat from one reactor to another, each site visit consisted of a period of introductory remarks by the reactor operators and the United States representatives, a thorough inspection of the reactor and all spent fuel storage locations, and a review of each question listed in the protocol. By way of introduction, the United States inspection team reviewed events since July 13, 1993, when Secretary of Energy O'Leary sent Secretary of State Christopher a letter announcing the Department of Energy's proposal to accept up to 15,000 foreign research reactor spent fuel elements containing uranium enriched in the United States for up to fifteen years. (This letter can be found at Appendix A.) The Secretary's letter noted that the potential environmental impacts of this proposed policy would be analyzed in the Foreign Research Reactor Spent Fuel Environmental Impact Statement that DOE plans to complete by the end of June 1995. It was evident from the discussions that many of the reactor operators had not understood that any decision to implement this policy proposal could not actually be made until after the completion of the Environmental Impact Statement.

Minimum Number of Spent Fuel Elements. The United States representatives also explained that DOE's proposal to accept a small number of spent fuel elements from foreign research reactors while the Foreign Research Reactor Spent Fuel Environmental Impact Statement was being prepared was based on a broad policy objective - to maintain the viability of the RERTR program so that longer-term policy choices would not be foreclosed by an abandonment of the RERTR program while the Environmental Impact Statement was being prepared. Considerable effort was expended to understand the factual circumstances at each reactor concerning the current spent fuel storage constraints, and the minimum number of spent fuel elements that would have to be transported offsite (whether to the United States for storage or to Dounreay for reprocessing, where that option existed) to allow the reactor to continue operating through December 1995. As a natural corollary to this inquiry, considerable time also was spent at each reactor to understand what feasible alternatives each reactor operator might have through December 1995 in lieu of transporting spent fuel to the United States.

Full versus Partial Casks. As a result of the site visits and a review of the supplemental information supplied by some of the reactor operators, the inspection teams gained an understanding of the regulatory and safety concerns that would require the reactor operators to find a "solution" to their spent fuel storage situations in order to continue operating through December 1995. As noted above, the minimum number of spent fuel elements that would need to be transported offsite was determined. When that number was compared to the capacity of the transportation cask that probably would be used to transport the fuel elements, it became apparent that the minimum number of spent fuel elements that would need to be transported would not always constitute a full cask. (Not all of the casks available worldwide for transporting spent fuel are licensed in all of the countries in which the eleven reactors are located. Accordingly, at least four different casks are presently under consideration for use in transporting the spent fuel considered in this Environmental Assessment.) Thus, in addition to determining the minimum number of spent fuel elements, the inspection teams also determined the number of fuel elements that would be transported if the reactor operator were to ship a full rather than a partial cask. The reactor operators pointed out that shipping partial casks would still require the same number of overall shipments as shipping full casks, but with significantly increased costs per element. 
Summary. As a result of the site visits, the inspection teams were able to estimate the number of spent fuel elements that the reactor operators would need to transport offsite to allow continued operations through December 1995 (i.e., until after the Foreign Research Reactor Spent Fuel Environmental Impact Statement process can be completed) under a variety of different options. Those options include whether the United States would require the reactors that have the option to reprocess to exercise that option to avoid shutdown, and whether the United States would accept the shipment of full casks rather than partial casks. These policy options result in a range of numbers of spent fuel elements that could be accepted by the United States. (See Chapters 3 and 4.)

\subsection{Criteria For Determining Reactors In Need Of Urgent Relief}

Having gained an understanding of the range of numbers of spent fuel elements that could be transported from these eleven reactors under a variety of policy options, DOE still had to decide which among the eleven reactors truly had a need for DOE acceptance of spent fuel. By definition, this question had to be resolved on the basis of deciding which of the eleven reactors might take action in the near term that could threaten the RERTR program. DOE developed the criteria listed below for determining whether conditions exist that could lead a foreign research reactor to take actions posing a near-term threat to the RERTR program that would be inconsistent with the United States nonproliferation policy to minimize and eventually eliminate the use of HEU in civil programs.

The criteria described below are based upon DOE's review of the comments received on the October 1993 and February 1994 Draft Environmental Assessments and the information DOE and the Department of State collected during the reactor site visits. A threat to the RERTR program, and its attendant policy goal of minimizing the civil use of HEU, could be posed by a variety of conditions, as defined in the following criteria. Satisfaction by a reactor of any one of the criteria results in its inclusion among those reactors from which DOE proposes to accept spent fuel.

\subsubsection{Criterion 1}

In the absence of acceptance of spent fuel by the United States, a reactor operator likely would take one or more of the following actions to avoid spent fuel storage problems in the interim prior to completion of the Foreign Research Reactor Spent Fuel Environmental Impact Statement:

a.Stop a conversion from HEU fuel to LEU fuel that is currently underway;

b.Terminate plans to convert from HEU fuel to LEU fuel in the future; or

c.Reconvert from LEU fuel to HEU fuel.

Discussion: As noted in Chapter 1, the RERTR program is aimed at reducing the demand for HEU by developing high density fuels containing LEU to replace the HEU fuels used in foreign research reactors. A retreat from the conversion of HEU to LEU fuels, which are not directly usable in nuclear weapons, would be directly antithetical to the nuclear 
nonproliferation policy goal of seeking to minimize and eventually eliminate the civil use of HEU.

\subsubsection{Criterion 2}

In the absence of acceptance of spent fuel by the United States, a reactor operator would be forced to ship spent fuel to Dounreay for reprocessing in order to avoid shutdown in the near term.

Discussion: As noted in Chapter 1, forcing those reactor operators who have the option of reprocessing to pursue that option would sustain the use, transport, processing and storage of HEU, contrary to the goals of the RERTR program -- a key policy initiative in minimizing and eventually eliminating the civil use of HEU worldwide.

\subsubsection{Criterion 3}

In the absence of acceptance of spent fuel by the United States, the reactor would be forced to shut down in the near term.

Discussion: As noted in Chapter 1, the consequences of reactor shutdowns resulting from a failure by the United States to accept near term shipments of foreign research reactor spent fuel would reach well beyond the impacts on affected reactors. Shutdown of reactors that had been participants in the RERTR program likely would result in the abandonment of the RERTR program by other reactors that did not face an immediate need to ship fuel but were relying on United States acceptance of spent fuel in the long run. This would lead to the charge that the United States is not honoring its NPT commitment to assist non-nuclear weapons countries in realizing the benefits of peaceful applications of nuclear energy and could erode support for indefinite extension of the NPT.

\subsection{Application of the Criteria}

DOE, in consultation with the Department of State, has determined that eight of the eleven research reactors visited by the inspection teams meet one or more of the criteria. The following chart (Table 2-2) summarizes the results of applying the criteria. The following 
Table 2-2. Application of the Criteria by Determining Reactors in Need of Urgent-Relief

\begin{tabular}{|c|c|c|c|c|}
\hline \multicolumn{2}{|c|}{ Reactor Country } & $\begin{array}{l}\text { CRITERION 1: } \\
\text { Would stop conversion } \\
\text { to LEU, reconvert to } \\
\text { HEU, or never convert }\end{array}$ & $\begin{array}{l}\text { CRITERION 2: } \\
\text { Would be forced } \\
\text { to reprocess }\end{array}$ & $\begin{array}{l}\text { CRITERION 3: } \\
\text { Would be forced to } \\
\text { shut down }\end{array}$ \\
\hline ASTRA & Austria & & & $\mathrm{X}$ \\
\hline DR-3 & Denmark & & & $X^{a}$ \\
\hline GRR-1 & Greece & & & $\mathrm{X}$ \\
\hline HOR & Netherlands & & 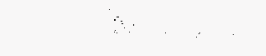 & $X^{b}$ \\
\hline HFR & Netherlands & & & $\mathrm{X}^{\mathrm{b}}$ \\
\hline $\mathrm{R}-2$ & Sweden & & & $\mathrm{X}$ \\
\hline BER-II & Germany & $X$ & $\mathrm{X}$ & \\
\hline SAPHIR & Switzerland & $\mathrm{X}$ & $\mathrm{X}^{\mathrm{c}}$ & \\
\hline
\end{tabular}

a Would be forced to shut down until dry storage facilities are completed and licensed in June 1994 at the earliest.

b The operators of HOR and HFR stated that they would work with their regulators to gain authorization to reprocess rather than shut down. However, according to their regulators, it is not clear if such authorization could be obtained in time to prevent shutdown. If authorization to reprocess is obtained, the reactors would abandon any LEU conversion plans and continue to use HEU fuel.

' Reprocessing at Dounreay would require United States authorization.

eleven reactor profiles describe in detail how the conditions specified in the criteria are satisfied on a reactor-by-reactor basis. The BR-2 (Belgium), FRG-1 (Germany), and HIFAR (Australia) reactors do not meet any of the criteria for acceptance and, therefore, do not appear in Table 2-2. The BR-2 (Belgium) reactor was listed for acceptance of spent fuel in the February 1994 Draft Environmental Assessment; but the operator informed DOE in March 1994 that he intended to ship 96 additional spent fuel elements to Dounreay for reprocessing in 1994. This eliminates the near-term spent fuel storage problem at BR-2. The FRG-1 (Germany) reactor is not included because failure to accept the requested $99 \mathrm{HEU}$ spent fuel elements under this Environmental Assessment would have no near-term effect on reactor operations. The HIFAR (Australia) reactor is not included because, although at some expense, approximately four years of additional storage can be created at the reactor site, which would eliminate the need to ship spent fuel to the United States at this time.

At the time this Environmental Assessment was being prepared, discussions regarding conversion of the HFR (Netherlands) reactor were ongoing between United States government officials and the Commission of the European Communities. Acceptance of spent fuel from the HFR reactor under this Environmental Assessment is contingent upon completion of an agreement between the Commission of the European Communities and the United States Government to convert the reactor to use of LEU fuel in an expeditious manner. 
The number of spent fuel elements from these eight reactors that are considered for acceptance by the United States is a function of policy determinations - namely, whether to accept full versus partial casks, and whether to require those reactors that can reprocess to do so rather than transporting spent fuel to the United States. Those policy choices are reflected in the proposed action and alternatives to the proposed action, as described in Chapters 3 and 4.

\subsubsection{Reactor Profiles}

The following eleven reactor profiles describe in detail the spent fuel storage situation for each reactor considered in this Environmental Assessment.

\subsubsection{BR-2}

Background - The BR-2 is an $80 \mathrm{MW}$ research reactor located in Mol, Belgium, that is operated by CEN/SCK. The reactor began operation in 1962. The reactor core consists of 32 tubular-type fuel elements containing 93 percent enriched uranium. The reactor generates $85-$ 90 spent fuel elements per year. To conserve spent fuel storage space in recent years, the reactor has reduced power levels from 120 to 85 percent of the nominal power rating and proportionately cutback operation from 210 to 133 days per year. CEN/SCK plans a general refurbishment of the BR-2 beginning in mid-1995 or mid-1996, involving replacement of the beryllium matrix, inspection of the reactor vessel, and replacement of all or part of the heat exchangers.

The reactor is currently used for production of radioisotopes and for reactor engineering and safety experiments. BR-2 is the only source of medical isotopes in Belgium and supplies medical isotopes for other countries in the region as well. Reactor engineering and safety experiments include studies of radiation damage to reactor structural materials, studies of reactor fuel pin performance, and studies of the propagation of cladding and fuel damage under accident conditions.

Relationship of the Reactor to the RERTR Program - CEN/SEK has been very cooperative with the RERTR Program. An extensive joint study between Argonne National Laboratory and CEN/SCK from 1985 to 1988 concluded that the BR-2 cannot be converted to the low enriched fuels currently developed and qualified by the RERTR Program without severe economic penalties. BR-2 officials have indicated that if the United States were to pursue development of the required high density fuels to enable conversion to LEU, they would cooperate in such a program if the United States could guarantee a continued supply of HEU during the development and testing period.

\section{Urgency of Need for Acceptance of Spent Fuel:}

a. Reactor Storage Pool Capacity.

The last shipment of BR-2 fuel to the United States took place in 1982. BR-2 operators had planned to ship 144 elements to the United States in 1988, but the shipment never occurred due to expiration of the Off-Site Fuels Policy. Due to the lack of spent fuel 
storage space, the operator began to rerack the storage pool with high density storage racks. However, because the BR-2 spent fuel storage pool was designed for three-to-five years cooldown storage before shipment and not for long term storage, the licensing authority allowed the increased storage capacity on the condition that inspection and maintenance begin by December 31, 1993. To meet this requirement and continue reactor operation, CEN/SCK shipped 144 spent fuel elements to Dounreay for reprocessing in late 1993 and early 1994.

In order to support continued reactor operation through the end of 1995, (i.e., until after the Research Reactor Spent Fuel Environmental Impact Statement can be completed) and to allow the inspection program to be completed by mid-1996, it was necessary to create 144 additional new spaces in the storage pool. The February 1994 draft Environmental Assessment stated that if the licensing authority granted permission to add one final high density rack with 96 spaces to the storage pool, a minimum of 48 spent fuel elements would need to be shipped to the United States under this Environmental Assessment to meet the required total of 144 new spaces. In March 1994, CEN/SCK announced that it had contracted with Dounreay to ship 96 additional elements to Dounreay for reprocessing. These 96 elements are more than the minimum number of 48 elements that were proposed for shipment to the United States in the February 1994 draft Environmental Assessment.

\section{Alternatives:}

a. Adding Additional Storage Racks.

The reactor pool has been used to store spent HEU fuel for over ten years. The licensing authority has already allowed the installation of dense storage racks on two occasions to replace existing racks on the condition that inspection and maintenance of the storage pool begin by December 31,1993. It is possible that licensing authorities may allow the installation of one final dense rack that would hold 96 elements.

b. Reprocessing.

In March 1994, CEN/SCK contracted with Dounreay to ship 96 spent fuel elements to the United Kingdom for reprocessing. These 96 elements are in addition to the 144 elements that were shipped to Dounreay in late 1993 and early 1994.

c. Possible Storage of Spent Fuel at Other Facilities.

Dounreay will not accept spent fuel for storage without reprocessing. The Belgian Government will not allow the re-entry of any exported fuel back into Belgium. Cogema, in France, is not available for temporary storage. Collocation of HEU spent fuel in dry storage on the Belgoprocess site with commercial nuclear power plant high level waste may be possible, but would require studies that could not be completed in time to meet BR-2 needs. 
d. Acceptance of Spent Fuel Under the Environmental Assessment.

The shipment of 240 spent fuel elements to Dounreay for reprocessing in 1993 and 1994 has eliminated BR-2's need for acceptance of spent fuel under this Environmental Assessment.

e. No Acceptance of Spent Fuel.

Failure to accept spent fuel elements under this Environmental Assessment would have no immediate effect on reactor operations or on the schedule for inspection and maintenance of the storage pool. CEN/SCK more than met its need to ship a minimum of 48 elements to the United States by contracting to ship 96 elements to Dounreay for reprocessing. Thus, there is no need for the United States to accept spent fuel from the BR-2 reactor until after the Foreign Research Reactor Spent Fuel Environmental Impact Statement is completed. This conclusion is based on our understanding that CEN/SCK can still work with its regulatory authorities to obtain permission to install one additional dense rack of 96 elements in the storage pool.

\subsubsection{HOR}

Background - The Hoger Onderwijs Reactor (HOR) is a light water, swimming-pool research reactor located at Delft University of Technology, Delft, the Netherlands. Within the university, the facility is operated and utilized by the Interfaculty Reactor Institute (IRI) for its educational and research programs. The HOR is IRI's main research tool and is the only university-associated facility of its kind in the Netherlands.

The reactor went critical in 1963 and is currently operated at a power level of 2 megawatts. Annually, it uses four standard fuel elements and one control fuel element.

The scientific studies carried out at the institute include: reactor physics, radiotracer applications, chemical radioanalysis, radiation damage, health physics and dosimetry, radiation chemistry, and neutron scattering. IRI has a unique central position concerning research and education in reactor sciences and applications for all the universities in the Netherlands and it participates in a national program aimed at maintaining and intensifying the national nuclear competence. The institute is presently involved in an extensive program of renewal and extension of the reactor's experimental facilities (e.g., construction of a neutron and positron beam hall is planned for 1994).

Relationship of the Reactor to the RERTR Program - Institute personnel have been long-time active participants and supporters of the RERTR program. In 1980, IRI announced its intention to convert the reactor to LEU fuel. This decision was formalized in 1986, after publication of the Federal Register notice stating the United States commitment to take back LEU fuel until the end of 1992 (Federal Register Volume 51, No. 32, February 18, 1986 and Volume 52, No. 250, December 31, 1987). The Dutch Government, as well as IRI, support LEU conversion because conversion is regarded as an important aspect of nonproliferation. 
Interatom, now part of Siemens AG, completed a safety analysis for LEU core conversion. The first LEU elements were ordered in 1990, but conversion was delayed due to tightened licensing requirements. Because of these delays, IRI is currently paying $\$ 25,000$ per year to store its new fabricated LEU fuel at CERCA, France. IRI has invested over $\$ 2.3$ million in preparations for conversion.

If a commitment is made to ship spent HEU fuel under the Environmental Assessment, a license application for use of LEU fuel will be submitted to Dutch authorities in April 1994. Conversion could begin in 1995 and would take approximately five years. Without a commitment to ship spent fuel under the Environmental Assessment, the reactor operator stated that he intends to cancel plans for LEU conversion and continue to use HEU fuel.

\section{Urgency of Need for Acceptance of Spent Fuel:}

\section{a. License Limitation of 15 Kilograms Uranium.}

The facility operating license allows a total uranium inventory of 15 kilograms (including fresh fuel, fuel in the core, and spent fuel). IRI is currently within 600 grams of the uranium limit. The reactor burns approximately 375 grams of uranium per year. To ensure compliance with this limit, the operator must ship two spent HEU elements offsite for each fresh fuel element he procures. ${ }^{1}$ The lead time for procuring fresh fuel elements is approximately eighteen months. Therefore, without a commitment to ship spent fuel by the beginning of 1995, the operator would be unable to order the ten fresh fuel elements needed to sustain operations in mid-1996. If no fresh fuel can be acquired, operation of the reactor would be suspended. The reactor operator indicated that it is unlikely that operations would be allowed to resume.

b. Reactor Pool Storage Capacity.

Spent fuel from the reactor was last shipped to the United States in 1981. A shipment of 26 fuel elements planned for 1989 was interrupted due to expiration of the Off-Site Fuel Policy. Since then, an inventory of $70 \mathrm{HEU}$ spent fuel elements has accumulated at the reactor site. However, the relationship between the number of spent fuel elements and the number of storage rack positions in the reactor pool does not drive the need for near-term spent fuel shipment. Rather, it is the $15 \mathrm{~kg}$ total uranium license limit and near-term licensing actions discussed below that drive the need for action.

c. Planned Conversion to LEU.

The Institute is currently preparing a new safety report and an Environmental Impact Statement as bases for the new license required for conversion from HEU to LEU, the construction of a beam hall and for some minor modifications. In the Environmental

\footnotetext{
1 The four standard elements and one control element that HOR uses annually contain a total of about 925 grams of $93 \%$ enriched uranium when they are fresh and approximately 550 grams of uranium when they are spent. Therefore, one fresh element has approximately the same uranium content as two spent elements.
} 
Impact Statement and license application, IRI needs to provide information regarding final disposition of spent fuel. The reactor operator stated that reference to a possible future renewal of the Off-Site Fuels Policy after completion of the Foreign Research Reactor Spent Fuel Environmental Impact Statement will not be sufficient evidence for the licensing authorities. The licensing authorities have stated that they will require a commitment that spent fuel could be shipped under the Environmental Assessment to proceed with the application. If it is clear that no fuel could be shipped under the Environmental Assessment by the time the license application is filed in April 1994, discussion of conversion to LEU will be left out of the application, in order to avoid delays in the licensing of the new beam hall. The reactor operator stated that such a postponement would lead to cancellation of LEU conversion plans and pursuit of the ability to reprocess HEU fuel at Dounreay. The reactor operator believes such steps are necessary to ensure his continued operations because Dounreay does not process LEU fuel.

\section{Alternatives:}

a. Adding Additional Storage Racks.

It is not possible to install additional storage racks in the reactor's pool. Even if this were possible, the 15 kilogram total uranium limit would still be the controlling limit and not physical storage capacity.

b. Reprocessing.

The reactor operator stated that he would request permission from Dutch authorities to arrange for reprocessing at Dounreay, if forced to do so by an inability to ship to the United States Dutch authorities indicated that if no other option were available to prevent reactor shutdown, they would be willing to consider seeking Parliamentary approval for acceptance of high level waste generated during reprocessing. Because of upcoming elections, Dutch officials indicated that they would not be able to pursue such approval for acceptance of high level waste until September 1994. Based on the previous experience with commercial power reactor fuel reprocessing approval, which took two years to complete, Dutch officials estimated that it would take at least that long to obtain approval for reprocessing of research reactor spent fuel. As such, reprocessing could not be implemented by HOR until late 1996.

c. Possible Storage of Spent Fuel at Other Facilities.

There is a current operating storage facility (COVRA) for high level waste from commercial power reactors. COVRA has proposed to Dutch officials to expand this facility to allow storage of intact Dutch research reactor spent fuel elements. If implemented, fuel storage could begin in about 2001 - well past the time frame of the Environmental Impact Statement. 
d. Acceptance of Spent Fuel under the Environmental Assessment.

Shipment of 33 elements under the Environmental Assessment would allow the reactor operator to order, with sufficient lead time, ten fresh HEU fuel elements, which are necessary to support continued operations in mid 1996 in the event that licensing for conversion is delayed or denied. Such a shipment may also convince Dutch licensing authorities of the viability of returning LEU spent fuel to the United States under the Foreign Research Reactor Spent Fuel Environmental Impact Statement and therefore approve the license application for LEU conversion. A minimum partial cask shipment of twenty spent fuel elements would also permit the ordering of fresh fuel, but would provide little contingency if the Environmental Impact Statement were delayed.

e. No Acceptance of Spent Fuel.

If spent fuel elements are not accepted under the Environmental Assessment, the reactor operator stated that he would cancel LEU conversion plans and work with his regulator to secure authorization to reprocess fuel in Dounreay. Given the delays in instituting reprocessing, it is also possible that the reactor may be forced to shutdown. Shutdown of HOR would result in the loss to Dutch Universities of the central facility for research and education in reactor-, radiation- and health-physics, radiochemistry, radiation chemistry, medicine, biology, materials science and environmental research.

\subsubsection{HFR}

Background - The HFR research reactor is located near Petten, the Netherlands, and is operated by the Commission of the European Community (EC), ${ }^{2}$ Joint Research Center, on behalf of the EC member states. The HFR is a 45 megawatt pool-type research reactor fueled with 33 fuel elements and six control fuel elements containing 93 percent enriched uranium. The reactor generates a total of 66 spent fuel and control elements per year.

The HFR supports a broad variety of research efforts for industrial and medical purposes and is a major supplier of medical isotopes in the Netherlands and neighboring countries. Irradiations are conducted in support of materials research, basic research and will soon commence to support research on boron neutron capture therapy for the treatment of various cancers, which is funded by the EC's Medical and Health Research Program.

Relationship of the Reactor to the RERTR Program - The Joint Research Center has cooperated with the RERTR program in the past. This included irradiation of three prototype LEU silicide fuel elements and irradiation testing of four other LEU test elements with aluminum and oxide fuels. Extensive joint technical and economic studies for LEU conversion were completed in 1985. The extensive fuel irradiation tests and analysis support the conclusion that the reactor is technically capable of pursuing conversion to LEU fuel.

\footnotetext{
2 Now referred to as the European Union.
} 
The February 1994 Draft Environmental Assessment stated that acceptance of spent fuel elements under the Environmental Assessment, was contingent upon a commitment by the EC to convert the HFR reactor to LEU fuel use. This criterion was applied because acceptance of spent fuel from a reactor that can but has not converted to the use of LEU fuel is inconsistent with the purpose of the Environmental Assessment - that is, support of the RERTR program. The EC has reviewed its position on LEU conversion of the HFR and has stated that it is ready to initiate the necessary steps for the application of a license amendment for conversion. Officials of the United States Government and the Commission of the European Communities are actively discussing the terms of this commitment.

\section{Urgency of Need for Acceptance of Spent Fuel:}

\section{a. Spent Fuel Storage Capacity.}

In early January 1994, the HFR had 482 spent fuel elements and control fuel elements in storage. The reactor pool has a storage capacity of eight standard storage racks with 42 positions each and one storage rack with 35 positions for control fuel elements. Total storage capacity is 371 spent elements. Spent fuel elements and control elements occupied 230 positions. Fifteen positions are used for experimental purposes and five positions are blocked because of mechanical deformations. Thirty-nine positions are reserved for emergency unloading of the core. This left 82 positions available for storage.

Adjacent to the reactor pool storage is a second spent fuel storage pool containing six standard storage racks with 42 positions each. All 252 of the positions are completely filled.

On the basis of the present production rate of 66 spent fuel elements per year, there was sufficient storage capacity in January 1994 to operate the reactor for 15 months - through March 1995. Based on an approximate one year lead time to arrange for spent fuel shipment and assuming the Foreign Research Reactor Spent Fuel Environmental Impact Statement is completed by December 1995, the reactor operator must provide for the disposition of approximately 116 spent fuels elements (i.e., 50 spent fuel elements for operation from April 1995 through December 1995 and 66 spent elements for operation during 1996). Such provisions could be realized by increasing onsite storage capacity, by shipment offsite, or by a combination of these options.

\section{Alternatives:}

a. Adding Additional Storage Racks.

Theoretically, two racks with 42 elements each could be added to the remaining space in the second storage pool. However, because the pool would be completely full, moving fuel racks to permit required safeguards inspections would increase the necessary inspection time to about one week and disrupt normal operations. Procuring and adding the racks would require authorization from EC officials and subsequent approval by Dutch regulatory authorities. The operator has expressed uncertainty whether Dutch authorities would agree on utilization of the additional storage racks. The United States team met 
separately with Dutch officials, who expressed considerable concern about the increasing amount of spent fuel accumulating in spent storage pools at the HFR. This concern was reiterated in a letter (Hermans to Grumbly, shown in Appendix A) from the government of the Netherlands, which further stated that adding storage racks cannot be considered a viable alternative to the take back option.

If approvals could be obtained for the two additional storage racks, the 84 storage positions would allow operation of the reactor through June 1996. Since the lead time required to arrange for spent fuel shipment is about one year, the reactor operator would still need a commitment from DOE to accept 32 fuel elements (i.e., 116 minus 84 equals 32) to assure continued operations until the Foreign Research Reactor Spent Fuel Environmental Impact Statement could be completed.

b. Reprocessing.

HFR has attempted to ship spent fuel to Dounreay in the past. If such an option were pursued, there are doubts that the Dutch authorities would grant permission for the return of the recovered HEU and associated high-level radioactive wastes to the Netherlands.

The reactor operator stated that he would take up the matter formally with the Dutch authorities to arrange for reprocessing at Dounreay or any other available option, as necessary, if forced to do so. Dutch authorities indicated that if no other option were available to prevent reactor shutdown, they would be willing to consider seeking Parliamentary approval for acceptance of high-level waste generated during reprocessing. Because of upcoming elections, Dutch officials indicated that they would not be able to pursue such approval for acceptance of high-level waste until September 1994. Based on the previous experience with commercial power reactor fuel reprocessing approval, which took two years to complete, Dutch officials estimated that it would take at least that long to obtain approval for reprocessing of research reactor spent fuel. As such, reprocessing could not be implemented by HFR until late 1996.

c. Possible Storage of Spent Fuel at Other Facilities.

There is a current operating storage facility (COVRA) for high level waste from commercial power reactors. COVRA has proposed to Dutch officials to expand this facility to allow storage of intact Dutch research reactor spent fuel elements. If implemented, fuel storage could begin in about 2001 - well past the time frame of the Foreign Research Reactor Spent Fuel Environmental Impact Statement.

d. Acceptance of Spent Fuel Under the Environmental Assessment.

United States acceptance of 66 spent fuel elements in conjunction with regulatory approval to utilize one additional storage rack in the second storage pool would allow reactor operation until the Foreign Research Reactor Spent Fuel Environmental Impact Statement is completed. 
United States acceptance of spent fuel elements from the HFR under this Environmental Assessment is contingent upon completion of an agreement between the United States government and the Commission of the European Communities to convert the HFR to use of LEU fuel.

e. No Acceptance of Spent Fuel.

Failure to accept shipment of spent fuel from the HFR under the Environmental Assessment will affect adversely the operation of the reactor. Addition of the two storage racks is not sufficient to solve HFR storage needs through completion of the Environmental Impact Statement and reprocessing is not a viable option based on comments by Dutch authorities. (See Haack letter to Adm. Watkins in Appendix A.)

\subsubsection{DR-3}

Background - The DR-3 research reactor is operated by the Risoe National Laboratory located near Roskilde about 35 kilometers west of Copenhagen. The objective of the laboratory is to further technological development in three main areas: energy, environment, and materials. Established in 1958, Risoe is a state institution under the Danish Ministry of Research and Technology. The laboratory has a staff of approximately 900 ; one third researchers and 40 $\mathrm{PhD}$ students. Risoe's annual budget is approximately $\$ 57$ million. Forty-two percent comes from research programs and commercial contracts; the remainder from government appropriations.

The reactor is a heavy water moderated 10 megawatt research reactor that is fueled using 26 LEU coaxial tube-type elements. It is operated on a four-week cycle, with 4.5 day scheduled shutdown per cycle for fuel element transfer and replacement. On the average, three elements are replaced in each cycle for an annual spent fuel generation rate of approximately 35 elements.

Neutron beams emerge from four horizontal through-tubes tangential to the reactor core. Two of the horizontal tubes are used for neutron scattering experiments in the field of materials research. The vertical tubes are predominantly used for isotope production and materials testing. Experimental capabilities include a cold neutron source and world-class facilities for neutron scattering experiments. The laboratory has a long-standing tradition of extensive international cooperation.

The DR-3 reactor is one of the world's largest producers of irradiated silicon for semiconductors and it supplies the Danish demand for short-lived and specialized radioisotopes. DR-3 processes 25 tons of silicon per year for the production of semiconductors. This accounts for one-third of the world market and the income offsets a substantial part of the reactor operating costs.

Relationship of the Reactor to the RERTR Program - The DR-3 reactor has had a strong beneficial relationship with the United States RERTR Program since the program's inception. As part of the RERTR program, Risoe developed its own manufacturing capability for LEU silicide fuel elements for the DR-3 reactor. Conversion of the reactor to LEU fuel began in 
1988 and was completed in 1990, at a cost of over \$1 million. The success of DR-3's conversion was demonstrated to more than 100 participants from eighteen countries who visited Risoe in connection with the 15th International RERTR Conference in 1992.

\section{Urgency of Need for Acceptance of Spent Fuel:}

a. Existing Spent Fuel Storage Capacity.

Risoe has $88 \mathrm{HEU}$ spent fuel elements; thirteen in the spent fuel storage pool and 75 in three formerly used shipping casks. Also stored are 139 LEU spent fuel elements; 83 in the storage pool, seventeen in the internal storage block, and 39 in the external storage block. The locations of these elements are presented in Table 2-3.

Table 2-3. Risoe Spent Fuel Storage Capacity

\begin{tabular}{||l|c|c|c|c||}
\hline \multicolumn{1}{|c|}{ Storage Location } & Total Capacity & $\begin{array}{c}\text { Available } \\
\text { Capacity }\end{array}$ & HEU & LEU \\
\hline Internal Storage Block & $61^{\mathrm{a}}$ & 24 & 0 & 17 \\
\hline External Storage Block & 80 & $50^{\mathrm{b}}$ & 0 & 39 \\
\hline Racks in Storage Pool & 96 & 96 & 13 & 83 \\
\hline Retired Shipping Casks & 75 & 75 & 75 & 0 \\
\hline \hline Total & 312 & 245 & 88 & 139 \\
\hline
\end{tabular}

a 26 positions must be available for unloading the core in an emergency and eleven positions are available for storage of fresh fuel only.

b 50 positions are available for storage of spent fuel, the rest being used for fresh fuel and irradiated experimental rigs.

Refueling in April 1994 with three fuel elements constitutes the last normal fuel loading operation. If no relief can be found, and the fuel cannot be removed from the storage pools, the reactor will be forced to shutdown until their dry storage facility can be completed and licensed in July 1994, at the earliest.

When fuel transfers are made, elements are unloaded with the transfer cask into an internal storage block in the reactor building. This block has 61 storage positions, 26 of which must be kept vacant for emergency unloading of the core and eleven of which are available for storage of fresh fuel only. Elements must cool for at least 40 days before transfer to the external storage block which has 50 positions for spent fuel. The elements are transferred using lifting plugs.

Fuel cannot be transferred until more lifting plugs are made available. These will not be available until they can be cropped from spent fuel elements in the storage pool. They cannot be cropped until new space is made in the racks in the storage pool for the cropped elements. Because the 96 rack positions are filled with 83 spent LEU fuel elements and the thirteen spent HEU fuel elements, no fuel elements can be transferred, cropped, and stored unless spent fuel is removed. Therefore, although there is sufficient space in the internal and external storage blocks to unload spent fuel after April 1994, 
there are no available lifting plugs. New lifting plugs cannot be manufactured in time to support continued operations, although they could quickly be cut from spent fuel elements if storage space were available for the cropped elements. Table 2-4 presents the location of all lifting plugs as of January 27, 1994.

Table 2-4. Location of All Ninety-one Lifting Plugs as of January 27, 1994

\begin{tabular}{||l|c|}
\hline \multicolumn{1}{|c|}{ Location } & Number \\
\hline Internal Storage Block & 17 \\
\hline External Storage Block & 39 \\
\hline In Reactor Core & 26 \\
\hline Fitted with New Elements & 9 \\
\hline \hline & 91 \\
\hline
\end{tabular}

b. Planned Dry Storage Capacity.

Because the Off-Site Fuels Policy was not renewed, Risoe built interim dry storage facilities which will hold 432 spent LEU fuel elements (four blocks of twelve holes each which can hold nine elements stacked). The reactor operator anticipated licensing approval in early 1994, but unexpected technical problems delayed the approval. Humidity detectors must be installed in each "hole" and a new transfer cask must be completed and licensed. After further difficulties, the goal for completing these tasks is late April 1994, which could result in license approval in July at the earliest.

\section{Alternatives:}

a. Adding Additional Storage Racks.

There is no room available in the storage pool for addition of more fuel racks. Dry storage is under construction and could be licensed for use in July 1994, at the earliest.

b. Reprocessing.

A proposal to reprocess spent fuel at Dounreay is not a feasible alternative in that it would require that high-level waste be returned to Denmark. Denmark has no nuclear power program and no plans for high level waste storage facilities. Furthermore, the reactor operator indicated that there is also a strong anti-reprocessing sentiment in Denmark due to the perception that the Dounreay facility in the United Kingdom has made regular discharges of radioactivity into the North Sea.

c. Possible Storage of Spent Fuel at Other Facilities.

Risoe provides low and intermediate radioactive waste storage for the entire country. Denmark has no nuclear power program, no high level waste storage facilities, and there are no other spent fuel storage facilities. 
d. Acceptance of Spent Fuel Under the Environmental Assessment.

Shipment of one Pegase cask of 36 spent fuel elements should provide a bridge between the time the reactor needs to refuel and the time the dry storage facility becomes available. A partial cask shipment of twelve spent fuel elements might be sufficient to support refueling from April 1994, if dry storage becomes available in July 1994. Shipment of twelve elements, however, would provide little or no contingency if resolution of technical and licensing issues delays the availability of dry storage.

e. No Acceptance of Spent Fuel.

Failure to accept shipment of spent fuel from DR-3 will result in shutdown of the reactor until the dry storage facilities can be completed and licensed in July 1994, at the earliest. However, even a temporary shutdown of several months could have unforeseeable consequences for the future operation of the reactor.

\subsubsection{R-2}

Background - The R-2 materials testing and research reactor is owned by Studsvik AB and is operated by its subsidiary Studsvik Nuclear AB. The Studsvik Group is part of Sweden's long history in nuclear power and research. The Studsvik Group has about 520 employees and an annual budget of about $\$ 60$ million. The R-2 reactor, the hot cell laboratory, and various other laboratories are located at Studsvik, about 100 kilometers south of Stockholm.

The R-2 is a light water, tank-in-pool reactor in operation since 1960. The reactor core is contained within an aluminum vessel at one end of a large open pool, which also serves as storage for spent fuel. The fuel elements contain either nineteen plates with HEU fuel or eighteen plates with LEU fuel. The R-2 reactor is now operated on LEU-fuel only. The reactor power was increased to 50 megawatts in 1969 and a new reactor vessel was installed in 1984-85. At the other end of the pool is a 1 megawatt moveable pool-type reactor, the R20 , which is operated with a lifetime core and has no spent fuel.

Reactor activities include fuel and materials testing, transmutation doping of silicon, neutron activation analysis, radioisotope production for radiation sources and radiopharmaceuticals, and basic research including thermal neutron scattering, nuclear chemistry, and neutron capture radiography. European, Japanese and United States fuel manufacturers, nuclear power utilities and research organizations have utilized the R-2 and its associated hot cell laboratories for bilaterally and multinationally sponsored research for many years.

Relationship of the Reactor to the RERTR Program - Sweden joined the RERTR program at its inception and has had an extensive joint study program with Argonne National Laboratory including exchanges and visits of personnel involved in LEU conversion studies. Four LEU silicide fuel elements were irradiation tested in the R-2 reactor as part of the cooperative effort. The gradual conversion of R-2 to the use of LEU fuel began in 1991 and was completed in 1993, demonstrating the reactor operator's commitment to the nonproliferation goals of the RERTR program. 
Urgency of Need for Acceptance of Spent Fuel:

\section{a. Reactor Pool Storage Capacity}

The reactor pool is divided into three compartments, separated by large movable ports. The first is occupied by the R-2 reactor tank and its operating equipment. The second (middle) pool is used for storage of the fuel elements and core equipment. This pool is also used to load and unload spent fuel into the transportation cask. The third pool contains the R2-0 reactor and associated storage racks. There is also a four-level fuel rack for fully burned (and cut) R-2 elements in this third pool.

The storage racks in the second pool contain 148 fuel elements and eighteen control elements. At the present time, there are 110 empty positions, which are sufficient to store spent LEU fuel until the end of 1995.

As described below, the reactor operator's request to ship spent fuel under the Environmental Assessment is not based directly on a need to ship spent fuel because of fuel storage constraints associated with operations. Rather, the reactor operators must upgrade physical protection capabilities for aging HEU fuel or ship it offsite and, additionally, they must demonstrate viable options for disposition of R-2 spent fuel to the licensing authorities by April 1994.

b. Additional Storage Pools.

Before 1989, spent HEU fuel was sent back to the United States for reprocessing. Since then, all spent fuel has been stored at the Studsvik site. Normal operation of the reactor would have been impossible with all spent fuel residing in the reactor pools, so additional storage space was urgently needed.

The concrete walls of one of three reloading pools from earlier research reactors in Sweden were retrofitted with an epoxy layer to improve water quality. A bottom layer storage rack with 144 positions was installed. Spent fuel from R-2 was placed in the pool for short-term storage after it had been cut for shipping.

When the Off-Site Fuels Policy was not renewed, it became clear that a second layer of fuel racks would be required. This was accomplished by construction of a moveable rack system, which provided for safeguards inspections of the lower level. Both layers of racks are high density ("poisoned" with cadmium) and cannot be expanded. This pool is completely filled (and sealed by IAEA) with 340 cold HEU fuel elements.

Of the other two pools in the reloading facility, one contains about 1.5 tons of natural uranium fuel from a 1960s-era heavy water reactor called R-1. Additional fuel cannot be moved into this pool because there are no racks available and they are not licensed to build additional racks. The other pool is used to load and unload transportation casks and cannot be used for storage. 
c. Physical Protection.

The Agreement for Cooperation between Sweden and the United States stipulates that irradiated fuel that cools to less than $100 \mathrm{rads} / \mathrm{hr}$ at one meter in air requires "Category I" protection for quantities above five effective kilograms rather than the "Category II" level of protection which is the normal operating condition for facilities such as research reactors. The oldest fuel from R-2 will begin to change class in June 1994, based on calculations using the ORIGEN-2 and GAMDOS computer codes. Before the Environmental Impact Statement is completed in late 1995, approximately 58 elements will change their physical protection category. Elements will continue to change category in 1996 and beyond.

There are no existing spent HEU storage facilities that are licensed, or could be costeffectively upgraded, to meet Category I requirements, either at Studsvik or at any other nuclear installations in Sweden. Moreover, the time necessary for planning, licensing and construction of a new storage facility, would exceed the time available before a significant amount of fuel reaches the Category I radiation level. Finally, the reactor operator indicated that the \$50-100 million costs associated with building a Class I "bunker-like" facility could not be justified. Consequently, the reactor operator does not view this as a realistic alternative to shipping fuel offsite.

d. License Renewal.

The current operating license for the R-2 reactor expires on June 30, 1994. An application has been submitted to the Swedish Nuclear Power Inspectorate (SKI) for a 10year extension. The application is in the final stages of evaluation, after which SKI will advise the government regarding whether or not to extend the license. This recommendation must be made in April 1994. In order to renew the license, Studsvik must demonstrate that it can "handle and finally dispose of in a safe manner nuclear waste arising in the activity of nuclear substances present in the waste that are not recycled." The key issue for SKI is the closure of the fuel cycle for both HEU and LEU fuels. The regulatory authorities implied that shipment of spent fuel under the Environmental Assessment would probably result in recommendation to issue a conditional license which would enable the reactor to keep operating. The regulators indicated that without action under the Environmental Assessment they would recommend to the Swedish authorities that the license not be extended. The reactor would then be shut down.

\section{Alternatives:}

a. Adding Additional Storage Racks.

The reactor operator has already incrementally added storage to the maximum extent possible. However, as discussed above, storage space itself is not the issue, rather it is storage in a facility that meets Category I physical protection requirements that is not available. 
b. Reprocessing.

The reactor operator has not until recently considered reprocessing at Dounreay or in France as a viable option. They prefer not to reprocess but would consider it if it was the only way to satisfy the license requirement and avoid excessive spending on long-term "bunker-like" storage. Reprocessing would be a solution for HEU fuel only, however, as Dounreay does not presently reprocess LEU fuel. The operator does not know if the government would approve such a request, which would require United States consent.

c. Possible Storage of Spent Fuel at Other Facilities.

Sweden currently has storage facilities only for intermediate storage of low and medium level radioactive wastes. The intermediate spent fuel storage facility is only licensed for LEU power reactor fuel. Putting Category I HEU fuel in this facility would require extensive modification to meet physical protection requirements and would seriously interfere with day to day operations. This would also require license modification. Work on high-level waste facilities is in progress but is not expected to be completed for about fifteen years, although this may provide a long-term solution for LEU fuel.

d. Acceptance of Spent Fuel Under the Environmental Assessment.

Shipment of one cask of 64 elements is necessary to meet the near-term physical protection requirements until late 1995. It would also encourage SKI to recommend to the Swedish government that a conditional license to operate the reactor be granted, pending the outcome of the Foreign Research Reactor Spent Fuel Environmental Impact Statement process.

The reactor operator stated that it has experience using a Transnuclear cask that holds 64 fuel elements. (TN 7-2). Their operating equipment, procedures and experience are based on this cask. If 64 elements were shipped by the end of June 1994, the second shipment would not have to take place until February 1996. Theoretically, a minimum partial cask shipment of 58 elements could be made based on the number of elements that are projected to change to Category I by the end of 1995 . This would leave little or no contingency, however, if the Foreign Research Reactor Spent Fuel Environmental Impact Statement were delayed or if it is not possible to arrange shipping of a second cask by February 1996.

e. No Acceptance of Spent Fuel.

If the United States takes no fuel back under the Environmental Assessment, regulators indicated that they would recommend to Swedish authorities that the reactor operating license not be extended when it expires on June 30, 1994. The reactor would then be forced to shutdown. Additionally, independent of the licensing issue, the reactor operator would be forced to consider reprocessing all Category I fuel to avoid excessive spending to build a Category I storage facility. Reprocessing would require United States consent. 


\subsubsection{BER-II}

Background - The BER-II reactor is located in Berlin and is operated by the Hahn-Meitner Institute (HMI), one of the sixteen German national laboratories. HMI is 90 percent funded by the federal research ministry and 10 percent by the state. The institute has about 900 employees, including 360 scientists, and has an annual budget of about $\$ 75$ million.

The BER-II is a 10 megawatt, light water, pool-type research reactor using 93 percent enriched plate-type fuel. The current core contains 36 fuel elements, and current operation generates 26 spent fuel element per year. A major reactor upgrade that was completed in the late 1980s included replacement of the grid plate, installation of a beryllium reflector, and increasing the power level from 5 to 10 megawatts. A cold neutron beam source was installed along with nine other beam tubes. Fifteen different major instruments are presently in use.

The BER-II is one of Europe's most modern neutron beam research facilities and is one of the most heavily-utilized reactors in Germany. Many foreign scientists, including Americans, are engaged in fundamental research work there. The institute intends to pursue whatever means necessary to ensure continued operation of this important facility.

Relationship of the Reactor to the RERTR Program - HMI was a founding member of the German RERTR Program and has been an active participant in the international RERTR Program since 1979. As evidence of its commitment to conversion, HMI hosted the 1989 RERTR International Meeting in Berlin.

BER-II personnel worked closely with the German firm Interatom, now part of Siemens AG, in the 1980s in performing extensive design and safety analyses for LEU conversion of the reactor. Safety studies for conversion have cost more than $\$ 1$ million. Recently ordered low enriched uranium cost $\$ 600,000$. HMI strongly supports international nonproliferation objectives and is ready to convert the BER-II to LEU operation, but needs assurances regarding the disposition LEU spent fuel before a license for conversion is granted.

Fabrication of LEU fuel elements could be initiated shortly after the license is issued and the first LEU fuel element could be inserted into the BER-II reactor within two years thereafter.

\section{Urgency of Need for Acceptance of Spent Fuel:}

a. Licensing Requirements Related to Continued Operations:

Regulatory requirements mandate that every three years the operator must demonstrate that there is closure of the fuel cycle for the next six years. The last three-year cycle ended on March 31, 1994. At that time, HMI had sufficient spent fuel storage capacity for four years and needed to demonstrate a solution for two additional years. Therefore, HMI needed to demonstrate a disposal solution for 52 fuel elements by March 31, 1994. HMI met this regulatory requirement by declaring that it would reprocess the 52 spent fuel elements at Dounreay if a commitment was not made to ship 52 spent HEU fuel elements to the United States under the Environmental Assessiment. Because of spent fuel 
storage constraints, HMI has already shipped 26 elements to Dounreay for reprocessing in July 1993.

b. Licensing Requirements Related to Conversion to LEU.

HMI is in the final stages of a licensing process aimed at converting the BER-II reactor from HEU to LEU fuel. Licensing officials indicated that the only remaining requirement was for HMI to provide assurances for a six year storage capacity for the spent LEU fuel so that the reactor site does not become a long-term storage facility.

c. Spent Fuel Storage Capacity.

There are two storage racks, which can hold 36 elements each, in the working area of the reactor pool. A separate storage pool can hold five racks, each with fifteen fuel elements. Total storage capacity is thus 147 elements. There are currently 22 spent fuel elements and five partly-burned fuel elements in storage. Thirty-six positions must be kept open to unload the core in the event of an emergency. Thus, immediate storage needs are not the problem at the BER-II.

\section{Alternatives:}

a. Adding Additional Storage Racks.

An increase in storage above ten percent of current capacity would require a new licensing procedure and would take at least two years. Thus, it was not possible to license and install additional racks to provide for two additional years of spent fuel storage by March 31, 1994.

b. Reprocessing.

HMI shipped 26 spent fuel elements to Dounreay for reprocessing in July 1993. If a commitment is not made to ship 52 spent HEU fuel elements under the Environmental Assessment, HMI plans to pursue a long-term reprocessing contract with Dounreay. In addition, the operator stated that he would actively work with other research reactors in the European community to keep Dounreay open, and work to ensure that sufficient spent fuel is sent there to keep reprocessing costs reasonable.

c. Possible Storage of Spent Fuel at Other Facilities.

COGEMA, in France, has refused storage or reprocessing of HMI fuel. HMI is promoting the development of a German national solution for spent HEU and LEU elements. A long term storage contract has been negotiated with the operator of a storage facility and will be signed soon, but this facility will not be available until after the year 2000. 
d. Acceptance of Spent Fuel Under the Environmental Assessment.

Acceptance of 52 elements would demonstrate closure of the HEU fuel cycle for two additional years and alleviate the need to ship these elements to Dounreay for reprocessing.

e. No Acceptance of Spent Fuel.

If a commitment is not made to ship 52 spent HEU fuel elements under the Environmental Assessment, HMI plans to pursue a long-term reprocessing contract with Dounreay. HMI would undertake strenuous efforts to preserve the Dounreay reprocessing option for European reactors and would cancel plans to convert the BER-II reactor to LEU fuel because Dounreay will not currently accept LEU silicide fuel for reprocessing. HMI has already shipped 26 elements to Dounreay for reprocessing in July 1993.

\subsubsection{FRG-1}

Background - The FRG-1 research reactor is operated by the GKSS research center in Geesthacht, Germany, near Hamburg. GKSS is one of sixteen national research centers in Germany and is funded 90 percent by the federal government and 10 percent by the state government. GKSS employs approximately 800 people and has an annual budget of about $\$ 80$ million.

The FRG-1 is a 5 megawatt, swimming-pool reactor that achieved initial criticality in 1958. Conversion to LEU fuel was completed in 1989. A second reactor, FRG-2, shares the same reactor pool with the FRG-1. The FRG-2 is a 15 megawatt research reactor formerly used for shielding and materials research. FRG-2 has been shutdown since May 1991 and GKSS has applied for a license to decommission this reactor. GKSS stated that they intend to operate FRG-1, however, for an additional twenty years.

The FRG-1 is the principal large research instrument at GKSS and supports materials research and some environmental research activities. Principally, FRG-1 is used for neutron scattering experiments to characterize the microstructure and properties of metallic, intermetallic, and ceramic materials, and for structural investigations of living matter. Since FRG-1 is the principal research tool at GKSS, the survival of the reactor is linked to the survival of this institute as a German national research center, and GKSS management emphasized that they will do what is necessary to ensure the survival of this reactor.

The reactor operator stated that he would not have converted to LEU fuel without assurance from the United States that it would accept the return of spent fuel. GKSS cites Federal Register Volume 51, No. 32, February 18, 1986 and Volume 52, No. 250, December 31, 1987 as examples of United States commitment to accept spent LEU and HEU fuels. GKSS emphasizes that the commitment published in the 1986 notice to accept the return of LEU fuel provided the necessary incentive for research reactor operators to convert their reactors to LEU. 
Relationship of the Reactor to the RERTR Program - The FRG-1 reactor has been fully converted to LEU fuel. The reactor operator was a founding member of the German RERTR Program and has been a leading proponent of the program within the international community. GKSS has cooperated extensively with the RERTR Program and has made numerous contributions on the safety, licensing, and fuels aspects of reactor conversions to LEU fuel.

Because of the lapse of the Offsite Fuels Policy, the GKSS operator has stated that he is now actively considering withdrawing from the RERTR Program and has published papers at international conferences suggesting that other countries also withdraw from the program.

\section{Urgency of Need for Acceptance of Spent Fuel:}

a. Spent Fuel Storage Capacity.

GKSS has a storage capacity of 280 fixed positions in the reactor pool plus an additional 54 positions in the moveable storage racks on the bottom of the reactor pool, for a total of 334 spent fuel storage positions. In October 1993, GKSS shipped 132 fuel elements to Dounreay for reprocessing. In January 1994, the reactor pool had 139 HEU spent fuel elements and about 30 partially-used LEU fuel elements. A further 26 positions are required to be reserved for unloading of the FRG-1 core in the unlikely event of an emergency and for some types of maintenance.

German law requires reactor operators to have a solution six years in advance for disposal of spent fuel elements produced by the reactor. As a result, approximately 240 of the 334 positions are either occupied, are reserved to meet emergency core unloading requirements, or are reserved to meet the six year storage requirements of German law. The reactor operator stated that they will also likely lose some of the 334 spent fuel storage positions through regulatory action when the FRG-2 reactor is formally decommissioned during 1994. Even so, with an annual production of nine LEU spent fuel elements, the limitations of spent fuel storage capacity do not provide an adequate basis for an urgent shipment of spent fuel.

The urgency of the next shipment is driven by future changes in the physical security category of the spent HEU fuel and the need to upgrade physical security. In the late 1990 s, some of the HEU fuel elements will not meet the requirements for radiation dose self protection (100 rem/ $/ \mathrm{hr}$, unshielded, at 1 meter) and will transition from Category II to Category I. With more than $5 \mathrm{~kg}$ HEU of such material at this site, the GKSS would need to construct expensive facilities to meet the much more stringent physical security requirements of Category I. None of the fuel elements will lose this self-protecting radiation shield prior to the scheduled completion of the Foreign Research Reactor Spent Fuel Environmental Impact Statement. However, the reactor operator stated his belief that the Environmental Impact Statement schedule is highly unreliable, that actual shipment would take place at least six months after the Environmental Impact Statement is completed, and therefore, a shipment of at least $99 \mathrm{HEU}$ elements was required under the Environmental Assessment to prevent the need to upgrade his physical security to store Category I spent fuel. 
b. Commitment to Develop Dry Storage Capability.

By March 31, 1994, GKSS needed to make contractual commitments with a developer of dry storage casks and with the operator of a German long-term interim storage facility in order to ensure operation of the FRG-1 reactor for its scheduled lifetime until the year 2010. Further information is provided in Section $c$. of the alternatives.

\section{Alternatives:}

a. Adding Additional Storage Racks.

Adding additional storage racks can relieve a storage overload, but would not mitigate the need to remove at least $99 \mathrm{HEU}$ spent fuel elements from the site so that GKSS would not need to upgrade its physical security infrastructure in the late 1990s. The reactor operator would be able to add only fourteen storage positions without requiring a new licensing procedure that includes a rigorous public hearing process.

b. Reprocessing.

GKSS shipped $132 \mathrm{HEU}$ spent fuel elements to Dounreay for reprocessing in October 1993. The reactor operator stated that he will pursue reprocessing in the future if forced by United States inaction on acceptance of HEU spent fuel. The reactor operator has offered to sell to the United States the HEU that was recovered from the reprocessing of the 132 elements recently shipped to Dounreay. The United States did not accept this offer. If all of the $139 \mathrm{HEU}$ spent fuel elements in the current inventory were reprocessed, this would provide sufficient storage capacity at GKSS for all of the LEU fuel elements that would be produced over the remaining twenty years of reactor life.

c. Possible Storage of Spent Fuel at Other Facilities.

Germany has a facility at Ahaus for long-term interim dry storage of commercial power reactor fuel. They are now considering adding capacity for dry cask storage of spent research reactor fuel at this facility and expect that this capability would be eventually available in 1997-2000 (depending on the outcome of the licensing procedures). GKSS has been asked to sign a contract for the 40 year period of interim storage for its spent HEU and LEU fuel as well as a contract to develop and build the necessary dry storage casks. The February 1994 Environmental Assessment states that GKSS had asked for an extension until March 31, 1994, to ascertain the status of the Environmental Assessment prior to making a decision. Because completion of the Environmental Assessment was delayed beyond March 31, 1994, GKSS requested and was granted a further extension until May 1994. However, GKSS stated that if the decision is made to undertake these large investments, the United States origin HEU will never be returned to the United States and will instead effectively remain in Ahaus until a German final disposal facility is operational. 
d. Acceptance of Spent Fuel Under the Environmental Assessment.

The reactor operator has requested shipment of $132 \mathrm{HEU}$ spent fuel elements because of his lack of faith in United States plans and schedules calling for completion of the Foreign Research Reactor Spent Fuel Environmental Impact Statement in mid-to-late 1995. However, return of $99 \mathrm{HEU}$ spent fuel elements under the Environmental Assessment would be sufficient to ensure that the facility never exceeds the $5 \mathrm{~kg}$ limit for Category I HEU materials and that GKSS would not need to implement expensive facility upgrades to meet the much more stringent Category I physical security requirements.

e. No Acceptance of Spent Fuel.

Failure to accept $99 \mathrm{HEU}$ spent fuel elements under the Environmental Assessment would have no immediate effect on reactor operations. If the Foreign Research Reactor Spent Fuel Environmental Impact Statement is significantly delayed beyond its scheduled completion date in mid-to-late 1995, there could be significant problems in four to five years due to the change in physical security category of the HEU spent fuel. The reactor operator believes that there is considerable uncertainty associated with the actual completion date of the Environmental Impact Statement and that actual shipment of spent fuel under the Environmental Impact Statement would not occur until at least six months after the it is completed. In order to avoid these uncertainties and the possible need to upgrade its physical security infrastructure, GKSS has stated that it is likely to contract with Dounreay to reprocess its HEU spent fuel elements and to contract with the German facility at Ahaus for long-term interim storage of its LEU spent fuel elements.

\subsubsection{SAPHIR}

Background - The SAPHIR research reactor at the Paul Scherrer Institute (PSI) in Switzerland began operation in 1957 as one of Europe's first reactors. PSI is Switzerland's only national research center with nuclear research installations and is closely affiliated with Swiss universities. PSI employs 1100 people, 200 of which are in the nuclear field.

SAPHIR is a 10 megawatt, light water, pool-type reactor which uses twelve plate-type fuel elements per year. The core was first converted to 45 percent enriched fuel in 1983 and began gradual conversion to LEU silicide fuel in 1986. It currently operates with a half core of LEU and a half core of either 93 or 45 percent enriched fuel. The reactor is temporarily shutdown for upgrading and retrofitting. PSI expects to operate the reactor from mid 1994, to the end of 1996, when it will be replaced by an accelerator-driven neutron source for neutron scattering experiments.

SAPHIR is currently the only significant neutron source in Switzerland. It is a multipurpose facility serving neutron scattering targets for research in high temperature superconductivity, material structure and magnetism and neutron radiography through five beam tubes. The incore radiation positions for radioisotope production, material testing, radiochemistry and neutron activation analysis are applied to many applications including radiopharmacy and material behavior. This highly utilized facility is in operation about 6000 hours per year (12 three week around the clock operating periods per year). In addition, SAPHIR is used 200 hours annually for student and power plant operator training. 
Relationship of the Reactor to the RERTR Program - PSI (the former EIR) has been an active participant in the RERTR Program since 1979. It participated in the preparation of IAEA guidebooks on LEU conversions during the period 1979-1985 and performed irradiation tests and measurements on fuel elements containing both 45 percent and less than 20 percent enriched uranium. The decision to convert the reactor to use LEU fuel was based on the United States commitment to take back HEU and LEU spent fuel published in Federal Register Notice, Volume 51, No. 32, February 18, 1986. The commitments expressed in the notice expired on December 31, 1988, and on December 31, 1992, for HEU and LEU fuel, respectively. Conversion to LEU operation has required a substantial investment to change the coolant loop and control systems.

\section{Urgency of Need for Acceptance of Spent Fuel:}

\section{a. Reactor Pool Storage Capacity.}

All storage capacity is currently utilized. The last shipment of spent fuel occurred in 1982. A shipment to the United States was scheduled in 1987, but was canceled due to shipping delays and the lapse of the United States Off-Site Fuels Policy in 1988.

One hundred twenty-three spent fuel elements are stored in the reactor pool, which has a total capacity of 198 positions. The remaining 75 spaces are currently filled or must remain open for emergency core unloading. Thirty positions are occupied by instruments regularly used in the core for experiments, 35 positions are reserved for emergency unloading of the core, and ten positions are occupied by beryllium reflectors. A minimum of ten additional positions (not currently available) are needed for special core arrangements, demonstrations and other experiments, all of which are a necessary part of normal operations.

The DIORIT reactor at PSI was taken out of service in 1977, and was decommissioned in 1991. Between 1977 and 1991, its storage pool had been used as the intermediate storage and transfer pool for SAPHIR spent fuel. Two years ago, because the DIORIT storage pool was no longer available for licensing reasons and spent fuel could not be shipped to the United States, additional racks were installed in the reactor pool above the critical water line for the emergency cooling system for the reactor core. In the unlikely event that the core cooling system would rupture, water would siphon out of the pool to the point that the reactor core would still be covered, but the upper row of storage racks, containing 25 spent fuel elements, would be uncovered. If such an accident occurred, it would result in high radiation doses in the reactor hall, the SAPHIR building, and its environment. These high doses would make it difficult to take actions to contain the accident.

There are 54 fresh HEU fuel elements and 25 fresh LEU fuel elements in the storage vault. This is more than sufficient fuel for the remaining life of the reactor (i.e., until the end of 1996). In addition to the ten fuel-elements used in special core-arrangements for demonstration and operator-training, the reactor uses approximately twelve fuel elements per year, approximately eighteen additional spent fuel elements would be generated by the end of 1995, (i.e., when the Foreign Research Reactor Spent Fuel Environmental Impact 
Statement is completed). Twelve more spent fuel elements would be generated by the end of reactor operations in late 1996 , for a total of 40 spent fuel elements more than today.

\section{Alternatives:}

a. Adding Additional Storage Racks.

Extension of the storage capability in the reactor pool has been investigated. Because it would create unacceptable radiation exposure in adjacent rooms, additional fuel racks cannot by attached to the east wall of the pool. Due to the placement of the primary loop, the south wall is not accessible. In order to be able to unload or move the reactor, fuel elements cannot be placed on the bottom of the pool. In order to comply with criticality requirements, more than two rows of spent fuel elements cannot be hung in one location. Therefore, no more room is available in the reactor pool for additional storage racks. Indeed, it was these limitations that necessitated adding racks above the critical water line.

b. Reprocessing.

The reactor operator, if necessary, would pursue reprocessing at Dounreay if a shipment cannot be made under the Environmental Assessment and has in hand an offer tendered by Dounreay. The transfer would require United States consent. If this option is pursued, the operator stated that conversion to LEU would be terminated and all remaining HEU elements would be burned in the reactor, rather than continuing to use the LEU fuel on hand. They would follow this course of action because Dounreay does not currently accept LEU fuel for reprocessing.

c. Possible Storage of Spent Fuel at Other Facilities.

The reactor operators indicated that it might be possible to purchase storage casks from the German commercial waste storage facility in Ahaus, Germany, to be used for storage in Switzerland. However, they would not be able to obtain them until the end of 1995 at the earliest. Other interim storage options may also be available in the future such as collocation of SAPHIR spent fuel (or wastes from reprocessing, if necessary) with high level waste from Swiss power reactors. However, construction of this facility must still be approved by Parliament, and it is not expected to be ready until 1998. Finally, a repository is being planned for commercial power reactor wastes, but the study recommendations will not be ready until the year 2000 .

d. Acceptance of Spent Fuel Under the Environmental Assessment.

Shipment of 66 spent fuel elements under the Environmental Assessment would: (1) allow removal of the 25 elements posing the safety concern because they are stored above the critical water line; (2) provide the ten spaces for fuel elements needed for special core arrangements supporting restart of the reactor in June 1994; and (3) accommodate the 30 elements that will be generated by the end of 1996, as part of normal operations. This shipment could take place in two full GNS-11 casks which hold 33 elements each. A 
minimum shipment alternative of 59 elements (one full cask and a partial cask containing 26 spent fuel elements ) would meet SAPHIR's near-term needs if the Environmental Impact Statement is not completed until the end of 1995.

e. No Acceptance of Spent Fuel.

Failure to accept spent fuel elements under the Environmental Assessment would very likely force the reactor operator to pursue reprocessing at Dounreay in order to minimize safety risks and provide sufficient storage capacity to support operations until the end of 1996. In this case, no further HEU-to-LEU conversion would take place, and all remaining HEU will be used in the core and subsequently reprocessed. A decision on a course of action must be taken by June 1994, for operational and management reasons concerning restart of the reactor. If it is not possible to ship spent fuel to the United States under the Environmental Assessment or arrange for reprocessing, restart of the reactor is unlikely.

\subsubsection{ASTRA}

Background - The ASTRA reactor is located near Vienna at the Austrian Research Center Seibersdorf, which is the largest research center in Austria. The center is 50.5 percent stateowned but is not state-operated. It has approximately 535 employees and has an international orientation focused on instrumentation, environmental engineering, life sciences, and economical issues. The annual operating cost of the research center is approximately $\$ 55$ million.

ASTRA is a 10 megawatt, swimming-pool-type reactor which uses light water for cooling and moderation. It uses aluminum-clad, uranium silicide fuel enriched to less than twenty percent in the U-235 isotope (i.e., LEU fuel). There are 23 fuel elements in the reactor core and it generates three-to-four spent fuel elements per year. The reactor went critical in 1960 and has been upgraded regularly. The operator sees no near-term limit on the life of the reactor.

The reactor is used by Austrian universities and a large number of public and private institutions. ASTRA is the only indigenous source of medical isotopes for the Austrian region. These include Yttrium-90 for applications in medical therapy, Dysprosium-165 for treatment of rheumatoid arthritis and Technetium-99 for radiopharmaceuticals for medical diagnosis.

The reactor also provides critical services to international users, such as the International Atomic Energy Agency including at least two IAEA programs $s^{3}$ for which no alternative arrangements exist. Specifically, the IAEA uses ASTRA for environmental analysis and nutrition research involving short (hours) half-life samples that must be analyzed immediately at the nearby IAEA radiochemical laboratory. ASTRA directly supports the IAEA safeguards

\footnotetext{
${ }^{3}$ Irradiation of environmental samples which require immediate analysis in IAEA laboratory and fast neutron irradiation of seeds to study genetic effects.
} 
inspectors training. The Safeguards Analytical Laboratory is located there and is operated by the IAEA.

Relationship of the Reactor to the RERTR Program - The operators of the ASTRA reactor were pioneers in the LEU conversion program and have a strong, beneficial relationship with the United States RERTR program. They participated with Argonne National Laboratory in LEU conversion studies between 1979 and 1981 and made significant contributions to IAEA guidebooks on LEU conversion. The reactor operator began conversion of ASTRA to LEU fuel in 1983 and completed conversion in 1990. The operator stated that conversion was undertaken with the expectation that the United States would accept the return of both HEU and LEU spent nuclear fuel in the future.

\section{Urgency of Need for Acceptance of Spent Fuel:}

a. Spent Fuel Storage Capacity.

ASTRA currently has 41 spent fuel elements: 33 which had an initial enrichment of 93 percent, five which had an initial enrichment of 45 percent, and three which had an initial enrichment of less than 20 percent.

There are 35 storage rack positions in the reactor pool and 24 mobile rack positions on the floor of the pool, for a total of 59 positions. Twenty-three positions should be kept vacant for emergency unloading of the reactor core. Due, however, to a competing need to store thirteen irradiated non-fuel elements, used regularly for experiments, only ten spaces are currently available for core unloading. All of the remaining positions are filled with spent fuel elements.

There are an additional 100 storage positions in the lower hot cell adjacent to the reactor pool. Five of the oldest HEU elements (i.e., those with the lowest radiation fields) were transferred to the hot cell in December 1993, with the expectation that they would be shipped to the United States in early 1994. The hot cell can only be used for short-term storage because the radiation field will degrade organic seals and gaskets, particularly those around the hot cell window.

b. Constraint on Ordering Fresh Fuel.

Since expiration of the Off-Site Fuels Policy in 1988, the Austrian government has required that for fresh fuel to enter the country, an equivalent quantity of spent fuel must be shipped out of the country.

ASTRA has sufficient fuel to operate until mid-1995. Two LEU elements, the fuel plates for which had been previously manufactured, were ordered in December 1993. Delivery of these elements would allow operations to continue until the end of 1995. However, the two fresh elements cannot be shipped to ASTRA until at least two spent fuel elements are shipped out of Austria. 
Manufacture and delivery of new fuel elements normally has a lead-time of approximately two years. (The time period is somewhat shorter if fuel plates have already been manufactured.) Thus, the reactor must order additional new fuel in early 1994 in order to have the fuel on hand in January 1996 to continue operations at that time. The reactor utilizes three to four fresh fuel elements per year. Ordering a minimum of six fresh elements in early 1994, (in addition to the two ordered last December) is necessary to ensure continued operations. This would provide fresh fuel until late-1997. If the Foreign Research Reactor Spent Fuel Environmental Impact Statement is completed on schedule in mid-to-late 1995, fresh fuel could then be ordered in time to provide the next increment of fresh fuel in late-1997.

Alternatives:

a. Adding Additional Storage Racks.

There is no space in the reactor pool for additional storage racks. The reactor pool design was based on removal of spent fuel on a regular basis and, as noted, the hot cell can only be used for short-term storage of spent fuel.

b. Reprocessing.

The Austrian government strongly opposes reprocessing on nonproliferation grounds, and its representative stated that Austria would not consider this option. Additionally, in 1978, an Austrian referendum eliminated nuclear power as an energy option for the country. As a result, there are no plans to build a high level waste storage facility in Austria and it would not be possible to take the high level waste back after reprocessing.

c. Possible Storage of Spent Fuel at Other Facilities.

As mentioned above, there are no other storage facilities for spent fuel in Austria. Construction of such facilities specifically for ASTRA has not been considered because the Austrian government had assumed that the United States would maintain its historic practice of taking back ASTRA spent fuel. The acquisition of a permanent storage facility solely to support ASTRA would be prohibitively expensive.

The Austrians have reportedly been approached by commercial interests from Belarus with an offer to store spent fuel for hard currency. The offer, which was rejected in support of nonproliferation policies, is an indication, however, of the types of scenarios that may develop as the pressure builds on reactor operators to close the back end of their fuel cycle.

d. Acceptance of Spent Fuel Under the Environmental Assessment.

Shipment of 26 spent fuel elements would provide the reactor operator sufficient storage positions to: (1) remove the five spent fuel elements from temporary storage in the hot cell; (2) off-load the 23 elements in the reactor core in event of an emergency without using the hot cell (which is difficult to access); and (3) provide the ability to order fuel to support operations until more fuel could be ordered after the Environmental Impact 
Statement is completed. This shipment could be completed using two GOSLAR casks, which are designed to be shipped in pairs that each hold thirteen spent fuel elements. A shipment of thirteen spent fuel elements (e.g., in one of the pair of GOSLAR casks) would allow ASTRA to order fresh fuel, but would not provide the desired margin of safety to fully unload the reactor core in an emergency.

e. No Acceptance of Spent Fuel.

The reactor operator cannot order and accept fresh fuel until spent fuel is shipped out of the country. The reactor power level, and as a result certain operations, have already been limited to conserve fuel and storage space. Failure to accept at least thirteen elements under the Environmental Assessment will result in shutdown of the reactor.

\subsubsection{GRR-1}

Background - The GRR-1 research reactor is operated by the National Center for Scientific Research "Demokritos", in Athens, Greece. The reactor is used mainly for activation analysis, radioisotope production, and reactor physics experiments. Modifications are underway with IAEA support to enhance the capability of the reactor to perform neutron scattering experimentation.

The GRR-1 is a 5 megawatt, swimming-pool-type, light water moderated and cooled reactor designed by the United States firm, AMF Atomics. The reactor first went critical with a power level of 1 megawatt in 1961 using LEU plate-type fuel donated by the United States. It was upgraded to 5 megawatts and converted to HEU fuel in 1971. The current core contains $36 \mathrm{HEU}$ fuel elements and generates seven spent fuel elements per year. A beryllium reflector is scheduled to be installed in conjunction with the conversion of the reactor to LEU fuel. The core size will be reduced to 33 elements.

In recent years, several modifications and improvements were made to the reactor to take into account aging phenomena, changing hardware technologies, safety philosophy, quality status of electronic/electrical components, and new software programs. An electronic surveillance system has recently been installed around the reactor building and adjusted for operation conditions to comply with the rules for physical protection and safeguarding of nuclear installations.

Relationship of the Reactor to the RERTR Program - In 1981, the reactor operator joined the international effort for conversion of research reactors from the use of HEU to LEU under the auspices of the RERTR Program. Through the operator's collaboration with Argonne National Laboratory, substantial work was done on design and safety analyses to support conversion of the GRR-1 to LEU fuel.

Based on the operator's belief that the United States would resume acceptance of spent HEU and LEU fuels, 38 LEU fuel elements were ordered in 1990 from CERCA, France. Fourteen elements fresh LEU elements were delivered in January 1994. However, the reactor operator cannot proceed with conversion to LEU fuel until sufficient space is created in the storage pools. 


\section{Urgency of Need for Acceptance of Spent Fuel:}

a. Reactor Pool Storage Capacity.

The reactor has a total of 118 spent HEU fuel elements and no additional fresh HEU fuel. As mentioned above, fresh LEU fuel was delivered in January 1994. In the next few months, fresh LEU fuel needs to be placed in the core in order to continue operation. If this is not possible, the power level must be reduced and the reactor will eventually be shut down. Before fresh LEU fuel can be loaded, however, fuel must be removed from the reactor storage pool to make room for spent HEU elements removed from the reactor core.

The reactor pool contains low density racks with 42 fuel element positions. There are seven empty spaces, which provide the capability to partially unload the reactor core in an emergency or for routine maintenance. The reactor generates approximately seven spent fuel elements per year. Therefore, an additional fourteen spaces must be evacuated to support continued operations until late 1995.

b. Additional Storage Pools.

A second spent fuel storage pool in the reactor building contains four 10-position racks and one 17-position rack. These racks are completely full with 57 spent elements. It is not possible to add more spent fuel to this pool.

A third pool is located outside but adjacent to the reactor building. This pool was built as a temporary transfer pool (the crane in the reactor building does not have sufficient capacity to handle spent fuel shipping casks) when the reactor operator initiated plans to ship 26 spent fuel elements back to the United States. The pool was not designed or intended to store fuel for more than a few weeks.

In 1987, when the reactor operator was ready to ship the spent fuel, the shipping casks' licenses expired. This caused several postponements in shipping dates and finally the United States Off-Site Fuels Policy expired in 1988. As yet there are no signs of corrosion or leakage of the fuel elements and the reactor operator has taken steps to ensure a high water quality in both storage pools. However, the operator is concerned that problems may develop due to the age of some of the fuel.

\section{Alternatives:}

a. Adding Additional Storage Racks.

Fabricating, licensing, and installing new high density racks in the reactor pool would take at least two years. 


\section{b. Reprocessing.}

There is no nuclear power program in Greece. Therefore, Greece has no plans to build a high level waste repository and could not accept the wastes that are required to be returned from reprocessing at Dounreay.

c. Possible Storage of Spent Fuel at Other Facilities.

Greece has no other in-country storage facilities. Dounreay will not store fuel without an agreement for reprocessing, which is not an option for Greece. France (CERCA or COGEMA) is currently unwilling to store spent fuel for others.

d. Acceptance of Spent Fuel Under the Environmental Assessment.

Shipment of 66 spent fuel elements under the Environmental Assessment would: (1) allow the 26 fuel elements to be removed from the outside transfer pool; (2) provide 33 positions which would be reserved for emergency unloading of the core; (3) provide seven new storage positions in the reactor pool, which along with the seven positions currently available, would allow for two years operation until the Environmental Impact Statement can be completed, and (4) support the immediate start of reactor conversion to LEU. The 66 elements could be shipped in two GNS-11 shipping casks holding 33 elements each. Shipment of 40 spent fuel elements would provide for continued operations, removal of fuel from the transfer basin, and for removal of seven elements from the core, but would not provide the desired capability to fully unload the reactor core in an emergency.

e. No Acceptance of Spent Fuel.

If no fuel is taken back under the Environmental Assessment, the reactor operator will be forced to reduce power, terminate services to a number of customers, and ultimately to shut down the reactor.

\subsubsection{HIFAR}

Background - The HIFAR reactor is operated by the Australian Nuclear Science and Technology Organization (ANSTO), in Lucas Heights, Australia. HIFAR is the only nuclear reactor (greater than $1 \mathrm{MW}$ ) in Australia and supports most of the research and development activities at ANSTO, which employs about 850 people.

The HIFAR reactor is used as a research facility, a training facility and a commercial neutron source. Scientific applications include investigations in physics, materials, crystals, polymers and biology. Several beam tubes are devoted to neutron scattering experiments. Commercial activities accounted for 35 percent of its income in 1992-93, including production of Technetium-99 for medical diagnostic imaging applications, silicon doping for use in semiconductors and neutron activation analysis.

HIFAR is a $10 \mathrm{MW}$ heavy water tank-type research reactor that went critical in 1958 . The tubular fuel elements contain 60 percent enriched HEU fuel of mixed United States and 
United Kingdom origin. ANSTO's fuel supply is sufficient to ensure normal operation through 1998. The HIFAR reactor normally generates 36 spent fuel elements per year.

Australia's long range plan has been to replace HIFAR with an LEU-fueled research reactor. Recently an independent review (the Review) of ANSTO's plans was completed. One central conclusion of the Review was that no decision on a future reactor can be undertaken until a waste management solution is identified. A government committee has now been formed to consider Australia's options for management of spent nuclear fuel and the permanent disposal problem. The committee is scheduled to issue its report in June 1994. Government officials indicated that United States decisions on foreign spent fuel acceptance under the Environmental Assessment are an important factor to be considered in this report.

Relationship to RERTR Program - Australia has been an active participant in the RERTR program and in international nonproliferation activities. In the RERTR program, ANSTO has cooperated extensively with Argonne National Laboratory, including visits and exchanges of scientists. It participated in the years $1980-1985$ in preparation of the IAEA guidebooks on LEU conversion and safety studies for heavy water reactors. The Australians intend for any replacement to HIFAR to be an LEU-fuelled reactor. In the meantime, the enrichment of HIFAR fuel has been reduced from the original 93 down to 60 percent.

\section{Urgency of Need for Acceptance of Spent Fuel:}

a. Reactor Spent Fuel Storage Capacity.

ANSTO has over 1600 spent fuel elements stored at Lucas Heights, about half of which contain HEU of United States origin. Approximately 1100 elements are stored in an interim dry storage facility built in 1967. The remainder of the spent fuel is stored in three pools in or near the reactor building and in several shipping casks at an ANSTO spent nuclear fuel storage yard, about 700 meters from the reactor building. One of these storage casks (LHRL-120, 114 fuel elements) was especially designed and constructed for an anticipated and contracted shipment to the United States in 1988. This shipment was halted by the lapse of the Offsite Fuels Policy. The remainder of the cask storage is United Kingdom origin spent fuel stored in seven "Dounreay Casks" that hold 25 fuel elements each.

Short-term spent fuel storage is not a critical problem at the ANSTO site since it is possible to add four-years worth of additional storage capacity by adding storage racks to existing storage pools. However, neither the pools nor the casks nor their locations have been intended or approved for indefinite storage of spent fuel. Temporary use of these locations has been adopted only on the basis of earlier commitments that the fuel would be accepted imminently by DOE. Two other bases were expressed by Australian authorities for requesting a shipment of spent fuel under the Environmental Assessment.

First, as established by the Review, Australia will need a permanent high or medium level waste facility no matter what the future of HIFAR or a replacement facility. The Review was critical of ANSTO's strategy which was heavily dependent on the uncertain return of spent fuel to the United States and recommended that the next five years should be used 
to begin the planning of such a waste facility. ANSTO estimates that additional long term storage capacity will require six years before it is operational as compared to the four years of additional storage capacity at ANSTO, leaving a two-year mismatch in the availability of spent fuel storage space. Hence, ANSTO is at a decision point now to commit to alternative spent fuel management arrangements. ANSTO argues that "unless agreement is obtained immediately for one urgent relief shipment this year, then the alternative arrangements to be determined as a result of the Government committee's review cannot place any reliance on the Environmental Impact Statement mechanism for ultimate return of spent fuel. The result could be that the spent HEU fuel will have to remain in storage in Australia for an indefinitely extended period, thereby defeating the objectives of the United States Off-Site Fuels Policy."

To avoid this potential lapse in storage space and because of Australian concerns over potential delays of the Foreign Research Reactors Spent Fuel Environmental Impact Statement, ANSTO requested shipment of 114 spent fuel elements in early 1994. The reactor operator believes that shipment of 114 spent fuel elements would allow for continued reactor operations until an indigenous solution for the spent fuel could be implemented.

The second concern expressed by Australian authorities was that the HEU spent fuel elements represent the largest storage of HEU in the region. Long-term storage of the HEU in Australia was believed to be damaging to Australia's nonproliferation credentials and the ability to achieve mutual nonproliferation objectives in the region. Near-term shipment of spent research reactor fuel would ameliorate this situation.

\section{Alternatives}

a. Adding Additional Storage Racks.

An underwater irradiation facility has been converted and is being used as an interim wet spent fuel storage facility. Additional racks could be added to this pool which would provide approximately four years of additional storage capacity.

Additional storage facilities in Australia are not a near term option because ANSTO is under pressure to reduce its storage at Lucas Heights and because it would take too long to put spent fuel storage facilities into operation.

b. Reprocessing.

ANSTO could relieve a major portion of its storage problem by returning United Kingdom-origin spent HEU fuel to the United Kingdom for reprocessing. The United Kingdom requires, however, that the high level waste be returned to the country of origin and Australia does not have any facilities to accept this waste. Therefore, this is not an option that could be pursued during the period prior to the completion of the Foreign Research Reactor Spent Fuel Environmental Impact Statement. 
c. Possible Storage of Spent Fuel at Other Existing Facilities.

Australia has no other nuclear facilities and no nuclear power program. Dounreay is not willing to store spent fuel without a reprocessing contract, and no other foreign facility is available to store HIFAR's spent fuel.

d. Acceptance of Spent Fuel under the Environmental Assessment.

Shipment of spent fuel is not necessary at this time because racks could be added to an existing storage pool, which would provide approximately four years of additional storage capacity until 1998. This capacity would provide for continued operations at HIFAR until the Foreign Research Reactor Environmental Impact Statement is completed in mid-1995.

e. No Acceptance of Spent Fuel.

As discussed above, shipment of spent fuel is not necessary at this time because approximately four years of additional storage can be created. 


\subsection{PROPOSED ACTION}

Chapter 3 presents a discussion of the proposed action. Section 3.1 generally describes the proposed number of spent fuel elements to be accepted by DOE from the eight foreign research reactors. More specifically, Section 3.1.1 describes how the proposed action is influenced by two policy options; Section 3.1.2 describes the proposed mode of ocean transport; Section 3.1.3 describes the proposed ports of entry; Section 3.1.4 describes the proposed mode of overland transport; and Section 3.1.5 describes the proposed storage of the spent fuel elements at DOE's Savannah River Site. Section 3.2 discusses the considerations reflected in the acceptance fee DOE proposes to charge the research reactors for receipt and storage acceptance of the spent fuel.

\subsection{Proposed Action}

DOE proposes to accept 409 (about 2 metric tons) spent fuel elements from eight foreign research reactors. These spent fuel elements contain HEU that was enriched in the United States. The number of elements from each reactor is listed in Table 3-1. The spent fuel

Table 3-1. Research Reactors In Need of Urgent Relief

\begin{tabular}{||l|c|c|c||}
\hline \multicolumn{1}{|c|}{ Reactor/Country } & $\begin{array}{c}\text { Proposed Number of } \\
\text { Cask Shipments }\end{array}$ & $\begin{array}{c}\text { Cask/Capacity } \\
\text { (maximum \# } \\
\text { elements) }\end{array}$ & $\begin{array}{c}\text { Proposed Number } \\
\text { of Spent Fuel } \\
\text { Elements to be } \\
\text { Shipped }\end{array}$ \\
\hline HOR, Delft, Netherlands & 1 & GNS-11 (33) & 33 \\
\hline HFR, Petten, Netherlands & 2 & GNS-11 (33) & 66 \\
\hline DR-3, Roskilde, Denmark & 1 & PEGASE (36) & 36 \\
\hline R-2, Studsvik, Sweden & 1 & TN-7 (64) & 64 \\
\hline BER-II, Berlin, Germany & 4 & GOSLAR (13) & 52 \\
\hline SAPHIR, Villigen, Switzerland & 2 & GNS-11 (33) & 66 \\
\hline ASTRA, Siebersdorf, Austria & 2 & GOSLAR (13) & 26 \\
\hline GRR-1, Athens, Greece & 2 & GNS-11 (33) & 66 \\
\hline TOTAL & 15 & - & 409 \\
\hline
\end{tabular}

a The casks used in this analysis were selected as being representative casks based on discussions with the reactor operators. Other appropriate casks could be used.

elements would be ioaded at the reactor site into multi-ton steel packagings called casks. The casks in turn would be placed in International Standards Organization (ISO) cargo containers (generally one cask per ISO container), for transport by ship to any one of five ports of entry in the United States. As discussed in further detail in Section 3.1.3, the proposed ports are Wilmington, North Carolina; Sunny Point, North Carolina; Charleston, South Carolina; Savannah, Georgia; and Jacksonville, Florida. After arriving at the port of entry, the ISO 
containers containing the spent fuel casks would be loaded onto trucks for transport to DOE's Savannah River Site in South Carolina, where DOE would take title to the spent fuel.

All of the spent fuel proposed to be accepted under the proposed action or the alternatives is intact, aluminum clad fuel that is essentially identical to a much larger quantity of spent fuel already in storage at the Savannah River Site. Spent nuclear fuel is designed to be physically stable, as it must maintain its integrity under elevated temperatures and pressures when submerged in water in the reactor core. A typical rectangular research reactor spent fuel element is approximately 40 inches (in.) $\times 3$ in. $\times 3$ in., weighs approximately nine to thirteen pounds, and contains approximately 0.44 to 2.2 pounds of U-235, less than 0.03 ounce of plutonium, and 100,000 curies of radioactive material. A typical tubular research reactor spent fuel element is cylindrical in shape but of similar size. ${ }^{1}$

DOE developed radionuclide inventories for the spent fuel elements proposed to be accepted based on data provided by the reactor operators on the burnup, age, and power history of the fuel. To be conservative when modelling and analyzing potential environmental impacts, DOE assumed that spent nuclear fuel had been cooled only 150 days after discharge from the reactor. As most of the spent fuel was discharged several years ago, the actual radionuclide inventory in the spent fuel to be shipped would be significantly lower. The representative inventories are reported in Appendix F.

In general, spent fuel casks fall into a broad category of radioactive material packaging referred to in international and national regulations as Type B packaging. Examples of the spent fuel casks that would be used to ship the foreign research reactor spent fuel are listed in Table 3-1. Use of these casks was assumed in the analyses of the potential impacts of the proposed spent fuel shipments since they are known to be under consideration for use by the foreign research reactor operators. Depending upon cask availability, it may be necessary to use other casks (e.g., the NAC-LWT) at the time of shipment. Even if casks with larger capacities were used, however, no more than 409 spent fuel elements would be accepted into the United States under the proposed action.

Type B casks have been designed and constructed in accordance with International Atomic Energy Agency standards and certified by their respective national authorities. These casks have demonstrated that they can withstand severe accident conditions (ERP 1986; GNS 1986; TN 1977a, 1977b; COGEMA, 1988). (See Section 6.1.2.2.) Casks manufactured outside the country in which they are to be used must obtain a Certificate of Competent Authority (COCA) from the designated Competent Authority of a country before they can be used in that country (IAEA, 1990a). In the United States, COCAs are based on compliance with United States packaging regulations. The Department of Transportation would review a package certificate of compliance approved by a foreign counterpart for a foreign manufactured cask proposed for shipment of spent fuel to and within the United States. If the

1 To put things into perspective, a typical nuclear power reactor spent fuel element is approximately 175 in. $x 8.5$ in. $x$ 8.5 in., weighs approximately 1500 pounds, contains approximately 30 pounds of U-235, over 10 pounds of plutonium and $4,700,000$ curies of radioactive material. 
Department of Transportation determines that the foreign certificate of compliance establishes that the package satisfies United States packaging regulations, it would issue a COCA.

\subsubsection{Acceptance of 409 Spent Fuel Elements Based on No Reprocessing and Shipment of Full Casks}

The proposal to accept 409 spent fuel elements reflects two policy options. First, the proposal reflects a policy option of not forcing reactors that can ship spent fuel to Dounreay for reprocessing to do so, for the reasons stated in Chapter 1. Only two of the eight reactors could realistically pursue shipment of their spent fuel to Dounreay for reprocessing in the near-term. These reactors are BER-II (Germany) and SAPHIR (Switzerland), and SAPHIR would need the consent of the United States before it could do so. For the remaining six reactors, HOR (Netherlands), HFR (Netherlands), DR-3 (Denmark), R-2 (Sweden), ASTRA (Austria), and GRR-1 (Greece), reprocessing is not a realistic option for the specific reasons discussed in the individual reactor profiles (Section 2.3.1).

The proposal to accept 409 spent fuel elements reflects another policy option to accept full cask shipments from each of the reactors. The 409 spent fuel elements would be transported in fifteen fully loaded casks. For the eight reactors in need of urgent relief, 359 spent fuel elements represent the minimum number of spent fuel elements that would need to be shipped to allow the reactors to continue operating through December 1995, without forcing reprocessing. Shipment of 359 spent fuel elements would result in the shipment of partially full casks by four reactors. (This alternative to the proposed action is discussed in Section 4.1.3.) Since transportation of 359 spent fuel elements would also require fifteen casks, there would be no difference in the number of casks that would need to be transported to the United States under the proposed action and the number that would need to be transported under the alternative of shipping partial casks with no forced reprocessing. For example, HOR (Netherlands) must ship at least twenty spent fuel elements to allow it to continue operating through December 1995. Under the proposed action, DOE proposes to accept 33 spent fuel elements from HOR, which represents a full cask. In both cases, because the cask that HOR probably would use accommodates 33 spent fuel elements, only one cask would be transported.

In proposing to accept full casks, DOE took note of the fact that there is no measurable difference in environmental impacts between shipping full and partially full casks. Moreover, requiring reactor operators to transport partial casks is viewed by all operators as being unnecessarily expensive in that the transportation costs (which run into hundreds of thousands of dollars) are essentially the same for full as for partially full casks. Based on these considerations, DOE believes that shipment of full casks is a prudent course to encourage the continued participation of foreign research reactors in the RERTR Program.

The proposal to accept 409. spent fuel elements represents a decrease of 39 elements from the previous proposal to accept 448 elements in the Draft Environmental Assessment distributed for public comment in February 1994. The decrease is the result of two developments. First, the BR-2 reactor (Belgium) no longer meets the criteria necessary to qualify for acceptance of spent fuel. This resulted in a decrease of 72 elements. The BR-2 reactor operator informed DOE in March 1994 that he has contracted to ship 96 spent fuel elements to Dounreay for 
reprocessing because of immediate operational needs for additional storage space and an inability to await DOE's completion of the NEPA process for this proposed action. Second, DOE is now proposing to accept 66 instead of 33 spent fuel elements from the HFR reactor (Netherlands) for the reasons detailed in Chapter 2, but based primarily on the inability to expand the reactor's storage pool capacity. These changes (a decrease of 72 elements from the BR-2 reactor and an increase of 33 elements from the HFR reactor) result in a net decrease of 39 elements from the 448 elements previously proposed for acceptance, for a total of 409 spent fuel elements.

As previously discussed and shown in Table 3-1, the 409 fuel elements would be shipped in fifteen casks. The proposal to accept fifteen casks represents a decrease of one cask from the previous proposal to accept sixteen casks in the February 1994 Draft Environmental Assessment. The decrease of one cask is the result of deleting the BR-2 fuel elements (a decrease of two casks), and the addition of a second cask for the HFR reactor (based on the proposed acceptance of 66 instead of 33 spent fuel elements).

\subsubsection{Proposed Mode of Ocean Transport}

DOE proposes that the ocean transport of spent fuel be accomplished either by commercial container ship or charter ship (sometimes referred to as a dedicated ship). Commercial container ships are common carriers operating on scheduled sailings over established trade routes. They provide service on a first-come, first-served basis. The spent fuel would be shipped along with the other commercial cargo on board.

Ocean transport by charter ship would involve the chartering of any of several commercially available vessels (e.g., "tramp" vessels, Military Sealift Command chartered vessels, or "purpose-built" ships). Appendix I provides additional information regarding the use of chartered vessels. In contrast to commercial liner operations, tramp or charter market vessels provide private or contract carrier service with no fixed route or predetermined schedule. These ships go wherever cargo is available and take it to whatever destination is requested. In the open tramp market, these vessels tend to be older and less reliable and, according to marine insurance and marine transportation experts, subject to higher casualty rates than vessels sailing on regular liner routes. The reason the less reliable vessels tend to be on the tramp market is that they cannot be relied upon to meet the tight schedules required of the commercial liners. There are, however, many well maintained and reliable vessels operating in the tramp or charter market. One method for selecting such a vessel would be to select a vessel meeting the standards of the American Bureau of Shipping or a similar classification organization. (See Appendix H.) If a well maintained vessel were obtained and chartered for carriage of the spent nuclear fuel, any port could be specified, assuming that the port had the necessary capabilities. To ensure that any chartered vessel used to transport spent fuel under this proposal is well maintained, DOE would require the research reactor operators to charter a vessel meeting the American Bureau of Shipping standards, or their equivalent.

One avenue for obtaining the services of a well built and maintained chartered vessel would be to use a chartered vessel under the control of the United States Military Sealift Command (MSC). The MSC charter would be a high-quality vessel because it would have undergone rigorous inspections by the MSC. A MSC-controlled vessel could be made available to 
transport foreign research reactor spent nuclear fuel from ports within Europe to any commercial or military ocean terminal in the United States. A MSC vessel of the type that would transport spent fuel would be a roll-on/roll-off or breakbulk ${ }^{2}$ vessel owned by private carriers.

Another option for charter services would be ocean transport by "purpose-built" ships. For example, British Nuclear Fuels Limited (BNFL) owns several ocean-going vessels that have been built specifically for transporting spent nuclear fuel. The major construction feature of these purpose-built ships is the double hull of the vessel, which would prevent the vessel from sinking in most collisions. The BNFL vessels also have radiation detection systems built into cargo holds to detect any abnormal incidents involving the spent fuel. In addition, the BNFL vessels have crew members who are trained to use radiation detection instruments and to respond to radiation incidents.

As shown in Chapter 6, the type of vessel per se (commercial or chartered) used to transport the foreign research reactor fuel would not affect the impacts on the environment from the trans-Atlantic crossing. Rather, the environmental impacts (e.g., ship crew radiation exposure and risks of accidents in port) are affected principally by the number of times the ship stops at intermediate ports before reaching the United States port of entry. (See Section 6.1.1.1.) Commercial container ships usually make several port stops in the course of unloading their cargo, and some of these stops could occur before the spent fuel would be off-loaded. 'In contrast, chartered ships could be directed to go to the port of entry where the spent fuel would be off-loaded. For example, if a ship were to make no intermediate port stops, the collective dose to crew members during transport would be reduced by approximately 30 percent over the dose that crew members would receive if the ship were to make three stops. However, since the reduction in risk would result only in reducing an already small risk to a somewhat smaller risk, DOE proposes to allow the foreign research reactor spent fuel to be transported either by a commercial or chartered vessel.

The proposed spent fuel shipments would probably begin in mid-1994 and end in 1995 . One or more of the fifteen casks would be transported on each individual vessel. Thus, for example, if only one cask were transported per ship, fifteen trips to the United States would be needed to accommodate the 409 fuel elements. If the services of a chartered ship were obtained, it would be necessary to ship several casks on a ship at one time in order to keep shipping costs per cask comparable to those for commercial container ships. Because of the limited availability of casks designed to ship foreign research reactor spent fuel, it is unlikely that more than eight casks could be transported in a single shipment. (The risk assessment of potential transportation related impacts in this Environmental Assessment accounted for a minimum of one and a maximum of eight casks per vessel.)

The total cost of transporting the spent fuel would depend on both the mode of transportation chosen and on the number of casks per shipment. There are many factors contributing to transportation costs including: fees for cask rental, land transport (by truck or rail) of the full

\footnotetext{
${ }^{2}$ A breakbulk vessel is one that carries all types of cargo in various packagings. These packagings range from bags, drums, and palletized cargo to containers.
} 
and empty casks, ocean transport of the full and empty casks, liability insurance, security, permits, fees, and planning and administration of the transportation process. These costs are summarized in Table 3-2, which presents rough approximations of total transportation costs to

Table 3-2. Representative Total Transportation Cost to Reactor Operator

\begin{tabular}{||l|r|r|c|}
\hline & $\$ / \mathrm{kg}$ & $\$ /$ Cask & $\begin{array}{c}\text { Costs Relative } \\
\text { to Commercial Container } \\
\text { Shipping }\end{array}$ \\
\hline Commercial Container Ship: & & & \\
\hline 1 Cask/ship & $\$ 700$ & $\$ 120,000$ & 1.0 \\
\hline & & & \\
\hline Chartered or Dedicated Ship: & & & 3.4 \\
\hline 1 Cask/ship & $\$ 2,400$ & $\$ 410,000$ & 1.7 \\
\hline 5 Casks/ship & & & \\
\hline 8 Casks/ship & $\$ 1,200$ & $\$ 210,000$ & 1.6 \\
\hline
\end{tabular}

a The " $\$ / k g "$ values appear to be the same for five and eight casks/ship due to rounding of the numbers. At a greater level of precision, the values are slightly different, as shown by the "\$/cask" and "Costs Relative to Commercial Container Shipping" values.

the reactor operators under different ocean transport scenarios. The costs are based on a typical cask containing 33 spent fuel elements (e.g., the GNS-11), and an average spent fuel element weight of 5 kilograms, for an average total spent fuel weight of 165 kilograms per cask $^{3}$.

The option of shipping one cask per chartered ship was evaluated to provide a comparison to shipment on commercial container ships, which would likely carry one cask per ship. The eight cask per ship option was included because, based on the number of casks available to ship research reactor spent fuel, eight casks is considered the maximum number that could be shipped on any one vessel. Since the proposed action consists of shipping fifteen casks, two shipments, one with eight and the other with seven casks, theoretically would provide for transportation of all of the spent fuel. The cost of shipping five casks per ship, which would involve three shipments, was included as a sensitivity analysis. The costs of using a charter ship vary from 1.6 to 3.4 times that for commercial container shipping depending on the number of casks shipped on a vessel. In the situation where a vessel would be chartered for shipment of only one cask, the cost could be as high as approximately $\$ 400,000 ; \$ 290,000$

\footnotetext{
${ }^{3}$ The cost data were obtained independently from a number of different sources, thus allowing their accuracy and reasonability to be checked. The sources included the following: Edlow International, British Nuclear Fuels Limited, the United States Military Sea Lift Command, contacts with various shipping companies, and DOE consultants.
} 
more than that for commercial shipping. If eight casks were shipped on a charter vessel, the costs per cask could be approximately $\$ 70,000$ higher than for commercial container shipping. In the extreme situation where an operator would be required to ship a partially filled cask (e.g., the Danish operator could send 12 elements weighing 3.5 kilograms each) on a chartered ship with no other casks, the cost could be as high as $\$ 10,000$ per kilogram.

\subsubsection{Proposed Ports of Entry}

As discussed in greater detail in Appendix C, DOE undertook an extensive effort to identify commercial and military ports that would be most advantageous for receipt of the spent nuclear fuel proposed for acceptance. These efforts included a number of port visits, and the development of criteria by which potential ports of entry could be evaluated. ${ }^{4} \mathrm{DOE}$ developed the screening criteria based on factors included in recently enacted legislation, the National Defense Authorization Act for Fiscal Year 1994 (Public Law 103-160, signed into law by President Clinton on November 30, 1993) (the Act). Section 3151 of the Act directs the Secretary of Energy, "if economically feasible and to the maximum extent practicable," to receive spent fuel at a port of entry that has "the lowest human population in the area surrounding the port of entry; is closest in proximity to the facility which will store the spent nuclear fuel; and has the most appropriate facilities for, and experience in, receiving spent nuclear fuel." In addition, criteria recommended at a DOE-sponsored workshop on port selection criteria for shipments of spent nuclear fuel at the United States Merchant Marine Academy (USMMA) were applied to potential ports of entry. These criteria were distance of the port from the open ocean, emergency preparedness and capabilities, and intermodal access.

Commercial Ports. The screening criteria were first applied to all 151 commercial seaports in the United States. ${ }^{5}$ The Act does not direct DOE to consider the three criteria in any particular order. As a first step, DOE applied the criterion relating to a port's facilities and experience as a reasonable means of evaluating which ports were in fact capable of receiving spent fuel. Unless a port had appropriate facilities, and therefore was in fact capable of receiving spent fuel, it would not matter how close the port was to the Savannah River Site or how low the population was in the area surrounding the port.

Because Congress did not define the term "most appropriate facilities and experience," DOE had to determine what port features would be necessary to service a large container vessel of the type most likely to be used under the proposed action. DOE concluded that ports that had regularly scheduled commercial container service from Europe would be adequately equipped to receive spent fuel, because such ports would have the capability for and experience in

\footnotetext{
4 These criteria are designed to address issues associated only with shipping a small number of casks over a short period of time through a United States port for transport to the Savannah River Site. The criteria are not designed to address issues associated with large numbers of shipments over a long period of time, such as the long-term proposed policy being considered in the Foreign Research Reactor Spent Fuel Environmental Impact Statement. For long-term proposals, considerations such as future port development plans and population trends would have to be considered.

5 The list of commercial seaports was obtained from the United States Maritime Administration (MARAD) and included all commercial ports handling foreign trade. Fishing ports, inland ports, and military ports are not included in the MARAD list. Thus, DOE independently identified and then evaluated military ports, taking into consideration the three factors listed in the Act.
} 
servicing a large container or breakbulk vessel. (As discussed above, the spent fuel elements would be loaded into multi-ton casks, which would be placed into large ISO containers for ocean transit.) Such ports have sufficient channel and pier depth to accommodate large, ocean-going vessels, as well as the cranes and infrastructure needed to unload and move containerized cargo. It would be important that any facilities needed to receive spent fuel already exist, because harbors and channels could not be deepened and dredged, nor port facilities constructed, in the time required for the proposed shipments. For the foregoing reasons, DOE concluded that screening for ports with demonstrated capability and experience in receiving ocean-going container vessels was an appropriate first step. When all 151 commercial seaports were screened on this basis, twenty out of the 151 commercial ports were found to meet the criterion. (See Appendix C, Table C-1.)

Second, DOE addressed the population criterion listed in the Act. The Act states that DOE should use to the maximum extent practicable the port that has the "lowest human population in the area surrounding the port of entry." Information on the populations potentially affected by shipments of spent fuel through each of the twenty commercial ports satisfying the first criterion was evaluated. It was appropriate to consider not only the population of the area surrounding the port, as provided in the Act, but also the population of the city and county in which a port is located, and the overall population in urban, suburban, and rural areas along the overland transportation routes to the Savannah River Site. All of these population characteristics were determined to be equally important and each of the twenty ports was evaluated on the basis of all three characteristics. No port ranked the best (i.e., had the lowest population density) in all three characteristics. Eleven ports, however, were determined to have roughly comparable and lower population characteristics than the other nine ports. (See Appendix C, Table C-2.)

The third step in evaluating commercial ports was to screen the remaining eleven ports on the basis of their "proximity to the facility which will store the spent nuclear fuel." Although one of the eleven ports (Charleston, South Carolina) is in fact closest to the Savannah River Site, four of the eleven ports were determined to be relatively closer to the Savannah River Site in comparison to the remaining seven ports. (See Table 3-3.) (See Appendix $C$ for a discussion of how the distances were compared.) The reasoning behind selecting several rather than "the closest" port is that no single port clearly meets all of the Act's criteria. For example, even though Charleston is closest in distance to the Savannah River Site, the port has no experience with spent fuel and is not the lowest in any of the population characteristics. Consequently, four ports were deemed to satisfy the "closest in proximity" criterion as the most balanced means of meeting the Act's criteria.

During the final step in evaluating commercial ports, criteria recommended at the USMMA workshop were applied to the four remaining ports (Wilmington, North Carolina; Charleston, South Carolina; Savannah, Georgia; and Jacksonville, Florida). All of the ports were found to have acceptable distances from the open ocean, emergency preparedness and other necessary capabilities to receive spent fuel, and well-connected access to the intermodal transportation system. 
Table 3-3. Ports Closest in Proximity to the Savannah River Site

\begin{tabular}{|c|c|c|}
\hline Port & $\begin{array}{c}\text { Highway Distance from } \\
\text { Savannah River Site }\end{array}$ & Normalized Score \\
\hline ) & 3 柆 & 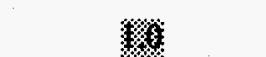 \\
\hline - & \% & 辣: \\
\hline K. & 30 & 樂 \\
\hline 1401713 & \% & 喽 \\
\hline Richmond & 471 & 2.3 \\
\hline Portsmouth & 485 & 2.4 \\
\hline Norfolk & 499 & 2.5 \\
\hline Newport News & 540 & 2.7 \\
\hline Everglades & 574 & 2.8 \\
\hline New Orleans & 643 & 3.2 \\
\hline Houston & 956 & 4.7 \\
\hline
\end{tabular}

Military Ports. Since MARAD's commercial seaport list excludes military ports, DOE evaluated United States military ports to provide a military alternative to the proposed commercial ports. DOE used a slightly different method for determining which military ports satisfy the screening criteria because the facilities at military ports may differ from those at commercial ports due to differences in the purposes served by military and commercial ports.

The first step was to locate military ports on the East Coast in close proximity to the Savannah River Site that were weapon stations, military ocean terminals, or military ports with nuclear material experience, and that could unload containerized cargo from a commercial vessel. If an area had more than one military facility, the weapons station was selected over the other facilities. Weapons stations tend to have lower populations in the immediate vicinity of the port due to safety zones. Also, weapons stations would have experience in loading and unloading cargo-carrying vessels. These facilities were the Naval Weapons Station in Yorktown, Virginia; the Naval Station in Kings Bay, Georgia; the Naval Weapons Station in Charleston, South Carolina; and the Army Military Ocean Terminal in Sunny Point, North Carolina. Of these bases, Kings Bay and Sunny Point have the lowest populations in the surrounding port areas. However, Kings Bay is a submarine base and does not have the most appropriate facilities for, or experience in, handling spent fuel or unloading cargo vessels. On the other hand, Sunny Point is a military cargo port and has appropriate facilities for handling spent fuel arriving on either container or breakbulk vessels.

Sunny Point also met the USMMA workshop criteria. Sunny Point is approximately twelve miles up the Cape Fear River from the open ocean. The passage is along well-maintained and marked navigation channels. Because Sunny Point's primary mission is movement of hazardous cargoes, there are dedicated teams of individuals trained in emergency response. Finally, Sunny Point has good intermodal system access. The Army owns and maintains over 
90 miles of rail track that services the port and connects into the CSX rail line. The federal, state, and county maintained roads servicing Sunny Point provide easy access to the interstate system. Trucks moving munitions to and from Sunny Point safely travel over these roads.

Multiple Ports of Entry. Based on the criteria in the Act and those recommended at the USMMA workshop, Wilmington, North Carolina; Sunny Point, North Carolina; Charleston, South Carolina; Savannah, Georgia; and Jacksonville, Florida; are proposed as ports of entry for the spent fuel shipments considered in this Environmental Assessment. The proposal to consider multiple ports results in part from the failure of any one port to appear unquestionably better than any other for receipt of spent fuel. As shown in Table 3-4 and further discussed in Appendix C, no port clearly stands out as the best in comparison to all other seaports in meeting all of the criteria set forth in the Act. For example, the port of Charleston compares well with other ports in terms of proximity to the Savannah River Site. It does not compare well with other ports, however, in terms of the population density along the transportation route. Each proposed port has comparative advantages and disadvantages over the other four proposed ports, but all five appear comparatively more advantageous than other United States seaports.

Table 3-4 Highway and Population Characteristics Associated with the Representative Routes for the Proposed Ports

\begin{tabular}{|c|c|c|c|c|}
\hline \multirow[t]{2}{*}{ Port Of Entry } & \multirow{2}{*}{$\begin{array}{l}\text { Highway Distance } \\
\text { km (mi) }\end{array}$} & \multicolumn{3}{|c|}{ Population Data } \\
\hline & & $\begin{array}{c}\text { Population Density } \\
\text { of City } \\
\left.\text { (person } / \mathrm{km}^{2}\right)\end{array}$ & $\begin{array}{l}\text { Population Density } \\
\text { of Port Route } \\
\text { (person } / \mathrm{km}^{2} \text { ) }\end{array}$ & $\begin{array}{l}\text { Total Population } \\
\text { Potentially } \\
\text { Exposed Along } \\
\text { Truck Route }\end{array}$ \\
\hline Charleston & $\begin{array}{c}355 \\
(221)\end{array}$ & 753 & 2251 & 139,403 \\
\hline Jacksonville & $\begin{array}{c}624 \\
(388)\end{array}$ & 395 & 310 & 60,036 \\
\hline Savannah & $\begin{array}{c}429 \\
(267)\end{array}$ & 998 & 2788 & 54,856 \\
\hline Sunny Point & $\begin{array}{c}710 \\
(441)\end{array}$ & 27 & 179 & 131,353 \\
\hline Wilmington & $\begin{array}{c}642 \\
(399)\end{array}$ & 693 & 1765 & 117,078 \\
\hline
\end{tabular}

\subsubsection{Proposed Mode of Overland Transport}

Once in port, the spent fuel casks in the ISO containers would be loaded on and secured to tractor-trailers that would transport the spent fuel to the Savannah River Site. As with the ocean transportation, the responsibility for overland transportation would be the responsibility of the shipper, as DOE would not take title to the spent fuel until it reached the Savannah River Site. The trucks would use Nuclear Regulatory Commission (NRC) and Department of 
Transportation (DOT) approved truck shipping routes, and the shipper would be responsible for compliance with all NRC and DOT regulations. To the maximum extent practicable, interstate highways would be used. State governors or their designees and appropriate agencies would be notified by the shipper prior to shipment. Each shipment would have the required escort to provide security. All required plans and agreements would be in place before any shipments would occur. The operational aspects of overland transportation are addressed in more detail in Appendix $\mathrm{H}$.

Existing emergency response plans are in effect for each port city. State plans also are in effect to cover emergencies along State highways. DOE, in cooperation with State and local governments, plans to provide for emergency training, if needed, in each of the States in which spent fuel is transported. In the unlikely event of a transportation accident involving spent fuel, DOE, if requested, would deploy radiological assistance teams to provide technical assistance to State and local officials.

The Price-Anderson Act provides liability protection in the unlikely event of a nuclear incident in the United States. Thus, the proposed transport of spent fuel from a United States port of entry to the Savannah River Site would be covered under the Price-Anderson Act, even though DOE would not take title to the spent fuel until it reaches the Savannah River Site. The Act not only covers harm caused by a nuclear incident, but also the costs of a precautionary evacuation (if ordered by the appropriate authorities).

\subsubsection{Proposed Storage at the Savannah River Site}

At the Savannah River Site, the casks would be unloaded and the spent fuel would be placed into existing pool storage in the Receiving Basin for Offsite Fuels (RBOF). RBOF is a versatile facility with provisions for the receipt and storage of irradiated nuclear fuel elements. Since 1963, irradiated fuel elements have been received from offsite reactors and from Savannah River Site reactors. The RBOF facility provides the capability for underwater unloading of shipping casks and the handling and storage of the fuel elements. Radiation shielding is provided by the water over the fuel. The spent fuel would be stored at RBOF until such time as the environmental reviews and program actions for long-term storage or other disposition of spent fuel are completed. RBOF currently is capable of storing all 409 spent fuel elements proposed to be accepted with little or no impact on other ongoing programs.

The 409 spent fuel elements (approximately two metric tons) proposed to be accepted at the Savannah River Site under this proposal represent less than 0.004 percent of all DOE spent fuel nationwide. In the Programmatic Spent Nuclear Fuel Management Environmental Impact Statement due to be completed by June 1995, DOE is considering where to manage all spent fuel within the DOE complex nationwide for the interim period (up to 40 years) prior to ultimate disposition. Decisions concerning the management of spent fuel will be based on the ability of the sites under consideration (including the Savannah River Site) to conduct various treatment and storage options. Additional site-specific environmental reviews will be conducted regarding treatment and storage options. Regarding Savannah River Site specific options, the proposed 409 elements represent less than two percent of the Savannah River Site inventory of materials that may require similar disposition (e.g., other aluminum clad highly 
enriched uranium materials). Therefore, the small increase in Savannah River Site's inventory of spent fuel that would result from the proposed action would not prejudice DOE's nationwide decisions on where and how to manage spent fuel or Savannah River Site decisions regarding disposition of material similar in nature to the 409 elements.

Regarding the ultimate disposition of foreign research reactor spent fuel, the Nuclear Waste Policy Act authorizes the disposal of spent nuclear fuel owned by the United States government and places no restriction on either the type or location of the reactor in which fuel owned by the government has been irradiated. Because, under the proposed action, the United States would take title to the spent fuel prior to disposal (i.e., when it reaches the Savannah River Site), the Nuclear Waste Policy Act provides authority for its disposal in a geologic repository. 


\subsection{ALTERNATIVES TO THE PROPOSED ACTION}

Chapter 4 presents a discussion of several alternatives to the proposed action, alternatives which reflect a number of different policy options. Section 4.1 discusses alternative numbers of spent fuel elements that could be accepted by the United States instead of 409 spent fuel elements under the proposed action. The range varies from 953 to zero depending on which set of policies are pursued. Section 4.2 examines receipt of spent fuel at additional United States ports as alternatives to the five considered in the proposed action. Section 4.3 discusses use of rail transportation from the port of entry to the Savannah River Site instead of the proposed use of trucks. Finally, Section 4.4 presents alternatives that were considered, but not analyzed in detail, because they were found to be unreasonable.

\subsection{Acceptance of Alternative Numbers of Spent Fuel Elements}

There are five alternative numbers of spent fuel elements that could be accepted by the United States instead of the proposed 409 spent fuel elements. These alternatives are based on a number of policy options, and range in number from no spent fuel elements under the No Action alternative, to 953 spent fuel elements under the original requests made by the eleven research reactors that were visited by United States inspection teams. In between, depending on the policy options (which are described below), 359, 291 or 248 spent fuel elements could be accepted as alternatives to the proposed action. (See Table 4-1.)

\subsubsection{No Action Alternative}

The No Action alternative would mean that DOE would not accept any spent fuel from the eight foreign research reactors listed in Table 3-1. The likely consequences of the No Action alternative would be reactor shutdowns in cases where spent fuel could not be sent to Dounreay for reprocessing. The operators of the BER-II (Germany) and SAPHIR (Switzerland) reactors have the option to send spent fuel to Dounreay for reprocessing, and presumably would exercise that option to avoid reactor shutdowns, although reprocessing of SAPHIR spent fuel would require United States authorization. The No Action alternative likely would result in the shutdown of HOR (Netherlands), DR-3 (Denmark), ASTRA (Austria), GRR-1 (Greece), HFR (Netherlands), and R-2 (Sweden). (See Chapter 2.)

\subsubsection{Acceptance of 953 Spent Fuel Elements as Requested by the Eleven Research Reactors}

Before the United States inspection teams visited the reactor sites, eleven reactor operators had requested in the aggregate that DOE accept approximately 953 spent fuel elements in the near term. During the site visits, the reactor operators and the inspection teams reviewed in detail each reactor operator's request for relief and the basis upon which each request was made. As a result of the site visits and developments pertaining to the HFR and BR-2 reactors, DOE now proposes to accept 409 spent fuel elements, less than one-half the amount originally requested. DOE and Department of State officials believe that the reduced number 
Table 4-1. Acceptance of Alternative Numbers of Spent Fuel Elements ${ }^{\mathrm{a}}$

\begin{tabular}{|c|c|c|c|c|}
\hline REACTOR & $\begin{array}{l}\text { Requested } \\
\text { DOE SNF } \\
\text { Acceptance }\end{array}$ & $\begin{array}{l}\text { No Reprocessing } \\
\text { - Ship Partially } \\
\text { Full Casks }\end{array}$ & $\begin{array}{c}\text { Force } \\
\text { Reprocessing - } \\
\text { Ship Full } \\
\text { Casks }^{\mathrm{b}}\end{array}$ & $\begin{array}{c}\text { Force } \\
\text { Reprocessing - } \\
\text { Ship Partially } \\
\text { Full Casks }\end{array}$ \\
\hline BR2 Belgium & $144^{\mathrm{d}}$ & 0 & 0 & 0 \\
\hline HOR Netherlands & 33 & 20 & 33 & 20 \\
\hline HFR Netherlands & 66 & 66 & 66 & 66 \\
\hline DR-3 Denmark & 72 & 12 & 36 & 12 \\
\hline R-2 Sweden & 64 & 58 & 64 & 58 \\
\hline BER-II Germany & $104^{\mathrm{d}}$ & 52 & 0 & 0 \\
\hline FRG-1 Germany & 132 & 0 & 0 & 0 \\
\hline SAPHIR Switzerland & $99^{d}$ & $59^{\mathrm{e}}$ & 0 & 0 \\
\hline ASTRA Austria & 26 & 26 & 26 & 26 \\
\hline GRR-1 Greece & $99^{d}$ & $66^{f}$ & 66 & 66 \\
\hline HIFAR Australia & 114 & 0 & 0 & 0 \\
\hline Total & 953 & 359 & 291 & 248 \\
\hline
\end{tabular}

a Number of spent fuel elements based on reactor operations through December 1995.

b Reactors that cannot reprocess are assumed to ship full casks to the United States.

c Reactors that cannot reprocess are assumed to ship partially full casks to the United States.

d These reactors requested DOE acceptance of the following number of elements: BR2(150), BER-II(105), SAPHIR(100), GRR-1(108). For simplicity of modeling, the requests were rounded to the nearest full cask.

e Shipment of 33 spent fuel elements provides for continued operations, but 59 resolves a safety concern.

f Shipment of 40 spent fuel elements provides for continued operation, but 66 resolves a safety concern.

of elements will provide sufficient storage space or otherwise allow the research reactors to meet regulatory requirements to support continued operation through December 1995.

As more fully described in Section 5.5.2, if DOE were to select this alternative, it would be possible to accommodate storage of 953 elements in RBOF.

\subsubsection{Acceptance of 359 Spent Fuel Elements Based on No Reprocessing and Acceptance of Partial Casks}

As noted in Chapter 3, the minimum number of spent fuel elements needed to be transported by all eight reactors from which DOE proposes to accept spent fuel without forcing

reprocessing is 359 spent fuel elements. Under this alternative, four reactor operators (HOR, DR-3, PSI, and SAPHIR) would be required to ship partially full casks. Reactor shutdowns would be avoided by this alternative, and existing safety concerns noted by the reactor operators would be addressed. Shipment of 359 elements would still involve the transport of fifteen casks, which is the same number of casks needed to transport 409 spent fuel elements under the proposed action.

Acceptance of a total of 359 spent fuel elements under this set of policy options also was proposed in the Draft Environmental Assessment distributed for public comment in February 
1994. Although the total number of elements remains the same, the number of elements for certain reactors has changed.

The number of elements was decreased by 48 because the operator of the BR2 (Belgium) reactor has contracted to send spent fuel elements to Dounreay for reprocessing. The number of elements was increased by the proposal to accept more spent fuel elements from the HFR reactor (Netherlands) and the PSI reactor (Switzerland). The number of elements proposed to be accepted from HFR in the February draft (24) has increased by 42 as a result of the operator's demonstrated need to ship 66 elements. The PSI reactor operator has demonstrated a need to ship 59 elements instead of the 53 proposed in the February draft, for an increase of six elements. The net result of adding 48 and subtracting 48 is that the number of elements under this alternative remains at 359 .

\subsubsection{Acceptance of 291 Spent Fuel Elements Based on Reprocessing and Acceptance of Full Casks}

The alternative to accept 291 spent fuel elements would be based on a policy option that may force the reactors in Germany and Switzerland to reprocess their spent fuel instead of transporting it to the United States in order to avoid reactor shutdowns. This alternative also reflects the policy option to allow the six remaining reactors that do not have a reprocessing option to transport spent fuel to the United States in fully versus partially loaded casks. This alternative would reduce the number of cask shipments from fifteen in the proposed action (and the alternative of accepting 359 spent fuel elements) to nine cask shipments.

Acceptance of 291 elements under this alternative represents an increase of 97 elements from the "force reprocessing and accept full casks" alternative described in the Draft Environmental Assessment distributed for public comment in February 1994. The increase is the result of the proposal to accept 66 instead of 33 elements from the HFR reactor (Netherlands), and 64 instead of no elements from the R-2 reactor (Sweden). (As noted in the Swedish reactor profile in Chapter 2, the Swedish operator informed DOE that it was highly unlikely that the Swedish authorities would grant a request to reprocess spent fuel at Dounreay. Accordingly, a full cask of 64 elements from R-2 is now included in this alternative.)

\subsubsection{Acceptance of 248 Spent Fuel Elements Based on Reprocessing and Acceptance of Partial Casks}

The alternative to accept 248 spent fuel elements would be based on forcing the reactors in Germany and Switzerland to reprocess their spent fuel instead of transporting it to the United States, but, in contrast to the alternative described in Section 4.1.4, would require the remaining six reactors to send only the minimum number of spent fuel elements required in partially full casks to avoid reactor shutdown. This alternative would reduce the number of cask shipments from fifteen in the proposed action (and the alternative of accepting 353 spent fuel elements) to nine cask shipments, which is the same number as discussed above in Section 4.1.4.

Acceptance of 248 elements under this alternative represents an increase of 100 elements from the "force reprocessing and accept partial casks" alternative described in the Draft 
Environmental Assessment distributed for public comment in February 1994. As discussed in Section 4.1.3, the increase is the result of the proposal to accept 66 instead of 33 elements from the HFR reactor (Netherlands), and a partially full cask of 58 elements from the R-2 reactor (Sweden).

\subsubsection{United States Purchase of European-Reprocessed HEU}

Under this alternative, DOE would buy research reactor HEU that was generated as a result of reprocessing in Europe (e.g., at the United Kingdom Atomic Energy Authority's facility at Dounreay). This option would provide a means of mitigating potential consequences associated with the reprocessing occurring under Alternatives 4.1.4 and 4.1.5. As previously discussed in Chapter 1, there could be a number of adverse impacts to the United States nonproliferation policy to minimize the civil use of HEU if research operators were forced to pursue reprocessing in order to avoid reactor shutdowns. Since reprocessing involves dissolution of spent fuel elements and recovery of the HEU, a research reactor could reuse the material to fabricate new fuel elements. This recycling of HEU could act as a disincentive for reactor operators to convert to LEU fuels. Alternatively, a reactor could make its recovered HEU available for sale to other research reactors that had not already converted to LEU fuels, which would compromise the aim of the RERTR Program to reduce the amount of HEU available in international commerce.

In an effort to mitigate these potential consequences of forcing research reactors to reprocess, the following two subalternatives are included for consideration in this Environmental Assessment.

Blending and Conversion to Low Enriched Uranium. Transport of Low Enriched Uranium to the United States or Sale in Europe. During reprocessing, HEU would be separated from the spent fuel element. The resulting product would consist of HEU with a uranium-235 (U-235) isotope content in excess of twenty percent (normally in the 70-80 percent range). The high level radioactive waste from the spent fuel would remain the responsibility of the owner of the fuel for ultimate disposition.

The recovered HEU could be converted into metal form. To prevent this recovered HEU from becoming available in international commerce, theoretically, the United States could purchase the HEU for blending and conversion to a commercial grade LEU (i.e., with an isotopic content of U-235 less than twenty percent), which could be done either in Europe or in the United States. (If the United States did not purchase the HEU, there is no mechanism to implement or enforce a blending requirement for those reactors for which United States consent is not required for reprocessing to occur.) If the blending and conversion were to occur in Europe, theoretically, the resulting LEU could be stored or sold by the United States government in Europe, or transported to the United States for sale. If the blending and conversion were to occur in the United States, the HEU would have to be transported to a facility in the United States where the blending and conversion could take place. After blending and conversion, the LEU could be stored in the United States or sold by the United States government. 
Purchase of Highly Enriched Uranium and Transport to the United States. Under this alternative, the United States would buy HEU recovered from reactors that could reprocess, but the HEU would be transported directly to the United States for storage. For example, the transportation of HEU from the reprocessing facility in Dounreay could be accomplished by the United States, on an acceptable European military transport, or a commercial carrier licensed by the Nuclear Regulatory Commission. (Currently, there are no known commercial carriers licensed to transport HEU to or within the United States, but such licenses have been granted in the past.)

Transportation of HEU to the United States could be accomplished by air or by sea. If air transport were to be used, the HEU most likely would be sent to a United States military installation. DOE could pick up the HEU at the military installation for transport via a Safe Secure Transport vehicle to a DOE storage facility.

\subsection{Receipt of Spent Fuel Elements at Alternate Ports}

As presented in Section 3.1.3, the proposed ports of entry are Wilmington, North Carolina; the Army's Military Ocean Terminal at Sunny Point, North Carolina; Charleston, South Carolina; Savannah, Georgia; and Jacksonville, Florida. Any of these ports could receive shipments of spent nuclear fuel from the eight foreign research reactors under the proposed action. In order to compare the risks of using alternate ports, several ports on the East; West, and Gulf coasts of the United States were analyzed in addition to the proposed ports.

Detailed descriptions of the alternate ports are found in Appendix J.

The alternate ports analyzed in this Environmental Assessment are: Oakland, California (for Australian fuel only); New Orleans, Louisiana; Elizabeth, New Jersey; Morehead City, North Carolina; Yorktown, Virginia; Kings Bay, Georgia; and Norfolk, Portsmouth, and Newport News, Virginia. The selection of some of these ports differs from the alternate ports analyzed in the Draft Environmental Assessment distributed for public comment in February 1994. Upon consideration of the comments received on the February draft, DOE decided to add the Army's Military Ocean Terminal at Sunny Point to the list of proposed ports, thereby dropping it from the list of alternate ports, and to drop the ports of Norfolk, Portsmouth and Newport News, Virginia from the list of proposed ports, but to add them to the list of alternate ports.

\subsubsection{Alternate Commercial Ports}

Were DOE to accept 953 elements as requested by the eleven research reactors visited by United States inspection teams, including the HIFAR reactor in Australia, it is possible that a West Coast port could be used to receive the HIFAR spent fuel. For this reason, Oakland, California, is analyzed as a potential port of entry, but only for receipt of spent nuclear fuel originating in Australia. (See Section 4.1.2 and Table 4-1.) As the second leading container port in the United States, it is the most frequent destination for container ships from Australia.

The spent fuel originating in Europe would most likely enter the United States through an East Coast commercial port using normal shipping lanes across the Atlantic Ocean. Several alternate East Coast ports have been analyzed, although they did not meet the port selection 
criteria used to select proposed ports of entry for the limited circumstances of the proposed action. (See Appendix C.) The five East Coast commercial ports selected as alternate ports ranged from a busy port in a high population area (e.g., Elizabeth, New Jersey) to a small port in a low population area (e.g., Morehead City, North Carolina.)

While almost all commercial liners coming from Europe call at East Coast ports, some vessels also call at Gulf Coast ports. As a result, the Port of New Orleans, Louisiana, was selected as an alternate port of entry to represent the transportation risks associated with Gulf Coast ports. While the Port of New Orleans has no experience in handling spent nuclear fuel, other radioactive materials have been routinely moved through the port and the marine terminals have cranes specifically designed for off-loading commercial container vessels.

\subsubsection{Alternate Military Ports}

Two military ports, the United States Naval Weapons Station in Yorktown, Virginia, and the United States Naval Submarine Base, in Kings Bay, Georgia, were analyzed as alternate military ports to the proposed Army Military Ocean Terminal at Sunny Point, North Carolina.

The Yorktown Naval Weapons Station is the largest storage and transfer facility for naval weapons on the East Coast. A major part of its mission is the renovation, maintenance, and assembly of all classes of ordnance in the Navy's inventory, with the exception of fleet ballistic missiles. The Yorktown Naval Weapons Station does have cranes capable of offloading containers, but has no experience in off-loading commercial container vessels, because its commercial cargo usually is off-loaded at one of the nearby commercial ports (Norfolk, Newport News, or Portsmouth, Virginia). The area around the base is not sparsely populated.

The Kings Bay Naval Submarine Base serves as the East Coast base for the Navy's fleet of ballistic missile submarines, with the primary mission of providing support for Atlantic fleet Trident submarines. Due to its mission, Kings Bay is operated as a high-security naval base for the submarines and their nuclear arsenals. Commercial liners have never called at the base and, while there are cranes capable of off-loading containers, berthing space is at a premium. Operationally, submarines have priority over any other vessel regardless of the vessel's cargo. The area surrounding the base is sparsely populated.

\subsection{Transport of Spent Fuel Elements By Rail from Commercial or Military Ports of Entry to the Savannah River Site}

Under the proposed action, once the spent fuel has been off-loaded in the United States, it would be transported overland to the Savannah River Site by truck. Alternatively, overland transportation of spent fuel could be accomplished by rail. All of the ports identified as proposed or alternate ports of entry have access to rail lines, and most have rail lines extending into the port which connect with major rail networks. While only one spent fuel cask could be transported at a time by truck, several casks could be transported in a single rail shipment. There are two different types of rail service, regular commercial rail and dedicated rail. Use of regular commercial rail service would mean that the train could transport other cargo along with the spent fuel. Use of a dedicated train would mean that a train would transport only the spent fuel. 
Two of the proposed ports (Jacksonville, Florida and Wilmington, North Carolina) have the capability to load the ISO containers (containing the spent fuel casks) directly from the ship to a rail car. The other proposed ports would off-load the ISO containers from the ship to a tractor-trailer, which would then move the containers to a staging area. From the staging area, the containers would be loaded onto a rail car, which would then be linked with a train. The ISO containers would be separated from both the crew and any sensitive cargo (e.g., photographic film) by other rail cars acting as buffers. These buffer cars could either be empty or contain cargo that would be unharmed by any potential radiation dose from the spent fuel elements. An escort rail car also would be attached to the train to accommodate two security personnel and communication equipment for each shipment. In the unlikely event of an incident, the security personnel would contact the local authorities. In high population density areas, armed escorts would be required. These security arrangements are consistent with those required for truck transport.

The Savannah River Site has a Railroad Classification Yard that is within the site boundary. At the Railroad Classification Yard, the train would de-couple the rail cars with the ISO containers. The ISO containers would be unloaded from the rail cars using an onsite mobile crane. Savannah River Site personnel are evaluating two options for staging the casks once they reach the site until they are transferred to RBOF. The first option would be to lift the ISO containers off the train and set them on the ground at the Railroad Classification Yard, where they would remain until transferred by truck to RBOF. The second option would be to off-load the ISO containers from the train directly onto trucks. The trucks would be staged at the Railroad Classification Yard or outside RBOF until ready for unloading at RBOF.

Radiation and contamination surveys of the exterior of the ISO containers would be performed at the Railroad Classification Yard upon receipt, and compared with the shipping records. Additionally, the exterior would be inspected for obvious visible damage. At RBOF, a detailed inspection of the cask would be performed, including detailed radiation and contamination surveys. When the inspection was complete, the spent fuel elements would be removed from the casks and placed into wet storage in RBOF.

The primary advantage of dedicated rail is that stops in classification yards are minimized. The resulting shorter overall trip time results in a reduction in rail worker and inspector dose. Based on discussions with rail companies, a regular commercial rail shipment from the furthest proposed port of entry (Sunny Point, North Carolina) to the Savannah River Site would be expected to take at least four days and normally would involve up to two stops. A dedicated train would be expected to make the trip in no more than two days, and would be expected to involve one stop. Accident rates are not known to differ substantially for dedicated rail and regular rail freight.

The spent fuel containers could be transported either one at a time or several in each rail shipment. When using a dedicated train, greater cost savings would be accomplished by shipping as many casks as possible on each train. As discussed in Chapter 3, however, due to the unavailability of casks worldwide it is unlikely that more than eight casks could be transported at one time. The cost of transporting eight casks per rail shipment is shown in Table 4-2. The cost of transporting five casks per rail shipment also is included as a sensitivity analysis. Finally, the cost of transporting one cask per rail shipment is included because it is possible that one cask could be transported per rail shipment. 
Total transportation costs have been calculated in dollars per kilogram for each potential mode of ground transportation, based on the distance of the proposed port farthest from the Savannah River Site (Sunny Point, North Carolina). Based on these assumptions, truck shipment would cost the least, followed by regular rail, and then dedicated rail. The costs begin to equalize, however, when several casks are transported per rail shipment, as shown in Table 4-2. When shipping several casks per shipment, the costs are not appreciably different

Table 4-2. Transportation Costs Per Type of Shipment

\begin{tabular}{||l||r|r|r||}
\hline \multicolumn{1}{|c|}{ TYPE OF SHIPMENT } & TRUCK $(\$ / \mathrm{kg})$ & RAIL $(\$ / \mathrm{kg})$ & $\begin{array}{r}\text { DEDICATED RAIL } \\
(\$ / \mathrm{kg})\end{array}$ \\
\hline \hline 1 Cask/Commercial & $\$ 710$ & $\$ 740$ & $\$ 840$ \\
\hline 1 Cask/Charter Ship & $\$ 2,400$ & $\$ 2,500$ & $\$ 2,600$ \\
\hline 5 Casks/Charter Ship & $\$ 1,200$ & $\$ 1,300$ & $\$ 1,300$ \\
\hline 8 Casks/Charter Ship & $\$ 1,200$ & $\$ 1,200$ & $\$ 1,200$ \\
\hline
\end{tabular}

a The costs appear to be the same for several values due to rounding of the numbers. At a greater level of precision, the values are slightly different. For example, when shipping five casks, there would be a total dollar difference of approximately $\$ 1,000$ between using regular rail or dedicated rail.

between use of truck or rail. For example, when shipping five casks, there would be a total dollar difference of approximately $\$ 6,000$ between using truck or dedicated rail.

\subsection{Alternatives Considered But Not Analyzed in Detail}

The following subsections describe alternatives to the proposed action that were considered, but not analyzed in detail, because they were found to be unreasonable.

\subsubsection{Transport of Spent Fuel Elements by Air to the United States}

Besides ocean transport by vessel, carriage by air is the only other mode of transportation between the United States and Europe. There are two distinct reasons why the air mode is not a feasible alternative to the sea mode for transportation of research reactor spent fuel.

First, with the possible exception of small sample quantities, spent fuel is required to be transported in packagings (casks) weighing several tons. As a general rule, casks would have to be shipped singly by air (i.e., one per airplane) because of their weight. This has made the air alternative so costly as to be prohibitive. As a result, there is no commercial operational experience in the United States with air transport of spent fuel. No "Standard Operating Procedures" have been written and no intermodal transfer procedures (air-truck or air-rail) have been developed. No agreements have been negotiated regarding airspace overflight of other nations or states. Because the United States has no experience with this type of transportation, no meaningful comparison can be made between air transport and ship transport regarding either incident-free doses to workers and the public or accident risks. 
Second, plutonium air transport (PAT) packaging standards clearly apply to movement by air of any non-excepted package containing more than one A2 amount ( 0.005 curies) of plutonium (Title 10, Code of Federal Regulations, section 71.88a). The research reactor spent fuel considered in this Environmental Assessment is non-excepted and could contain more than 0.005 curies of plutonium per cask. Therefore, the spent fuel would have to be transported in a cask meeting PAT packaging standards. Because no spent fuel shipping cask has been certified to meet PAT packaging standards, transporting research reactor spent fuel by air to the United States could not be accomplished in the near term.

\subsubsection{Receipt of Foreign Research Reactor Spent Fuel Elements at Alternate DOE Facilities}

There are four DOE controlled sites in the United States, in addition to the Savannah River Site, to which foreign research reactor spent nuclear fuel potentially could be shipped for storage in the near-term. These are the Idaho National Engineering Laboratory (INEL), Idaho; the Hanford Site, Washington; the Nevada Test Site, Nevada; and the Oak Ridge National Laboratory, Tennessee. The criteria used to select these sites for evaluation in this Environmental Assessment are listed in Appendix B. For the following reasons and those discussed in greater detail in Appendix B, none of these sites is a viable alternative to the Savannah River Site.

1. INEL is currently under a court order barring receipt of any additional spent nuclear fuel from offsite, except as specifically allowed by the court. The portions of this court order that apply to foreign research reactor spent nuclear fuel are unlikely to be lifted in the time required to address the near-term needs of the foreign research reactors.

2. The Hanford Site, while having a large inventory of spent nuclear fuel, does not have existing appropriate facilities available for receipt and storage of the spent fuel covered by the proposed action. Constraints which prevent receipt and storage at the various existing Hanford facilities include, but are not limited to, storage system capacities, nuclear criticality limitations, and fuel transport cask receipt/handling capabilities. It would not be possible to construct new facilities or convert and qualify existing facilities in the time required to implement the proposed action. (See Appendix B for a detailed discussion.)

3. The Nevada Test Site currently does not have any spent fuel storage facilities. It would not be possible to construct and bring such facilities into operation in the time required to address the near-term needs of the foreign research reactors.

4. Although the Oak Ridge National Laboratory has three possible locations for receipt and storage of the spent fuel covered by the proposed action, none of these sites has the existing capacity for storage of 409 foreign research reactor spent fuel elements. Existing wet storage facilities currently do not have existing excess capacity to accommodate these elements, or are not, for a variety of reasons, operationally capable of receiving the spent fuel. It would not be possible to construct new facilities or convert and qualify existing facilities in the time required to implement the proposed action. (See Appendix B for a detailed discussion.) 


\subsubsection{Spent Fuel Storage Assistance for Foreign Research Reactors}

One alternative to the near-term acceptance of the foreign research reactor spent fuel by the United States would be for DOE to provide assistance to the foreign research reactor operators for the continued storage of the spent fuel at the reactor sites. This is not a viable alternative for the following reasons and those described in greater detail in the individual reactor profiles in Chapter 2.

1. As demonstrated by the actions taken by the operators of the FRG-1 and BR-2 reactors, many of the reactor operators do not have the option to continue to store spent fuel at their sites for regulatory and other reasons. Offers to assist such reactor operators with continued storage would be fruitless.

2. Other reactor operators are required by local regulatory requirements to demonstrate that they have a mechanism for disposing of their spent fuel. Continued storage and/or expansion of existing storage facilities on site would not satisfy this regulatory requirement, and therefore would not be permitted by the regulatory authorities.

3. The research reactors facing near-term storage problems from which DOE proposes to accept spent fuel could not enlarge their storage capabilities within the required time period, even with DOE's assistance and the approval of cognizant regulatory authorities. For example, dry storage of spent fuel is a proven technology which has been used in Europe, Australia and the United States for several years. However, construction and licensing of new storage facilities in Europe could not be accomplished in time to meet the near-term storage or disposal needs of the research reactors.

\subsubsection{Transport of Spent Fuel by Barge from Port of Entry to the Savannah River Site}

Under this alternative, the spent fuel would be transported by ocean-going vessel to one of the proposed or alternate ports of entry. At the port the container(s) of spent nuclear fuel would be off-loaded onto a barge equipped with special tie-downs. The barge would be towed to the mouth of and then up the Savannah River to the Savannah River Site barge facility, where the container(s) would be offloaded and trucked to RBOF.

The United States Corps of Engineers no longer dredges or maintains a navigation channel on the Savannah River between Savannah, Georgia and the Savannah River Site, and movement by barge would be difficult. Because river transport is possible only under controlled conditions utilizing specialized towing and barge equipment, this alternative was not considered further. 


\subsection{AFFECTED ENVIRONMENT}

\section{$5.1 \quad$ Introduction}

The potentially affected environments include the marine environment, United States ports of entry, highway corridors from the ports to the Savannah River Site, and the Savannah River Site itself. Each of these environments is described in this section.

\subsection{Marine Environment}

Because the proposed action involves ocean transport, DOE considered the environmental impacts of the proposed action on the global commons in accordance with Executive Order 12114 (U.S. Federal Register, 1981).

Ships transporting foreign research reactor spent nuclear fuel from European ports to the proposed ports would use normal shipping lanes through the North and Mediterranean Seas and the Atlantic Ocean. The sea route distances are given in Table 5-1.

Table 5-1. Sea Distances From Foreign Ports to the Proposed Ports of Entry

\begin{tabular}{||l|c|c|c|c|c||}
\hline \multirow{2}{*}{ Foreign Port } & \multicolumn{5}{c|}{ Distance km (miles) } \\
Charleston & \multicolumn{1}{c|}{ Jacksonville } & \multicolumn{1}{c||}{ Savannah } & Sunny Point & Wilmington \\
\hline Antwerp, Belgium & $7061(4378)$ & $7433(4619)$ & $7672(4767)$ & $6943(4314)$ & $6943(4314)$ \\
\hline $\begin{array}{l}\text { Bremerhaven/Hamburg, } \\
\text { Germany }\end{array}$ & $7557(4685)$ & $7929(4927)$ & $7676(4770)$ & $7439(4623)$ & $7439(4623)$ \\
\hline Piraeus, Greece & $9437(5851)$ & $9709(6033)$ & $9831(6109)$ & $9309(5785)$ & $9309(5785)$ \\
\hline Rotterdam, Holland & $7071(4384)$ & $7443(4625)$ & $7565(4701)$ & $6952(4320)$ & $6952(4320)$ \\
\hline Stockholm, Sweden & $9091(5636)$ & $9463(5880)$ & $8767(5448)$ & $8973(5576)$ & $8973(5576)$ \\
\hline
\end{tabular}

${ }^{1}$ Fuel from the Austrian ASTRA, the Swiss SAPHIR, and the Danish DR-3 reactors are modeled as being shipped via either Bremerhaven or Hamburg.

All sea routes were obtained from "Distances Between Ports," (DMA, 1991), and use normal shipping lanes. The routes are used for the purpose of risk assessment and are not meant to describe the exact route of an actual shipment, which is subject to weather, changes in foreign port of departure, and other unpredictable influences. Other possible routes would traverse the same seas and oceans as the routes described here, and thus the affected environment generally would remain the same. 
Sea water is a complex solution containing the majority of the known elements. The average salinity of ocean water is about 35 parts per thousand. A significant feature of sea water is that while the total concentration of dissolved salt varies from place to place, the ratios of the more abundant components remain almost constant. This may be taken as evidence that over geologic time the oceans have become well mixed (Pickard, 1979).

Naturally occurring radionuclides such as uranium-234, uranium-235, uranium-238, and polonium-210 are present in seawater and in marine organisms at concentrations generally greater than their concentrations in terrestrial ecosystems. The ocean water concentrations of uranium isotopes are: U-234, 1.04-1.30 $\mathrm{pCi} / \mathrm{L}^{1}$; U-235, 0.04-0.07 $\mathrm{pCi} / \mathrm{L}$; and U-238, $0.9-1.13 \mathrm{pCi} / \mathrm{L}$ (Cherry, 1974). The total inventory of natural radioactivity in the oceans is approximately 500,000,000,000 curies (IAEA, 1976).

The high natural radionuclide levels make the ocean ecosystems the highest backgroundradiation domains in the biosphere (IAEA, 1976). Concentrations of polonium-210 have been measured in midwater crustaceans and fish from depths to $1500 \mathrm{~m}$. Unusually high levels were found in certain benthic organisms (deep sea-bottom dwellers). The doses received by organisms with high levels of polonium-210 are very large by human standards - up to approximately $400 \mathrm{rem} / \mathrm{yr}$ (Cherry, 1974).

The relationship between environmental concentrations of radionuclides and the concentration found in organisms is important in the study of food web effects. Bioamplification, the increase in concentration in organisms progressively further up the food web (as occurs with organic pesticides in terrestrial environments), is observed in marine food webs. In the marine environment, uranium has not been found to bioamplify in fish and only slightly bioamplifies in crustaceans and mollusks (IAEA, 1976). The readiness with which other constituents of spent nuclear fuel may enter the food web is variable, but generally low (USDOE, 1980).

The deep sea-bottom dwellers, or benthos, are highly diverse, with many taxonomic groups being represented there by more species than in most shallow-water communities (Hessler, 1967). However, the number of individual organisms in a given volume does decrease in the deep sea and this, together with a general tendency for the average size of the organisms also to decrease, results in a dramatic reduction in standing stock or biomass on the deep ocean floor. In round figures, the total wet weight of bottom-living organisms in and on each square meter of seabed decreases from 10-100 g on the continental shelf, to 1-10 $\mathrm{g}$ on the continental slope, and to only $0.1-1.0 \mathrm{~g}$ on the abyssal plain (Rice, 1978).

The continental shelf, averaging $65 \mathrm{~km}$ (40.3 miles) wide and less than $200 \mathrm{~m}(0.124$ miles) deep, has the greatest biomass concentration in the ocean and is where most fisheries are

\footnotetext{
${ }^{1}$ One picocurie $(\mathrm{Pci})=0.000000000001 \mathrm{Ci}$.
} 
located. The deep ocean is an average of four $\mathrm{km}$ (2.48 miles) deeper than the continental shelf (Pickard, 1979).

The biotic resources of the North Atlantic are generally described in an assessment of the transport of chemical munitions prepared by the Construction Engineering Resources Laboratory (CERL), U.S. Army Corps of Engineers (CERL, 1990). The reader is referred to that reference for additional descriptive information of the North Atlantic. Subsequent to that assessment, the National Oceanic and Atmospheric Administration proposed designation of critical habitat for the right whale (Eubalaena glacialis) (U.S. Federal Register, 1993). The regions considered by the National Oceanic and Atmospheric Administration include portions of Cape Cod Bay, Stellwagen Bank, and waters adjacent to Georgia and Florida. The latter designations include waters out to about fifteen nautical miles from shore from the Altamaha River, Georgia, to Jacksonville, Florida (approximately between 30 and 31 degrees north latitude), including waters off Fernandina Beach, Florida and out to about five nautical miles offshore at Sebastian Inlet, Florida (approximately between 28 and 30 degrees north latitude).

\subsection{Proposed United States Ports of Entry}

The following subsections describe the facilities and capabilities of the five proposed ports of entry. The information reflects the status of the facilities overseen by each appropriate port authority. No private marine terminals were considered for this assessment as private terminals are not typically available for commercial freight operations. This information is based on information from Frederick R. Harris, Inc., who conducted several port assessments for DOE (FHI, 1993a, 1993b, 1993c, 1993d, and 1993e) and the United States Army (MTMCTEA, 1992).

\subsubsection{Charleston, South Carolina}

\section{General Information}

The Port of Charleston, South Carolina, is one of the largest general cargo ports on the Atlantic Coast, handling up to 850,000 twenty foot containers or their equivalents per year including approximately 120 metric tons/yr (132 tons per year) of uranium products (JoC, 1992). The port is located near the confluence of the Cooper and Wando Rivers near the Atlantic Ocean and has four principal handling terminals under the control of the South Carolina State Ports Authority (SPA): Union Pier Terminal, Columbus Street Terminal, North Charleston Container Terminal, and Wando Marine Terminal. Wando Marine Terminal, a container-ship terminal, has been designated as a hazardous-material receiving terminal. The City of Charleston has a local ordinance prohibiting the movement of certain types of explosives and radioactive material through the city without proper authorizations (FHI, 1993a).

Two terminals, Columbus Street Intermodal Terminal and Union Pier Terminal, are near downtown Charleston, which is about seven miles from the open Atlantic. A 35-foot-deep by 
600 -foot-wide channel provides access to these facilities. This channel continues about eight miles up the Cooper River, at a minimum width of 600 feet, to the North Charleston Container Terminal.

Another major terminal, the Wando Container Terminal, is on the lower reach of the Wando River. It is about five miles northwest of the Columbus Street Intermodal Terminal. The 450-foot-wide and 35-foot-deep Wando River Channel branches off the Cooper River Channel south of Daniel Island and leads to the terminal.

Berths at the terminals are dredged on a two-year rotational basis. The channel has a tidal range from 4.3 feet to 6.5 feet. The channel going north to the North Charleston Container Terminal and the Wando Container Terminal flows under a pair of Cooper River bridges. The bridge over Town Creek has a clearance of 136 feet mean high water (MHW). The bridge over Hog Island Reach has a vertical clearance of 150 feet MHW.

The Columbus Street Intermodal Terminal has a 1,200-foot-wide turning basin. All the other terminals have 1,400-foot-wide turning basins. Charleston Harbor has four major anchorage areas. Charleston Harbor forms part of the route of the Atlantic Intracoastal Waterway. The waterway enters Charleston Harbor from the northeast through the Sullivan's Island Narrows. It continues southwestward from the harbor by way of Wappoo Creek.

\section{Highway Access}

The major highway to Charleston from the northwest is Interstate Route 26. Charleston is about 50 miles from Interstate Route 95, the major East Coast north-south artery. U.S. Route 17 connects Charleston with nearby coastal cities.

Wando Terminal is located near Mount Pleasant in Charleston County, South Carolina, eight $\mathrm{km}$ (five miles) east of Charleston proper. The closest residential dwellings are separated from the Wando Terminal by wetland buffer zones of between 0.4 to 4 sq. $\mathrm{km} \mathrm{(100}$ to 1000 acres) of varying width (down to 100 feet between the nearest house and the fence outside the terminal), but not less than approximately $300 \mathrm{~m}$ (300 yards) to the wharf area. The terminal is $8.1 \mathrm{~km}$ (five miles) from the Mark Clark Expressway (Interstate Route 526) via a direct access road (Long Point Road). Interstate Route 526 joins Interstate Route 26 several miles north of the Charleston city limits. Therefore, no highway travel from the Wando Terminal would pass through the City of Charleston.

\section{Rail Access}

Two railroads provide service to Charleston. Norfolk Southern Railway operates the Bennett Intermodal Terminal off Dorchester Road near Interstate 26. The rail net serving the port is in good condition. The Seaboard System Rail (CSX) operates Cooper Yard near the intersection of Meeting Street Extension and Spruill Avenue. CSX and Norfolk Southern 
Railway jointly own and operate Cosgrove Switching Yard. This yard has fifteen tracks and holds up to 350 cars.

The South Carolina Public Railway Commission provides track between switching yards and each of the terminals, except for the Wando Container Terminal. The commission also switches cars within the terminals. The Wando Container Terminal has no rail service.

\section{Equipment and Operations}

For all terminals, a seven-foot chain link fence topped with barbed wire encloses the terminal. The South Carolina State Police provide security guards and patrols. Also, an automated monitoring system provides additional security and fire detection. In cooperation with the local Fire Department, the SPA has established Standard Operating Procedures (SOPs) for hazardous material handling and emergency response procedures. The local fire department also conducts regular onsite training exercises. The SPA's Operation and Engineering Department controls berth and crane assignments, oversees facility maintenance, and implements SOPs. Although numerical data on container drops were not available, the Director of the SPA has stated that most have been due to faulty containers rather than mishandling (FHI, 1993a). The containers that would be used for the foreign research reactor spent fuel casks conform to the International Organization for Standardization requirements (ISO, 1990) and usually are specially reinforced. They also are inspected by the United States Coast Guard prior to being off-loaded. Thus, the likelihood of container failure during handling is lessened.

\subsubsection{Savannah, Georgia}

\section{General Information}

The Port of Savannah is on the Savannah River, about fifteen miles from the Atlantic Ocean. Its two main facilities, Ocean Terminal and Containerport/Garden City Terminal, are on the right bank of the river. Ocean Terminal is about four miles downstream from the Containerport/Garden City Terminal.

The deepwater entrance to the mouth of the Savannah River is across the ocean bar through Tybee Roads. At the ocean bar, the channel is 40 feet deep and 600 feet wide. From the ocean bar to the first turning basin, about one mile below Ocean Terminal, the channel is 38 feet deep and 500 feet wide. From the turning basin to the Containerport/Garden City Terminal, the channel is 38 feet deep and 400 feet wide. The mean tidal variation is about seven feet. Silting is a serious problem in the Savannah River. Dredging is carried out on a continuous basis. Floodgates and a sediment basin are also used in the Back River to reduce silt buildup in the main channel of the Savannah River. A fixed bridge (Talmadge Memorial Bridge) at the Ocean Terminal location used to restrict channel sailing headroom to a vertical clearance of 135 feet at MHW. This bridge has been replaced by a new structure that provides 175 feet of clearance. 
The Port of Savannah has had experience with shipments of irradiated nuclear materials in the past. ${ }^{2}$ The port handles about $9,800,000$ metric tons of cargo per year, of which about 100 metric tons were uranium products in 1992-93 (JoC, 1993). The city of Savannah requires written notice of spent nuclear fuel shipments. The largest of Savannah's port facilities is the 284-acre CONTAINERPORT, located within the Garden City Terminal. CONTAINERPORT offers 5,500 feet of docking space at six berths, as well as inside and outside storage dedicated solely to the specialized needs of high-speed container operations. The other main terminal is the 83 acre Ocean Terminal. It handles breakbulk and some container cargos.

\section{Highway Access}

The major highway access to the port is Interstate Route 16. That interstate highway continues to Macon, Georgia, where it joins Interstate Route 75 to Atlanta, Georgia. Just a few miles from Savannah, Interstate 16 joins Interstate Route 95, the major north-south corridor on the East Coast.

\section{Rail Access}

The Norfolk Southern Railway and CSX serve Savannah. The Savannah State Docks Railroad performs switching at the Containerport/Garden City Terminal. This terminal has a 600-car holding capacity. Ocean Terminal has no railcar holding capacity, although the adjacent Norfolk Southern Railway can hold 600 cars.

\section{Equipment and Operations}

The Garden City Terminal has a total of eleven berths (six for containers and five for liquid bulk, breakbulk, and drybulk). CONTAINERPORT has nine container cranes with capacities from 40 to 45 metric tons. Twenty-four hour security is provided by chain link fencing and the Georgia Port Authority Police. There is a 24-hour security and fire protection patrol. The municipal fire department is located adjacent to the main gate.

Ocean Terminal has 5,988 feet of marginal wharf and slip berths. It has a 175-ton gantry crane, one 100-ton gantry crane, two 50-ton gantry cranes, and a 40-ton container crane.

\subsubsection{Jacksonville, Florida}

\section{General Information}

The Port of Jacksonville, Florida is on the St. Johns River. The port has two main terminals, Blount Island Marine Terminal and Talleyrand Docks and Terminals. Blount Island Marine

\footnotetext{
2 The U.S. Department of Transportation Radioactive Materials Postnotification (RAMPOST) database has five records of Highway Route Controlled shipments being transported through the port of Savannah between November 1987 and August 1988.
} 
Terminal is eleven nautical miles from the river's mouth. Talleyrand Docks and Terminals is another eight nautical miles inland. The Atlantic Intracoastal Waterway crosses the St. Johns River about six miles downstream from Blount Island Marine Terminal. Access to the terminals is via a 400 - to 1,200 -foot-wide channel that has a depth of 38 feet at MLW. Although no turning basins exist, the channel width in front of the terminals is sufficient for a vessel to turn.

\section{Highway Access}

Interstate Route 10 from the west and Interstate Routes 95 and 295 and U.S. Route 17 from the north and south provide access to the Jacksonville area.

\section{Rail Access}

Three rail carriers provide rail service to Jacksonville: The CSX, Florida East Coast Railway, and Norfolk Southern Corporation (Southern Railway System). CSX provides rail service into the terminals (one track).

\section{Equipment and Operations}

Security at the Talleyrand Docks and Terminals consists of eight-foot-high perimeter fencing topped with barbed wire. Security guards monitor the gates and patrol the terminal 24 hours per day. Blount Island Marine Terminal does not have perimeter fencing. The highway and rail bridge restrict access. A guard station, on the island side of the highway bridge, controls access 24 hours per day.

Blount Island Terminal has 867 acres of paved, lighted and secured terminal area, and 360,000 square feet of warehouse space. The terminal is principally used for general cargo, containers, and automobiles. The container berthing space has five 40-ton capacity container cranes. In addition, there are two gantry whirly cranes with 100-ton and 50-ton working loads. The terminal also has a roll-on/roll-off ramp and an auto wharf.

Talleyrand Docks and Terminals has 173 acres of paved, lighted, and secured space, 120,000 square feet of warehouse space, and 40,000 feet of refrigerated warehousing. The terminal is principally used for steel, lumber, automobiles, coffee, paper, and frozen goods. The terminal has two 40-ton container cranes and one 100-ton multi-purpose, level luffing gantry whirly crane. The terminal is also equipped with tanker discharge facilities. 


\subsubsection{Sunny Point, North Carolina}

\section{General Information}

The Army's Military Ocean Terminal at Sunny Point (MOTSU), North Carolina is located on the west bank of the Cape Fear River about ten miles up river from the sea buoy. It is served by a 40 -foot-deep by 500 -foot-wide channel, with a depth of 34 feet at the MOTSU berths.

MOTSU is a defense transportation facility used to move military cargo into and out of the United States. The majority of the cargo is dry cargo, primarily ammunition. On average, 70 vessels per year call at Sunny Point and move approximately 433,000 metric tons of cargo through the port. The terminal is easily accessed from the Atlantic Ocean (in fact, vessels destined for Wilmington, North Carolina pass MOTSU) and has three large wharves which have the capability to off-load container vessels. The south wharf has a shore mounted crane capable of off-loading container vessels. Mobile cranes or ship's gear would be used if the other wharves are used. Since MOTSU was designed for handling ammunition, each pier has been designed and built so that an explosion at one wharf or at one of the holding areas would not cause a sympathetic detonation of explosives at another wharf. Therefore, MOTSU could safely unload spent nuclear fuel on one wharf without concern for an accident on another vessel impacting the spent fuel. It is important to note that there has never been an explosion accident at MOTSU. The spent fuel handling at Sunny Point would be scheduled during periods when there are no other vessels loading/unloading ammunition or explosives at any wharf at Sunny Point.

While no commercial liners regularly call at MOTSU, commercial vessels on charter to military agencies do routinely call at the port. The port's depth of 34 feet at mean low water would accommodate most commercial liners. The approximately ten nautical mile transit up the Cape Fear River from the sea buoy to MOTSU is mostly characterized by unpopulated marsh land, except for the town of Southport, North Carolina.

\section{Highway Access}

MOTSU can be accessed directly by State Route 87 from the northwest and State Route 133 from the north. Route 87 provides access to U.S. 17, which runs southwest to South Carolina or northeast into Wilmington, North Carolina. Route 133 runs north directly to U.S. 17 just outside Wilmington. From Wilmington, U.S. 74 runs west 75 miles to Interstate 95 , the nearest major north-south artery. Interstate 95 also is accessible via Interstate 40 , about 100 miles to the north.

\section{Rail Access}

MOTSU has a 97.4-mile dedicated railroad system which is owned and maintained by the United States Army, including an eighteen-mile access line connecting the terminal to the interchange yard at Leland, North Carolina. Commercial railcars are delivered to the 
interchange yard by the CSX Transportation Company. Army locomotives, operated by civil service crews, provide all rail services to move railcars from the terminal holding areas to the rail interchange in Leland. Other prominent features of the terminal rail system include the railcar inspection pit, which allows a person to visually inspect incoming/outgoing railcars on each side, on top and underneath, and the classification yard, where railcars are separated by load before being placed into rail holding yards. These yards, like truck and container holding pads throughout the terminal, are surrounded by earthen barricades as an added safety feature.

MOTSU maintains its rail lines in accordance with federal regulations (49 CFR Parts 200-399, Standards for Class 2 Railroads). All inspections and routine recurring maintenance are preformed under the supervision of United States Army-certified track inspectors in accordance with all Federal Railroad Administration criteria. Existing track is in compliance and is constantly monitored to ensure safe operations. All engineers are trained and licensed to United States Department of Defense standards and have frequent, unscheduled checks by the Federal Railroad Administration. Other train crew members undergo regular training, and the records are checked by the Federal Railroad Administration. Federal Railroad Administration representatives are also on board all trains taking spent nuclear fuel from the Carolina Power and Light Company to the CSX Transportation interchange at Leland (for movement to Raleigh).

\section{Equipment and Operations}

The terminal was designed with three 2,000-foot wharves, each with three berths. Operating facilities on all wharves include three parallel sets of rail tracks, a two-story operations building, two smoke houses, water and public address systems, firefighting and safety support equipment. No smoking rules are rigidly enforced throughout the operational/restricted area. In these areas, smoking is allowed only in specific buildings equipped with electric lighters.

Original design of the south wharf was modified to more efficiently accommodate container handling. Berth 1 has two 50-ton rail mounted Pacebo container cranes. Berth 3 has been modified with a 100-foot wide, reinforced concrete apron. These modifications of berth 3 allow either breakbulk or container cargo handling, using mobile container cranes, or roll on/roll off operations to meet full mobilization mission requirements.

Under a contractual partnership, the MOTSU rail system provides movement of essential goods for three local industries: Archer-Daniels-Midland, Colorado; Carolina Power and Light Company and Cogentrix, Inc. Carolina Power and Light Company uses the MOTSU rail line to ship spent fuel from its Brunswick Nuclear Power Plant.

MOTSU also has a dedicated patrol boat for security purposes. Stevedoring services at the port are privately obtained and all cargo handling activities, including explosive cargo, are performed by members of the International Longshoremen Association. 


\subsubsection{Wilmington, North Carolina}

\section{General Information}

The Port of Wilmington is on the east bank of the Cape Fear River, about three miles south of the junction of the Cape Fear and Northeast Cape Fear Rivers. It is 25 miles from the sea and 17 miles north of MOTSU. Access to the port from the Atlantic Ocean is via a 40-foot-deep and 500-foot-wide channel. From Southport, North Carolina, to the anchorage basin at the Port of Wilmington, the channel is 400 feet wide and 38 feet deep. The anchorage basin is about 2,000 feet long, 38 feet deep, and from 1,000 to 1,200 feet wide. Good anchorage is also available downstream in the Southport area of the river. Both anchorages are suitable for instream loading operations. A 38-foot-deep, 1,200-foot-long, and 800-foot-wide turning basin lies off the north end of the terminal. The basin extends to 1,350 feet, with a depth of 35 feet, beyond the 1,200-foot limits. The mean tidal range at the Port of Wilmington is 4.2 feet, with tidal currents averaging 1.7 knots at floodtide, and 1.5 knots at ebbtide. The port maintains a continuous water depth monitoring program and dredges as necessary. No bridges cross the Cape Fear River downstream of the terminal. However, a power cable crosses the river about 2-1/2 miles south of the port, restricting sailing headroom to 175 feet, 6 inches above MHW.

The Port of Wilmington is a general cargo and bulk port which handles approximately 2.3 million metric tons ( 2.5 million tons) of cargo annually. Its volume of containerized cargo is relatively modest with an annual volume of 110,000 twenty foot equivalent units (TEU's) or 670,000 metric tons ( 750,000 tons) which represents approximately 30 percent of total tonnage (FHI, 1993d). No record of recent radioactive material shipments was found (JoC, 1993), but in the 1980's there were shipments of spent fuel through the Port of Wilmington, according to records in the USDOT RAMPOST database.

The port has one central cargo handling facility which is located on the east bank of the Cape Fear River, $42 \mathrm{~km}$ (26 miles) from the open ocean. The channel can accommodate ships up to $290 \mathrm{~m}$ (950 feet) in length and traffic through the river has been estimated by port personnel at approximately 500 ships per year (not including barge traffic).

\section{Highway Access}

The main highways into the City of Wilmington are Interstate Route 40 to the north, U.S. Route 17 from the north and south, U.S. Route 421 from the north, and U.S. Routes 74 and 76 from the west. Interstate Route 95, the nearest major north-south artery, is about 75 miles to the west via U.S. 74, and approximately 100 to the north via Interstate Route 40.

The intersection of the main highways into the City of Wilmington is about 1.5 miles north of the port. From this intersection, traffic usually takes Front Street and Burnett Boulevard to the port entrances. 


\section{Rail Access}

The CSX serves the Port of Wilmington with one rail line. The Davisville Yard at Navassa, about 25 miles west of the port, is the nearest classification yard.

\section{Equipment and Operations}

The perimeter of the terminal is secured with a two meter (six foot) high chain link fence topped with barbed wire. The two entrance facilities to the port terminal have manned security booths which control vehicle access and egress. A seventeen-man port police force provides overall site security 24 hours a day.

The port facilities, which are administered and operated by the North Carolina State Ports Authority (NCSPA), total 1.1 developed sq. $\mathrm{m}$ (280 developed acres), have $2100 \mathrm{~m}$ (7,000 feet) of berthing space and over $0.3 \mathrm{sq} . \mathrm{km}$ ( 75 acres) of open paved container storage area. The NCSPA exercises a high degree of control over the day-to-day operations of the port facilities. The NCSPA provides management and supervision of the terminal and its operations, including vessel berthing, crane assignment, yard and gate operations, equipment and facility maintenance.

Five container cranes are available at the port terminal. Three of the cranes, which have a 40 metric ton (44 ton) capacity, have a 32 foot rail gauge and serve approximately $1000 \mathrm{~m}$ $(3,300$ feet) of the container berthing area. The other two cranes, which have a 50 metric ton ( 56 ton) capacity, have a rail gauge of $15 \mathrm{~m}$ ( 50 feet) and serve only $270 \mathrm{~m}$ (900 feet) of the container berthing area. The 50 metric ton crane is adequate and suitable for offloading of spent fuel.

\subsection{Highway Corridors}

Any potential environmental impacts along the various highway corridors would depend upon which of the five proposed ports, singly or in combination, would be used to receive the spent fuel shipments. As shown in Table 5-2, the representative highway distances from these ports and the Savannah River Site range from $355 \mathrm{~km}$ (221 miles) for Charleston, South Carolina, to $710 \mathrm{~km}$ (441 miles) for Sunny Point, North Carolina. Although the proposed shipments would be routed on major traffic routes whenever practical, at some point all these routes would pass through urban, suburban, and rural areas. Table 5-2 also lists the total population estimates for a representative route from each proposed port to the Savannah River Site. Methodologies used to identify these routes, characterize general corridor land uses, and quantify populations that might be affected are described in Appendix E. 
Table 5-2. Representative Highway Distances from U.S. Ports of Entry to the Savannah River Site

\begin{tabular}{|c|c|c|}
\hline Proposed Ports & $\begin{array}{c}\text { Highway } \\
\text { Distance } \\
\mathrm{km} \text { (miles) }\end{array}$ & $\begin{array}{c}\text { Total Route } \\
\text { Population }\end{array}$ \\
\hline Charleston & $355(221)$ & 139,400 \\
\hline Savannah & $429(267)$ & 54,900 \\
\hline Jacksonville & $624(388)$ & 60,100 \\
\hline Wilmington & $642(399)$ & 117,100 \\
\hline Sunny Point & $710(441)$ & 131,400 \\
\hline
\end{tabular}

\subsection{Savannah River Site}

\subsubsection{General Site Description}

The Savannah River Site occupies an area of approximately 800 sq. km $(198,737$ acres) in Aiken, Barnwell, and Allendale counties in southwestern South Carolina (Figure 5-1). The site is approximately $40 \mathrm{~km}$ (25 miles) southeast of Augusta, Georgia, and $32 \mathrm{~km}$ (20 miles) south of Aiken, South Carolina. Savannah River Site facilities include five inactive nuclear production reactors, an inactive nuclear fuel and target fabrication facility, two chemical separation facilities, tritium facilities, waste management facilities, and administration facilities. Public access to the Savannah River Site is restricted to state and Federal highways that border and traverse the site. The entire Savannah River Site boundary is fenced with the exception of the bank of the Savannah River, which forms the site's western boundary for approximately $27 \mathrm{~km}$ (17 miles). Detailed site information on the Savannah River Site and its physical and environmental characteristics can be obtained from the Final Environmental Impact Statement for Continued Operation of $K$-, L-, and P-Reactors (USDOE, 1990). In addition, the Savannah River Site Environmental Report for 1992 (WSRC, 1993) provides an overview of site operations and describes the findings of site environmental monitoring and research programs.

\subsubsection{Description of the Receiving Basin for Offsite Fuels}

The Receiving Basin for Offsite Fuels (RBOF) performs a number of processes, utilities, and services. Building 244-H contains the RBOF facility, and Building $245-\mathrm{H}$ contains the adjoining Resin Regeneration Facility, which is considered an integral part of the RBOF facility. RBOF is a versatile facility with provisions for the receipt and storage of irradiated nuclear fuel elements from offsite reactors and from Savannah River Site reactors. Casks containing spent fuel elements can be delivered to the RBOF facility either by truck or rail 
Figure 5-1. Location of the Savannah River Site

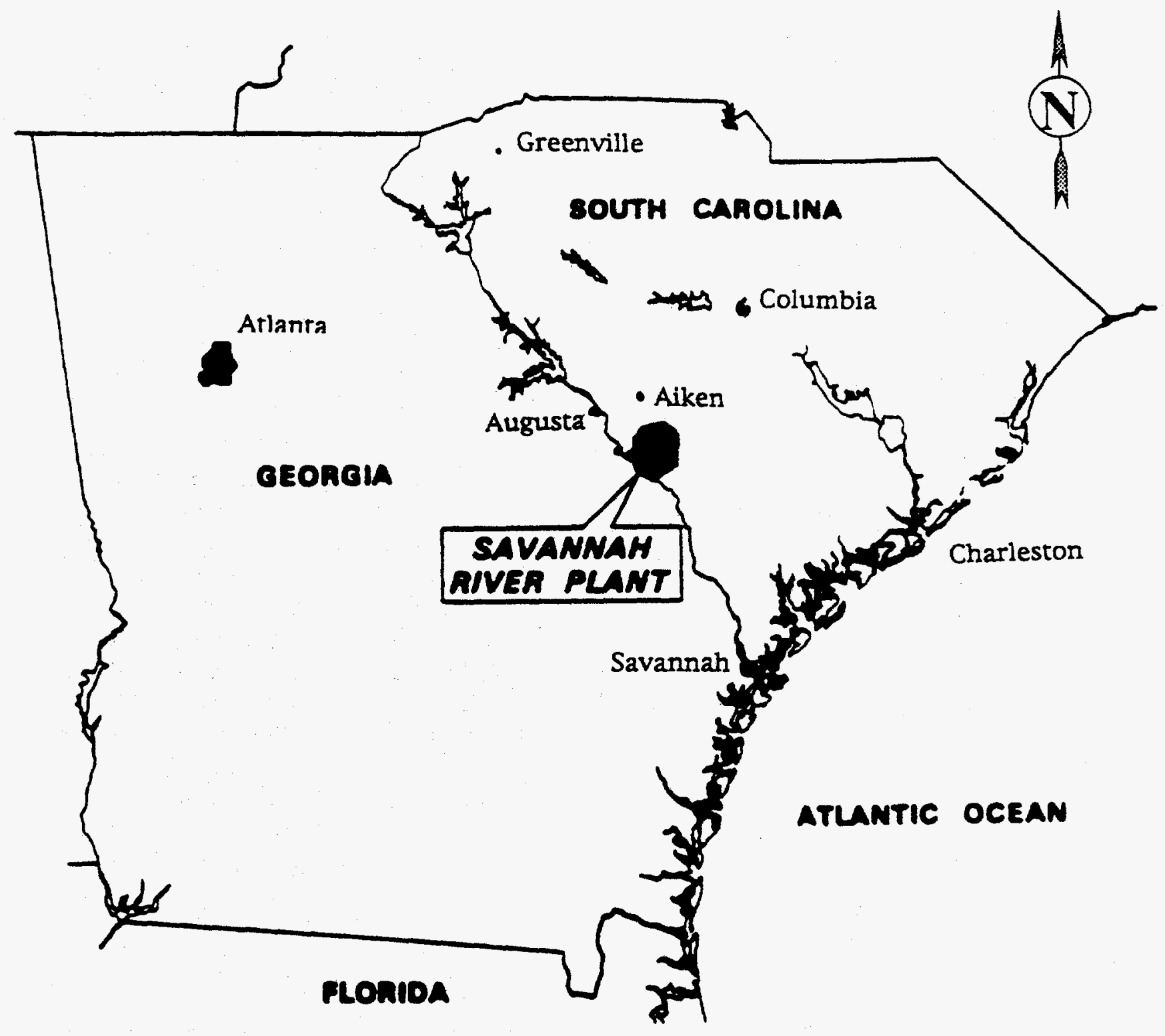


car. The RBOF facility provides the capability for underwater unloading of shipping casks and the handling and storage of the fuel elements. Unloading of casks at RBOF is performed via overhead cranes and movement of the fuel within RBOF is performed via the monorail system that is manually controlled by trained RBOF personnel. Radiation shielding is provided by the water over the fuel.

$\mathrm{RBOF}$ is organized into areas for row storage, tube storage, bundle storage and bucket storage. Research reactor spent fuel is typically located in row storage. The number of fuel elements that can fit into a particular row depends on the size, configuration, and reactivity of the fuel elements. Criticality evaluations are performed to analyze the spacing required between fuel elements. Some fuels may not be stored adjacent to other fuels due to criticality concerns, resulting in empty spaces that cannot be utilized. In April 1993, it was determined that RBOF had the capacity to accept up to 757 additional spent fuel elements in row storage. This estimate was based on nuclear criticality spacing evaluations of the arrangement of fuel elements stored in RBOF at that time. However, as the result of recent criticality evaluations performed on repositioning certain fuels, as described below, the available capacity of the RBOF soon will increase to approximately 1,400 spaces.

Fuel in the RBOF is periodically repositioned in order to make the most efficient use of the facility. The most recent repositioning began in February 1994 and involved the Experimental Breeder Reactor II (EBR II) and Taiwan Research Reactor (TRR) fuels. The purpose of this repositioning was to provide additional space for Missouri University Research Reactor (MURR) fuel, which is larger in diameter than typical university and foreign research reactor fuel received at RBOF. New criticality evaluations (Nuclear Safety Data Sheet 209 Rev. 1 and 215 Rev. 5) principally performed for this repositioning indicate that the EBR II fuel may be stored adjacent to specific fuels, thereby eliminating the need for empty criticality rows and resulting in the availability of additional space. No physical modification of the facility's structure, including the addition of new racks, was required. The Savannah River Site will continue consolidating and repositioning fuels as part of normal facility operations.

Since the number of foreign fuel elements in the proposed action is limited to 409 elements, the continued consolidation and repositioning of fuels in RBOF associated with the domestic receipts from DOE and university research reactors will support the storage of the domestic shipments regardless of the proposed action. The proposed action would increase cask receipts at RBOF by fifteen casks over an approximate two-year period through December 1995. During this same time period, it is expected that domestic research reactor shipments would generate up to two receipts each month. The RBOF facility would require additional staffing to accommodate the increased receipts. In the event multiple casks would be received in one foreign fuel shipment (e.g., up to eight casks on a chartered or dedicated vessel), the casks that could not be unloaded immediately would be placed in temporary storage at RBOF or at the Savannah River Site Railroad Classification Yard, if shipped by rail. 
Routine operations at RBOF related to the storage of offsite research reactor spent fuel include shipping cask receipt, fuel unloading, inspection, fuel transfer, possible fuel element cutting, fuel storage, and ancillary operations. At the time of receipt, each shipping cask is visually inspected by trained personnel to ensure that it has not been damaged. In addition, a survey for radiological contamination is performed and the results are compared with shipping papers. Prior to returning an empty cask, a radiological survey is performed to ensure that the cask meets all U.S. Department of Transportation transport limits. Certain projecting hardware on a fuel element and excess aluminum metal (but not the fuel matrix itself) may be cut to facilitate accommodation in storage racks in the basin. Routine water quality monitoring and visual inspections are performed by RBOF personnel to detect failed fuel elements. (The RBOF facility has the capacity to repackage failed fuel elements for safe storage, although the proposed acceptance of 409 spent fuel elements involves intact fuel.) Ancillary operations include basin water purification and resin regeneration. Basin water purification is performed through a filter-deionizer system at RBOF which removes the impurities and radioactivity from the basin water. The ion exchange resins employed in this filter-deionizer system are regenerated through a chemical process within the RBOF Resin Regeneration Facility so that the resins can be reused.

The overall physical condition of RBOF is considered good. The Spent Fuel Working Group Report, issued by DOE in November 1993, provides an itemized inventory of reactor irradiated nuclear materials within the DOE complex and provides an initial assessment of the environmental, safety, and health vulnerabilities associated with the current storage and handling of these materials. The report notes that RBOF is "...an example of the successful operation of an older wet facility (vintage 1963) that stores reactor irradiated nuclear materials for extended periods." (USDOE-EH, 1993) (Volume I). The report goes on to say that "overall quality of design and facility management have ensured safe storage of aluminum-clad [reactor irradiated nuclear materials] in the basin for over 10 years." The report also notes that $\mathrm{RBOF}$ maintains excellent water quality, leading to a good storage environment for aluminum clad spent fuel for extended periods. Although some fuels have been stored in RBOF for up to 30 years, they show no visible signs of corrosion.

Issues identified in the November 1993 report related to RBOF include seismic evaluations, accidents involving "tornado missile" (objects picked up by high winds) projectiles, the lack of an updated safety analysis report, the lack of basin leakage detection systems, and enhanced training for personnel. Most of these issues had previously been identified, and measures to address them already are in place. Issues concerning seismic evaluations, tornado missile projectiles, and safety analysis are being addressed in a new safety analysis report and related technical evaluations that are being prepared for RBOF. The facility has an existing, approved safety analysis report that considers the accident consequences of seismic and tornado events. Any operational changes or new activities proposed for RBOF would have to undergo a technical review to ensure that their potential impacts are within those considered in existing safety documentation. Measures to address the lack of a basin leakage detection system currently are being evaluated. However, the Savannah River Site continues to monitor the groundwater in the RBOF area, as well as site-wide, and to monitor the water losses of 
$\mathrm{RBOF}$ for evaporation trending. Modifications to ongoing qualification and training programs have been made to address issues identified in the November 1993 report.

A concern was raised during the public comment period that certain Type B casks previously used in shipment of Taiwan research reactor spent fuel may have "leaked" during shipment to Savannah River Site. DOE believes that this concern was caused by an instance where a small amount of radioactive contamination was found on the surface of two casks used in the Taiwan shipments while performing radiological surveys prior to unloading the fuel at RBOF. The manner in which such surface contaminations can occur is explained below.

When casks used to transport spent fuel are loaded or unloaded, they are often lowered into the water-filled pools in which the spent fuel is stored, or into transfer pools similar to the storage pools. The radioactivity from the spent fuel storage pools is primarily caused by small particles which are exposed to or entrained in the pool water. These particles may be agitated by movement of the cask and spent fuel during the cask loading or unloading operation, and can adhere to the surface of the cask.

The casks are routinely decontaminated to levels of contamination below DOT mandated limits upon being removed from the pool (i.e., washed to remove radioactive particles adhering to their outer surfaces). However, some of the radioactive particles are so small that they can become imbedded in microscopic pores in the surface of a shipping cask. Such imbedded contamination cannot be detected since its presence is masked by the much larger radiation field of the spent fuel inside the cask. During transportation, minute amounts of this imbedded contamination can migrate to the surface of the cask. Receiving organizations routinely check for such contamination by wiping the surface of the cask with a clean cloth and measuring the cloth for contamination after it is moved away from the cask. Any transferrable surface contamination detected that is above the DOT limits is then removed from the cask. As a consequence of this phenomenon, the DOT regulations specify that the contamination limits for casks are ten times lower at the point from which the shipment is initiated than the limits applicable at the point of destination. If radioactive particles migrate to the cask surface, they can contaminate other surfaces with which they come into contact. This may have been the origin of the contamination found on a trailer used to transport Taiwan spent fuel. After detecting this surface contamination, both the cask and the trailer were cleaned to below DOT limits.

In the case of the Taiwan research reactor spent fuel, twelve shipments were received by the Savannah River Site, involving over one hundred cask receipts. Available records indicate that two casks had transferrable contamination levels that exceeded the DOT receipt limits. In those two instances, the transferrable contamination levels were 8,000 disintegrations per minute (dpm) per 100 square centimeter (beta-gamma) above the 22,000 dpm DOT limit. No transferrable alpha radiation above the DOT-limits was detected. Such events are bounded by the normal transportation impact analysis included in Chapter 6 of this Environmental Assessment. 


\subsubsection{Radiation Levels in the Affected Environment at the Savannah River Site}

A person residing in the Central Savannah River Area within 80 kilometers (50 miles) of the Savannah River Site receives an average annual radiation dose of approximately $380 \mathrm{mrem}$ from all sources. ${ }^{3}$ Major sources of natural radiation exposure include short-lived decay products of radon ( $200 \mathrm{mrem})$, terrestrial radiation such as $\mathrm{K}-40$ (43 mrem), internal radiation due to assimilation of radionuclides into the body ( $39 \mathrm{mrem}$ ), and cosmic radiation ( 33 mrem). Significant sources of man-made radiation include consumer products $(10 \mathrm{mrem})$ and medical x-rays/nuclear medicine ( $53 \mathrm{mrem})$. The Savannah River Site contributes less than one mrem (less than one percent) to the total radiation dose. The Savannah River Site Environmental Report for 1992 (WSRC, 1993) contains additional information regarding radiation levels in the Central Savannah River Area.

\footnotetext{
${ }^{3}$ This compares to a national average annual radiation dose of approximately 360 mrem from all sources.
} 


\subsection{ENVIRONMENTAL IMPACT ANALYSIS}

This Environmental Assessment considers the potential environmental impacts associated with the transportation of foreign research reactor spent fuel to the Savannah River Site, South Carolina, for storage. Shipment of spent fuel, from a total of eleven reactors in nine countries (eight in Europe and Australia), was analyzed. The primary focus of the analysis, however, was on the proposed action, which is acceptance of up to 409 spent fuel elements from eight reactors in Europe.

The environmental impact analysis examines the following for both routine and accident conditions:

a. impacts while transporting spent nuclear fuel by ship (port departure, ocean crossing, and port arrival),

b. impacts at the proposed and alternate ports of entry into the United States, including possible intermediate port stops and short-term lag storage of spent fuel at the delivery port(s),

c. impacts of overland transport of spent fuel to the Savannah River Site, and

d. impacts from spent fuel storage at the Savannah River Site.

Radiological (i.e., impacts from potential exposure to radioactivity) and nonradiological impacts (i.e., nonradiological accidents involving trucks or trains moving spent fuel to the Savannah River Site) are estimated. Potentially affected groups of people would include ship crews, dock workers, inspectors, truck crews, Savannah River Site workers, and members of the general public.

There is considerable international experience in shipping spent fuel by sea and land. Since the early 1960's, more than 480 shipments of foreign research reactor spent fuel have entered United States ports with subsequent land transportation to a DOE facility. The majority of these shipments have come through the Port of Hampton Roads, Virginia, and were shipped by truck to either the Savannah River Site or the Idaho National Engineering Laboratory (INEL). There have been no accidents resulting in any radioactive releases for these or any other spent fuel shipments.

Section 6.1 describes the potential impacts of the proposed action. Section 6.2 describes the potential impacts of alternatives to the proposed action. Section 6.3 describes cumulative impacts - the effects of impacts from the proposed action when added to past, present and reasonably foreseeable future actions. Before Section 6.1 begins, the following several paragraphs describe radiation exposure terminology and methods used to calculate transportation risks discussed in this chapter. 
Potential radiological impacts are measured by estimating the highest radiation exposure any single person might receive, as well as the collective exposure of a particular population (e.g., all those living in the vicinity of a port). Two primary units of radiation measurement are used in this Environmental Assessment to estimate these impacts, the rem and person-rem. The rem (Roentgen equivalent man) is a measure of radiation damage to biological tissue. Specifically, it is the amount of damage done when 1 gram of biological tissue absorbs 100 ergs of x-ray (or gamma-ray) energy. Absorbed radiation energy is measured directly in rad (radiation absorbed dose); one rad is the absorption of 100 ergs of energy by 1 gram of absorbing substance. Thus, one rem is the biological damage done when one rad of $x$-ray or gamma rays is absorbed. Rems and rads are quite large, so radiation doses are usually measured in millirems (mrem, or $1 / 1000$ of a rem) or millirads (mrad, or 1/1000 of a rad). The concept of dose equivalent accounts for the different amounts of biological damage done by different types of ionizing radiation (alpha, gamma, etc.). The ratio of dose equivalent (rem or mrem) to absorbed energy (rad or mrad) is called the quality factor (QF). For gamma radiation and $\mathrm{x}$-rays, the $\mathrm{QF}$ is one, and the dose equivalent in mrem is equal to the dose in mrad.

An individual may be exposed to ionizing radiation externally, from a radioactive source outside the body, and/or internally, from eating or inhaling radioactive material. The external dose is different from the internal dose. In calculation of an external dose equivalent, one may assume that the effect of the dose is distributed uniformly over the body. However, when radionuclides are deposited in various body tissues and organs, the exposure and effects are not uniform. A few organs in the body may receive a large dose; others may receive none. The effective dose equivalent (EDE) is the sum of the tissue or organ weighted dose equivalents for all irradiated tissues and organs.

An external dose equivalent is delivered only during the actual time of exposure to the external radiation source. An internal dose equivalent, however, continues to be delivered as long as the radioactive source is in the body, although both radioactive decay and elimination of the radionuclide by ordinary metabolic processes decrease the dose with the passage of time. The dose equivalent for internal exposure is calculated for 50 years following the initial exposure, and the result is expressed as the committed effective dose equivalent (CEDE).

In this study, dose equivalents from incident-free transportation and CEDE risks from transportation accidents are the basis for calculated health effects. For brevity, however, they are referred to as "doses" and "dose risks."

The maximum annual allowable radiation exposure established by DOE, as well as the Nuclear Regulatory Commission, to protect individual members of the general public is 100 mrem (DOE Order 5400.5, 1990). It is estimated that the average individual in the United States receives a dose of about 360 mrem per year from all sources, including natural and medical sources of radiation (NAS, 1990). For perspective, a modern chest X-ray results in an approximate dose of $8 \mathrm{mrem}$, while a diagnostic hip X-ray results in an approximate dose of 83 mrem (Shleien, 1992). For further perspective, an individual must receive an acute 
exposure of approximately $600 \mathrm{rem}(600,000 \mathrm{mrem})$ before there is a high probability of near term death (NAS, 1990).

Radiation exposure to a population or a group of persons is measured in person-rem. The total population exposure - all the person-rems - is derived by adding up all the individual doses in the exposed group. This measurement is particularly important when trying to take into account the potential impacts of very small doses on very large populations (e.g., all those living along the truck route).

Health effects may be calculated from doses by multiplying the dose by an appropriate conversion factor, known as a risk factor. This risk factor has the dimensions of health effect per unit dose per person and may include a time factor. The National Academy of Sciences study on the biological effects of ionizing radiation (NAS, 1990) includes a number of examples of such risk factors. These risk factors have been developed from epidemiological studies of health effects in populations exposed to ionizing radiation, primarily the Atomic Bomb Survivors Life Study (NAS, 1990) and occupational exposures, and therefore include considerable uncertainties.

Using such a conversion factor, the estimated exposures can be converted into estimated numbers of health effects. Because the exposures predicted in this study are far below those known to cause immediate illness or fatality, only delayed health effects are estimated. A delayed effect is measured in latent cancer fatalities (LCFs), which is defined as a fatal malignancy that may occur after ten years or more, and has a probability of occurrence that increases with exposure. The conversion factor used in this Environmental Assessment is 0.0005 LCFs/person-rem (United States Federal Register, 1991). This same source recommends a slightly lower conversion factor (0.0004 LCFs/person-rem) for worker populations. Worker groups tend to be healthy adults and do not represent as broad a spectrum of susceptible people (e.g., children) as does the general population. However, for ease of comparison of risks across all population groups, the same conversion factor $(0.0005$ LCFs/person-rem) was used for both workers and the general public. The difference between the two conversion factors is very small when considered within the context of the uncertainties of the dose estimates. Use of the $0.0005 \mathrm{LCF}$ /person-rem value for all persons potentially exposed results in a conservative estimate of the potential number of latent cancer fatalities. Applying the conversion factor to a general population, a collective dose of 2,000 person-rem is estimated to result in one additional latent cancer fatality.

Genetic effects in subsequent generations are another type of health effect that may occur as a result of low level radiation exposure such as that associated with the proposed action in this Environmental Assessment. The conversion factor is smaller, and the uncertainty is greater than for latent cancer fatalities. The International Committee on Radiation Protection (ICRP) has recommended a conversion factor about five times lower than that used to estimate cancer fatalities (ICRP, 1991). For comparison with the latter, one can state that in a general population, a collective dose of 10,000 person-rem is estimated to result in one additional genetic effect in all subsequent generations.

For fish, birds, plant life, and other biota, the radiation dose received by the organism is expressed simply in the term of rads. The effects of radiation on non-humans are expressed 
exposure of approximately $600 \mathrm{rem}(600,000 \mathrm{mrem})$ before there is a high probability of near term death (NAS, 1990).

Radiation exposure to a population or a group of persons is measured in person-rem. The total population exposure - all the person-rems - is derived by adding up all the individual doses in the exposed group. This measurement is particularly important when trying to take into account the potential impacts of very small doses on very large populations (e.g., all those living along the truck route).

Health effects may be calculated from doses by multiplying the dose by an appropriate conversion factor, known as a risk factor. This risk factor has the dimensions of health effect per unit dose per person and may include a time factor. The National Academy of Sciences study on the biological effects of ionizing radiation (NAS, 1990) includes a number of examples of such risk factors. These risk factors have been developed from epidemiological studies of health effects in populations exposed to ionizing radiation, primarily the Atomic Bomb Survivors Life Study (NAS, 1990) and occupational exposures, and therefore include considerable uncertainties.

Using such a conversion factor, the estimated exposures can be converted into estimated numbers of health effects. Because the exposures predicted in this study are far below those known to cause immediate illness or fatality, only delayed health effects are estimated. A delayed effect is measured in latent cancer fatalities (LCFs), which is defined as a fatal malignancy that may occur after ten years or more, and has a probability of occurrence that increases with exposure. The conversion factor used in this Environmental Assessment is 0.0005 LCFs/person-rem (United States Federal Register, 1991). This same source recommends a slightly lower conversion factor (0.0004 LCFs/person-rem) for worker populations. Worker groups tend to be healthy adults and do not represent as broad a spectrum of susceptible people (e.g., children) as does the general population. However, for ease of comparison of risks across all population groups, the same conversion factor $(0.0005$ LCFs/person-rem) was used for both workers and the general public. The difference between the two conversion factors is very small when considered within the context of the uncertainties of the dose estimates. Use of the $0.0005 \mathrm{LCF}$ /person-rem value for all persons potentially exposed results in a conservative estimate of the potential number of latent cancer fatalities. Applying the conversion factor to a general population, a collective dose of 2,000 person-rem is estimated to result in one additional latent cancer fatality.

Genetic effects in subsequent generations are another type of health effect that may occur as a result of low level radiation exposure such as that associated with the proposed action in this Environmental Assessment. The conversion factor is smaller, and the uncertainty is greater than for latent cancer fatalities. The International Committee on Radiation Protection (ICRP) has recommended a conversion factor about five times lower than that used to estimate cancer fatalities (ICRP, 1991). For comparison with the latter, one can state that in a general population, a collective dose of 10,000 person-rem is estimated to result in one additional genetic effect in all subsequent generations.

For fish, birds, plant life, and other biota, the radiation dose received by the organism is expressed simply in the term of rads. The effects of radiation on non-humans are expressed 
exposure of approximately $600 \mathrm{rem}(600,000 \mathrm{mrem})$ before there is a high probability of near term death (NAS, 1990).

Radiation exposure to a population or a group of persons is measured in person-rem. The total population exposure - all the person-rems - is derived by adding up all the individual doses in the exposed group. This measurement is particularly important when trying to take into account the potential impacts of very small doses on very large populations (e.g., all those living along the truck route).

Health effects may be calculated from doses by multiplying the dose by an appropriate conversion factor, known as a risk factor. This risk factor has the dimensions of health effect per unit dose per person and may include a time factor. The National Academy of Sciences study on the biological effects of ionizing radiation (NAS, 1990) includes a number of examples of such risk factors. These risk factors have been developed from epidemiological studies of health effects in populations exposed to ionizing radiation, primarily the Atomic Bomb Survivors Life Study (NAS, 1990) and occupational exposures, and therefore include considerable uncertainties.

Using such a conversion factor, the estimated exposures can be converted into estimated numbers of health effects. Because the exposures predicted in this study are far below those known to cause immediate illness or fatality, only delayed health effects are estimated. A delayed effect is measured in latent cancer fatalities (LCFs), which is defined as a fatal malignancy that may occur after ten years or more, and has a probability of occurrence that increases with exposure. The conversion factor used in this Environmental Assessment is 0.0005 LCFs/person-rem (United States Federal Register, 1991). This same source recommends a slightly lower conversion factor (0.0004 LCFs/person-rem) for worker populations. Worker groups tend to be healthy adults and do not represent as broad a spectrum of susceptible people (e.g., children) as does the general population. However, for ease of comparison of risks across all population groups, the same conversion factor $(0.0005$ LCFs/person-rem) was used for both workers and the general public. The difference between the two conversion factors is very small when considered within the context of the uncertainties of the dose estimates. Use of the $0.0005 \mathrm{LCF}$ /person-rem value for all persons potentially exposed results in a conservative estimate of the potential number of latent cancer fatalities. Applying the conversion factor to a general population, a collective dose of 2,000 person-rem is estimated to result in one additional latent cancer fatality.

Genetic effects in subsequent generations are another type of health effect that may occur as a result of low level radiation exposure such as that associated with the proposed action in this Environmental Assessment. The conversion factor is smaller, and the uncertainty is greater than for latent cancer fatalities. The International Committee on Radiation Protection (ICRP) has recommended a conversion factor about five times lower than that used to estimate cancer fatalities (ICRP, 1991). For comparison with the latter, one can state that in a general population, a collective dose of 10,000 person-rem is estimated to result in one additional genetic effect in all subsequent generations.

For fish, birds, plant life, and other biota, the radiation dose received by the organism is expressed simply in the term of rads. The effects of radiation on non-humans are expressed 
exposure of approximately $600 \mathrm{rem}(600,000 \mathrm{mrem})$ before there is a high probability of near term death (NAS, 1990).

Radiation exposure to a population or a group of persons is measured in person-rem. The total population exposure - all the person-rems - is derived by adding up all the individual doses in the exposed group. This measurement is particularly important when trying to take into account the potential impacts of very small doses on very large populations (e.g., all those living along the truck route).

Health effects may be calculated from doses by multiplying the dose by an appropriate conversion factor, known as a risk factor. This risk factor has the dimensions of health effect per unit dose per person and may include a time factor. The National Academy of Sciences study on the biological effects of ionizing radiation (NAS, 1990) includes a number of examples of such risk factors. These risk factors have been developed from epidemiological studies of health effects in populations exposed to ionizing radiation, primarily the Atomic Bomb Survivors Life Study (NAS, 1990) and occupational exposures, and therefore include considerable uncertainties.

Using such a conversion factor, the estimated exposures can be converted into estimated numbers of health effects. Because the exposures predicted in this study are far below those known to cause immediate illness or fatality, only delayed health effects are estimated. A delayed effect is measured in latent cancer fatalities (LCFs), which is defined as a fatal malignancy that may occur after ten years or more, and has a probability of occurrence that increases with exposure. The conversion factor used in this Environmental Assessment is 0.0005 LCFs/person-rem (United States Federal Register, 1991). This same source recommends a slightly lower conversion factor (0.0004 LCFs/person-rem) for worker populations. Worker groups tend to be healthy adults and do not represent as broad a spectrum of susceptible people (e.g., children) as does the general population. However, for ease of comparison of risks across all population groups, the same conversion factor $(0.0005$ LCFs/person-rem) was used for both workers and the general public. The difference between the two conversion factors is very small when considered within the context of the uncertainties of the dose estimates. Use of the $0.0005 \mathrm{LCF}$ /person-rem value for all persons potentially exposed results in a conservative estimate of the potential number of latent cancer fatalities. Applying the conversion factor to a general population, a collective dose of 2,000 person-rem is estimated to result in one additional latent cancer fatality.

Genetic effects in subsequent generations are another type of health effect that may occur as a result of low level radiation exposure such as that associated with the proposed action in this Environmental Assessment. The conversion factor is smaller, and the uncertainty is greater than for latent cancer fatalities. The International Committee on Radiation Protection (ICRP) has recommended a conversion factor about five times lower than that used to estimate cancer fatalities (ICRP, 1991). For comparison with the latter, one can state that in a general population, a collective dose of 10,000 person-rem is estimated to result in one additional genetic effect in all subsequent generations.

For fish, birds, plant life, and other biota, the radiation dose received by the organism is expressed simply in the term of rads. The effects of radiation on non-humans are expressed 
in terms of rads because plants and animals rarely live long enough to develop cancer or other long-latency health effects.

\section{General transportation modeling}

The transportation risk analysis of port and overland transportation segments was performed using the "RADTRAN 4" computer code (Neuhauser and Kanipe, 1992). RADTRAN 4 models have been developed to yield estimates that tend to overstate the impact. For example, RADTRAN 4 postulates that, in the event of an accident, people would not be evacuated for 24 hours. In actuality, people would most likely be evacuated sooner, thereby reducing the time of exposure.

Detailed information regarding the route and population distribution in the port area and for the overland transportation routes to the Savannah River Site is necessary for use with RADTRAN. This information was obtained using the HIGHWAY computer program (ORNL, 1992a). HIGHWAY is essentially a computerized atlas that can be used to minimize a combination of distance and driving time for a highway route between two points while maximizing use of interstate system highways. This feature allows the user to establish baseline routes for shipments of radioactive materials that conform to Department of Transportation (DOT) routing regulations which require that interstate system highways be used to the maximum extent possible. The population density distribution is calculated for several segments of the highway route, representing rural, suburban, and urban population densities. Population densities are determined using 1990 federal Census Bureau data. The Census Bureau updates the census data only every ten years. There is no other national database available for population densities. Use of the Census Bureau's decennial census data is consistent with the practice in government and private industry when there is a need to model population characteristics.

The routes that might ultimately be taken cannot be predicted with precision now because of changing conditions such as weather, construction, and accidents involving other vehicles. Moreover, if consistent with DOT regulation, State authorities can change the route that must be used for transportation. The representative routes analyzed in this Environmental Assessment, based on conformity with general DOT criteria, provide a basis for comparing potential impacts associated with using different ports of entry into the United States. These routes are discussed in more detail in Chapter 5 and are presented in Appendix $\mathrm{H}$.

\subsection{Impacts of Proposed Action}

As discussed in Chapter 3, DOE proposes to ship 409 spent fuel elements from eight reactors in seven European countries to the Savannah River Site in South Carolina. Under the proposed action, the Environmental Assessment analyzed all the fuel coming into any one of five East Coast ports. Criteria by which the ports under consideration were chosen are discussed in detail in Appendix C. As is evident throughout this chapter, differences in radiological risk depend primarily on the truck shipping distances and on the population densities along the overland routes. The overseas shipping distance is approximately the same for all East and Gulf Coast ports capable of handling the shipments, and most of the ports considered had similar population densities in the port city area. The five East Coast ports discussed in this chapter were the closest to the Savannah River Site, and generally had 
the lowest overall population densities along the overland route. (See Tables 5-2 and C-2.) The 409 spent fuel elements would be transported in fifteen shipping casks. Shipment of these casks was analyzed in two ways: (1) one cask per ship for a total of fifteen shipments; and (2) eight casks per ship for a total of two shipments ${ }^{1}$.

Section 6.1.1 describes potential impacts to the environment from the trans-Atlantic crossing. Section 6.1.2 describes potential impacts of receiving spent fuel at a United States port and transporting it by land to the Savannah River site for storage. Section 6.1.3 describes potential impacts from storing the spent fuel at the Savannah River Site.

\subsubsection{Marine Environment}

Because the proposed action involves ocean transport, DOE considered the environmental impacts of the proposed action on the global commons (i.e., portions of the ocean not within the territorial boundary of any nation) in accordance with Executive Order 12114 (U.S. Federal Register, 1981). Section 6.1.1.1 discusses incident-free operations; Section 6.1.1.2 discusses potential accident conditions.

\subsubsection{Impacts of Routine Operations}

The National Marine Fisheries Service has recently indicated that, under routine transportation conditions, shipments of low-enriched uranium (LEU) (as uranium hexafluoride) from Russia by commercial vessel would be indistinguishable from any other commercial shipment, and that impacts to threatened or endangered species or critical habitat were unlikely (USEC, 1993). Because the integrity of spent fuel casks is greater than that of uranium hexafluoride containers and because the package dose rates (i.e., the radiation exposure at the surface of the shipping cask) are of the same order of magnitude, the same conclusion can be drawn for routine transportation of research reactor spent fuel. In other words, under routine operations, there would be no impact on the marine environment.

Under incident-free conditions of transport, most ship crew members would be shielded most of the time by the ship structure and other cargo from radiation emitted by the spent fuel. Ship crew exposure, therefore, is primarily limited to crew members who inspect cargo on a daily basis to ensure secure stowage and structural safety of the vessel. The estimated dose to crew members during transport is given in Table 6.1-1. The highest estimate is $0.0046 \mathrm{rem}$. This estimate represents the maximum dose that would be received by a single cargo inspector if that same cargo inspector were present for each of the fifteen shipments. The other members of the crew would receive negligible dose due to the separation distance between the cargo and the crew and shield effects from other cargos and the ship's structures. Incidentfree dose estimates to the cargo inspectors would be essentially the same for all port alternatives, largely because the exposure is proportional to the number of inspections over time and the distances from the European ports to the proposed United States ports are very similar. Table 6.1-1 presents radiation exposures for the scenario where the ship stops at

\footnotetext{
${ }^{1}$ Under a two shipment scenario, one shipment would be made with eight casks and one shipment with seven casks, for a total of the fifteen casks that make up the proposed action.
} 
three intermediate ports before onloading the spent fuel at a fourth port. If no intermediate port stops are assumed, the collective dose would be reduced by 0.0013 to 0.0015 rem for the various ports, or by approximately 30 percent. For example, without intermediate stops the collective dose for the ship's crew with a destination of Sunny Point would be 0.0028 rem. No dose is received by the general public during ocean transport. The number in the column titled "Latent Cancer Fatalities" may be interpreted as meaning that there would be approximately a one in 450,000 chance of a single fatal cancer among the entire crews of all the ships used in the proposed action.

Table 6.1-1. Ship's Crew (Cargo Inspectors) Dose for Incident-free Shipment of 409 Elements Through the Proposed Ports of Entry Assuming Three Intermediate Port Stops

\begin{tabular}{|l|c|c|}
\hline \multicolumn{1}{|c|}{ Port of Entry } & \\
& Collective Ship's Crew Dose (rem) & Latent Cancer Fatalities \\
\hline Charleston & 0.0045 & 0.0000022 \\
\hline Jacksonville & 0.0046 & 0.0000023 \\
\hline Savannah & 0.0046 & 0.0000023 \\
\hline Sunny Point & 0.0043 & 0.0000022 \\
\hline Wilmington & 0.0043 & 0.0000022 \\
\hline
\end{tabular}

a The values presented for each port assume that all fifteen shipments of the proposed action are routed to that port, in which case the risk at other ports would be zero.

\subsubsection{Impacts of Accidents}

With the exception of the no action alternative, the proposed action and alternatives could have an impact on the marine environment in the event of an accident which involved the release of radioactive materials from the spent fuel.

\section{Description of Scenario}

During ocean transport (port departure, ocean crossing, and port arrival), the most severe accident would be a ship collision followed by a fire. It is possible that a spent fuel cask carried on a ship involved in such a collision could be exposed to impact forces resulting from the collision and a fire which is assumed to follow: In that event the cask could be damaged. However, in most port approaches and harbor transits, where the probability of a collision is greatest, collisions occur at relatively low velocities. Furthermore, only a small fraction, at most, of the force generated in a collision of a ship with another ship would be brought to bear on a spent fuel cask for several reasons. First, the force of a ship-ship collision would be distributed over the entire area of contact between the two ships, which means that the force density (force per square meter) resulting from a collision must be considered. The maximum cross-sectional area presented by a spent fuel cask is small in comparison to the typical impacted area, so that even if a cask were located directly in the path of the collision and unprotected by intervening hulls, bulkheads, etc., the force that might be exerted on such a cask would be limited by the force density. Second, ships floating on water are yielding objects, so that some portion of the force of impact would be transmitted to the water. Even large impact forces would not result by themselves in catastrophic failure of 
a spent fuel cask. Thus, it would be even more unlikely for a simple collision to result in the breach of a spent fuel cask and the release of any of its contents. However, in order to fully understand the potential environmental impacts of the proposed action, a collision followed by fire is postulated to occur in the most severe accident severity category in the risk analysis for this Environmental Assessment.

\section{Impacts of Accident - Losing a Cask at Sea}

In an accidental fire at sea, in which a cask was sufficiently damaged by fire to release its contents, members of the ship's crew near the fire would be exposed to the released radioactive material. However, any crew member close enough to the fire to suffer a significant radiation dose likely would be more severely injured from the fire than the radiation dose. A combination of mechanical damage and fire severe enough to release a non-negligible fraction of a cask's contents would probably either kill or critically injure anyone nearby. A resulting plume carrying radioactive particles that was released from the ship's confines would disperse over the ocean, where there is no human population. As discussed below, because the oceans are a very dilute system, effects on marine biota would not be discernible. (Impacts and effects of a fire in port are discussed in Section 6.1.2.2.)

If a collision or other accident (e.g., loss of a cask over the side in a storm) occurred in which an intact cask fell overboard, the fact that the cask would be immersed would not necessarily result in a release of its contents. Spent fuel casks are designed to withstand at least a fifteen meter immersion, and it has been demonstrated that the cask seals will remain intact at much greater depths (IAEA, 1990a). Spent fuel casks, damaged or undamaged, can be recovered from water up to 200 meters deep: well beyond the range typical of coastal and port depths. (Recovery at great depths, e.g., more than 2,000 meters, is possible, but would be costly). It is reasonable to believe that a cask would be recovered in any incident involving the immersion of a cask in waters up to 200 meters in depth.

The Nuclear Energy Agency (NEA) of the Organization for Economic Cooperation and Development, Paris, France, estimated the impacts of various accident scenarios involving shipment of reprocessed commercial spent fuel. The NEA estimated that a damaged and unrecovered cask of high level waste in coastal waters would result in a peak individual human dose of $110 \mathrm{mrem} / \mathrm{yr}$ per metric ton of heavy metal (MTHM) (NEA, 1988). The foreign research reactor spent fuel has a radionuclide inventory comparable to that of 0.1 MTHM of high level waste. In the most extreme situation, where the accident occurs in coastal waters, the fuel is not recovered, and both the fuel and cask are damaged, the peak dose to an individual human is estimated at $11 \mathrm{mrem} / \mathrm{yr}$ based on a comparison to the NEA analysis. The individual is assumed to reside near the shore and ingest seafood (fish, mollusk, and seaweed) harvested from the area in the immediate vicinity of the spent fuel cask. Since the spent fuel cask could be retrieved, the actual impacts from such an accident would be considerably less than $11 \mathrm{mrem} / \mathrm{yr}$. For intact fuel, the dose would be expected to be inconsequential (no radiological impact). Peak biota doses are estimated at $0.24 \mathrm{mrad} / \mathrm{yr}$ for fish, $0.32 \mathrm{mrad} / \mathrm{yr}$ for crustaceans, and $13 \mathrm{mrad} / \mathrm{yr}$ for mollusks, if the cask is damaged and not retrieved from coastal waters. With retrieval, the biotic impacts would be considerably smaller. 
In deep waters, the radioactive constituents of spent fuel would be released slowly over time into the surrounding waters if the cask were not recovered. Some of the radioactive material would be removed from the water by sorption on suspended sediments. Assuming a damaged cask of spent fuel were submerged on the deep ocean bottom, the peak human individual dose to an individual residing along the coast and ingesting seafood harvested from the general area in which the breached submerged spent fuel cask is located would be $0.00012 \mathrm{mrem} / \mathrm{yr}$. Similar consequences associated with spent fuel casks submerged in the ocean have been estimated in earlier studies (USDOE, 1980). In the event of an accident and fire at sea, where the cask did not sink but its contents were released, the accident was assumed to occur far enough out at sea that essentially no public exposure to the fire-induced plume would result and that all released activity would be deposited in the ocean. (Impacts to workers associated with a shipboard fire, as well as to people living in the port area, are addressed in Section 6.1.2.2.)

Of course, humans would not be the principally exposed species in a deep ocean accident involving spent nuclear fuel. Using estimates of the NEA and assuming that the damaged spent fuel cask lay on the ocean floor where it slowly released its radioactive inventory, the peak doses to biota residing on the ocean floor in or near the uppermost sediment layer would be $110 \mathrm{mrad} / \mathrm{yr}$ for fish, $170 \mathrm{mrad} / \mathrm{yr}$ for crustaceans, and $7300 \mathrm{mrad} / \mathrm{yr}$ for mollusks (NEA, 1988).

Deleterious effects of chronic irradiation have not been observed in natural aquatic populations at dose rates less than 365 rad per year (NCRP, 1991). At doses below 10 rad per year, as would be the case in an accident involving the foreign research reactor spent fuel, it is unlikely that either a population of marine biota or individual members of that population would be harmed by the radiation resulting from a spent fuel accident. Additionally, uranium, the major constituent of the spent fuel, has not been found to bioaccumulate in fish and bioaccumulates only slightly in crustaceans and mollusks (IAEA, 1976). No significant chemical hazard would be expected from the release of the contents of the spent fuel elements into the open ocean.

\subsubsection{Port and Overland Transport}

The results of the analysis of risks associated with the transportation of spent fuel from the proposed United States ports of entry to the Savannah River Site are presented in this section, along with a summary of the methodology supporting the calculations. Section 6.1.2.1 presents the radiological impacts to port workers from routine operations and to truck crew during overland transport of fifteen shipments of spent nuclear fuel to the Savannah River Site. Maximum individual exposures and exposures to population subgroups are analyzed. Section 6.1.2.2 presents the impacts to these same groups in the case of an accident. Potential radiological impacts for port operators and overland transport are summarized in Section 6.1.2.3. Section 6.1.2.4 presents the non-radiological transportation impacts. (Section 6.2.3 presents the transportation risks for the alternative ports of entry and a comparison to the impacts from the proposed action.) 


\subsubsection{Impacts of Routine Operations}

During routine transportation operations, individuals near the spent fuel casks would receive low levels of external exposure to radiation (gamma and x-rays) emitted by the spent fuel elements. No internal exposures would be received since the spent fuel would be contained within the shipping cask. The various groups of persons potentially at risk from routine operations resulting from the port and overland transportation phases of the proposed action are described in Table 6.1-2. Also included in the table are key parameters and conditions used in the risk analysis.

Table 6.1-2. Description of Risk Groups for Port Handling and Overland Transport

\begin{tabular}{||l|l||}
\hline \multicolumn{1}{|c|}{ Risk Group } & \multicolumn{1}{|c|}{ Description $^{\mathrm{a}}$} \\
\hline Port Handlers and Workers & $\begin{array}{l}15 \text { people at 1 meter from each package for 10 } \\
\text { minutes }\end{array}$ \\
\hline Port Staging Personnel and Other Port Workers & $\begin{array}{l}20 \text { people at } 100 \text { meters for } 24 \text { hours; 50 people at } \\
50 \text { meters for } 16 \text { hours }\end{array}$ \\
\hline Truck Crew & $\begin{array}{l}\text { Truck - Two persons at 10 meters for duration of } \\
\text { overland segment }\end{array}$ \\
\hline General Public & $\begin{array}{l}\text { General population within 800 meters of the } \\
\text { shipment while in transit or during stops, including } \\
\text { those sharing the roadway with the shipment }\end{array}$ \\
\hline
\end{tabular}

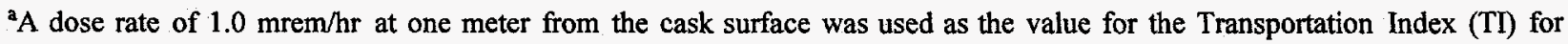
the incident-free dose estimate calculations. Operational experience with shipments of research reactor spent fuel indicate that the actual dose rate is typically much lower and can be as low as $0.1 \mathrm{mrem} / \mathrm{hr}$ at one meter.

Port workers, inspectors, and truck drivers are not considered as radiation workers as defined by the Nuclear Regulatory Commission's (NRC) regulations. Thus, the maximum annual allowable exposure for these personnel would be $100 \mathrm{mrem}$, the same radiation dose limit established by the NRC to protect individual members of the general public (DOE Order $5400.5,1990)$.

\section{Impacts in Port}

Once a shipment arrives in port, the spent fuel packages would be inspected by customs officials, United States Coast Guard personnel, etc. Up to three inspections, estimated at ten minutes per person per spent fuel cask, were assumed. After being inspected, the cask would be off-loaded by port workers, and arrangements would be made for the immediate departure of the spent fuel from the port for transport to the Savannah River Site. In recognition of instances where some delay may occur, the transportation risk was modeled to include a delay of up to 24 hours in a secure staging area. The 24-hour period for the staging of spent fuel casks was selected because it is possible that on occasion the spent fuel casks would not leave the secure staging area on the same day that they arrived, depending on variables such as the time of day the casks clear customs, the weather, etc. Nonetheless, it would be unlikely that the casks would remain in the staging area for longer than 24 hours. 
During routine port operations, the highest exposure would be to handlers and inspectors of the casks. Exposures would be essentially the same at all ports because of the uniformity of container cargo handling throughout the world. The potentially exposed population was assumed to vary from 15 to 225 persons. The smallest population represents the unlikely scenario in which the same group of ten handlers and five inspectors (presumably at the same port) handled/inspected all fifteen shipments. The largest exposed population represents the scenario in which an entirely different group of ten handlers and five inspectors handled/inspected each cask shipment. The actual situation likely would be between these two extremes. The maximally exposed port worker - the handler/inspector who inspected all fifteen casks - would receive a dose of approximately $5.2 \mathrm{mrem}(0.0052 \mathrm{rem})$; about five percent of the applicable DOE and NRC standard and about 1.5 percent of the typical annual radiation exposure received by residents of the United States (Table 6.1-3). The collective exposure to the handlers/inspectors is estimated as 0.078 person-rem seen in Table 6.1-4. (This collective exposure is the product of the dose estimate to the maximally exposed person, $0.0052 \mathrm{rem}$, and the number of workers, fifteen.)

Table 6.1-3. Maximum Individual Incident-Free Radiological Impacts for the Proposed Action: 409 Spent Fuel Elements Shipped to the Savannah River Site via Highway Transportation

\begin{tabular}{||l|c|c|c||}
\hline \multirow{2}{*}{\begin{tabular}{|l|} 
Port of Entry \\
\cline { 2 - 4 }
\end{tabular}} & $\begin{array}{c}\text { Maximum Individual Port } \\
\text { Worker (Handler/Inspector) }\end{array}$ & $\begin{array}{c}\text { Maximum In-Transit } \\
\text { Individual: Truck Crew } \\
\text { Member }\end{array}$ & $\begin{array}{c}\text { Maximum In-Transit } \\
\text { Member of Public }\end{array}$ \\
\hline Charleston & 5.2 & 2.4 & 0.002 \\
\hline Jacksonville & 5.2 & 3.9 & 0.002 \\
\hline Savannah & 5.2 & 2.7 & 0.002 \\
\hline Sunny Point & 5.2 & 4.5 & 0.002 \\
\hline Wilmington & 5.2 & 4.1 & 0.002 \\
\hline
\end{tabular}

Long-term health-effect risks, in terms of latent cancer fatalities, are also shown in Table 6.1-4. Assuming a conversion factor of 0.0005 LCF per person-rem, the additional average risk of a port worker dying from cancer as a result of the proposed action is about 1 in 380,000 . The average risk of a single genetic effect in all subsequent generations as a result of the proposed action is about 1 in 2 million. By comparison, the current incidence of spontaneous genetic abnormalities is between 32 and 42 per 1,000 live births, or about one in 27 , on the average (NAS, 1990, p.91). 
Table 6.1-4. Incident-Free Radiological Risk for the Proposed Action: Shipment of 409 Spent Nuclear Fuel Elements to the Savannah River Site via Highway Transportation "

\begin{tabular}{|c|c|c|c|}
\hline Port of Entry & Exposure Category & $\begin{array}{l}\text { Annual Dose } \\
\text { (person-rem) }\end{array}$ & Latent Cancer Fatalities \\
\hline \multirow[t]{5}{*}{ Charleston } & Port Handlers/Inspectors & 0.078 & 0.000039 \\
\hline & Other Port Workers & 0.0039 & 0.000002 \\
\hline & Public & 0.031 & 0.000015 \\
\hline & Truck Crew & 0.0047 & 0.0000024 \\
\hline & Total & 0.12 & 0.000061 \\
\hline \multirow[t]{5}{*}{ Jacksonville } & Port Handlers/Inspectors & 0.078 & 0.000039 \\
\hline & Other Port Workers & 0.0039 & 0.000002 \\
\hline & Public & 0.05 & 0.000025 \\
\hline & Truck Crew & 0.0078 & 0.0000039 \\
\hline & Total & 0.14 & 0.000072 \\
\hline \multirow[t]{5}{*}{ Savannah } & Port Handlers/Inspectors & 0.078 & 0.000039 \\
\hline & Other Port Workers & 0.0039 & 0.000002 \\
\hline & Public & 0.035 & 0.000018 \\
\hline & Truck Crew & 0.0054 & 0.0000027 \\
\hline & Total & 0.12 & 0.000063 \\
\hline \multirow[t]{5}{*}{ Sunny Point } & Port Handlers/Inspectors & 0.078 & 0.000039 \\
\hline & Other Port Workers & 0.0039 & 0.000002 \\
\hline & Public & 0.067 & 0.000033 \\
\hline & Truck Crew & 0.0090 & 0.0000045 \\
\hline & Total & 0.16 & 0.000081 \\
\hline \multirow[t]{5}{*}{ Wilmington } & Port Handlers/Inspectors & 0.078 & 0.000039 \\
\hline & Other Port Workers & 0.0039 & 0.000002 \\
\hline & Public & 0.053 & 0.000026 \\
\hline & Truck Crew & 0.0082 & 0.0000041 \\
\hline & Total & 0.14 & 0.000073 \\
\hline
\end{tabular}

The analysis presented for each port assumes that all shipments in the proposed action pass through that port. In that event, the risk to all other groups at each of the other ports would be zero. If casks were shipped to more than one port, the risks would be directly proportional to the number of casks actually onloaded at each port.

\section{Impacts to truck crew}

The overland transportation of spent fuel was modeled by identifying the most direct route from the gate of each marine terminal to the nearest interstate highway using detailed city maps. The most direct route would generally minimize the risk to the crew because they would spend less time in the truck. From the city road connection to the interstate system, a representative route to the gate of the Savannah River Site was developed with the HIGHWAY routing model, as discussed earlier. For truck transportation, the truck-crew 
population could vary in size from two to 30 persons. The population would be at the minimum of two if every shipment were trucked from the port of entry to the Savannah River Site by the same two-person truck crew. It would achieve its maximum of 30 if each of the fifteen shipments for the proposed action had a different two-person crew. The largest truck crew population dose is for the port option of Sunny Point because it is the farthest from the Savannah River Site. The maximally exposed individual truck crew member (i.e., the same person exposed to all fifteen shipments) would receive $4.5 \mathrm{mrem}(0.0045 \mathrm{rem})$; about 5 percent of the applicable DOE and NRC standard and about one percent of the typical annual radiation exposure received by residents of the United States (Table 6.1-3). The estimated maximum population exposure is 0.009 person-rem (Table 6.1-4), which is the population of two truck crew members times the maximum individual exposure. The lowest maximally exposed individual truck crew member would receive 2.4 mrem $(0.0024 \mathrm{rem})$ enroute from Charleston, which is the closest port to the Savannah River Site. The lowest estimated truck crew dose is for the port option of Charleston, estimated at 0.0047 person-rem (Table 6.1-4). The average risk of a single crew member getting cancer as a result of transporting spent fuel from Sunny Point to the Savannah River Site is about one in 440,000. The average risk of a single genetic effect occurring in all subsequent generations as a result of the proposed action is about one in 2.2 million.

\section{Impacts to public from overland transport}

The estimated maximum in-transit exposure to an individual not actively involved in shipping the spent fuel was estimated in two different ways: (1) a hypothetical maximum dose that would be received by an individual member of the general public who lives beside the highway route, and (2) the potential exposure received by an individual located near a stopped truck (e.g., in a traffic jam).

The first individual is assumed to be exposed to each of the fifteen shipments at a distance of 30 meters. The maximum in-transit individual dose under this scenario was calculated to be approximately $0.002 \mathrm{mrem}(0.000002 \mathrm{rem})$ for routine operations; about 0.001 percent of the typical annual radiation exposure received by residents of the United States (Table 6.1-3). This exposure was estimated to be the same for any port of entry since the person is assumed to be present for all shipments from each port at the same distance from the highway. The average increased lifetime risk of dying from cancer from a 0.002 mrem exposure is approximately one in a billion.

Secondly, in the event that the truck had to stop at a service area or was stopped in traffic due to congestion, road construction, etc., there is a potential for exposing a member of the public to the spent fuel at a relatively close distance for a prolonged period of time. If this situation were to occur, it would be possible to receive a dose higher than $0.002 \mathrm{mrem}$, depending on the duration of the stop and the distance of the individual from the truck. For example, in the unlikely event that a person were standing outside next to the stopped truck for a period of one-half hour at a distance of two meters, the person could receive a dose of one mrem. If the person were inside a vehicle, some shielding would be provided and the dose would be less than one mrem, about one percent of the applicable DOE limit and 0.3 percent of the typical annual radiation exposure received by residents of the United States. The average increased lifetime risk of death from a radiation induced cancer from a $0.002 \mathrm{mrem}$ exposure 
would be one in one billion. The port selection criteria, however, require overland travel distance to be minimized. This consideration and previous operational experience with truck shipments of research reactor spent fuel indicate that a minimum number of stops would be expected to occur during the fifteen truck shipments in the proposed action, regardless of the port selected.

Minimal doses would be received by members of the general public during port operations because residences are separated from dock facilities by buffer spaces, parking lots, warehouses, and other port facilities. The public risk in Table 6.1-4 represents the dose to the total population potentially exposed to the proposed shipments. This population includes people who reside within 800 meters $(0.5$ miles) of the transportation route, people driving on the same roads the spent fuel traverses, and people in the vicinity of truck stop areas. No doses large enough to result in acute health effects are predicted among either the general public or workers for the proposed action.

The total annual incident free dose of between 0.12 and 0.16 person-rem, as shown in Table $6.1-4^{2}$, represents the cumulative dose from the proposed activity to all persons potentially exposed. The potentially exposed population would range from about 50,000 persons for the port of Savannah option to 140,000 for the part of Charleston option. As shown in Table 6.1 .2 , the total worker population exposed to each shipment would be about 90 people. Although these cumulative doses may be viewed for the sake of conservatism as being just as damaging as a single dose of the same amount of radiation, scientific evidence exists to indicate that doses accumulated over time as a series of smaller doses are less damaging than an equivalent single dose (Ullrich et al., 1987; Miller et al., 1989). Accordingly, health-effect risks reported in this section can be considered to be extremely conservative estimates of the actual health-effect risks (Gilbert, 1993 and NAS, 1990).

Estimates of the dose from incident-free transportation vary only a little among the port studies because these doses are dominated by radiological exposure of handlers and inspectors, and these were assumed to be essentially the same for all of the ports. The small differences that are reflected in these estimates are due to differences in the size of the population residing or driving along the proposed truck routes and between the port of entry and the Savannah River.

\subsubsection{Impacts of Accidents}

\section{Methodology}

Risk analysis of potential accidents differs from calculations for incident-free transportation because the analyst must account for the probability of an accident occurring. In the incidentfree scenario, some exposure is expected from radiation emitted from the casks. In the case of accidents, the probability of exposure is only an estimate of a hypothetical event. Probabilities are derived from published accident rates for maritime, truck, and rail

\footnotetext{
${ }^{2}$ Although the shipments of spent fuel could take place over a period of approximately two years, they were conservatively estimated to take place in one year to allow for comparison with annual exposure limits.
} 
transportation modes. In order to bound the potential risk from accidents, transportation of spent fuel in this Environmental Assessment was modeled as taking place one cask per shipment, which results in the maximum number of shipments (fifteen) and, hence, the maximum probability of an accident. Because accidents can be of any severity from a "fender-bender" to one involving severe impact and prolonged fire, the RADTRAN code allows the analyst to divide the severity spectrum into a number of accident-severity categories. Each category is assigned a probability of occurrence -- that is, a probability, given that an accident occurs, that it will be of that particular severity. The more severe the accident, the more remote the chance of such an accident. In this analysis, the accident severity spectrum is divided into six categories (Wilmot, 1981) for both maritime and highway transportation (see Appendix $\mathrm{E}$ for further discussion of these categories). The six severity categories include all accidents with a probability of occurrence of one in a million or greater for the entire campaign of up to fifteen shipments, well within the levels found acceptable by the United States Environmental Protection Agency (EPA) and other agencies (Hallenbeck and Cunningham, 1986). ${ }^{3}$

During port transit and unloading, a probability of an accident has been assigned although experience indicates that such an accident would be unlikely to result in severe consequences. To be conservative, all accidents involving a container breach and fire on a ship are assumed to occur at pier-side. This assumption is highly conservative in that it ignores the fact that transits to ports are typically past lower population density areas and an accident in such a location would typically expose fewer numbers of people. Additionally, in the event of a port accident and fire, the radioactive cloud (plume) is assumed to travel over the port area and out to a distance of $80 \mathrm{~km}$. In reality, the plume would be subject to prevailing winds and might blow away from populated areas. In addition, although the urban population around ports is typically much greater than the population in surrounding outlying areas, the accident model treats the port population density as continuing-out for the full $80 \mathrm{~km}$. Another conservative assumption incorporated into the risk assessment is that the entire population remains in the area for 24 hours and therefore is exposed to the greatest extent possible to radioactive material deposited on the ground from the plume. In reality, individuals close to an accident would be evacuated.

Atmospheric dispersion is usually the primary mechanism for dispersing any material that might be released in a severe accident. Weather conditions cannot be predicted with any certainty far in advance, and transportation analyses must consider the fact that weather may vary from one point on a route to another. Therefore, national average weather conditions are used for transportation by highway. Because port activities represent relatively prolonged stops, conservative assumptions have been made about port meteorology. For example, the wind is assumed to be blowing toward land, even though most coastal locations experience such winds only for a part of each day. Hypothetical releases analyzed in this study are conservatively modeled as occurring at ground level, except for those resulting from shipboard fires in which the elevation above grade of the vessel is taken into account.

\footnotetext{
${ }^{3}$ A severe accident with probability of occurrence approximately one in 10 million was also analyzed. See Consequences of Severe Accidents in Port later in this Chapter.
} 


\section{Cask Behavior}

The behavior of the package in accidents of each accident severity category is accounted for in this analysis. "Type B" spent fuel casks (the kind in which the foreign reactor spent fuel would be shipped) are massive, highly damage-resistant packagings. Moveover, the spent fuel itself consists mostly of solid metallic materials that are not readily dispersed. Therefore, large releases are not likely to occur even in the severest of accident conditions. (See Appendix E.)

Type B packages are required to pass two series of rigorous tests: those associated with normal or routine transportation and those associated with hypothetical accident conditions that might be encountered. The accident conditions are listed in Table 6.1-5. These certification tests were developed by the International Atomic Energy Agency (IAEA) and promulgated as model regulations (IAEA, 1990a). These model regulations have been adopted by the United States and all of the nations proposing to ship foreign research reactor spent nuclear fuel to the United States under the proposed action.

\section{Table 6.1-5. Hypothetical Accident Conditions for Type B Packages}

\begin{tabular}{|l|l|}
\hline \multicolumn{1}{|c|}{ ACCIDENT } & \multicolumn{1}{|c|}{ CONDITIONS } \\
\hline Free Drop & $\begin{array}{l}\text { Free drop through a distance of } 30 \text { feet }(9 \mathrm{~m}) \text { onto a flat unyielding surface, striking the } \\
\text { surface in a position for which maximum damage is expected. }\end{array}$ \\
\hline Puncture & $\begin{array}{l}\text { Followed by free drop through a distance of } 40 \text { inches }(1 \mathrm{~m}) \text { in a position in which } \\
\text { maximum damage is expected onto upper end of solid steel bar. }\end{array}$ \\
\hline Thermal & $\begin{array}{l}\text { Followed by, exposure for not less than } 30 \text { minutes to thermal environment of } 1475^{\circ} \mathrm{F} \\
\left(800^{\circ} \mathrm{C}\right) .\end{array}$ \\
\hline Immersion & $\begin{array}{l}\text { Subjected to water pressure equivalent to immersion under a head of water at least } 50 \\
\text { feet }(15 \mathrm{~m}) \text { for at least eight hours. }\end{array}$ \\
\hline
\end{tabular}

Source: Title 10, Code of Federal Regulations, Part 71, Subpart F.

\section{Risk during port operations}

Table 6.1.6 presents radiological accident risks during port operations associated with receiving fifteen casks containing 409 spent nuclear fuel elements at the proposed ports of entry. The results were determined by adding all of the risks for all exposure pathways for all accidents that could occur in port. The results are presented for two shipping cases: (1) fifteen shipments, one cask per ship with three intermediate port calls before final delivery, and (2) two shipments of up to eight casks per ship with no intermediate port stops. The multi-cask carrying vessel would likely be a dedicated ship chartered to go directly to the port of entry. 
Table 6.1-6. Radiological Accident Risks in Port: 409 Spent Fuel Elements Shipped Assuming Three Intermediate Port Stops and One Cask Per Ship, Versus No Intermediate Port Stops and Eight Casks Per Ship ${ }^{a}$

\begin{tabular}{||l|c|c|c|}
\hline \multicolumn{1}{|c|}{ Port of Entry } & Number of Port Stops & Person-rem & Latent Cancer Fatalities \\
\hline Charleston & 4 & 0.054 & 0.000027 \\
\cline { 2 - 4 } & 1 & 0.00055 & 0.00000028 \\
\hline \multirow{2}{*}{ Jacksonville } & 4 & 0.051 & 0.000024 \\
\cline { 2 - 4 } & 1 & 0.00016 & 0.00000008 \\
\hline Savannah & 4 & 0.056 & 0.000028 \\
\hline \multirow{2}{*}{ Sunny Point } & 1 & 0.00068 & 0.00000034 \\
& 4 & 0.050 & 0.000025 \\
\hline \multirow{2}{*}{ Wilmington } & 1 & 0.000076 & 0.000000037 \\
\cline { 2 - 5 } & 4 & 0.053 & 0.000026 \\
\hline
\end{tabular}

${ }^{a}$ The scenario wherein a ship makes three intermediate port stops prior to onloading the spent fuel at a fourth port would result in a total of four port stops.

To interpret the results in Table 6.1-6, one must consider the collective (or total) risk of population exposure and determine the associated fatal cancer risk. Accident dose risks are reported in person-rem, but are risks rather than doses, since they include probability of accident occurrence. The maximum accident risk is less than 0.06 person-rem if one assumes three intermediate port stops. This translates into a latent cancer fatality risk of about 0.00003 (a one in 30,000 chance that one additional fatal cancer would result from the proposed action). If no intermediate port stops are assumed, the risk is less than 0.007 person-rem, or less than one chance in $2,800,000$ that one additional fatal cancer will develop.

A comparison of the one-cask, three-intermediate-port-stops and the eight-casks, nointermediate-port-stops shows that the port accident risks are lower for the multiple-cask shipment option than for the single-cask shipment option. The reason for the lower risk is that the fewer the transits, the lower the probability of an accident involving a ship collision or fire. Although all risks are shown to be small, the risks are seen to range between one hundred and six hundred times lower for direct shipment with no intermediate port calls. The smallest differences are shown for the ports of Charleston and Savannah because they have relatively high populations in the port areas, which are similar to the populations assumed for the intermediate port stops. The largest difference is for the port of Sunny Point, which has a very low population in the port area in contrast to the high populations assumed for the intermediate port stops. The risks of shipping one cask per vessel and assuming three intermediate port calls bound the total risk for the proposed action. 
The possible use of purpose-built ships is discussed in the proposed action. These ships have been specifically designed for carriage of spent nuclear fuel cargo. Though these vessels are specially designed, there is no difference in accident risk among these vessels and a commercial container ship in the model used in the Environmental Assessment. The reasons for this are as follows.

Severe accident consequences during ocean transport of spent fuel could occur as a result of a collision in which a cask was badly damaged and subsequently exposed to fire that caused airborne spent-fuel particles to be released. For an airborne release of this type to occur, the cask-carrying vessel must stay afloat during and immediately after an accident. In practice, this means the ship must stay afloat for a period of some hours following an accident of the requisite severity. This latter condition must be satisfied for downwind dispersal to occur, even though marine casualty files indicate that a common outcome of severe ship collisions is rapid sinking, often within a matter of minutes. The analysis in this Environmental Assessment was based on a conservative analysis that modeled all ships involved in severe collisions and fires as not sinking after the accident (USDOE, 1986). However, the primary benefit of the purpose-built vessel design is that it makes the vessel less likely than an ordinary commercial container ship to sink after a collision. The conservative analysis does not distinguish between the two vessel types. As shown in Table 6.1-6, however, the transportation risk could be reduced relative to the risk estimated for commercial container liners, if the purpose-built ship made no intermediate port calls.

\section{Consequences of Severe Accidents in Port}

The greatest risk to the public estimated in this Environmental Assessment occurs during the port operations. This is primarily a result of the fact that accidents involving high impact forces or severe fires are somewhat more likely during ship port transits than during overland transportation by truck. For alternatives involving intermediate port stops, the port-related risks are particularly dominant. The risk is also strongly influenced by the fact that port population densities are larger on average than population densities around most segments of the truck routes from the proposed ports to the Savannah River Site. Sunny Point has the lowest population density in the vicinity of the port $\left(179\right.$ persons $\left./ \mathrm{km}^{2}\right)$; Savannah, the highest $\left(2,788\right.$ persons $\left./ \mathrm{km}^{2}\right)$. This difference is reflected in the risks shown in Table 6.1-6. However, as stated earlier, there has never been a failure of a spent fuel shipping cask, and events necessary to result in a failure are highly improbable.

In the event of the most severe foreseeable accident involving major mechanical damage, fire, oxidation of 100 percent of the fuel, and release of radioactive materials from a cask containing 33 assemblies of spent fuel ${ }^{4}$, the dose to a maximally exposed individual located 34 meters (112 feet $)^{5}$ from the cask and exposed to the entire plume passage and the next 24 hours of exposure to resultant fallout would be $25 \mathrm{rem}$. At such close distance, it is highly

\footnotetext{
${ }^{4}$ The HFR spent fuel was used in this example because it has the highest activity of all the fuel shipments.

${ }^{5}$ A distance of 34 meters is the maximum distance away from the accident site of the highest downwind concentration used in the risk calculations because the plume would rise for a short downwind distance before starting to fall.
} 
probable that the individual, if not evacuated, would be harmed more by the explosion and fire engulfing the cask than by the radiation dose. A dose of 25 rem in a 24 hour or shorter period would cause no observable clinical effects. An individual must receive an acute exposure of around 600 rem before there is a high probability of a near term death. If an individual is assumed to be inside a building 34 meters from the accident and remains for the 24 hours after the accident, the dose would be 0.22 rem or reduced by a factor of more than 100 .

At a more likely distance, where an individual may be located outside for a period of 24 hours after the accident, the dose at $1,000 \mathrm{~m}(0.6$ miles) would be $0.21 \mathrm{rem}$ (about 60 percent of annual background exposure). If a person were indoors at $1,000 \mathrm{~m}(0.6 \mathrm{miles})$, the dose would be $0.002 \mathrm{rem}$. These estimates are the potential consequences of the most severe foreseeable accident occurring in a port area. When considered in conjunction with the probability of occurrence $(0.00000013$ or a one chance in 7.7 million $)$, this accident has an extremely small risk. For example, the risk to an individual located outside at a distance of only 34 meters from a cask involved in such an accident is equivalent to a one in 600 million chance of developing a fatal cancer. More information on the accident scenario is found in Appendix E.

\section{Risks during overland transportation}

The radiological risks from a truck accident were also calculated assuming that a group of people was exposed to a contaminated plume that might result from an accident. These people were modeled as staying in the same location for 24 hours following an accident, which is probably a conservative assumption. The number of persons potentially exposed varied by route segment and was based on the segment population density and downwind travel of the plume out to a distance of $80 \mathrm{~km}$. The truck transportation risk is the same for one or eight casks per ship because, as trucks can only transport one cask at a time, either option would require fifteen truck shipments to the Savannah River Site. Similarly, overland transportation risks are not affected by the number of intermediate port stops. The truck accident risks shown in Table 6.1-7 vary with the number of miles driven and the population potentially exposed. The accident risk associated with highway transportation of the spent fuel from Sunny Point to the Savannah River Site is slightly higher than for the other proposed ports because the distance is longer and the potentially exposed population along this route is slightly higher than along the routes for the other proposed ports of entry. However, the total accident risk is dominated by risks associated with port operations, as can be seen by comparing the risk estimates of Table 6.1-6 (port accident risks) and Table 6.1-7 (highway accident risks). The projected risks from truck accidents are thousands of times lower than the already low risks from port operations presented in Table 6.1-6. 
Table 6.1-7 Radiological Accident Risks for Highway Transportation: 409 Spent Fuel Elements Shipped to the Savannah River Site via Truck

\begin{tabular}{||l|c|c|}
\hline \multicolumn{1}{|c|}{ Port of Entry } & Person-rem & Latent Cancer Fatalities \\
\hline \hline Charleston & 0.0000018 & 0.00000000087 \\
\hline Jacksonville & 0.0000024 & 0.0000000012 \\
\hline Savannah & 0.0000015 & 0.00000000075 \\
\hline Sunny Point & 0.0000035 & 0.0000000017 \\
\hline Wilmington & 0.0000028 & 0.0000000014 \\
\hline
\end{tabular}

\subsubsection{Summary of Transportation Radiological Risks}

For perspective, Figure 6-1 compares the incident-free and accident risks for the proposed action with the dose from natural background radiation and the federal regulatory limit for radiation exposure of a member of the general public.

As shown in the figure, the maximum incident-free doses for potentially exposed individuals are well below the regulatory limit.

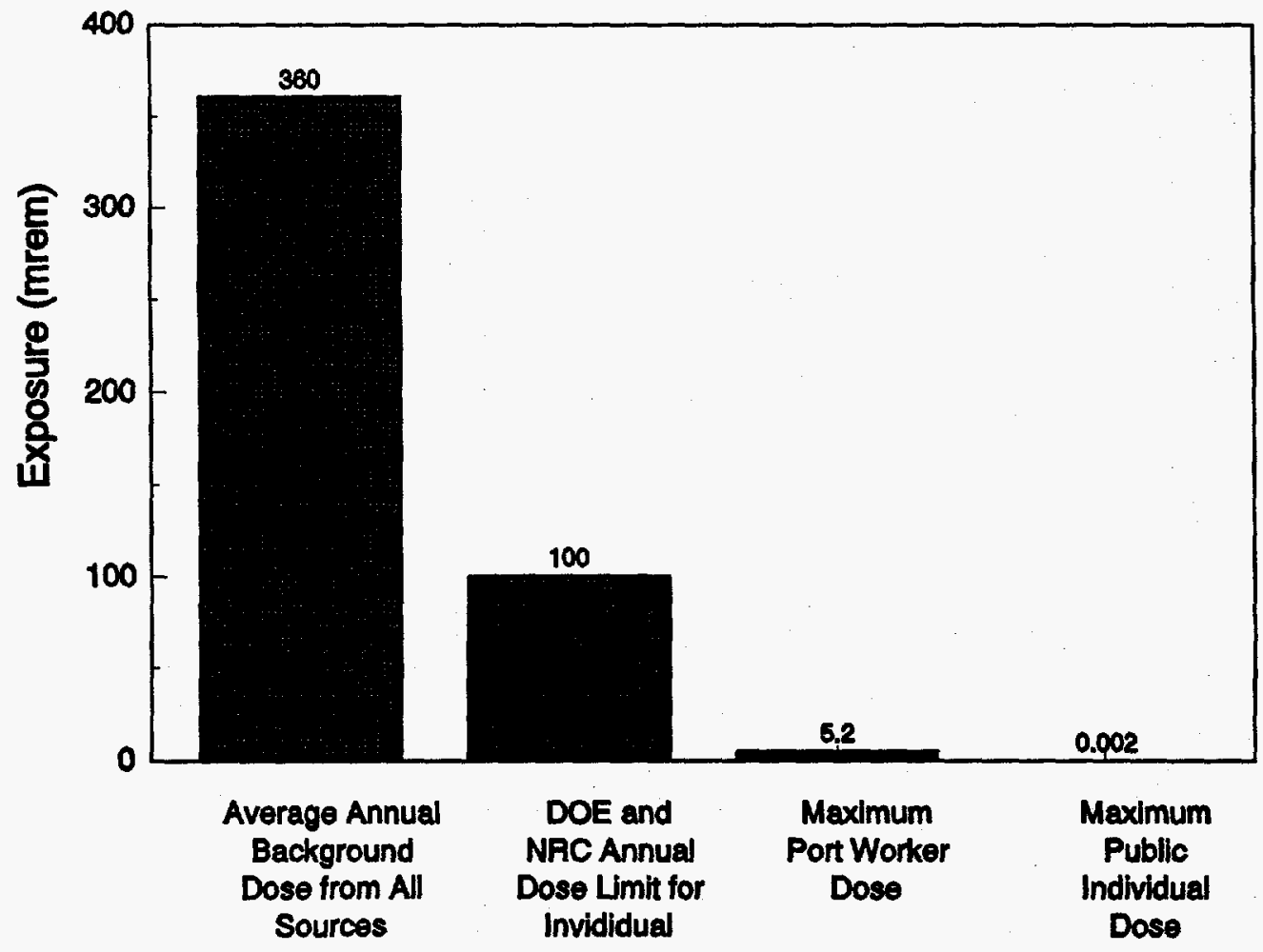

Figure 6-1. Maximum Incident-Free Doses for Potentially Exposed Individuals for Proposed Action for Any Port Option 
The total population dose (or collective dose) was also estimated. Incident-free and accident impact estimates for the transportation and handling of 409 spent nuclear fuel elements are summarized in Table 6.1-8 assuming three intermediate port stops and one cask per vessel.

Table 6.1-8. Transportation Radiological Impacts for Shipment of 409 Elements via the Proposed Ports and Truck Overland Transport Assuming Three Intermediate Port Stops and One Cask Per Vessel

\begin{tabular}{||l|c|c|c|c||}
\hline \multirow{2}{*}{ Port Of Entry } & \multicolumn{2}{|c|}{$\begin{array}{c}\text { Transportation Dose Risk } \\
\text { (Person-Rem) }\end{array}$} & \multirow{2}{*}{ Total Person-Rem } & Total LCFs \\
\cline { 2 - 3 } & Incident-Free & Accident & & 0.000088 \\
\hline Charleston & 0.12 & 0.054 & 0.18 & 0.000098 \\
\hline Jacksonville & 0.14 & 0.051 & 0.20 & 0.000091 \\
\hline Savannah & 0.13 & 0.056 & 0.18 & 0.00010 \\
\hline Sunny Point ${ }^{a}$ & 0.16 & 0.050 & 0.21 & 0.00010 \\
\hline Wilmington $^{\text {a }}$ & 0.15 & 0.053 & 0.21 & . \\
\hline
\end{tabular}

a Transportation from Sunny Point and Wilmington was assumed to occur via Interstate 40 to Interstate 95 . The total personrem exposures would be slightly reduced to 0.19 and 0.18 for Sunny Point and Wilmington, respectively, if shipments were to occur on an alternate route using U.S. Route 74 instead of Interstate 40. (See Appendix L, Table L-19)

For comparison, Table 6.1-9 shows the risks from shipping 409 elements with no intermediate port stops and eight casks per vessel (i.e., a situation that could arise if using a chartered vessel). Table 6.1-8 indicates that the total risk is approximately 1.5 times higher when the ship was assumed to stop at three intermediate ports compared to the risks in Table 6.1-9 for no intermediate ports. This difference is probably artificially high because all three intermediate port stops were assumed to be at high populations density ports. The risk due to accidents comprises about 25-30 percent of the total risk when the intermediate stops are made while only 0.5 percent of the total risk when no intermediate stops are made. The highest population dose risk ( 0.21 person-rem) is associated with a scenario with three intermediate stops and unloading at Sunny Point or Wilmington. This exposure risk would result in an approximately one in 9,500 chance of an additional fatal cancer occurring from the shipment of 409 spent fuel elements.

The lowest population dose ( 0.12 person-rem) is associated with transporting eight casks per vessel to Charleston with no intermediate port stops. This exposure would result in approximately a one in 16,000 chance of an additional fatal cancer occurring.

\subsubsection{Non-Radiological Transportation Impacts}

A series of unit-risk factors (that is, risk per kilometer traveled) was developed based on national statistics for accident-related deaths for highway and rail modes (Wilmot et al. 1983). These statistics were used to calculate the expected numbers of fatalities from mechanical and physical accidents associated with highway and rail transportation of fifteen spent nuclear fuel shipments on each potential route from a port of entry to the Savannah River Site. No 
Table 6.1-9. Transportation Radiological Impacts for Shipment of 409 Elements via the Proposed Ports and Truck Overland Transport Assuming No Intermediate Port Stops and Eight Casks Per Vessel

\begin{tabular}{|c|c|c|c|c|}
\hline \multicolumn{5}{|c|}{ Proposed Ports - 409 Elements } \\
\hline \multirow{2}{*}{ Port Of Entry } & \multicolumn{2}{|c|}{ Transportation Dose Risk - Person-Rem } & \multirow{2}{*}{ Total Person-Rem } & \multirow[b]{2}{*}{ Total LCFs } \\
\hline & Incident-Free & Accident & & \\
\hline Charleston & 0.12 & 0.00055 & 0.12 & 0.000061 \\
\hline Jacksonville & 0.14 & 0.00016 & 0.14 & 0.000072 \\
\hline Savannah & 0.13 & 0.00068 & 0.13 & 0.000063 \\
\hline Sunny Point ${ }^{\mathrm{a}}$ & 0.15 & 0.00076 & 0.15 & 0.000073 \\
\hline Wilmington ${ }^{\mathrm{a}}$ & 0.15 & 0.00043 & 0.15 & 0.000073 \\
\hline
\end{tabular}

a Transportation from Sunny Point and Wilmington was assumed to occur via Interstate 40 to Interstate 95 . The total personrem exposures would be slightly reduced to 0.13 for both Sunny Point and Wilmington if shipments were to occur on an alternate route using U.S. Route 74 instead of Interstate 40. (See Appendix L, Table L-20)

chemical-hazards analysis was performed because no hazardous materials other than spent nuclear fuel would be carried in these shipments. The unit-risk factors do not apply to the fatal accident rate for any one particular road or distance along a route. Instead, total distance in urban, suburban, and rural areas is determined and the probability of an accident is estimated using national data. National data were used rather than road-specific data because fatal accidents have not occurred on most road segments so that such segments would have a zero unit-risk factor. The best method for estimating truck accident fatalities for many roads and routes is to use national data gathered over long periods of time.

The estimated nonradiological impacts of fatalities from overland transportation of the proposed action are given in Table 6.1-10. The primary impact is death from mechanical causes in traffic accidents. Traffic accidents also may cause non-fatal injuries, but no estimate of the expected number of injuries was made in this analysis. In general, between 98 percent of traffic-related injuries in urban areas and 94 percent in rural areas are non-fatal. Recovery rates for cancer are far more variable and depend on the site of the cancer, ranging from 99.8 percent for skin cancer to less than 10 percent for leukemia, for example. In part because of the large variation in relative incidence of non-fatal health effects, fatalities are the only measure of harm that allows direct comparison between radiological and nonradiological consequences. Estimates of consequences of incident-free transportation (latent cancer fatalities associated with release of pollutants by trucks in urban areas) are presented for completeness. These estimates include very large uncertainties. The estimates presented in Table 6.1-10 were calculated with published nonradiological risk factors (Wilmot et al., 1983) used in combination with the truck transportation distances associated with each port alternative. The nonradiological impact estimates include the contribution from the return trip of the empty cask to the port of entry. However, the empty casks could be returned to their country of origin from any United States port and would not necessarily retrace the route back to the port of entry. Thus, the estimates given above are expected, rather than maximum, values. The nonradiological fatality risks are roughly of the same order of magnitude as the 
radiological accident fatality risks (Table 6.1-7). This is partly the result of the fact that nonradiological fatalities can occur even in very low severity accidents and partly a result of the additional distance traveled.

Table 6.1-10. Maximum Annual Nonradiological Fatalities Associated with Highway Shipments for the Proposed Action

\begin{tabular}{||l|c|c|c|}
\hline \multirow{2}{*}{ Port of Entry } & $\begin{array}{c}\text { Annual Health Effects from } \\
\text { Emissions } \\
\text { (latent cancer fatalities) }\end{array}$ & \multicolumn{2}{|c|}{$\begin{array}{c}\text { Annual Traffic Accident Fatalities } \\
\text { (deaths) }\end{array}$} \\
\cline { 2 - 4 } & All Population Groups & Public & Workers \\
\hline Charleston & 0.0000023 & 0.000028 & 0.0000080 \\
\hline Jacksonville & 0.000000040 & 0.000056 & 0.000016 \\
\hline Savannah & 0.00000064 & 0.000038 & 0.000011 \\
\hline Sunny Point & 0.00000038 & 0.000013 & 0.000046 \\
\hline Wilmington & 0.0000014 & 0.000043 & 0.000012 \\
\hline
\end{tabular}

\subsubsection{Savannah River Site}

Only minor environmental impacts are anticipated from the proposed action, because the receipt and storage of 409 spent fuel elements would represent only a small increase to an existing site activity and involve no new construction. The proposed action would not affect threatened or endangered species, cultural resources, wetlands, floodplains, or other environmental resources of the site.

The environmental impacts of routine operations at the Savannah River Site associated with the proposed action are described in Section 6.1.3.1 The onsite and offsite consequences and risks from potential accidents, including the minimal potential for impacts to surface and groundwater, are summarized in Section 6.1.3.2 and more fully described in Appendix G.

\subsubsection{Impacts of Routine Operations}

The proposed receipt and storage of 409 spent fuel elements at the Savannah River Site would result in small increases in radiological emissions and in waste generation during routine operations. The average annual individual worker dose at the RBOF facility for all operations is approximately 150 mrem. The maximum annual increase in the average individual worker dose at the facility as a result of receiving the 409 foreign fuel elements is estimated to be 60 mrem, which is about one percent of the DOE limit for radiation workers. This dose was derived by multiplying the estimated individual dose received from each cask by the number of casks. The estimated individual worker dose is based on operational experience at RBOF. This estimate assumes that: 1) all proposed elements would be received within a one year period; 2) the same individuals unload all fifteen casks; and 3) the proposed shipments would not affect scheduled facility operations, including domestic fuel shipments. The shipments will probably take place over a longer period and several groups of workers will rotate 
through the unloading operations. Therefore, the $60 \mathrm{mrem}$ is considered to be a conservative dose estimate.

The radiation exposure increase to facility personnel from the storage of the foreign fuel elements will not be detectable. Because of the radiation shielding provided by the basin water over the stored fuel, the measurable background radiation levels would not be expected to increase. This assessment is based on the facility design and on the similarities of the proposed foreign fuel elements with the fuel already stored in RBOF.

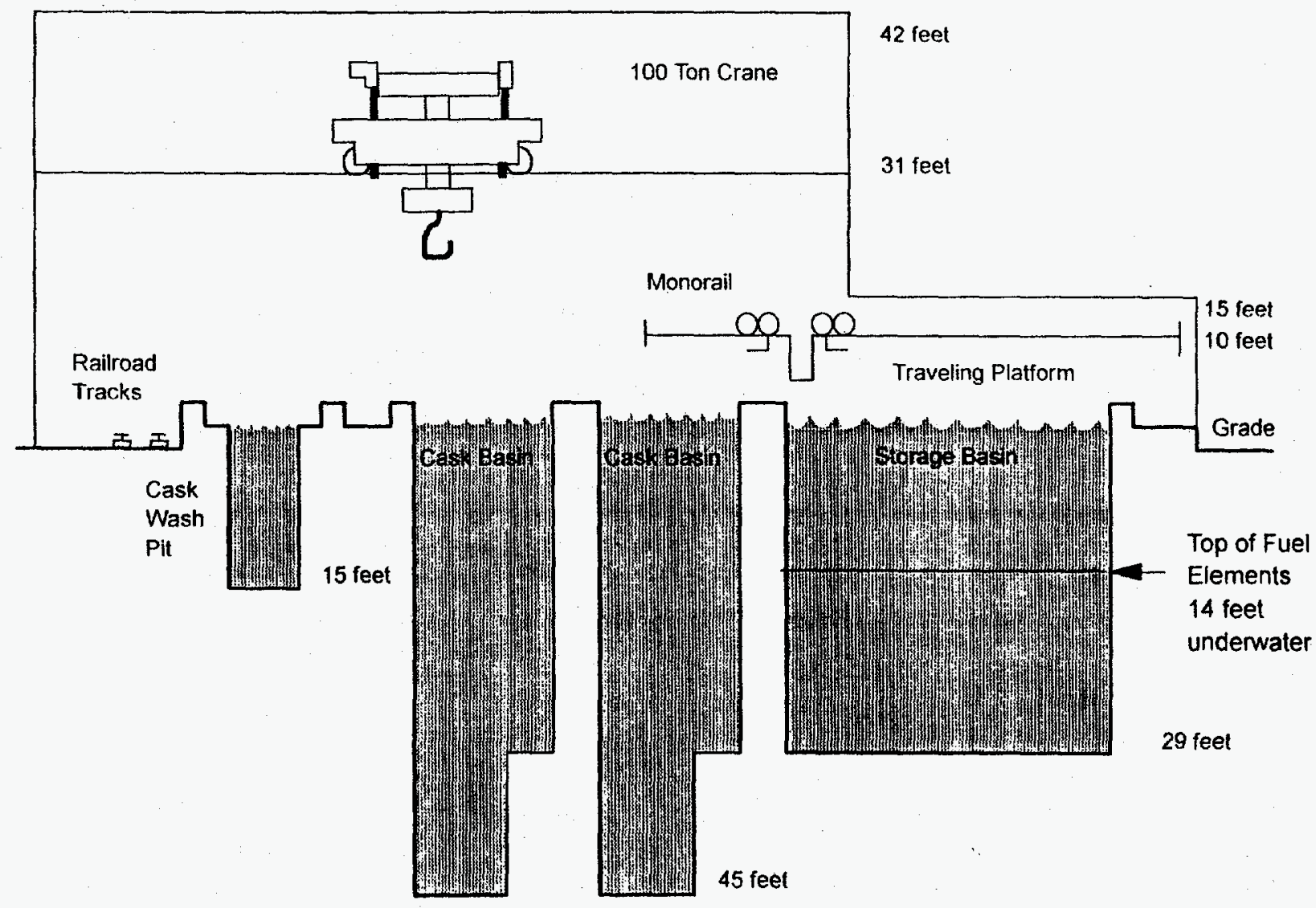

Figure 6-2. Schematic View of the Reactor Basin for Offsite Fuel 
Approximately $0.5 \mathrm{~m}^{3}\left(15 \mathrm{ft}^{3}\right)$ of laundry-type waste is generated per cask; $0.2 \mathrm{~m}^{3}\left(5.5 \mathrm{ft}^{3}\right)$ of solid waste is generated per cask. The proposed action would add less than 4 percent to the total average annual solid waste normally generated at RBOF. To put this in perspective, the total low-level solid waste generated at the Savannah River Site during 1991 was approximately $24,000 \mathrm{~m}^{3}\left(31,000 \mathrm{yd}^{3}\right)$.

During receipt of fuel at $\mathrm{RBOF}$, most of the liquid waste results from the flushing and decontamination of the fuel casks. For the proposed action, the total estimated amount of liquid waste generated during receipt would be $56,750 \mathrm{~L}(15,000 \mathrm{gal})$. This amount is equivalent to the current liquid waste generation for similar cask receipts. During storage at $\mathrm{RBOF}$, the liquid waste is generated mainly from processing the RBOF and Savannah River Site reactor basin deionizers at the RBOF Resin Regeneration Facility. This is approximately $1,500,000 \mathrm{~L}$ (400,000 gal) per year during normal operations. Although the proposed receipt would increase by about 7 percent the total fuel in the RBOF, the incremental increase of the liquid waste generated from the RBOF basin deionizer system would be small since the proposed action involves intact fuel elements (no failed fuel). Furthermore, the RBOF basin accounts only for approximately 10 percent of the total RBOF deionizer processing waste. The remaining RBOF deionizer processing waste is generated from operation of the Savannah River Site Reactor Basins.

Receipt and storage of foreign research reactor spent nuclear fuel would not change the types, quantities, or utilization of hazardous compounds stored in the RBOF. Further, none of the hazardous compounds stored in the RBOF are characterized as human carcinogens using the Weight-of Evidence toxicity classification system ${ }^{6}$ established by the USEPA. Employee awareness of hazardous compound properties is reinforced by the availability of Material Safety Data Sheets and their exposure to hazardous compounds in the workplace is minimized because the compounds are stored and utilized in accordance with applicable OSHA regulations. Since compound toxicity characteristics and worker exposure conditions are unaffected by the receipt of foreign research reactor spent nuclear fuel at the RBOF, there are essentially no incremental risks imposed on workers as a result of the continued presence and utilization of these hazardous compounds.

\subsubsection{Impacts of Accidents}

This section describes events involving foreign research reactor spent fuel that could lead to a release of radioactivity to the environment. The description includes a summary of the methodology employed. Appendix G contains additional details.

Potential accident consequences, frequencies, and risks are determined using the methods normally used in the Savannah River Site safety analyses (WSRC, 1991). Fault-tree analysis is used to determine the frequency of postulated accidents that result directly in the release of radioactivity. Fault-tree analysis is a formalized procedure that can be used to identify highrisk areas in a complex system. It is a deductive process whereby the analyst first postulates

\footnotetext{
${ }^{6}$ Integrated Risk Information System (IRIS) database as of March 31, 1993 [as presented in ORNL/M-3271, "Environmental Regulatory Update Table," DOE Office of Environmental Guidance (EH-23), March 1994].
} 
an unsafe or otherwise undesired condition, and then systematically analyzes the system to determine the lower-order fault events and component failures that will result in the unsafe condition.

The primary sources of data used in these fault trees for the Savannah River Site 200-Area facilities, which include the RBOF facility, are internal documents, audits, logbooks, and incident reports. Failure and maloperation information from these sources are stored in the Savannah River Technology Center computerized data bank (Durant et al., 1993). A computer program retrieves the sorted information according to area, facility, unit operation, type of equipment, or type of failure. From these data, failure frequencies for specific components or other errors are determined.

Quantities of radionuclides potentially released to the environment were estimated from the inventory present within the spent fuel, the airborne release mechanisms, and potential severity for each accident.

An evaluation of possible release scenarios based upon postulated initiating events resulted in four potential accidents that could release radionuclides to the atmosphere from offsite research reactor spent fuel:

- nuclear criticality

- fuel rupture in storage

- fuel rupture in cutting ${ }^{7}$

- release of Resin Regeneration Waste Tank activity ${ }^{8}$

The analysis for this EA is conservative, because the estimates of radionuclide inventories are for fuel discharged from the reactor exactly 150 days prior to shipment.

Radiological doses to the offsite maximally exposed individual are computed using the AXAIR89Q computer code (Pillinger and Huang, 1986; Huang and Lux, 1989; Hamby, 1990). The maximally exposed onsite person is defined as a worker at a distance of $640 \mathrm{~m}$ $(2080 \mathrm{ft}$.). Offsite population doses are based on population within 80 kilometers (50 miles) of the Savannah River Site using the 1990 census data. All releases are conservatively considered to be at ground level.

The following present the risk from storage of up to 1,000 (see Section 6.2.2) foreign research reactor spent fuel elements in the RBOF. As a result, this information represents a bounding estimate of impacts from any amount of foreign research reactor spent fuel elements up to

\footnotetext{
${ }^{7}$ Hardware projecting from ends of fuel rods may be cut-off to facilitate storage.

${ }^{8}$ The frequency and consequences of this accident would not change measurably after adding to RBOF the amount of fuel considered in the proposed action.
} 
1,000. Additional conservatism is built into the analyses due to the assumption that spent fuel has only cooled 150 days after being discharged from the reactor. In reality, most of the fuel has been in storage for several years. The accident analysis information presented here is based on the analysis detailed in Appendix G. The tables in this Chapter represent the consequences and risks for each significant potential accident.

The potential accident consequences, in terms of curies released to the atmosphere, are shown in Table 6.1-11 for four categories of release accidents that might occur during RBOF operations. Fifty-year committed effective dose equivalents to the maximally exposed individual at the Savannah River Site boundary and the maximally exposed co-located worker are shown in Tables 6.1-12 and 6.1-13 for the potential accident releases. Table 6.1-14 represents the committed effective dose equivalents to the off-site population within 80 kilometers (50 miles) of the Savannah River Site for the range of postulated accidents.

\section{Table 6.1-11. Radionuclide Releases and Frequencies Associated with a Potential Accident at the Savannah River Site}

\begin{tabular}{|l|c|c||}
\hline \multicolumn{1}{|c|}{ Potential Accident } & $\begin{array}{c}\text { Frequency } \\
\text { (per year) }\end{array}$ & Release (curies) \\
\hline \hline Criticality & 0.0031 & $3400 / 265^{\mathrm{a}}$ \\
\hline Fuel Rupture During Storage & 0.11 & 85 \\
\hline Fuel Cutting & 0.16 & 85 \\
\hline $\mathrm{RRF}^{\mathrm{b}}$ Waste Release to Cell & 0.0024 & 5 \\
\hline
\end{tabular}

${ }^{a}$ Releases (3400/265) are based on quantity of radionuclides present at one and 45 minutes after a potential criticality accident.

${ }^{b}$ RRF stands for Resin Regeneration Facility. 
Table 6.1-12. Consequences and Risks from Potential Accidents Maximally Exposed Individual at the Site Boundary

\begin{tabular}{|l|c|c|c|c|}
\hline Potential Accident & $\begin{array}{c}\text { Frequency } \\
\text { (per year) }\end{array}$ & $\begin{array}{c}\text { Release Dose } \\
\text { (rem) }\end{array}$ & $\begin{array}{c}\text { Dose Risk } \\
\text { (rem/year) }\end{array}$ & $\begin{array}{c}\text { Latent Cancer } \\
\text { Fatalities }\end{array}$ \\
\hline \hline Criticality & 0.0031 & 0.00015 & 0.00000045 & 0.00000000023 \\
\hline $\begin{array}{l}\text { Fuel Rupture } \\
\text { During Storage }\end{array}$ & 0.11 & 0.0000083 & 0.00000091 & 0.00000000046 \\
\hline Fuel Cutting & 0.16 & 0.0000083 & 0.0000013 & 0.00000000065 \\
\hline $\begin{array}{l}\text { RRF Waste Release } \\
\text { to Cell }\end{array}$ & 0.0024 & 0.0012 & 0.0000028 & 0.0000000010 \\
\hline & & & $\begin{array}{c}\text { Total Dose Risk: } \\
0.0000056\end{array}$ & \\
\hline
\end{tabular}

${ }^{2}$ Fifty-year committed effective dose equivalent.

Table 6.1-13. Consequences and Risks from Potential Accidents, Co-located Worker Maximally Exposed Individual

\begin{tabular}{|l|c|c|c|c||}
\hline Potential Accident & $\begin{array}{c}\text { Frequency } \\
\text { (per year) }\end{array}$ & $\begin{array}{c}\text { Release Dose } \\
\text { (rem) }\end{array}$ & $\begin{array}{c}\text { Dose Risk } \\
\text { (rem/year) }\end{array}$ & Latent Cancer Fatalities \\
\hline Criticality & 0.0031 & 0.0071 & 0.000022 & 0.0000000080 \\
\hline $\begin{array}{l}\text { Fuel Rupture } \\
\text { During Storage }\end{array}$ & 0.11 & 0.000081 & 0.0000089 & 0.0000000030 \\
\hline Fuel Cutting & 0.16 & 0.000081 & 0.000013 & 0.0000000050 \\
\hline $\begin{array}{l}\text { RRF Waste Release } \\
\text { to Cell }\end{array}$ & 0.0024 & 0.0099 & 0.000024 & 0.0000000090 \\
\hline & & & $\begin{array}{c}\text { Total Dose Risk: } \\
0.000068\end{array}$ & \\
\hline
\end{tabular}

a Fifty-year committed effective dose equivalent. 
Table 6.1-14. Consequences and Risks From Potential Savannah River Site Accidents, Offsite Population

\begin{tabular}{||l|c|c|c|c|}
\hline $\begin{array}{c}\text { Potential } \\
\text { Accident }\end{array}$ & $\begin{array}{c}\text { Frequency } \\
\text { (per year) }\end{array}$ & $\begin{array}{c}\text { Release Dose } \\
\text { (person-rem) }\end{array}$ & $\begin{array}{c}\text { Dose Risk } \\
\text { (person-rem } \\
\text { per yr) }\end{array}$ & $\begin{array}{c}\text { Latent Cancer } \\
\text { Fatalities }\end{array}$ \\
\hline Criticality & 0.0031 & 0.44 & 0.0014 & 0.0000007 \\
\hline Fuel Rupture & 0.11 & 0.07 & 0.0077 & 0.0000039 \\
\hline Fuel Cutting & 0.16 & 0.07 & 0.011 & 0.0000055 \\
\hline $\begin{array}{l}\text { RRF Waste } \\
\text { Release to Cell }\end{array}$ & 0.0024 & 10.0 & 0.024 & 0.000012 \\
\hline TOTAL & & & $\begin{array}{c}\text { Total Dose Risk: } \\
0.044\end{array}$ & \\
\hline
\end{tabular}

a Fifty-year committed effective dose equivalent.

The average consequence from the worst potential accident analyzed was estimated to result in a maximally exposed individual at the site boundary receiving a dose of $1.2 \mathrm{mrem}$ or 0.0012 rem (Table 6.1-12, RRF Waste Release to Cell). This dose corresponds to the potential accident of a fire and explosion at RBOF resulting from a flammable or explosive concentration of vapors. As a comparison, a person living in the Central Savannah River Area receives an average dose of approximately 380 mrem per year ${ }^{9}$ from all sources as cited in the Savannah River Site Environmental Report for 1992 (WSRC, 1993). This accident translates to a latent cancer fatality of 0.000000001 or a 1 in $1,000,000,000$ chance that an individual at the site boundary would develop a latent cancer fatality.

For the offsite population dose, the average consequence of the worst potential accident analyzed could result in a dose of 10 person-rem (Table 6.1-14). This exposure would be estimated to produce a 1 in 84,000 chance that a single fatal cancer would develop in the exposed population. As a comparison, for a general population, a collective dose of 2,000 person-rem is estimated to result in one additional latent cancer fatality.

For a bounding analysis, the maximum release dose was analyzed for all 4 potential accidents as discussed in Appendix G. The highest dose was attributed to the potential accident of 1000 fuel foreign fuel elements rupturing at RBOF. This event results in a $8.3 \mathrm{mrem}(.0083$ rem) maximum dose to the individual at the site boundary and 70 person-rem dose for the offsite population. Assuming a very conservative frequency of 0.00050 per year, the dose risk would be 0.0000042 rem per year or 0.000000002 latent cancer fatalities for the individual at the site boundary and 0.035 person-rem per year or 0.000018 latent cancer fatalities for the offsite population. This translates to a 1 in $500,000,000$ chance that the

\footnotetext{
${ }^{9}$ Throughout the document, the average annual radiation exposure from all sources to an individual living in the United States is represented as $360 \mathrm{mrem}$. Use of $380 \mathrm{mrem}$ in this chapter represents data more directly associated with the area around the Savannah River Site.
} 
individual at the site boundary would develop a latent fatal cancer or a 1 in 55,000 chance that a single fatal cancer would develop in the exposed population.

\subsection{Impacts of Alternatives to the Proposed Action}

The impacts of the following alternatives are discussed in the corresponding sections:

- No Action, Section 6.2.1

- Alternative Numbers of Fuel Elements, Section 6.2.2

- Receipt of Spent Fuel Elements at Alternate Ports, Section 6.2.3

- Transport of Spent Fuel by Rail, Section 6.2.4

- Transport of Low or Highly Enriched Uranium After Reprocessing Abroad, Section 6.2.5

\subsubsection{No Action}

A decision to take no action would result in no immediate environmental impacts in the United States. However, if no action is taken to accept spent fuel from the reactors that require urgent relief under the Environmental Assessment there will be immediate impacts upon each of the reactors, upon national and regional communities they support, and upon U.S. nonproliferation policy.

\subsubsection{Direct Impact Upon the Reactor Operators and National and Regional Communities}

For each of these reactors, shutdown would have a major impact. If the no action alternative results in the shutdown of these reactors, their spent nuclear fuel storage problem will not be solved. If stored in pools or placed in dry storage, the fuel elements will remain a potential target for terrorists instead of being removed from HEU inventories, as advocated in the United States' non-proliferation policy.

Additionally, shutdown of these reactors would have an impact upon the national and regional communities they support. Most of these reactors are the only sources of radiopharmaceuticals in their regions, sometimes encompassing more than one country. Often these reactors are important centers of medical and biological research. The sites where these reactors are located, many of them universities, are unique training facilities for students in many fields of research and development; materials science, environmental science, physics, biology and electronics.

In the medical arena, research reactors have proven to be vital to cancer therapy, diagnostic imaging, studies of the biological effects of radiation and other important medical applications. In Europe, there are 8,000 to 10,000 medical treatments per day using medical isotopes produced in research reactors. The reactors typically make deliveries of important, short half-life isotopes to regional hospitals for treatment of bone cancer and other cancers, 
heart and kidney disease and various other diseases. Demand for medically important radioisotopes cannot be expected to decrease merely because a nearby source of supply shuts down. The continuing demand means that medical facilities formerly supplied by shutdown reactors would satisfy their radioisotope needs by placing orders with remaining reactors, which would often be farther away. Many medically important isotopes (e.g., iodine-131) have such short half-lives that the amount shipped must include enough to allow for radioactive decay during shipment. Therefore, shutdown of reactors will result in the need to produce and ship even larger quantities of radiopharmaceuticals than is currently occurring.

One commercial enterprise which many of these reactors are engaged in is doping of silicon crystals through neutron irradiation. The doped silicon chips are widely used in electronic components such as the computers that control functions in automobile engines.

Graduates trained at these facilities contribute to a wide variety of nuclear industries and to government agencies involved with monitoring nuclear technology, e.g., regulatory agencies, IAEA inspections, hardware for inspections and remote monitoring.

\subsubsection{Impact Upon U.S. Nonproliferation Policy}

As described in Chapter 1, if prompt return of this fuel does not take place, the survival of the RERTR Program and the success of the United States policy to minimize and eliminate the civil use of HEU would be seriously jeopardized. Several reactor operators have stated categorically that, if the United States is unable to accept any near-term spent fuel shipments, they would have no practical choice but to terminate their participation in the RERTR Program, and rely on HEU fuels in the future. If some reactor operators were to withdraw from the RERTR Program and rely on HEU fuels, with the attendant lower costs and enhanced performance, other operators would demand to be put on the same footing. Additionally, a number of the countries involved are exporters of research reactor technology. In recent years, they have required those reactors exported to other countries to be fueled with LEU. However, if the reactor operators in the exporting country continue to use HEU, foreign reactor purchasers would demand HEU-fueled reactors as well. This could lead to renewed international commerce in weapons-useable HEU and would be directly contrary to the policy goal of seeking to minimize and eventually eliminate the civil use of HEU, reversing the significant progress made by the RERTR Program over the last decade.

Increased civil use of HEU brings with it the increased risk of diversion by rogue nations or terrorists. U.S. exports of HEU - which represented the lion's share of international commerce in this material - have declined steadily for more than a decade, reaching zero in 1993. This progress could be reversed and ultimately lost if HEU is re-legitimized as a reactor fuel. The dangers to society from even one possible nuclear explosion would dwarf all other possible environmental consequences identified under any of the other alternatives identified in this Environmental Assessment.

\subsubsection{Alternative Numbers of Fuel Elements}

The incident-free and accident risks associated with receipt of the alternative numbers of spent nuclear fuel elements discussed in Section 4.2 are illustrated in Tables 6.2-1 through 6.2-8. 
Table 6.2-1 and 6.2-2 show that the risks for the 953-element alternative are slightly more than double the risks for shipping 409 elements through the proposed ports (see Tables 6.1-8 and 6.1-9). This result is consistent with shipping slightly more than twice as many elements. Tables 6.2-3 through 6.2-8 show that the risks for the 353-, 291-, and 248-element alternatives are less than the values shown in Table 6.1-8 for the proposed ports. Again, the decreases are proportionate to the decreases in the number of elements shipped with the risks from shipping 248 elements being roughly 60 percent of the proposed action. As with the proposed action, the impacts associated with the shipment of the alternate numbers of elements are extremely small and somewhat less for direct shipment to the port of entry with no intermediate port stops.

Table 6.2-1 Transportation Radiological Impacts for Shipment of 953 Elements via the Proposed Ports and Truck Overland Transport Assuming Three Intermediate Port Stops and One Cask per Vessel

\begin{tabular}{||l|c|c|c|c||}
\hline \multirow{3}{*}{ Port Of Entry } & Transportation Dose Risk - Person-Rem & \multirow{2}{*}{ Total Person-Rem } & \multirow{2}{*}{ Total LCFs } \\
\cline { 2 - 5 } & Incident-Free & Accident & & \\
\hline Charleston & 0.28 & 0.110 & 0.38 & 0.00019 \\
\hline Jacksonville & 0.32 & 0.097 & 0.42 & 0.00021 \\
\hline Savannah & 0.29 & 0.110 & 0.39 & 0.00020 \\
\hline Sunny Point & 0.34 & 0.096 & 0.44 & 0.00022 \\
\hline Wilmington & 0.34 & 0.11 & 0.44 & 0.00022 \\
\hline
\end{tabular}

Table 6.2-2 Transportation Radiological Impacts for Shipment of 953 Elements via the Proposed Ports Assuming No Intermediate Port Stops and Eight Casks Per Vessel

\begin{tabular}{||l|c|c|c|c||}
\hline \multicolumn{5}{|c||}{ Alternative Ports - 953 Elements } \\
\hline \multirow{2}{*}{ Port Of Entry } & Transportation Dose Risk - Person Rem & \multirow{2}{*}{ Total Person-Rem } & Total LCFs \\
\cline { 2 - 5 } & Incident-Free & Accident & 0.28 & 0.00014 \\
\hline Charleston & 0.28 & 0.0011 & 0.32 & 0.00016 \\
\hline Jacksonville & 0.32 & 0.00033 & 0.29 & 0.00014 \\
\hline Savannah & 0.29 & 0.0014 & 0.34 & 0.00017 \\
\hline Sunny Point & 0.34 & 0.00015 & 0.34 & 0.00017 \\
\hline Wilmington & 0.34 & 0.00088 & & \\
\hline
\end{tabular}


Table 6.2-3 Transportation Radiological Impacts for Shipment of 359 Elements via the Proposed Ports and Truck Overland Transport Assuming Three

Intermediate Port Stops and One Cask Per Vessel

\begin{tabular}{||l|c|c|c|c||}
\hline \multirow{2}{*}{ Port Of Entry } & Transportation Dose Risk - Person-Rem & \multirow{2}{*}{ Total Person-Rem } & \multirow{2}{*}{ Total LCFs } \\
\cline { 2 - 5 } & Incident-Free & Accident & 0.17 & 0.000085 \\
\hline Charleston & 0.12 & 0.049 & 0.19 & 0.000095 \\
\hline Jacksonville & 0.14 & 0.046 & 0.18 & 0.000090 \\
\hline Savannah & 0.13 & 0.050 & 0.19 & 0.000094 \\
\hline Sunny Point & 0.16 & 0.045 & 0.18 & 0.000091 \\
\hline Wilmington & 0.15 & 0.048 & 0.959 Elements \\
\hline
\end{tabular}

Table 6.2-4 Transportation Radiological Impacts for Shipment of 359 Elements via the Proposed Ports and Truck Overland Transport Assuming No Intermediate Port Stops and Eight Casks Per Vessel

\begin{tabular}{||l|c|c|c|c||}
\hline \multirow{3}{*}{ Port Of Entry } & \multicolumn{5}{|c|}{ Transportation Dose Risk - Person-Rem } & \multirow{2}{*}{ Total Person-Rem } & \multirow{2}{*}{ Total LCFs } \\
\cline { 2 - 5 } & Incident-Free & Accident & & \\
\hline Charleston & 0.12 & 0.00055 & 0.12 & 0.000061 \\
\hline Jacksonville & 0.14 & 0.00016 & 0.14 & 0.000072 \\
\hline Savannah & 0.13 & 0.00068 & 0.13 & 0.000063 \\
\hline Sunny Point & 0.15 & 0.000075 & 0.15 & 0.000075 \\
\hline Wilmington & 0.15 & 0.00043 & 0.15 & 0.000075 \\
\hline
\end{tabular}


Table 6.2-5 Transportation Radiological Impacts for Shipment of 291 Elements via the Proposed Ports and Truck Overland Transport Assuming Three Intermediate Port Stops and One Cask Per Vessel

\begin{tabular}{||l|c|c|c|c||}
\hline \multirow{3}{*}{ Port Of Entry } & Transportation Dose Risk - Person-Rem & \multirow{2}{*}{ Total Person-Rem } & \multirow{2}{*}{ Total LCFs } \\
\cline { 2 - 5 } & Incident-Free & Accident & & \\
\hline Charleston & 0.076 & 0.030 & 0.11 & 0.000053 \\
\hline Jacksonville & 0.090 & 0.028 & 0.12 & 0.000059 \\
\hline Savannah & 0.079 & 0.031 & 0.11 & 0.000055 \\
\hline Sunny Point & 0.10 & 0.028 & 0.13 & 0.000065 \\
\hline Wilmington & 0.096 & 0.029 & 0.13 & 0.000063 \\
\hline
\end{tabular}

Table 6.2-6 Transportation Radiological Impacts for Shipment of 291 Elements via the Proposed Ports and Truck Overland Transport Assuming No Intermediate Ports and Eight Casks Per Vessel

\begin{tabular}{|c|c|c|c|c|}
\hline \multicolumn{5}{|c|}{ Proposed Ports - 291 Elements } \\
\hline \multirow{2}{*}{ Port Of Entry } & \multicolumn{2}{|c|}{ Transportation Dose Risk - Person-Rem } & \multirow{2}{*}{ Total Person-Rem } & \multirow{2}{*}{ Total LCFs } \\
\hline & Incident-Free & Accident & & \\
\hline Charleston & 0.075 & 0.00055 & 0.076 & 0.000038 \\
\hline Jacksonville & 0.089 & 0.00016 & 0.090 & 0.000045 \\
\hline Savannah & 0.079 & 0.00068 & 0.079 & 0.000040 \\
\hline Sunny Point & 0.091 & 0.000074 & 0.091 & 0.000046 \\
\hline Wilmington & 0.091 & 0.00043 & 0.091 & 0.000046 \\
\hline
\end{tabular}


Table 6.2-7 Transportation Radiological Impacts for Shipment of 248 Elements via the Proposed Ports and Truck Overland Transport Assuming Three Intermediate Port Stops and One Cask Per Vessel

\begin{tabular}{||l|c|c|c|c||}
\hline \multirow{3}{*}{ Port Of Entry } & Transportation Dose Risk - Person-Rem & \multirow{2}{*}{ Total Person-Rem } & \multirow{2}{*}{ Total LCFs } \\
\cline { 2 - 3 } & Incident-Free & Accident & & \\
\hline Charleston & 0.076 & 0.027 & 0.10 & 0.000051 \\
\hline Jacksonville & 0.090 & 0.025 & 0.12 & 0.000058 \\
\hline Savannah & 0.079 & 0.027 & 0.11 & 0.000053 \\
\hline Sunny Point & 0.010 & 0.025 & 0.13 & 0.000065 \\
\hline Wilmington & 0.096 & 0.026 & 0.12 & 0.000059 \\
\hline
\end{tabular}

Table 6.2-8 Transportation Radiological Impacts for Shipment of 248 Elements via the Proposed Ports and Truck Overland Transport Assuming No Intermediate Port Stops and Eight Casks Per Vessel

\begin{tabular}{|c|c|c|c|c|}
\hline \multicolumn{5}{|c|}{ Proposed Ports - 248 Elements } \\
\hline \multirow{2}{*}{ Port Of Entry } & \multicolumn{2}{|c|}{ Transportation Dose Risk - Person-Rem } & \multirow{2}{*}{ Total Person-Rem } & \multirow{2}{*}{ Total LCFs } \\
\hline & Incident-Free & Accident & & \\
\hline Charleston & 0.075 & 0.00055 & 0.076 & 0.000038 \\
\hline Jacksonville & 0.089 & 0.00016 & 0.090 & 0.000045 \\
\hline Savannah & 0.079 & 0.00068 & 0.079 & 0.000040 \\
\hline Sunny Point & 0.091 & 0.000074 & 0.091 & 0.000046 \\
\hline Wilmington & 0.091 & 0.00043 & 0.091 & 0.000046 \\
\hline
\end{tabular}

\subsubsection{Receipt of 409 Spent Fuel Elements at Alternate Commercial or Military Ports ${ }^{10}$}

The incident-free impacts associated with shipping the spent fuel through alternate commercial or military ports are shown in Tables 6.2-9 and 6.2-10. The overall impacts for the alternate ports are in some cases slightly higher than those of the proposed ports and in other cases the same or lower depending primarily on the distance from the port to the Savannah River Site. As shown in Table 6.2-9, similar to the risks for the proposed ports, the risks for the alternate ports are extremely small and are estimated to result in a one in 7,700 to a one in 10,000

\footnotetext{
${ }^{10}$ Risk estimates associated with alternate numbers of fuel elements associated with alternate ports are found in Appendix $\mathrm{L}$.
} 
chance of an additional latent cancer fatality depending on the port. Essentially no distinction can be drawn between the risks for the proposed and alternative ports.

The incident-free results display a marked correlation between the overland shipping distance for each port and the population dose. There are four factors that contribute to this observation:

1. The dose to handlers and port workers would essentially be the same from port to port, except perhaps for Yorktown and Kings Bay. Port operations may take longer at these military ports because of the lack of experience of the handlers in handling this type of cargo, and the lack of the specialized handling equipment found in normal container ship ports.

2. The dose to the ship crew is based on sea-route distance, and the dose to the truck crew is based on highway distance. For most of the proposed action ports and the alternative ports, the sea-route distances are roughly equal. Therefore, the overall differences in risk are dominated by the truck shipping distances.

Table 6.2-9 Transportation Radiological Impacts for Shipment of 409 Elements via the Alternate Ports and Truck Overland Transport Assuming Three Intermediate Port Stops and One Cask Per Vessel

\begin{tabular}{||l|c|c|c|c||}
\hline \multirow{2}{*}{ Port Of Entry } & Transportation Dose Risk - Person-Rem & \multirow{2}{*}{ Total Person-Rem } & \multirow{2}{*}{ Total LCFs } \\
\cline { 2 - 3 } & Incident-Free & Accident & & 0.00013 \\
\hline Elizabeth & 0.21 & 0.057 & 0.27 & 0.00010 \\
\hline Kings Bay & 0.15 & 0.053 & 0.20 & 0.00010 \\
\hline Morehead City & 0.15 & 0.053 & 0.20 & 0.00012 \\
\hline New Orleans & 0.18 & 0.054 & 0.24 & 0.00011 \\
\hline Newport News & 0.16 & 0.052 & 0.22 & 0.00011 \\
\hline Norfolk & 0.16 & 0.052 & 0.21 & 0.00011 \\
\hline Portsmouth & 0.16 & 0.053 & 0.21 & 0.00011 \\
\hline Yorktown & 0.17 & 0.048 & 0.22 & \\
\hline
\end{tabular}


Table 6.2-10 Transportation Radiological Impacts for Shipment of 409 Elements via the Alternate Ports and Truck Overland Transport Assuming No Intermediate Port Stop and Eight Casks Per Vessel

\begin{tabular}{||l|c|c|c|c|}
\hline \multirow{2}{*}{ Port Of Entry } & Transportation Dose Risk - Person-Rem & \multirow{2}{*}{ Total Person-Rem } & \multirow{2}{*}{ Total LCFs } \\
\cline { 2 - 3 } & Incident-Free & Accident & 0.20 & 0.000100 \\
\hline Elizabeth & 0.20 & 0.00091 & 0.14 & 0.000069 \\
\hline Kings Bay & 0.14 & 0.00043 & 0.14 & 0.000071 \\
\hline Morehead City & 0.14 & 0.00043 & 0.18 & 0.000088 \\
\hline New Orleans & 0.18 & 0.00056 & 0.16 & 0.000082 \\
\hline Newport News & 0.16 & 0.00034 & 0.16 & 0.000081 \\
\hline Norfolk & 0.16 & 0.00027 & 0.16 & 0.000080 \\
\hline Portsmouth & 0.16 & 0.00045 & 0.16 & 0.000079 \\
\hline Yorktown & 0.16 & 0.00014 & & \\
\hline
\end{tabular}

3. Most of each truck and rail route for each port traverses rural population zones, rather than urban or suburban routes, even for routes originating from ports in large cities.

4. The exposure of the public during routine truck rest and refueling stops is the major contributor to the overland component of dose. As noted in Section 6.1.2.1, stops would be minimized in actual practice.

The accident dose risk associated with the alternate ports studied is also shown in Table 6.2-9 for three intermediate port stops and one cask per vessel. Table 6.2-10 shows the accident risk for no intermediate port stop and eight casks per vessel. The variation in accident risk across all of the port options is small. Just as for the proposed action (Tables 6.1-8 and 6.19), the accident risk associated with port operations at each port alternative is sufficiently greater than the contribution of the truck shipment to that risk. The contribution of the latter does not influence the total. Because of this disparity, accident dose risk, unlike incident-free impacts, is relatively insensitive to shipment route distance.

\subsubsection{Transport of 409 Spent Fuel Elements by Rail from Proposed Ports of Entry to the Savannah River Site}

The combined incident-free and accident risks associated with receipt of 409 spent nuclear fuel elements at the proposed ports and transport overland by rail to the Savannah River Site are illustrated in Tables 6.2-11 and 6.2-12, for shipment assuming one cask per ship and three intermediate port stops and eight casks per ship with no intermediate port stops, respectively.

Only a slight increase in overall risk would be expected if rail were used for overland transportation instead of truck. A comparison of the total dose risk associated with use of rail 
transportation and the proposed action assuming three intermediate port stops (Table 6.1-8) indicates that the total dose risk estimate is fifteen percent higher for the options of Charleston and Savannah. There is essentially no difference in the dose risk estimates for Jacksonville, Sunny Point, and Wilmington. A similar trend is shown for the shipment of eight casks per vessel with no intermediate port stops (compare Tables 6.2-12 and 6.1-9). As with the proposed shipment by truck under the proposed action, the risks are extremely low using rail transportation and result in an estimated increased chance of one additional cancer death of one in 10,000 .

The small differences in the total risk are due primarily to differences in incident free dose estimates. A comparison of the incident-free dose estimates associated with this alternative (Table 6.2-13) and the proposed action (Table 6.1-4) illustrate these differences. The difference between incident-free estimates for truck and rail are due to differences in: the handler dose, public exposure along the transportation route, and conveyance crew exposure.

The port handler dose estimates for rail are approximately 50 percent higher than for truck. This is because the spent fuel casks would very likely be shipped two to a rail car, and handlers could receive additional dose from the first cask on a rail car as the second cask was loaded. When casks are loaded onto trucks each cask is immediately removed from the berth apron before another would be loaded. If casks were shipped one to a rail car, the handler dose estimates would be essentially the same as for loading the casks onto trucks.

Incident-free exposure to the public would be less for rail than for truck varying from between a factor of 25 for Savannah and 40 for Sunny Point. There typically are fewer members of the public sharing rail lines (e.g., passengers on AMTRAK) than for highways, and trains tend to stop only at rail yards to which the public does not have free access. Whereas, trucks tend to stop at rest areas or truck stops at which the public is more likely to be exposed.

The rail crew dose estimates are higher than for truck by a factor of between three to five. Inspection procedures practiced by railways require a rail worker to inspect the rail car and cask at each stop during transit.

Another potential difference in rail transportation versus truck could occur in the process of loading the casks from the ship. The port handler dose estimates in Table 6.2-13 are based on a single intermodal transfer of the spent fuel cask involving a direct ship-to-rail transfer. The cask would be directly off-loaded from the ship and loaded onto a rail car at the berth apron. However, it is not uncommon at ports for cargo to be first off-loaded from the ship onto a truck trailer and then transported a short distance within the terminal complex to a rail yard, where the cargo is then loaded onto rail cars. This process would involve two intermodal transfers and handling of the spent fuel casks at the port of entry. If this method were to be employed, the handler dose estimates could be approximately double those shown in Table 6.2-13. Incident-free dose estimates for this ship-to-truck/truck-to-ship intermodal transfer model are shown in Table L-21 of Appendix L. The only difference between the results of Table 6.2-13 (direct ship-to-rail intermodal transfer) and in Table L-21 (ship-to-truck/truck-toship intermodal transfer) are the dose estimates to the handlers. 
Rail shipment of the proposed action from the port of entry to the Savannah River Site would double the number of handling operations of each cask at the Savannah River Site depending on the option used for staging the casks at the Savannah River Site (Section 4.3). The lift height required to unload the cask would be less than 15 feet and therefore not challenge the cask integrity since the cask design assures no release of radioactive materials from a 30 foot drop onto an unyielding surface. The additional exposures and risks expected from handling the casks in the Savannah River Site rail classification yard can be compared to the risks calculated for the port handlers/inspectors discussed in Sections 6.1 and 6.1.2. Additional Savannah River Site personnel exposures during handling operations of the casks, prior to unloading at RBOF, would be similar to the port handlers.

Table 6.2-11 Transportation Radiological Impacts for Shipment of 409 Elements via the Proposed Ports and Rail Overland Transport Assuming Three Intermediate Port Stops and One Cask per Vessel

\begin{tabular}{||l|c|c|c|c||}
\hline \multicolumn{5}{|c|}{ Proposed Ports - Rail - 409 Elements } \\
\hline \multirow{2}{*}{ Port of Entry } & Transportation Dose Risk - Person-Rem & \multirow{2}{*}{ Total Person-Rem } & \multirow{2}{*}{ Total LCFs } \\
\cline { 2 - 5 } & Incident-Free & Accident & & \\
\hline Charleston & 0.16 & 0.054 & 0.21 & 0.00011 \\
\hline Jacksonville & 0.16 & 0.051 & 0.20 & 0.00010 \\
\hline Savannah & 0.16 & 0.055 & 0.21 & 0.00011 \\
\hline Sunny Point & 0.16 & 0.050 & 0.21 & 0.00011 \\
\hline Wilmington & 0.16 & 0.053 & 0.21 & 0.00011 \\
\hline
\end{tabular}

Table 6.2-12 Transportation Radiological Impacts for Shipment of 409 Elements via the Proposed Ports and Rail Overland Transport Assuming No Intermediate Port Stops and Eight Casks per Vessel

\begin{tabular}{||l|c|c|c|c||}
\hline \multirow{2}{*}{ Port of Entry } & \multicolumn{5}{|c|}{ Proposed Ports - Rail - 409 Elements } \\
\cline { 2 - 4 } & Incident-Free & Accident & & \multirow{2}{*}{ Total LCFs } \\
\hline Charleston & 0.15 & 0.0048 & 0.15 & 0.000075 \\
\hline Jacksonville & 0.15 & 0.0014 & 0.15 & 0.000075 \\
\hline Savannah & 0.15 & 0.0057 & 0.16 & 0.000080 \\
\hline Sunny Point & 0.16 & 0.0005 & 0.16 & 0.000080 \\
\hline Wilmington & 0.16 & 0.0038 & 0.16 & 0.000080 \\
\hline
\end{tabular}


Table 6.2-13. Incident-Free Radiological Risk for the Alternative Action: Shipment of 409 Spent Nuclear Fuel Elements to the Savannah River Site via Rail Transportation with Direct Ship-to-Rail Intermodal Transfer at the Port Of Entry a

\begin{tabular}{|c|c|c|c|}
\hline Port of Entry & Exposure Category & $\begin{array}{l}\text { Annual Dose } \\
\text { (person-rem) }\end{array}$ & Latent Cancer Fatalities \\
\hline \multirow[t]{5}{*}{ Charleston } & Port Handlers/Inspectors & 0.12 & 0.000059 \\
\hline & Other Port Workers & 0.0039 & 0.0000020 \\
\hline & Public & 0.0012 & 0.00000059 \\
\hline & Rail Crew & 0.029 & 0.000015 \\
\hline & Total & 0.15 & 0.000077 \\
\hline \multirow[t]{5}{*}{ Jacksonville } & Port Handlers/Inspectors & 0.12 & 0.000059 \\
\hline & Other Port Workers & 0.0039 & 0.0000020 \\
\hline & Public & 0.0014 & 0.00000068 \\
\hline & Rail Crew & 0.031 & 0.000015 \\
\hline & Total & 0.15 & 0.000079 \\
\hline \multirow[t]{5}{*}{ Savannah } & Port Handlers/Inspectors & 0.12 & 0.000059 \\
\hline & Other Port Workers & 0.0039 & 0.0000020 \\
\hline & Public & 0.0010 & 0.00000051 \\
\hline & Rail Crew & 0.029 & 0.000014 \\
\hline & Total & 0.15 & 0.000078 \\
\hline \multirow[t]{5}{*}{ Sunny Point } & Port Handlers/Inspectors & 0.12 & 0.000059 \\
\hline & Other Port Workers & 0.0039 & 0.0000020 \\
\hline & Public & 0.0017 & 0.00000083 \\
\hline & Rail Crew & 0.032 & 0.000016 \\
\hline & Total & 0.16 & 0.00008 \\
\hline \multirow[t]{5}{*}{ Wilmington } & Port Handlers/Inspectors & 0.12 & 0.000059 \\
\hline & Other Port Workers & 0.0039 & 0.0000020 \\
\hline & Public & 0.0017 & 0.00000083 \\
\hline & Rail Crew & 0.032 & 0.000016 \\
\hline & Total & 0.16 & 0.00008 \\
\hline
\end{tabular}

a The values presented for each port assume that all shipments in the proposed action pass through the port. In that event, the risk to all other groups at each of the other ports would be zero. The risks would be directly proportional to the number of casks actually unloaded at each port.

Rail accident risk is also similar to truck accident risk. For either transportation option, overland accident risk is a small contribution to the total accident risk, which is dominated by port accident risk. 


\subsubsection{Transport of Low or Highly Enriched Uranium to the United States After Reprocessing Spent Fuel Abroad}

The potential environment impacts of transporting low-enriched uranium (LEU) by oceangoing vessel into the United States were analyzed in detail in two recently issued Environmental Assessments (USEC, 1993 and USEC, 1994). These Environmental Assessments were issued by the United States Enrichment Corporation (USEC), which determined that many shipments of large quantities of LEU through United States seaports and their overland transport to a gaseous diffusion plant entailed insignificant impacts. These conclusions were reached after a thorough evaluation of postulated accidents and routine impacts and recognition of the fact that LEU is a common commercial product that has been safely shipped around the world by air, water, and land transport modes for over 30 years.

Under this alternative, the United States would purchase at a maximum approximately $1,000 \mathrm{~kg}$ of highly enriched uranium (HEU) retrieved during reprocessing. If the HEU were blended down in Europe to LEU at a commercial assay (the concentration by weight percent of U-235 to the total uranium content) of about five percent and assuming the HEU was 80 percent U-235, the HEU would produce $16,000 \mathrm{~kg}$ (16 metric tons) of LEU. In comparison, the USEC will purchase and ship 15,250 metric tons of LEU in only one of their programs. The LEU quantities resulting from reprocessing foreign research reactor fuel would be much less than the USEC LEU quantities. Accordingly, the potential impacts would be much less than the previously determined insignificant impacts resulting from LEU shipments.

If the HEU were not blended down to LEU in Europe but transported to the United States for blending, HEU would have to be transported from Dounreay in Scotland to the United States. The shipment of HEU was not assessed in the USEC's Environmental Assessments. Shipment of HEU would require extensive security activities and would likely include involvement or the use of military assets for protection and safety. The military has considerable experience in shipment of HEU and has safely transported such materials throughout the world.

The potential environmental impacts of shipping HEU to the United States for storage would be the same as those of shipping HEU to the United States for blending into LEU. There would be some potential risk associated with the storage of the HEU, but DOE has safely stored HEU, without incident, at various facilities for many years. As a result, DOE has significant experience with storage of HEU and has in place appropriate safeguard and security measures.

\subsection{Cumulative Impacts}

Cumulative impacts are those that result from the incremental impact of the proposed action when added to other past, present, and reasonably foreseeable future actions. (See 40 CFR $\$ 1508.7)(C E Q, 1978)$. This section describes the cumulative impacts resulting from the proposed action. 
To calculate cumulative radiological impact, maximum annual doses from the proposed action and from other radioactive materials transportation in the same facilities, along the same routes, and projected to occur during the same time as the proposed action are added. This approach neglects the fact that dose fractionation (delivery of a total dose in a number of separate doses spread over time) may reduce the effect of the total cumulative dose (Ullrich et al., 1987; Miller et al., 1989).

In addition to the fifteen shipments of spent nuclear fuel from the proposed action, the Savannah River Site also plans to transport approximately 50 shipments of spent nuclear fuel as part of its normal operations. Also, Barnwell, a low-level waste disposal facility located east of the Savannah River Site, receives approximately $22,650 \mathrm{~m}^{3}\left(800,000 \mathrm{ft}^{3}\right)$ of low-level radiological waste per year. This translates to 412,000 curies. This waste is shipped from throughout the United States to Barnwell by truck, resulting in approximately 2,700 individual truck shipments per year. Some of these shipments use the same transportation routes described in the proposed action.

\subsubsection{Cumulative Transportation Impacts}

The following sections discuss the cumulative radiological impacts that the proposed action would have on the workers and the general public who would be exposed as a result of the proposed action. The first section describes the results of the "Final Environmental Statement on the Transportation of Radioactive Material by Air and Other Modes," NUREG-0170 (USNRC, 1977). The section discusses the doses received from the proposed action in relation to natural background radiation and estimates from NUREG-0170. The second section summarizes the cumulative effect evaluation.

\subsubsection{NUREG-0170 and Other Studies on Population Exposures}

The proposed action is similar in every respect to spent nuclear fuel transportation activities that have already taken place in the same locations and along the same routes. The proposed action is similar in many respects to other radioactive material transportation that is taking place in the same locations and along similar routes. The transportation of radioactive materials and shipments of spent nuclear fuel to support the fuel cycle, in particular, were assessed in the "Final Environmental Statement on the Transportation of Radioactive Material by Air and Other Modes, NUREG-0170" (USNRC, 1977). This Environmental Statement considered the risk of transporting various types of packages of radioactive materials including spent fuel along transportation corridors, such as the ones which would be used for the proposed action, and determined that the total annual incident-free and accident risk was minimal. More recent studies of radioactive material shipments indicate no substantial change in the number of shipments or in their characteristics that would invalidate the general result of NUREG-0170 (Weiner, et al., 1991). Because the transportation of the spent nuclear fuel would meet the same regulations as cited in NUREG-0170, the total risk for all transportation activities is still negligible. For individuals residing near principal transportation routes, NUREG-0170 estimated that the average annual individual dose from radioactive material transportation activities was about $0.09 \mathrm{mrem}$. Recently, Weiner et al. (1991) estimated that a maximally exposed individual member of the public would not receive more than 0.14 mrem if exposed to the in-transit passage of all of the $1,611,443$ radioactive materials packages 
shipped in the United States in a single year. This is, of course, not a realistic scenario, but it does place an upper bound on the individual in-transit dose from other shipments.

Mills and Neuhauser (1994) estimated the individual in-transit dose, for a person located 30 meters from an average route segment, as only $0.00009 \mathrm{mrem}$. However, the number of radioactive materials shipments occurring annually in the vicinity of the Savannah River Site could exceed the average radioactive materials traffic on the nation's roadways because of (1) the proximity of a low-level waste repository near Barnwell, South Carolina, and (2) the variety of shipments that enter and leave the Savannah River Site to support other DOE programs. NUREG-0170 used annual shipment levels for the United States as a whole to obtain maximum individual dose estimates. The two classes of shipments considered in NUREG-0170 that can be used to conservatively model traffic in the Savannah River Site vicinity are spent fuel shipments (250 commercial reactor shipments) and secondary transport. Secondary transport is the shipment by light-duty vehicles of consignments of a large variety of packages (Type A and small Type B packages) in cities and suburbs along secondary roadways and city streets. NUREG-0170 estimated that the dose to an individual living $30 \mathrm{~m}$ from a roadway on which all 250 spent fuel shipments pass would be $0.009 \mathrm{mrem}$ and that no individual would receive more than an additional 0.009 mrem from secondary transport, which gives a total of 0.018 mrem from these sources. The maximum annual dose to a person exposed to local highway traffic in the vicinity of the Savannah River Site is unlikely to exceed $0.018 \mathrm{mrem}$. Therefore, the average annual individual dose remains valid for considering the cumulative impacts associated with the proposed action.

\subsubsection{Estimated Doses for the Proposed Action}

Calculations have been carried out to estimate the maximum occupational and public doses associated with the transportation of the foreign research reactor spent nuclear fuel. The calculated maximum annual exposure a member of the public would receive from routine transportation activities associated with the proposed action is 0.002 mrem (see Table 6.1-6.) This dose is small in comparison with the individual dose estimated in NUREG-0170, which is the accumulation over all shipments, not just those of an individual agency. Along the transportation corridors that would be used in implementing the proposed action, the average annual effective dose equivalent for a member of the general population from all sources of radiation is 360 mrem (NAS, 1990).

The maximum exposure for a worker involved in transporting the foreign research reactor spent nuclear fuel is predicted to result from activities associated with the unloading of the spent fuel casks in port, cask inspection and preparation for truck shipment of the cask to the Savannah River Site. If the same individuals were present for all proposed shipments of spent nuclear fuel (a conservative assumption), the maximum dose would be 0.0052 rem or 5.2 mrem. Each of the ports proposed as a port of entry routinely receives commercial shipments of radioactive materials.

An additional source of radiation exposure could be from shipments resulting from the purchase of Russian LEU under the Agreement Suspending the Antidumping Investigation of Uranium from the Russian Federation. The ports and estimated doses associated with this action are described in the United States Enrichment Corporation Environmental Assessment 
(USEC, 1993a). An additional action proposed by the USEC is the import of Russian LEU derived from the dismantlement of nuclear weapons in Russia (USEC, 1994). If the same individuals were present for all shipments under the proposed action, one-third of all commercial shipments of radioactive material shipped during a 12-month period, one-third of the Anti-Dumping Investigation Shipments of LEU, and one-third of the proposed first year's shipment of Russian weapons-derived LEU, the annual cumulative dose for the proposed ports of entry would be $10 \mathrm{mrem}$ or less as shown in Table 6.3-1. As can be seen in Table 6.3-1, the cumulative dose is small for all ports, and well below the regulatory limit of $100 \mathrm{mrem} / \mathrm{yr}$ established by NRC regulations to protect a member of the general public (FR, 1991).

The maximum exposure for a port worker involved in transporting the foreign research reactor spent nuclear fuel is approximately $\mathbf{5 . 2} \mathrm{mrem}$, while the maximum exposures for transportation workers are approximately 4.5 and 4 mrem for ship and truck crew members respectively (see Tables 6.1-1 and 6.1-3) and could be up to $10 \mathrm{mrem}$ for a rail inspector who inspected rail cars carrying all fifteen casks. The exposure estimate for port workers is a function of the number of cask shipments. The exposure estimate for the ship and truck crews is a function of the distance between the European and U.S. ports and the Savannah River Site.

\subsubsection{Summary of Cumulative Transportation Effect Evaluation}

The analysis contained in NUREG-0170 includes shipments of spent nuclear fuel. As a result, the doses to the general public that would result from the proposed action are encompassed by the estimated average individual dose of $0.09 \mathrm{mrem}$. The average annual individual dose to members of the public from incident free transportation associated with the proposed action is calculated by dividing the public population dose estimates in Table $6.1-4$ by the appropriate potentially exposed population for each port option (Appendix E). For each port option, this value would be less than $0.001 \mathrm{mrem}$, which is well below NUREG-0170's estimated average dose for all radioactive material shipments in the United States.

\subsubsection{Cumulative Storage Impacts}

As stated in Section 6.1.3.3 the proposed action is expected to result in a maximum individual worker dose of $60 \mathrm{mrem}$ over the life of the proposed action, assuming the same workers are involved in each unloading evolution (a conservative assumption). DOE requirements allow workers to receive occupational radiation exposure of up to $5,000 \mathrm{mrem}$ per year although the DOE administrative control level is 2,000 mrem per year, per person, for all DOE activities (DOE N 5480.6, U.S. Department of Energy Radiological Control Manual, prepared by the Assistant Secretary for Environment, Safety, and Health. June 1992). Because the amount of foreign research reactor spent nuclear fuel involved in the proposed action would not measurably affect the RBOF's current inventory of spent fuel, no measurable cumulative impacts would be associated with the proposed action and any foreseeable future annual activities. 
Table 6.3-1. Cumulative Individual Annual Radiation Dose for Maximally Exposed Individuals in Proposed Ports of Entry

\begin{tabular}{||l|c|c|c|c|c||}
\hline & \multicolumn{5}{|c|}{ Dose from Port Activity (mrem) } \\
\hline Port of Entry & $\begin{array}{c}\text { Proposed } \\
\text { Action }\end{array}$ & $\begin{array}{c}\text { Commercial } \\
\text { Shipments }\end{array}$ & $\begin{array}{c}\text { Anti-Dumping LEU } \\
\text { Shipments }\end{array}$ & $\begin{array}{c}\text { Weapons- } \\
\text { Derived LEU }\end{array}$ & $\begin{array}{c}\text { Total Annual } \\
\text { Dose }\end{array}$ \\
\hline Charleston & 5.2 & 0.3 & 0.9 & 1.4 & 7.8 \\
\hline Jacksonville & 5.2 & NA & NA(A) & NA(A) & 5.2 \\
\hline Savannah & 5.2 & 3.4 & NA(A) & 1.4 & 10.0 \\
\hline Sunny Point & 5.2 & NA & NA(A) & NA(A) & 5.2 \\
\hline Wilmington & 5.2 & NA & NA(A) & NA(A) & 5.2 \\
\hline \hline
\end{tabular}

The values presented for each port assume that all shipments of the proposed action pass through that port. In that event, the risk to the public from the proposed action at each of the other ports would be zero.

bee USEC 1993 for details on the calculations of this estimated dose.

$\mathrm{NA}=$ information not available, assumed to be zero.

$\mathrm{NA}(\mathrm{A})=$ not applicable because LEU was not proposed for shipment through this port. 


\subsection{AGENCIES CONSULTED}

The following agencies were consulted in the development of the Environmental Assessment.

Federal Agencies

Arms Control Disarmament Agency

U.S. Department of State

U.S. Department of Defense

U.S. Department of Army

U.S. Coast Guard

U.S. Merchant Marine Academy

\section{Port Authorities}

Georgia Ports Authority

Jacksonville Port Authority (Florida)

North Carolina Port Authority

South Carolina Port Authority

Virginia Port Authority

\section{Other}

Belgian Nuclear Research Centre

Interfaculty Reactor Institute, Delft University of Technology, The Netherlands Joint Research Centre-Petten, Institute for Advanced Materials, The Netherlands Risoe National Laboratory, Denmark

Studsvik Nuclear AB, Sweden

Hahn-Meitner Institut Berlin, Germany

GKSS Research Center, Germany

Paul Scherrer Institute, Switzerland

Austrian Research Centre, Austria

National Center for Scientific Research, "Demokritos", Greece

Australian Nuclear Science \& Technology Organization (ANSTO)

United Kingdom Atomic Energy Authority, Thurso, Dounreay Caithness, Scotland 
APPENDIX A

SUPPLEMENTAL MATERIAL REGARDING THE NEED FOR THE PROPOSED ACTION 


\section{APPENDIX A}

\section{SUPPLEMENTAL MATERIAL REGARDING THE NEED FOR THE PROPOSED}

ACTION

1. Karsten Haack (RERTR Conference Secretary) Letter to Admiral Watkins (Secretary of Energy), October 1, 1992

2. Lawrence S. Eagleburger (Secretary of State) letter to Admiral Watkins, October 26, 1992

3. Ronald F. Lehman II (Director of ACDA) letter to Admiral Watkins, December 7, 1992

4. Hans Blix (Director General of the IAEA) letter to Hazel O'Leary (Secretary of Energy), July 1, 1993

5. Warren Christopher (Secretary of State) letter to Secretary O'Leary, July 2, 1993

6. Secretary O'Leary letter to Secretary Christopher, including the Proposed Foreign Research Reactor Spent Nuclear Fuels Acceptance Policy, July 13, 1993

7. Dr. W. Krull (GKSS) letter to Victor Alessi (DOE), October 15, 1993

8. Paper presented at the 1993 International RERTR Conference by Dr. W. Krull

9. Peter Tarnoff (State) letter to Secretary O'Leary, November 30, 1993

10. Thomas P. Grumbly (DOE) letter to E. D. Hondros, March 25, 1994

11. White House Fact Sheet, Nonproliferation and Export Control Policy, September 27, 1993

12. Secretary O'Leary letter to Secretary Christopher, January 19, 1994

13. Letter to Mr. Thomas P. Grumbly (DOE), April 6, 1994, from Arand Hermans, Deputy Director of Electricity, Ministerie van Economische Zaken 
15 INTERNATIONAL MEETING ON REDUCED ENRICHMENT FOR RESEARCH AND TEST REACTORS

SEPTEMBER 27 TO OCTOBER 1, 1992 IN ROSKILDE, DENMARK

\author{
Adn. James D. Watkins \\ secretary of Energy \\ Onited states Department of inergy \\ Forrestal Bullding \\ 1000 Independence Avenue \\ s.H. Hashington, DC 20585 \\ USA
}

1992-10-01

$\mathrm{Ks} / \mathrm{KuH} / \mathrm{GC}$

Dear secrotary watkins,

Is you may know, some one-hundred attendees from across the globe are gathered this week In Roskilde, Denmark, for the 15th snnual Conference on Reduced Bnricbwent for Research and lest Resctors (RIRTR). I am writing to inform you that the attendees, representing non-0s reactor operators, oxpressed thair deep concern on the situation with the back-and of the fuel cycle and draw your attention to the Iollowing:

Iany of the research reactor operators, in agreoment with thoir respective governments, beve Joined the RiRTR Programe, thus eupporting the US policy to reduce the proliferation riske. An important consideration zor this common effort has been the roturn of the spent fuel from research reactors to the United States under the off-site ruels polloy of the Department of Energy, covering Low Enriched Uranium (IEU) and High Enrtahed Uraniux (HED) IUal.

The United states Departmont of inergy has not renewod - and appears unwilling to comit to renew - the off-gite Fuels Pollcy for the recelpt of epent HEJ-fual Irom forelgn research and test reactors.

The Department of Energy's programe for the receipt of opent IvU fuel from foreign rescarch and tost reactors is set to oxpire on December 31, 2992.

Heny of the partlelpants in the RERIR Programme therefore have no means to cope with the beok-end of the nuclear fuel oycle, in partioular those which do not have a nuclear power programe. 
roreign research and test reactors have incurred substantial offorts in switching from $B B D$ fuel to LED fual and in continuing to maintain LEU Iuel without any tanglble corresponding benefits.

It is the opinion of the majority of attendees, representing the non-US research and tests reactor operators at the 1992 RERTR conference, that the non-renewal of the off-site Fuels Polidy feopardizes the non-proliferation achievements up to now and removes the incentive for a contiunued support to us nonproliferation efforts.

I submit this natter for your consideration with the hope that the Department of Energy may yet find it feasible to reverse this widespread sentiment among the foreign research reactor comunity.

Very sincerely yours,

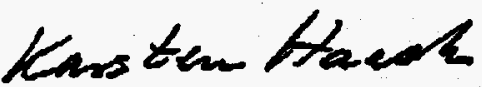

Karsten Haack

secretary of the Conference

c/0 Research Reactor DR 3

Risø Mational Laboratory

P.0. Box 49

DK-4000 Roskilde

Denmark

$(\operatorname{Fax}+45-46-755052)$

ce:

- John Baston,

Assistant secretary for Dowestic and International Bnergy Policy

Fax: 009-1-202-586-0861

- Victor Alessi

Director of the office of Arms Control and Nonprofileration Fax: 009-1-202-586-6789 


\section{DEPARTMENT OF STATE WASHINGTON}

October 26,1992

Dear Mr.

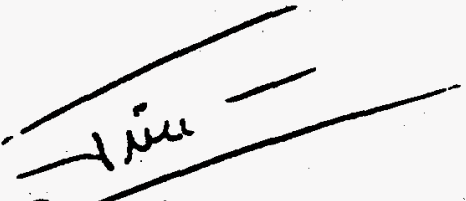

During the 1992 International Meeting on Reduced Enrichment for Research and Test Reactors (RERTR) in Denmark, participants voiced very strong concern regarding the apparent reluctance of the Department of Energy to renew the off site Fuels Policy, to take back spent research reactor fuel from abroad.

Since 1978, the United States has encouraged countries to convert from the use of high enriched fuel (HEU) to low enriched fuel (LEU). This effort constitutes a key element of U.S. nuclear non-proliferation policy, which has been accepted with some reluctance by other countries, since it entails additional effort and expense on their part. Historically, the off Site Fuels Policy has been an integral part of the conversion effort, which is perceived by countries as essential to meet reactor operating licensing requirements for disposition of spent fuel and to assure that their research reactor spent fuel is disposed of in a safe and reliable manner.

I fully recognize that renewal of this program will require DOE to resolve difficult and complex budgetary, environmentai and technical issues. However, for a variety of reasons, I believe it is essential for DOE to move promptly to renew its policy of taking back foreign research reactor fuel.

We have worked hard for many years to reestablish the position of the United states as a reliable partner in nuclear commerce. We should not forfeit this effort by appearing uncertain about a policy which we have long supported and which is so critical to our non-proliferation objective of eliminating HEU from commercial use.

Clearly, we also do not want to forfeit the significant nuclear non-proliferation gains which have resulted from the RERTR program and our agreement to take back foreign research reactor spent fuel. Limiting the use and location of HEU abroad serves the security interests of both the United states

The Honorable

James D. Watkins,

Secretary of Energy. 
and the international community as a whole. Hence, it is particularly disturbing to hear that some countries are considering halting their conversion programs, and even reverting to the use of HEU fuels in the event the United States does not agree to take back U.S.-supplied LEU spent Euel.

Over the past four years, we have maintained a dialogue with DOE concerning the importance of the spent fuel policy. Given the urgent need to resolve this matter, I strongly urge that DOE move quickly to reassure other governments that their spent fuel needs will be fully addressed and that we will continue to honor our comitments to them.

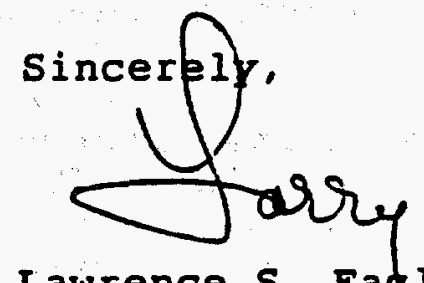

Lawrence S. Eaqleburger Acting Secretaty 


\section{UNITED STATES ARMS CONTROL AND DISARMAMENT AGENCY \\ Washington, D.C. 20451}

THE DIRECTOR

O TOEC 1992

\section{MEMORANDUM FOR THE SECRETARY OF ENERGY}

SUBJECT: Reducing Foreign Inventories of U.S.-Supplied Highly Enriched Uranium

For many years the United States has encouraged reduced use of highly enriched uranium (HEU) for civil purposes as a key component of U.S. nuclear nonproliferation policy. This effort has met with some success, and the civil use of HEU has diminished, bringing reduced stockpiles and reduced transportation and diversion risks. An important incentive for foreign users of U.S.-supplied HEU to convert their reactors to low enriched uranium (LEU) fuel was the United states' program to take back the spent fuel.

Recent historic political developments have also presented opportunities for further reducing stockpiles of HEU abroad, thereby further promoting our nuclear nonproliferation objectives. We are arranging to purchase 500 metric tons of HEU from Russia for peaceful uses. South Africa has ended its HEU production and has offered to sell its stockpile to the United States.

I believe we shculd consolidate these gains and encourage further reduction of civil HEU use. It is essential to act soon to avoid damaging the longstanding and successful U.S. program that encouraged foreign operators to convert HEU research reactors fueled by the United states to the use of LEU fuel. Without appropriate action, some foreign operators might decide against conversion and others may switch back to HEU fuel. Moreover, new foreign suppliers of HEU may emerge.

In this regard, I have three recommendations:

1. Conclude contractual arrangements with appropriate foreign organizations to take back U.S.-supplied research reactor fuel following any necessary environmental determination.

2. Examine the feasibility of additional incentives that would be helpful or necessary toward ensuring the conversion 
$-2-$

of those reactors for which alternative LEU fuels have been identified. A general review of the conversion program may be appropriate in any event in view of the recent amendment to the Atomic Energy Act which severely restricts future HEU licensing. In regard to that legislation, we would also support efforts to reestablish the LEU target development program for production of medical isotopes.

3. Ensure that the United States will make South Africa an attractive offer for its HEU.

I do not underestimate the difficulties posed by these recommendations. However, actions such as these would maintain and strengthen a longstanding and successful U.S. policy of reducing HEU stockpiles abroad -- a policy which will continue to promote global nuclear nonproliferation objectives.

Ronald 2. Lehman II

Ronald F. Lehman II 


\section{Dear Madam Secretary,}

Since 1978, the United States has encouraged countries to convert the cores of their research and test reactors from the use of highly enriched uranium (HEU) to nuclear fuels of low enriched uranium (LEU). This effort, initiated by President Carter, was an important element of the U. S. non-proliferation policy throughout most of the 1980s and was fully supported through the Reduced Enrichment for Research and Test Reactors (RERTR) programme by the International Atomic Energy Agency. The expiration of the U. S. Department of Energy's Off-Site Fuels Policy (the Policy) in 1988 has led to a crisis for the operators of research reactors in many countries where the laws are such that continuation of licensing and/or purchase of new nuclear fuels is contingent upon a resolution of spent fuel management problems. This situation is exacerbated for many reactor operators who complied with the wishes of the U. S. and converted their cores to LEU. They now have interim storage pools filled with irradiated HEU fuels and are trying to cope with a greater throughput of LEU fuels. The anticipated announcement that the U.S. DOE will renew the Policy and in due course begin the take back of research reactor fuels of U.S. origin from around the world will be very much welcomed by the Agency and many of its Member States.

However, because of the problems of spent fuel management facing the operators of many research reactors the Agency urges the earliest implementation of the Policy renewal. Some of these research facilities are the only sources of radioisotope production for medical uses in the countries in question, but face imminent closure unless they can resolve their problems of spent fuel management quickly. The Agency has initiated programmes to advise them, but the real solution for most of them is to return their irradiated research reactor fuels of $U$. S. origin. It is understood that the renewal of the Policy will require the solution of difficult and complex budgetary, environmental, transportation, legal and technical issues. Nevertheless, the Agency is confident that when the resources of the U. S. DOE are brought to bear on these problems that they will be resolved as soon as possible. 
Limiting the use and location of HEU fuels throughout the world remains a valuable objective and will serve the security interests of all nations. The Agency stands ready to help in any way it can consistent with its mandate and budgetary constraints.

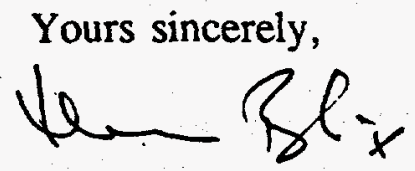

Hans Blix 


\section{THE SECRETARY OF STATE}

WASHINGTON

July 2, 1993

Dear Madam Secretary:

I am writing to urge your personal support for renewal by the Department of Energy of the off Site Fuels Policy for the acceptance of spent research reactor fuel from abroad.

The Department of state has strongly supported this pojicy because of its importance in gaining foreign cooperation in converting reactors from highly enriched uranium (HEU) to low enriched (LEU) fuel under the aegis of the Reduced Enrichment in Research and Test Reactors (RERTR) Program.

We recall Secretary Watkins confirmed in 1992 that the Department of Energy proposed to renew the off site Fuels Policy, but with the caveat that meeting the requirements of the National Environmental Policy Act (NEPA) could take as long as 2 to 3 years. We are concerned, however, about reports of substantial delays in the amendment of the existing Environmental Assessment, an essential early step in the NEPA prucess.

Foreign research reactor operators are reportedly highly concerned about a perceived change in DOE policy and have threatened to withdraw from further RERTR cooperation and to seek resumption of HEU supply from sources such as Russia.

A breakdown of the international consensus on conversion of research and test reactors to LEU and a return to an HEU fuel economy would undermine 15 years of intensive U.S. non-proliferation efforts on this matter and substantially renure the ability of the r.s. to influenre nuclear poljoy in bilateral and international fora.

In light of current developments, I urge your support for early reaffirmation by DOE to other governments of our continued commitment as a reliable supplier to Eully address their spent fuel needs.

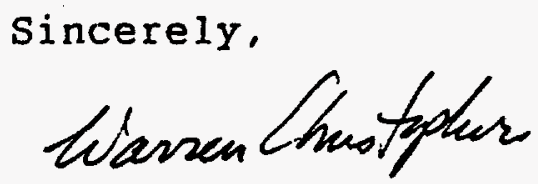

Warren Christopher

The Hono:able

Hazel R. O'Leary, Secretary of Energy. 


\section{DRAFT}

\section{Proposed Foreign Research Reactor Spent Nuclear Fuels Acceptance Policy}

PURPOSE - This proposed Department of Energy policy would support United States nonproliferation policy, including one of its key elements, the Reduced Enrichment Research and Test Reactors Program. It would provide opportunities and incentives for research reactor operators in foreign countries holding United States origin spent nuclear fuel containing highly enriched uranium to return that spent nuclear fuel to the United States for storage and eventual geologic disposal. This proposed policy is intended to support the United States nonproliferation objective of eliminating United States origin highly enriched uranium from research reactor use. It is also consistent with Section 903(a) of the Energy Policy Act of 1992, which places further restrictions on the export of highly enriched uranium from the United States. This proposed policy would provide incentives to encourage and assist developing countries (defined below) in returning their United States origin highly enriched uranium research reactor spent nuclear fuel to the United States for storage and disposal. For developed countries, the policy would allow return of United States origin research reactor spent nuclear fuel to the United States for storage and disposal on a full-cost-recovery basis.

PROPOSED POLICY - The United States proposes to adopt a policy under which:

1. For developing countries (i.e., those eligible for assistance under the United Nations Assistance Program), the United States would offer to accept United States origin research reactor spent nuclear fuel containing highly enriched uranium for storage and disposal in the United States. The United States would reimburse the developing country for costs incurred in transportation of the spent nuclear fuel from the developing country to a receipt facility in the United States. Upon acceptance of the spent nuclear fuel in the United States, the United States would assume all responsibility for the spent nuclear fuel, including storage of the spent nuclear fuel in the United States, any preparation of the spent nuclear fuel for disposal, all transportation in the United States subsequent to spent nuclear fuel acceptance, and ultimate geologic disposal of the spent nuclear fuel in the United States.

2. For developed countries, the United States would offer to accept all United States origin research reactor spent nuclear fuel containing highly enriched uranium for storage, preparation for disposal, and eventual geologic disposal in the United States. Such acceptance would be conducted on a full-costrecovery basis, with the developed country responsible for transportation of the spent nuclear fuel to a designated receipt facility in the United States and paying the United States the full cost of all storage, all transportation within the United States subsequent to spent nuclear fuel acceptance, disposal preparation, and ultimate geologic disposal. 
3. To encourage the conversion of foreign research reactors currently using United States origin highly enriched uranium fuels to low enriched uranium fuels, the United States would offer to accept for storage and ultimate disposal certain United States origin low enriched uranium research reactor spent nuclear fuel. Specifically, low enriched uranium research reactor spent nuclear fuel of United States origin would be accepted for a ten year period following implementation of this policy from reactors that have already converted, or that were constnucted to use and operate with low enriched uranium fuels. United States origin low enriched uranium research reactor spent nuclear fuel exported to research reactors that convert within five years of the effective date of this policy would also be accepted for a ten-year period following their initial order for low enriched uranium fuel.

The acceptance of low enriched uranium research reactor spent nuclear fuel from developed and developing countries would be conducted on the same terms as stated in 1 and 2 above for highly enriched uranium research reactor spent nuclear fuel.

\section{CONDITIONS}

1. This proposed policy would apply only to receipt of spent research reactor nuclear fuel of United States origin.

2. Ownership of the spent nuclear fuel would be transferred to the United States upon acceptance of the spent nuclear fuel by the United States at a designated receipt and inspection facility in the United States.

3. All transportation within a developing country and to the United States receipt facility would be the responsibility of the developing country, but would be paid for by the United States (subject to United States approval of the transportation arrangements and costs).

All transportation within a developed country and to the United States receipt facility would be the responsibility of, and would be paid for by, the developed country.

4. Criteria concerning the required condition of the spent nuclear fuel would be published by the United States as part of the announcement of this policy, to clarify conditions for acceptance of the spent nuclear fuel. In general terms, all spent nuclear fuel to be accepted by the United States would be required to be either intact and free of defects or canned to ensure the ability to safely contain and manage the spent nuclear fuel.

5. For developed countries, the fee to be paid to achieve full cost recovery would be established by the Department prior to entering into the agreements to accept the spent nuclear fuel. This fee would be based on estimates of the cost of the storage and disposal activities that would be required. The fee 


\section{The Secretary of Energy \\ Washington, DC 20585}

July $13,19.93$

The Honorable Warren Christopher

Secretary of State

Hashington, D.C. 20520

Dear Mr. Secretary:

This is in response to your letter dated July 2, 1993, urging my support for renewal of the Department of Energy's policy for the acceptance of spent research reactor fuel from abroad.

The Department of Energy remains committed to the Reduced Enrichment for Research and Test Reactors (RERTR) program, and to the proposal to establish a policy for the return of U.S. origin spent fuel from foreign research

reactors. In response to your letter, and other inquiries we have received on this subject, we have taken a hard look at how we can expedite actions in these areas. We have decided on a three-tiered approach, as follows:

1. For any foreign research reactor spent fuel returns for which we can mutually agree that a bona fide emergency exists, the Department of Energy will join with you in consulting with the Council on Environmental Quality on the implementation of alternative arrangements for compliance with environmental review requirements pursuant to the emergency provisions of the Council on Environmental Quality"s regulations implementing the National Environmental Policy Act (40 CFR 1506.11).

2. In order to be able to respond to any near-term situation in which the expiration of the Department's acceptance of foreign research reactor spent fuel may threaten the Reduced Enrichment for Research and Test Reactors Program, the Department has begun an expeditious Environmental Assessment of the proposed return of sufficient spent fuel to eliminate that threat. It is proposed that any near-term spent fuel returns would be conducted under the terms and conditions of the enclosed proposed policy and be limited to approximately 550 spent fuel elements which can be stored in existing DOE capacity. This Environmental Assessment is scheduled to be completed by September 1993, and, if appropriate, a proposed Finding of No Significant Impact will be issued for public review by no later than September 30,1993. Our goal is to complete the National Environmental Policy Act review process of this proposed limited foreign research reactor spent fuel acceptance by the end of this calendar year.

3. For the longer term, the Department will undertake preparation of an Environmental Impact Statement that addresses the proposed return of all U.S. origin foreign research reactor spent fuel, as specified in the enclosed proposed policy. A notice of intent for preparation of this Environmental Impact Statement is in preparation and should be issued in August 1993. The Department intends to issue the draft of the Environmental Impact Statement for public review by no later than the 
2

end of December 1994, and the final Environmental Impact Statement by the end of June 1995.

We cannot continue to address this issue in a business as usual manner. The actions outlined above reflect our determination to move forward promptly and our acknowledgement of the need for a new definition of national security one that includes both nonproliferation and environmental concerns. To provide added emphasis to the urgency of this effort, the Department requests that the Department of State participate as a cooperating agency in preparation of this environmental documentation.

In conclusion, the Department is committed to work with you and representatives of the Council on Environmental Quality at any time that you consider an emergency situation may be developing. In the meantime, we are proceeding as expeditiously as possible on the actions outlined above.

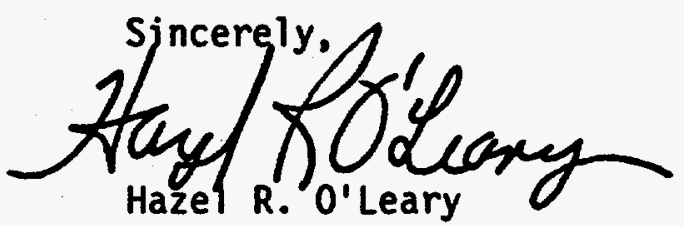

Enclosure 
schedule would be updated annually to account for items such as inflation, and experience with the program.

TERMINATION - This policy of accepting low enriched uranium research reactor spent nuclear fuel would expire ten years after the effective date of this policy for ten years following placement of an order for low enriched uranium research reactor fuel to replace highly enriched uranium research reactor fuel, if such an order is placed within five years of the effective date of this policy). Therefore, countries and research reactor operators that plan to take advantage of this policy for spent nuclear fuel containing low enriched uranium should begin planning for their own national or regional means of storage and disposal of low enriched uranium research reactor spent nuclear fuel for use following termination of this policy.

The proposed policy for accepting research reactor spent nuclear fuel containing highly enriched uranium of United States origin would encourage all countries to return this United States origin research reactor spent nuclear fuel as soon as possible. 


\section{FORSCHUNGSZENTRUM GEESTHACHT GMBH}

GKS5, Poutheh 1160, D-21494 Geacthedht

Mr. Director

Victor Alessi

Office of Arms Control

and Nonproliferation

Office of the Secretary

Department of Energy

Washington, DC 20585
Max-Prenck-8trage, D-21802 Gowtheont I

Totofon: 04T52/87-0

Tolex: 218712 gleed

Thlosramm: GKSS - Cesthacht

Telefex: 04162/37-1338

ZENTRALABTEILUNG FORSCHUNGSREAKTOREN

Laltert D. W. Kuill

Ine zoringes

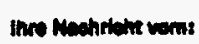

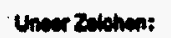

Dartalts:

Telation-Ourehmin:

Dotem:

R-Dr.Kratri

Dr. Krull

outeysy 1200

10/15, 1993

Dear Mr. Alessi,

as discussed with your staff member, Mr. McClary, at the 16. RERTR meeting this month in Oarai, Japan, and at the meeting a few days later which has been organized from Edlow Company at Washington, DC, the GKSS is at present shipping some of their spent HEU fuel slements to ABA Dounresy. From this reprocessing we are getting around $16 \mathrm{~kg} U$. $80 \%$ eariched. I am interested to hear soon under what conditions (including price, enrichment and chemical composition*) the US is willing to take this fuel. We are at present discussing with some interested parties upon this subject.

The GKSS is not willing to use this reprocessed Uranium within the next future for its own needs. This is thie reason why we want to sell it. As there is the necessity to make some decisions soon and there are some honostly interested clients we are interested to get your reply soon hopefully within this month.

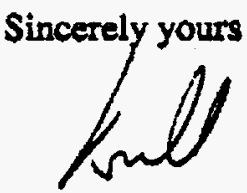

*) oxide or metal

$\varnothing:$ Mr. M. McClary

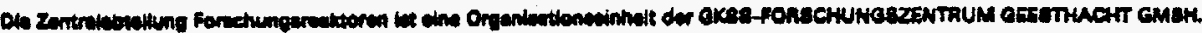

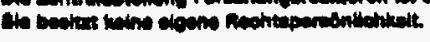


"No special reprocessing problems are anticipated for high-concentration current-type elements. However, for very-high-concentration fuels of new types, some development effor may be needed if these fuels cannot be treated with conventional reprocessing methods."

Following these general statements and conclusions, as all of you know; since 1980 extremely successful (in par) national and intemational activities have occurred.

- development and qualification of high density fuel up to $4,8 \mathrm{~g} \mathrm{U/cc}$ and higher

- fundamental and detailed safety studies

- principles of conversion procedure developed and actual conversion taken place

- many studies on different topics (e.g. reprocessing, reuse of reprocessed $U$, cost figures).

Many of you have been involved in these activities which were sponsored and organized in many cases by the IAEA and have taken part in a large number of national programs. But what where the fields of activities

- reducing the enrichment to less than $20 \%$

- reduction of stockpiles.

Some others are on the way, but others are still missing

- reduction in the annual production of fissile material

This will be realized by using LEU. But there will be an extra activity which may increase this reduction. This is the possible shutdown of some or more reactors.

- using enriched uranium in cases where natural uranium has been used.

I know of none of these reactors making this conversion. Do you know of any?

\section{WHERE ARE WE NOW?} cussed.

In the following some of the INFCE conclusions and development steps will be dis-

\section{REPROCESSING}

Many research reactor operators like GKSS promoted all national and intemational acivities to decrease the proliferation risk from the beginning. For this reason we are well informed about the background for making decisions in the past Therefore we are aware and we believe it is necessary to point out today that from the beginning, reprocessing was considered as the key point in the RERTR program. It was clear that the RERTR program would only be successful if there was a solution for reprocessing LEU fuel. This has been stated many times at IAEA meetings and international conferences. It was agreed at that time by ail US representatives from DOE, DOS, NRC, ACDA, ANL and other US research centres and universities. For this reason some actual repons on reprocessing of LEU fuel were published by US-DOE in 1982. These reports included, as an important result that reprocessing of LEU silicide fuel should pose no real technological problem. One additional step within the chemical process for separating the silicide in all that is necessary. This very important result has been discussed in detail at RERTR meetings. The conclusions which were drawn are the following:

- one of the key problems in converting research reactors has been solved. This was the signal to the operator that he could get rid of the LEU fuel after conversion

- the US-DOE should start the next step and give the political signal to all research reactor operators. 
The fundamental need to prove the possibility of reprocessing of spent LEU fuel and to demonstrate the willingness of the US-DOE to take back this fuel to encourage operators to conver their reactors to LEU was the reason for publishing the Fed. Reg. Note Vol. 51, No. 32, Feb. 18, 1986 "Receipt and Financial Settlement Provisions for Nuclear Research Reactor Fuels". It was clear at that ime and it is still valid today that there will not be enough spent LEU fuel elements to start reprocessing activities before the end of the nineries. The only reason for publishing this Fed. Reg. Note at that ime (more than 10 years in ldvance) was to give a US-govemment guarantee to foreign research reactor operators using fuel of US origin that the US-DOE will take back the spent LEU fuel elements.

Only this guarantee enabled the operators at that time and today to follow the RERTR activities and the RERTR program despite the penalties involved in the process.

It is understandable that due to the drastic political changes that have taken place there is no longer a need for reprocessing any HEU or LEU fuel by US-DOE. But this should only make a small change in the promises. The need for the research reactor operator was and is to get rid of the fuel and not reprocessing per se. At all times reprocessing has been expensive and the credit for the reprocessed $U$ was small compared to the overall fuel cycle cost.

Therefore the reference solution was to take back the fuel to enable core conversion to LEU. In the early eighties everyone believed in the economical need for the reuse of U. There were and there are extremely large stockpiles of HEU available in many countries throughout the world This was known to US-DOE officials but it was not known by many research reactor operators. Therefore, even at imes when operators believed in the necessity of reprocessing, the US-DOE was aware about the real siruation.

The present hiatus in fulfilling its promises on the part of the US-DOE causes great concerns and severe difficulties to many research reactor operators and counnries. A few examples:

- Countries without any power reactor program do not have programs for a final disposal of radioactive waste or spent fuel elements

- other countries have no possibility of storing research reactor spent fuel

- licensing authorities demand that no new fuel elements can be insered into the reactor core (e.g. ASTRA (A), IRIGA Heidelberg (D)). This limits the operational life

- lack of spent fuel storage capacity forces termination of operation (e.g. FRG-2 (D))

- many operators are constructing new spent fuel racks. This increases the stockpile of spent fuel substantially at different locations worldwide.

\section{PENALTIES}

Demands from p. 256 of the summary of DFCE are:

- safety margins should not be lower compared with the design based on HEU

- fuel reliability should not be lower compared with the design based on HEU

- $\quad$ only marginal loss in reactor performance e.g. flux per unit power

- only marginal loss in operating cost

No definition has been offered for the term marginal ( $1 \%, 10 \%, 50 \%$ ?). I believe only

$10 \%$ can be taken as marginal.

What is the reality?

After performing the first calculations it was clear that there is no chance of meeting 


\author{
W. Krall \\ GKSS Research Centre \\ Geesthacht GmbH \\ Postrach 1160 \\ D-21494 Geesthacht
}

\begin{abstract}
Over many years enormous national and internarional efforts have been made to investigate the possibilities of reducing the enrichment of research and test reactors (RERTR) from HEU to LEU. Within some limits and accepting some difficulties, the conversion is rechnically achievable. But as these efforts have been made not only as an end in itself all research reactor operators, their regulatory bodies and especially the governments should consider all relevant factors and the leading idea before making the decision to convert. The idea when staring the RERTR activities was to reduce the proliferation risk. Due to the termination of the return of spent fuel to the country of origin of the enriched $U$ and other factors it may be necessary to make the following decision:

- to continue the development of high densiry fuel

- to stop all conversion activities for research reactors presently operated with HEU.

Starting with a historical overview, the present situation is described and conclusions are drawn which lead directly to the above mentioned recommendations.
\end{abstract}

\title{
HISTORICAL OVERVIEW
}

Due to the increasing availability and knowiledge of nuclear weapons technology at the end of the sixties and in the seventies actions were taken to reduce the threat of proliferation of nuclear weapons. The main steps involved are the Non-Proliferation Treaty (1968), INFCE (1977) and the US Nuclear Non-Proliferation Act (1978). From the Summary Volume of INFCE the following citations are taken as they highlight the demands:

Page 1: "The International Nuclear Fuel Cycle Evaluation (INFCE) was organized at a conference held in Washington, DC, on 19-21 October 1977, in which 40 countries and four international organizations were represented. In the communique issued by the Conference the participants were conscious of the urgent need to meet the world's energy requirements and that nuclear energy for peaceful purposes should be made widely available to that end; were convinced that effective measures can and should be taken at the national level and through international agreements to minimize the danger of proliferation of nuclear weapons without jeopardizing energy supplies or the development of nuclear energy for peaceful purposes; recognized that special consideration should be given to the specific needs of and conditions in developing countries"

Page 273: "The Final Plenary Conference of the Intemational Nuclear Fuel Cycle Evaluarion (INFCE) took place, as scheduled, at the Hofburg in Vienna, on 25-27 February 1980. Fifty nine states and six intemational organizations participated in the Conference."

General conclusions were:

Page 276: "Finally, the Conference wishes to state that the findings of INFCE have strengthened the view 
- that nuclear energy is expected to increase its role in meeting the viorld's energy needs and can and should be widely available to that end;

- that effective measures can and should be taken to meet the specific needs of developing countries in the peaceful uses of nuclear energy; and

- that effective measures can and should be taken to minimize the danger of the proliferation of nuclear weapons without jeopardizing energy supplies or the development of nuclear energy for peaceful purposes.

The Conference recognized that the objectives mentioned above can only be achieved through continued international co-operation and the parricipants are determined to preserve the climate of mutual understanding and co-operation in the international nuclear energy field that is one of the major achievements of INFCE"

Special conclusions were:

Page 255, 256 "4.2 Measures to increase proliferations resistance.

Research reactors utilize the excess neutrons from the fission chain reaction for experiments and irradiations. In these reactors U-238 acts as a parasitic absorber by capruring neutrons that otherwise could be used for experiments. Thus, highly enriched uranium has usually been selected to give the best reactor performance.

The trade in and widespread use of highly eariched uranium and the production of fissile materials constiwte proliferations risks with which DNFCE is concerned. Proliferation resistance can be increased by:

(1) Enrichment reduction preferably to $20 \%$ or less which is intemationally recognized to be fully adequate isotopic barrier to weapons usability of U-235;

(2) Reduction of stockpiles of highly enriched uranium;

(3) Reduction of the annual production of fissile materials in research reactors, although attainment of weapons-usable material would require spent fuel reprocessing. For example, for some research rectors fuelled with natural uranium the proliferations resistance might be improved by utilizing slightly enriched uranium, which reduces the annual plutonium production.

It must be stressed that in an overall assessment of the proliferation resistance and safeguard of a particular research reactor, it is necessary to consider all of the above factors. tion

Most of the contributions discussed in detail only the possibility of enrichment reduc-

\subsection{Measures and criteria for enrichment reduction}

The bases of the various enrichment reduction studies contributed to INFCE were quite different but agreement was obtained to apply the following approach:

In assessing the practical feasibility of utilizing lower enriched fuel in existing research reactors, the agreed criteria are that safety margins and fuel reliability should not be lower than for the current design based on highly enriched uranium and that neither any loss in reactor performance, e.g. flux-per-unit power, nor any increase in operating cost should be more than marginal."

In addition to this there is a small chapter on reprocessing on page 148 of the report of INFCE Working Group 8. 
the first demand. Nevertheless it has been agreed to allow a reduction in safety margins if these are small enough.

The fuel reliability for HEU aluminide fuel is excellent even for bumups up to $100 \%$. The oxide and $U_{3} \mathrm{Si}$ fuel is at present far from meering this demand. Only the $\mathrm{U}_{3} \mathrm{Si}_{2}$ fuel has a comparably high fuel reliability (after increasing extensively the inspection procedures during and after the fabrication of the fuel). .

If one looks at the reactor performance it was and is clear that the $10 \%$ (marginal) limit is achievable only in a few cases. Many have to accept a severe decrease in overall performance. In these cases only radical redesign followed by-severe licensing problems would lead to a "marginal" reduction in performance.

For the GKSS research reactors the penalies were

1) 3 licensing procedures for the performance tests of fuel elements (UAl $\mathrm{U}_{\alpha}$ (MEU), $\mathrm{U}_{3} \mathrm{O}_{8}$ (LEU), $\mathrm{U}_{3} \mathrm{Si}_{2}$ (LEU)).

2) Licensing procedures for the full conversion of the FRG-1 research reactor.

Public interventions including court proceedings were possible. Demands for additional upgrading could be made and have been made.

3) Increase in fuel cycle cost by more than $20 \%$ due to higher fuel element fabrications cost. We have to accept partially bumed HEU fuel elements which will cause relatively high reprocessing, interim storage or final disposal cost and at present occupying valuable storage places for spent fuel elements.

4) Reduction of neutron flux for beam tube experiments by more than $10 \%$.

The GKSS research centre like many others was willing to accept all these penalties and difficulties in demonstrating their willingness to fulfill the INFCE promises.

\section{GERMAN LICENSING DIFFICULTIES}

There are some special German licensing difficulnes:

Published in "Bundesgesetzblatt I" of February 18, 1977, with some additions March 31,1982 , is an ordinance "Verordnung über das Verfahren bei der Genehmigung von Anlagen nach $\$ 7$ des Atomgesetzes".

In chapter $4(2) 5$ of this ordinance there is an express demand that an increase of the storage capacity for spent fuel elements by more than $10 \%$ requires a public hearing procedure. In practice the licensing authorities require such hearing procedure (including normally court proceedings) if there is an application for an increase of the storage capacity by more than $5 \%$. Such a decision can be made by the state licensing authority.

Published in "Bundesanzeiger Nr. 58 of March 22, 1980" is the announcement of the basis of the "Entsorgungsvorsorge" for nuclear power plants. At present it is scheduled to have a new ordinance "Reststoffverordnung"* published at the end of 1993. These demands applicable at present only for power reactors and the HMI research reactor will become effective according to "Entsorgungsvorsorge" for all research reactors, too. In chapter 2.2.2 there is an express demand that for a six vear (rolling) period in advance one has to demonstrate the future (final) storage of spent fuel elements in existing storage capacity and /or through contracts with third parties for reprocessing and/or storage of these spent fuel elements.

*) dealing with all existing radioactive samples (waste and others) 
- Stated in chapter 2.1 of the above mentioned announcement in the Bundesanzeiger there is written a demand that there must be enough storage capacity at anv time for a $100 \%$ unloading of the reactor core.

This situation is a severe threat for the furure operacion of research reactors within Germany as, on the one hand, the chance in increasing the spent fuel storage capacity is near to zero and, on the other hand, operators have to get rid of the fuel as soon as possible to ensure the operacional life of their reactors.

\section{SPENT FUEL IS FRESH FUEL}

Due to international and German regulations spent fuel must be considered as fresh fuel if the radiation dose at $1-\mathrm{m}$ distance in air per $\mathrm{kg} \mathrm{U}$ is below $1 \mathrm{~Gy} / \mathrm{h}$. If there is no shipment of spent fuel within the next few years, at many research reactor facilities an increasing number of spent fuel elements for which the radiation dose level is below that limit will develop. This will cause a severe crisis because additional extraordinary demands on physical protection and safeguarding are due to be introduced.

The demands for inspecions to safeguard nuclear fuel are fixed in LAEA publications. The controlling parameters are the enrichment of $U$ (LEU or HEU) and the effecrive $\mathrm{kg}$ of $U^{*}$ The IAEA has published the estimated inspection efforts.

Esrimated Agency Inspection Effort for Research Reactors (Manday/year)

\begin{tabular}{|c|c|c|c|}
\hline & Type and Quanrity of Fuel & Maximum Effort & Actual Effort \\
\hline a). & $\begin{array}{l}\text { Enrichment }<20 \% 0-235 \text {; or } \\
\text { Inventory less than } 5 \mathrm{ekg} \text {. }\end{array}$ & $2-3$ & $0,5-1$ \\
\hline b) & $\begin{array}{l}\text { Ennchment > 2090 U-235; } \\
\text { Inventory }<25 \mathrm{~kg} \text { U-235 }\end{array}$ & 50 & $1-2$ \\
\hline c) & $\begin{array}{l}\text { Enrichment }>20 \% U-235 \\
\text { Inventory }>25 \mathrm{~kg} U-235 \\
\text { but }<25 \mathrm{~kg} \text { in fresh fuel }\end{array}$ & 50 & $9=15$ \\
\hline$\overline{d)}$ & $\begin{array}{l}\text { Enrichment }>20 \% \text { U-235 } \\
\text { Inventory }>25 \mathrm{~kg} \mathrm{U}-235 \\
\text { in fresh fuel }\end{array}$ & 50 & 50 \\
\hline
\end{tabular}

Therefore: A research reactor which has been converted to LEU fuel has normally an actual inspection effort of $0.5-1$ mandays/year. But due to the decreasing radiation dose level all converted research reactors - and there are some - are on the way to an actual inspection effort of 50 mandays/year. They will reach these 50 mandays/year probably within this decade. At present neither the operator, their licensing authorities nor the IAEA is aware of that problem.

The demands on physical protection are depending in a similar way on the amount of effective $\mathrm{kg}$, the enrichment (LEU or HEU) and some other safety related features.

Within the Federal Republic of Germany the demands are identical for

- power reactors and

- for facilities storing fresh HEU fuel in an amount of $\geq 5 \mathrm{ekg} \mathrm{U}$.

For research reactors using LEU fuel and/or having less than 5 ekg $U$ in the form of fresh HEU fuel (see definition above for spent fuel to be considered as fresh fuel) the demands are far less stringent.

*) The effective $\mathrm{kg}(\mathrm{ekg})$ is the weight of $\mathrm{U}$ in $\mathrm{kg}$ multiplied by the square of its enrichment 
Fulfilling the demands on physical protection for power reactors is impossible for any research reactor within Germany. Therefore, as we approach the $5 \mathrm{ekg} U$ limit the difficulties will become unsolvable. It may (will?) lead to the final shutdown of facility in question.

What are the consequences of conversion from HEU to LEU and holding the spent fuel for a long period of ime. The operator runs into increasing difficulies within demands on safeguarding and physical protection. But as he will expertence these difficulies anyway, why bother to conver in the first place. There are at present real advantages to stay within HEU: besides avoiding with spent fuel the difficulties he avoids all penalties and concems with the conversion process as described above.

For a research reactor with relatively low power $(\sim 1 \mathrm{MW})$ or a liferime core a decision to convert to LEU is illogical in the existing circumstances. The operation will replace the self-shielding and self-protecting HEU fuel by LEU fuel. The HEU fuel will become progressively non self protecting. Thus, in addition to the conversion difficulties the operator will experience safeguarding and physical protection difficulties he never had to worry about before. Instead of reducing the difficulties by conversion such a reactor operator will have to cope with many more problems and headaches.

\section{UNIQUE PURPOSE REACTORS}

Definition:

"Unique purpose" means a project program, or commercial activity which cannot reasonably be accomplished without the use of HEU fuel, and may include: (1) A specific experiment, program, or commercial activity (typically long term) that significantly serves the US national interest and cannot be accomplished without the use of HEU fuel; (2) Reactor physics or reactor development based explicitly on the use of HEU fuel: (3) Research projects based on neutron flux level and spectra attainable only with HEU fuel or (4) reactor core of special dèsign that could not perform its intended function without using HEU fuel.

This definition can be found in e.g. Fed. Reg. Vol. 47 no. 131, July 8, 1984, and Fed. Reg. Vol. 51, no. 37, February 25, 1988.

This definition and resulting consequences - of staving with HEU - are primarily valid only for US domestically licensed research and test reactors. But nevertheless everyone should look at such definitions and compare his reactor design and utilization with these definitions. At present it is believed that there are some reactors worlduride which may be considered to belong to the group of unique purpose reactors:

US: $\quad$ ATR, HBWR, NIST, Missouri, MIT

Europe: HFR-ILL, OTphee, BR-2 (HFR-Petten?)

Others: There will probably be more research reactors which have not been examined by these criteria before.

But, in principle, the above definition gives a recipe to everyone to reconsider the design of his reactor (even if he is operating at power levels of $5 \mathrm{MW}$ ) e.g. there may be a need for high neuton flux levels which makes the use of HEU necessary. This is easy and it is being demonstrated. Otherwise, the operator will have to accept severe penalties for the use of LEU.

The distinction between "unique purpose reactors" and "non-unique purpose reactors" is arbitrary. There are two groups of research reactors

- one group with all advantages of using HEU and none of the disadvantages from the conversion procedure (licensing, cost, ....). This is the group of rich reactors. The annual consumption of U-5 for these few reactors is of the same order as for all other reactors. Therefore, the continuing operation of these reactors with HEU reduces the stockpile of HEU, the fabrication of HEU fuel elements, the transportation of fresh and spent HEU fuel elements only by about a factor of 2 . This is surely not enough. 
- the second group contains some large reactors but the majority are small and financially poor research reactors. They have to accept all disadvantages discussed above and become unattractive for many reasons. This creates severe concern for the future of the operation of these reactors and may signal the end of nuclear research in many countries.

The conclusion is that the somewhat arbitrary separation into these two groups is absolutely unfair. Unique purpose reactors should convert in the same way as other research reactors. Of course, there should be an ongoing program to qualify higher density fuel to reduce the penalties from the conversion to the lowest possible degree.

In the same way - to bave a fair treament for everyone - exemptions for new research reactors to use HEU should not be based only on definition no. 4 above.

The definition of unique purpose reactors is believed to be to simple. If there are excepvons from the conversion all other conditions and questions arising during a conversion process must be looked at equitably e.g. safety margins, operation cost, licensing demands, physical protection demands, safeguarding. All these points are for an operating research reactor of the same quality and of the same importance as the decision to operate or to shutdown the reactor is depending in the same way on all these factors.

\section{SUMMMARY AND CONCLUSION}

At present no reprocessing is available (except AEA?) worldwide to get rid of irradiated fuel elements. The AEA option is really only available to a few research reactor operators who can take back the waste from the reprocessing.

Considering this simarion one can conclude:

a) Conversion of a research reactor from HEU to LEU leads to severe difficulties for all involved parties:

- the operator has to accept many penalties, licensing problems and increasing operation cost

- the licensing authority must deal with new problems and consider increasing physical protection demands

- the IAEA has to prepare for increasing safeguards inspections

- the public internationally feels deeply concerned about the increasing proliferation risk.

No one has any advantage from converting a specific reactor.

b) If there is no conversion there is an increasing proliferation risk with the HEU spread wordwide

c) If there is no shipment of spent HEU fuel elements to a central storage (the country of origin of the $U$ ) there is an increasing proliferation risk with the HEU spread worldwide.

d) The countries of origin (US, Russia (USSR), China, UK and others?) of the enriched U have to take back the spent fuel elements for a given time to allow the research reactor operator 
- to look at other solutions for e.g. an interim storage or final disposal in the home country

- to shutdown the reactor and without having remaining spent fuel elements during the decommissioning period.

e) To reduce the proliferation risk the ideal situation would be to have no research reactor in operation worldwide with HEU. Therefore, all research reactors should be converted from HEU to LEU including e.g. the unique purpose reactors, the reactors build by the USSR and operated in many countries $(36 \%, 80 \%, 90 \%)$, the reactors in China and others. Otherwise conversion makes little sense.

From the forgoing sections the following conclusions can be drawn.

From INFCE-summary volume p. 255

- Where is the program, where is the effort and where are the reactors operated in the past with natural uranium and that have converted to the use of slightly enriched uranium?

Reprocessing, get rid of spent fuel

- The need for reprocessing has been stated in INFCE.

- US announcements in the Fed. Reg. in 1986 to take back spent LEU fuel demonstrated the willingness of the US to take back the spent fuel after conversion to LEU.

- At the time of the announcement and for the next several years there was (is) no real need for such a guarantee as there were not enough spent fuel elements for reprocessing.

- The US decision to stop any reprocessing activities should not make any change to that guarantee in principal.

- The intention of the Fed Reg. Note was that research reactor operators would be able get rid of their spent fuel.

- Some reactors will shutdown.

- Worldwide the stockpiles of spent fuel are increasing rapidly.

Penalties have to be paid when performing conversion.

- Reduction of safety margins great during conversion, small after conversion

- Fuel reliability is only comparable for $\mathrm{U}_{3} \mathrm{Si}_{2}$

- Neutron flux levels are decreased by $10 \%$ or more

- Fuel element fabrication cost are increased by $20 \%$ or more

- Complex licensing procedures are necessary

- In many cases additional upgrading measures must be made 


\section{German licensing specifics}

- Increase of spent fuel storage capacity by more than $10 \%$ requires a public hearing procedure with an unforeseeable outcoming.

- For a 6 year (rolling) period in advance, a solution for all discharged and exisuing spent fuel elements must be shown by contracts.

\section{Spent fuel is fresh fuel}

- Spent fuel is by definition fresh fuel if the radiation dose per $\mathrm{kg} \mathrm{U}$ is below $1 \mathrm{~Gy} / \mathrm{h}$ at 1 $\mathrm{m}$ distance in air.

- The spent fuel will become fresh fuel in due course.

- Fresh HEU fuel requires safeguarding inspection efforts of up to 50 mandays/year instead of $<1$ manday/year.

- Fresh HEU fuel requires physical protection demands identical with physical protection demands for power reactor.

- If there is no solution to getring rid of the spent fuel, it is completely illogical to convert to LEU.

\section{Unique purpose reactors}

- These reactors (5 US, 3 abroad, $+\ldots$ ) are excluded from the conversion demands.

- The listing of such exclusions is far from being complete.

- Reactors are not treated equitably.

- The definition must be extended to licensing, cost, reactor performance, physical protection, safeguarding.

- These reactors should convert to LEU, too.

- Higher density fuel should be qualified to limit the penalties for these reactors.

- $\quad$ New research reactors must use LEU.

\section{FINAL}

- Reduction of the proliferation risk should be an indispensable goal of the international policy. Therefore enrichment reduction should be made for all research reactors in a fair and equitable way and in a reasonable time.

- The announcement by the secretary of US-DOE on July 13,1993 , is an extremely important signal. This must be followed soon by further steps to reach the status approved Policy with contracts for the first shipments agreed with the countries in question.

- Where are the adequate signals from the other countries of origin of enriched $U$ ?

- We hear the signal and we all want to reach the goal which is 
DEPARTMENT OF STATE WASHINGTON

November 30,1993

\section{Dear Madam Secretary:}

Thank you for informing us in your July 13 letter that the Department of Energy (DOE) has proposed to adopt a policy to receive United states-origin spent fuel from foreign research reactors and to undertake the necessary environmental reviews in order to implement the policy.

DOE's agreement to use the emergency procedures in the Council on Environmental Quality's National Environmental Policy Act (NEPA) regulations in order to accept for disposition in the United States an emergency shipment of 144 spent fuel elements from the BR-2 research reactor at Mol, Belgium, is significant and praiseworthy.

Even though the Belgian reactor operator has decided not to break its contract with the Atomic Energy Authority of the United Kingdom for reprocessing these 144 fuel elements and therefore will not send them to the United states for disposition, I believe that DOE's offer to accept the Belgian Euel under NEPA's emergency procedures has made an important contribution to U.S. nuclear non-proliferation interests. If DOE had not taken this decision, there would have been a grave risk that other research reactor operators and their governments would have abandoned their support for our efforts to minimize the use of highly enriched uranium in civil nuclear programs.

Rapid completion of the Environmental Assessment that would provide the basis for importing into the United states up to 700 fuel elements from other foreign research reactors with

The Honorable

Hazel R. O'Leary,

Secretary of Energy. 
pressing spent fuel disposition requirements and completion of the Environmental Impact Statement is essential to the President's nuclear non-proliferation policy. For that reason, I hope that it will be possible for DOE to complete these actions as soon as possible in order to maintain foreign commitment to the Reduced Enrichment for Research and Test Reactors program.

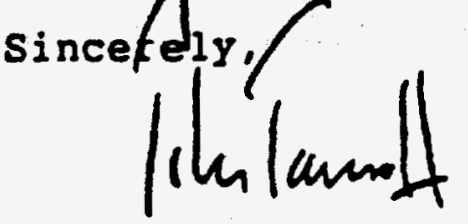

Peter Tarnoff, Acting 


\section{Department of Energy \\ Washington, DC 20585 \\ MAR 25199}

Mr. E. D. Hondros

Commission of the European Communities

Joint Research Centre - Petten Establishment

1755 ZG, Petten

The Netherlands

Dear Mr. Hondros:

I am writing in response to your letter of March 2, 1994, in which you provided comments on the February draft Environmental Assessment (EA) on Urgent-Relief Acceptance of Foreign Research Reactor Spent Nuclear Fuel as well as to followup on the telephone conversation that you had with Mr. Huizenga of my staff on March 11, 1994.

I understand that you have discussed with the Dutch authorities the possibility of adding two more storage racks to the High-Flux Reactor (HFR) spent fuel storage pool and that you have serious concerns as to whether they will grant such an expansion. The proposal in the February draft EA to accept 33 spent fuel elements was based on the assumption that this storage could be added in a timely manner. Because this does not appear to be a viable solution to your immediate storage problem, we have agreed to increase the number of spent fuel elements proposed to be accepted from HFR from 33 to 66 in the revised EA, which the Department is currently completing.

I understand that you have confirmed that the Commission of the European Communities (EC) will enter into an agreement with the United States Government in the near future that would result in the expeditious conversion of the HFR to use low-enriched uranium fuel. The proposed acceptance of the HFR spent fuel, as part of the urgent relief shipments considered by the EA, would be contingent on the signing of such an agreement that would set forth the undertakings of the parties regarding the conversion. We anticipate that the following major steps would be required for HFR to convert to low-enriched uranium: (1) completion of the required safety documentation; (2) completion of the licensing procedure; and (3) ordering and delivery of lowenriched uranium fuel elements. Because this is such an important priority, the United States will make available technical resources from the Argonne National Laboratory to assist you in performing technical analyses. We expect that these actions should result in HFR beginning conversion in four to five years.

In your March 2 letter, you indicated that the agreement to convert HFR to low-enriched uranium fuels would be contingent upon the United States' agreement to accept all spent fuel generated by HFR in the future. As my staff has discussed with you, the Department has proposed a policy to accept both low and highly-enriched uranium spent fuel from foreign research reactors for a period of up to fifteen years. This proposal is currently being evaluated in an Environmental Impact Statement prepared under the National Environmental Policy Act. 
If, after the Environmental Impact Statement is complete, the Department decides to adopt and implement such a policy, HFR spent fuel of United States origin (both low and highly-enriched uranium) would be eligible for acceptance by the United States for the period the policy is in effect.

As discussed in the March 11 telephone conversation with my staff, I understand that you will confirm these understandings in a letter to be forwarded to me the week of March 28. We are delighted to be able to work with you on this important nonproliferation effort and hope that we can complete an agreement that results in a strengthened Reduced Enrichment for Research and Test Reactor Program. I look forward to hearing from you, and working together to effectuate the conversion of HFR to low-enriched uranium fuels.

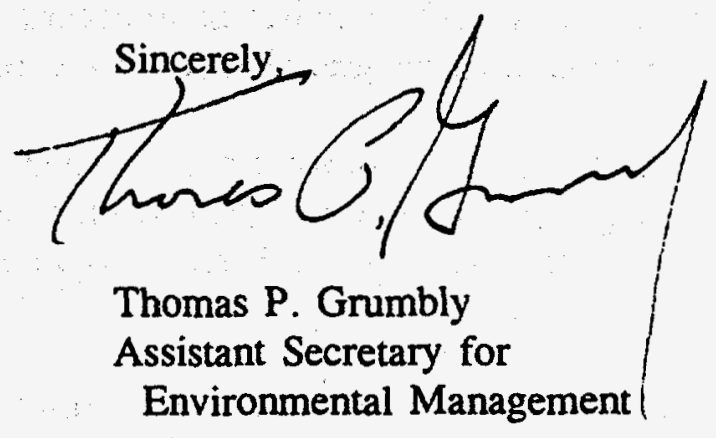

cc: The Honorable Adriaan Jacobovits de Szeged Ambassador of the Netherlands 


\section{FACT SHEET \\ NONPROLIFERATION AND EXPORT CONTROL POLICY}

The President today established a framework for U.S. efforts to prevent the proliferation of weapons of mass destruction and the missiles that deliver them. He outlined three major principles to guide our nonproliferation and export control policy:

-- Our national security requires us to accord higher priority to nonproliferation, and to make it an integral element of our relations with other countries.

-- $\quad$ To strengthen U.S. economic growth, democratization abroad and international stability, we actively seek expanded trade and technology exchange with nations, including former adversaries, that abide by global nonproliferation norms.

-- We need to build a new consensus -- embracing the Executive and Legislative branches, industry and public, and friends abroad -- to promote effective nonproliferation efforts and integrate our nonproliferation and economic goals.

The President reaffirmed U.S. support for a strong, effective nonproliferation regime that enjoys broad multilateral support and employs all of the means at our disposal to advance our objectives.

Key elements of the policy follow.

\section{Fissile Material}

The U.S. will undertake a comprehensive approach to the growing accumulation of fissile material from dismantled nuclear weapons and within civil nuclear programs. Under this approach, the U.S. will:

-- Seek to eliminate where possible the accumulation of stockpiles of highlyenriched uranium or plutonium, and to ensure that where these materials already exist they are subject to the highest standards of safety, security, and international accountability.

-- $\quad$ Propose a multilateral convention prohibiting the production of highly-enriched uranium or plutonium for nuclear explosives purposes or outside of international safeguards.

-- Encourage more restrictive regional arrangements to constrain fissile material 
production in regions of instability and high proliferation risk.

-- $\quad$ Submit U.S. fissile material no longer needed for our deterrent to inspection by the International Atomic Energy Agency.

- $\quad$ Pursue the purchase of highly-enriched uranium from the former Soviet Union and other countries and its conversion to peaceful use as reactor fuel.

-- $\quad$ Explore means to limit the stockpiling of plutonium from civil nuclear programs, and seek to minimize the civil use of highly-enriched uranium.

-- Initiate a comprehensive review of long-term options for plutonium disposition, taking into account technical, nonproliferation, environmental, budgetary and economic considerations. Russia and other nations with relevant interests and experience will be invited to participate in this study.

The United States does not encourage the civil use of plutonium and, accordingly, does not itself engage in plutonium reprocessing for either nuclear power or nuclear explosive purposes. The United States, however, will maintain its existing commitments regarding the use of plutonium in civil nuclear programs in Western Europe and Japan.

\section{Export Controls}

To be truly effective, export controls should be applied uniformly by all suppliers. The United States will harmonize domestic and multilateral controls to the greatest extent possible. At the same time, the need to lead the international community or overriding national security or foreign policy interests may justify unilateral export controls in specific cases. We will review our unilateral dual-use export controls and policies, and eliminate them unless such controls are essential to national security and foreign policy interests.

We will streamline the implementation of U.S. nonproliferation export controls. Our system must be more responsive and efficient, and non inhibit legitimate exports that play a key role in American economic strength while preventing exports that would make a material contribution to the proliferation of weapons of mass destruction and the missiles that deliver them.

\section{$\underline{\text { Nuclear Proliferation }}$}

The U.S. will make every effort to secure the indefinite extension of the Non-Proliferation Treaty in 1995. We will seek to ensure that the International Atomic Energy Agency has the resources needed to implement its vital safeguards responsibilities, and will work to strengthen the IAEA's ability to detect clandestine nuclear activities. 


\section{Missile Proliferation}

We will maintain our strong support for the Missile Technology Control Regime. We will promote the principles of the MTCR Guidelines as a global missile nonproliferation norm and seek to use the MTCR as a mechanism for taking joint action to combat missile proliferation. We will support prudent expansion of the MTCR's membership to include additional countries that subscribe to international nonproliferation standards, enforce effective export controls and abandon offensive ballistic missile programs. The United States will also promote regional efforts to reduce the demand for missile capabilities.

The United States will continue to oppose missile programs of proliferation concern, and will exercise particular restraint in missile-related cooperation. We will continue to retain a strong presumption of denial against exports to any country of complete space launch vehicles or major components.

The United States will maintain its general policy of not supporting the development or acquisition of space-launch vehicles in countries outside the MTCR.

For MTCR member countries; we will not encourage new space launch vehicle programs, which raise questions on both nonproliferation and economic viability grounds. The United States will, however, consider exports of MTCR-controlled items to MTCR member countries for peaceful space launch programs on a case-by-case basis. We will review whether additional constraints or safeguards could reduce the risk of misuse of space launch technology. We will seek adoption by all MTCR partners of policies as vigilant as our own.

\section{Chemical and Biological Weapons}

To help deter violations of the Biological Weapons Convention, we will promote new measures to provide increased transparency of activities and facilities that could have biological weapons applications. We call on all nations -- including our own -- to ratify the Chemical Weapons Convention quickly so that it may enter into force by January 13, 1995. We will work with others to support the international Organization for the Prohibition of Chemical Weapons created by the Convention.

\section{Regional Nonproliferation Initiatives}

Nonproliferation will receive greater priority in our diplomacy, and will be taken into account in our relations with countries around the world. We will make special efforts to address the proliferation threat in regions of tension such as the Korean peninsula, the Middle East and South Asia, including efforts to address the underlying motivations for weapons acquisition and to promote regional confidence-building steps.

In Korea, our goal remains a non-nuclear peninsula. We will make every effort to secure North Korea's full compliance with its nonproliferation commitments and effective. implementation of the North-South denuclearization agreement.

In parallel with our efforts to obtain a secure, just, and lasting peace in the Middle East, we will promote dialogue and confidence-building steps to create the basis for a Middle East free 
of weapons of mass destruction. In the Persian Gulf, we will work with other suppliers to contain Iran's nuclear, missile, and CBW ambitions, while preventing reconstruction of Iraq's activities in these areas. In South Asia, we will encourage India and Pakistan to proceed with multilateral discussions of nonproliferation and security issues, with the goal of capping and eventually rolling back their nuclear and missile capabilities.

In developing our overall approach to Latin America and South Africa, we will take account of the significant nonproliferation progress made in these regions in recent years. We will intensify efforts to ensure that the former Soviet Union, Eastern Europe and China do not contribute to the spread of weapons of mass destruction and missiles.

\section{Military Planning and Doctrine}

We will give proliferation a higher profile in our intelligence collection and analysis and defense planning, and ensure that our own force structure and military planning address the potential threat from weapons of mass destruction and missiles around the world.

\section{Conventional Arms Transfers}

We will actively seek greater transparency in the area of conventional arms transfers and promote regional confidence-building measures to encourage restraint on such transfers to regions of instability. The U.S. will undertake a comprehensive review of conventional arms transfer policy, taking into account national security, arms control, trade budgetary and economic competitiveness considerations. 


\section{The Secretary of Energy}

Washington, DC 20585

January 19, 1994

The Honorable Warren Christopher

Secretary of State

Washington, D.C. 20520

Dear Mr. Secretary:

On July 13,1993, I wrote to you concerning the Department of Energy's proposal to adopt and implement a new policy on the acceptance of foreign research reactor spent fuel containing uranium enriched in the United States. In addition to expressing the Department's intention to prepare an environmental impact statement on the proposed policy, I also indicated that the Department was planning to complete by the end of 1993 an environmental assessment for the proposed urgent-relief acceptance of enough spent fuel to eliminate any near-term threat to the Reduced Enrichment for Research and Test Reactor Program while the environmental impact statement is being prepared. On November 30,1993, Under Secretary Tarnoff wrote to me on your behalf, urging rapid completion of the environmental assessment and noting the importance of this effort to the President's nuclear nonproliferation policy.

I want to assure you that we are proceeding as rapidly as possible toward completion of the environmental assessment. You should be aware, however, that in response to the draft assessment that we made available to affected States and interested groups and individuals for their review on October 18, 1993, we received numerous comments from elected officials at all levels of government and from private groups and individuals questioning the merits of the Department's proposal to receive any spent fuel from foreign research reactors. It is apparent from these comments that we need to provide a clearer explanation of the nonproliferation concerns that underlie the need for the United States to accept this spent fuel prior to completion of the environmental impact statement.

The need to address the concerns of the public and the evolving list of reactor operators professing a need for "urgent-relief" acceptance of their spent fuel have delayed the completion of the environmental assessment. In order to proceed in light of the concerns expressed and the changing parameters of the proposed action, we have developed, in consultation with your staff, the enclosed action plan leading to completion of the assessment by the end of March 1994. 
I would like specifically to call your attention to the forum scheduled for February and ask that the Department of State participate as a co-host. The purpose of this forum is to have a meaningful dialogue among key stakeholders and policymakers regarding the purpose of, and need for, the proposed urgent-relief acceptance of spent fuel. This will allow a thorough airing of both the international and domestic policy components of this issue and provide an opportunity to explore how to better harmonize these policies.

The meeting on February 10, which would be designed in part to prepare for the discussion on February 25, would involve representatives of all of the key stakeholders. Any new ideas that emerge from the discussion on February 10, could then be brought before the senior policymakers on February 25 . This latter meeting is intended for policymakers, including elected officials from affected States and senior representatives of the appropriate Federal agencies and public interest groups. Observers will be accomodated at both of these meetings.

It is essential that the Department of State actively participate in this forum so that the foreign policy and nonproliferation concerns underlying the urgency of this action are effectively presented. As a practical matter, this Department's ability to proceed with acceptance of urgent-relief spent fuel shipments may depend upon our collective ability to convince stakeholders that the proposed action is necessary.

I request that you make available a senior member of your staff to join with Assistant Secretary Thomas P. Grumbly, Director John G. Keliher, and Special Assistant Robert DeGrasse of my staff to participate in this forum. Please feel free to contact Mr. Grumbly concerning this request. In addition, I would like to express my appreciation for your support in completing the environmental assessment and look forward to the Department of State's participation as a cooperating agency under the National Environmental Policy Act in preparation of the environmental impact statement on the proposed policy to accept foreign research reactor spent fuel.

The Department remains committed to the expeditious completion of the environmental reviews of the proposed acceptance of foreign research reactor spent fuel and to the support of the Nation's nuclear nonproliferation policies.

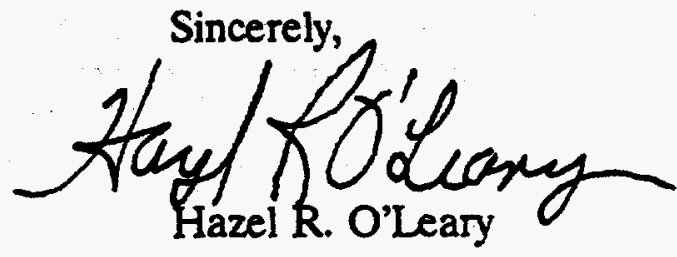

Enclosure 


\author{
Plan of Action \\ for \\ Completion of the Environmental Assessment of the \\ Urgent-Relief Acceptance of Foreign Research Reactor Spent Fuel
}

January 3-14, 1994

Department of Energy and Department of State teams visited each of the foreign research reactors from which we are considering accepting spent fuel under the environmental assessment to verify the need for urgent-relief assistance.

February 4, 1994

A draft environmental assessment, revised to include the results of reactor site visits and consideration of comments received in response to the previous comment period, will be released for a 30-day public review and comment period.

February 10, 1994

A preparatory public meeting will be held involving appropriate Federal agency representatives interacting with interested parties, with invitations being sent to representatives of environmental and non-proliferation public interest groups, State and local government, private sector interests, reactor operators and representatives of key affected communities.

February 25, 1994

A half-day meeting of senior policymakers, including Congress, elected officials from affected States and senior representatives of the appropriate Federal agencies and public interest groups, will include a summary of the discussions that took place at the February meeting.

March 4, 1994

Close of the 30-day public comment period.

March 5-31, 1994

Address public comments.

March 31, 1994

Complete the environmental review process associated with the environmental assessment. 


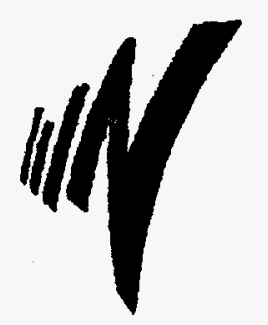

\section{Ministerie ven Economische Zaken}

An

m. T.2, Grumb19

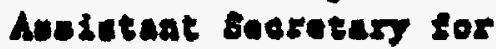

Bovizonmentel Marogument

Depertane of Raere

Hactington, DC 2058

טaม

Donom

Un

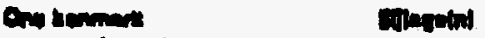

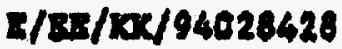

endenware

Decr Mr. Grumbly,

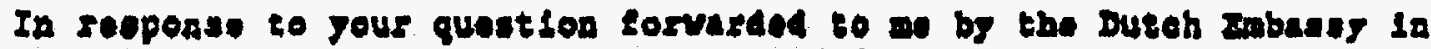

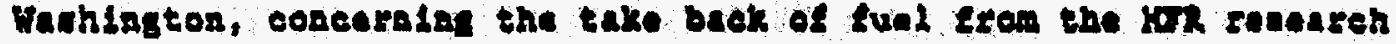

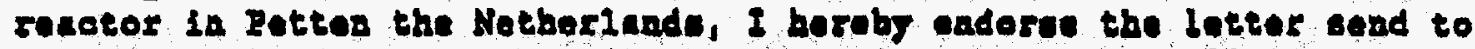

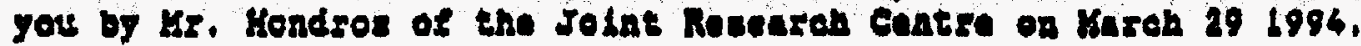

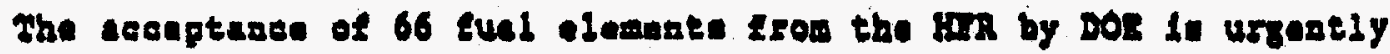
raquired.

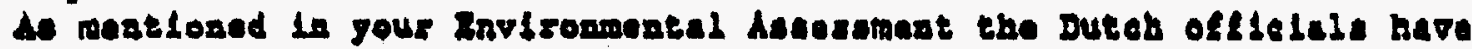

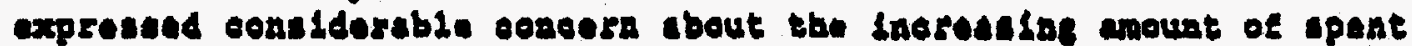
Fuel socuroulating in the spoat storege pooln at tho frk.

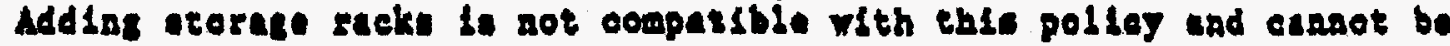
conaldered to be a vible alternative to the exke buck opt1on.

I look torvard to mutuadly astinfylag colutlon of the teke back problem in the secr sutura,

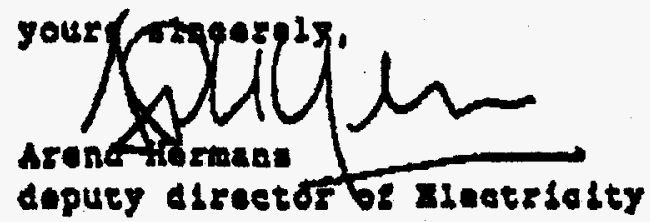

6.s. Stata Departmant 
APPENDIX B

CRITERIA FOR EVALUATION OF SITES FOR STORAGE OF FOREIGN RESEARCH REACTOR SPENT NUCLEAR FUEL 


\title{
APPENDIX B
}

\section{CRITERIA FOR EVALUATION OF STORAGE SITES FOR THE URGENT-RELIEF ACCEPTANCE AND STORAGE OF FOREIGN RESEARCH REACTOR SPENT NUCLEAR FUEL}

The initial selection of sites for evaluation regarding the urgent-relief acceptance and storage of foreign research reactor spent nuclear fuel was based on the following criteria:

- DOE must have jurisdiction over the site.

- Because of the limited time available in which to complete the proposed action, the facility must have sufficient available storage space to accommodate the spent fuel elements proposed to be accepted.

- The site must have existing experience in spent nuclear fuel management.

- The site must be accessible by major highway systems and transportation infrastructure.

Based on consideration of these site criteria, the following sites have been selected for evaluation in the Environmental Assessment:

\author{
Idaho National Engineering Laboratory \\ Savannah River Site \\ Hanford Site \\ Oak Ridge National Laboratory \\ Nevada Test Site
}

The Savannah River Site is discussed in detail in Chapter 3 of the Environmental Assessment. The Idaho National Engineering Laboratory, the Hanford Site, the Oak Ridge National Laboratory, and the Nevada Test Site are discussed in Chapter 4 of the Environmental Assessment. In addition to the factors discussed therein, the following information was considered regarding the Hanford Site and the Oak Ridge National Laboratory.

\section{$\underline{\text { Hanford Site }}$}

The Hanford Site, while having a large inventory of spent nuclear fuel, does not have existing appropriate facilities available for receipt and storage of the spent fuel covered by the proposed action. Several Hanford facilities were evaluated to ascertain their capability to receive aluminum clad spent fuel in the near-term: 105-KE Basin, 105-KW Basin, N Basin, the Purex Plant, T Plant, and 308 Building. Near-term receipt and storage at these facilities are not viable for the following reasons:

1. The 105-KE and 105-KW Basins currently are used to store Hanford defense production reactor fuels. Receipt of the fuel in the proposed action at the 105-KE and the 105-KW Basins is not practical in light of key corrective actions that are being 
undertaken to address concerns identified in the "Spent Fuel Working Group on Inventory and Storage of the Department's Spent Nuclear Fuel and Other Reactor Irradiated Nuclear Material and Their Environmental, Safety and Health Vulnerabilities" (USDOE-EH, 1993).

Additionally, near term receipt would not be practical due to the following restrictions: 1) existing basin safety analyses support storage of low enriched fuel only $(1.25$ percent or less); 2) criticality analyses would be required at each facility to establish safe storage arrays, spacing, shielding, poison, etc.; 3) physical change in fuel storage racks would also be required; 4) existing safety limits at $105-\mathrm{KE}$ and $105-\mathrm{KW}$ do not allow handling of fuels identified as being 50 inches and 60 inches; 5) load out pit configuration in each of the basins would restrict shipping cask handling and size; and 6) any fuel entering $105-\mathrm{KW}$ must be encapsulated.

2. N Basin cleanup activities are scheduled to take place over the next few years to ready the basin for turnover to a Decontamination and Decommissioning status. The $\mathrm{N}$ Basin support systems have already been shut down as part of N Reactor shutdown activities. A formal safety basis for receipt of the fuel at the $\mathrm{N}$ Basin would be required. Near-term receipts of fuels within the proposed action would not be practical due to the current basin status and physical and administrative requirements to ready the basin for fuel receipt.

3. The existing Shippingport PWR Core II pool cell within the 221-T Building canyon is approximately 27 feet by 13 feet. The PWR core II fuel utilizes roughly 50 percent of the available storage space in the pool cell. The 221-T Building canyon includes 36 additional process cells. However, all but two of the cells are filled with contaminated equipment and the two empty cells are designated as decontamination cells.

T Plant is a Limited Control Facility, meaning that the facility currently can contain no greater than one-third of a minimum critical mass of fissionable material, unless the form or distribution of the material ensures that a safe mass cannot be exceeded. Criticality analyses and criticality safety measures would be required prior to storage of fuel that would cause the Limit Control Facility limits to be exceeded. The facility satisfies requirements for storage of safeguards category IV E materials. Additional measures would be required for storage of some of the fuels within the proposed action.

4. The 308 Building contains a TRIGA reactor and 104 TRIGA fuel elements. The elements are stored in racks in the water pool around the reactor. The existing Hanford TRIGA fuel occupies essentially 100 percent of the available capacity in the pool. Plans are being implemented to remove the fuel from the 308 Building to enable transition of the facility to a Decontamination and Decommissioning status. Fuel removal from the facility will not be completed until 1996. Further, the 308 Building cannot readily be reconfigured to receive and store most fuels within the proposed action. 
5. The Purex Plant Storage Basin is a small pool cell ( 31 feet by 20 feet) that currently is used to store Hanford defense production reactor fuel that was originally sent to the PUREX Plant for reprocessing. The PUREX Plant currently is in transition to a Decontamination and Decommissioning status. Activities to remove nuclear material inventories, including the fuel, from the PUREX Plant are being implemented to support facility deactivation.

The existing safety analyses and criticality controls for the PUREX Plant do not accommodate high enriched uranium. The storage basin does not have a water treatment system and the water quality within the basin is not controlled. The PUREX Plant is not configured to receive fuel from casks that would be utilized for foreign research reactor fuel. PUREX Plant modifications and readiness to receive fuel under the proposed action likely could not be achieved within the time required to implement the proposed action.

\section{Oak Ridge National Laboratory}

The Oak Ridge National Laboratory has three possible locations for wet storage of the foreign research reactor spent fuel elements: (1) the High Flux Isotope Reactor (HFIR) pool; (2) the Oak Ridge Reactor (ORR) pool; and (3) the Bulk Shielding Reactor (BSR) pool. Near-term receipt and storage at these facilities is not viable for the following reasons:

1. The HFIR pool is currently full. An effort is in progress to support the reracking of the pool to allow for additional capacity needed for about five years of operation of the HFIR reactor. This reracking will use all of the remaining storage space in the HFIR pool; there would be no room for the storage of 409 foreign research reactor spent fuel elements.

2. The ORR pool has been shut down for a number of years. The pool's Safety Analysis Report and other related safety documentation are no longer current, and the pool has been designated for unrestricted use. In order to store foreign research reactor spent fuel elements in the ORR pool, the safety documentation would need to be redone, a new Safety Analysis Report prepared and approved, and the facility returned to restricted use. This process would likely take well in excess of the time required to implement the proposed action.

3. The BSR pool currently contains BSR spent fuel elements. Although with reracking this pool could accommodate 409 foreign research reactor spent fuel elements, several operational issues preclude its use in the near term. The pool water chemistry is currently being controlled with a demineralized water feed and bleed process. To accommodate the foreign research reactor spent fuel elements, a major upgrade of the pool water cleanup system likely would be required and could not be completed in the near term. Because the facility crane is inadequate to handle the casks associated with the foreign research reactor spent fuel elements, a new crane would have to be installed or the fuel would have to be unloaded in the HFIR facility and then transferred to the BSR pool. The latter option is not viable because the HFIR pool does not have interim storage capacity. 


\section{APPENDIX C}

CRITERIA FOR INITIAL SELECTION AND ANALYSIS OF MARINE PORTS OF ENTRY FOR FOREIGN RESEARCH REACTOR SPENT NUCLEAR FUEL 


\section{APPENDIX C}

\section{CRITERIA FOR INITIAL SELECTION AND ANALYSIS OF MARINE PORTS OF ENTRY FOR FOREIGN RESEARCH REACTOR SPENT NUCLEAR FUEL}

\section{C.1 SUMMARY}

The Department of Energy (DOE) undertook for this Environmental Assessment a series of efforts to develop a list of proposed ports of entry that best addresses the proximity of the ports to the proposed storage facility, the population density surrounding the ports, the experience and capability of the ports in receiving spent nuclear fuel, and other factors relevant to the assessment of risk. The efforts included port visits and contacts with selected ports to collect detailed information on port capabilities and operations, meetings with concerned citizens at potential ports of entry, rigorous calculations of potential risks, a workshop of maritime experts, and review of public comments on two drafts of the Environmental Assessment. The result was a detailed picture of the environmental and other considerations required for selecting marine ports of entry for proposed shipments of spent nuclear fuel under the proposed action.

Based on this information, DOE has identified five ports of entry for the proposed shipments of spent nuclear fuel from foreign research reactors. These ports are Wilmington, North Carolina; Sunny Point, North Carolina; Charleston, South Carolina; Savannah, Georgia; and Jacksonville, Florida. This list differs in some respects from the list of proposed ports included in the Draft Environmental Assessment distributed for public comment in February 1994. In response to public comment and upon further consideration of all factors, Sunny Point, North Carolina was added, and the ports of Portsmouth, Norfolk and Newport News, Virginia were dropped from the list of proposed ports.

\section{C.2 PORT AND MARITIME INDUSTRY DATA COLLECTION ACTIVITIES}

Prior to the development of criteria for port selection and the application of those criteria to a list of ports, detailed information on seaports in the United States and on the economic, safety, and practical considerations of the maritime industry was obtained. The data collection activities undertaken for this Environmental Assessment are described in the following sections.

\section{C.2.1 INVENTORY OF UNITED STATES SEAPORTS}

The data collection activities began with a search for United States ports available for potential receipt of shipments of spent nuclear fuel. A list of all 151 commercial United States seaports was obtained from the United States Maritime Administration (MARAD) (see Table C-1). The seaport inventory contains the names of all commercial ports handling foreign trade. The MARAD seaport inventory does not include pure fishing ports, inland 
ports (e.g., Pittsburgh and St. Louis), ${ }^{1}$ and pure military ports. No efforts were made to include fishing ports or inland ports since ocean-going commercial vessels would not and have not typically called at these ports. Military ports were evaluated separately as discussed in Section C.5.

\section{C.2.2 U.S. Merchant Marine Academy Workshop on Port Selection Criteria}

A DOE-sponsored workshop on port selection criteria for shipments of spent nuclear fuel was held at the United States Merchant Marine Academy (USMMA) in Kings Point, New York on November 15-16, 1993. Participants in the workshop included experts from key sectors within the maritime industry. Disciplines represented included marine transportation, intermodal systems, marine insurance, admiralty law, United States Coast Guard Operations, United States Navy Operations, Military Sealift Command Operations, national cargo bureau, pilotage, and ships operations.

Through a series of panel discussions, a description of how spent nuclear fuel would be transported to the United States was developed. The key points of discussion were the economic and practical constraints of the maritime industry as they pertained to shipments by sea of spent nuclear fuel and factors which could potentially increase the safety of such shipments. The workshop participants clarified several points of fact regarding shipments of spent nuclear fuel and described the advantages and disadvantages of various types of vessels, the impracticality of specifying small ports not on regular shipping routes, and factors which may be desirable if potential and perceived risks associated with the spent nuclear fuel were to be avoided (SNL, 1994).

One of the more important issues agreed upon by the panel of experts assembled was that any port capable of handling an ocean-going vessel is capable of receiving spent nuclear fuel. Some ports may have features which would be more desirable, such as easy access to open water, on-site cargo cranes, full-time safety or emergency staff, etc., but no port which could receive an ocean-going vessel carrying cargo has limitations which would prevent safe receipt of the cargo.

\section{C.2.3 Port Visits}

A number of port visits were conducted on behalf of DOE to obtain detailed information on several ports that appeared to be reasonable ports of entry based on past experience with other shipments of radioactive materials and the location of the proposed spent nuclear fuel storage site. The port visits provided detailed information on topics such as emergency response resources and the number and capabilities of shore cranes as opposed to more general information such as the distance from the port to the Savannah River Site.

\footnotetext{
'An inland port is one that cannot service a commercial ocean-going liner. Any port (regardless of its location) that can service such a vessel is included on the MARAD list of commercial seaports.
} 


\section{C.2.4 Other Activities}

In addition to port visits and the USMMA workshop, contacts were made by telephone and correspondence with other ports and shipping companies (private and government) to obtain information on maritime capabilities and requirements. Navigational charts of potential ports were assessed for information such as harbor and channel depth, distance from the open ocean, vessel maneuvering room, etc. Computer database searches were conducted for pertinent information, such as ports receiving shipments of radioactive materials, to determine the quantities and comparative risks associated with commercial shipping activities.

\section{C.3 Port Selection Criteria and Screening Process}

Once information on United States ports of entry and the maritime industry was collected, the criteria by which potential ports of entry would be evaluated were developed. These criteria were designed to address issues associated only with shipping a small number of casks over a short period of time through a United States port for transport to the Savannah River Site. These criteria were not designed to address issues associated with a larger number of shipments over a long period of time, such as the long-term proposed policy being considered in the Foreign Research Reactor Spent Fuel Environmental Impact Statement. For long-term proposals, considerations such as future port development plans and population trends would have to be considered.

The criteria development process began with the incorporation of criteria pertaining to shipments of spent nuclear fuel in Section 3151 of Public Law 103-160, National Defense Authorization Act for Fiscal Year 1994 (the Act), which was signed into law by President Clinton on November 30, 1993. Section 3151 of the Act provides, in pertinent part:

"The Secretary of Energy shall, if economically feasible and to the maximum extent practicable, provide for the receipt of spent nuclear fuel under this section at a port of entry in the United States which, as determined by the Secretary and compared to each other port of entry in the United States that is capable of receiving the spent nuclear fuel-

(1) has the lowest human population in the area surrounding the port of entry;

(2) is closest in proximity to the facility which will store the spent nuclear fuel; and

(3) has the most appropriate facilities for, and experience in, receiving spent nuclear fuel."

The full text of Section 3151 is provided at the end of this Appendix.

In addition to these requirements, additional criteria recommended by the USMMA workshop were incorporated. These criteria were considered important from a maritime perspective, taking into account environmental, safety, and practical considerations. These additional criteria were: 
(1) distance of the port from the open ocean;

(2) emergency preparedness and capabilities; and

(3) intermodal access.

DOE determined that it would be appropriate to apply the screening criteria to the MARAD list of commercial ports using a step-by-step approach. The first three criteria applied were those set forth in the Act (i.e., most appropriate facilities, lowest population, and closest in proximity to the Savannah River Site). If a port failed to meet one of these criteria, the port was excluded from further consideration. Although the Act did not direct DOE to consider the three criteria in any particular order, DOE applied the criterion relating to a port's facilities and experience first as a reasonable means of evaluating which ports were in fact capable of receiving the spent nuclear fuel. Unless a port had such facilities and therefore was in fact capable of receiving spent nuclear fuel, it would not matter how close the port was to the Savannah River Site or how low the population was in the area surrounding the port.

In the final step, criteria recommended at the USMMA workshop were applied to determine if the ports that met the first three criteria had other characteristics deemed important, but not necessary, to safely receiving shipments of spent fuel. These criteria were distance from the ocean, emergency preparedness and capabilities, and intermodal access. The criteria were not applied singly but as a group, because failure to meet any one of those criteria would not necessarily mean a port could not safely receive spent nuclear fuel. Based on the lessons learned in the USMMA workshop, there is nothing to prevent a port that can receive cargo (containerized or not) from receiving a vessel carrying spent nuclear fuel. The fact that failure to meet any of the last three criteria would not physically prevent safe handling of spent fuel led DOE to conclude that these criteria should be applied as a means of weighing the relative merits of ports. In this manner, DOE could consider many factors relevant to the safe and practicable shipment of spent nuclear fuel to select the port(s) most "capable of receiving spent nuclear fuel."

\section{C.4 Application and Results of the Port Selection Screening Process}

DOE believes that any well-maintained port with certain basic characteristics could safely and reliably receive spent nuclear fuel. Failure of a port to be selected as one of the proposed ports of entry does not mean that such a port is not a safe port of entry for shipment of spent nuclear fuel. DOE does believe that certain ports are more advantageous than others, and the selection of these ports on well-defined criteria provides the basis for the port selection effort undertaken for this Environmental Assessment.

\section{Criterion 1: Most Appropriate Facilities for Receipt of Spent Fuel}

The first step in the screening process was to determine which ports would best meet the Act's criterion of having the "most appropriate facilities for... receiving spent fuel." Since Congress did not define the term "most appropriate facilities" in the Act, DOE had to determine what port features would be necessary to service a large container vessel of the type possibly used under the proposed action. Since DOE does not know if a container vessel, breakbulk freighter or roll-on/roll-off vessel would be used, ports that could service all 
types of vessels were considered so as not to preclude selection of a particular type of oceangoing vessel. Ports that had regularly scheduled commercial container service from Europe would be adequately equipped to receive spent fuel, i.e., these ports would have the harbor depth, pier depth, berthing space, cranes, and crane operators, etc., necessary for servicing a large container or breakbulk vessel. Moreover, these ports would have experience in handling containerized cargo. Because of the near-term nature of the proposed action, it is important that any facilities needed to receive spent fuel already exist, since harbors and channels could not be deepened and dredged, nor port facilities constructed, in the time required for the proposed shipments.

The decision to use current commercial liner schedules was based on recommendations made at the USMMA workshop. Workshop participants concluded that the "most appropriate facilities" criterion would best be met by ports which were regularly serviced by commercial liner operations, where ships provide services as common carriers between specified ports (much like a scheduled airline service between specific cities). Liner operations were restricted to those steamship companies servicing the European ports likely to be the point of origin of the spent nuclear fuel. Unless a port had the facilities needed to service a large ocean-going liner, it would not matter how close the port was to the Savannah River Site or how low the population was surrounding the port.

Commercial liners are common carriers operating ships on scheduled sailings over established trade routes. They provide service to all on a first-come, first-served basis. In contrast to liner operations, tramp ships provide private or contract carrier service on no fixed route or predetermined schedule. These ships go wherever cargo is available and take it to whatever destination is requested. While some companies advertise that, "subject to inducement," ports not on their regular schedule may be added, the cost of adding a port would be significant. However, it was the opinion of the USMMA workshop participants that the better vessels and crews would be working on well-established and regular routes, and that the companies operating these vessels would be unlikely to change their schedules.

Since commercial liners would likely be unavailable even with inducement to call at a port not on their schedule, the shipping companies that would entertain special port calls for very small increments of cargo would tend to manage vessels operating in the tramp (i.e., charter) market. Such vessels tend to be older and less reliable and, according to marine insurance and marine transportation experts at the USMMA workshop, subject to higher casualty rates than vessels sailing on regular liner routes. Less reliable vessels tend to be on the tramp market because they cannot be relied upon to meet a tight and well-defined schedule. There are well maintained and reliable vessels, however, operating in the tramp or charter market. One method for selecting such a vessel would be to select a vessel meeting the standards of the American Bureau of Shipping or a similar classification organization. (See Appendix H.) If a well maintained vessel was obtained and chartered for carriage of the spent nuclear fuel, any port could be specified, assuming that the port had the necessary capabilities.

Based on port facility requirements for importing spent nuclear fuel by sea from Europe on a regularly scheduled commercial liner, ports were assessed using liner schedules of shipping companies listed in the Journal of Commerce's Shipcards. Twenty of the original list of 151 ports met the "most appropriate facility" criterion as shown in Table C-1. These twenty ports 
are identified in Table $\mathrm{C}-1$. Although military ports were not listed in the port inventory shown in Table C-1, no military ports would have met the "most appropriate facility" criterion since commercial liners do not routinely call at military terminals or bases. Military ports were evaluated separately, as discussed in Section C.5.

\section{Criterion 2: Lowest Population Density}

The Act requires DOE to consider the port of entry having "the lowest human population in the area surrounding the port of entry." Of the twenty appropriate facility ports, none is obviously superior when compared to the others with respect to the "population" criterion for two reasons. First, population densities are usually determined by dividing the population of a city or county by the entire area of that city or county. As a result, the population density of a city or county may not be representative of the density around the port. A port may be located well away from the population centers of a city or county, or may be more centrally located. Morehead City, North Carolina is often cited as a low population density port since the county has a population density of 97 people/sq.mi. However, when the population around the port and the transportation link to the closest interstate highway access is examined, the population density is 4572 people/sq.mi. Moreover, the spent fuel would transit not only through the city and county in which it is unloaded, but also would transit through other population centers along the route to the Savannah River Site. Not only the population density in any one area, but the total potentially exposed population should be considered. DOE determined that both population densities (total city/county and initial route from port) and total population residing along route should be used to assess the suitability of the twenty ports.

Table C-2 contains the three population characteristics for each port. In order to compare the population characteristics in a meaningful way, the population for each characteristic was normalized with respect to the lowest population of all ports for that characteristic. For example, along the initial route away from the twenty ports meeting the first criterion, the Port of Jacksonville has the lowest population density, 395 persons $/ \mathrm{km}^{2}$. To normalize the population characteristic for route population density, each port's population density was divided by 395 .

The result was that Jacksonville had a "score" of 1, while Newport News had a score of 2. A score of two means that Newport News has an initial port route population density twice as great as that of Jacksonville. All three population characteristics were normalized in this manner. The average of the three scores was then determined. Each characteristic was given an equal weight, since all are important. An average score of two for a port would mean that the port's population characteristics were two times greater than a port which had the lowest score for all three characteristics.

No port had the lowest numbers for all three population characteristics. Based on the results shown in Table C-2, the decision was made to use an average score of 5.4 or less as meeting the lowest population criterion, since eleven ports were determined to have roughly comparable low population characteristics. 
Table C-1. Capability to Unload Containerized Cargo

\begin{tabular}{|c|c|c|c|c|c|c|c|}
\hline U.S. SEAPORT & $\begin{array}{c}\text { CAPABILITY TO } \\
\text { UNLOAD } \\
\text { CONTAINERIZED } \\
\text { CARGO }\end{array}$ & U.S. SEAPORT & $\begin{array}{c}\text { CAPABILITY TO } \\
\text { UNLOAD } \\
\text { CONTAINERIZED } \\
\text { CARGO }\end{array}$ & U.S. SEAPORT & $\begin{array}{l}\text { CAPABILITY TO } \\
\text { UNLOAD } \\
\text { CONTAINERIZED } \\
\text { CARGO }\end{array}$ & U.S. SEAPORT & $\begin{array}{c}\text { CAPABILITY TO } \\
\text { UNLOAD } \\
\text { CONTAINERIZED } \\
\text { CARGO }\end{array}$ \\
\hline Alameda, CA & No & Carpinteria, CA & No & Freeport, TX & No & K & Yes \\
\hline Albany, NY & No & 4) & Yes & 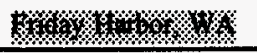 & No & Mandalay Beach, $\mathrm{CA}$ & No \\
\hline Alexandria, VA & No & Chicago, IL & No & Galveston, TX & No & Manitowoc, WI & No \\
\hline Anacortes, WA & No & Cleveland, $\mathrm{OH}$ & No & Gaviota, $\mathrm{CA}$ & No & Marcus Hook, PA & No \\
\hline Antioch, CA & No & Conneaut, $\mathrm{OH}$ & No & Georgetown, SC & No & Marine City, MI & No \\
\hline Ashtabula, $\mathrm{OH}$ & No & Coos Bay, OR & No & Gloucester City, NJ & No & 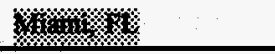 & Yes \\
\hline Astoria, OR & No & Corpus Christi, TX & No & Gramercy, LA & No & Milwaukee, WI & No \\
\hline W(t) & 次 & Crescent City, CA & No & Grays Harbor, WA & No & Mobile, AL & No \\
\hline Baton Rouge, LA & No & Crocket, CA & No & Green Bay, WI & No & Morehead City, NC & No \\
\hline Bay City, MI & No & Delaware City, DE & No & Gulfport, MS & No & Moss Landing, CA & No \\
\hline Beaumont, TX & No & Detroit, MI & No & Hopewell, VA & No & Muskegon, MI & No \\
\hline Bellingham, WA & No & Duluth, $\mathbf{M N}$ & No & 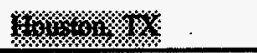 & Yes & New Bedford, MA & No \\
\hline Benicia, CA & No & Edmonds, WA & No & Huntington Beach, CA & No & New Haven, CT & No \\
\hline 6) & Yes & El Segundo, CA & No & Huron, $\mathrm{OH}$ & No & New London, CT & No \\
\hline Bridgeport, CT & No & Erie, PA & No & 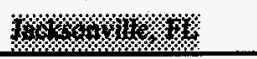 & Yes & 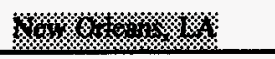 & Yes \\
\hline Brownsville, TX & No & Essexville, MI & No & Kalama, OR & No & 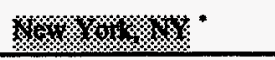 & Yes \\
\hline Brunswick, GA & No & Estero Bay, CA & No & Kenosha, WI & No & Krox & Yes \\
\hline Buffalo, NY & No & Eureka, CA & No & La Place, LA & No & Newport, OR & No \\
\hline Burns Harbor, $\mathbf{I N}$ & No & Everett, WA & No & Lake Charles, LA & No & \%1, & Yes \\
\hline Cambridge, $\mathrm{MD}$ & No & Fairport Harbor, OH & No & W.1\% & Yes & 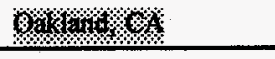 & Yes \\
\hline Camden, NJ & No & Fall River, MA & No & Longview, CA & No & Ogdensburg, NY & No \\
\hline Carlsbad, CA & No & Ferndale, WA & No & Lorain, $\mathrm{OH}$ & No & Olympia, WA & No \\
\hline
\end{tabular}




\begin{tabular}{|c|c|c|c|c|c|c|c|}
\hline U.S. SEAPORT & $\begin{array}{l}\text { CAPABILITY TO } \\
\text { UNLOAD } \\
\text { CONTAINERIZED } \\
\text { CARGO }\end{array}$ & U.S. SEAPORT & $\begin{array}{c}\text { CAPABILITY TO } \\
\text { UNLOAD } \\
\text { CONTAINERIZED } \\
\text { CARGO }\end{array}$ & U.S. SEAPORT & $\begin{array}{c}\text { CAPABILITY TO } \\
\text { UNLOAD } \\
\text { CONTAINERIZED } \\
\text { CARGO }\end{array}$ & U.S. SEAPORT & $\begin{array}{c}\text { CAPABILITY TO } \\
\text { UNLOAD } \\
\text { CONTAINERIZED } \\
\text { CARGO }\end{array}$ \\
\hline Orange, TX & No & \%l & Yes & Reedsport, OR & No & Tacoma, WA & No \\
\hline Ostrica, LA & No & Port Hueneme, CA & No & Reserve, LA & No & Taft, LA & No \\
\hline Oswego, NY & No & Port Manatee, FL & No & Wonowo & Yes & Tampa, FL & No \\
\hline Palm Beach, FL & No & Port Neches, TX & No & Richmond, CA & No & Texas City, TX & No \\
\hline Panama City, FL & No & Port Royal, SC & No & Rochester, NY & No & Toledo, $\mathrm{OH}$ & No \\
\hline Pascagoula, MS & No & Port San Luis, CA & No & Sacramento, CA & No & Uncle Sam, LA & No \\
\hline Paulsboro, NJ & No & Port Sulphur, LA & No & Saginaw, MI & No & Vallejo, CA & No \\
\hline Pensacola, FL & No & Port St. Joe, FL & No & San Diego, CA & No" & Vancouver, WA & No \\
\hline Wrimom & No & Port Townsend, WA & No & San Francisco, CA & No & Venice, LA & No \\
\hline Pilottown, LA & No & Portland, OR & No & Sandusky, OH & No & Ventura, $\mathrm{CA}$ & No \\
\hline Pittsburg, CA & No & W & Yes & \% & Yes & Willapo Harbor, WA & No \\
\hline Point Wells, WA & No & Portsmouth, NH & No & Searsport, ME & No & Wilmington, DE & No \\
\hline Port Angeles, WA & No & W & Yes & Seattle, WA & No & WHorom & Yes \\
\hline Port Arthur, TX & No & Providence, RI & No & Sheboygan, WI & No & Winslow, WA & No \\
\hline Port Canaveral, FL & No & Raymond, WA & No & Stockton, CA & No & & 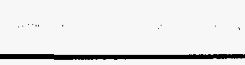 \\
\hline Port Costa, CA & No & Redwood City, CA & No & Superior, WI & No & & \\
\hline
\end{tabular}


Table C-2. Seaports Meeting First Criterion and Evaluated for Lowest Population

\begin{tabular}{|c|c|c|c|c|c|c|c|}
\hline \multirow[b]{2}{*}{ Port } & \multicolumn{3}{|c|}{ Human Population } & \multicolumn{3}{|c|}{ Normalized Population Characteristic } & \multirow[b]{2}{*}{$\begin{array}{c}\text { Average } \\
\text { Score }\end{array}$} \\
\hline & $\begin{array}{c}\text { Population } \\
\text { Density Port } \\
\text { Route (person/ } \\
\mathrm{km}^{2} \text { ) }\end{array}$ & $\begin{array}{c}\text { Population } \\
\text { Density } \\
\text { City } \\
\text { (person/ } \\
\mathrm{km}^{2} \text { ) }\end{array}$ & $\begin{array}{c}\text { Total Population } \\
\text { Residing Along } \\
\text { Truck Route }\end{array}$ & $\begin{array}{c}\text { Port } \\
\text { Route } \\
\text { Population } \\
\text { Density Score }\end{array}$ & $\begin{array}{c}\text { City } \\
\text { Population } \\
\text { Density } \\
\text { Score }\end{array}$ & $\begin{array}{l}\text { Total } \\
\text { Population } \\
\text { Score }\end{array}$ & \\
\hline h & $\%$ & 30 & $61 \times$ & \% & 1 & \% & 然 \\
\hline 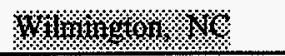 & \% & 6 & 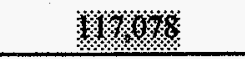 & \%聯 & \% & 列 & 㢺 \\
\hline 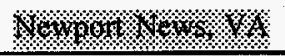 & $\%$ & 6 & m. & \%) & $\%$ & W. & \% \\
\hline \%10\% & $\%$ & $\%$ & $1 \%$ & 誉. & $\%$ & 器 & \% \\
\hline \%ow & $6 \%$ & 30 & 16 & 1) & $6 \%$ & 兹 & 桨 \\
\hline 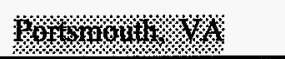 & 38 & 13 & W & 3 & \% & 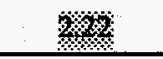 & \% \\
\hline W\%1, wh & 38 & \% & 34 & 梦 & 梦篗 & 烈然: & 3. \\
\hline 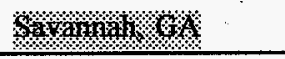 & $\%$ & $\%$ & 3.6\% & $\%$ & 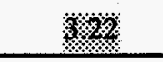 & i & 获 \\
\hline 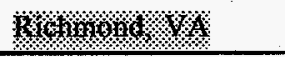 & \%60 & 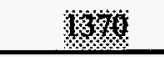 & $1 \%$ & $\%$ & \% & \%: & 玨 \\
\hline $1 / \% 1 \%$ \% & 格 & $10 \%$ & \% & 稵 & 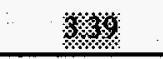 & 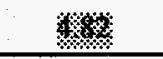 & 㱛 \\
\hline \%o & 20 & \% & \%or & 5 & 6 & 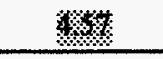 & 3 \\
\hline Elizabeth, NJ & 3652 & 3442 & 340,806 & 9.25 & 11.1 & 6.21 & 8.6 \\
\hline Baltimore, $\mathrm{MD}$ & 3263 & 3546 & 334,944 & 8.26 & 11.44 & 6.1 & 8.6 \\
\hline Miami, FL & 2979 & 4208 & 353,000 & 7.54 & 13.57 & 6.43 & 9.0 \\
\hline $1010 \times 10 \%$ & $\%$ & \% & $\%$ & 然格 & \%) & 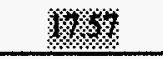 & 6 \\
\hline \% & \% & $\%$ & $16 \%$ & 6 & \%) & 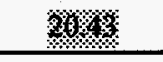 & 1\% \\
\hline 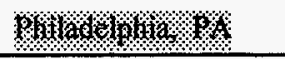 & 66 & 469 & \% & \% & \% & \% & 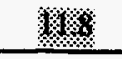 \\
\hline Long Beach, CA & 3478 & 3009 & $1,049,686$ & 8.81 & 9.71 & 19.14 & 12.5 \\
\hline Los Angeles, CA & 3505 & 2646 & $1,099,020$ & 8.87 & 8.54 & 20.03 & 12.5 \\
\hline Boston, MA & 3407 & 4597 & 975,615 & 8.63 & 14.83 & 17.78 & 13.7 \\
\hline
\end{tabular}

\section{C-10}




\section{Criterion 3: Closest in .Proximity to the Facility That Will Store the Spent Nuclear Fuel}

The third step of the port selection process was to determine which of the eleven ports of entry having the most appropriate facilities and lowest population densities were closest in proximity to the Savannah River Site (Aiken, South Carolina). As with the other criteria, "closest in distance" could have several different interpretations. Distance could be interpreted as distance the crow flies, distance via rail line, distance via water route, distance via small back country roads, or distance using interstate highways to the maximum extent possible. Since no definition of "closest in proximity" was provided in the Act, ports were normalized with respect to the distance of the closest port to the Savannah River Site using interstate highways to the maximum extent possible. The use of interstate highways tends to increase distances from the Savannah River Site for ports located close geographically. For example, there are roads over which the distance from Charleston, South Carolina to the Savannah River Site measures only about 130 miles. Maximizing the use of interstate highways, which were designed to carry heavy trucks and hazardous materials, the distance increases to about 200 miles. The distance from the ports to the Savannah River Site were determined using the computer program "HIGHWAY" (ORNL, 1993).

The highway distances and their normalized scores are presented in Table C-3. Charleston, South Carolina is the closest of the eleven ports and all distances were normalized with respect to Charleston. Based on the results of Table C-3, ports with a normalized score greater than 2 were eliminated from further consideration. Four of the eleven ports had scores of 2 or less. (A score of 2 would mean that the port was twice as far away as the closest port.)

Although Charleston is in fact closest to the Savannah River Site, four of the eleven ports were relatively closer to the Savannah River Site in comparison to the remaining seven ports. The reasoning behind selecting several rather than "the closest" port is that no one port clearly meets all of the Act's criteria. For example, even though Charleston is the closest in distance to the Savannah River Site, the port has no experience with spent fuel and is not the lowest in any of the population characteristics. Consequently, four ports were deemed to satisfy the "closest in proximity" criterion as the most balanced means of meeting the Act's criteria.

\section{Application of USMMA Workshop Criteria}

During the final step in evaluating commercial ports, several criteria recommended by the USMMA workshop were applied to all four remaining ports. The first criterion in this step was to apply a "distance from sea" criterion. Most ship collisions and groundings occur in restricted waters where there are frequent course and speed changes, other vessels, and hazards to navigation. Loss of engines or steering on a vessel on the open seas seldom leads to a collision or grounding, but would probably result in some incident in restricted waters. 
Table C-3 Closest in Proximity to the Savannah River Site

\begin{tabular}{|c|c|c|}
\hline Port & $\begin{array}{l}\text { Highway Distance from } \\
\text { Savannah River Site }\end{array}$ & Normalized Score \\
\hline 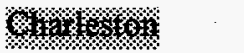 & ख़ & W \\
\hline S. & 26 & \% \\
\hline Hatsom & 380 & 9 \\
\hline 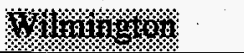 & 398 & 3) \\
\hline Richmond & 471 & 2.3 \\
\hline Portsmouth & 485 & 2.4 \\
\hline Norfolk & 499 & 2.5 \\
\hline Newport News & 540 & 2.7 \\
\hline Everglades & 574 & 2.8 \\
\hline New Orleans & 643 & 3.2 \\
\hline Houston & 956 & 4.7 \\
\hline
\end{tabular}

Therefore, in recognition of the recommendation of the USMMA workshop, DOE determined that distance from the sea would be considered in evaluating whether ports have the most appropriate facilities for receiving spent nuclear fuel. Instead of specifying an exact transit distance as the cutoff for use as the criterion, DOE assessed the distance from the sea for the four ports which had met the first three criteria. As shown in Table C-4, the average distance from the sea to each port is not significantly different. A port transit of between 10 and 26 nautical miles would take about two to four hours. In comparison to other port transits that can take up to twelve or more hours, these distances are not large. Additionally, each of the four ports listed have open sea-to-port transits characterized by well maintained aids to navigation. Based on these reasons, no port was eliminated from consideration using distance from the open ocean.

A second criterion suggested by the USMMA workshop was emergency preparedness and capabilities. This criterion is similar to the Act's consideration of most appropriate facilities and experience in handling spent fuel. Only a few ports have historically handled spent nuclear fuel, and the port with the best facilities and most experience (Hampton Roads) was eliminated from consideration by the distance criterion. Of the four commercial ports meeting the first three criteria, only Wilmington and Savannah have had experience in receiving commercial spent nuclear fuel (NRC, 1993). 
Table C-4. Distance from Sea for Ports with Most Appropriate Facilities, Lowest in Population, and Closest in Distance

\begin{tabular}{||l|c|}
\hline \multicolumn{1}{|c|}{ U.S. SEAPORT } & \multicolumn{1}{c|}{$\begin{array}{c}\text { Distance from Sea } \\
\text { (nautical miles) }\end{array}$} \\
\hline Charleston & 16 \\
\hline Jacksonville & 10 \\
\hline Savannah & 26 \\
\hline Wilmington & 26 \\
\hline
\end{tabular}

In reality, no special equipment or expertise is required to off-load a container of spent nuclear fuel as opposed to a container of similar weight containing hazardous or nonhazardous cargo. Any port that can receive containerized cargo has the capability to receive spent nuclear fuel. Simply stating that a port has received spent fuel in the past does not mean that the experience with that shipment resulted in any knowledge or practices at the port which would affect future shipments. If a port has good cargo handling equipment and emergency response capabilities, the port has facilities for handling spent nuclear fuel. In the event of an accident, a port with these characteristics would have the resources needed for an appropriate response. If the port had a risk management staff on-site or on contract, it was deemed to have emergency preparedness and response capabilities. No attempt was made to evaluate the ports subjectively with respect to their capabilities, but simply to determine if they had such capabilities. All four ports had these characteristics.

The final USMMA workshop criterion by which the ports were evaluated was access to the intermodal transportation system. Ports well connected to the intermodal transportation system have well defined routes, capabilities, and experience in quickly, securely, and safely moving containerized cargo from a port of entry to its destination point. Typically, these routes maximize the use of interstate highways, a desirable feature for transporting hazardous cargo. Each of the four ports is well connected to the intermodal system and has facilities specifically designed for intermodal shipping.

\section{C.5 Selection of Proposed Military Ports of Entry}

Since MARAD's commercial seaport list excludes military ports, DOE evaluated United States military ports to provide a military alternative to the proposed commercial ports. DOE used a slightly different approach for determining which military ports satisfy the screening criteria because the facilities at military ports may differ from those at commercial ports due to the differences in the purposes served by military and commercial ports.

The first step was to locate military ports on the East Coast in close proximity to the Savannah River Site that were weapon stations, military ocean terminals, or military ports with nuclear material experience, and that could unload containerized cargo from a 
commercial vessel. $^{2}$ These facilities were the Naval Weapons Station in Yorktown, Virginia; the Naval Station in Kings Bay, Georgia; the Naval Weapons Station in Charleston, South Carolina; and the Army Military Ocean Terminal in Sunny Point, North Carolina. Of these bases, Kings Bay and Sunny Point have the lowest populations in the area surrounding the port. However, Kings Bay is a submarine base and does not have the most appropriate facilities for, or experience in, handling spent fuel arriving on either container, breakbulk, or roll on/roll off vessels. On the other hand, Sunny Point is a military cargo port and has appropriate facilities for handling spent fuel.

The next step in the evaluation of a military port was to apply the USMMA workshop criteria. The ability of the port to meet the USMMA criteria would ensure that the military port had additional features deemed important to safe shipment of spent fuel. Sunny Point is approximately twelve miles up the Cape Fear River from the open ocean. The passage is along well maintained and marked navigation channels. The short and easy transit from the open ocean to Sunny Point meets the distance from the ocean criterion. Because Sunny Point's primary mission is movement of hazardous cargoes, there are dedicated teams of individuals trained in emergency response. The full-time staff, port response plans, and staff training amply address the emergency preparedness concern. Finally, Sunny Point has good intermodal system access. The Army owns and maintains over 90 miles of rail track that services the port and connections into the CSX rail line. The federal, state, and county maintained roads servicing Sunny Point provide easy access to the interstate system. Trucks moving munitions to and from Sunny Point safely travel over these roads. Based on an evaluation of Sunny Point, the terminal met all three USMMA criteria.

\section{C.6 Selection of Proposed Ports of Entry}

Based on the criteria in the Act and the criteria recommended by the USMMA workshop participants, the following commercial and military ports of entry were proposed as most reasonably meeting the port selection criteria for purposes of this proposed action: Wilmington, North Carolina; Sunny Point, North Carolina; Charleston, South Carolina; Savannah, Georgia; and Jacksonville, Florida.

\section{C.7 Public Law 103-160, National Defense Authorization Act for Fiscal Year 1994}

\section{SEC. 3151. LIMITATIONS ON THE RECEIPT AND STORAGE OF SPENT NUCLEAR FUEL FROM FOREIGN RESEARCH REACTORS}

(a) Purpose - It is the purpose of this section to regulate the receipt and storage of spent nuclear fuel at the Department of Energy defense nuclear facility located at the Savannah River Site, South Carolina (in this section referred to as the "Savannah River Site").

(b) Receipt in Emergency Circumstances - When the Secretary of Energy determines that

\footnotetext{
${ }^{2}$ If an area had more than one military facility, the weapons station was selected over the other facilities. Weapons stations tend to have lower populations in the immediate vicinity of the port due to safety zones. Also, weapons stations would have experience in loading and unloading cargo carrying vessels.
} 
emergency circumstances make it necessary to receive spent nuclear fuel, the Secretary shall submit a notification of that determination to the Congress. The Secretary may not receive spent nuclear fuel at the Savannah River Site until the expiration of the 30-day period beginning on the date on which the Congress receives the notification.

(c) Limitation on Storage in Non-Emergency Circumstances - The Secretary of Energy may not, under other than emergency circumstances, receive and store at the Savannah River Site any spent nuclear fuel in excess of the amount that (as of the date of the enactment of this Act) the Savannah River Site is capable of receiving and storing, until, with respect to the receipt and storage of any such spent nuclear fuel--

(1) the completion of an environmental impact statement under section $102(2)(\mathrm{C})$ of the National Environmental Policy Act of 1969 (42 U.S.C. 4332(2)(C));

(2) the expiration of the 90 -day period (as prescribed by regulation pursuant to such Act) beginning on the date of such completion; and

(3) the signing by the Secretary of a record of decision following such completion.

(d) Limitations on Receipt - The Secretary of Energy may not, under emergency or nonemergency circumstances, receive spent nuclear fuel if the spent nuclear fuel--

(1) cannot be transferred in an expeditious manner from its port of entry in the United States to a storage facility that is located at a Department of Energy facility and is capable of receiving and storing the spent nuclear fuel; or

(2) will remain on a vessel in the port of entry for a period that exceeds the period necessary to unload the fuel from the vessel pursuant to routine unloading procedures.

(e) Criteria for Port of Entry - The Secretary of Energy shall, if economically feasible and to the maximum extent practicable, provide for the receipt of spent nuclear fuel under this section at a port of entry in the United States which, as determined by the Secretary and compared to each other port of entry in the United States that is capable of receiving the spent nuclear fuel -

(1) has the lowest human population in the area surrounding the port of entry;

(2) is closest in proximity to the facility which will store the spent nuclear fuel; and

(3) has the most appropriate facilities for, and experience in, receiving spent nuclear fuel.

(f) Definition - In this section, the term "spent nuclear fuel" means nuclear fuel that--

(1) was originally exported to a foreign country from the United States in the form of highly enriched uranium; and

(2) was used in a research reactor by the Government of a foreign country or by a foreign-owned or foreign-controlled entity. 
APPENDIX D

SUMMARY OF REGULATIONS 


\section{APPENDIX D}

\section{SUMMARY OF REGULATIONS}

\section{D.1 International Regulations}

\section{$\underline{\text { Regulations of the International Atomic Energy Agency }}$}

The International Atomic Energy Agency (IAEA) is an agency of the United Nations headquartered in Vienna, Austria. The IAEA establishes standards for radioactive materials transportation. These are published as model regulations (Safety Series No. 6) that may be adopted by individual nations. These model regulations are regularly revised and updated. Safety Series 6 was revised in 1990 (IAEA, 1990a). The U.S. Nuclear Regulatory Commission (NRC) and the U.S. Department of Transportation (DOT) both periodically review and revise their regulations to bring them into general accord with the IAEA regulations to the extent considered feasible. The U.S. regulations are discussed in the next section.

The emphasis of the IAEA model regulations is on package integrity. To that end, packagings must be shown to survive a hypothetical accident sequence that includes impact, crush, puncture, fire, and immersion. The level of protection is defined by the nature of the contents. The intent of the regulations is to maximize the shipper's contribution to safety, and the shipper (consignor) must certify "that the contents of this consignment are properly described by name; are properly packaged, marked and labeled; and are in proper condition for transport ... " (IAEA, 1990a). The carrier is responsible for following rules for stowage and for segregation from persons.

\section{International Maritime Organization}

The International Maritime Organization (IMO) ${ }^{1}$ publishes the International Maritime Dangerous Goods (IMDG) Code (IMO, 1984), which was developed to supplement the provisions of the 1960 International Convention on the Safety of Life at Sea (SOLAS), as amended, (IMO, 1992) to which the United States is a signatory. These regulations include those that deal with carriage of radioactive material (Class 7 materials). They are based on the IAEA regulations and deal with segregation of radioactive materials packages from other dangerous goods and other aspects of stowage.

\footnotetext{
${ }^{1}$ Formerly known as the Inter Governmental Maritime Consultative Organization (IMCO).
} 


\section{D.2 Domestic Regulations}

\section{D.2.1 NRC Packaging Certification}

An NRC certificate is issued as evidence that a packaging and its contents meet applicable Federal regulations. The certificate is issued on the basis of a Safety Analysis Report (SAR) on the packaging design. Type B packaging must survive certain severe hypothetical accident conditions of impact, puncture, fire, and immersion. The tests are not intended to duplicate accident environments, but rather to produce damage equivalent to extreme accidents. The complete accident sequence is described in Title 10 of the Code of Federal Regulations, Part 71.73 (10 CFR 71.73) and is summarized here.

\section{Test Sequence for Type B Packagings}

The effects on a package of the tests may be evaluated either by subjecting a scale model sample package to the test or by other methods acceptable to the NRC. NRC Regulatory Guide 7.9 allows assessment of package performance by analysis, prototype testing, model testing, or comparison to a similar package. To be judged as surviving, the packaging must not exceed allowable releases defined in $10 \mathrm{CFR} 71.51$. The dose rate outside the packaging must not exceed $1 \mathrm{rem} /$ hour at a distance of 1 meter from the packaging surface. The first three tests must be performed on the same package in this order: drop test; puncture test; and thermal test (with an immersion test following for fissile material packagings only).

The drop test consists of a 9-meter (30-foot) drop onto a flat, essentially unyielding, /horizontal surface, striking the surface in the position for which maximum damage is expected. The puncture test consists of a 1-meter (40-inch) drop onto the upper end of a 15-centimeter (6-inch) solid, vertical, cylindrical bar of mild steel mounted on an essentially unyielding surface. The top of the bar must be horizontal and its edge rounded to a radius of not more than 6 millimeters ( 0.25 inches). An essentially unyielding surface is one that absorbs very little of the energy of impact, which means that the energy of impact is absorbed almost entirely by the test object (cask). Unyielding surfaces are constructed of a monolithic concrete base, reinforced by Re-bar and covered with a plate of battleship armor.

In the thermal test, the packaging must be exposed for not less than 30 minutes to a heat flux not less than that of a radiative environment of $800^{\circ} \mathrm{C}\left(1475^{\circ} \mathrm{F}\right)$ with an emissivity coefficient of at least 0.9 . The surface absorptivity must be either the value that the package may be expected to possess if exposed to a fire, or 0.8 - whichever is greater. When it might be significant, convective heat input must be included on the basis of still, ambient air. The packaging may not be artificially cooled after external heat input ceases, and any combustion of materials of construction must be allowed to proceed until it terminates naturally.

Fissile materials packagings for which water in-leakage has not been assumed for criticality analysis must be subjected to submersion under a head of water of at least 0.9 meters ( 3 feet) for not less than 8 hours and in the attitude for which the maximum leakage is expected. All packages must be subjected to a separate test in which an undamaged cask is submerged under a head of water of at least 15 meters ( 50 feet) for not less than 8 hours. 
Although spent fuel casks have been involved in several accidents, their integrity has never been compromised. The regulatory tests are structured to place an upper bound on the kinds of damage seen in actual severe transportation accidents. Furthermore, after completion of this series of performance qualification tests, Type B packagings are further subjected to a post-accident leak-rate performance test (10 CFR 71.51). In this test, no escape of radioactive material is allowed that exceeds an A2 amount in a week. The A2 amount of an isotope is the maximum activity of that isotope in a potentially dispersable form that is allowed to be shipped in a Type A packaging, which is non-accident resistant. Safety Series No. 6 lists A2 values for all commonly transported isotopes.

The use of an essentially unyielding target makes the regulatory certification tests extremely demanding. Real targets are much more yielding. For example, a lead-shield steel cask was dropped 610 meters (2,000 feet) from a helicopter onto undisturbed soil (USNRC, 1977). Impact velocity was 396 kilometers per hour ( 235 miles per hour). The cask penetrated 2.4 meters ( 8 feet) into the hard soil but suffered no measurable deformation. An identical cask dropped 9 meters ( 30 feet) onto an essentially unyielding surface during regulatory testing suffered considerably more deformation (Jefferson and Yoshimura, 1978). More recent research has expanded the study of yielding targets (e.g., concrete surfaces) and their comparison with the regulatory surface (Gonzalez, 1986).

\section{D.2.2 Transportation Regulations}

\section{Oversea Carriage}

Relevant regulations applying to transport of spent nuclear fuel by vessel are found in 10 CFR Parts 71 and 73, and 49 CFR Part 176. The U.S. Coast Guard (USCG), part of the DOT, inspects vessels for compliance with applicable regulations and requires 24-hour prenotification (33 CFR 160.207, 211, and 213).

Section 49 CFR 171.12 (d) states that: "Radioactive materials being imported into or exported from the U.S., or passing through the U.S. in the course of being shipped between places outside the U.S., may be offered and accepted for shipment in accordance with IAEA "Regulations for the Safe Transport of Radioactive Materials, Safety Series No. 6, 1988 Edition". Certain specified conditions of this section must be complied with. For example, highway-route-controlled quantities (HRCQs) of radioactive material must be shipped in accordance with appropriate provisions of the hazardous materials regulations and a Certificate of Competent Authority (COCA) must be obtained, with any necessary revalidations. A COCA fulfills the IAEA requirement for multilateral approval for a shipment of Type B packages in international commerce (IAEA, 1990a).

Section 49 CFR 176.5 details the application of the regulations to vessels: "...this subchapter applies to each domestic or foreign vessel when in the navigable waters of the U.S., regardless of its character, tonnage, size or service, and whether self-propelled or not, whether arriving or departing, underway, moored, anchored, aground, or while in drydock." Excepted from the regulations are vessels not engaged in commercial service, a vessel used exclusively for pleasure, a vessel of 500 gross tons, or smaller, engaged in fisheries, etc. 
Section 49 CFR 176.15 provides for enforcement of 49 CFR Subchapter C:

"(a) An enforcement officer of the U.S. Coast Guard may at any time and at any place, within the jurisdiction of the U.S., board any vessel for the purpose of enforcement of this subchapter and inspect any shipment of hazardous materials as defined in this subchapter."

Provision is also made in this section to detain a vessel which is in violation of the hazardous materials regulations.

The Coast Guard may accept a certificate of loading issued by the National Cargo Bureau, Inc., as evidence that the cargo is stowed in conformity with law and regulatory requirements. The National Cargo Bureau, Inc., is a non-profit organization directed by government and industry representatives (49 CFR 176.18). 49 CFR 176.18 authorizes inspectors of the National Cargo Bureau, Inc., to assist the Coast Guard in administering the hazardous materials regulations. Their functions are as follows:

"(1) Inspection of vessels for suitability for loading hazardous materials;

(2) Examination of stowage of hazardous materials;

(3) Making recommendations for stowage requirements of hazardous materials cargo; and,

(4) Issuance of certificates of loading setting forth that the stowage of hazardous materials is in accordance with the requirements of 46 U.S.C. 170 and its subchapter."

Detailed requirements for radioactive material are located in Part 176 Subpart $M$ of the Hazardous Materials Regulations. General radioactive material stowage requirements of 176.700 state that "(b) A package of radioactive materials which in still air has a surface temperature more than $5^{\circ} \mathrm{C}\left(9^{\circ} \mathrm{F}\right)$ above the ambient air may not be overstowed with any other cargo. If the package is stowed under the deck, the hold or compartment in which it is stowed must be ventilated."

Except for exclusive-use shipments, requirements of 176.704(c) relating to transport indexes state that:

"the number of freight containers with packages of radioactive materials contained therein must be limited so that the total sum of the transport indexes in the containers in any hold or defined deck area does not exceed 200, and:

(1) The sum of transport indexes for any individual freight container, or group of freight containers, does not exceed 50; and, 
(2) Each freight container or group of freight containers is (are) handled and stowed in such a manner that groups are separated from each other by a distance of at least six meters (20 feet)."

Section 176.76(a) includes provision for freight containers with hazardous materials to be carried on board a vessel in accordance with the following:

"(1) The material must be in proper condition for transportation according to the requirements of this subchapter;

(2) All packages in the transport vehicle or container must be secured to prevent movement in any direction. However, vertical restraint is not required if the shape of the packages and the stuffing pattern precludes shifting of the load;

(3) Bulkheads made of dunnage which extend to the level of the cargo must be provided unless the packages are stowed flush with the sides or ends;

(4) Dunnage must be secured to the floor when the cargo consists of dense materials or heavy packages."

Each freight container must be placarded as required by Subpart F of Part 172 of the Hazardous Materials Regulations [176.76(f)].

Section 176.80 requires that radioactive materials be segregated from other hazardous materials so that they do not interact dangerously in an accident or, alternatively, requires that the radioactive material be in separate holds when stored under deck. In 49 CFR 176.83(b), a table is provided (Table II) that specifies the minimum separation distances for different classes of hazardous materials on board a vessel. A minimum horizontal separation distance of 10 feet projected vertically from the reference package is required. For specified hazardous materials, the "separate from" requirement means that the materials must be placed in separate holds when stowed under deck.

\section{Overland Carriage}

Overland shipments (by rail car or by truck) are regulated by a variety of DOT and NRC regulations dealing with packaging, notification, escorts and communication. In addition there are specific regulations for carriage by truck and carriage by rail.

When provisions are made to secure a package so that its position within the transport vehicle remains fixed during transport, with no loading or unloading between the beginning and end of transport, a package shipped overland in exclusive-use closed transport vehicles may not exceed the following radiation levels as provided in 49 CFR 173.441(b):

- $1,000 \mathrm{mrem} / \mathrm{hr}$ on the external package surface;

- $200 \mathrm{mrem} / \mathrm{hr}$ at any point on the outer surface of the vehicle; 
point 2 meters from the vertical planes projected from the outer edges of the vehicle;

- $\quad 2 \mathrm{mrem} / \mathrm{hr}$ in any normally occupied position in the vehicle, except that this provision does not apply to private motor carriers when the personnel are operating under a radiation protection program and wear radiation-exposure monitoring devices.

The shipper of record must comply with the requirements of 10 CFR 71.5 and 73.37. Section 71.5 provides that all overland shipments must be in compliance with DOT and NRC regulations, these regulations provide for security of irradiated reactor fuel. General requirements include: provide notification to NRC in advance of each shipment, develop a shipping plan, provide escort instructions, establish a communication center to be staffed 24 hours a day, make arrangements with local law enforcement agencies along the route for their response, if not using law enforcement personnel as escort, ensure that the escorts are trained in accordance with 73.37 Appendix D, and ensure that escorts make notification calls every two hours to the communication center. Additional requirements include having two armed escorts within heavily populated areas (when not in heavily populated areas, only one escort is needed) and the capability of communicating with the communications center and local law enforcement agencies through a radiotelephone or other NRC approved means of two-way voice communications.

The shipper of record, required by 49 CFR 173.22 , provides physical security measures for spent fuel shipments equivalent to those of the NRC. The shipper and his agent will provide notification for unclassified spent fuel shipments to state officials.

For carriage by truck the, carrier will use interstate highways or state-designated preferred routes for movement of radioactive materials in conformity with the DOT rulemaking known as Docket HM-164. These regulations, found in 49 CFR 397.101, establish routing and driver training requirements for highway carriers of packages containing "highway-route-controlled quantities" of radioactive materials. Spent fuel shipments constitute such quantities. DOT rules make those routes designated by appropriate state agencies enforceable by the Federal government according to DOT's own determination that such route designations, when accompanied by an adequate safety analysis, are likely to result in further reduction of radiological risk.

For carriage by rail car, each shipment by the railroad must comply with 49 CFR 174, in particular, 174 Subpart K - Detailed Requirements for Radioactive Materials. 
APPENDIX E

INPUT PARAMETERS FOR TRANSPORTATION RISK ANALYSIS 


\section{APPENDIX E}

\section{INPUT PARAMETERS FOR TRANSPORTATION RISK ANALYSIS}

Transportation risk analysis with the RADTRAN 4 computer code requires that the user develop a number of input parameter values that describe the particulars of the shipments being analyzed. These input parameters and the sources of the values used in this analysis are described in this appendix.

The radiation fields around Type B packages result in small doses to populations and individuals in proximity to the casks during routine transportation. With the RADTRAN 4 computer code, doses to all major groups of potentially exposed persons are estimated (Neuhauser and Kanipe, 1993). These groups are discussed here.

- $\quad$ Ship Crew: Because of the large amount of shielding provided by partitions, bulkheads, and other cargo, and because distances between cargo areas and most crew areas are large, radiation doses to crew members are generally negligible. However, dose to a cargo inspector is calculated. In the case of foreign research reactor spent nuclear fuel that is most likely to be shipped as a single container on a container or other type ship, the placement of the container among others may provide so much shielding that the inspector dose is greatly overestimated. Thus, the ship-crew dose, taken to be equal to the inspector dose, is considered to be conservative. Sea lanes are considered to be devoid of population.

- $\quad$ Handlers and Inspectors at the Port: Containerized cargo is usually off-loaded with a maximum of five handlers: four actual handlers, one at each corner of the container where the crane engages the built-in corner-fittings, and one spotter who signals the crane operator. The crane lifts the container above the deck and then moves it laterally to the dock where it is lowered onto a waiting truck trailer. There, another group of up to five workers guides the container corner-fittings into the built-in tiedowns on the trailer chassis, makes sure that they are secure, and signals the crane to disengage. The entire process usually takes about two minutes. At a large port, hundreds of such container moves occur every day. Containerized spent fuel casks are handled just like any other cargo, and the above description applies.

In addition, however, radiological and other compliance inspections may be required by the U.S. Coast Guard, the state within which the port is located, and the carrier and/or the shipper. Because the relative location of inspectors with respect to the container is approximately the same as for handlers, handlers and inspectors are considered as a single exposure group.

- $\quad$ Other Persons at the Port: The period of time that the container remains in port after being offloaded is considered a special type of stop. The stop represents the time required to complete all inspections, paperwork, placarding, and weighing. The group involved consists of port workers other than handlers and inspectors. 
- $\quad$ Truck Crew: Dose rates in the cabs of tractor trucks carrying radioactive material are required by regulation to be less than two mrem per hour (Title 49 Code of Federal Regulations, Part 173). In the case of foreign research reactor spent nuclear fuel, the dose rates are expected to be much smaller. All trucks are modeled as having two-person crews.

- $\quad$ Persons along the Highway Route: This group, often referred to as the off-link population, generally receives the smallest doses. Population doses to persons within 800 meters ( 0.5 miles) on each side of the transport route are estimated.

- $\quad$ Persons Sharing the Highway Route: Population doses to persons in vehicles traveling in the same direction (including passing vehicles) and in the opposite direction (collectively referred to as the on-link population) are estimated, although these doses too are usually very small.

- $\quad$ Persons at Highway Stops: Population doses to persons at fuel and rest stops, tire inspection stops, etc. along the route are estimated.

- $\quad$ Rail Crew: Because of large separation distances and massive shielding from intervening railcars, rail crews do not receive significant doses while in transit. Only doses to rail crew members at rail stops are calculated.

- Persons along the Rail Route: This group, who are also part of the off-link population, generally receives the smallest doses. Population doses to persons within $800 \mathrm{~m}$ $(0.5 \mathrm{mi})$ on each side of the transport route are estimated.

- $\quad$ Persons Sharing the Rail Route: Population doses to persons in trains traveling in the opposite direction (part of the on-link population) are estimated, although these doses too are usually very small.

- $\quad$ Persons at Rail Stops: Population doses to persons at rail classification stops are estimated. Because rail inspectors are required to be in proximity to railcars carrying spent fuel during routine inspections, the inspector dose at rail stops is modeled.

\section{E.1 Carriage By Vessel}

Because of the large amount of shielding provided by partitions, bulkheads, and other cargo, and because distances between cargo areas and crew areas are large, radiation doses to crew members are not calculated in RADTRAN 4 (Neuhauser and Kanipe, 1993). However, dose to a cargo inspector is calculated. In the case of foreign research reactor spent nuclear fuel, which is likely to be shipped as single containers on separate container cargo ships, the placement of the cask-container among other containers may provide so much shielding that the inspector dose is overestimated. Thus, the ship-crew dose, taken to be equal to the inspector dose, is considered to be conservative. Ship inspector dose is calculated from input data on the length of the voyage, the number of intermediate stops, and the speed of the ship. Shipboard inspections are conservatively modeled as occurring once every 24 hours and as taking one inspector at a distance of two meters (6.6 feet) one minute to complete (Neuhauser 
and Kanipe, 1993). Since cargo inspections are related to total trip duration, the duration of intermediate port calls is added to the travel time. In this study, each voyage was modeled as having three intermediate port calls, each lasting $\mathbf{4 8}$ hours, prior to the offloading of the spent nuclear fuel at one of the ports analyzed.

\section{E.2 Routine Port Operations}

Much of the information in this section is from actual observations and measurements made during the intermodal transfer of twelve cask shipments of Taiwan spent nuclear fuel in February 1991 (Neuhauser and Cashwell, 1991; Neuhauser and Weiner, 1992b). The transfer took place at the Port of Hampton Roads, Virginia, which is an alternative port in the present analysis. Since handling of containerized cargo is highly standardized, the actual transfer process would be approximately the same for all ports. Potential differences between ports involve experience, especially the importance of experience in reducing delays, and the presence or absence of port infrastructure features and operational controls (e.g., clearing the scale area of unnecessary personnel while weighing the truck shipments prior to departure from the port).

Berths are assigned to ships by port authority personnel. Berth assignments for ships carrying Highway Route Controlled Quantities (HRCQs) of radioactive material are made by the Port Authority. For example, at the Port of Charleston, berth assignments are made by the Port Authority's Operations and Engineering Department (FHI, 1993a).

Inspectors from the U.S. Coast Guard (USCG) conduct an onboard inspection before the casks are offloaded from the ship; the inspectors may take radiation readings at the surface of the International Standards Organization (ISO) container. Transfer begins only after the on-board inspection is complete.

With modern containerized-cargo-handling equipment, intermodal transfer of a single ISO container from a ship to a truck usually takes less than two minutes, but can take up to five minutes in some cases; the procedure includes: (1) positioning the crane over the container; (2) locking onto the container; (3) lifting it up and moving it horizontally to the dock; (4) lowering it onto a waiting trailer; (5) securing the tiedowns; and (6) releasing the crane. The longer time is unusual and is generally associated with difficulty aligning or securing the tiedowns on the truck chassis and the corner fittings on the container. A time of ten minutes is conservatively used to model this process in the analysis for this Environmental Assessment. The number of persons involved at any one time in this process is at most five. There are, at most, five persons near the ISO container while it is on the ship - one handler at each corner and a spotter. There are also at most five persons near the container on the dock - one handler at each tiedown on the truck chassis and a spotter, who may also be the one who locks the tiedowns into place. An exposure time of ten minutes is also assigned to the five-person group on the dock.

Once a cask container is transferred to a truck chassis, placards may have to be replaced (if in a language other than English); each truck is weighed; and shipping papers are finalized. At Hampton Roads, the dock and weigh-station areas were cleared of unnecessary personnel during offloading, and parking was provided in a remote staging area during completion of 
the paperwork. The entire process took about three hours for sequential processing of a total of twelve cask shipments at Hampton Roads. Intermodal transfer of only one or two casks, in a port with experience in handling radioactive cargoes, should take one hour or less. In ports with little or no experience and/or limited facilities, the time could increase. Therefore, three $\mathrm{hr}$ was used in this analysis for the intermodal-transfer stop time for all ports, and the default value of 50 persons within a 50-meter radius of the shipment was used for the number of workers other than handlers and inspectors (Neuhauser and Weiner, 1992b). Where rail access is immediately adjacent to the berthing area, the rail transfer process is similar to that for a truck, but if the rail siding is at some distance from the berthing area, a container would have to be transferred from the ship to a container chassis, which would carry it to the rail siding where it would be transferred to a railcar. In the latter case, the intermodal stop time and handler dose would increase.

A port security police vehicle must be provided to escort a truck shipment during moves within the port facility; the shipment is escorted out of the port gate by the regular escort that is required for HRCQ shipments in urban areas. Shipments from Virginia ports were escorted beyond the port urban area all the way to the state border (Neuhauser and Cashwell, 1991), but escort practices may vary by state.

Each cask may be subjected to several inspections beginning with a USCG inspection on the vessel. Independent radiological inspections may be performed by other entities (e.g., the state, the shipper). An independent mechanical inspection of the tiedowns is usually performed (by the carrier). In the past, a total of five inspections, each by a single inspector and lasting as much as five minutes each, have occurred. For this reason, the total time spent near (i.e., within 1 to $2 \mathrm{~m}$ ) an ISO container by handlers/inspectors was estimated to be 30 minutes.

\section{E.3 Routing}

\section{Sea Routes}

All routes were obtained from "Distances Between Ports," published by the Defense Mapping Agency (DMA, 1991), and use normal shipping lanes.

\section{Highway Routes}

Data on highway routes were obtained from the HIGHWAY routing code (ORNL, 1992a), which also gives population densities for each route segment derived from 1990 Census Bureau data. The nature of their data as structured for input into the RADTRAN computer analysis is illustrated in Tables E-1 through E-5. Each route segment is labeled as to whether it is rural, suburban, or urban according to the following breakdown: rural population densities range from 0 to 54 persons $/ \mathrm{km}^{2}\left(0-139\right.$ persons $\left./ \mathrm{mi}^{2}\right)$; the suburban range is 55 to 1284 persons $/ \mathrm{km}^{2}\left(140-3326\right.$ persons $\left./ \mathrm{mi}^{2}\right)$; and urban is classified as all population densities above 1284 persons $/ \mathrm{km}^{2}$ (3326 persons $/ \mathrm{mi}^{2}$ ) (Neuhauser and Kanipe, 1992). The total population is given for persons within $800 \mathrm{~m}(0.5 \mathrm{mi})$ on each side of the route. The summary of highway route data for all ports of entry is given in Table E-6. 


\section{E.4 Accident Environments}

\section{Modal Considerations}

Maritime accident rate data from a variety of sources were examined for environmental assessments of Taiwan spent nuclear fuel shipments (USDOE, 1991a) and an earlier study of other proposed foreign research reactor shipments (Cashwell et al., 1990). The data indicate that the basic accident rate in and near ports is $3.2 \mathrm{E}-04$ per port transit; that is, approximately three accidents per 10,000 port visits. The conditional probabilities of occurrence of each accident severity were developed from these data. A conditional probability is defined as the probability given that an accident has occurred, that it will be of a certain severity. In order to calculate overall probability of an accident of a particular severity, the base accident probability (accident rate) must be multiplied by the conditional probability. The severity categories are based on event trees originally developed for spent fuel shipped by truck and rail (Wilmot, 1981); they are used for maritime shipments because the same accident environments may occur in other modes (Dennis et al., 1977). These categories and their frequency values are shown in Tables E-7 and E-8. Accident rate data for the truck and maritime modes are also shown in Table E-8. These are taken from DOT national data on tractor-trailer accidents on Interstate highways (USDOT, 1985). Table E-9 contains release fractions for the various accident severities.

Other researchers have used eight-category (USNRC, 1977) and 20-category schemes (Fischer et al., 1990) to describe the same spectrum of highway accidents. All give approximately the same results when applied to similar problems and are essentially interchangeable (Fischer et al., 1990; Whitlow and Neuhauser, 1992). Consistent with the general principles of probabilistic risk assessment, extremely low probability events (Helton, 1991) are not considered reasonably foreseeable, and therefore are not included among the accident-severity categories. Thus, for example, a "worst case" accident, although physically possible, is so remote (i.e., improbable) as to render it not reasonably foreseeable to occur. The six severity categories include all accidents with a probability of occurrence of one in a million or greater for the entire campaign of up to 25 shipments, well within the levels found acceptable by U.S. Environmental Protection Agency (EPA) and other agencies (Hallenbeck and Cunningham, 1986). 
Table E-1. Highway Route for Proposed Port of Charleston to the Savannah River Site

\begin{tabular}{|c|c|c|c|c|}
\hline Route Segment ${ }^{\mathrm{a}}$ & $\begin{array}{l}\text { Distance } \\
\mathrm{km}(\mathrm{mi})\end{array}$ & $\begin{array}{l}\text { Pop. Density } \\
\text { (persons } / \mathrm{km}^{2} \text { ) }\end{array}$ & Type $^{b}$ & $\begin{array}{c}\text { Total } \\
\text { Population }\end{array}$ \\
\hline 1 & $3.2(2.0)$ & 2250.7 & $U$ & 11588.2 \\
\hline 2 & $15.4(9.6)$ & 2250.7 & $\mathrm{U}$ & 55623.4 \\
\hline 3 & $208.5(129.6)$ & 15.2 & $\mathbf{R}$ & 5064.8 \\
\hline 4 & $67.4(41.9)$ & 296.3 & $\mathrm{~S}$ & 31965.9 \\
\hline 5 & $7.2(4.5)$ & 2127.0 & $\mathrm{U}$ & 24641.1 \\
\hline 6 & $1.0(0.6)$ & 8.9 & $\mathrm{R}$ & 13.8 \\
\hline 7 & $3.9(2.4)$ & 802.3 & $\mathrm{~S}$ & 4956.9 \\
\hline 8 & $3.2(2.0)$ & 511.6 & S & 2634.2 \\
\hline 9 & $2.9(1.8)$ & 30.0 & $\mathbf{R}$ & 138.9 \\
\hline 10 & $5.1(3.2)$ & 159.0 & $S$ & 1309.8 \\
\hline 11 & $14.2(8.8)$ & 29.0 & $\mathrm{R}$ & 657.2 \\
\hline 12 & $3.5(2.2)$ & 141.6 & S & 802.2 \\
\hline 13 & $4.8(3.0)$ & 0.0 & $\mathrm{R}$ & 0.0 \\
\hline 14 & $14.5(9.0)$ & 0.3 & $\mathrm{R}$ & 6.3 \\
\hline TOTAL & $354.9(220.6)$ & & & 139402.6 \\
\hline
\end{tabular}

${ }^{a}$ Route segments are sequential segments of highway route, beginning with the port access road and ending with the SRS access road. Each segment is defined on the basis of population density and highway type.

${ }^{b} R, S$, and $U$ refer to rural, suburban, and urban, respectively. 
Table E-2. Highway Route for Proposed Port of Jacksonville to the Savannah River Site

\begin{tabular}{|c|c|c|c|c|}
\hline Route Segment ${ }^{a}$ & Distance $\mathrm{km}(\mathrm{mi})$ & $\begin{array}{l}\text { Pop. Density } \\
\text { (persons } / \mathrm{km}^{2} \text { ) }\end{array}$ & Type $^{b}$ & $\begin{array}{c}\text { Total } \\
\text { Population }\end{array}$ \\
\hline 1 & $4.3(2.7)$ & 395.2 & $\mathbf{S}$ & 2736.7 \\
\hline 2 & $13.4(8.3)$ & 395.2 & S & 8454.4 \\
\hline 3 & $34.1(21.2)$ & 12.4 & $\mathbf{R}$ & 678.8 \\
\hline 4 & $1.3(0.8)$ & 89.8 & $\mathbf{S}$ & 185.0 \\
\hline 5 & $149.2(92.7)$ & 12.6 & $\mathbf{R}$ & 3014.3 \\
\hline 6 & $32.5(20.2)$ & 138.2 & $\mathrm{~S}$ & 7187.1 \\
\hline 7 & $273.9(170.2)$ & 13.6 & $\mathrm{R}$ & 5974.5 \\
\hline 8 & $62.3(38.7)$ & 209.1 & S & 20831.1 \\
\hline 9 & $0.2(0.1)$ & 1765.4 & $\mathrm{U}$ & 454.5 \\
\hline 10 & $1.0(0.6)$ & 8.9 & $\mathrm{R}$ & 13.8 \\
\hline 11 & $3.9(2.4)$ & 802.3 & S & 4956.9 \\
\hline 12 & $3.2(2.0)$ & 511.6 & $\mathrm{~S}$ & 2634.2 \\
\hline 13 & $2.9(1.8)$ & 30.0 & $\mathrm{R}$ & 138.9 \\
\hline 14 & $5.1(3.2)$ & 159.0 & S & 1309.8 \\
\hline 15 & $14.2(8.8)$ & 29.0 & $\mathrm{R}$ & 657.2 \\
\hline 16 & $3.5(2.2)$ & 141.6 & $\mathrm{~S}$ & 802.2 \\
\hline 17 & $14.5(9.0)$ & 0.3 & $\mathrm{R}$ & 6.3 \\
\hline TOTAL & $624.1(387.9)$ & & & 60035.7 \\
\hline
\end{tabular}

${ }^{a}$ Route segments are sequential segments of highway route, beginning with the port access road and ending with the SRS access road. Each segment is defined on the basis of population density and highway type.

${ }^{b} \mathrm{R}, \mathrm{S}$, and $\mathrm{U}$ refer to rural, suburban, and urban, respectively. 
Table E-3. Highway Route for Proposed Port of Savannah to the Savannah River Site

\begin{tabular}{||c|c|c|c|c||}
\hline \hline Route Segment $^{\mathrm{a}}$ & Distance $\mathrm{km}(\mathrm{mi})$ & $\begin{array}{c}\text { Pop. Density } \\
\left(\text { persons } / \mathrm{km}^{2}\right)\end{array}$ & Type $^{\mathrm{b}}$ & $\begin{array}{c}\text { Total } \\
\text { Population }\end{array}$ \\
\hline 1 & $3.0(1.9)$ & 2787.8 & $\mathrm{U}$ & 13492.6 \\
\hline 2 & $26.9(16.7)$ & 19.0 & $\mathrm{R}$ & 817.0 \\
\hline 3 & $10.1(6.3)$ & 170.6 & $\mathrm{~S}$ & 2766.5 \\
\hline 4 & $273.9(170.2)$ & 13.6 & $\mathrm{R}$ & 5974.5 \\
\hline 5 & $62.3(38.7)$ & 209.1 & $\mathrm{~S}$ & 20831.1 \\
\hline 6 & $0.2(0.1)$ & 1765.4 & $\mathrm{U}$ & 454.5 \\
\hline 7 & $1.0(0.6)$ & 8.9 & $\mathrm{R}$ & 13.8 \\
\hline 8 & $3.9(2.4)$ & 802.3 & $\mathrm{~S}$ & 4956.9 \\
\hline 9 & $3.2(2.0)$ & 511.6 & $\mathrm{~S}$ & 2634.2 \\
\hline 10 & $2.9(1.8)$ & 30.0 & $\mathrm{R}$ & 138.9 \\
\hline 11 & $5.1(3.2)$ & 159.0 & $\mathrm{~S}$ & 1309.8 \\
\hline 12 & $14.2(8.8)$ & 29.0 & $\mathrm{R}$ & 657.2 \\
\hline 13 & $3.5(2.2)$ & 141.6 & $\mathrm{~S}$ & 802.2 \\
\hline 14 & $4.8(3.0)$ & 0.0 & $\mathrm{R}$ & 0.0 \\
\hline 15 & $14.5(9.0)$ & 0.3 & $\mathrm{R}$ & 6.3 \\
\hline TOTAL & $429.4(266.9)$ & & & 54855.5 \\
\hline
\end{tabular}

${ }^{a}$ Route segments are sequential segments of highway route, beginning with the port access road and ending with the SRS access road. Each segment is defined on the basis of population density and highway type.

${ }^{b} \mathrm{R}, \mathrm{S}$, and $\mathrm{U}$ refer to rural, suburban, and urban, respectively. 
Table E-4. Highway Route for Proposed Port of Sunny Point to the Savannah River Site

\begin{tabular}{|c|c|c|c|c|}
\hline Route Segment ${ }^{2}$ & Distance $\mathrm{km}(\mathrm{mi})$ & $\begin{array}{l}\text { Pop. Density } \\
\text { (persons } / \mathrm{km}^{2} \text { ) }\end{array}$ & Type & $\begin{array}{c}\text { Total } \\
\text { Population }\end{array}$ \\
\hline 1 & $17.7(11.0)$ & 178.6 & $S$ & 5059.0 \\
\hline 2 & $19.3(12.0)$ & 21.9 & $\mathbf{R}$ & 675.4 \\
\hline 3 & $6.4(4.0)$ & 118.6 & $\mathbf{S}$ & 1221.1 \\
\hline 4 & $14.5(9.0)$ & 26.3 & $\mathbf{R}$ & 609.5 \\
\hline 5 & $4.8(3.0)$ & 0.4 & $\mathbf{R}$ & 3.0 \\
\hline 6 & $2.3(1.4)$ & 0.2 & $\mathbf{R}$ & 0.7 \\
\hline 7 & $0.3(0.2)$ & 667.4 & s & 343.6 \\
\hline 8 & $0.6(0.4)$ & 1765.4 & $\mathrm{U}$ & 1818.0 \\
\hline 9 & $4.8(3.0)$ & 1765.4 & U & 13634.8 \\
\hline 10 & $4.8(3.0)$ & 1765.4 & $\mathrm{U}$ & 13634.8 \\
\hline 11 & $6.4(4.0)$ & 1765.4 & $\mathrm{U}$ & 18179.7 \\
\hline 12 & $221.2(137.5)$ & 15.6 & $\mathbf{R}$ & 5523.9 \\
\hline 13 & $66.8(41.5)$ & 162.1 . & $\mathrm{s}$ & 17320.1 \\
\hline 14 & $210.9(131.1)$ & 19.9 & $\mathbf{R}$ & 6726.9 \\
\hline 15 & $73.5(45.7)$ & 260.3 & $\mathrm{~S}$ & 30629.5 \\
\hline 16 & $1.9(1.2)$ & 1765.4 & $\mathrm{U}$ & 5453.9 \\
\hline 17 & $1.0(0.6)$ & 8.9 & $\mathbf{R}$ & 13.8 \\
\hline 18 & $3.9(2.4)$ & 802.3 & $\mathrm{~s}$ & 4956.9 \\
\hline 19 & $3.2(2.0)$ & 511.6 & $\mathrm{~s}$ & 2634.2 \\
\hline 20 & $2.9(1.8)$ & 30.0 & $\mathrm{R}$ & 138.9 \\
\hline 21 & $5.1(3.2)$ & 159.0 & $\mathrm{~S}$ & 1309.8 \\
\hline 22 & $14.2(8.8)$ & 29.0 & $\mathrm{R}$ & 657.2 \\
\hline 23 & $3.5(2.2)$ & 141.6 & $S$ & 802.2 \\
\hline 24 & $4.8(3.0)$ & 0.0 & $\mathrm{R}$ & 0.0 \\
\hline 25 & $14.5(9.0)$ & 0.3 & $\mathrm{R}$ & 6.3 \\
\hline TOTAL & $709.6(441.0)$ & & & 131353.3 \\
\hline
\end{tabular}

${ }^{a}$ Route segments are sequential segments of highway route, beginning with the port access road and ending with the SRS access road. Each segment is defined on the basis of population density and highway type.

${ }^{b} \mathrm{R}, \mathrm{S}$, and $\mathrm{U}$ refer to rural, suburban, and urban, respectively. 
Table E-5. Highway Route for Proposed Port of Wilmington to the Savannah River Site

\begin{tabular}{|c|c|c|c|c|}
\hline Route Segment ${ }^{\mathrm{a}}$ & Distance $\mathrm{km}(\mathrm{mi})$ & $\begin{array}{l}\text { Pop. Density } \\
\text { (persons } / \mathrm{km}^{2} \text { ) }\end{array}$ & Type $^{b}$ & $\begin{array}{c}\text { Total } \\
\text { Population }\end{array}$ \\
\hline 1 & $1.6(1.0)$ & 1765.4 & $\mathrm{U}$ & 4544.9 \\
\hline 2 & $1.6(1.0)$ & 1765.4 & $\mathrm{U}$ & 4544.9 \\
\hline 3 & $4.8(3.0)$ & 1765.4 & $\mathrm{U}$ & 13634.8 \\
\hline 4 & $6.4(4.0)$ & 1765.4 & $\mathrm{U}$ & 18179.7 \\
\hline 5 & $221.2(137.5)$ & 15.6 & $\mathbf{R}$ & 5523.9 \\
\hline 6 & $66.8(41.5)$ & 162.1 & $\mathrm{~S}$ & 17320.1 \\
\hline 7 & $210.9(131.1)$ & 19.9 & $\mathrm{R}$ & 6726.9 \\
\hline 8 & $73.5(45.7)$ & 260.3 & $\mathrm{~S}$ & 30629.5 \\
\hline 9 & $1.9(1.2)$ & 1765.4 & $\mathrm{U}$ & 5453.9 \\
\hline 10 & $1.0(0.6)$ & 8.9 & $\mathrm{R}$ & 13.8 \\
\hline 11 & $3.9(2.4)$ & 802.3 & $\mathrm{~S}$ & 4956.9 \\
\hline 12 & $3.2(2.0)$ & 511.6 & $\mathrm{~S}$ & 2634.2 \\
\hline 13 & $2.9(1.8)$ & 30.0 & $\mathrm{R}$ & 138.9 \\
\hline 14 & $5.1(3.2)$ & 159.0 & $\mathrm{~S}$ & 1309.8 \\
\hline 15 & $14.2(8.8)$ & 29.0 & $\mathbf{R}$ & 657.2 \\
\hline 16 & $3.5(2.2)$ & 141.6 & $\mathrm{~S}$ & 802.2 \\
\hline 17 & $4.8(3.0)$ & 0.0 & $\mathbf{R}$ & 0.0 \\
\hline 18 & $14.5(9.0)$ & 0.3 & $\mathbf{R}$ & 6.3 \\
\hline TOTAL & $642.0(399.0)$ & & & 117078.0 \\
\hline
\end{tabular}

a Route segments are sequential segments of highway route, beginning with the port access road and ending with the SRS access road. Each segment is defined on the basis of population density and highway type.

${ }^{b} \mathrm{R}, \mathrm{S}$, and $\mathrm{U}$ refer to rural, suburban, and urban, respectively. 
Table E-6. Summary of Highway Route Data for all Ports of Entry

\begin{tabular}{||l|c|c|}
\hline \multicolumn{1}{|c|}{ Port of Entry } & $\begin{array}{c}\text { Distance to SRS } \\
\text { Km(mi) }\end{array}$ & $\begin{array}{c}\text { Population } \\
\text { Along Route }\end{array}$ \\
\hline Charleston & $354.9(221)$ & 139,403 \\
\hline Jacksonville & $624.1(388)$ & 60,036 \\
\hline Savannah & $429.4(267)$ & 54,856 \\
\hline Sunny Point & $709.6(441)$ & 131,353 \\
\hline Wilmington & $642.0(399)$ & 117,078 \\
\hline
\end{tabular}

Table E-7. Accident Severity Categories Used in Analysis

\begin{tabular}{|c|l||}
\hline RADTRAN Severity Category & \multicolumn{1}{|c|}{ Description } \\
\hline Severity Category 1 & $\begin{array}{l}\text { Conditions do not exceed those for a Type A } \\
\text { package; no release of contents }\end{array}$ \\
\hline Severity Category 2 & $\begin{array}{l}\text { Conditions equal to those for Type B certification } \\
\text { tests; no release of contents }\end{array}$ \\
\hline Severity Category 3 & $\begin{array}{l}\text { Seal damage creates leak path, but fuel undamaged; } \\
\text { only CRUD could be expelled from package }\end{array}$ \\
\hline Severity Category 4 & $\begin{array}{l}\text { Impact damage great enough to cause damage to } \\
\text { spent fuel; fuel particulates and fission gases may be } \\
\text { released }\end{array}$ \\
\hline Severity Category 5 & $\begin{array}{l}\text { Impact damage to seals plus fire severe enough to } \\
\text { cause thermal burst with release of fission gases, } \\
\text { volatiles, and particulates }\end{array}$ \\
\hline Severity Category 6 & $\begin{array}{l}\text { Severe impact damage plus fire severe enough to } \\
\text { cause fuel oxidation with release of greater amounts } \\
\text { of fuel particulates than Category } 5\end{array}$ \\
\hline
\end{tabular}

a CRUD (Chalk River Unidentified Deposits) consists of corrosion products deposited on the fuel cladding during reactor operation. Loosely adhered CRUD is observed on power reactor spent fuel but is absent on foreign research reactor spent fuel. 
Table E-8. RADTRAN Accident Probability Data by Mode

\begin{tabular}{|c|c|c|}
\hline RADTRAN Input Parameter & $\begin{array}{l}\text { RADTRAN } \\
\text { Keyword }\end{array}$ & Values Used in This Study \\
\hline Base Accident Rate - Ship in Port Vicinity & $\begin{array}{l}\text { ARAMTZ } \\
\text { MODE }=4\end{array}$ & $3.2 \mathrm{E}-4 /$ port transit \\
\hline Base Accident Rates - Truck in Urban Areas & $\begin{array}{l}\text { ARAMTZ } \\
\text { MODE }=1\end{array}$ & $\begin{array}{cc}\text { Access Rd } & 1.34 \mathrm{E}-06 / \mathrm{km} \\
\text { Interstate } & 1.60 \mathrm{E}-05 / \mathrm{km} \\
\end{array}$ \\
\hline Base Accident Rates - Truck in Suburban Areas & $\begin{array}{l}\text { ARAMTZ } \\
\text { MODE }=1\end{array}$ & Interstate $3.00 \mathrm{E}-06 / \mathrm{km}$ \\
\hline Base Accident Rates - Truck in Rural Areas & $\begin{array}{l}\text { ARAMTZ } \\
\text { MODE }=1\end{array}$ & $\begin{array}{l}\text { Access Rd } 1.82 \mathrm{E}-06 / \mathrm{km} \\
\text { Interstate } 1.37 \mathrm{E}-07 / \mathrm{km}\end{array}$ \\
\hline $\begin{array}{l}\text { Conditional Probability of Accident Severity } \\
\text { Category } 1\end{array}$ & SEVFRC & $\begin{array}{rr}\text { Ship } & .603 \\
\text { Urban } & .604 \\
\text { Suburban } & .602 \\
\text { Rural } & .603 \\
\end{array}$ \\
\hline $\begin{array}{l}\text { Conditional Probability of Accident Severity } \\
\text { Category } 2\end{array}$ & SEVFRC & $\begin{array}{rr}\text { Ship } & .395 \\
\text { Urban } & .393 \\
\text { Suburban } & .394 \\
\text { Rural } & .395\end{array}$ \\
\hline $\begin{array}{l}\text { Conditional Probability of Accident Severity } \\
\text { Category } 3\end{array}$ & SEVFRC & $\begin{array}{rr}\text { Ship } & .002 \\
\text { Urban } & .003 \\
\text { Suburban } & .004 \\
\text { Rural } & .002\end{array}$ \\
\hline $\begin{array}{l}\text { Conditional Probability of Accident Severity } \\
\text { Category } 4\end{array}$ & SEVFRC & $\begin{array}{rr}\text { Ship } & 4.0 \mathrm{E}-04 \\
\text { Urban } & 3.8 \mathrm{E}-07 \\
\text { Suburban } & 4.0 \mathrm{E}-06 \\
\text { Rural } & 3.0 \mathrm{E}-06\end{array}$ \\
\hline $\begin{array}{l}\text { Conditional Probability of Accident Severity } \\
\text { Category } 5\end{array}$ & SEVFRC & $\begin{array}{rr}\text { Ship } & 4.0 \mathrm{E}-04 \\
\text { Urban } & 2.5 \mathrm{E}-07 \\
\text { Suburban } & 3.0 \mathrm{E}-06 \\
\text { Rural } & 5.0 \mathrm{E}-06\end{array}$ \\
\hline $\begin{array}{l}\text { Conditional Probability of Accident Severity } \\
\text { Category } 6\end{array}$ & SEVFRC & $\begin{array}{rr}\text { Ship } & 4.0 \mathrm{E}-04 \\
\text { Urban } & 1.3 \mathrm{E}-07 \\
\text { Suburban } & 2.0 \mathrm{E}-06 \\
\text { Rural } & 7.0 \mathrm{E}-06\end{array}$ \\
\hline
\end{tabular}


Table E-9 Release Fractions for Foreign Research Reactor Spent Fuel By Accident Severity Category

\begin{tabular}{||c|c|c|c|c|c|c||}
\hline \multirow{2}{*}{ Isotope } & \multicolumn{7}{|c||}{ Accident Severity Category } \\
\cline { 2 - 7 } & 1 & 2 & 3 & 4 & 5 & 6 \\
\hline Cobalt-60 & 0 & 0 & $1.2 \mathrm{E}-2$ & $1.2 \mathrm{E}-2$ & $1.2 \mathrm{E}-2$ & $1.2 \mathrm{E}-2$ \\
\hline Krypton-85 & 0 & 0 & 0 & $1.0 \mathrm{E}-2$ & $1.0 \mathrm{E}-1$ & $1.1 \mathrm{E}-1$ \\
\hline $\begin{array}{l}\text { Cesium 134 \& } \\
\text { Cesium-137 }\end{array}$ & 0 & 0 & 0 & $1.0 \mathrm{E}-8$ & $9.0 \mathrm{E}-4$ & $9.8 \mathrm{E}-4$ \\
\hline Ruthenium-106 & 0 & 0 & 0 & $1.0 \mathrm{E}-8$ & $1.0 \mathrm{E}-6$ & $4.2 \mathrm{E}-5$ \\
\hline Other Materials & 0 & 0 & 0 & $1.0 \mathrm{E}-8$ & $5.0 \mathrm{E}-8$ & $5.0 \mathrm{E}-8$ \\
\hline
\end{tabular}

\section{Container Drops During Intermodal Transfer}

The possibility of cask damage during handling at the dock was considered. Historical data from Hampton Roads, a large port with extensive container handling experience, has a handling accident rate of less than 3E-06 mishaps annually; that is, less than 3 per million container moves (USDOE, 1991a, Appendix C). The major cause is container defects rather than mishandling (USDOE, 1991a, Appendix C; FHI, 1993a). As noted in the main text, ISO containers used to transport spent nuclear fuel are reinforced and can be expected to be less likely to have defects than the average container. There is a possibility that the likelihood of mishandling is greater at ports with less experience in handling containerized cargo, but quantitative data are not available.

Berths at all ports considered in this analysis consist of either concrete aprons constructed on friction pilings driven into the sediment or bedrock or on tamped earth contained within sheet pilings and surfaced with concrete. Both are yielding surfaces, and the water and the deck of a ship are even more yielding than a dock surface. Previous studies have shown that a package can be dropped onto a yielding surface from much higher than $10 \mathrm{~m}(30 \mathrm{ft})$ without sustaining damage (Gonzalez, et al., 1986; Waddoups, 1976).

In conclusion, the probability of a container drop is low, and such a drop would be expected to be considerably less severe than the certification drop test conditions even if the container were dropped from greater than $10 \mathrm{~m}(30 \mathrm{ft})$ because of the yielding nature of the surfaces onto which they might fall. Therefore, container drops during intermodal transfer are not considered a threat to a massive Type B cask and they are not considered further in this analysis. Port accidents that are considered consist mainly of vessel accidents, including accidents in which a moored ship is struck, usually by another ship (Warwick and Anderson, 1976; ORI 1979). Since truck velocities within the immediate confines of a port are low and cask movements are preceded by a port police escort vehicle, truck accidents in port are not a significant contributor. 


\section{Cask Response to Thermal Conditions}

Spent fuel casks are designed to survive the thermal load specified in the Type B cask certification tests with no release of contents (see Appendix D). Total heat input to the cask is what is important, not a particular temperature or duration. A fire that meets or exceeds the regulatory fire temperature of $800^{\circ} \mathrm{C}\left(1470^{\circ} \mathrm{F}\right)$, for example, may have no effect whatsoever on a cask if it does not engulf the cask (i.e., if it does not satisfy the test condition of the entire cask being exposed to the fire) and/or if it does not last at least as long as the 30 min specified in the test (Fischer et al., 1987).

The fact that a cask is much smaller than a water carrier (ship) makes the collocation criterion an important consideration in maritime modes. Consideration must be given to the likelihood that a fire will occur in the same location as the cargo. Many ship fires are confined to engine rooms, etc., and do not affect cargo areas (ORI, 1979). The small container-to-ship size ratios typical of maritime transport must also be considered in relation to the fire-duration criterion. Although shipboard fires have been described as burning for days, that is not, by itself, sufficient information to determine whether any particular location as small in volume as a single container is exposed to fire at all, much less for "days." Indeed, shipboard fires are often traveling fires, which progress through a ship during the course of the fire and in which no single location in the fire's path is exposed for a prolonged period of time. Fires involving tanker ships are not directly relevant to conditions onboard container-cargo ships; tanker fires are discussed by Abkowitz and Galarraga (1985). In a rare historical accident involving the collision of an oil tanker and a cargo ship, conditions onboard the tanker and container ship were quite different (USCG, 1975; USDOT, 1975).

The ISO container provides additional surfaces for the radiation of heat and could provide shielding from flame heat (Considine, 1984), although no credit is taken for the ISO container in this analysis. In 1978, an older model of a spent fuel cask was subjected to prolonged extra regulatory fire test at Sandia National Laboratories (SNL). The JP-4 fuel flow to the fully engulfing fire was stopped after $100 \mathrm{~min}$ (over three times the regulatory fire test duration); the fire also burned at somewhat hotter temperatures than the minimum $800^{\circ} \mathrm{C}$ $\left(1470^{\circ} \mathrm{F}\right)$ called for in the certification test requirements. The test was terminated because the lead shielding had melted and was being expelled from microcracks on the external surface of the cask. The cask was an older model cask of a type no longer in use, which was shipped with water in the cask cavity and was fitted with a pressure-relief valve for venting of water/steam in a fire. The pressure-relief valve functioned as designed, and hot water/steam was expelled through the valve from the cask cavity during the test. A thorough post-mortem examination showed that even in this extreme fire environment, no spent nuclear fuel would have been released (Rack and Yoshimura, 1980). The results of this test remain relevant to discussions of newer casks (which are shipped with inert gas in the cask cavity and which have no pressure-relief valve) because much of the heat resistance is attributable to the fact all spent fuel casks are massive structures that act as large heat sinks and take a long time to heat up. [For example, the contents of a spent fuel cask typically experiences little or no heat rise after the $30 \mathrm{~min}$ certification thermal (fire) test at $800^{\circ} \mathrm{C}\left(1470^{\circ} \mathrm{F}\right)$.] Inert gas or air (the latter in the event of seal damage) in the cask cavity serves as an insulating layer. 
Studies of time-vs-temperature behavior of zircaloy-clad commercial spent fuel rods indicate that burst rupture (corresponds to Severity Category 5 in this EA) could begin to occur after a cask was exposed to an $800^{\circ} \mathrm{C}\left(1470^{\circ} \mathrm{F}\right)$ engulfing fire for approximately $4 \mathrm{hr}$ (Burion, 1985). The temperature of the cask cavity does not reach even a fraction of the external $800^{\circ} \mathrm{C}$ $\left(1470^{\circ} \mathrm{F}\right)$ temperature during a 30 -min certification test. Actual data from tests with commercial power reactor spent fuel indicate that gaseous and highly volatile components are expelled through localized cracks that form in the cladding as a result of burst rupture (Lorenz et al., 1978; Lorenz et al., 1980a, 1980b; Burion et al., 1985). Since any subsequent pressure buildup is relieved by the formation of the cracks, extensive release into the cask cavity of spent fuel isotopes cannot be achieved by fire alone. Furthermore, release to the cask cavity would not result in any release to the environment unless cask containment was also affected, and as noted above, to compromise cask containment, an $800^{\circ} \mathrm{C}$ fire would have to last for many hours and be collocated (i.e., engulf the cask for the entire duration of the fire). The foreign research reactor spent nuclear fuel analyzed in this EA is aluminum-clad rather than zircaloy-clad. Calculations show that the thermal response of the two cladding types in the temperature range of interest is similar (Stevens, 1986).

The release of volatiles such as cesium-137 from foreign research reactor spent fuel is modeled as being slightly higher than from commercial power reactor spent fuel because the former is in metallic rather than oxide form. There is no basis for modeling large cesium releases from burst rupture of spent fuel (Luna et al., 1986).

\section{Failed Fuel}

No failed fuel is proposed for shipment under this action.

\section{Atmospheric Dispersal}

Atmospheric dispersal of material potentially released during a severe accident is usually the means of spreading any released material beyond the immediate accident location and into the human environment. Dispersal is affected by the degree of turbulence in the atmosphere, which can vary from unstable (Class A) to extremely stable (Class F). The Pasquill system of atmospheric stability classes is commonly used to describe this variation, although there are other systems (Till and Meyer, 1983). A conservative representation of atmospheric conditions at ports generated by the DIFOUT dispersion code (Church and Luna, 1969) for Class D, which has been used in previous port analyses (USDOE, 1986; USDOE, 1988; USDOE, 1991a;), was used for this assessment. For overland truck transportation, the defaults available in RADTRAN 4, which represent national average data, were used (Turner, 1970; Neuhauser and Kanipe, 1993). 


\section{APPENDIX F}

RADIONUCLIDE INVENTORIES OF FOREIGN RESEARCH REACTOR

SPENT NUCLEAR FUEL 


\section{APPENDIX F}

\section{RADIONUCLIDE INVENTORIES OF FOREIGN RESEARCH REACTOR SPENT NUCLEAR FUEL}

The radionuclide inventories of urgent-relief foreign research reactor spent nuclear fuel are presented in Table F-1. The values are from output files generated by the ORIGEN-79 (ORNL, 1979) isotope generation and depletion code. Among the input parameters required by ORIGEN are the cross-section libraries. Research reactors are designed and operated differently than light water power reactors, and therefore have a markedly different neutron flux spectra. As no library was available, Argonne National Laboratory (ANL) specifically modified the ORIGEN-79 code, implementing neutron interaction cross-sections more appropriate to research reactors. The radionuclide inventories were calculated using the ANL specially modified version of ORIGEN-79, utilizing input parameters derived from the most recent information provided by the reactor operators documented by Shaw, Pittman, Potts and Trowbridge (Shaw, 1993). Where data was insufficient or incomplete, the International Atomic Energy Agency (IAEA) directory of nuclear research reactors (IAEA, 1991), was utilized as a secondary source of information.

Table F-2 lists the various input parameters required by the Argonne version of ORIGEN to calculate the foreign research reactor spent nuclear fuel radionuclide inventories. The majority of the inputs were extracted directly from either of the two references, with the remainder requiring only simple calculations. The two most significant factors are the initial amount of fissile material present, in grams of Uranium 235 (U-235) isotope per fuel element, and the average burnup expressed in percent of fissile material consumed. The two parameters provide the basis from which the majority of the other inputs were derived.

All reactors were modeled as of a typical high enrichment fuel type, and operated continuously at full thermal power until achievement of the average fissile content burnup. Test reactors have irregular irradiation profiles and are typically operated intermittently and at various power levels. Treatment of the reactors as continuously operated at full power yields conservative radionuclide inventories, as more reactions occur with no decay interval resulting in higher concentrations of fission products. In addition, as the spent fuel is allowed to cool only 150 days following discharge from the reactor, the inventories presented are even further conservatively represented. 
Table F-1. Radionuclide Inventories of Foreign Research Reactor Spent Nuclear Fuel (Curies)

\begin{tabular}{|c|c|c|c|c|c|c|c|c|c|c|c|}
\hline Reactor & HOR & BER2 & GRR1 & ASTRA & DR3 & HIFAR & SAPHIR & FRG & HFR & R2 & BR2 \\
\hline $\begin{array}{l}\text { Power } \\
\text { Level } \\
\end{array}$ & $2 \mathrm{MW}$ & $10 \mathrm{MW}$ & $5 \mathrm{MW}$ & $10 \mathrm{MW}$ & $10 \mathrm{MW}$ & $10 \mathrm{MW}$ & $10 \mathrm{MW}$ & $15 \mathrm{MW}$ & $50 \mathrm{MW}$ & $50 \mathrm{MW}$ & $80 \mathrm{MW}$ \\
\hline $\begin{array}{l}\text { Elements } \\
\text { Per Cask } \\
\end{array}$ & 33 & 13 & 33 & 13 & 36 & 28 & 33 & 33 & 33 & 64 & 36 \\
\hline \multicolumn{12}{|l|}{ Isotope } \\
\hline C14GAS & $4.36 \mathrm{e}-03$ & $5.23 e-04$ & $2.15 e-04$ & $1.08 \mathrm{e}-03$ & $8.49 \mathrm{e}-04$ & $2.62 \mathrm{e}-04$ & $5.84 \mathrm{e}-03$ & $4.83 \mathrm{e}-04$ & $4.59 \mathrm{e}-04$ & $1.59 \mathrm{e}-03$ & $5.68 \mathrm{e}-04$ \\
\hline H3GAS & $5.65 \mathrm{e}+01$ & $1.81 \mathrm{e}+01$ & $2.72 \mathrm{e}+01$ & $3.31 \mathrm{e}+01$ & $3.63 e+01$ & $2.09 \mathrm{e}+01$ & $1.06 \mathrm{e}+02$ & $3.40 \mathrm{e}+01$ & $8.44 \mathrm{e}+01$ & $1.10 \mathrm{e}+02$ & $8.54 \mathrm{e}+01$ \\
\hline H3GAS & $1.92 \mathrm{e}-01$ & $2.30 \mathrm{e}-02$ & $9.43 e-03$ & $4.75 e-02$ & $3.74 \mathrm{e}-02$ & $1.15 \mathrm{e}-02$ & $2.58 \mathrm{e}-01$ & $2.12 \mathrm{e}-02$ & $2.02 \mathrm{e}-02$ & $7.01 \mathrm{e}-02$ & $2.50 \mathrm{e}-02$ \\
\hline I129 & $3.02 \mathrm{e}-03$ & $8.82 \mathrm{e}-04$ & $1.33 e-03$ & $1.62 \mathrm{e}-03$ & $1.74 \mathrm{e}-03$ & $1.00 \mathrm{e}-03$ & $5.30 \mathrm{e}-03$ & $1.65 \mathrm{e}-03$ & $4.03 \mathrm{e}-03$ & $5.24 \mathrm{e}-03$ & $4.08 \mathrm{e}-03$ \\
\hline I131 & $1.74 \mathrm{e}-01$ & $2.76 \mathrm{e}-01$ & $3.81 \mathrm{e}-01$ & $5.08 \mathrm{e}-01$ & $1.14 \mathrm{e}+00$ & $8.92 \mathrm{e}-01$ & $9.13 \mathrm{e}-01$ & $5.86 \mathrm{e}-01$ & $3.60 \mathrm{e}+00$ & $4.67 \mathrm{e}+00$ & $3.64 \mathrm{e}+00$ \\
\hline $\mathrm{P} 32$ & $1.73 \mathrm{e}-12$ & $7.70 \mathrm{e}-14$ & $1.55 \mathrm{e}-15$ & $5.45 \mathrm{e}-13$ & $7.63 \mathrm{e}-14$ & $6.26 \mathrm{e}-15$ & $8.48 \mathrm{e}-12$ & $1.45 \mathrm{e}-14$ & $2.04 \mathrm{e}-14$ & $1.75 \mathrm{e}-13$ & $3.07 \mathrm{e}-14$ \\
\hline U233 & $9.28 \mathrm{e}-07$ & $4.40 \mathrm{e}-07$ & $1.03 e-06$ & $5.80 \mathrm{e}-07$ & $1.03 \mathrm{e}-06$ & $7.23 \mathrm{e}-07$ & $1.19 \mathrm{e}-06$ & $1.10 \mathrm{e}-06$ & $2.73 \mathrm{e}-06$ & $3.06 \mathrm{e}-06$ & $2.68 \mathrm{e}-06$ \\
\hline U235 & $1.46 \mathrm{e}-03$ & $1.47 e-03$ & $8.42 e-03$ & $1.34 \mathrm{e}-03$ & $4.53 \mathrm{e}-03$ & $4.99 \mathrm{e}-03$ & $1.73 \mathrm{e}-03$ & $6.08 \mathrm{e}-03$ & $1.55 \mathrm{e}-02$ & $1.31 \mathrm{e}-02$ & $1.44 \mathrm{e}-02$ \\
\hline U238 & $1.31 \mathrm{e}-04$ & $5.56 \mathrm{e}-05$ & $1.56 \mathrm{e}-04$ & $8.06 \mathrm{e}-05$ & $1.28 \mathrm{e}-04$ & $3.35 \mathrm{e}-04$ & $2.21 \mathrm{e}-04$ & $1.41 \mathrm{e}-04$ & $3.54 \mathrm{e}-04$ & $3.75 \mathrm{e}-04$ & $3.42 \mathrm{e}-04$ \\
\hline Y91 & $2.58 \mathrm{e}+04$ & $3.80 \mathrm{e}+04$ & $5.31 \mathrm{e}+04$ & $6.97 \mathrm{e}+04$ & $1.31 \mathrm{e}+05$ & $8.80 \mathrm{e}+04$ & $1.32 \mathrm{e}+05$ & $7.94 \mathrm{e}+04$ & $3.58 \mathrm{e}+05$ & $4.64 \mathrm{e}+05$ & $3.62 \mathrm{e}+05$ \\
\hline AM241 & $4.88 \mathrm{e}-01$ & $8.02 \mathrm{e}-02$ & $4.86 \mathrm{e}-02$ & $1.65 \mathrm{e}-01$ & $1.11 \mathrm{e}-01$ & $1.19 \mathrm{e}-01$ & $6.42 \mathrm{e}-01$ & $9.28 \mathrm{e}-02$ & $1.86 \mathrm{e}-01$ & $3.25 \mathrm{e}-01$ & $2.02 \mathrm{e}-01$ \\
\hline AM243 & $6.82 \mathrm{e}-02$ & $3.95 \mathrm{e}-03$ & $2.71 \mathrm{e}-04$ & $2.00 \mathrm{e}-02$ & $3.20 \mathrm{e}-03$ & $1.20 \mathrm{e}-03$ & $1.74 \mathrm{e}-01$ & $1.38 \mathrm{e}-03$ & $2.96 \mathrm{e}-03$ & $1.02 \mathrm{e}-02$ & $3.72 \mathrm{e}-03$ \\
\hline CE141 & $6.18 e+03$ & $9.36 \mathrm{e}+03$ & $1.30 \mathrm{e}+04$ & $1.71 \mathrm{e}+04$ & $3.67 e+04$ & $2.67 e+04$ & $3.15 e+04$ & $1.99 \mathrm{e}+04$ & $1.08 \mathrm{e}+05$ & $1.40 \mathrm{e}+05$ & $1.09 \mathrm{e}+05$ \\
\hline
\end{tabular}


Table F-1. Radionuclide Inventories of Foreign Research Reactor Spent Nuclear Fuel (Continued)

\begin{tabular}{|c|c|c|c|c|c|c|c|c|c|c|c|}
\hline Reactor & HOR & BER2 & GRR1 & ASTRA & DR3 & HIFAR & SAPHIR & FRG & HFR & $\mathbf{R} 2$ & $\mathrm{BR2}$ \\
\hline $\begin{array}{l}\text { Power } \\
\text { Level }\end{array}$ & $2 \mathrm{MW}$ & $10 \mathrm{MW}$ & $5 \mathrm{MW}$ & $10 \mathrm{MW}$ & $10 \mathrm{MW}$ & $10 \mathrm{MW}$ & 10MW & $15 \mathrm{MW}$ & $50 \mathrm{MW}$ & $50 \mathrm{MW}$ & $80 \mathrm{MW}$ \\
\hline $\begin{array}{l}\text { Elements } \\
\text { Per Cask }\end{array}$ & 33 & 13 & 33 & 13 & 36 & 28 & 33 & 33 & 33 & 64 & 36 \\
\hline \multicolumn{12}{|l|}{ Isotope } \\
\hline CE144 & $9.36 \mathrm{e}+04$ & $7.37 \mathrm{e}+04$ & $1.09 e+05$ & $1.35 e+05$ & $1.73 e+05$ & $1.03 e+05$ & $3.50 \mathrm{e}+05$ & $1.43 e+05$ & $4.18 \mathrm{e}+05$ & $5.42 \mathrm{e}+05$ & $4.23 e+05$ \\
\hline $\mathrm{CF} 252$ & $3.88 \mathrm{e}-07$ & $1.88 \mathrm{e}-10$ & $5.65 \mathrm{e}-15$ & $1.84 \mathrm{e}-08$ & $1.60 \mathrm{e}-11$ & $1.14 \mathrm{e}-13$ & $3.21 \mathrm{e}-06$ & $9.29 \mathrm{e}-13$ & $1.54 \mathrm{e}-12$ & $6.15 \mathrm{e}-11$ & $3.30 \mathrm{e}-12$ \\
\hline CM242 & $9.95 e+01$ & $4.64 e+00$ & $1.09 \mathrm{e}+00$ & $1.36 \mathrm{e}+01$ & $2.76 \mathrm{e}+00$ & $1.41 \mathrm{e}+00$ & $1.01 e+02$ & $2.86 \mathrm{e}+00$ & $2.70 \mathrm{e}+00$ & $6.29 e+00$ & $3.12 \mathrm{e}+00$ \\
\hline CM244 & $9.39 e+00$ & $2.70 \mathrm{e}-01$ & $6.74 \mathrm{e}-03$ & $2.09 e+00$ & $1.60 \mathrm{e}-01$ & $3.59 \mathrm{e}-02$ & $2.84 \mathrm{e}+01$ & $5.33 \mathrm{e}-02$ & $1.10 \mathrm{e}-01$ & $5.21 \mathrm{e}-01$ & $1.48 \mathrm{e}-01$ \\
\hline CS134 & $3.46 \mathrm{e}+04$ & $6.96 e+03$ & $4.23 e+03$ & $1.79 e+04$ & $1.01 \mathrm{e}+04$ & $3.50 \mathrm{e}+03$ & $7.89 e+04$ & $7.94 e+03$ & $1.73 e+04$ & $3.00 \mathrm{e}+04$ & $1.87 e+04$ \\
\hline $\mathrm{CS} 137$ & $1.42 \mathrm{e}+04$ & $4.32 \mathrm{e}+03$ & $6.52 \mathrm{e}+03$ & $7.89 e+03$ & $8.62 \mathrm{e}+03$ & $4.94 e+03$ & $2.55 e+04$ & $8.10 \mathrm{e}+03$ & $2.00 \mathrm{e}+04$ & $2.59 e+04$ & $2.02 \mathrm{e}+04$ \\
\hline EU152 & $.2 .88 \mathrm{e}-01$ & $7.09 \mathrm{e}-02$ & $4.52 \mathrm{e}-01$ & $6.17 e-02$ & $1.17 \mathrm{e}-01$ & $9.88 \mathrm{e}-02$ & $1.42 \mathrm{e}-01$ & $2.82 \mathrm{e}-01$ & $3.09 \mathrm{e}-01$ & $2.55 \mathrm{e}-01$ & $2.85 \mathrm{e}-01$ \\
\hline EU154 & $1.19 e+03$ & $2.22 \mathrm{e}+02$ & $1.31 \mathrm{e}+02$ & $5.49 e+02$ & $3.30 \mathrm{e}+02$ & $1.15 \mathrm{e}+02$ & $2.28 \mathrm{e}+03$ & $2.49 e+02$ & $5.72 e+02$ & $9.96 e+02$ & $6.18 e+02$ \\
\hline EU155 & $2.23 \mathrm{e}+02$ & $4.25 \mathrm{e}+01$ & $3.74 \mathrm{e}+01$ & $1.03 e+02$ & $6.64 \mathrm{e}+01$ & $2.94 \mathrm{e}+01$ & $4.56 \mathrm{e}+02$ & $5.42 \mathrm{e}+01$ & $1.27 \mathrm{e}+02$ & $2.00 e+02$ & $1.34 \mathrm{e}+02$ \\
\hline KR85 & $1.57 \mathrm{e}+03$ & $5.18 \mathrm{e}+02$ & $7.86 e+02$ & $9.41 \mathrm{e}+02$ & $1.04 \mathrm{e}+03$ & $6.00 \mathrm{e}+02$ & $2.97 \mathrm{e}+03$ & $9.78 \mathrm{e}+02$ & $2.43 e+03$ & $3.15 \mathrm{e}+03$ & $2.46 \mathrm{e}+03$ \\
\hline MO99 & $5.61 \mathrm{e}-12$ & $9.19 \mathrm{e}-12$ & $1.28 \mathrm{e}-11$ & $1.67 \mathrm{e}-11$ & $3.82 \mathrm{e}-11$ & $2.99 \mathrm{e}-11$ & $2.93 \mathrm{e}-11$ & $1.96 \mathrm{e}-11$ & $1.21 \mathrm{e}-10$ & $1.56 \mathrm{e}-10$ & $1.22 \mathrm{e}-10$ \\
\hline NB94 & $3.85 e-06$ & $1.05 \mathrm{e}-06$ & $1.50 \mathrm{e}-06$ & $1.99 \mathrm{e}-06$ & $2.03 e-06$ & $1.24 \mathrm{e}-06$ & $6.93 e-06$ & $1.89 \mathrm{e}-06$ & $4.64 e-06$ & $6.12 e-06$ & $4.71 \mathrm{e}-06$ \\
\hline
\end{tabular}


Table F-1. Radionuclide Inventories of Foreign Research Reactor Spent Nuclear Fuel (Continued)

\begin{tabular}{|c|c|c|c|c|c|c|c|c|c|c|c|}
\hline Reactor & HOR & BER2 & GRR1 & ASTRA & DR3 & HIFAR & SAPHIR & FRG & HFR & $\mathbf{R} 2$ & BR2 \\
\hline $\begin{array}{l}\text { Power } \\
\text { Level }\end{array}$ & $2 \mathrm{MW}$ & $10 \mathrm{MW}$ & $5 \mathrm{MW}$ & $10 \mathrm{MW}$ & $10 \mathrm{MW}$ & $10 \mathrm{MW}$ & $10 \mathrm{MW}$ & $15 \mathrm{MW}$ & $50 \mathrm{MW}$ & $50 \mathrm{MW}$ & $80 \mathrm{MW}$ \\
\hline $\begin{array}{l}\text { Elements } \\
\text { Per Cask }\end{array}$ & 33 & 13 & 33 & 13 & 36 & 28 & 33 & 33 & 33 & 64 & 36 \\
\hline \multicolumn{12}{|l|}{ Isotope } \\
\hline NB95 & $6.34 \mathrm{e}+04$ & $9.08 e+04$ & $1.28 \mathrm{e}+05$ & $1.67 \mathrm{e}+05$ & $2.94 \mathrm{e}+05$ & $1.93 \mathrm{e}+05$ & $3.23 \mathrm{e}+05$ & $1.88 \mathrm{e}+05$ & $7.82 \mathrm{e}+05$ & $1.01 \mathrm{e}+06$ & $7.91 \mathrm{e}+05$ \\
\hline NP237 & $5.48 \mathrm{e}-02$ & $1.02 \mathrm{e}-02$ & $6.48 \mathrm{e}-03$ & $2.56 \mathrm{e}-02$ & $1.60 \mathrm{e}-02$ & $5.84 \mathrm{e}-03$ & $1.10 \mathrm{e}-01$ & $1.18 \mathrm{e}-02$ & $2.89 \mathrm{e}-02$ & $4.98 \mathrm{e}-02$ & $3.11 \mathrm{e}-02$ \\
\hline PM147 & $9.07 e+03$ & $6.92 \mathrm{e}+03$ & $1.64 \mathrm{e}+04$ & $9.22 \mathrm{e}+03$ & $1.85 e+04$ & $1.34 \mathrm{e}+04$ & $1.69 e+04$ & $1.79 e+04$ & $5.06 \mathrm{e}+04$ & $5.82 \mathrm{e}+04$ & $5.00 \mathrm{e}+04$ \\
\hline PU236 & $5.98 \mathrm{e}-02$ & $5.85 \mathrm{e}-03$ & $1.46 \mathrm{e}-03$ & $2.12 \mathrm{e}-02$ & $6.14 \mathrm{e}-03$ & $1.31 \mathrm{e}-03$ & $1.40 \mathrm{e}-01$ & $3.94 \mathrm{e}-03$ & $7.88 \mathrm{e}-03$ & $1.81 \mathrm{e}-02$ & $9.04 \mathrm{e}-03$ \\
\hline PU238 & $3.96 \mathrm{e}+02$ & $4.02 \mathrm{e}+01$ & $1.15 \mathrm{e}+01$ & $1.31 \mathrm{e}+02$ & $4.32 \mathrm{e}+01$ & $9.77 \mathrm{e}+00$ & $7.70 \mathrm{e}+02$ & $2.95 \mathrm{e}+01$ & $5.73 \mathrm{e}+01$ & $1.25 \mathrm{e}+02$ & $6.51 \mathrm{e}+01$ \\
\hline PU239 & $1.13 \mathrm{e}+00$ & $3.45 \mathrm{e}-01$ & $6.22 \mathrm{e}-01$ & $6.01 \mathrm{e}-01$ & $7.24 \mathrm{e}-01$ & $1.51 \mathrm{e}+00$ & $2.13 \mathrm{e}+00$ & $7.01 \mathrm{e}-01$ & $1.78 \mathrm{e}+00$ & $2.17 \mathrm{e}+00$ & $1.78 \mathrm{e}+00$ \\
\hline PU240 & $1.08 \mathrm{e}+00$ & $2.92 \mathrm{e}-01$ & $3.17 \mathrm{e}-01$ & $5.42 \mathrm{e}-01$ & $5.36 \mathrm{e}-01$ & $8.44 \mathrm{e}-01$ & $1.97 \mathrm{e}+00$ & $4.69 \mathrm{e}-01$ & $1.13 \mathrm{e}+00$ & $1.59 \mathrm{e}+00$ & $1.17 \mathrm{e}+00$ \\
\hline PU241 & $4.34 \mathrm{e}+02$ & $9.51 \mathrm{e}+01$ & $5.13 e+01$ & $2.09 e+02$ & $1.46 \mathrm{e}+02$ & $1.59 \mathrm{e}+02$ & $8.18 \mathrm{e}+02$ & $1.07 \mathrm{e}+02$ & $2.50 \mathrm{e}+02$ & $4.41 \mathrm{e}+02$ & $2.72 e+02$ \\
\hline PU242 & $8.93 \mathrm{e}-03$ & $9.56 \mathrm{e}-04$ & $1.72 \mathrm{e}-04$ & $3.31 \mathrm{e}-03$ & $1.04 \mathrm{e}-03$ & $6.44 \mathrm{e}-04$ & $1.99 \mathrm{e}-02$ & $5.74 \mathrm{e}-04$ & $1.28 \mathrm{e}-03$ & $3.22 \mathrm{e}-03$ & $1.50 \mathrm{e}-03$ \\
\hline RU103 & $6.46 \mathrm{e}+03$ & $9.06 \mathrm{e}+03$ & $1.24 \mathrm{e}+04$ & $1.69 \mathrm{e}+04$ & $3.39 \mathrm{e}+04$ & $2.41 \mathrm{e}+04$ & $3.31 \mathrm{e}+04$ & $1.89 \mathrm{e}+04$ & $9.70 \mathrm{e}+04$ & $1.26 \mathrm{e}+05$ & $9.82 \mathrm{e}+04$ \\
\hline RU106 & $8.42 e+03$ & $5.06 \mathrm{e}+03$ & $7.22 \mathrm{e}+03$ & $9.49 \mathrm{e}+03$ & $1.12 \mathrm{e}+04$ & $6.91 \mathrm{e}+03$ & $2.76 e+04$ & $9.51 \mathrm{e}+03$ & $2.66 e+04$ & $3.49 \mathrm{e}+04$ & $2.70 \mathrm{e}+04$ \\
\hline
\end{tabular}


Table F-1. Radionuclide Inventories of Foreign Research Reactor Spent Nuclear Fuel (Continued)

\begin{tabular}{|c|c|c|c|c|c|c|c|c|c|c|c|}
\hline Reactor & HOR & BER2 & GRR1 & ASTRA & DR3 & HIFAR & SAPHIR & FRG & HFR & $\mathbf{R} 2$ & BR2 \\
\hline $\begin{array}{l}\text { Power } \\
\text { Level }\end{array}$ & $2 \mathrm{MW}$ & $10 \mathrm{MW}$ & $5 \mathrm{MW}$ & $10 \mathrm{MW}$ & $10 \mathrm{MW}$ & $10 \mathrm{MW}$ & $10 \mathrm{MW}$ & $15 \mathrm{MW}$ & $50 \mathrm{MW}$ & $50 \mathrm{MW}$ & $80 \mathrm{MW}$ \\
\hline $\begin{array}{l}\text { Elements } \\
\text { Per Cask }\end{array}$ & 33 & 13 & 33 & 13 & 36 & 28 & 33 & 33 & 33 & 64 & 36 \\
\hline \multicolumn{12}{|l|}{ Isotope } \\
\hline SB125 & $4.77 \mathrm{e}+02$ & $1.94 \mathrm{e}+02$ & $2.85 \mathrm{e}+02$ & $3.61 \mathrm{e}+02$ & $4.02 \mathrm{e}+02$ & $2.35 e+02$ & $1.13 \mathrm{e}+03$ & $3.63 \mathrm{e}+02$ & $9.38 \mathrm{e}+02$ & $1.22 \mathrm{e}+03$ & $9.50 \mathrm{e}+02$ \\
\hline SM151 & $9.64 \mathrm{e}+01$ & $3.71 \mathrm{e}+01$ & $8.18 \mathrm{e}+01$ & $6.37 \mathrm{e}+01$ & $8.30 \mathrm{e}+01$ & $5.81 \mathrm{e}+01$ & $1.95 \mathrm{e}+02$ & $8.52 \mathrm{e}+01$ & $2.14 \mathrm{e}+02$ & $2.46 \mathrm{e}+02$ & $2.11 \mathrm{e}+02$ \\
\hline SR89 & $1.65 \mathrm{e}+04$ & $2.49 e+04$ & $3.49 \mathrm{e}+04$ & $4.57 \mathrm{e}+04$ & $8.88 \mathrm{e}+04$ & $6.07 e+04$ & $8.49 e+04$ & $5.25 \mathrm{e}+04$ & $2.47 \mathrm{e}+05$ & $3.20 \mathrm{e}+05$ & $2.50 \mathrm{e}+05$ \\
\hline SR90 & $1.41 \mathrm{e}+04$ & $4.33 \mathrm{e}+03$ & $6.56 \mathrm{e}+03$ & $7.90 \mathrm{e}+03$ & $8.66 e+03$ & $4.95 \mathrm{e}+03$ & $2.54 \mathrm{e}+04$ & $8.15 \mathrm{e}+03$ & $2.01 \mathrm{e}+04$ & $2.61 \mathrm{e}+04$ & $2.04 e+04$ \\
\hline TC99 & $1.89 \mathrm{e}+00$ & $5.94 \mathrm{e}-01$ & $9.22 \mathrm{e}-01$ & $1.06 \mathrm{e}+00$ & $1.21 \mathrm{e}+00$ & $7.01 \mathrm{e}-01$ & $3.29 \mathrm{e}+00$ & $1.13 \mathrm{e}+00$ & $2.83 \mathrm{e}+00$ & $3.64 \mathrm{e}+00$ & $2.85 e+00$ \\
\hline TE125M & $1.14 \mathrm{e}+02$ & $4.44 \mathrm{e}+01$ & $6.56 \mathrm{e}+01$ & $8.24 \mathrm{e}+01$ & $8.79 \mathrm{e}+01$ & $5.04 \mathrm{e}+01$ & $2.64 \mathrm{e}+02$ & $8.25 \mathrm{e}+01$ & $2.01 \mathrm{e}+02$ & $2.63 e+02$ & $2.04 e+02$ \\
\hline TE127 & $2.28 \mathrm{e}+02$ & $2.72 \mathrm{e}+02$ & $3.83 e+02$ & $5.05 \mathrm{e}+02$ & $7.78 \mathrm{e}+02$ & $4.98 \mathrm{e}+02$ & $1.11 \mathrm{e}+03$ & $5.46 \mathrm{e}+02$ & $1.99 \mathrm{e}+03$ & $2.59 \mathrm{e}+03$ & $2.01 \mathrm{e}+03$ \\
\hline TE127M & $2.33 \mathrm{e}+02$ & $2.78 \mathrm{e}+02$ & $3.91 \mathrm{e}+02$ & $5.15 \mathrm{e}+02$ & $7.95 \mathrm{e}+02$ & $5.09 e+02$ & $1.13 \mathrm{e}+03$ & $5.57 \mathrm{e}+02$ & $2.03 \mathrm{e}+03$ & $2.64 \mathrm{e}+03$ & $2.05 e+03$ \\
\hline TE129 & $1.27 \mathrm{e}+02$ & $1.84 \mathrm{e}+02$ & $2.52 \mathbf{e}+02$ & $3.42 \mathrm{e}+02$ & $7.14 \mathrm{e}+02$ & $5.20 \mathrm{e}+02$ & $6.54 \mathrm{e}+02$ & $3.87 \mathrm{e}+02$ & $2.09 \mathrm{e}+03$ & $2.71 \mathrm{e}+03$ & $2.11 \mathrm{e}+03$ \\
\hline TE129M & $1.99 \mathrm{e}+02$ & $2.90 \mathrm{e}+02$ & $3.97 \mathrm{e}+02$ & $5.38 \mathrm{e}+02$ & $1.12 \mathrm{e}+03$ & $8.19 \mathrm{e}+02$ & $1.03 \mathrm{e}+03$ & $6.09 \mathrm{e}+02$ & $3.29 \mathrm{e}+03$ & $4.27 \mathrm{e}+03$ & $3.33 \mathrm{e}+03$ \\
\hline XE133 & $5.69 \mathrm{e}-04$ & $8.91 \mathrm{e}-04$ & $1.25 \mathrm{e}-03$ & $1.60 \mathrm{e}-03$ & $3.86 \mathrm{e}-03$ & $3.03 \mathrm{e}-03$ & $2.82 \mathrm{e}-03$ & $1.92 \mathrm{e}-03$ & $1.22 \mathrm{e}-02$ & $1.57 \mathrm{e}-02$ & $1.23 \mathrm{e}-02$ \\
\hline
\end{tabular}


Table F-1. Radionuclide Inventories of Foreign Research Reactor Spent Nuclear Fuel (Continued)

\begin{tabular}{||c|c|c|c|c|c|c|c|c|c|c|c||}
\hline Reactor & HOR & BER2 & GRR1 & ASTRA & DR3 & HIFAR & SAPHIR & FRG & HFR & R2 & BR2 \\
\hline $\begin{array}{c}\text { Power } \\
\text { Level }\end{array}$ & $2 \mathrm{MW}$ & $10 \mathrm{MW}$ & $5 \mathrm{MW}$ & $10 \mathrm{MW}$ & $10 \mathrm{MW}$ & $10 \mathrm{MW}$ & $10 \mathrm{MW}$ & $15 \mathrm{MW}$ & $50 \mathrm{MW}$ & $50 \mathrm{MW}$ & $80 \mathrm{MW}$ \\
\hline $\begin{array}{c}\text { Elements } \\
\text { Per Cask }\end{array}$ & 33 & 13 & 33 & 13 & 36 & 28 & 33 & 33 & 33 & 64 & 36 \\
\hline \hline Isotope & & & & & & & & & & \\
\hline ZR95 & $3.40 \mathrm{e}+04$ & $4.91 \mathrm{e}+04$ & $6.88 \mathrm{e}+04$ & $9.02 \mathrm{e}+04$ & $1.64 \mathrm{e}+05$ & $1.09 \mathrm{e}+05$ & $1.73 \mathrm{e}+05$ & $1.02 \mathrm{e}+05$ & $4.42 \mathrm{e}+05$ & $5.73 \mathrm{e}+05$ & $4.47 \mathrm{e}+05$ \\
\hline TOTAL & $3.32 \mathrm{e}+05$ & $3.25 \mathrm{e}+05$ & $4.62 \mathrm{e}+05$ & $5.98 \mathrm{e}+05$ & $9.84 \mathrm{e}+05$ & $6.42 \mathrm{e}+05$ & $1.32 \mathrm{e}+06$ & $6.60 \mathrm{e}+05$ & $2.60 \mathrm{e}+06$ & $3.37 \mathrm{e}+06$ & $2.63 \mathrm{e}+06$ \\
\hline
\end{tabular}




\begin{tabular}{|c|c|c|c|c|c|c|c|c|c|c|c|}
\hline 3.9. & io & $\tilde{\infty}$ & $\bar{\sim}$ & i্ণ & $i$ & 趈 & $\bar{\Xi}$ & $\bar{\infty}$ & $\begin{array}{l}N \\
\infty \\
\infty\end{array}$ & $\overline{8}$ & ra \\
\hline 6. & $\begin{array}{l}\infty \\
\tilde{\delta}\end{array}$ & స్తి & $\overline{8}$ & $\overline{8}$ & 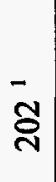 & $\begin{array}{l}N \\
\infty \\
m \\
m\end{array}$ & $\overline{8}$ & $\bar{\Xi}$ & $\stackrel{\leftrightarrow}{8}$ & $\overline{\text { สิ }}$ & 章 \\
\hline$\frac{3}{3}+\frac{3}{3}$ & $\frac{-}{2}$ & $\bar{n}$ & $\bar{g}$ & $\tilde{m}$ & $\bar{n}$ & $\tilde{n}$ & $\bar{n}$ & $\bar{n}$ & $\bar{\infty}$ & $\bar{m}$ & $\tilde{g}$ \\
\hline 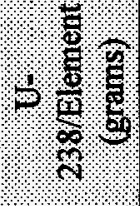 & 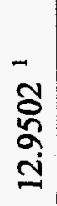 & $\begin{array}{c}n \\
\tilde{n} \\
\dot{n} \\
\end{array}$ & is & $\begin{array}{l}\overrightarrow{0} \\
\dot{\infty} \\
\dot{m} \\
\dot{m}\end{array}$ & 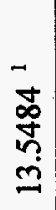 & $\begin{array}{l}N \\
8 \\
8 \\
8 \\
\dot{1}\end{array}$ & 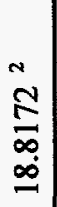 & 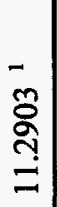 & $\frac{-}{n}$ & $\bar{\Xi}$ & 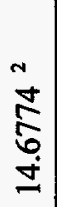 \\
\hline \%. & 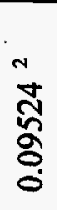 & 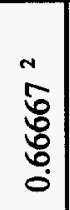 & 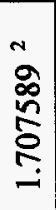 & 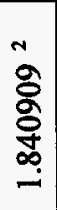 & $\stackrel{n}{0}$ & 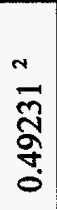 & 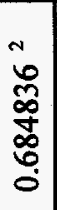 & \begin{tabular}{l}
$n$ \\
\multirow{2}{n}{} \\
$\tilde{n}$ \\
$\tilde{n}$ \\
0
\end{tabular} & $\begin{array}{l}n \\
\tilde{n} \\
n \\
n \\
0\end{array}$ & గొ & $\frac{n}{2}$ \\
\hline \% & $\vec{N}$ & $n$ & 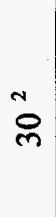 & $\ddot{\sim}$ & $\tilde{n}$ & శ్ & బొ & $\stackrel{2}{a}$ & ă & iి & i̊ \\
\hline 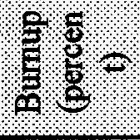 & $\bar{q}$ & $\bar{b}$ & $\bar{n}$ & $\bar{n}$ & $\overline{\mathcal{Y}}$ & 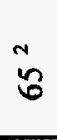 & $\overline{\mathcal{O}}$ & $\bar{n}$ & $\ddot{z}$ & $\bar{b}$ & 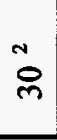 \\
\hline ?. & $\overline{2}$ & 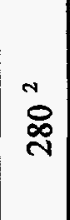 & $\overrightarrow{8}$ & $\overline{8}$ & $\ddot{\infty}$ & స్ల్ల & 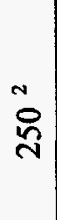 & $\ddot{n}$ & $\vec{n}$ & $\bar{\infty}_{\infty}$ & $\approx$ \\
\hline$\frac{6}{6} 3$ & $\stackrel{N}{N}$ & $\overline{0}$ & 응 & $\tilde{f}$ & in & $\hat{0}$ & $\tilde{n}$ & 호 & $\overline{0}$ & 응 & in \\
\hline 8 & $\frac{6}{8}$ & \%? & 19 & $\sqrt[\frac{4}{4}]{4}$ & $\frac{9}{8}$ & $\frac{20}{4}$ & $\sqrt[1]{4}$ & $1 \%$ & $\sqrt{\frac{1}{4}}$ & $\frac{1}{6 \%}$ & $\sqrt{6}$ \\
\hline
\end{tabular}




\section{APPENDIX G}

\section{RISK ANALYSIS OF FOREIGN RESEARCH REACTOR}

STORAGE AT SAVANNAH RIVER SITE 


\section{APPENDIX G}

\section{RISK ANALYSIS OF FOREIGN RESEARCH REACTOR STORAGE AT SAVANNAH RIVER SITE}

\section{G.1 Risk}

The material in this appendix is taken in great part directly out of Risk Analysis of Foreign Research Reactor Storage at Savannah River Site, (Shornhorst, 1993). This risk assessment was performed to support this environmental assessment. Postulated events that could initiate a sequence leading to release of radioactivity to the environment from foreign research reactor spent fuel are described in the following section. Risk analyses for potential release events are then given. The description includes a summary of the methodology employed and the release frequency, average and maximum consequences, and risks for each significant potential accident.

Receipt and storage of foreign research reactor spent fuel will not increase the quantities of hazardous chemicals in RBOF. The risk to any individual from hazardous chemicals is, therefore, not increased.

\section{G.1.1 Release Scenarios}

The potential release initiators (Allen, 1983) from natural phenomena, external effects, and operations-induced events related to foreign research reactor spent fuel follow.

\begin{tabular}{|c|c|c|c|}
\hline Natural Phenomena & External Events & $\begin{array}{c}\text { Operations Induced } \\
\text { Events }\end{array}$ & Criticality \\
\hline $\begin{array}{l}\text { Temperature } \\
\text { Extreme }\end{array}$ & Aircraft Crash & Fuel Cutting & Fuel Bundling Error \\
\hline Snow & Helicopter Crash & Spill at Hose Rack & Cask Loading Error \\
\hline Rain & $\begin{array}{l}\text { Surface Vehicle } \\
\text { Crash }\end{array}$ & $\begin{array}{l}\text { Fuel Rupture in } \\
\text { Storage }\end{array}$ & $\begin{array}{l}\text { Fuel Identification } \\
\text { Problem }\end{array}$ \\
\hline Lightning & & Fire and Explosion & $\begin{array}{l}\text { Fuel Movement } \\
\text { Error }\end{array}$ \\
\hline Tornado & & $\begin{array}{l}\text { Fuel Near Basin } \\
\text { Surface }\end{array}$ & Dropped Fuel \\
\hline Earthquake & & Spills and Leaks & $\begin{array}{l}\text { Cranes or Hoist } \\
\text { Collapse }\end{array}$ \\
\hline Meteorite Impact & & RRF Waste to Cell & $\begin{array}{l}\text { Cask Immersion } \\
\text { Error }\end{array}$ \\
\hline
\end{tabular}


Evaluation, in the Safety Analysis Report (Allen, 1983), of these accident initiators indicated that seven potential accidents could release radionuclides to the atmosphere. Of these, the following four are applicable to offsite research reactor spent fuel:

- Nuclear criticality

- Fuel rupture in storage

- Fuel rupture in cutting

- Resin regeneration facility (RRF) waste to cell

\section{G.1.2 Methodology}

Potential accident consequences, frequencies, and risks are determined using the methods (Allen, 1983; WSRC, 1991) normally used in Savannah River Site (SRS) safety analyses.

Fault tree analysis is used to determine the frequency of postulated accidents that result directly in the release of radioactivity. Fault tree analysis is a formalized procedure that can be used to identify high risk areas in a complex system. It is a deductive process whereby the analyst first postulates an unsafe or otherwise undesired state of a system, and then systematically analyzes the system to determine the lower order fault events and component failures that will result in the defined undesired system state.

The primary sources of data used in these fault trees for the 200-Area facilities are internal documents, audits, logbooks, and incident reports. Failure and maloperation information from these sources are stored in a computerized data bank (Durant et al., 1993). A computer program retrieves the sorted information according to area, facility, unit operation, type of equipment, or type of failure. From these data, failure frequencies for specific components or other errors are determined.

Quantities of radionuclides released to the environment were estimated from the inventory present within the spent fuel, the airborne release mechanisms, and the potential energy for each accident. Section G.1.4 discusses the releases for each accident scenario.

Airborne release of particles and gaseous radionuclides followed by atmospheric transport to man is the only mechanism for radioactivity release included in this analysis. Because of the layout and elevation of the RBOF facility, release of liquids directly to surface streams, which would transport radionuclides to man, is not considered a credible event. Subsurface release of activity followed by migration through the soil before release to surface streams is considered. However, because very long travel times permit most of the activity to decay before reaching surface streams, the consequences of release into the soil are negligible (Randall and Landon, 1979; Poe, 1974; Durant, 1979; and Haselow, 1993).

Radiological doses to the offsite maximum individual are computed using the AXAIR89Q computer code (Pillinger and Huang, 1986; Huang and Lux, 1989; and Hamby, 1990). The offsite maximum individual is located at the site boundary along the centerline of the compass 
sector (total of 16) having the highest value of X/Q (based on 1987-1991 statistics, 99.5 percentile worst sector meteorology). Fifty year committed effective dose equivalent conversion factors are taken from ICRP-30.

The maximally exposed onsite receptor is defined as a collocated worker at a distance of $640 \mathrm{~m}(2100 \mathrm{ft})$. Average meteorology is used (USDOE, 1993). Offsite population doses are based on the 1990 census data.

All releases are conservatively considered to be at ground level.

\section{G.1.3 Accident Frequencies}

The expected frequencies of the postulated accidents are taken from the SAR (Allen, 1983). Since this foreign fuel represents less than ten percent of the RBOF capacity (historically RBOF is filled to about 60 percent of capacity - it is currently about 85 percent full), the use of historical data is conservative. Table G-1 gives the frequency of release of radionuclides for each of the four credible potential accidents with significant consequences. As illustrated in Figures G-1 and G-2, the conclusions of this report are not sensitive to the exact accident frequencies.

Table G-1. Potential Accident Radionuclide Releases and Frequencies

\begin{tabular}{||l|c|c|c||}
\hline \multicolumn{1}{|c|}{ Potential Accident } & $\begin{array}{c}\text { Average } \\
\text { Frequency } \\
\text { (per year) }\end{array}$ & $\begin{array}{c}\text { Average Release } \\
\text { (curies) }\end{array}$ & $\begin{array}{c}\text { Maximum } \\
\text { Release } \\
\text { (curies) }\end{array}$ \\
\hline \hline Criticality & $3.1 \mathrm{E}-03$ & $3400 / 265^{\mathrm{a}}$ & $68,000 / 5300^{\mathrm{a}}$ \\
\hline Fuel Rupture During Storage & $1.1 \mathrm{E}-01$ & 85 & 85,000 \\
\hline Fuel Cutting & $1.6 \mathrm{E}-01$ & 85 & 425 \\
\hline RRF Waste Release to Cell & $2.4 \mathrm{E}-03$ & 5 & 25 \\
\hline
\end{tabular}

a Based on quantity of radionuclides present at 1 minute (on-site release) and 45 minute (off-site release) after a potential criticality accident.

\section{G.1.4 Accident Consequences}

Table G-1 lists the average and maximum radiological releases from each of the considered accidents. The following subsections provide details on the release quantities. 


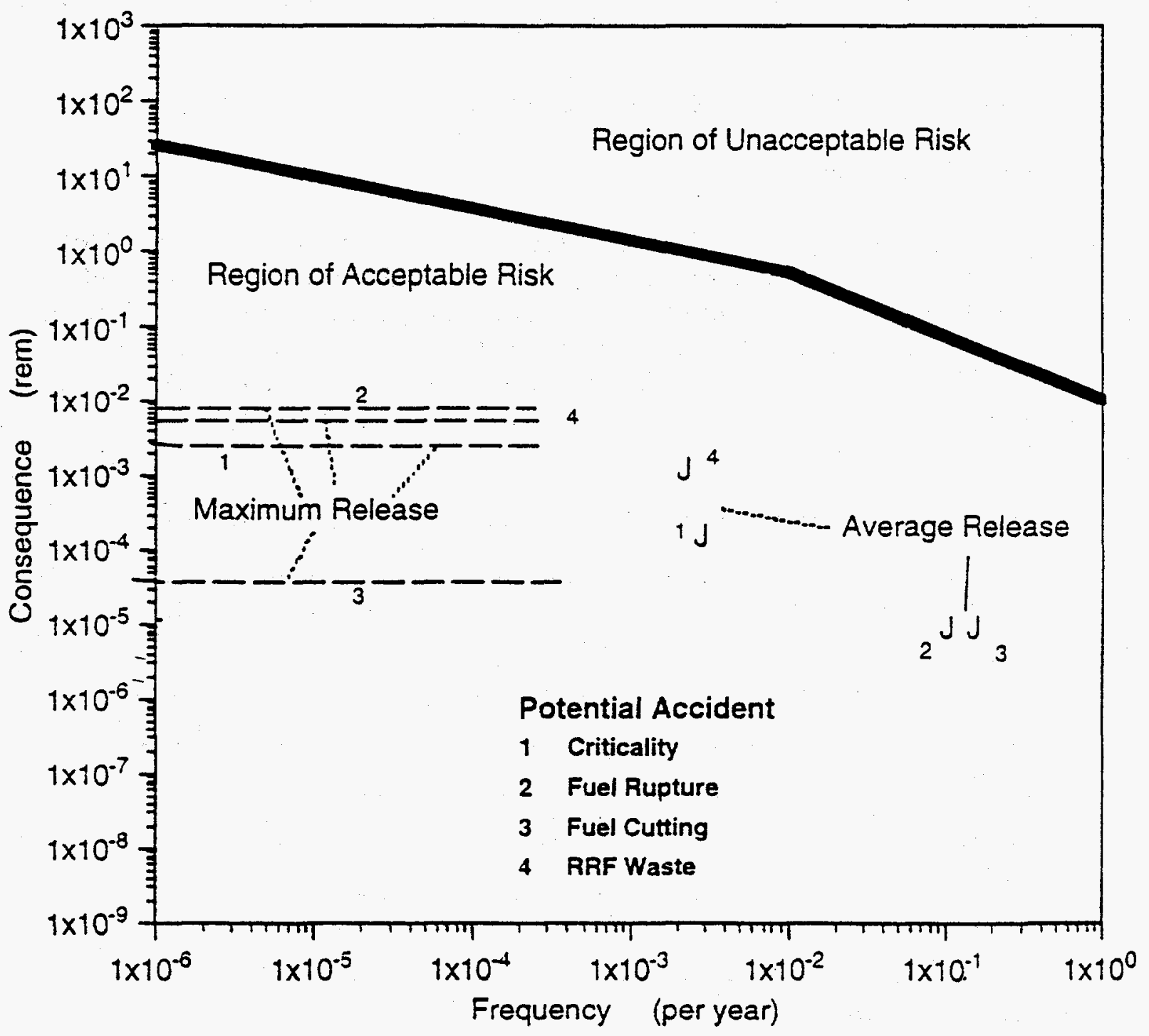

Figure G-1. Individual Site Boundary Risks from Potential Accidents 


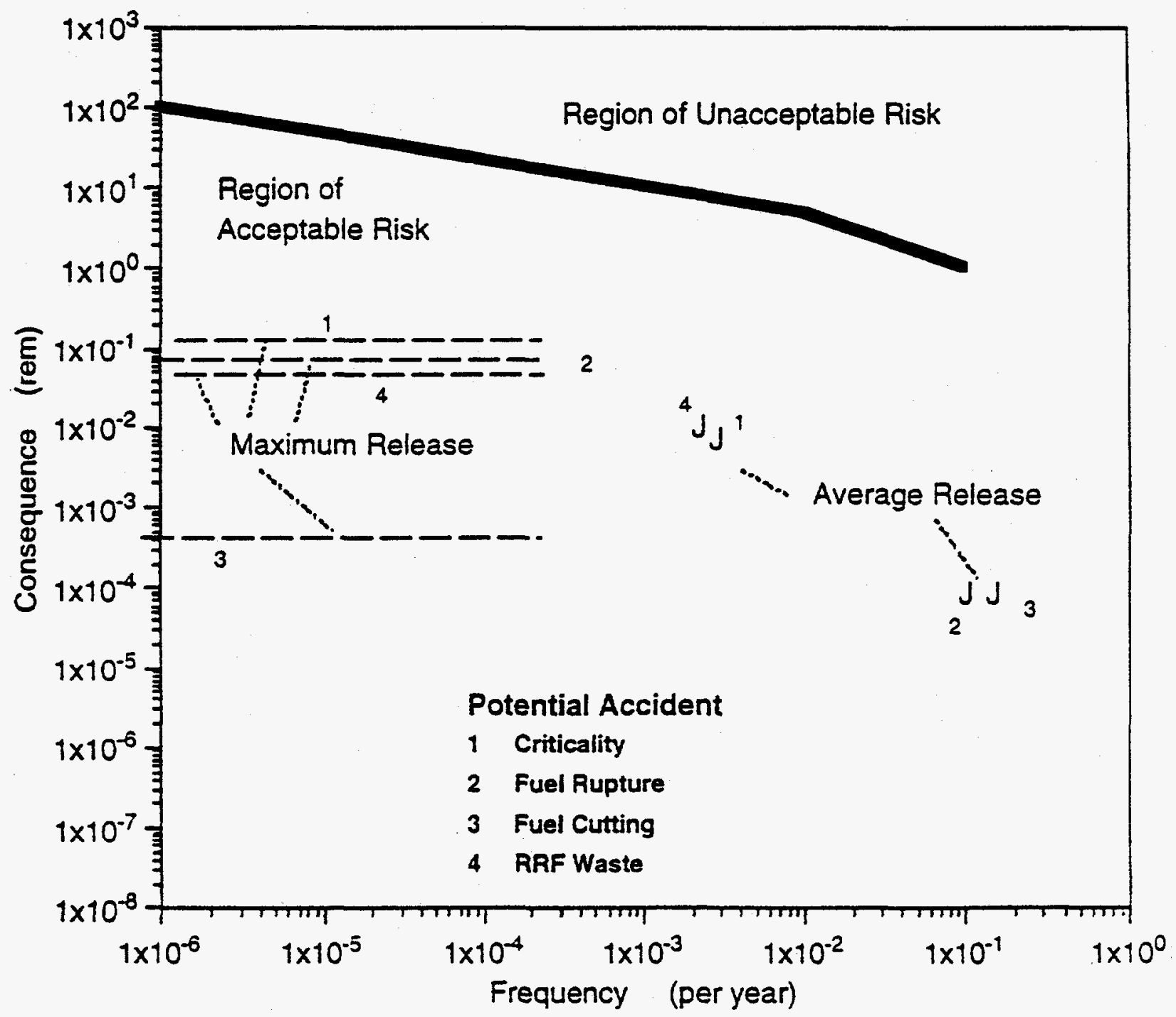

Figure G-2. Collocated Worker Risks from Potential Accidents 
Fifty year committed effective dose equivalents to the maximally exposed individual at the SRS site boundary are shown in Table G-2 for both average and maximum potential accident releases. Table G-3 gives the onsite collocated worker doses.

Table G-2. Site Boundary Maximally Exposed Individual Consequences and Risks from Potential Accidents

\begin{tabular}{||l|c|c|c|c|c|c||}
\hline \multicolumn{1}{|c|}{$\begin{array}{c}\text { Potential } \\
\text { Accident }\end{array}$} & $\begin{array}{c}\text { Average } \\
\text { Frequency } \\
\text { (per year) }\end{array}$ & $\begin{array}{c}\text { Average } \\
\text { Release Dose } \\
\text { (rem) }\end{array}$ & $\begin{array}{c}\text { Dose Risk } \\
\text { (rem/year) }\end{array}$ & $\begin{array}{c}\text { Latent Cancer } \\
\text { Fatalities }\end{array}$ & $\begin{array}{c}\text { Maximum } \\
\text { Release } \\
\text { Dose (rem) }\end{array}$ & $\begin{array}{c}\text { Maximum } \\
\text { Latent Cancer } \\
\text { Fatalities }^{\mathrm{b}}\end{array}$ \\
\hline \hline Criticality & $3.1 \mathrm{E}-03$ & $1.5 \mathrm{E}-04$ & $4.5 \mathrm{E}-07$ & $2.3 \mathrm{E}-10$ & $3.0 \mathrm{E}-03$ & $7.5 \mathrm{E}-10$ \\
\hline $\begin{array}{l}\text { Fuel Rupture } \\
\text { During Storage }\end{array}$ & $1.1 \mathrm{E}-01$ & $8.3 \mathrm{E}-06$ & $9.1 \mathrm{E}-07$ & $4.6 \mathrm{E}-10$ & $8.3 \mathrm{E}-03$ & $2.0 \mathrm{E}-09$ \\
\hline Fuel Cutting & $1.6 \mathrm{E}-01$ & $8.3 \mathrm{E}-06$ & $1.3 \mathrm{E}-06$ & $6.5 \mathrm{E}-10$ & $4.2 \mathrm{E}-05$ & $1.2 \mathrm{E}-11$ \\
\hline $\begin{array}{l}\text { RRF Waste } \\
\text { Release to Cell }\end{array}$ & $2.4 \mathrm{E}-03$ & $1.2 \mathrm{E}-03$ & $2.8 \mathrm{E}-06$ & $1.0 \mathrm{E}-09$ & $6.0 \mathrm{E}-03$ & $1.0 \mathrm{E}-09$ \\
\hline & & Total Risk & $5.6 \mathrm{E}-06$ & & & \\
\hline
\end{tabular}

${ }^{a}$ Fifty-year committed effective dose equivalent.

based on the frequency of 5E-04 per year.

Table G-3. Collocated Worker Consequences and Risks from Potential Accidents

\begin{tabular}{||l|c|c|c|c||c|c||}
\hline \multicolumn{1}{|c|}{$\begin{array}{c}\text { Potential } \\
\text { Accident }\end{array}$} & $\begin{array}{c}\text { Average } \\
\text { Frequency } \\
\text { (per year) }\end{array}$ & $\begin{array}{c}\text { Average Release } \\
\text { Dose }^{\mathrm{a}} \\
\text { (rem) }\end{array}$ & $\begin{array}{c}\text { Dose Risk } \\
\text { (rem/year) }\end{array}$ & $\begin{array}{c}\text { Latent } \\
\text { Cancer } \\
\text { Fatalities }\end{array}$ & $\begin{array}{c}\text { Maximum } \\
\text { Release } \\
\text { Dose (rem) }\end{array}$ & $\begin{array}{c}\text { Maximum } \\
\text { Latent } \\
\text { Cancer } \\
\text { Fatalities }^{\mathrm{b}}\end{array}$ \\
\hline Criticality & $3.1 \mathrm{E}-03$ & $7.1 \mathrm{E}-03$ & $2.2 \mathrm{E}-05$ & $8.0 \mathrm{E}-09$ & $1.4 \mathrm{E}-01$ & $2.8 \mathrm{E}-08$ \\
\hline $\begin{array}{l}\text { Fuel Rupture } \\
\text { During Storage }\end{array}$ & $1.1 \mathrm{E}-01$ & $8.1 \mathrm{E}-05$ & $8.9 \mathrm{E}-06$ & $3.0 \mathrm{E}-09$ & $8.1 \mathrm{E}-02$ & $1.6 \mathrm{E}-08$ \\
\hline Fuel Cutting & $1.6 \mathrm{E}-01$ & $8.1 \mathrm{E}-05$ & $1.3 \mathrm{E}-05$ & $5.0 \mathrm{E}-09$ & $4.0 \mathrm{E}-04$ & $8.0 \mathrm{E}-11$ \\
\hline $\begin{array}{l}\text { RRF Waste } \\
\text { Release to Cell }\end{array}$ & $2.4 \mathrm{E}-03$ & $9.9 \mathrm{E}-03$ & $2.4 \mathrm{E}-05$ & $9.0 \mathrm{E}-09$ & $5.0 \mathrm{E}-02$ & $1.0 \mathrm{E}-08$ \\
\hline & & Total Risk & $6.8 \mathrm{E}-05$ & & & \\
\hline
\end{tabular}

${ }^{a}$ Fifty-year committed effective dose equivalent.

${ }^{b}$ Based on the frequency of $5 \mathrm{E}-04$ per year. 
Table G-4. Offsite Population Consequences and Risks from Potential Accidents

\begin{tabular}{|c|c|c|c|c|c|c||}
\hline $\begin{array}{c}\text { Potential } \\
\text { Accident }\end{array}$ & $\begin{array}{c}\text { Average } \\
\text { Frequency } \\
\text { (per year) }\end{array}$ & $\begin{array}{c}\text { Average } \\
\text { Release Dose } \\
\text { (person-rem) }\end{array}$ & $\begin{array}{c}\text { Dose Risk } \\
\text { (Person- } \\
\text { rem/yr) }\end{array}$ & $\begin{array}{c}\text { Latent } \\
\text { Cancer } \\
\text { Fatalities }\end{array}$ & $\begin{array}{c}\text { Maximum } \\
\text { Release Dose } \\
\text { (person-rem) }\end{array}$ & $\begin{array}{c}\text { Maximum } \\
\text { Latent } \\
\text { Cancer } \\
\text { Fatalities }\end{array}$ \\
\hline Criticality & $3.1 \mathrm{E}-03$ & $4.4 \mathrm{E}-01$ & $1.4 \mathrm{E}-03$ & $7.0 \mathrm{E}-07$ & $8.8 \mathrm{E}+00$ & $2.2 \mathrm{E}-06$ \\
\hline $\begin{array}{c}\text { Fuel Rupture } \\
\text { During Storage }\end{array}$ & $1.1 \mathrm{E}-01$ & $7.0 \mathrm{E}-02$ & $7.7 \mathrm{E}-03$ & $3.9 \mathrm{E}-06$ & $7.0 \mathrm{E}+01$ & $1.8 \mathrm{E}-05$ \\
\hline Fuel Cutting & $1.6 \mathrm{E}-01$ & $7.0 \mathrm{E}-02$ & $1.1 \mathrm{E}-02$ & $5.5 \mathrm{E}-06$ & $3.5 \mathrm{E}-01$ & $8.7 \mathrm{E}-08$ \\
\hline $\begin{array}{c}\text { RRF Waste } \\
\text { Release to Cell }\end{array}$ & $2.4 \mathrm{E}-03$ & $1.0 \mathrm{E}+01$ & $2.4 \mathrm{E}-02$ & $1.2 \mathrm{E}-05$ & $5.0 \mathrm{E}+01$ & $1.3 \mathrm{E}-05$ \\
\hline & & Total Risk & $4.4 \mathrm{E}-02$ & & & \\
\hline
\end{tabular}

aifty-year committed effective dose equivalent.

${ }^{b}$ Based on the frequency of $5 \mathrm{E}-04$ per year.

\section{G.1.4.1 Nuclear Criticality}

An estimate of the consequences of a criticality incident requires an estimate of the number of fissions that might occur. In the absence of actual data for an incident in a fuel storage basin, historical data elsewhere are used. Criticality incidents have produced from $E+14$ to $E+19$ fissions with a mean of $2 E+18$ fissions for incidents involving fissile solutions and a mean of $5 \mathrm{E}+17$ fissions for those involving solids. There is uncertainty in applying these values to a receiving basin because uncertainties exist as to the duration of the incident and the nature of the mechanism that would terminate the nuclear excursion. The mean value for solid systems ( $5 \mathrm{E}+17$ fissions) is used in this analysis along with the bounding value (E+19 fissions) for the maximum consequence estimate. The bounding value of $\mathrm{E}+19$ fissions is consistent with NRC regulations (USNRC, 1979). 
The isotopic distribution for airborne release (Allen, 1983) from a criticality accident is:

\begin{tabular}{cccc} 
Isotope & Curie Fraction & Isotope & Curie Fraction \\
\hline Br-83 & $8.8 \mathrm{E}-03$ & $\mathrm{Kr}-85$ & $1.1 \mathrm{E}-02$ \\
$\mathrm{Br}-84$ & $3.4 \mathrm{E}-02$ & $\mathrm{Kr}-87$ & $5.7 \mathrm{E}-02$ \\
$\mathrm{Br}-85$ & $3.9 \mathrm{E}-05$ & $\mathrm{Kr}-88$ & $7.2 \mathrm{E}-02$ \\
$\mathrm{I}-131$ & $6.4 \mathrm{E}-04$ & $\mathrm{Kr}-89$ & $1.6 \mathrm{E}-04$ \\
$\mathrm{I}-132$ & $1.1 \mathrm{E}-02$ & $\mathrm{Xe}-133$ & $1.1 \mathrm{E}-04$ \\
$\mathrm{I}-133$ & $2.1 \mathrm{E}-02$ & $\mathrm{Xe}-135$ & $3.8 \mathrm{E}-02$ \\
$\mathrm{I}-134$ & $3.6 \mathrm{E}-01$ & $\mathrm{Xe}-135 \mathrm{~m}$ & $7.9 \mathrm{E}-03$ \\
$\mathrm{I}-135$ & $9.1 \mathrm{E}-02$ & $\mathrm{Xe}-137$ & $3.4 \mathrm{E}-03$ \\
$\mathrm{Kr}-83$ & $1.9 \mathrm{E}-03$ & Xe-138 & $2.8 \mathrm{E}-01$
\end{tabular}

Nonvolatile materials are also released from the fuel to the basin water; however, these are not included in the dose calculations because the material remains in the basin water.

\section{G.1.4.2 Fuel Cutting}

The inert, non-uranium containing extremities of some fuel elements may need to be cut off (cropped) in the repackaging basin prior to storage of the elements. The fuel core could be inadvertently cut, causing a release of airborne and/or high water activity to the work area. With foreign research reactor spent fuel, 85 curies of fission product gases are generated in one element with the following radionuclide distribution.

\begin{tabular}{|c|c|c|}
\hline Radionuclide & Curies per Element & Fraction of Release \\
\hline $\mathrm{Kr}-85$ & 85 & 0.998 \\
\hline I-129 & $1.5 \mathrm{E}-06$ & $2.0 \mathrm{E}-08$ \\
\hline $\mathrm{I}-131$ & $1.3 \mathrm{E}-03$ & $1.5 \mathrm{E}-05$ \\
\hline $\mathrm{Xe}-131 \mathrm{~m}$ & 0.19 & 2.0E-03 \\
\hline $\mathrm{Xe}-133$ & 3.4E-04 & 4.1E-06 \\
\hline & 85 & 1.00 \\
\hline
\end{tabular}

This radionuclide content is from an ORIGEN computer code analysis of representative 50 MW MTR fuel 150 days after discharge from the reactor. (Spent fuels that could release more fission gases than given above will require an Unreviewed Safety Question analysis before acceptance in RBOF.) The amount of gases that is released to the basin water in any accident is much less than the quantity generated. All the generated krypton, xenon, and iodine are conservatively assumed to escape from the basin water to the atmosphere. This is 
an extremely conservative assumption -- the actual release should be at lease one order of magnitude less.

The airborne release for an average accidental release from the cutting of one fuel element is, therefore, 85 curies (Table G-1).

The fuel cutting operation involves only one fuel element at a time. However, to provide an upper bound or maximum release estimate, the non mechanistic failure of five fuel elements is assumed.

\section{G.1.4.3 Fuel Rupture in Storage}

Consistent with the SAR (Allen, 1983), one research reactor spent fuel element is assumed to fail for an average release accident. The release to the atmosphere is the same as the Fuel Cutting accident.

Since failure of more than one fuel element cannot absolutely be precluded, the bounding or maximum release is very conservatively taken as failure of all 1000 foreign research reactor spent fuel elements in RBOF.

\section{G.1.4.4 Release of RRF Waste Tank Activity}

A fire and explosion could occur in a waste tank in the event that the coolant of a received cask, when discharged to the waste tank, results in a flammable or explosive concentration of vapors in the tank. Rupture of the tank by an explosion could result in an airborne release of 5 curies to the shielded cell (Allen, 1983). The maximum release was taken as five times the release in the SAR or 25 Curies.

For the Resin Regeneration Facility accident, the distribution of radionuclides is:

\begin{tabular}{cc} 
Isotope & Curie Fraction \\
\hline Cs-134 & 0.15 \\
Cs-137 & 0.15 \\
Co-60 & 0.70
\end{tabular}

\section{G.1.5 Risk Analysis}

Tables G-2 and G-3 give the risks to an offsite and onsite collocated maximally exposed individual for potential RBOF accidents with foreign research reactor spent fuel. Table G-4 gives risks to the offsite population from potential RBOF accidents with foreign research reactor spent fuel. Risk is defined as the product of expected frequency and average or nominal release consequences. Figures G-1 and G-2 illustrate the maximum individual risks in a Farmer plot format and compare them to the WSRC radiological criteria (WSRC, 1992). 
The figures also indicate the maximum release consequences. Considering the very conservative assumptions made in determining the maximum release consequences, it is expected that the corresponding release frequencies would be significantly lower than those associated with nominal releases. Frequencies associated with the maximum release consequences were not calculated. However, using the frequency range shown in the figures for the maximum release consequences, a conservative frequency per year of 5.0E-04 was assumed to determine the maximum latent cancer fatalities.

\section{G.2 Conclusions}

The risk to the general public from receipt and storage of up to 1000 foreign research reactor spent fuel elements added to existing RBOF inventory is insignificant when compared to normal public exposure to background and radiation from other sources, Westinghouse Savannah River Company radiological guidelines, and the DOE radiological guidelines. This conclusion is based upon the following.

- Background Radiological Consequences and Risk.

A member of the general public living in the vicinity of the SRS site will receive about 380 mrem per year from natural background and radiation from other sources (Cummins et al., 1991). The average and maximum consequences from the worst of the credible accidents with respect to storing this fuel are 1.2 and $8.3 \mathrm{mrem}$ to a person at the site boundary. Since the total dose rate from the proposed research reactor offsite fuel storage is only $0.0056 \mathrm{mrem} / \mathrm{year}$, the increase in risk is less than 0.002 percent of the background radiological risk.

- WSRC Guidelines

WSRC safety guidelines for nonreactor nuclear facilities provide a measure for assessment of risk acceptability. Curves of event release frequency versus onsite and offsite consequences are provided with regions of acceptable risk and of unacceptable risk. Figures G-1 and G-2 show that the radiological risks from receipt and storage of these fuel elements are several orders of magnitude below the WSRC guidelines.

- DOE Guidelines

Current DOE facility safety policy is based on Secretary of Energy Notice 35-91, issued September 9, 1991 (USDOE, 1991b). The risk goals are:

The risk to an average individual in the vicinity of a DOE nuclear facility for prompt fatalities that might result from accidents should not exceed one-tenth of one percent 10.1 percent) of the sum of prompt fatalities resulting from other accidents to which members of the population are generally exposed. For evaluation purposes, individuals are assumed to be located within one mile of the site boundary.

The risk to the population in the area of a DOE nuclear facility for cancer fatalities that might result from operations should not exceed one-tenth of one percent ( 0.1 percent) of 
the sum of all cancer fatality risks resulting from all other causes. For evaluation purposes, individuals are assumed to be located within 10 miles of the site boundary.

Compliance with the WSRC guidelines has been shown to comply with the DOE safety guidance (Kim and Bradley, 1993). Therefore, the risk from storage of offsite research reactor spent fuel elements satisfies the DOE facility safety policy. 


\section{APPENDIX H}

\section{OPERATIONAL ASPECTS OF TRANSPORTATION}




\section{APPENDIX H}

\section{OPERATIONAL ASPECTS OF TRANSPORTATION}

\section{Sea Operations}

The foreign research reactors from which DOE proposes to accept spent fuel would be required to take those actions necessary to ensure an extremely high level of safety in the shipment of foreign research reactor spent nuclear fuel to DOE's Savannah River Site in the United States.

International Atomic Energy Agency (IAEA) regulations regarding the transportation of radioactive material (IAEA, 1990b) clearly specify special requirements regarding segregation, stowage, in transit storage, and other aspects of transporting radioactive cargo by sea. Accordingly, the foreign research reactor operators would be required by their contracts with DOE to take the following actions with respect to the foreign research reactor spent nuclear fuel shipments discussed in this Environmental Assessment:

1. All applicable regulatory requirements would be satisfied. This includes regulations issued by (a) foreign nations in which the spent fuel is located or through which any foreign research reactor spent fuel would be transported; (b) origin, interim, and destination ports; (c) IAEA and International Maritime Organization (IMO); (d) the cognizant United States agencies - Nuclear Regulatory Commission (NRC), United States Coast Guard (USCG) and Department of Transportation (DOT); and (e) the State in which the United States port of entry is located.

2. Any ocean carrier utilized would be required to (a) meet the American Bureau of Shipping's highest classification or equivalent, as approved by DOE, and (b) utilize communications and navigation equipment that meets or exceeds industry standards.

3. Inspections are performed by appropriate authorities to ensure that the cask never exceeds the rated capacity of the container and that the cranes utilized at the loading and unloading ports have sufficient capacity to lift the casks and ocean container.

4. Ocean carrier companies would be advised that the shipment route should be the most direct route available, and scheduled intermediate stops should be avoided to the extent practicable. It must be recognized that liner service is less flexible in this regard than dedicated service. The shipping companies publish schedules well in advance of sailing and these schedules are normally not altered, except in extreme emergency situations. Ocean carriers will be advised that the foreign research reactor spent fuel casks must be loaded and unloaded on a last-on-and-first-off basis to the extent practicable.

5. A charter vessel would be subjected to a "Condition and Suitability Survey" prior to finalizing the booking arrangements. Any deficiencies noted would be required to be 
repaired. Inspections would then be conducted a second time to ensure that the repairs have been completed.

6. Casks would be loaded at the research reactor sites by specifically trained personnel in accordance with applicable regulatory requirements. Casks would be inspected subsequent to loading at the reactor site. Casks would be reinspected prior to loading at the port.

7. Procedures would be employed with the goal of ensuring that casks are loaded on board vessels within 24 hours of arrival at the port. In the event of unanticipated or unavoidable delay at the port, procedures would be employed in cooperation with "Competent Authorities" to ensure that loaded casks are appropriately monitored while at the port. Representatives of the shipper would be required to monitor loading operations at the port to ensure compliance with applicable requirements.

8. Advance notification would be provided to all "Competent Authorities" along the route from the reactor to the port in accordance with IAEA regulations.

9. The U.S. Coast Guard at the port of entry would be notified prior to the arrival of an ocean carrier in U.S. territorial waters.

10. As required by 10 CFR $\$ 73.37(b)(4)$, representatives of the shipper would maintain a communication center at a designated location staffed continuously by at least one individual who would monitor the shipment and notify the appropriate authorities in the event of a safeguards emergency. The communications center would be maintained from the time that the ship enters U.S. territorial waters until it arrives at its destination. At least one dedicated phone line would be installed at the communications center, the status of the shipment would be checked at least every two hours by telephone, and communications center personnel would maintain a written log of the status reports received and any significant events, which would be available to authorized NRC personnel for a period of at least three years following completion of the shipment.

11. In accordance with $10 \mathrm{CFR} \$ 73.37(\mathrm{e})(1)$, if the vessel is docked at a U.S. port within a heavily populated area, it would be protected by two armed escorts or a member of a local law enforcement agency (LLEA) stationed on board the vessel or on the dock at a location that permits observation of the shipment vessel. As required by $\$ 73.37(\mathrm{e})$, an escort would also be provided for ships within U.S. territorial waters or docked at ports not within heavily populated areas. All escorts would have the required communications equipment. Escorts would call the communications center at least every two hours to advise on the status of the shipment while docked at the port and during the land transport segment as required by 10 CFR $\$ 73.37(b)(11)$.

12. Representatives of the shipper would be required to be present at the U.S. port when the vessel arrives and to take actions to ensure that the container carrying the cask is unloaded as soon as possible and immediately taken to an appropriate area at the port for inspection. Once it is ascertained that the cask meets applicable regulatory 
requirements and the vehicle (truck or rail car) meets inspection standards, the cask would be promptly placed on the vehicle and begin the trip to the destination point. Shipments would leave the port within 24 hours unless, upon agreement with local authorities, the shipments are delayed to avoid specific conditions (e.g., holiday, weekend, or rush hour traffic).

\section{Overland Operations}

Arrangements for U.S. land carriers (truck or rail) would be made well in advance of the expected arrival date of the vessel. All DOT, NRC, and State regulations applicable to the overland transport (e.g., route selection in accordance with DOT regulations, required escorts, prenotification of NRC and State governors or their designees, NRC route approval, safeguarding of route information, arrangements along route and in ports with local law enforcement agencies) would be satisfied. Representatives of the shipper would be required to be present at the port prior to arrival to assess the port situation and monitor the unloading operation to ensure regulatory compliance.

1. The shipper and his representative are required to have emergency response plans for these shipments.

2. Emergency response plans are in effect for each port city. State plans are also in effect to cover emergencies along State highways. The Department of Labor regulations require that hazardous materials training for local and State emergency responders be provided by their employers.

3. DOE, in cooperation with Federal, State, and local governments, is engaged in providing the type of training required to react in an emergency situation involving these shipments. As part of DOE's responsibilities under Federal Response plans, DOE has trained Radiological Assistance Teams that are prepared to assist State and local governments in the event of an accident, when requested by the State. The closest team, for the purposes of this Environmental Assessment, is located at the Savannah River Site.

4. Only qualified motor carriers would be used to perform the land transportation portion of this movement. A qualified motor carrier (common, contract or private) is one which has no safety condition imposed on its certificate, permit or record by the DOT, and has the required minimum levels of financial responsibility in effect as evidenced by the proper documentation, and is otherwise in compliance with applicable Federal and State transportation regulations. All vehicles would be inspected by cognizant State or Federal agencies and the carrier prior to use.

DOE has a Carrier Evaluation program that reviews additional criteria for a carrier selected for DOE shipments. A list of DOE evaluated carriers will be supplied to the shipper's agent, if requested. 
5. The railroad that best serves each origin and destination would be considered as a potential carrier of these shipments. The level of service required would be negotiated if above the baseline requirements. Figure $\mathrm{H}-1$ shows representative rail routes.

6. The Department of Transportation Hazardous Materials Transportation Regulations, which are now incorporated in the Federal Motor Carrier Safety Regulations, govern the routing of trucks transporting radioactive materials and require the use of Interstate Highways for all highway route controlled shipments. The Nuclear Regulatory Commission, under Security Regulations in Title 10 of the Code of Federal Regulation Part 73, also conducts route surveys to determine the adequacy of the routes. In addition, if a State Routing Agency has approved an alternative route, which is consistent with DOT and NRC requirements, it may be used. In combination, these are referred to as the preferred routes. The regulations also require that the shortest, safest local routes be used for pickup, delivery, and access to the preferred routes. Figure $\mathrm{H}-2$ shows representative highway routes.

7. Shipments would be made in accordance with all applicable Federal, State, Tribal, and local laws and regulations. State oversight of transportation, in cooperation with the military and/or Coast Guard, is contemplated by the Environmental Assessment to the extent that State involvement would be appropriate at a military base.

8. DOE would ensure that the shipper gives advance notification of shipments to the Governor of any State through which foreign research reactor spent fuel is transported, or his/her representative. Specific arrangements regarding notification would be mutually agreed on by the States, the carrier and DOE.

9. If an incident results in liability, the financial responsibility minimum limits requirement in the Hazardous Materials Transportation Regulations provide for a minimum of $\$ 5$ million in personal liability and property damage, including environmental recovery coverage by the motor carrier. For the railroads, the liability coverage amount is underwritten through the outside purchase of insurance coverage, which is usually in excess of that required by law for motor carriers. In any event, under the Price Anderson Act, as amended, the liability coverage is no less than $\$ 7.3$ billion. This indemnification extends to "any person" in the event of a nuclear incident, and covers transportation activities. 


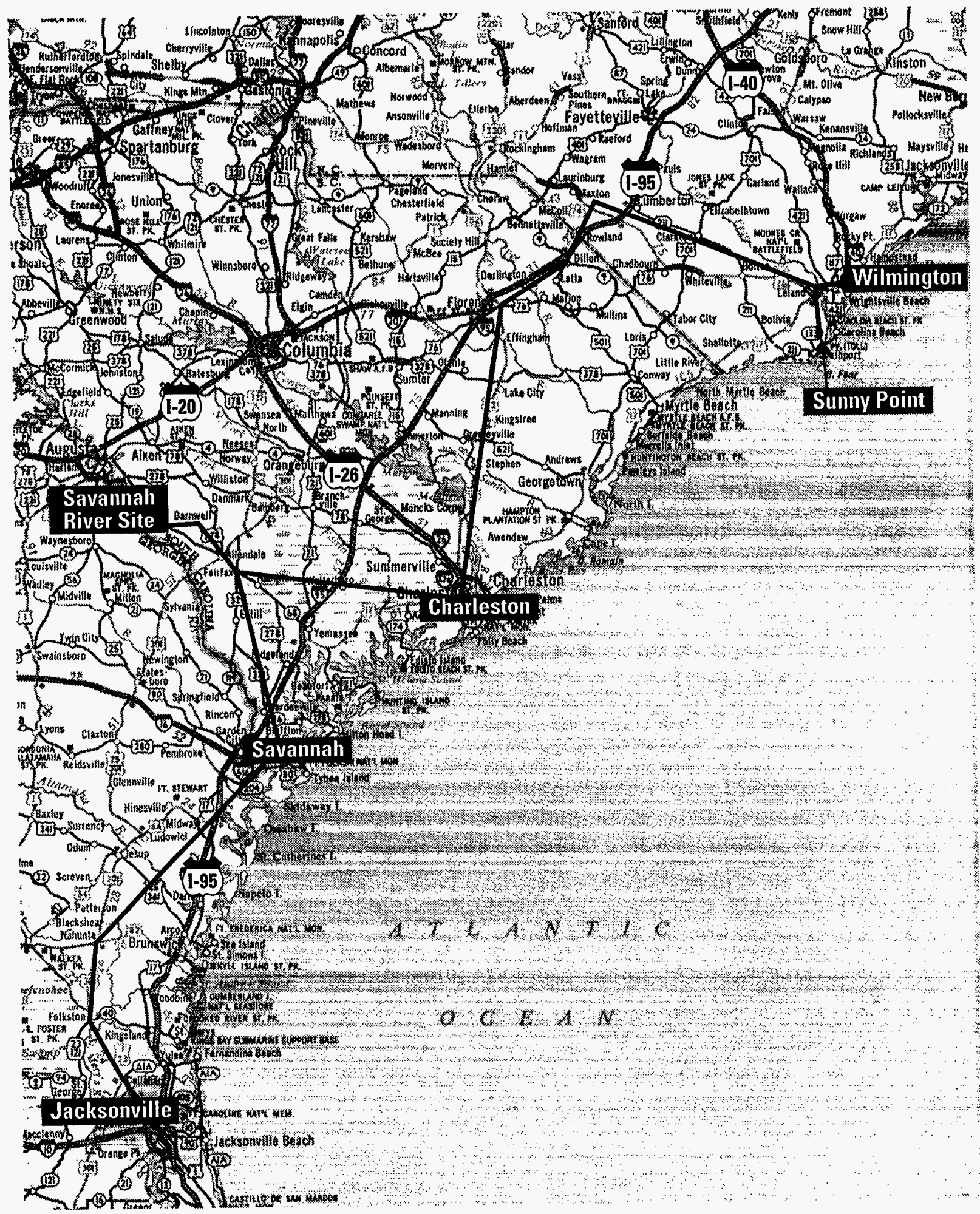

Figure H-1. Representative Rail Routes 


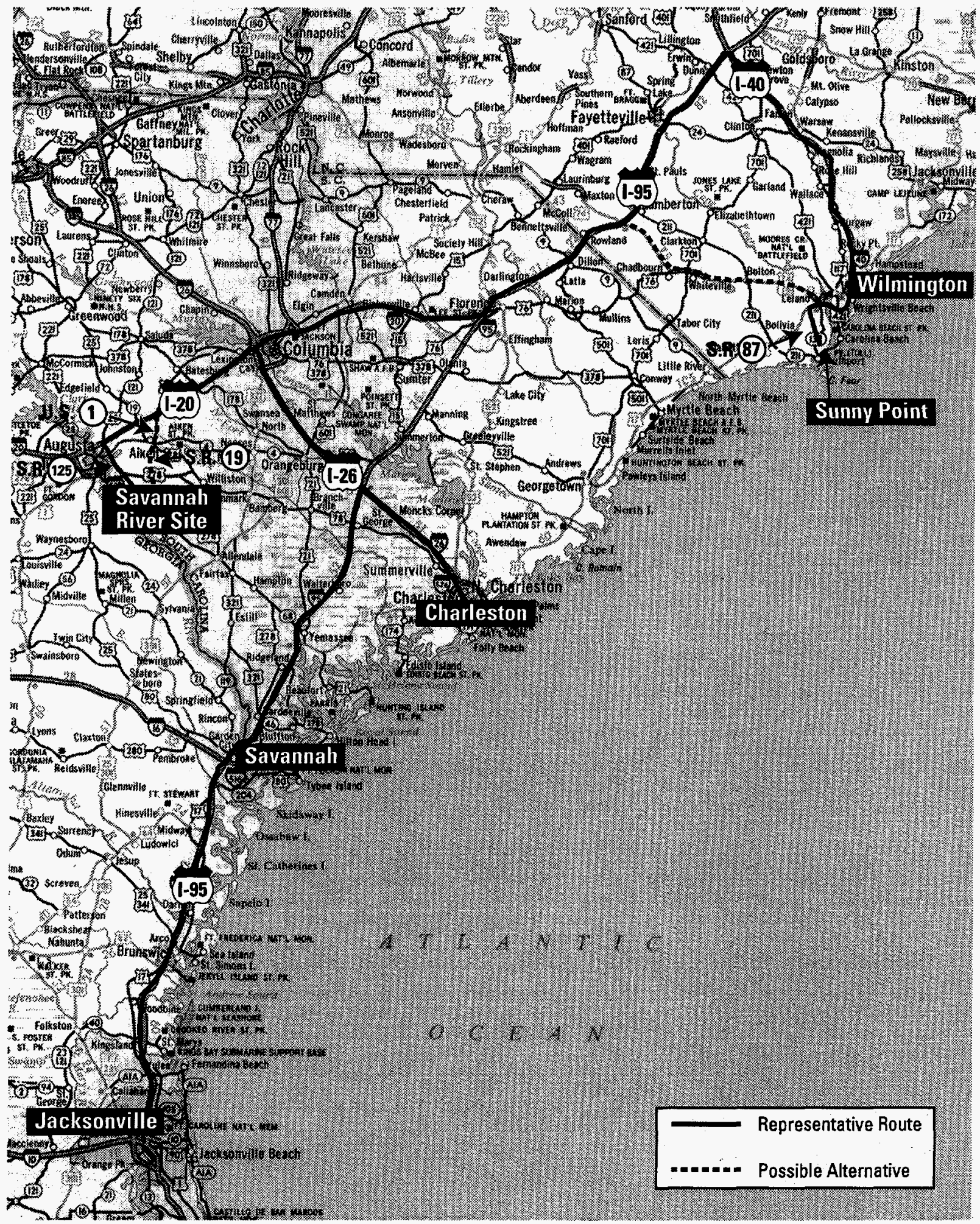

Figure H-2. Representative Highway Routes 


\section{APPENDIX I}

DISCUSSION OF MARITIME TRANSPORT OPTIONS 


\section{APPENDIX I \\ DISCUSSION OF MARITIME TRANSPORT OPTIONS}

\section{I.1 Commercial Container Ships}

Commercial liners (i.e., commercial container ships) are common carriers operating on scheduled sailings over established trade routes. They provide service on a first-come, firstserved basis. Most international maritime trade goods, other than those shipped as liquids or bulk cargo, are transported via such ships. The cargo on container ships is loaded into individual ISO (International Standards Organization) containers (i.e., large metal boxes roughly the size and shape of the trailer of an 18 wheeler truck) that can be lifted onto and off-of the ship with their cargo inside. The containers are used to minimize the need to handle the cargo since the cargo is loaded into the container at the cargo's point of origin and not touched again until the cargo is unloaded at its final destination. Use of the containers also facilitates and speeds loading and unloading of the ship and the transfer of the cargo to and from truck or rail transport in the ports. The ports servicing container ships are equipped with specially built cranes, specifically designed to automate as much of the loading/unloading operation as possible.

Commercial container ships are among the most modern and reliable that are available, due to the demands for meeting the tight schedules inherent in the commercial containership trade. The spent fuel would be shipped in shipping casks, with the shipping casks loaded into reinforced, standard size ISO containers, one cask per container. The spent fuel would be shipped along with other commercial cargo on board the container ships.

\section{I.2 Purpose-Built Ships}

British Nuclear Fuels Limited (BNFL) owns six ocean-going vessels which have been built specifically for transporting spent nuclear fuel. These vessels are known as "purpose-built" ships. The major construction feature for the vessels is a double hull, which would prevent the vessel from sinking in most collisions. It is assumed that if a BNFL vessel was used in the proposed action, it would be a double hull vessel dedicated only to the movement of foreign research reactor spent fuel, and the vessel would not be transporting any other spent fuel for continued transport from Japan or other destinations. BNFL ships are capable of carrying over 50 casks. However, there is a much lower practical limit imposed by the availability of casks for carrying the foreign research reactor spent fuel.

BNFL Pacific class ships (3000-4000 GT) are designed to withstand a collision with a 23,400 GT vessel traveling at 15 knots in order to meet certain standards of the Japanese government (Milne et al., 1986). About 25 percent of the collisions in the data considered by Warwick and Anderson (1976) involved a similar combination of ships (i.e., a collision between a ship of 1000-5000 GT and a ship of greater than 15,000 GT). Warwick and Anderson's data were extracted from the United States Coast Guard Casualty files for the period 1970-1974. During this period, 296 collisions involving 602 vessels occurred among 78,000 transits in five major United States ports. Since Warwick and Anderson did not give ship speeds, however, the 
fraction of these accidents that were of a severity equivalent to or greater than the designbasis accident cannot be estimated. Since the degree to which collision survival of a BNFL ship might be improved cannot be determined from these data, no quantitative expression of the difference between a BNFL Pacific class ship and an ordinary cargo ship can be developed beyond the reduction attributable to the absence of intermediate port stops, given that casks are stowed with the same minimum separation distance as that required by the International Atomic Energy Agency for nonexclusive use shipments on commercial container ships. Since the BNFL ships are capable of carrying over 50 casks, maintaining the separation distance should present no difficulty to the carrier, and doing so would reduce the likelihood of common-cause accidents ${ }^{1}$ to the same insignificant level as that of regular freight carriers.

\section{I.3 Military-Controlled Vessels}

The primary purpose of the Defense Transportation System (DTS) of the United States is to deliver troops and cargo during a contingency or war. The seagoing segment of the DTS, which includes sealift of both dry and liquid cargo, is the responsibility of the Military Sealift Command (MSC). The MSC controls its own ships, which are known as the MSC force. This force varies continuously in size and mix, and includes break-bulk and partial container ships, roll-on/roll-off ships, tankers, and barge carriers. Some of the ships of the MSC force are bareboat-chartered, some are government-owned, and others are chartered as needed for specific periods of time.

Another responsibility of DTS is the operation of military terminals. Military Ocean Terminals (MOTs) and ports for military cargo shipments ring the continental United States. They include such sites as Bayonne, New Jersey; Baltimore, Maryland; New Orleans, Louisiana; Charleston, South Carolina; Mobile, Alabama; Beaumont, Texas; San Diego, Port Hueneme, and Oakland in California; and Seattle and Tacoma in Washington. Military terminals used for loading ammunition onto ocean-going ships are located in Earle, New Jersey; Concord, California; and Sunny Point, North Carolina.

In addition to stateside terminals, there are a number of overseas terminals operated by the Military Traffic Management Command. Included are the MOTs at Rotterdam, Netherlands; Bremerhaven, Germany; Leghorn, Italy; and Felixstowe, England.

The foreign research reactor spent nuclear fuel would be categorized as dry cargo. Most of MSC's dry cargo sealift capacity is obtained from commercial charters. Based on discussions with MSC, one of their controlled vessels could be made available to transport the foreign research reactor spent nuclear fuel from ports within Europe to any commercial or military ocean terminal in the United States. The vessels that could be used are roll-on/roll-off or break-bulk vessels owned by private carriers. In this situation, the foreign research reactor spent nuclear fuel would be transported by a military-controlled chartered vessel, whose charter would be transferred to the DOE, and would deliver the foreign research reactor spent nuclear fuel to any of the proposed ports. Because of the limited number of casks available

\footnotetext{
${ }^{1}$ A common-cause accident is one in which more than one package (cask) is damaged as a result of a single accident event.
} 
worldwide at any one time, however, a ship likely would carry no more than eight casks on each voyage.

While there is regular service between Bremerhaven (actually Nordenham) and Sunny Point, the vessels on this route are all retrograde ${ }^{2}$ ammunition vessels. It would not be desirable to carry a mixed cargo of spent nuclear fuel and ammunition on the same vessel. Therefore, a ship would be chartered to carry only the spent nuclear fuel.

\footnotetext{
2 Retrograde ammunition is ammunition that is being withdrawn from service and returned to the United States for disposal.
} 


\section{APPENDIX J}

\section{DESCRIPTIONS OF ALTERNATE PORTS OF ENTRY}




\section{DESCRIPTIONS OF ALTERNATE PORTS OF ENTRY}

In addition to the proposed ports, nine other ports, seven commercial and two military, were analyzed as alternative ports of entry. ${ }^{1}$ A brief description and discussion of each alternative port is provided in this Appendix. Three of these ports, (Norfolk, Newport News, and Portsmouth, Virginia), like the proposed ports, are frequent destinations for container cargo ships traveling from ports throughout the world, and have a great deal of experience handling containerized cargo of all kinds. However, large, busy ports that are centers of commerce with good transportation links are generally surrounded by large populations. Three low-population-density alternatives, Morehead City, North Carolina, the U.S. Naval Submarine base of Kings Bay, Georgia, and the U.S. Naval Weapons Station of Yorktown, Virginia, were also analyzed. Neither Morehead City, North Carolina, nor any other small commercial port on the Atlantic (e.g., Fernandina Beach, Florida), are likely to be a frequently scheduled destination for transatlantic container cargo ships. King's Bay Naval Submarine Base, Georgia, and Yorktown Weapons Station, Virginia, have never been destinations for commercial container or freight cargo ships. The three other alternative ports are Oakland, California; New Orleans, Louisiana; and Elizabeth, New Jersey.

Sea-route distances from each foreign port to each of the alternative ports are shown in Table J-1.

\section{J.1 Port of New York and New Jersey - Elizabeth, New Jersey, Terminals}

The Port of New York and New Jersey handles the world's greatest volume of intermodal traffic, much of it ship-to-truck containers, such as would be used for foreign research reactor spent nuclear fuel. The port also provides security. However, container damage from mishandling has been a continuing problem at this port (Cigna, 1989). The marine terminals in Elizabeth, New Jersey, are better situated for access to Interstate highway and avoidance of heavily populated areas than are terminals in New York. The terminals are separated from residential areas by storage areas and other industrial concerns. However, the surrounding area is densely populated $\left(3,650\right.$ persons $/ \mathrm{km}^{2}$ [9454 persons $\left.\left./ \mathrm{mi}^{2}\right]\right)$. The highway route from Elizabeth to the SRS is 1328 $\mathrm{km}(825 \mathrm{mi})$ (Table J.2) and passes through the periphery of the Baltimore and Washington, DC, metropolitan areas.

\section{J.2 Hampton Roads}

The Port of Hampton Roads, Virginia, is comprised of three major port facilities: 1) Newport News Marine Terminal; 2) Norfolk International Terminal; 3) and Portsmouth Marine Terminal.

\footnotetext{
${ }^{1}$ The Port of Oakland is only proposed as an alternative in the event that 953 fuel elements would be accepted. Under this larger number of elements, spent fuel would be received from Australia and could enter the U.S. through a west coast port.
} 
Table J-1. Distances in Kilometers (km) Between Foreign Ports and Alternative Atlantic Ports

\begin{tabular}{|c|c|c|c|c|c|c|c|c|c|}
\hline \multirow[b]{2}{*}{ Foreign Port } & \multicolumn{9}{|c|}{ Distances in kilometers (miles) to: } \\
\hline & Elizabeth & Kings Bay & Morehead City & New Orleans & Oakland $^{2}$ & Yorktown & Norfolk & $\begin{array}{l}\text { Newport } \\
\text { News }\end{array}$ & Portsmouth \\
\hline Antwerp, Belgium & $6264(3884)$ & $9165(5682)$ & $6686(4145)$ & $8939(5542)$ & N/A & $6550(4070)$ & $\begin{array}{l}6568 \\
(4081)\end{array}$ & $6562(4078)$ & $\begin{array}{l}6568 \\
(4061)\end{array}$ \\
\hline $\begin{array}{l}\text { Bremerhaven/ } \\
\text { Hamburg1, Germany }\end{array}$ & $6760(4191)$ & $9661(5990)$ & $7182(4453)$ & $9435(5850)$ & N/A & $7046(4378)$ & \begin{tabular}{|l}
7063 \\
$(4389)$
\end{tabular} & 7057 (4385) & $\begin{array}{l}7063 \\
(4389)\end{array}$ \\
\hline Piraeus, Greece & $8665(5384)$ & $\begin{array}{l}11024 \\
(6962)\end{array}$ & $9089(5648)$ & $11176(6945)$ & N/A & $8972(5575)$ & $\begin{array}{l}8960 \\
(5568)\end{array}$ & 8954 (5564) & $\begin{array}{l}8960 \\
(5568)\end{array}$ \\
\hline Rotterdam, Holland & $6273(4075)$ & $9174(5688)$ & $6695(4151)$ & $8948(5548)$ & N/A & $6560(4076)$ & $\begin{array}{l}6577 \\
(4087)\end{array}$ & $6571(4083)$ & $\begin{array}{l}6577 \\
(4087)\end{array}$ \\
\hline Stockholm, Sweden & $8294(5142)$ & $\begin{array}{l}11194 \\
(6940)\end{array}$ & $8715(5403)$ & $10969(6801)$ & N/A & $8580(5332)$ & $\begin{array}{l}8597 \\
(5342)\end{array}$ & $8591(5338)$ & $\begin{array}{l}8597 \\
(5342)\end{array}$ \\
\hline
\end{tabular}

${ }^{1}$ Fuel from the Austrian ASTRA, Swiss SAPHIR, and Danish DR-3 reactors is modeled as being shipped from the ports of Bremerhaven or Hamburg.

${ }^{2}$ Oakland is considered as an option only for the Australian HIFAR fuel if 953 fuel elements were accepted as an alternative to the proposed action. 
Table J-2. Distances from Proposed Alternate Ports of Entry to the SRS

\begin{tabular}{|c|c|c|c|c|}
\hline \multirow[b]{2}{*}{ Elizabeth, NJ } & \multicolumn{2}{|c|}{$\begin{array}{l}\text { Highway Distance } \\
\mathbf{k m}\end{array}$} & \multicolumn{2}{|c|}{$\begin{array}{lr}\text { Rail Distance } \\
\mathrm{km} & (\mathrm{mi})\end{array}$} \\
\hline & 1328 & (825) & 1403 & $(872)$ \\
\hline $\begin{array}{l}\text { Hampton Roads } \\
\text { Newport News, VA } \\
\text { Norfolk, VA } \\
\text { Portsmouth, VA }\end{array}$ & $\begin{array}{l}839 \\
815 \\
852\end{array}$ & $\begin{array}{c}(521)(507) \\
(530)\end{array}$ & $\begin{array}{l}971 \\
852 \\
---\end{array}$ & $\begin{array}{l}(603) \\
(530) \\
-\end{array}$ \\
\hline Kings Bay, GA Naval Base & 589 & (366) & 498 & (309) \\
\hline Morehead City, NC & 689 & (426) & 932 & (579) \\
\hline New Orleans, LA & 1031 & (641) & 1173 & (729) \\
\hline Oakland, CA & 4600 & (2859) & 5646 & (3514) \\
\hline Yorktown Navy Base, VA & 873 & (543) & --- & ---- \\
\hline
\end{tabular}

\section{J.2.1 General Information}

The Port of Hampton Roads, Virginia, is located at the confluence of the James River and the Chesapeake Bay, approximately $29 \mathrm{~km}$ (18 miles) west of the Atlantic Ocean. Combined, these terminals total over 3.4 sq. $\mathrm{km}$ ( 840 acres), are equipped with 17 container cranes capable of handling spent fuel and have $3127 \mathrm{~m}(10,260 \mathrm{ft})$ of marginal wharf. In 1982, the ports at Hampton Roads were unified under the banner of the Ports of Virginia to be managed by the Virginia Port Authority (VPA). VPA, a state agency, established an operating arm, Virginia International Terminals Inc., to operate the cargo terminals which fall under the purview of the VPA. Overall strategic direction, sales, and marketing activities for the cargo terminals remain the responsibility of the VPA.

The port facilities at Hampton Roads are closely ranked with the Port of Charleston as the second or third most active container port of the East and Gulf Coasts, having handled in 1992 approximately 5.9 million metric tons (6.5 million tons) and 875,000 20-foot-equivalent units of containerized cargo. These ports have prior experience handling radioactive materials with port officials referencing 1000 metric tons (1,100 tons) (primarily uranium dioxide) moved in 1992 (FHI, 1993c).

The Virginia International Terminals Safety Manual sets forth rules and policies for a diversity of operations including, but not limited to, cargo arrangement, hazardous cargo, facilities maintenance, fire emergency procedures, crane maintenance, container control, hazardous materials, emergency procedures, and general safety. The manual also provides a policy for the handling of radioactive materials, including an emergency response section. Additionally, the manual sets forth emergency procedures that prioritize personnel protection, facility protection, environmental protection, and cargo protection. 


\section{J.2.2 Equipment and Operations/Newport News Marine Terminal (NNMT)}

- $\quad$ NNMT is situated east of the James River in the City of Newport News and encompasses 0.57 sq. km (140 acres) of land. This terminal has two major piers: Pier B and Pier C. All are highly efficient operations with the latest technology incorporated into the network of cranes and loading systems available.

- $\quad$ Combined, Piers B and C provide

- $\quad 760 \mathrm{~m}(2,500 \mathrm{ft})$ of berthing space

- Four cranes

- $\quad 36,620$ sq. $\mathrm{m}(394,200$ sq. feet) of covered pier storage

- $\quad 10,400$ sq. $\mathrm{m}(112,000$ sq. feet $)$ of dry storage

- $\quad 0.13 \mathrm{sq} . \mathrm{km}(32.8$ acres) of open-yard storage.

- Roadway access is via major arteries that connect the terminal with Interstate 64, U.S. Route 17, and Interstate 664.

- Rail service is provided by CSX. Shipside rail service is available at this terminal.

- Channel depth at NNMT is recorded at $11 \mathrm{~m}$ (35 feet).

- $\quad$ The VPA is spending $\$ 16$ million to expand and improve this terminal facility, including a new 9300 sq. $m(100,000$ sq. foot) warehouse.

\section{J.2.3 Equipment and Operations/Norfolk International Terminal (NIT)}

- $\quad$ NIT is situated east of the Elizabeth River, north of Portsmouth Marine Terminal. NIT consists of $1.9 \mathrm{sq} . \mathrm{km}$ (480 acres) of land and pier area with $1320 \mathrm{~m}(4,320$ feet) of berthing space.

- $\quad$ NIT provides the following facilities:

- Three dual-hoist cranes

- $\quad$ Four single-hoist cranes

- $\quad 84,000$ sq. $\mathrm{m}(900,000$ sq. feet $)$ of covered pier storage

- $\quad 93,000$ sq. $m(1,000,000$ sq. feet $)$ of dry storage

- $\quad 28,000$ sq. $\mathrm{m}(300,000$ sq. feet) of cold storage.

- Roadway access is via International Terminal Boulevard, which connects to Interstate 64 (a major east/west corridor).

- Rail access consists of a direct connection with the Norfolk Southern Corporation and service by CSX Corporation and Eastern Shore Railroad via the Norfolk and Portsmouth Belt Line Railroad. Shipside rail service is available at this terminal by prior arrangement.

- $\quad$ Channel depth at NIT is approximately $9.8 \mathrm{~m}$ (32 feet). 
- It is proposed to expand NIT by an additional $1.2 \mathrm{sq} . \mathrm{km}$ (300 acres) and $1300 \mathrm{~m}(4,300$ feet) of berthing space as part of a $\$ 400$ million project intended to double NIT's current size.

\section{J.2.4 Equipment and Operations/Portsmouth Marine Terminal (PMT)}

- PMT is situated east of the Elizabeth River in the City of Portsmouth, Virginia. It encompasses 0.9 sq. $\mathrm{km}$ ( 219 acres) of land and provides $1080 \mathrm{~m}$ (3,540 feet) of berthing space. PMT specializes in container cargo.

- $\quad$ PMT provides the following facilities:

- $\quad$ Five dockside container cranes

- A 98-metric-ton (110-ton) gantry crane

- $\quad 15,000$ sq. $\mathrm{m}(160,000$ sq. feet $)$ of dry storage

- $\quad$ Container storage for 2,000 containers

- Miscellaneous equipment, including 14 straddle carriers, three forklifts, and two fumigation chambers.

- $\quad$ Roadway access is via U.S. Route 58, connecting to Interstate 95 (a major north-south corridor).

- Rail access consists of a direct connection of the CSX Corporation and service by the Norfolk Southern Corporation and Eastern Shore Railroad via the Norfolk \& Portsmouth Belt Line Railroad. Shipside rail service is available at this terminal with axle loading not to exceed $27,000 \mathrm{~kg}(60,000$ pounds) on $1.5-\mathrm{m}$ (5-foot) centers.

- Channel depth at PMT is approximately $14 \mathrm{~m}$ (45 feet).

\section{J.3 Kings Bay Naval Submarine Base, Georgia}

The Kings Bay Naval Base is located in Kings Bay, Camden County, Georgia. The 64-sq.-km (16000-acre) site is situated between Jacksonville, Florida, approximately $40 \mathrm{~km}$ (25 miles) to the south, and Brunswick, Georgia, which lies approximately $32 \mathrm{~km}$ (20 miles) north of the site. The Kings Bay site was acquired by the U.S. armed forces in the 1950s, and in 1978, the Department of the Navy selected Kings Bay as the east coast base for its Fleet Ballistic Missile Submarine Support Facility. The primary mission of the base is to provide support for Atlantic Fleet submarines. Kings Bay is designated as a high-security naval base to protect military equipment and information relating to the submarines, the submarine launched missiles they carry, and the nuclear warheads on the missiles. Due to the potential for large, explosive releases of destructive energy if the propellant in one of the missiles should explode, the base is located and laid out internally to separate its facilities from one another and from the surrounding sparse population with buffer zones. The entire waterfront area of the base is within one of the explosion separation zones. 
The buffer areas (at least $14 \mathrm{sq} \mathrm{km}$ or 3400 acres) around the base are uninhabited. The population of the surrounding Camden County is 16,800 , and the average population density is 10 persons $/ \mathrm{km}^{2}$ (approximately 26 persons $/ \mathrm{mi}^{2}$ ).

Because it is most uncommen to consider a high-security naval submarine base as a possible port for commercial cargo, permission was obtained from the Chief of Naval Operations for DOE to conduct a site visit. The following information regarding naval policies and procedures was obtained on that visit (FHI, 1993b).

- The base was constructed specifically for the support of Trident submarines and its use is dedicated to that purpose. Since many of the normal operations of Kings Bay could not be continued while a container ship was in the facility (due to security and safety concerns) operations involving the docking and unloading of a container ship at the port would be likely to either significantly interfere with the operational readiness of the TRIDENT submarines, or significantly delay the container ship (i.e., it would have to wait for a "window" in the Navy's operations). For example, schedules regarding nuclear submarines potentially carrying ballistic nuclear missiles are neither published nor otherwise released to the public. Whenever a submarine enters Kings Bay, no other vessels are allowed to transit base waters or utilize any of the required berthing spaces.

- During missile handling activities, a safety zone with a $1500-\mathrm{m}(5,000-\mathrm{ft})$ radius is established around the missile handling area. All of the berthing areas at Kings Bay would be included in any safety zone established. Only personnel involved in missile handling or other essential activities are allowed to be within the safety zone for safety and security reasons.

- There are three wharfs at Kings Bay for vessel berthing. The Service Wharf does not have equipment that could be used for unloading a container ship and is not wide enough or structurally capable of accommodating such equipment. The Explosive Handling Wharf has heavy lift cranes which could be used to offload containers, but the berth can only accommodate vessels up to $150 \mathrm{~m}$ (500 feet) in length, less than the 200 - to $260-\mathrm{m}$ (650 to 850-foot) length of typical container ships. The Refit Wharf is used to support maintenance and repair activities on submarines. The wharf can accommodate three submarines. It is therefore long enough to berth a container ship, as long as there is only one submarine present at the wharf, and it is in a position which would allow berthing of a large ship, and if that submarine is not using the one crane that could offload containers weighing up to 41 metric tons ( 45 tons).

- While not prohibited in specific written policies, to date, only military vessels have been allowed to enter the channel to Kings Bay for security reasons. No foreign flag ships (apart from British naval vessels, with whom the U.S. has treaties of cooperation) or commercial ships have ever been allowed to enter the facility.

- No foreign nationals are allowed on base without prior approval from the U.S. State Department, also for security reasons. This would rule out essentially all commercial container ships, since their crews are highly unlikely to be composed solely of U.S. citizens. 
- The Navy does not have the personnel and equipment at Kings Bay that would be required to provide hazardous materials emergency response support for accidents involving the foreign research reactor spent nuclear fuel.

- Kings Bay has no container handling equipment and no experience in the handling of containers or container ships. This means that all operations involving docking of a container ship at Kings Bay and unloading of the containers would be unfamiliar to the personnel conducting them, thus increasing the time (and resulting radiation exposures) required for the operations. Furthermore, since the equipment that is available at Kings Bay was not designed for handling containers, and the personnel would not normally be experienced in container handling, the potential for an accident would be increased.

- The base contains both threatened and/or endangered species of plants and animals (FHI, 1993b).

While Kings Bay could theoretically be used to offload foreign research reactor spent nuclear fuel, the many procedural, safety, and logistical difficulties, such as those summarized above, make it highly impractical. The only acceptable wharf, the Refit Wharf, is unlikely to be available for berthing of a container ship for long periods, and the few available periods could be altered without notice at any time the Navy needed to use the facilities. The container ships would be operating on a tight schedule. However, the period when they could enter or exit the port could be altered without notice whenever the Navy needed to use the facilities, thereby making it impossible to know if and when a ship carrying spent nuclear fuel would be allowed to enter or leave the port. Furthermore, the presence of large quantities of high explosive material on the base would considerably increase the level of the consequences of an accident. As a result, the use of the Kings Bay Naval Base as a port of entry for foreign research reactor spent nuclear fuel is neither reasonable nor possible.

\section{J.4 Port of Morehead City Terminal}

The Port of Morehead City, North Carolina is a small dry bulk and neobulk port that handles approximately 1.8 million metric tons ( 2.0 million tons) of cargo annually. Primary cargos are woodchips, phosphate, and potash. Its volume of containerized cargo is very small, with an annual volume of less than 200 containers. During the mid- to late-seventies, the Port handled an annual volume of approximately 10,000 containers. The Port has one central cargo handling facility, which is located along the Newport River and Bogue Sound, 4 miles from the open ocean. The channel serving the Port has a depth of 12.2-12.8 m (40-42 feet), MLW, and the berths have depths ranging between 10.7-12.2 $\mathrm{m}$ (35-40 feet) MLW. A dredging program, currently underway, will deepen the approach channel to $13.7 \mathrm{~m}$ (45 feet) MLW. The Port facilities, which are administered and operated by the North Carolina State Ports Authority, total 0.5 developed sq. $\mathrm{km}$ (115 developed acres), have $2,100 \mathrm{~m}$ (7,000 feet) of berthing space, two general-purpose gantry cranes, and approximately $0.06 \mathrm{sq} . \mathrm{km}$ (15 acres) of open paved storage area. Over 74,000 sq. $m(800,000 \mathrm{sq}$ feet) of covered warehouse space is available on the terminal. Currently there are no shipping lines providing container service to the Port. The Port has limited experience handling hazardous cargo (primarily Class A explosives) and no experience handling civilian radioactive materials (FHI, 1993d). 
The Ports Authority exercises a high degree of control over the day-to-day operations of the Port facilities. Through its Port General Manager, the Port Authority manages and supervises the terminal and the operations conducted therein. This includes vessel berthing, crane assignment, warehouse usage, yard and gate operations, and equipment and facility maintenance.

According to the Port General Manager, to his knowledge, spent fuel has never passed through this Port. Explosives and possibly radioactive cargo are likely to have been handled at this facility for military purposes during "desert storm" operations. However, neither commodity class is routinely carried through the Port. The port general manager was not aware of any local ordinances prohibiting or regulating this material, and, to his knowledge, special permits or approvals were not obtained prior to offloading of the military shipments. However, the Coast Guard is required to be notified of spent fuel shipments.

The 2,100 $\mathrm{m}$ (7,000 feet) of berthing area in the Port is divided into a 450-m (1,480-foot) barge area with a draft of $3.7 \mathrm{~m}$ (12 feet) $\mathrm{MLW}$, a 1,680-m (5,520-foot) area with drafts ranging between 10.7-12.2 m (35-40 feet) MLW. Approximately 50 percent of this berthing area, which is served by two general-purpose gantry cranes, is restricted to vessels with a $10.7-\mathrm{m}$ (35-foot) maximum draft MLW. One berth in the lower draft area is equipped with a roll-on/roll-off ramp for stern unloading and loading. Berths are generally assigned on a first-come-first-served basis, with berths reserved on a 24-48-hour notice basis. Some berths are guaranteed to specific customers, primarily the dry bulk operators and military vessels that call at the Port from time to time. The Port General Manager exercises direct control over the berths. Berth occupancy is relatively low; few vessel berthing conflicts exist.

Stevedoring of cargo to and from vessels is performed primarily by contract stevedores who are hired by the ship owner or operator. In the Morehead City Port area, two principal stevedores operate. These stevedores supply the management and supervision for the stevedoring operation, hire the labor, plan the stevedoring process and provide any miscellaneous equipment that may be required. The gantry crane operators are non-union employees of the Port Authority. In the case of certain dry bulk operations (wood chips), the stevedoring process is controlled by the cargo owner/shipper.

Although the Port of Morehead City does not handle containerized cargo on a regular basis and its current volumes are insignificant, it does have the capability to handle containers on a limited basis. The principal berthing area for container vessel handling would be at berths 8 and 9 along the western edge of the terminal. These berths have a draft limit of $10.7 \mathrm{~m}$ ( $35 \mathrm{feet}) \mathrm{MLW}$, which is satisfactory to most vessels, but not the largest container vessels. Two 102-metric-ton (115-ton), 32-foot rail-gauge general-purpose gantry cranes serve these berths and provide the container handling capability. These cranes are presently not equipped with container handling attachments, but could be equipped relatively easily.

A Safety Officer on the staff of the Port Authority reports to the Port General Manager. This officer is responsible for all safety aspects of the terminal and maintains close contacts with the Coast Guard and the local fire department. There are very few instances of major accidents or injury on the terminal; accidents involving cargo handling are very minimal, with no drops recollected. 
The perimeter of the terminal is only partially secured with a 2-m (6-foot)-high chain link fence topped with barbed wire. The terminal areas adjacent to the rail yard and the terminal access road are not secured. The primary entrance facility to the terminal has a manned security booth which controls vehicle access and egress. A seven-man Port police force provides overall site security 24 hours per day. Six members of the police force are licensed, carry weapons, and have arrest capability. This police force reports to the Safety Officer.

The Port facilities are located along U.S. Highway 70, just east of the main town of Morehead City. There are no interstate highways near the Port. Norfolk Southern provides rail service, through an intermediary switching railroad, directly to the Port. On-dock and even under- crane loading of rail cars are possible. Transfer of containers between the vessel, the yard area and the rail loading tracks can be easily performed by the Port Authority. Norfolk Southern's main line leaving the Port travels directly down the middle of "main street" Morehead City.

State Highway 70 (Main Street) is the main route into and out of the Port facility. This road bisects the busy downtown area. This local secondary road is characterized by periodic heavy local traffic flow and numerous stop lights. Highway 70 serves as the main route to Interstate 95 which is located approximately $160 \mathrm{~km}$ (100 miles) northwest of the terminal (approximately 1-1/2-hour drive). Access to I-95 requires travel through several small towns.

This geographically remote peninsular location is serviced by small two lane secondary roads, characterized by local traffic (especially during peak tourist season) and many stoplights. The main route to Interstate 95 requires travel through numerous, small, but relatively populated towns.

There are sensitive receptor populations in close proximity to the Port terminal. These include human receptors (i.e., yacht basins, state parks, barrier island communities), wildlife (possible threatened and endangered flora and fauna on current and historic dredge spoil disposal islands), and valuable historic resources (downtown historic Beaufort).

The terminal personnel have never handled civilian radioactive shipments. Though emergency plans/policies/drills are in place, none is specific to the types of hazards associated with the handling of radioactive materials.

\section{J.5 Port of New Orleans}

The Port of New Orleans, Louisiana, is a Gulf Coast port. It has container cranes and port security, but no experience handling spent nuclear fuel. A marine terminal with relatively direct access to Interstate 10 was used for this analysis. Low- to medium-population-density Gulf Coast ports such as Tampa, Florida, Gulfport, Mississippi, and Port Arthur, Texas, are primarily bulk cargo handling ports. Therefore, no low-population-density Gulf Coast port was analyzed. The other two major Gulf Coast ports, Houston and Galveston, Texas, have extensive containerhandling facilities, but are congested. The accident rate in the Houston Ship Channel, in particular, is relatively high, and the port security record is poor (Warwick and Anderson 1976; CIGNA, 1989). The highway distance from New Orleans to the Savannah River Site is $1029 \mathrm{~km}$ (639 miles), and the rail distance is $1173 \mathrm{~km}$ (729 miles). 


\section{J.6 Port of Oakland}

The Port of Oakland, California, is a major Pacific Coast port. As the second leading container port in the United States, it is the most frequent destination for container-cargo ships from Australia. Oakland has an extensive inventory of container cranes, and more than $80 \%$ of the Port's annual tonnage is containerized cargo. Oakland also is a consolidation port for overland movement of containerized cargo to inland destinations; that is, containerized cargo from smaller Pacific Coast ports are trucked to Oakland for consolidation prior to going overland. These considerations make Oakland the most likely Pacific Coast port of entry for spent nuclear fuel shipments destined for the SRS. The surrounding area is densely populated [ 2557 person $/ \mathrm{km}^{2}$ (6623 persons $\left.\left./ \mathrm{mi}^{2}\right)\right]$. The highway distance from Oakland to the Savannah River Site is $4500 \mathrm{~km}$ (2795 miles) (Table C-1). Other ports along the central and south Pacific Coast were not considered because they handle primarily bulk cargo, even though they may have container cranes. As noted above, container cargo transferred to trucks at these ports may be hauled to Oakland for consolidation. The ports (all in California) are Long Beach, Port Hueneme, Sacramento, and San Diego.

\section{J.7 U.S. Naval Weapons Station, Yorktown, Virginia}

The U.S. Naval Weapons Station in Yorktown, Virginia, is the largest storage and transfer facility for military weapons on the east coast. This facility is located on the Virginia Peninsula, which is $40 \mathrm{~km}$ ( 25 miles) long and flanked by the York River to the north and the James River to the south. The site is situated $81 \mathrm{~km}$ ( 50 miles) west of the Atlantic Ocean, approximately $130 \mathrm{~km}$ (80 miles) southeast of Richmond (Virginia's capital) and $290 \mathrm{~km}$ (180 miles) south of Washington, D.C. The 42-sq.-km (10,500-acre) Yorktown Weapons Station was acquired by Presidential Proclamation in 1918 and was initially developed as a U.S. Mine Depot to support the laying of mines in the North Sea during World War I. For 20 years following World War I, the facility received, reclaimed, stored, and issued mines, depth charges, and related materials. This facility expanded in 1927 to accommodate the growing accumulation of TNT by constructing three additional loading plants. In 1944, a research and development laboratory for experimentation with high explosives was established. The U.S. Mine Depot was redesignated the U.S. Naval Weapons Station in 1958. Since 1918, the Weapons Station has experienced periods of high and low activity, new mission assignments, and new facilities, all within the original 42-sq.-km (10,500-acre) site (FHI, 1993e).

A major part of the Station's mission includes the renovation, maintenance, and assembly of all classes of ordnance in the Navy's inventory, with the exception of fleet ballistic missiles. The station has depot-level responsibilities for many of these items.

With regard to scheduling considerations, since the facility has not historically accepted anything other than military vessels, no "normal scheduling protocol" was discussed. As a general rule, the Navy does know in advance the scheduled maintenance periods for the U.S. submarines. However, the base must remain open to both U.S. and British vessels that may need to enter the base for emergency repairs, either with or without prior notification. These vessels' needs would obviously supersede any non-military needs, regardless of how far in advance notice of entry was provided. In addition, if a berthing area was being used by a non-military vessel, and a military 
vessel needed that berthing location, the non-military vessel would be required to relinquish its location, regardless of whether or not it had completed offloading its cargo.

The constraints imposed by various operational and safety criteria on the development and use of land at the Weapons Station in Yorktown primarily revolve around explosive safety. The Explosive Safety Quantity Distance (ESQD) criteria dictate the physical separation required to minimize the adverse impacts of an unplanned explosive detonation. The ESQD "arcs" circumscribe safety areas in which all non-essential personnel must evacuate and all non-essential operations must desist during missile-handling operations. Of the 42-sq.-km (10,500-acre) site, only $10 \%$, or 4.1 sq. $\mathrm{km}(1,037$ acres), are free of ESQD arc restrictions. The ESQD arc around the pier comprises an area within $2,030 \mathrm{~m}(6,650$ feet) of the loading pier. The Colonial Parkway, however, is exempt and lies within the pier ESQD arc. As the entire berthing area of the Yorktown Weapons Station is within the ESQD arcs, any suspension in activities would affect container unloading, and the time required could be lengthened significantly.

When missile-handling operations are being conducted and the arc clearance area is being enforced, gates along the vehicular roadways automatically close to secure the area within these arcs. At those times, the area within the arc may be accessed only by showing special identification badges. The area is guarded by armed military security personnel. The duration that this clearance arc must be observed varies with the type of activity being conducted.

It should be noted that the Yorktown facility has never offloaded containers onsite and does not maintain any equipment normally used for this purpose. As a result, personnel on the base have no knowledge or experience in the safe and efficient handling methods associated with this activity.

The primary marine asset of the Station is a U-shaped pier on the northeastern portion of the Station along the banks of the York River. This pier facility provides $686 \mathrm{~m}(2,250$ feet $)$ of berthing space at a depth of $11 \mathrm{~m}$ (36 feet) MLW, and a general-purpose gantry crane. The pier has a width of $29 \mathrm{~m}$ (94 feet) and provides an additional $564 \mathrm{~m}$ (1,850 feet) of berthing space on the inboard side, for berthing small barges, which is controlled by a lift span on the northern approach leg. A dredging program is underway to increase the water depth at the outboard berth to 42 feet MLW. The controlling depth for vessels approaching the Station is currently $9.8 \mathrm{~m}$ (32 feet) MLW, which occurs at the confluence of the York River and the Chesapeake Bay. Discussions to alleviate this vessel draft limitation for vessels navigating between the York River and the Chesapeake Bay are ongoing, with no dredging plan in sight. The Coleman Memorial Bridge, which spans the York River $2.4 \mathrm{~km}$ (1-1/2 miles) southeast of the loading pier, restricts vessel access in the closed position. Most vessels accessing the Station require the bridge to be opened, which is not allowed during rush hours. In the open position, there is adequate clearance for vessel passage.

The general-purpose gantry crane has a 40-metric-ton (44-ton) maximum capacity, and sits on a 9-m (30-foot) rail gauge 30 feet from the fender face of the wharf. This crane is not intended for handling containers, but has adequate height and outreach to perform container unloading from a vessel. The crane characteristic of most concern is the single lifting point, which compromises safety and productivity compared to a standard container gantry crane. The Station 
Commanding Officer, David Jones, stated that any berthing of vessels at this facility is controlled by him, and that any unloading of spent fuel at his facility would be accomplished by his staff.

Security for the Station perimeter and ordnance production storage area is provided by the Navy Security Force, which consists of 67 personnel. A 42-man civilian guard force component patrols the industrial areas, provides law enforcement Base-wide, and, in conjunction with the Security Force, patrols and guards facilities containing highly pilferable ordnance items. A 210-man Marine Corps Security Force Company provides security for special weapons. Maintaining security of the Station's 26-km (16-mile) perimeter is made difficult by the presence of the Colonial National Parkway, which travels along the York River, intersecting the route between the Station and the ammunition pier. Traffic between the Station and the pier must travel under the Parkway via two short underpasses. Because the parkway's overpasses could pose a threat to security, marine guards are posted to prevent sightseers from stopping during certain logistic movements. The parkway is temporarily closed to traffic during the movement of certain ordnance categories.

The transportation system at the Weapons Station in Yorktown includes a network of $90 \mathrm{~km}$ (56 miles) of paved roads and $56 \mathrm{~km}$ (35 miles) of unpaved roads, a Station-operated $81-\mathrm{km}$ (50mile) rail system, helicopter facilities, and pier facilities.

Transportation into and out of the base is achieved primarily through highway and rail lines. Interstate 64 is adjacent to the western perimeter of the Weapons Station at Yorktown. Interstate 64 is a four-lane, primary east-west route linking the peninsula to Richmond and Washington, D.C. Interstate 60 also serves as a major east-west transportation corridor running parallel to Interstate 64. State Highway 238 is a two-lane secondary road which borders the southern perimeter of the Weapons Station. This State highway provides access from Interstate Route 64 directly into the Station. Access to the Stations waterfront facilities is through two underpasses crossing the Colonial Parkway.

The Station operates its own $81-\mathrm{km}$ (50-mile) railroad system connecting to CSX Rail Transport, which runs generally parallel to and between Interstate Routes 60 and 64 .

The railroad system is used primarily to move ordnance from the magazines to the ammunitions pier and vice-versa. The majority of ordnance arriving from off-station or to be shipped to another facility is carried by commercial carrier truck transport.

In accordance with the Master Plan for the U.S. Navy Weapons Station in Yorktown, the privately owned land adjacent to the Station is sparsely settled with residences; undeveloped areas are covered primarily with large tracts of forested lands. The southern boundary is well protected from community growth by Interstate 64 . South of Interstate 64, land use remains primarily lowdensity residential and agricultural. A small portion along the northwest boundary adjoins privately owned land that has recently been zoned for a commercial/tourist area. The Colonial National Historic Park, the small community of Lackey, and open farm land adjoin the Station's eastern boundary.

The Yorktown Naval Weapons Station is located in the central portion of York County and near the historic Village of Yorktown. The Virginia Peninsula is comprised of the following 
municipal jurisdictions: Hampton, James City County, Newport News, Poquoson, Williamsburg, and York County. Pertinent demographic information is provided in the draft Environmental Impact Statement prepared in July 1992 for U.S. Navy Fast Combat Support Ship Homeporting. According to that information, of these six municipal jurisdictions, Hampton and Newport News [both located at least $32 \mathrm{~km}$ ( 20 miles) south of the Station] represent the most highly populated areas, comprising approximately 75 percent of the population of the entire Peninsula. In contrast, York County, within which the Station is located, represents $10.5 \%$ of the population of the entire peninsula.

Approximately 3,000 people live and work on the Yorktown Naval Base. The current housing inventory at the Station consists of 225 bachelor enlisted quarters, seventeen bachelor officer quarters, 473 units of family housing, and 40 mobile home pads available for use by military personnel. 
APPENDIX K

U.S. DELEGATION RESEARCH REACTOR SITE VISIT QUESTIONS 


\section{U.S. DELEGATION RESEARCH REACTOR SITE VISIT QUESTIONS}

1. Identify the current spent fuel storage facility type and capacity. Identify the limiting criteria for determination of the maximum capacity of the spent fuel storage facility. Identify the current contents of the storage facility by fuel type [characteristics (mass, isotopics, clad, etc.) including origin] and quantity.

2. Identify any fuel corrosion concerns or other potential or ongoing releases of fission products from fuel currently in storage or soon to be placed in storage.

3. Describe the capability to upgrade in place the existing storage capacity to increase the capacity including a description of the costs, timing, and licensing procedures for such a modification. Identify the status of any plans or efforts to modify the existing storage facility.

4. Describe the capability to add now storage capacity such as additional storage ponds or dry cask storage including a description of the costs, timing, and necessary licensing procedures. As appropriate, discuss licensing prospects. Identify the status of any plans or efforts to add additional storage capacity.

5. Provide a listing of all potential spent nuclear fuel storage sites within the country (third site) or region (third country) including commercial facilities (e.g., COGEMA, Dounreay, or a commercial reactor site). Describe your ability to make use of these facilities for storage of excess spent research reactor fuel on a temporary basis (18-24 months).

6. Identify the current plans and status of replacing the existing reactor core with a LEU fuelled reactor core. For those reactor cores unable to convert to LEU provide the underpinning technical justification.

7. Identify the preferred and latest possible schedules for the shipment of spent fuel. Describe the key factors underpinning these analyses. Include in your description:

a. Detailed characterization of the spent fuel requiring near-term shipment. This characterization should include mass, isotopics, number of elements, clad descriptions, country of origin, corrosion characteristics, and any other features relevant to the assessment of the environmental impacts of the spent fuel shipment.

b. Describe the facilities to be used to ship the spent fuel including physical descriptions, locations, and relevant operating histories. Describe likely transportation routes and methods.

c. Describe the status of necessary procurements to support the shipment including casks, shipping contracts, handling equipment, and local transfer contracts. 
d. Describe the status of any licensing or institutional approvals within your country or region necessary to ship the spent fuel.

e. Describe the status of any required environmental documentation within your country or region to support the shipment of your spent reactor fuel.

8. Describe the consequences if the spent fuel is not shipped from your reactor site on schedule. What will be the consequences to your reactor, domestic programs, international obligations, etc.?

9. Identify contingency plans if the spent fuel shipping schedules are not met. Identify the status of any contingency efforts, including contracting efforts, for reprocessing or storing or shipping the spent fuel.

10. Describe the current nuclear waste management capabilities and plans for your country including both interim and final disposal measures.

11. Using your current reactor operating schedule, describe the role of this reactor in the conduct of research and development, isotope production, etc. Describe the future plans for this reactor through planned decommissioning.

12. Provide a detailed description of the reactor and reactor complex and its surrounding environments. To allow a better understanding of future spent fuel shipment needs, provide a detailed characterization of the fuel currently in the reactor core and that planned for loading in the near future. This should include mass, isotopics, clad, origin, etc. Also include in the descriptions of the reactor complex the owner/operators, licensing authorities, other oversight organizations (safeguards and environment), and reporting relationships.

13. Describe planned future shipments to the U.S. of spent research reactor fuel. Given that the U.S. Environmental Impact Statement will be completed in about two years, how many of these shipments must in your view occur before completion of that EIS. Why can't they be deferred?

14. Are the plans you have provided regarding the future operations of this reactor and necessary spent fuel shipments contingent on any other factors such as receipt of other U.S. guarantees, new program funding, life extension programs, or changes in your domestic policies?

15. Are there fuels of other than U.S. origin within your spent fuel storage facility? To provide interim relief, could these fuels be returned to the country of origin?

16. Please document any U.S. commitments you have received regarding the return of spent fuel to the U.S. 
APPENDIX L

ENVIRONMENTAL CONSEQUENCES ASSOCIATED WITH ALTERNATE PORTS AND NUMBERS OF CASKS 


\section{L.1 Introduction}

This Appendix includes the results of RADTRAN analyses of the radiological impacts of shipments alternative to those discussed in Chapter 6. The analyses consider shipment to the Savannah River Site of 248, 291, 359, 409, and 953 fuel elements, with no intermediate stops and one cask per vessel, via each of the five proposed ports in tables L-1 through L-5. The analyses also consider shipments of 248,291,359, and 953 fuel elements to the eight alternative ports discussed in Appendix J, for both cases - three intermediate stops and no intermediate stops, in Tables L-6 through L-18.

\section{L.2 Comparison Between Alternate Ports and Proposed Ports}

Comparison of appropriate tables in this Appendix confirms the designation of the proposed ports as providing lower risk from transportation than the eight alternative ports. For example, comparing the shipment of 248 fuel elements, one cask per vessel and no intermediate stops, shown in Table L-5 with the same shipments shown in Table L-14, it is apparent that, in all except two cases, the accident risks (total LCFs) for the proposed ports (Table L-5) are lower than the LCFs for the eight alternative ports (Table L-14). A similar observation may be made in comparing Table L-2 with Table L-11.

\section{L.3 Comparison of Alternate Representative Routes for Truck Shipment From Sunny Point and Wilmington to Savannah River Site}

Tables L-19 and L-20 contain summaries of incident-free dose estimates and risk estimates for the shipment of 409 fuel elements through the proposed ports, assuming three intermediate port calls and one cask per vessel. These tables are analogous to Tables 6.2-8 and 6.2-9. The only difference is that the representative highway routes for shipment from Wilmington and Sunny Point to the Savannah River Site are different. For the information in Tables 6.2-8 and $6.2-9$, the representative route is such that shipments from both Sunny Point and Wilmington leave the Wilmington area via Interstate 40 to reach Interstate 95 , from which point the shipments would go south to South Carolina. Tables L-19 and L-20 have results based on a representative route for both Sunny Point and Wilmington where the shipments would leave the Wilmington area via U.S. Route 74 to reach Interstate 95, at which point the shipments would go south towards South Carolina. The routes, and thus the analyses, for all other ports are the same between the two sets of tables.

A comparison of these results indicate that the U.S. Route 74 option would have slightly lower incident-free dose estimates. Any differences in total accident risk would be imperceptible since the port risk, which dominates the risk estimates, would be the same regardless of the choice of highway route. The increase in incident-free dose estimates for the Interstate 40 route option is attributable to longer highway distances and greater numbers of potentially exposed persons along the route. The differences in route options are summarized below: 
Distance to

Savannah River Site
Potentially Exposed

Population
Port

U.S. 74

Interstate 40

Wilmington

U.S. 74

Interstate 40
Sunny Point

$546 \mathrm{~km}$

$710 \mathrm{~km}$

$501 \mathrm{~km}$

$642 \mathrm{~km}$
70,127

131,353

86,553

117,078

U.S. 74 has, in the past, been designated by the State of North Carolina as a preferred route for shipments of Highway Route Controlled Quantities (HRCQ) of radioactive material. However, in 1991 that designation was discontinued. HRCQ shipments which were shipped by vessel through the port of Wilmington in the 1980's used U.S. 74. Because of the history of HRCQ shipments along U.S. 74, the alternative analysis in Tables L-19 and L-20 was performed. The assessment of risks associated with this alternative route should in no way suggest that the State of North Carolina is currently considering redesignating U.S. 74 as a preferred route. The assessment was performed merely to develop an informed comparison between two representative routes, both of which have the potential to satisfy the requirements of the HRCQ routing requirements as specified in 49 CFR 177.825 .

The shipper of the proposed shipments could request different routes than those representative routes incorporated into the risk assessment of this EA for any port of entry. The NRC and the State have the authority to grant permission for the use of alternative routes after determining that such routes conform with the requirements of HM- 164 .

\section{L-4 Comparison Between Intermodal Transfer Methods for Transfer From Ship to Rail}

Table L-21 contains results for the incident-free dose estimates for the ship-totruck/truck-to-rail intermodal transfer model for port operations. This model is discussed in Section 6.2.4 and compared to the single direct ship-to-rail intermodal transfer model. Table L-21 is analogous to Table 6.2-11 and results of the two tables shows that the double intermodal transfer operations would result in a doubling of the dose estimates for port handlers of the casks. All other dose estimates and risk calculations would be the same regardless of the port intermodal operations.

\section{L.5 Conclusion}

This Appendix may also be used together with Chapter 6 to compare impacts of truck transportation with those of rail transportation and to compare the effects of different numbers of fuel elements. In sum, this Appendix complements the analyses of Chapter 6 and completes the data set provided in that chapter. 
Table L-1. Transportation Radiological Impacts for Shipment of 953 Elements via the Proposed Ports and Truck Overland Transport Assuming No Intermediate Port Stops and One Cask Per Vessel

\begin{tabular}{||l|c|c|c|c||}
\hline \multirow{3}{*}{ Port Of Entry } & Transportation Dose Risk - Person-Rems & \multirow{2}{*}{ Total Person-Rem } & \multirow{2}{*}{ Total LCFs } \\
\cline { 2 - 5 } & Incident-Free & Accident & & .00014 \\
\hline Charleston & .28 & .0092 & .29 & .00016 \\
\hline Jacksonville & .32 & .0027 & .32 & .00015 \\
\hline Savannah & .28 & .0110 & .29 & .00017 \\
\hline Sunny Point & .33 & .0010 & .33 & .00017 \\
\hline Wilmington & .33 & .0072 & .34 & .34 \\
\hline
\end{tabular}

Table L-2. Transportation Radiological Impacts for Shipment of 409 Elements Via the Proposed Ports and Truck Overland Transport Assuming No Intermediate Port Stops and One Cask Per Vessel

\begin{tabular}{||l|c|c|c|c||}
\hline \multirow{2}{*}{ Port Of Entry } & Transportation Dose Risk - Person-Rems & \multirow{2}{*}{ Total Person-Rem } & \multirow{2}{*}{ Total LCFs } \\
\cline { 2 - 3 } & Incident-Free & Accident & & .000063 \\
\hline Charleston & .12 & .0048 & .13 & .000072 \\
\hline Jacksonville & .14 & .0014 & .14 & .000066 \\
\hline Savannah & .13 & .0057 & .13 & .000074 \\
\hline Sunny Point & .15 & .0005 & .15 & .000075 \\
\hline Wilmington & .15 & .0038 & .15 & .075 \\
\hline
\end{tabular}


Table L-3. Transportation Radiological Impacts for Shipment of 359 Elements Via the Proposed Ports and Truck Overland Transport Assuming No Intermediate Port Stop and One Cask Per Vessel

\begin{tabular}{||l|c|c|c|c|}
\hline \multirow{3}{*}{ Port Of Entry } & Transportation Dose Risk - Person-Rems & \multirow{2}{*}{ Total Person-Rem } & \multirow{2}{*}{ Total LCFs } \\
\cline { 2 - 5 } & Incident-Free & Accident & & \\
\hline Charleston & .12 & .0044 & .12 & .000062 \\
\hline Jacksonville & .14 & .0013 & .14 & .000072 \\
\hline Savannah & .13 & .0054 & .13 & .000066 \\
\hline Sunny Point & .15 & .00052 & .15 & .000074 \\
\hline Wilmington & .15 & .0034 & .15 & .000075 \\
\hline
\end{tabular}

Table L-4. Transportation Radiological Impacts for Shipment of 291 Elements Via the Proposed Ports and Truck Overland Transport Assuming No Intermediate Port Stops and One Cask Per Vessel

\begin{tabular}{||l|c|c|c|c||}
\hline \multirow{3}{*}{ Port Of Entry } & \multicolumn{5}{|c|}{ Transportation Dose Risk - Person-Rems } & \multirow{2}{*}{ Total Person-Rem } & \multirow{2}{*}{ Total LCFs } \\
\cline { 2 - 3 } & Incident-Free & Accident & 0.078 & 0.000039 \\
\hline Charleston & 0.075 & 0.0027 & 0.090 & 0.000045 \\
\hline Jacksonville & 0.089 & 0.00077 & 0.082 & 0.000041 \\
\hline Savannah & 0.079 & 0.0030 & 0.091 & 0.000046 \\
\hline Sunny Point & 0.091 & 0.00035 & 0.093 & 0.000046 \\
\hline Wilmington & 0.091 & 0.0021 & & 0.041 Elements \\
\hline
\end{tabular}


Table L-5. Transportation Radiological Impacts for Shipment of 248 Elements Via the Proposed Ports and Truck Overland Transport Assuming No Intermediate Port Stops and One Cask Per Vessel

\begin{tabular}{||l|c|c|c|c||}
\hline \multirow{2}{*}{ Port Of Entry } & Transportation Dose Risk - Person-Rems & \multirow{2}{*}{ Total Person-Rem } & \multirow{2}{*}{ Total LCFs } \\
\cline { 2 - 3 } & Incident-Free & Accident & 0.078 & 0.000039 \\
\hline Charleston & 0.075 & 0.0024 & 0.090 & 0.000045 \\
\hline Jacksonville & 0.089 & 0.00069 & 0.081 & 0.000041 \\
\hline Savannah & 0.079 & 0.0029 & 0.091 & 0.000046 \\
\hline Sunny Point & 0.091 & 0.00028 & 0.093 & 0.000047 \\
\hline Wilmington & 0.091 & 0.0019 & & 0.048 \\
\hline
\end{tabular}

Table L-6. Transportation Radiological Impacts for Shipment of 953 Elements Via the Alternate Ports and Truck Overland Transport Assuming Three Intermediate Port Stops and One Cask Per Vessel

\begin{tabular}{|c|c|c|c|c|}
\hline \multicolumn{5}{|c|}{ Alternative Ports - 953 Elements } \\
\hline \multirow{2}{*}{ Port Of Entry } & \multicolumn{2}{|c|}{ Transportation Dose Risk - Person-Rems } & \multirow{2}{*}{ Total Person-Rem } & \multirow{2}{*}{ Total LCFs } \\
\hline & Incident-Free & Accident & & \\
\hline Elizabeth & .48 & .11 & .58 & .00029 \\
\hline Kings Bay & .33 & .10 & .43 & .00022 \\
\hline Morehead City & .34 & .10 & .44 & .00022 \\
\hline New Orleans & .41 & .10 & .52 & .00026 \\
\hline Newport News & .37 & .10 & .47 & .00024 \\
\hline Norfolk & .37 & .099 & .46 & .00023 \\
\hline Oakland $^{1}$ & .12 & .0063 & .12 & .000062 \\
\hline Portsmouth & .36 & .10 & .46 & .00023 \\
\hline Yorktown & .38 & .092 & .47 & .00024 \\
\hline
\end{tabular}

1 Only fuel from the Australian HIFAR reactor was modeled for the option of the Port of Oakland 
Table L-7. Transportation Radiological Impacts for Shipment of 359 Elements via the Alternate Ports and Truck Overland Transport Assuming Three Intermediate Port Stops and One Cask Per Vessel

\begin{tabular}{|c|c|c|c|c|}
\hline \multicolumn{5}{|c|}{ Alternative Ports - 359 Elements } \\
\hline \multirow{2}{*}{ Port Of Entry } & \multicolumn{2}{|c|}{ Transportation Dose Risk - Person-Rems } & \multirow{2}{*}{ Total Person-Rem } & \multirow{2}{*}{ Total LCFs } \\
\hline & Incident-Free & Accident & & \\
\hline Elizabeth & .21 & .051 & .26 & .00013 \\
\hline Kings Bay & .15 & .048 & .19 & .000097 \\
\hline Morehead City & .15 & .048 & .20 & .000099 \\
\hline New Orleans & .18 & .049 & .23 & .00012 \\
\hline Newport News & .16 & .047 & .21 & .00011 \\
\hline Norfolk & .16 & .047 & .21 & .00010 \\
\hline Portsmouth & .16 & .048 & .21 & .00010 \\
\hline Yorktown & 17 & .046 & .21 & .00011 \\
\hline
\end{tabular}

Table L-8. Transportation Radiological Impacts for Shipment of 291 Elements via the Alternate Ports and Truck Overland Transport Assuming Three Intermediate Port Stops and One Cask Per Vessel

\begin{tabular}{|c|c|c|c|c|}
\hline \multicolumn{5}{|c|}{ Alternative Ports - 291 Elements } \\
\hline \multirow{2}{*}{ Port Of Entry } & \multicolumn{2}{|c|}{ Transportation Dose Risk - Person-Rems } & \multirow{2}{*}{ Total Person-Rem } & \multirow{2}{*}{ Total LCFs } \\
\hline & Incident-Free & Accident & & \\
\hline Elizabeth & 0.13 & 0.031 & 0.16 & 0.000082 \\
\hline Kings Bay & 0.092 & 0.029 & 0.12 & 0.000060 \\
\hline Morehead City & 0.094 & 0.029 & 0.12 & 0.000062 \\
\hline New Orleans & 0.12 & 0.030 & 0.15 & 0.000073 \\
\hline Newport News & 0.10 & 0.029 & 0.13 & 0.000066 \\
\hline Norfolk & 0.10 & 0.029 & 0.13 & 0.000065 \\
\hline Portsmouth & 0.10 & 0.029 & 0.13 & 0.000065 \\
\hline Yorktown & 0.10 & 0.026 & 0.13 & 0.000065 \\
\hline
\end{tabular}


Table L-9. Transportation Radiological Impacts for Shipment of 248 Elements via the Alternate Ports and Truck Overland Transport Assuming Three Intermediate Port Stops and One Cask Per Vessel

\begin{tabular}{|c|c|c|c|c|}
\hline \multicolumn{5}{|c|}{ Alternative Ports - 248 Elements } \\
\hline \multirow{2}{*}{ Port Of Entry } & \multicolumn{2}{|c|}{ Transportation Dose Risk - Person-Rems } & \multirow{2}{*}{ Total Person-Rem } & \multirow{2}{*}{ Total LCFs } \\
\hline & Incident-Free & Accident & & \\
\hline Elizabeth & 0.13 & 0.028 & 0.16 & 0.000080 \\
\hline Kings Bay & 0.092 & 0.026 & 0.12 & 0.000059 \\
\hline Morehead City & 0.094 & 0.026 & 0.12 & 0.000060 \\
\hline New Orleans & 0.12 & 0.027 & 0.14 & 0.000071 \\
\hline Newport News & 0.10 & 0.026 & 0.13 & 0.000065 \\
\hline Norfolk & 0.10 & 0.025 & 0.13 & 0.000064 \\
\hline Portsmouth & 0.10 & 0.026 & 0.13 & 0.000063 \\
\hline Yorktown & 0.10 & 0.025 & 0.13 & 0.000065 \\
\hline
\end{tabular}

Table L-10. Transportation Radiological Impacts for Shipment of 953 Elements via the Alternate Ports and Truck Overland Transport Assuming No Intermediate Port Stops and One Cask Per Vessel

\begin{tabular}{||l|c|c|c|c||}
\hline \multirow{2}{*}{ Port Of Entry } & Transportation Dose Risk - Person-Rems & \multirow{2}{*}{ Total Person-Rem } & \multirow{2}{*}{ Total LCFs } \\
\cline { 2 - 3 } & Incident-Free & Accident & & .47 \\
\hline Elizabeth & .45 & .015 & .32 & .00024 \\
\hline Kings Bay & .31 & .0072 & .33 & .00016 \\
\hline Morehead City & .32 & .0072 & .40 & .00020 \\
\hline New Orleans & .39 & .0092 & .37 & .00019 \\
\hline Newport News & .37 & .0055 & .37 & .00018 \\
\hline Norfolk & .36 & .0044 & .11 & .000057 \\
\hline Oakland & .11 & .00063 & .36 & .00018 \\
\hline Portsmouth & .36 & .0074 & .36 & .00018 \\
\hline Yorktown & .36 & .0023 & .36 & \\
\hline
\end{tabular}

Results for Oakland represent estimates associated with transportation of the Australian HIFAR reactor fuel only. 
Table L-11. Transportation Radiological Impacts for Shipment of 409 Elements Via the Alternate Ports and Truck Overland Transport Assuming No Intermediate Port Stops and One Cask Per Vessel

\begin{tabular}{||l|c|c|c|c||}
\hline \multirow{2}{*}{ Port Of Entry } & Transportation Dose Risk - Person-Rems & \multirow{2}{*}{ Total Person-Rem } & \multirow{2}{*}{ Total LCFs } \\
\cline { 2 - 5 } & Incident-Free & Accident & .21 & .00011 \\
\hline Elizabeth & .20 & .0078 & .14 & .000071 \\
\hline Kings Bay & .14 & .0038 & .15 & .000073 \\
\hline Morehead City & .14 & .0038 & .18 & .000091 \\
\hline New Orleans & .18 & .0048 & .17 & .000083 \\
\hline Newport News & .16 & .0029 & .16 & .000082 \\
\hline Norfolk & .16 & .0023 & .16 & .000081 \\
\hline Portsmouth & .16 & .0039 & .16 & .000080 \\
\hline Yorktown & .16 & .0012 & .16 & \\
\hline
\end{tabular}

Table L-12. Transportation Radiological Impacts for Shipment of 359 Elements via the Alternate Ports and Truck Overland Transport Assuming No Intermediate Port Stops and One Cask Per Vessel

\begin{tabular}{||l|c|c|c|c||}
\hline \multirow{2}{*}{ Port Of Entry } & Transportation Dose Risk - Person-Rems & \multirow{2}{*}{ Total Person-Rem } & \multirow{2}{*}{ Total LCFs } \\
\cline { 2 - 5 } & Incident-Free & Accident & & .00011 \\
\hline Elizabeth & .20 & .0073 & .21 & .000071 \\
\hline Kings Bay & .14 & .0035 & .14 & .000073 \\
\hline Morehead City & .14 & .0035 & .15 & .000090 \\
\hline New Orleans & .18 & .0045 & .18 & .000083 \\
\hline Newport News & .16 & .0026 & .17 & .000082 \\
\hline Norfolk & .16 & .0021 & .16 & .000081 \\
\hline Portsmouth & .16 & .0035 & .16 & .000080 \\
\hline Yorktown & .16 & .0011 & .16 & \\
\hline
\end{tabular}


Table L-13. Transportation Radiological Impacts for Shipment of 291 Elements via the Alternate Ports and Truck Overland Transport Assuming No Intermediate Port Stops and One Cask Per Vessel

\begin{tabular}{||l|c|c|c|c||}
\hline \multirow{2}{*}{ Port Of Entry } & Transportation Dose Risk - Person-Rems & \multirow{2}{*}{ Total Person-Rem } & \multirow{2}{*}{ Total LCFs } \\
\cline { 2 - 3 } & Incident-Free & Accident & 0.13 & 0.000066 \\
\hline Elizabeth & 0.13 & 0.0043 & 0.088 & 0.000044 \\
\hline Kings Bay & 0.086 & 0.0021 & 0.090 & 0.000045 \\
\hline Morehead City & 0.088 & 0.0021 & 0.11 & 0.000056 \\
\hline New Orleans & 0.11 & 0.0027 & 0.10 & 0.000052 \\
\hline Newport News & 0.10 & 0.0016 & 0.10 & 0.000051 \\
\hline Norfolk & 0.10 & 0.0013 & 0.10 & 0.000051 \\
\hline Portsmouth & 0.099 & 0.0021 & 0.099 & 0.000050 \\
\hline Yorktown & 0.099 & 0.00066 & & 0.0050 \\
\hline
\end{tabular}

Table L-14. Transportation Radiological Impacts for Shipment of 248 Elements Via the Alternate Ports and Truck Overland Transport Assuming No Intermediate Port Stops and One Cask Per Vessel

\begin{tabular}{||l|c|c|c|c||}
\hline \multirow{2}{*}{ Port Of Entry } & \multicolumn{3}{|c|}{ Alternative Ports - 248 Elements } & \multirow{2}{*}{ Total LCFs } \\
\cline { 2 - 3 } & Transportation Dose Risk - Person-Rems & \multirow{2}{*}{ Total Person-Rem } & \\
\hline Elizabeth & 0.13 & Accident & 0.13 & 0.000066 \\
\hline Kings Bay & 0.086 & 0.0040 & 0.088 & 0.000044 \\
\hline Morehead City & 0.088 & 0.0020 & 0.090 & 0.000045 \\
\hline New Orleans & 0.11 & 0.0020 & 0.11 & 0.000056 \\
\hline Newport News & 0.10 & 0.0025 & 0.10 & 0.000052 \\
\hline Norfolk & 0.10 & 0.0014 & 0.10 & 0.000051 \\
\hline Portsmouth & 0.099 & 0.0011 & 0.10 & 0.000051 \\
\hline Yorktown & 0.099 & 0.0019 & 0.099 & 0.000050 \\
\hline
\end{tabular}


Table L-15. Transportation Radiological Impacts for Shipment of 953 Elements via the Alternate Ports and Truck Overland Transport Assuming No Intermediate Port Stops and Eight Casks Per Vessel

\begin{tabular}{||l|c|c|c|c||}
\hline \multicolumn{3}{|c|}{ Alternative Ports - 953 Elements } \\
\hline \multirow{3}{*}{ Port Of Entry } & Transportation Dose Risk - Person Rems & \multirow{2}{*}{ Total Person-Rems } & \multirow{2}{*}{ Total LCFs } \\
\cline { 2 - 3 } & Incident-Free & Accident & .46 & .00023 \\
\hline Elizabeth & .45 & .0018 & .31 & .00016 \\
\hline Kings Bay & .31 & .00088 & .32 & .00016 \\
\hline Morehead City & .32 & .00088 & .40 & .00020 \\
\hline New Orleans & .39 & .0011 & .37 & .00018 \\
\hline Newport News & .37 & .00068 & .36 & .00018 \\
\hline Norfolk & .36 & .00054 & .36 & .00018 \\
\hline Portsmouth & .36 & .00091 & .36 & .00018 \\
\hline Yorktown & .36 & .00029 & & \\
\hline \hline
\end{tabular}

Table L-16. Transportation Radiological Impacts for Shipment of 359 Elements via the Alternate Ports and Truck Overland Transport Assuming No Intermediate Port Stops and Eight Casks Per Vessel

\begin{tabular}{||l|c|c|c|c|}
\hline \multicolumn{3}{|c|}{ Alternative Ports - 359 Elements } & \multirow{2}{*}{ Total LCFs } \\
\cline { 2 - 4 } Port Of Entry & Transportation Dose Risk - Person-Rems & \multirow{2}{*}{ Total Person-Rems } & Tot \\
\cline { 2 - 3 } & Incident-Free & Accident & .20 & .00010 \\
\hline Elizabeth & .20 & .00090 & .14 & .000069 \\
\hline Kings Bay & .14 & .00043 & .14 & .000071 \\
\hline Morehead City & .14 & .00043 & .18 & .000088 \\
\hline New Orleans & .18 & .00055 & .16 & .000082 \\
\hline Newport News & .16 & .00033 & .16 & .000081 \\
\hline Norfolk & .16 & .00027 & .16 & .000080 \\
\hline Portsmouth & .16 & .00045 & .16 & .000079 \\
\hline Yorktown & .16 & .00014 & & \\
\hline
\end{tabular}


Table L-17. Transportation Radiological Impacts for Shipment of 291 Elements via the Alternate Ports and Truck Overland Transport Assuming No Intermediate Port Stops and Eight Casks Per Vessel

\begin{tabular}{|c|c|c|c|c|}
\hline \multicolumn{5}{|c|}{ Alternative Ports - 291 Elements } \\
\hline \multirow{2}{*}{ Port Of Entry } & \multicolumn{2}{|c|}{ Transportation Dose Risk - Person-Rems } & \multirow{2}{*}{ Total Person-Rems } & \multirow{2}{*}{ Total LCFs } \\
\hline & Incident-Free & Accident & & \\
\hline Elizabeth & 0.13 & 0.0009 & 0.13 & 0.000064 \\
\hline Kings Bay & 0.086 & 0.00043 & 0.086 & 0.000043 \\
\hline Morehead City & 0.088 & 0.00043 & 0.089 & 0.000044 \\
\hline New Orleans & 0.11 & 0.00055 & 0.11 & 0.000055 \\
\hline Newport News & 0.10 & 0.00033 & 0.10 & 0.000051 \\
\hline Norfolk & 0.10 & 0.00026 & 0.10 & 0.000051 \\
\hline Portsmouth & 0.099 & 0.00045 & 0.10 & 0.00005 \\
\hline Yorktown & 0.099 & 0.00014 & 0.099 & 0.000049 \\
\hline
\end{tabular}

Table L-18. Transportation Radiological Impacts for Shipment of 248 Elements via the Alternate Ports and Truck Overland Transport Assuming No Intermediate Port Stops and Eight Casks Per Vessel

\begin{tabular}{||l|c|c|c|c||}
\hline \multirow{2}{*}{ Port Of Entry } & Transportation Dose Risk - Person-Rems & \multirow{2}{*}{ Total Person-Rems } & \multirow{2}{*}{ Total LCFs } \\
\cline { 2 - 5 } & Incident-Free & Accident & 0.13 & 0.000064 \\
\hline Elizabeth & 0.13 & 0.0009 & 0.086 & 0.000043 \\
\hline Kings Bay & 0.086 & 0.00043 & 0.089 & 0.000044 \\
\hline Morehead City & 0.088 & 0.00043 & 0.11 & 0.000055 \\
\hline New Orleans & 0.11 & 0.00055 & 0.10 & 0.000051 \\
\hline Newport News & 0.10 & 0.00033 & 0.10 & 0.000051 \\
\hline Norfolk & 0.10 & 0.00026 & 0.10 & 0.000050 \\
\hline Portsmouth & 0.099 & 0.00045 & 0.099 & 0.000049 \\
\hline Yorktown & 0.099 & 0.00014 & & 0.048 \\
\hline
\end{tabular}


Table L-19 Transportation Radiological Impacts for Shipment of 409 Elements via the Proposed Ports and Truck Overland Transport Assuming Three Intermediate Port Stops and One Cask Per Vessel

\begin{tabular}{||l|c|c|c|c||}
\hline \multirow{3}{*}{ Port Of Entry } & \multicolumn{5}{|c|}{ Transportation Dose Risk - Person-Rems } & \multirow{2}{*}{ Total Person-Rem } & \multirow{2}{*}{ Total LCFs } \\
\cline { 2 - 5 } & Incident-Free & Accident & & \\
\hline Charleston & 0.12 & 0.054 & 0.18 & 0.000088 \\
\hline Jacksonville & 0.14 & 0.051 & 0.20 & 0.000098 \\
\hline Savannah & 0.13 & 0.056 & 0.18 & 0.000091 \\
\hline Sunny Point & 0.14 & 0.050 & 0.19 & 0.000095 \\
\hline Wilmington $^{\mathrm{a}}$ & 0.14 & 0.053 & 0.18 & 0.000093 \\
\hline
\end{tabular}

${ }^{2}$ Highway shipment from Sunny Point and Wilmington to the Savannah River Site would be via U.S. Route 74 to Interstate 95, instead of via Interstate 40 to Interstate 95.

Table L-20. Transportation Radiological Impacts for Shipment of 409 Elements via the Proposed Ports and Truck Overland Transport Assuming No Intermediate Port Stops and Eight Casks Per Vessel

\begin{tabular}{|c|c|c|c|c|}
\hline \multicolumn{5}{|c|}{ Proposed Ports - 409 Elements } \\
\hline \multirow{2}{*}{ Port Of Entry } & \multicolumn{2}{|c|}{ Transportation Dose Risk - Person-Rems } & \multirow{2}{*}{ Total Person-Rem } & \multirow{2}{*}{ Total LCFs } \\
\hline & Incident-Free & Accident & & \\
\hline Charleston & 0.12 & 0.00055 & 0.12 & 0.000061 \\
\hline Jacksonville & 0.14 & 0.00016 & 0.14 & 0.000072 \\
\hline Savannah & 0.13 & 0.00068 & 0.13 & 0.000063 \\
\hline Sunny Point ${ }^{a}$ & 0.13 & 0.00068 & 0.13 & 0.000063 \\
\hline Wilmington ${ }^{\star}$ & 0.13 & 0.00068 & 0.13 & 0.000063 \\
\hline
\end{tabular}

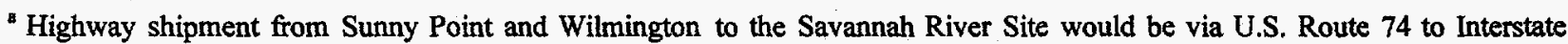
95 , instead of via Interstate 40 to Interstate 95. 
Table L-21. Incident-Free Radiological Risk for the Alternative Action: Shipment of 409 Spent Nuclear Fuel Elements to the Savannah River Site via Rail Transportation with Ship-to-Truck/Truck-to-Rail Intermodal Transfer at the Port Of Entry

\begin{tabular}{|c|c|c|c|}
\hline Port of Entry & Exposure Category & $\begin{array}{l}\text { Annual Dose } \\
\text { (person-rem) }\end{array}$ & Latent Cancer Fatalities \\
\hline \multirow[t]{5}{*}{ Charleston } & Port Handlers/Inspectors & 0.23 & 0.00012 \\
\hline & Other Port Workers & 0.0039 & 0.0000020 \\
\hline & Public & 0.0012 & 0.00000059 \\
\hline & Rail Crew & 0.029 & 0.000015 \\
\hline & Total & 0.27 & 0.00013 \\
\hline \multirow[t]{5}{*}{ Jacksonville } & Port Handlers/Inspectors & 0.23 & 0.00012 \\
\hline & Other Port Workers & 0.0039 & 0.0000020 \\
\hline & Public & 0.0014 & 0.00000068 \\
\hline & Rail Crew & 0.031 & 0.000015 \\
\hline & Total & 0.27 & 0.00014 \\
\hline \multirow[t]{5}{*}{ Savannah } & Port Handlers/Inspectors & 0.23 & 0.00012 \\
\hline & Other Port Workers & 0.0039 & 0.0000020 \\
\hline & Public & 0.0010 & 0.00000051 \\
\hline & Rail Crew & 0.029 & 0.000014 \\
\hline & Total & 0.27 & 0.00013 \\
\hline \multirow[t]{5}{*}{ Sunny Point } & Port Handlers/Inspectors & 0.23 & 0.00012 \\
\hline & Other Port Workers & 0.0039 & 0.0000020 \\
\hline & Public & 0.0017 & 0.00000083 \\
\hline & Rail Crew & 0.032 & 0.000016 \\
\hline & Total & 0.27 & 0.00014 \\
\hline \multirow[t]{5}{*}{ Wilmington } & Port Handlers/Inspectors & 0.23 & 0.00012 \\
\hline & Other Port Workers & 0.0039 & 0.0000020 \\
\hline & Public & 0.0017 & 0.00000083 \\
\hline & Rail Crew & 0.032 & 0.000016 \\
\hline & Total & 0.27 & 0.00014 \\
\hline
\end{tabular}




\section{LITERATURE CITED}

Abkowitz, M. and J. Galarraga, "Tanker Accident Rates and Expected Consequences in U.S. Ports and High Seas Regions," Proceedings of Conference on Recent Advances in Hazardous Materials Transportation Research: An International Exchange," Transportation Research Board, National Research Council, Washington, DC, November, 1985.

Allen, P. M., "Safety Analysis -- 200 Area, Savannah River Plant, Separations Area Operations, Receiving Basin for Offsite Fuel (Sup 3)," DPSTSA-200-10-3, Savannah River Laboratory, E.I. du Pont de Nemours \& Co., Aiken, SC, September 1983.

Boice, J. D., "Epidemiologic Studies of Radioactively Contaminated Environments and Cancer Clusters," National Council on Radiation Protection and Measurements, 26th Annual Meeting, Bethesda, MD, 1990.

Burion, R. J. et al., "Response of Spent LWR Fuel to Extreme Environments," (Draft Report), Battelle Columbus Laboratories, Columbus, OH, 1985.

Cashwell, J. W., K. S. Neuhauser, P. C. Reardon, and G. W. McNair, 1986, Transportation Impacts of the Commercial Radioactive Waste Management Program, SAND85-2715, Sandia National Laboratories, Albuquerque, NM.

CEQ (Council on Environmental Quality), "Regulations on Implementing NEPA Procedures, Part 1500-1508," 43 FR 55990, Washington, DC, 1978.

CERL (Construction Engineering Research Laboratory), "Global Commons Environmental Assessment," U.S. Army Corps of Engineers, Champaign, IL, 1990.

CIGNA Companies, "Ports of the World, A Guide to Cargo Loss Control," 14th Edition, Philadelphia, PA, 1989.

COGEMA, Safety Analysis Report for IU-004 Type B(U) Cask, IU004-RS-002, Rev.0, France, March 1988.

Cashwell, J. W., R. E. Luna and K. S. Neuhauser, "The Impacts of Transportation within the United States of Spent Reactor Fuel from Domestic and Foreign Research Reactors," SAND88-0714, Sandia National Laboratories, Albuquerque, NM, January 1990.

Cherry, R. D. and L. V. Shannon, "The Alpha Radioactivity of Marine Organisms," Atomic Energy Reviews, 12 (3-45), 1974.

Church, H. and R. E. Luna, "DIFOUT: A Model for Computation of Aerosol Transport and Diffusion in the Atmosphere," SC-RR-68-555, Sandia National Laboratories, Albuquerque, NM, 1969. 
Considine, M. "Thermal Radiation Hazard Ranges from Large Fuel Fires," SRD-R-297, United Kingdom Atomic Energy Authority, Culchetch, Warrington, England, 1984.

Cummins, C. L., D. K. Martin, and J. L. Todd, "Savannah River Site Environmental Report (1990)," WSRC-IM-91-28, Westinghouse Savannah River Company, Aiken, SC, 1991.

DMA (Defense Mapping Agency), "Distances Between Ports," Publication 151, No. NVPUB151, DMA, Washington DC, 1991.

Dennis, A. W. et al., "Severities of Transportation Accidents Involving Large Packages," SNAD77-0001, Sandia National Laboratories, Albuquerque, NM, 1977.

Durant, W. S., "Offsite Consequences of a Leak Beneath 221-S Building and of an Extended Air Reversal," Internal Memorandum DPST-79-569, E. I. du Pont de Nemours \& Co., Savannah River Laboratory, Aiken, SC, November 1979.

Durant, W. S., D. F. Baughman, and C. S. Townsend, "Separation Facilities Fault Tree Data Bank (SEPR), 1992 Status Report (Unclassified)," WSRC-TR-93-309, Westinghouse Savannah River Company, Aiken, SC, May 1993.

ERP (Eggers Ridihalgh Partners, Inc.), "Safety Analysis Report for the LHRL-120 Irradiated Fuel Shipping Cask," ERP LHRL-120 Cask SAR (Rev.0), Columbus, OH, June 1986.

FHI (Frederic R. Harris, Inc.), "Port of Charleston Assessment for Receipt of FRR SNF," Frederic R. Harris, Inc., Iselin, NJ, 1993a.

FHI (Frederic R. Harris, Inc.), "Kings Bay Naval Submarine Base Assessment for Receipt of FRR SNF," Frederic R. Harris, Inc., Iselin, NJ, $1993 b$.

FHI (Frederic R. Harris, Inc.), "Ports of Virginia Ports Authority Norfolk Terminal, Portsmouth Terminal, Newport News Terminal Assessment For Receipt of FRR SNF", Frederic R. Harris, Inc., Iselin, NJ, 1993c.

FHI (Frederic R. Harris, Inc.), "Ports of North Carolina Ports Authority Wilmington Terminal, Morehead city Terminal Assessment For Receipt of FRR SNF", Fredrick R. Harris, Inc., Iselin, NJ, 1993d.

FHI (Frederic R. Harris, Inc.), "Yorktown Naval Weapons Station, Yorktown, Virginia Assessment For Receipt of FRR SNF", Frederic R. Harris, Inc., Iselin, NJ, 1993 e.

Finley, N. C. et al., "Transportation of Radionuclides in Urban Environs: Draft Environmental Assessment," SAND79-0369 (NUREG/CR-0743), Sandia National Laboratories, Albuquerque, NM July 1980.

Fischer, L. E. et al., "Shipping Container Response to Severe Highway and Railway Accident Conditions," NUREG/CR-4829, USNRC, Washington, DC, 1987 
GNS (Gesellschaft fur-Nuklear-Service mbH), "Safety Analysis Report - GNS 11," GNS-B-40/86E (Rev.0), Essen, Germany, October 1986. [English Summary]

Gilbert, E. et al., Mortality of Workers at the Hanford Site, 1945-1986, Health Physics 64(6), 1993.

Glasstone, S. and A. Sesonske, "Nuclear Reactor Engineering," 3rd Edition, Krieger Publishing Co., Malabar, FL, 1991.

Godbee, H. W., "Use of Evaporation for the Treatment of Liquids in the Nuclear Industry," ORNL-4790, Oak Ridge National Laboratory, Oak Ridge, TN, September 1973.

Gonzalez, A., J. Pierce and D. Stenberg, "Target Hardness Comparison to IAEA Unyielding Target," IAEA-SM-114, SAND86-0052, Sandia National Laboratories, Albuquerque, NM, 1986.

Hallenbeck, W. H. and K. M. Cunningham, "Quantitative Risk Assessment for Environmental and Occupational Health," Lewis Publ., Chelsea, MI, 1986.

Hamby, D. M., "Verification of the AXAIR89Q Dose Assessment Code (Unclassified)," WSRCRP-90-1222, Westinghouse Savannah River Company, Aiken, SC, November 1990.

Haselow, J. S., "Estimated Exposure from Hypothetical Tank Farm Release (Unclassified)," Inter-Office Memorandum, SRT-ESS-93-0143, Westinghouse Savannah River Company, Aiken, SC, January 1993.

Hawkins, D., Risk Manager, Virginia International Terminals, Inc., Letter of Information, February 1991.

Helton, J. C., "Performance Assessment Overview," in "Preliminary Comparison with 40 CFR Part 191, Subpart B, for the Waste Isolation Pilot Plant, December 1991," SAND91-0893, Sandia National Laboratories, Albuquerque, NM, 1991.

Hessler, R. R. and H. L. Sanders, "Faunal Diversity in the Deep-Sea, "Deep Sea Resources, Vol. 14, pp. 65-78, 1967.

Huang, J. C. and C. R. Lux, "AXAIR89: An Improved Version of the AXAIR Code," WSRC-RP-89-1197, Westinghouse Savannah River Company, Aiken, SC, November 1989.

Huerta, M. and H. R. Yoshimura, "A Study of Full-Scale Test of a High-Velocity Grade-Crossing Simulated Accident of a Locomotive and a Nuclear Spent Fuel Shipping Cask," SAND79-2291, Sandia National Laboratories, Albuquerque, NM, February 1983.

IAEA (International Atumic Energy Agency), "Effects of Ionizing Radiation on Aquatic Organisms and Ecosystems," Tech. Rep. Series No. 172, Vienna, Austria, 1976.

IAEA (International Atomic Energy Agency), "Regulations for the Safe Transport of Radioactive Material," Safety Series No, 6, IAEA, Vienna, Austria, 1990a. 
IAEA (International Atomic Energy Agency), "Advisory Material for the IAEA Regulations for the Safe Transport of Radioactive Material," Safety Series No. 37 IAEA, Vienna, Austria, 1990b.

IAEA (International Atomic Energy Agency), "Nuclear Research Reactors in the World," Vienna, Austria, 1991.

ICRP (International Commission on Radiological Protection), "Limits for Intakes of Radionuclides by Workers," ICRP Publication 30, Pergamon Press, Oxford, UK, 1982.

ICRP (International Commission on Radiological Protection), "1990 Recommendations of the International Commission on Radiation Protection," ICRP Publication 60, Oxford, United Kingdom, 1991.

IMO (International Maritime Organization), International Maritime Dangerous Goods (IMDG) Code, IMO, London, UK, 1984.

IMO (International Maritime Organization), "SOLAS - Consolidated Text of the International Convention for the Safety of Life at Sea" [incorporates all amendments up to and including the 1991 amendments], London, UK, 1992.

ISO (International Standards Organization), "Series 1 Freight Container Specifications and Testing - Part 1: General Cargo Containers," ISO 1496/1-1990, ISO, Geneva, 1990.

Jefferson, R. M. and H. R. Yoshimura, "Crash Testing of Nuclear Fuel Shipping Containers," SAND77-1462, Sandia National Laboratories, Albuquerque, NM, 1978.

JoC (Journal of Commerce), "Piers Imports and Exports Database" Journal of Commerce, New York, NY, 1992.

Kanipe, F. L. and K. S. Neuhauser, "RADTRAN 4 - Vol. 4: Programmer's Manual," SAND89-2370, Sandia National Laboratories, Albuquerque, NM, July 1992.

Kim, K. S. and R. F. Bradley, "Overall Risk for Nonreactor Nuclear Facilities and Implementation of Safety Goals (Unclassified)," WSRC-TR-92-550, Westinghouse Savannah River Company, Aiken, SC, 1974, June 1993.

Lorenz, R. A. et al., "Fission Product Release from Simulated LWR Fuel," NUREG/CR-0274, Nuclear Regulatory Commission, Washington, DC, 1978.

Lorenz, R. A. et al., "Fission Product Release for Highly Irradiated LWR Fuel," NUREG/CR0722, Nuclear Regulatory Commission, Washington, DC, 1980a.

Lorenz, R. A. et al., "Fission Product Release from Highly Irradiated LWR Fuel Heated to $1300^{\circ}$ $1600^{\circ} \mathrm{C}$ in Steam," NUREG/CR-1386, Nuclear Regulatory Commission, Washington, DC, 1980b.

Luna, R. E, J. Cashwell, J. D. McClure, K. S. Neuhauser, R. M. Ostmeyer, P. C. Reardon, and T. A. Wolff, "Response to the Report Entitled "Transportation Risks: Appendix A, DOE 
Environmental Assessment - Analysis of RADTRAN II Model and Assumptions, " SAND86-1312, Sandia National Laboratories, Albuquerque, NM, June 1986.

MTMCTEA (Military Traffic Management Command Transportation Engineering Agency), "Ports for National Defense," MTMCTEA Report SE 90-3d-21, Newport News, Virginia, 1992.

Madsen, M. and E. Wilmot, "Truck Transportation of Radioactive Materials," Proceedings of PATRAM '83, p. 724, New Orleans, LA, May 1983.

Miller, A. B., G. R. Howe, et al., "Mortality From Breast Cancer After Irradiation During Fluoroscopic Examinations in Patients Being Treated for Tuberculosis," New Eng. Jour. Med. 321 (1285-1289), 1989.

Mills, G.S. and K.S. Newhauser, "Cumulative Dose to Members of the Public from Routine Highway Transportation of RAM," Waste Management '94, University of Arizona, Tucson, Arizona, 1994.

Milne, W. G. et al., 1986, "Design and Operation of Nuclear Fuel Carriers," PATRAM'86 International Symposium on the Packaging and Transport of Radioactive Materials, Davos, Switzerland.

NAC (Nuclear Assurance Corporation), "Sea Transportation Safety Analysis Report," Norcross, GA, 1989.

NAS (National Academy of Sciences Committee on the Effects of Ionixing Radiation), "Health Effects of Exposure to Low Levels of Ionizing Radiation (BEIR V)," National Academy of Sciences, Washington, D.C., 1990.

NCRP (National Council on Radiation Protection and Measurements), "Ionizing Radiation Exposures of the Population of the United States," NCRP Report No. 93, Bethesda, MD, 1987.

NCRP (National Council on Radiation Protection and Measurements), "Effects of Ionizing Radiation on Aquatic Organisms," NCRP Report No. 116, Bethesda, MD, 1991.

NEA (Nuclear Energy Agency), Office of Economic Cooperation and Development, "Dispersal of Radionuclides in the Oceans: Models, Data Sets, and Regional Descriptions," NEA/OECD, Paris, 1988.

NRC (National Research Council), "Health Effects of Exposure to Low Levels of Ionizing Radiation, BEIR V," National Academy Press, Washington, DC, January 1990.

Neuhauser, K. S. and J. Cashwell, "Port Operations at Hampton Roads, VA, and Offloading of Taiwan Research Reactor Spent Fuel on February 19, 1991," TTC-1068, Sandia National Laboratories, Albuquerque, NM, 1991.

Neuhauser, K. S. and F. L. Kanipe, "RADTRAN 4 - Vol. 3: User Guide," SAND89-2370, Sandia National Laboratories, Albuquerque, NM, January 1992. 
Neuhauser, K. S. and F. L. Kanipe, "RADTRAN 4 - Vol. 2: Technical Manual," Sandia National Laboratories, Albuquerque, NM, 1993.

Neuhauser, K. S. and R. F. Weiner, "Application of RADTRAN 4 to Route-Specific Analysis," Proceedings of Waste Management '92, University of Arizona, Tucson, AZ, March 1992a.

Neuhauser, K. S. and R. F. Weiner, "RADTRAN Parameter Values for Intermodal Transfers of Spent Fuel,". Proceedings of 10th International Symposium on the Packaging and Transportation of Radioactive Materials (PATRAM '92), Yokohama City, Japan, September 1992.

ORI (Operations Research, Inc.), "Hazardous Environments Experienced by Radioactive Material Packages Transported by Water," Contractor Report to Sandia National Laboratories, ORI, Silver Spring, MD, November 1979.

ORI, Hazardous Environments Experienced by Radioactive Material Packages Transported by Water, TTC-0081, prepared for Sandia National Laboratories by ORI, Inc., Silver Spring, MD, 1980.

ORNL (Oak Ridge National Laboratory), ORIGEN-79 Isotope Generation and Depletion Code," CCC-212, Oak Ridge, TN, 1979.

ORNL (Oak Ridge National Laboratory), "HIGHWAY 3.1 - An Enhanced Highway Routing Model: Program Description, Methodology, and Revised User's Manual," ORNL/TM-12124, Oak Ridge, TN, 1992a.

ORNL (Oak Ridge National Laboratory), "INTERLINE 5.0-An Expanded Railroad Routing Model: Program Description, Methodology, and Revised User's Manual," ORNL/TM-12090, ORNL, Oak Ridge, TN, $1992 \mathrm{~b}$.

Pickard, G. L. "Descriptive Physical Oceanography," 3rd Ed., Pergamon Press, 1979.

Pillinger, W. L., and J. C. Huang, "AXAIR: A Computer Code for FSAR Assessment of PlumeExposure Doses from Potential Process-Accident Release to Atmosphere," DPST-85-304, E. I. du Pont de Nemours \& Co., Savannah River Laboratory, Aiken, SC, June 1986.

Poe, W. L., "Leakage from Waste Tank 16 - Amount, Fate, and Impact,". DP-1358, E. I. du Pont de Nemours \& Co., Savannah River Laboratory, Aiken, SC, 1974.

Port of New York and New Jersey, "Oceanborne Foreign Trade Handbook 1992," The Port Authority of New York and New Jersey, August 1993.

Rack, H. J. and H. R. Yoshimura, "Postmortem Metallurgical Examination of a Fire-Exposed Spent Fuel Shipping Cask," SAND79-1424, Sandia National Laboratories, Albuquerque, NM, April 1980. 
Randall, C. T., and L.F. Landon, "Safety Analysis Report - Liquid Radioactive Waste Handling and Storage Facilities (200-Areas)," DPSTSA-200-3, Savannah River Laboratory, E.I. du Pont de Nemours \& Co., Aiken SC, 1979.

Rice, A. L., "Radioactive Waste Disposal and Deep Sea Biology," Oceanol, Acta, 1, 483-491, 1978.

Sandoval, R. P. et al., "An Assessment of the Safety of Spent Fuel Transportation in Urban Environs," SAND82-2365, Sandia National Laboratories, Albuquerque, NM, June 1983.

Shaw, Pittman, Potts, Trowbridge, "Compilation of Information From Foreign Research Reactors in the Edlow Group." Shaw, Pittman, Potts, Trowbridge, Washington, D.C., 1993

Shleien, B., "The Health Physics and Radiological Health Handbook," Revised Edition, Scinta, Inc., Silver Spring, MD, 1992.

Shornhorst, J. R., and J. M. Pareizs, "Storage Risk of Foreign Research Reactor Spent Fuel in the Receiving Basin for Offsite Fuel (U)." WSRC-TR-93-40, Rev. 2, Westinghouse Savannah River Compnay, Aiken, SC, 1993.

Spink, H. E., 1983, "Notes on the Design of Ships Used in International Transport of Irradiated Nuclear Fuel," PATRAM'83 International Symposium on the Packaging and Transport of Radioactive Materials, New Orleans, LA, USA.

Steele, J. H., J. R. Barrett, and L.V. Worthington, "Deep Currents South of Iceland," Deep-Sea Resources, Vol. 9, pp. 465-474, 1962.

Stevens, J., Memorandum to K. S. Neuhauser, Sandia National Laboratories, Albuquerque, NM, December 5, 1986.

Swallow, J. C. and L. V. Worthington, "Deep Currents in the Labrador Sea." Deep Sea Resources 16 (77-84), 1960.

TN (Transnuclear Inc.), "TN-7/MTR Package Design Safety Report," TN Report No. TN-7701, January 1977a.

TN (Transnuclear Inc.), "TN-1/MTR Package Design Safety Report," TN Report No. TN-7704, March 1977b.

Till, J. E. and H. R. Meyer, "Radiological Assessment, A Textbook on Environmental Dose Analysis," NUREG/CR-3332, Nuclear Regulatory Commission, Washington, DC, September 1983.

Turner, D. B., "Workbook of Atmospheric Dispersion Estimates," Publication No. 999-AP-26, U.S. Public Health Service, Washington, DC, 1970. 
UNSCEAR (United Nations Scientific Committee on the Effects of Atomic Radiation), "Sources, Effects, and Risks of Ionizing Radiations," UN Publication E.88.IX.7.647. New York; United Nations, 1988.

USCG (U.S. Coast Guard), "Marine Casualty Report, SSCV Sea Witch - SS Esso Brussels (Belgium), Collision and Fire with Loss of Life," USCG/NTSB-MAR-75-6, Washington, DC, 1975.

U.S.D.D.C. (United States District Court for the District of Columbia), "Sierra Club v. Watkins, 808F Supp 852" (D.C. 1991).

USDOC (U.S. Department of Commerce), City and County Data Book, USDOC, Washington, DC, 1988.

USDOE, 1986, Environmental Assessment on Shipment of Taiwanese Research Reactor Spent Nuclear Fuel, DOE/EA-0321, USDOE, Washington, DC.

USDOE (U.S. Department of Energy), "Final Environmental Impact Statement: Storage of U.S. Spent Power Reactor Fuel," DOE/EIS-0015, USDOE, Washington, DC, May 1980.

USDOE (U.S. Department of Energy), "Environmental Assessment on Shipment of Taiwanese Research Reactor Spent Fuel," DOE/EA-0321, USDOE, Washington, DC, December 1986.

USDOE (U.S. Department of Energy), "Environmental Assessment on Shipment of Taiwanese Research Reactor Spent Fuel (Phase II)," DOE/EA-0363, USDOE, Washington, DC, June 1988.

USDOE (U.S. Department of Energy), "Environmental Assessment of the Risks of the Taiwan Research Reactor Spent Fuel Project," DOE/EA-0515, USDOE, Washington, DC, June 1991a.

USDOE (U.S. Department of Energy), "Nuclear Safety Policy," Secretary of Energy Notice, SEN-35-91, Washington, DC, September 1991b.

USDOE (U.S. Department of Energy), "Definitions and Criteria for Accident Analysis," DOE Standard, DOE-DP-STD-3005-93, Proposed, Washington, DC, March 1993.

USDOE (U.S. Department of Energy), "Final Environmental Impact Statement for Continued Operation of K-, L-, and P-Reactors, Savannah River Site, Aiken, South Carolina," DOE/EIS0147, USDOE, Washington, DC, 1990.

USDOE-EH, "Spent Fuel Working Group Report on Inventory and Storage of the Department's Spent Nuclear Fuel and Other Reactor Irradiated Nuclear Materials and Their Environmental, Safety and Health Vulnerabilities, Washington, D.C., 1993.

USDOT (U.S. Department of Transportation), "SSCV Sea Witch Container Fire Experience/Report," USDOT, Washington, DC, 1975. 
USDOT (U.S. Department of Transportation), "Annual Report of Bureau of Motor Carrier Safety," Washington D.C., 1985

USEC (U.S. Enrichment Corporation), "Environmental Assessment for the Purchase of Low Enriched Uranium from the Russian Federation Pursuant to the Agreement Suspending the Antidumping Investigation on Uranium" [Draft], USEC/EA-93001, USEC, Washington, DC, 1993.

USEC (U.S. Enrichment Corporation) "Environmental Assessment for the Purchase of Russian Low Enriched Uranium Derived from the Dismantlement of Nuclear Weapons in the Countries of the Former Soviet Union," USEC/EA-94001, USEC, Bethesda, Maryland, 1994.

USNRC (U.S. Nuclear Regulatory Commission), "Assumptions Used for Evaluating the Potential Radiological Consequences of a Fuel Handling Accident in the Fuel Handling and Storage Facility for Boiling and Pressurized Water Reactors," Safety Guide 25, USNRC, Washington, DC, March 1972.

USNRC (U.S. Nuclear Regulatory Commission), "Final Environmental Statement on the Transportation of Radioactive Material by Air and Other Modes," NUREG-0170, Vols. I and II, Office of Standards Development, USNRC, Washington, DC, 1977.

USNRC (U.S. Nuclear Regulatory Commission), "Assumptions Used for Evaluating the Potential Radiological Consequences of Accidental Nuclear Criticality in a Uranium Fuel Fabrication Plant," Regulatory Guide 3.34, Revision 1, USNRC, Washington, DC, July 1979.

USNRC (U.S. Nuclear Regulatory Commission), "Atmospheric Dispersion Models for Potential Accident Consequence Assessments at Nuclear Power Plants," Regulatory Guide 1.145, Rev. 1, USNRC, Washington, DC, November 1982.

USNRC (U.S. Nuclear Regulatory Commission), "Shipping Container Response to Sever Highway and Railway Accident Conditions," NUREG/CR-4829, February, 1987.

U.S. Code of Federal Regulations 49 Part 173. "Shippers - General Requirements for Shipments and Packagings," October, 1992.

U.S. Federal Register (1981), "Final Guide for Implementation of Executive Order 12114," 46 FR 1007, Washington, DC, January 5, 1981.

U.S. Federal Register, "Designated Critical Habitat: Northern Right Whale," Proposed Rule, National Oceanic and Atmospheric Administration, 58 FR29186, Washington, DC, May 19, 1993.

Ullrich, R. L., M. C. Jernigan, et al., "Radiation Carcinogenesis: Time-Dose Relationships," Radiat. Res. 111 (179-184), 1987.

Waddoups, I. G., "Air Drop Test of Shielded Radioactive Material Containers," SAND75-0276, Sandia National Laboratories, Albuquerque, NM, 1975. 
Warwick, J. E. and A. L. Anderson, "The Nature of Ship Collisions Within Ports," Contractor Report for the U.S. Maritime Administration, Todd Shipyard Corp., Galveston, TX, April 1976.

Warwick, J. E. and A. L. Anderson, 1976, Nature of Ship Collisions within Ports, PB-255-304, prepared for National Maritime Research Center - Galveston by Todd Shipyards Corp, 1976.

Weiner, et. al. (Weiner, R. S., La Plante, P.A., and Hageman, J.P.), "Risks of Incident Free Transportation of Radioactive Materials by Highway," Risk Analysis, Vol. 11, pp. 660-666, December, 1991.

Weiner, R. F. and K. S. Neuhauser, Near-field Radiation Doses from Transported Spent Fuel, Proceedings of the International High-Level Radioactive Waste Conference, Las Vegas, NV, April 1992.

Weiner, R. F. and K. S. Neuhauser, "Conservatism of RADTRAN Line-Source Model for Estimating Worker Exposures," Proceedings of 10th International Symposium on the Packaging and Transportation of Radioactive Materials (PATRAM '92), Yokohama City, Japan, September 1992.

Whitlow, J. D. and K. S. Neuhauser, "A Methodology for the Transfer of Probabilities Between Accident Severity Classification Schemes," Proceedings of 1 st International Consensus Conference of the Risks of Transporting Dangerous Goods, Institute for Risk Research, Waterloo, Ontario, Canada, 1992.

Wilmot, E. L., "Transportation Accident Scenarios for Commercial Spent Fuel," SAND80-2124, Sandia National Laboratories, Albuquerque, NM, February 1981.

Wilmot, E. L. et al., "A Preliminary Analysis of the Cost and Risk of Transporting Nuclear Waste to Potential Candidate Repository Sites," SAND83-0867, Sandia National Laboratories, Albuquerque, NM, June 1983.

Wolff, T. A., "The Transportation of Nuclear Materials," SAND84-0062, TTC-0471, Sandia National Laboratories, Albuquerque, NM, December 1984.

Wooden, D. G., "Railroad Transportation of Spent Nuclear Fuel," SAND86-7083, Sandia National Laboratories, Albuquerque, NM, 1986.

WSRC (Westinghouse Savannah River Company), "Methodology Manual for Nuclear Processes Safety Analysis (Unclassified)," WSRC-TM-90-13, Aiken, SC, February 1991.

WSRC (Westinghouse Savannah River Company), "WSRC Facility Safety Analysis Manual (Unclassified)," Procedure Manual 9Q, Rev. 0, Westinghouse Savannah River Company, Aiken, SC, 1992.

WSRC (Westinghouse Savannah River Company), "Savannah River Site Environmental Report for 1992," WSRC-TR-93-075, Aiken, SC, 1993. 